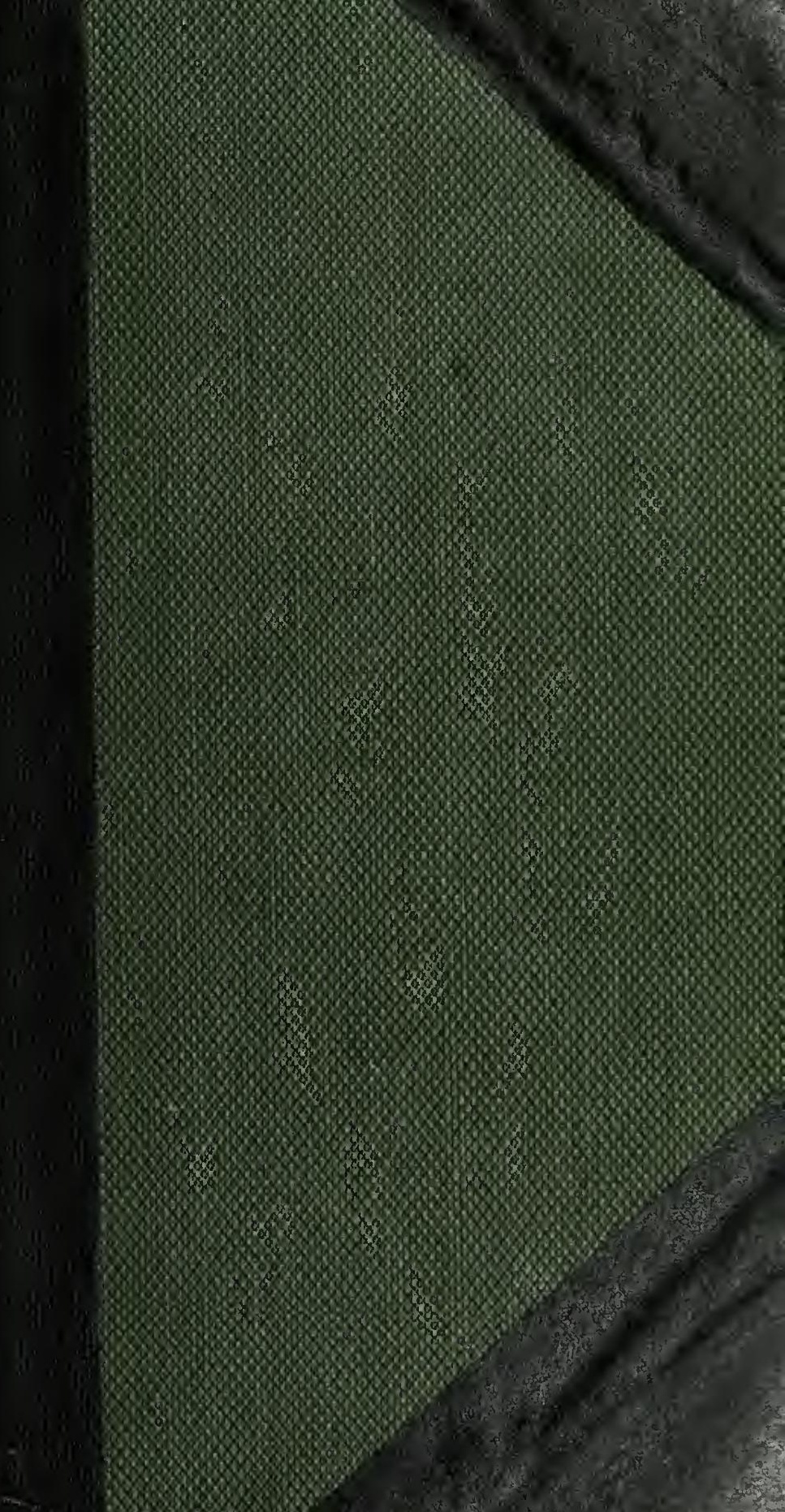




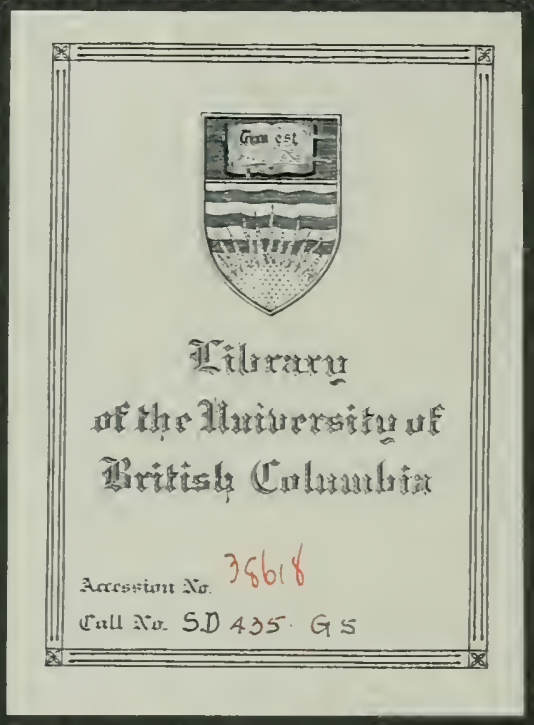




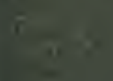

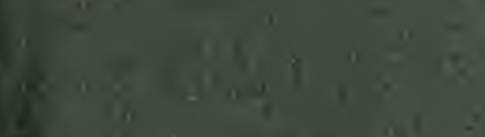

4

$1,-$

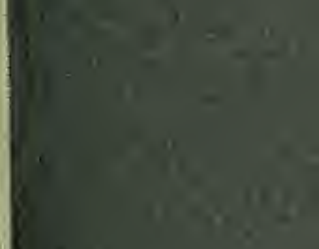

$+x^{2}+1$

$=$ 

Digitized by the Internet Archive in 2010 with funding from University of British Columbia Library 



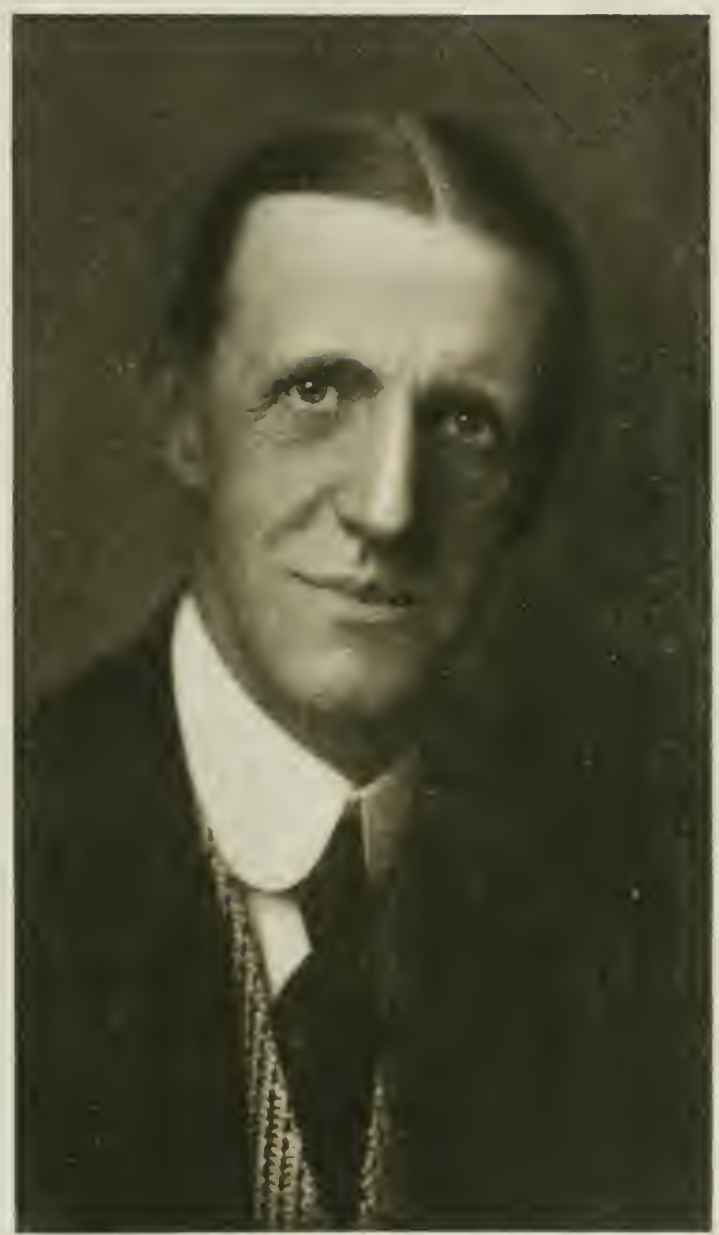

HENRY H. GIBSON 


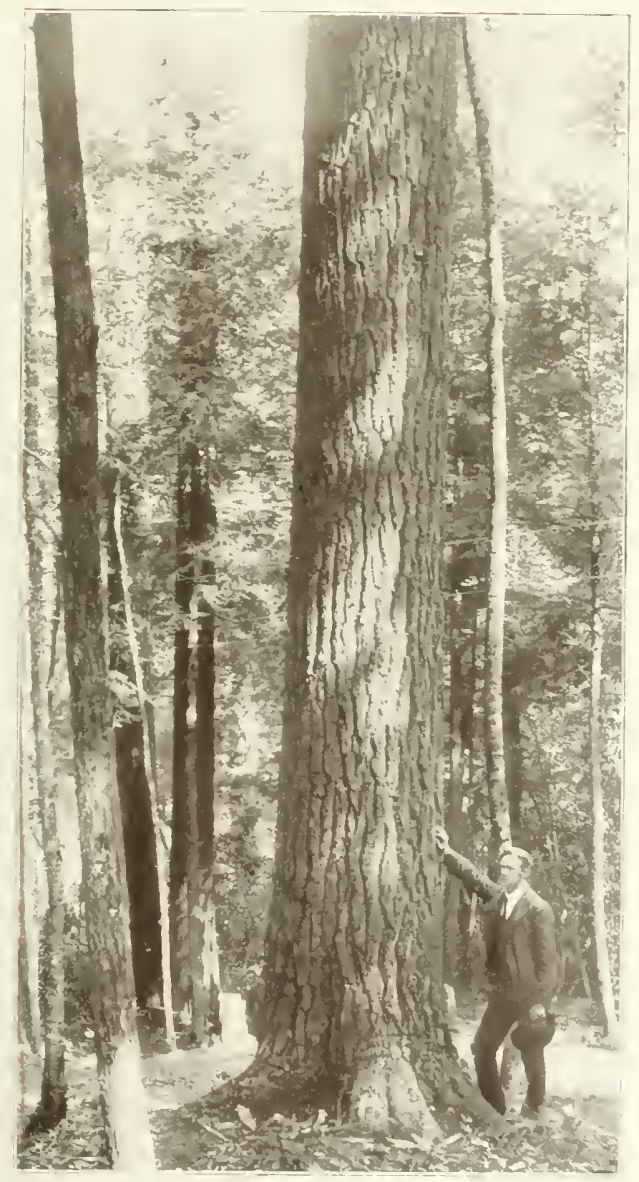

White PINe 
WHITE PINE 


\section{AMERICAN \\ FOREST TREES}

HENRY H. GIBSON

EDTtad BY

HU MAXWELL

HARDWOOD RECORD

CHICAGO

1913 
COPTRIGHT 1913 BY

HARDWOOD RECORD

Chucago, Ill.

The Regan Printing Hodse Chicago. 


\section{PREFACE}

THE material on which this volume is based, appeared in 1 Hardwood Record, Chicago, in a series of articles beginning in 1905 and ending in 1913, and descriptive of the forest trees of this country. More than one hundred leading species were included in the series. They constitute the principal sources of lumber for the United States. The present volume includes all the species described in the series of articles, with a large number of less important trees added. Every region of the country is represented; no valuable tree is omitted, and the lists and descriptions are as complete as they can be made in the limited space of a single volume. The purpose held steadily in view has been to make the work practical, simple, plain, and to the point. Trees as they grow in the forest, and wood as it appears at the mill and factory, are described and discussed. Photographs and drawings of trunk and foliage are made to tell as much of the story as possible. The pictures used as illustrations are nearly all from photographs made specially for that purpose. They are a valuable contribution to tree knowledge, because they show forest forms and conditions, and are as true to nature as the camera can make them. Statistics are not given a place in these pages, for it is no part of the plan to show the product and the output of the country's mills and forests, but rather to describe the source of those products, the trees themselves. However, suggestions for utilization are offered, and the fitness of the various woods for many uses is particularly indicated. The prominent physical properties are described in language as free as possible from technical terms, and yet with painstaking accuracy and clearness. Descriptions intended to aid in identification of trees are given; but simplicity and clearness are held constantly in view, and brevity is carefully studied. The different names of commercial trees in the various localities where they are known, either as standing timber or as lumber in the yard and factory, are included in the descriptions as an assistance in identification. The natural range of the forest trees, and the regions where they abound in commercial quantities, are outlined according to the latest and best authorities. Estimates of present and future supply are offered, where such exist that seem to be authoritative. The trees are given the common and the botanical names recognized as official by the United States Forest Service. This lessens misunderstanding and confusion in the discussion of species whose common names are not the same in different regions, and whose botanical names 
are not agreed upon among scientific men who mention or describe them. The forests of the United States contain more than five hundred kinds of trees, ranging in size from the California sequoias, which attain diameters of twenty feet or more and heights exceeding two hundred, down to indefinite but very small dimensions. The separating line between trees and shrubs is not determined by size alone. In a general way, shrubs may be considered smaller than trees, but a seedling tree, no matter how small, is not properly called a shrub. It is customary, not only among botanists, but also among persons who do not usually recognize exact scientific terms and distinctions, to apply the name tree to all woody plants which produce naturally in their native habitat one main, erect stem, bearing a definite crown, no matter what size they may attain.

The commercial timbers of this country are divided into two classes, hardwoods and softwoods. The division is for convenience, and is sanctioned by custom, but it is not based on the actual hardness and softness of the different woods. The division has, however, a scientific basis founded on the mechanical structures of the two classes of woods, and there is little disagreement among either those who use forest products or manufacture them, or those who investigate the actual structure of the woods themselves, as to which belong in the hardwood and which in the softwood class.

Softwoods-The needleleaf species, represented by pines, hemlocks, firs, cedars, cypresses, spruces, larches, sequoias, and yews, are softwoods. The classification of evergreens as softwoods is erroneous, because all softwoods are not evergreen, and all evergreens are not softroods. Larches and the southern cypress shed their leaves yearly. Most other softwoods drop only a portion of their foliage each season, and enough is always on the branches to make them evergreen. Softwoods are commonly called conebearers, and that description fits most of them, but the cedars and yews produce fruit resembling berries rather than cones. Though the needleleaf species are classed as softwoods, there is much variation in the absolute hardness of the wood produced by different species. The white pines are soft, the yews hard, and the other species range between. If there were no other means of separating trees into classes than tests of actual hardness of wood, the line dividing hardwoods from softwoods might be quite different from that now so universally recognized in this country.

Hardwoods - The broadleaf trces are hardwoods. Most, but not all, shed their foliage yearly. It is, therefore, incorrect to classify deciduous trees as hardwoods, since it is not true in all cases, any more than it is true that softwoods are evergreen. Live oaks and American holly are 
evergreen, and yet are true hardwoods. In a test of hardness they stand near the top of the list.

There are more species of hardwoods than of softwoods in this country; but the actual quantity of sof wood timber in the forests greatly exceeds the hardwoods. Nearly two hundred species of the latter are seldom or never seen in a sawmill, while softwoods are generally cut and used wherever found in accessible situations.

As in the case of needleleaf trees, there is much variation in actual hardness of the wood of different broadleaf species. Some which are classed as hardwoods are softer than some in the softwood list. It is apparent, therefore, that the terms hardwood and softwood are commercial rather than scientific.

Palm, cactus, and other trees of that class are not often employed as lumber, and it is not customary to speak of them as either hardwoods or softwoods.

Sapwood and Heartwood-Practically all mature trees contain two qualities of wood known as sap and heart. The inner portion is the heartwood, the outer the sap. They are usually distinguished by differences of color.

The terms are much used in lumber transactions and are well understood by the trade. The two kinds of wood need be described only in the most general way, and for the guidance and information of those who are not familiar with them. Differences are many and radical in the relative size and appearance of the two kinds of wood in different species, and even between different trees of the same species. No general law is followed, except that the heartwood forms in the interior of the tree, and the sapwood in a band outside, next to the bark. In the majority of cases young trees have little heartwood, often none. It is a development attendant on age, yet age does not always produce it. Some mature trees have no heartwood, others very little.

The two kinds of wood belong to needleleaf and broadleaf trees alike; but palms, owing to their manner of growth, have neither. Their size increases in height rather than in diameter. With palns, the oldest wood is in the base of the trunk, the newest in the top; but in the ordinary timber tree the oldest wood is in the center of the trunk, the youngest in the outside layers next the bark. It is the oldest that beconies heartwood, and it is, of course, in the center of the tree. The band of sapwood is of no certain thickness, but averages much thicker in some species than in others. The sapwood of Osage orange is scarcely half an inch thick, and in loblolly pine it may be six inches or more.

Heartwood is known by its color. The eye can detect no other difference between it and the surrounding band of sapwood. There is 
no fundamental difference. The heart was once sapwood, and the latter will sometime become heartwood if the tree lives long enough. As the trunk increases in size and years, the wood near the heart dies. It no longer has much to do with the life of the tree, except that it helps support the weight of the trunk. The heartwood is, therefore, deadwood. The activities of tree life are no longer present. The color changes, because mineral and chemical substances are deposited in the wood and fill many of the carities. That process begins at the center of the trunk and works outward year by year, forming a pretty distinct line between the living sapwood and the dead and inert heartwood.

For some reason, the heartwood of certain species is prone to decay. Sycamore is the best example. The largest trunks are generally hollow. The heart has disappeared, leaving only the thin shell of sapwood, and this is required not only to maintain the tree's life and activities, but to support the trunk's weight. In most instances the substances deposited in the heartwood, and associated with the coloring matter, tend to preserve the wood from decay. For that reason heart timber lasts longer than sap when exposed in damp situations. The dark and variegated shades of the heartwood of some species give them their chief value as cabinet and furniture material. The sapwood of black walnut is not wanted by anybody, for it is light in color and is characterless; but when the sap has changed to heart, and its tones have been deepened by the accumulation of pigments, it becomes a choice material for certain purposes. The same is true of many other timbers, notably sweet and yellow birch, black cherry, and several of the oaks.

It sometimes happens that when sapwood is transformed into heart, a physical change, as well as a coloring process, affects it. Persimmon and dogwood are examples, and hickory in a less degree. The sapwood of persimmon and dogwood makes shuttles and goll heads, but after the change to heartwood occurs, it is considered unsuitable. Handle makers and the manufacturers of buggy spokes prefer hickory sapwood, but use the red heartwood if it is the same weight as the sap.

Annual Rings-The trunks of botli hardwoods and softwoods are made up of concentric rings. In most instances the eye easily detects them. They are more distinct in a freshly cut trunk than in weathered wood, though in a few instances weathering accentuates rather than obliterates them. A count of the rings gives the tree's age in years, each ring being the growth of one year. An occasional exception should be noted, as when accident checks the tree's growth in the middle of the season, and the growth is later resumed. In that case, it may develop two rings in one year. A severe frost late in spring after leaves have started niay produce that result; or defoliation by caterpillars in early 
summer may do it. Perhaps not one tree in a thousand has that experience in the course of its whole life. Trees in the tropics where seasons are nearly the same the year through, seldom have rings. Imitations of mahogany are sometimes detected by noting clearly marked annual rings. It is difficult for the woodfinisher to obliterate the annual rings, but some of the French woodworkers very nearly accomplish it.

No law of growth governs the width of yearly rings, but circumstances have much to do with it. When the tree's increase in size is rapid, rings are broad. An uncrowded tree in good soil and climate grows much faster than if circumstances are adverse. Carolina poplar and black willow sometimes have rings nearly three-fourtlss of an inch broad, while in the white bark pine, which grows above the snow line in California, the rings may be so narrow as to be invisible to the naked eye.

There is no average width of yearly rings and no average age of trees. A few (very few) of the sequoias, or "big trees" of California, are two thousand years old. An age of six or seven centuries appears to be about the limit of the oldest of the other species in this conntry, though an authentic statement to that effect cannot be made. There are species whose life average scarcely exceeds that of men. The aspen generally falls before it is eighty; and fire cherry scarcely averages half of that. Of all the trees cut for lumber, perhaps not one in a hundred has passed the three century mark. That ratio would not hold if applied to the Pacific coast alone.

Spring and Summeruood-These are not usual terms with lumbermen and woodworkers, but belong more to the engineer who thinks of physical properties of timber, particularly its strength. Yet, sawmill and factory men are well acquainted with the two kinds of wood, but they are likely to apply the term "grain" to the combination of the two.

Spring and summerwood make the annual ring. Springwood grows early in the season, summerwood later. In fact, it usually is the contrast in color where the summerwood of one season abuts against the springwood of the next which makes the ring visible. The inside of the ring-that portion nearest the heart of the tree-is the springwood, the rest of the ring is the summerwood. The former is generally lighter in color. Sometimes, and with certain species, the springwood is much broader than the other. The summerwood may be a very narrow band, not much wider than a fine pencil mark, but its deeper color makes it quite distinct in most instances. In other instances, as with some of the oaks, the summerwood is the wider part of the annual ring. The 
figure or "grain" of southern yellow pine is largely due to the contrast between the dark summerwood and light springwood of the rings. The same is true of ash, chestnut, and of many other woods.

Pores- Wood is not the solid substance it seems to be when seen in the mass. If magnified it appears filled with cavities, not unlike a piece of coral or honeycomb; but to the unaided eye only a few of the largest openings are visible, and in some roods like maple, none can be seen. The large openings are known as pores. They are so prominent in some of the oaks that in a clean cut end or cross section they look like pin holes. Very little magnifying is required to bring them out distinctly. A good reading glass 's sufficient.

Pores belong to hardwoods only. The resin ducts in some softwoods present a similar appearance, but are far less numerous. All pores are, of course, situated in the annual rings, but in different species they are differently located as to spring and summerwood. In some woods the largest pores are in the springwood only and therefore run in rings. Such woods are called "ring porous," and the oaks are best examples. In other species the pores are scattered through all parts of the ring in about the same proportion, and such woods are called "diffuse porous," as the birches. Softwoods have no pores proper, and are classed "non-porous."

Medullary Ray's-A smoothly-cut cross section of almost any oak, but particularly white oak and red oak, exhibits to the unaided eye narrow, light-colored lines radiating from the center of the tree toward the bark like spokes of a wheel. They are about the breadth of a fine pencil mark, and are generally a sixth of an inch or less apart. They are among the most conspicuous and characteristic features of oak wood, and are known as medullary or pith rays.

Oak is cited as an example because the rays are large and prominent, but they are present in all wood, and constitute a large part of its body. They vary greatly in size. In some woods a few are visible unmagnified; but even in oak a hundred are invisible to the naked eye to one that can be seen. Some species show none until a glass is used. Some pines have fifteen thousand to a square inch of cross section, all of which are so small as to elude successfully the closest search of the unaided eye.

The medullary rays influence the appearance of most wood. They determine its character. Oak is quarter-sawed for the purpose of bringing out the bright, flat surfaces of these ray's. The prominent flecks, streaks, and patches of silvery wood are the flat sides of medullary rays. In cross section, only the line-like ends are seen, but quarter-sawing exposes their sides to view. 
That explains in part why some species are adapted to quartersawing and others are not. If no broad rays exist in the wood, as with white pine, red cedar, and cottonwood, quarter-sawing cannot add much to the wood's appearance.

Grain-The grain of wood is not a definite quality. The word does not mean the same thing to all who use it. It sometimes refers to rings of yearly growth, and in that sense a narrow-ringed wood is fine grained, and one with wide rings is coarse grained. A curly, wavy, smoky, or birdseye wood does not owe its quality to annual rings, yet with some persons, all of these figures are called grain. The term sometimes refers to medullary rays, again to hardness, or to roughness. Some mahogany is called "woolly grained" because the surface polishes with difficulty. The pattern maker designates white pine as "even grained", because it cuts easily in all directions. The handle maker classes hickory as "smooth grained", hecause it polishes well and the sole idea of the maker is smoothness to the touch. There are other grains almost as numerous as the trades which use wood. In numerous instances "figure" is a better term than "grain." Feather mahogany, birdseye birch, burl ash, are figures rather than grains. There is no authority to settle and decide what the real meaning of grain is in wood technology. It has a number of meanings, and one man has as much authority as another to interpret it in accordance with his own ideas, and the usage in his trade. It is a loose term which covers several things in general and nothing in particular.

Weight-The weight of wood is calculated from different standpoints. It has a green weight, an air-dry weight, a kiln-dry weight, and an oven-dry weight. All are different, but the differences are due to the relative amounts of water weighed. Sawlogs generally go by green weight; yard lumber by air-dry or partly air-dry weight; while the wood used in ultimate manufacture, such as furniture, is supposed to be kiln-dry.

The absolute weight of wood, with all air spaces, moisture, and other foreign material removed, is about 100 pounds per cubic foot, which is 1.6 times heavier than water; but that is not a natural form of wood. It is known only in the laboratory.

The actual wood substance of one species weighs about the same as another. Dispense with all air spaces, all water, and all other foreign substance, and pine and ebony weigh alike. It is apparent that the different weights of woods, as between cedar and oak for cxample, are due chiefly to porosity. The smaller the aggregate space occupied by pores and other cavities, the heavier the wood. That accounts for the differences in weights of absolutely dry woods of different kinds, except 
that a small amount of other foreign material may remain after water has been driven ofi. Florida black ironwood is rated as the heaviest in the United States, and it weighs $\$ 1.14$ pounds per cubic foot, oven-dry. The lightest in this country is the golden fig which is a native of Florida also. It weighs 16.3 pounds per cubic foot, oven-dry. When weights of wood are given, the specimen is understood to be oven-dry, unless it is stated to be otherwise: it is a laboratory weight, calculated from small cubes of the wood. Such weights are always a little less than that of the dryest wood of the same kind that can be obtained in the lumber market.

Moisture in Wood-The varying weights of the same wood indicate that moisture plays an important part. No man ever saw absolutely dry wood. If heated sufficiently to drive off all the moisture, the wood is reduced to charcoal and other products o: destructive distillation.

The pores and other cavities in green timber are more or less filled with water or sap. This may amount to one-third, one-half, or even more, of the dry weight of the wood. The water is in the hollow vessels and cell walls. A living tree contains about the same quantity of water in winter as in summer, though the common belief is otherwise. It is misleading to say that the sap is "down" in one season and "up" in another, although there is more activity at certain times than in others. Strictly speaking, there is a difference between the water in a tree, and the tree's sap; but in common parlance they are considered identical. II'hat takes place is this: water rises from the tree's roots, through the wood, carrying certain minerals in solution. Some of it reaches the leares in summer where it mixes with certain gases from the air, and is converted into sap proper. Most of the surplus water, after giving up the mineral substance held in solution, is evaporated through the leaves into the air; but the sap, starting from the leaves which act as laboratories for its manufacture, goes down through the newly-formed (and forming), layer of wood just beneath the bark, and is converted into wood. This newly-formed wood is colorless at first. It builds up the annual ring, first the springwood very rapidly, and then the summerwood more slowly.

The force which causes water to rise through the trunk of a tree is not fully understood. It is one of nature's mysteries which is yet to be solved. Forces known as root pressure, capillary attraction, and osmosis, are believed to be active in the process, but there seems to be something additional, and no man has yet been able to explain what it is.

The seasoning of wood is the process of getting rid of some of the water. As soon as lumber is exposed to air, the water begins to escape. 
Long exposure to dry air takes out a large percentage of the moisture which green wood holds, and the lumber is known as air-dry. But some of the original moisture remains, and air at climatic temperature is unable to expel it. The greater heat of a drykiln drives away some more of it, but a quantity yet remains. The lumber is then kiln-dry. Greater heat than the drykiln's is secured in an oven, and a little more of the wood's moisture is expelled; but the only method of driving all the moisture out is to heat the wood sufficiently to break down its structure, and reduce it to charcoal.

Wood warps in the process of drying unless it seasons equally on all sides. It curls or bends toward the side which dries most rapidly. Dry wood may warp if exposed to dampness, if one side is more exposed and receives more moisture than another. It curls or bends toward the dryer side.

Warping is primarily due to the more rapid contraction or expansion of wood cells on one side of the piece than on the other. Saturated cells are larger than dry ones.

Moisture in wood affects its strength, the dryer the stronger, at least within certain limits. Architects and builders carefully study the seasoning of timber, because it is a most important factor in their business. The moisture which most affects a wood's strength is that absorbed in the cell walls, rather than that contained in the cell cavities themselves.

Some woods check or split badly in seasoning unless attended with constant care. Checking is due chiefly to lack of uniformity in seasoning. One part of the stick dries faster than another, the dryer fibers contract, and the pull splits the wood. The checks may be small, even microscopic, or they may develop yawning cracks such as sometimes appear in the ends of hickory and black walnut logs. Greenwood checks worse in summer than in winter, because the weather is warmer, the wood's surface dries faster, and the strain on the fibers is greater. Phases of the moon have no influence on the seasoning, checking, warping, or lasting properties of timber.

Stiffness, Elasticity', and Strength-Rules for measuring the stiffness of timber are involved in mathematical formulas; but the practical quality of stiffness is not difficult to understand. Wood which does not bend easily is stiff. If it springs back to its original position after the removal of the force which bends it, the wood is elastic. The greatest load it can sustain without breaking, is the measure of its strength. The load required to produce a certain amount of bending is the measure of its stiffness. Flexibility, a term much used by certain classes of workers in wood, is the opposite of stiffness. A brittle wood is not nccessarily 
weak. It may sustain a heavy load without breaking, but when it fails, the break is sudden and complete. A tough wood behaves differently; though it may not be as strong as a brittle one. When a tough wood breaks, the parts are inclined to adhere after they have ceased to sustain the load. Hickory is tough, and in breaking, the wood crushes and splinters. Mesquite is brittle, and a clean snap severs the stick at once.

Builders of houses and bridges, and the manufacturers of articles of wood, study with the greatest care the stiffness, elasticity, strength, toughness, and brittleness of timber. Its chief value may depend upon the presence or absence of one or more of these properties. Take away hickory's toughness and elasticity and it would cease to be a great vehicle and handle material. Reduce the stiffness and strength of longleaf pine and Douglas fir and they would drop at once from the high esteem in which they are held as structural timbers. Destroy the brittleness of red cedar and it would lose one of the chief qualities which make it the leading lead pencil wood of the world.

There are recognized methods of measuring these important physical properties of roods, but they are expressed in language so technical that it means little to persons who are not specialists. For ordinary purposes, it is unnecessary to be more explicit than to state a certain wood is or is not strong, stiff, tough and elastic. Some species possess one or more of these properties to double the degree that others possess then. Different trees of the same species differ greatly, and even different parts of the same tree. Most tables of figures which show the various physical properties of woods, give averages only, not absolute values.

Hardness-In some woods hardness is considered an advantage, but not in others. If sugar maple were as soft as white pine, it would not be the great floor material it is; and if white pine were as hard as mapie, pattern makers would not want it, door and sash manufacturers would get along with less, and it would not be the leading packing box material in so wide a region.

It is generally the summer growth in the annual rings which makes a wood hard. The summerwood is dense. A given bulk of it contains more actual wood substance and less air and water than the springwood. For the same reason, summerwood gives weight, and a relationship between hardness and weight holds generally. It may be added that strength goes with weight and hardness, but it is not a rule without apparent exceptions.

Some woods possess twice or three times the hardness of others. Among some of the hardest in the United States are hickory, sugar maple, mesquite, the Florida ironwoods, Osage orange, locust, persim- 
mon, and the best oak and elm. Among the softest species are buckeye, basswood, cedar, redirood, some of the pines, spruce, hemlock, and chestnut.

The hardness of wood is tested with a machine which records the pressure required to indent the surface. The condition of the specimen, as to dryness, has much to do with its hardness. So many other factors exercise influence that nothing less than an actual test will determine the hardness of a sample. A table of figures can show it only approximately and by averages.

Cleavability - Wood users generally demand a material which does not split easily, but the reverse is sometimes required. Rived staves must come from timbers which split easily. Many handles are from billets which are split in rough form and are afterwards dressed to the required size and shape. In these instances, splitting is preferable to sawing, because a rived billet is free from cross grain.

The cleavability of woods differs greatly. Some can scarcely be split. Black gum is in that list, and sycamore to a less extent. Young trees of some species split more readily than old, while with others, the advantage is with the old. Young sycamore may generally be split with ease, but old trunks seem to develop interlocked fibers which defy the wedge. A white oak pole is hard to split, but the old tree yields readily. Few woods are more easily split than chestnut. With most timbers clearage is easiest along the radial lines, that is, from the heart to the bark. The flat sides of the medullary rays lie in that plane. Cleavage along tangential lines is easy with some moods. The line of cleavage follows the soft springwood. Green timber is generally, but not always, more easily split than dry. As a rule, the more elastic a wood is, the more readily it may be split.

Durability - In Egypt where climatic conditions are highly favorable, Lebanon cedar, North African acacia, East African persimmon, and oriental sycamore have remained sound during three or four thousand years. In the moist forests of the northwestern Pacific coast, an alder $\log \operatorname{six}$ or eight inches in diameter will decay through and through in a single year. No wood is immune to decay if exposed to influences which induce it, but some resist for long periods. Osage orange and locust fence posts may stand half a century. Timber from which air is excluded, as when deeply buried in wet earth or under water, will last indefinitely; but if it is exposed to alternate dampness and dryness, decay will destroy it in a few years.

It is apparent that resistance to decay is not a property inherent in the wood, but depends on circumstances. However, the ability to resist decay varies greatly with different species, under similar circum- 
stances. Buckeye and red cedar fence posts, situated alike, will not last alike. The buckeye may be expected to fall in two or three y'ears, and the cedar will stand twenty. Timbers light in weight and light in color are, as a class, quick-decaying when exposed to the weather.

The rule holds in most cases that sapwood decays more quickly than heart when both are subject to similar exposure. The matter of decay is not important when lumber and other products intended for use are in dry situations. Furniture and interior house finish do not decay under ordinary circumstances, no matter what the species of wood may be; but resistance to decay overshadows almost any other consideration in choosing mine timbers, crossties, fence posts, and tanks and silos.

Decay in timber is not simply a chemical process, but is due primarily to the activities of a low order of plants known as fungi, sometimes bacteria. The fungi produce thread-like filaments which penetrate the body of the wood, ramifying in and passing from cell to cell, absorbing certain materials therein, and ultimately breaking down and destroying the structure of the wood. Both air and dampness are essential to the growth of fungus. That is the reason why timbers deep beneath ground or water do not decay. Air is absent, though moisture is abundant; while in the dry Egyptian tombs, air is abundant but moisture is wanting, fungus cannot exist, and consequently decay of the wood does not occur. Nothing is needed to render timber immune to decay except to keep fungus out of the cells. Some of the fungus concerned in wood rotting is microscopic, while other appears in forms and sizes easily seen and recognized.

Timber may be protected for a time against the agencies of decay by covering the surface with paint, thereby preventing the entrance of fungus. By another process, certain oils or other materials which are poisonous to the insinuating threads of fungus, are forced into the pores of the wood. Creosote is often used for this purpose. Attacks are thus warded off, and decay is hindered. The preservative fluid will not remain permanently in wood exposed to weather conditions, but the period during which it affords protection and immunity extends over some years; but different woods vary greatly in their ability to receive and retain preservative mixtures.

The better seasoned, the less liable is timber to decay, because it contains less moisture to support fungi. It is generally supposed that timber cut in the fall of the year is less subject to decay than if felled in summer. If it is so, the reason for it lies in the fact that fungus is inactive during winter, and before the conning of warm weather the timber has partly dried near the surface, and fungi cannot pass through the dry outside to reach the interior. Timber cut in warm weather may be 
attacked at once, and before cold weather stops the activities of fungus it has reached the interior of the wood and the process of rotting is under way. When the agents of decay have begun to grow in the wood, destruction will go on as long as air and moisture conditions are favorable.

The bluing of wood is an incipient decay and is generally due to fungus. Some kinds of wood are more susceptible to bluing than others. Though boards may quickly season sufficiently to put a stop to the bluing process before it has actually weakened the material, the result is more or less injurious. The wood's natural color and luster undergo deterioration; it does not reflect light as formerly, and seems dead and flat.

Decay affects sapwood more readily than heart. The reason may be that sapwood contains more food for fungus, thereby inducing greater activity. The sapwood is on the outside of timbers and is of ten more exposed thau the heart. In some instances greater decay may be due to greater exposure. Another reason for more rapid decay of sapwoor than heart is the fact that the pores of the heartwood are more or less filled with coloring matter deposited while the growth of the tree was in progress. The coloring matter, in many cases, acts as a preservative; it shuts the threads of fungus out. Sometimes the sapwood of a dead tree or a $\log$ is totally destroyed while the heart remains sound. This often happens with red cedar and sometimes with black walnut, yellow poplar, and cherry. Occasionally a tree's bark is more resistant to decay than its wood. Paper birch and yellow birclı logs in damp situations occasionally show this. What appears to be a solid fallen trunk, proves to be nothing more than a shell of bark with a soft, pulpy mass of decayed wood within. 



\title{
WHITE PINE*
}

\author{
(Pinus Strobus)
}

$T^{\prime}$

HE best known wood of the United States las never been burdened with a multitude of names, as many minor species have. It is commonly known as white pine in every region where it grows, and in many where the living tree is never seen, except when planted for ornament. The light color of the wood suggests the name. The bark and the foliage are of somber hue, though not as dark as hemlock and many of the pines. The name Weymouth pine is occasionally heard, but it is more used in books than by lumbermen. It is commonly supposed that the name refers to Lord Weymouth who interested himself in the tree at an early period, but this has been disputed. In Pennsylvania it is occasionally called soft pine to distinguish it from the harder and inferior pitch pine and table mountain pine with which it is sometimes associated. It is the softest of the pines, and the name is not inappropriate. In some regions of the South, where it is well known, it is called northern spruce pine in recognition of the fact that it is a northern species which has followed the Appalachian mountain ranges some hundreds of miles southward. There is no good reason for this name when applied to white pine. It should be remembered, however, that no less than a dozen tree species in the United States are sonetimes called spruce pine. Cork pine is a trade name applied more frequently to the wood than to the living tree. It is the wood of old, mature, first class trunks, as nearly perfect as can be found. Pumpkin pine is another name given to the same class of wood. It is so named because the grain is homogeneous, like a pumpkin, and may be readily cut and carved in any direction. It is the ideal wood for the pattern maker, but it is now hard to get because the venerable white pines, many hundred years old, are practically gone.

The northern limit of the range of white pine stretches from Newfoundland to Manitoba, more than 1800 miles east and west across the Dominion of Canada, and southward to northern Georgia, 1200 miles in a north and soutl direction. But white pine does not grow in all parts of the territory thus delimited. It attained magnificent

*The following 12 species are usually classed soft pines: White l'inc (Pimus strobus); Sugar Pine (Pinus lambertiana); Western White Pine (Pinus monticola); Mexican White Pine (Pinus strobiformis); Limber Pine (Pinus flexilis); Whitebark Pine (Pinus albicaulis); Foxtail Pine (Pinus balfouruna); Parry Pine (Pinus quadrifolia); Mexican Pinon (Pinus cembraides); Pinon (Pinus edulis); Singleleaf Pinon (Pinus monophylla); Bristlecone Pine (Pinus aristata). 
development in certain large regions before lumbering began, and in others it was scarce or totally wanting. Its ability to maintain itself on land too thin for vigorous hardwood growth gave it a monopoly of enormous stretches of sandy country, particularly in the Lake States. It occupied large areas in New England and southern Canada; developed splendid stands in New York and Pennsylvania; and it covered certain mountains and uplands southward along the mountain ranges across Maryland, West Virginia, and the elevated regions two or three hundred miles farther south.

A dozen or more varieties of white pine have been developed under cultivation, but they interest the nurseryman, not the lumberman. In all the wide extension of its range, and during all past time, nature was never able to develop a single variety of white pine which departed from the typical species. For that reason it is one of the most interesting objects of study in the tree kingdom. True, the white pine in the southern mountains differs slightly from the northern tree, but botanically it is the same. Its wood is a little heavier, its branches are more resinous and consequently adhere a longer time to the trunk after they die, resulting in lumber with more knots. The southern wood is more tinged with red, the knots are redder and usually sounder than in the North.

It is unfortunately necessary in speaking of white pine forests to use the past tense, for most of the primeval stands have disappeared. The range is as extensive as ever, because wherever a forest once grew, a few trees remain; but the merchantable timber has been cut in most regions. The tree bears winged seeds which quickly scatter over vacant spaces, and new growth would long ago, in most cases, have taken the place of the old, had not fires persistently destroyed the seedlings. In parts of New England where fire protection is afforded, dense stands of white pine are coming on, and in numerous instances profitable lumber operations are carried on in second growth forests. That condition does not exist generally in white pine regions. Primeval stands were seldom absolutely pure, but sometimes, in bodies of thousands of acres, there was little but white pine. Generally hardwoods or other softwoods grew with the pine. At its best, it is the largest pine of the United States, except the sugar pine of California. The largest trees grew in New England where diameters of six or more feet and heights exceeding 200 feet were found. A diameter of four and five feet and a height of 150 feet are about the size limits in the Lake States and the southern mountains. Trees two or three feet through and ninety and 120 tall are a fair average for mature timber.

The wood of white pine is among the lightest of the commercial 
timbers of this country, and among the softest. While it is not strong, it compares favorably, weight for weight, with most others. It is of rather rapid growth, and the rings of annual increase are clearly defined, and they contain comparatively few resin ducts. For that reason it may be classed as a close, compact wood. It polishes well, may be cut with great ease, and after it is seasoned it holds its form better than most woods. That property fits it admirably for doors and sash and for backing of veneer, where a little warping or twisting would do much harm.

The medullary rays are numerous but are too small to be easily seen separately, and do not figure much in the appearance of the wood. The resin passages are few and small, but the wood contains enough resin to give it a characteristic odor, which is not usnally considered injurious to merchandise shipped in pine boxes. The white color of the wood gives it much of its value. Though rather weak, white pine is stiff, rather low in elasticity, is practically wanting in toughness, has little figure, and when exposed to alternate dryness and dampness it is rated poor in lasting properties; yet shingles and weather boarding of this wood have been known to stand half a century. The sapwood is lighter in color than the heart, and decays more quickly.

As long as white pine was abundant it surpassed all other woods of this conntry in the amount used. It was one of the earliest exports from New England, and it went to the West Indies and to Europe. England attempted to control the cutting and export of white pine, bnt was unsuccessful. At an early period the rivers were ntilized for transporting the logs and the lumber to market, and that method has continued until the present time. Spectacular log drives were common in early times in New England, later in New York and Pennsylvania, and still later in Michigan and the other Lake States. Many billions of feet of fanltless logs have gone down flooded rivers. The scenes in the woods and the life in lumber camps have been written in novels and romances, and the central figure of it all was white pine.

There are a few things for which this wood is not snitable; otherwise its nse has been nearly universal in some parts of this conntry. It went into masts and matches, which are the largest and smallest commodities, and into almost every sliape and size of product between. Most of the early honses and barns in the pine region were built of it. Hewed pine was the foundation, and the shingles were of split and shaved pine. It formed floors, doors, sash, and shutters. It was the ceiling within and the weather boarding without. It fenced the fields and bridged the streams. It went to market as rongh lumber, and planing mills turned it out as dressed stock in various forms. It has probably 
been more extensively employed by box makers than any other wood, and though it is scarcer than formerly, hundreds of millions of feet of it are still used annually by box makers. Scores of millions of feet yearly are demanded by the manufacturers of window shade rollers, though individually the roller is a very small commodity. In this, as for patterns and many other things, no satisfactory substitute for white pine has been found.

As a timber tree, it will not disappear from this country, though the days of its greatest importance are past. Enormous tracts where it once grew will apparently never again produce a white pine sawlog. The prospect is more encouraging in other regions, and there will always be a considerable quantity of this lumber in the American market, though the high percentage of good grades which prevailed in the past will not continue in the future.

White pine belongs in the five needle group, that is, five leaves grow in a bundle. They turn yellow and fall in the autumn of the second year. The cones are slender, are from five to eleven inches in length, and ripen and disperse their seeds in the autumn of the second year.

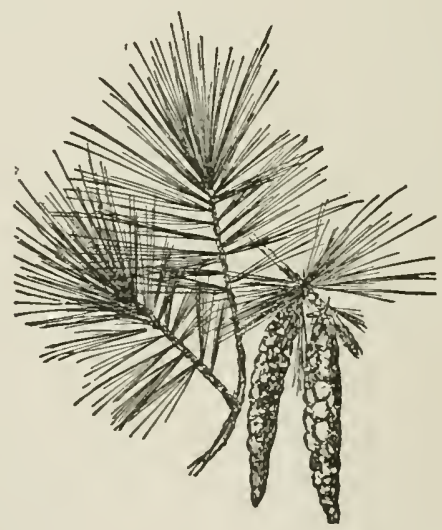


WESTIRT IIHTE PINE 


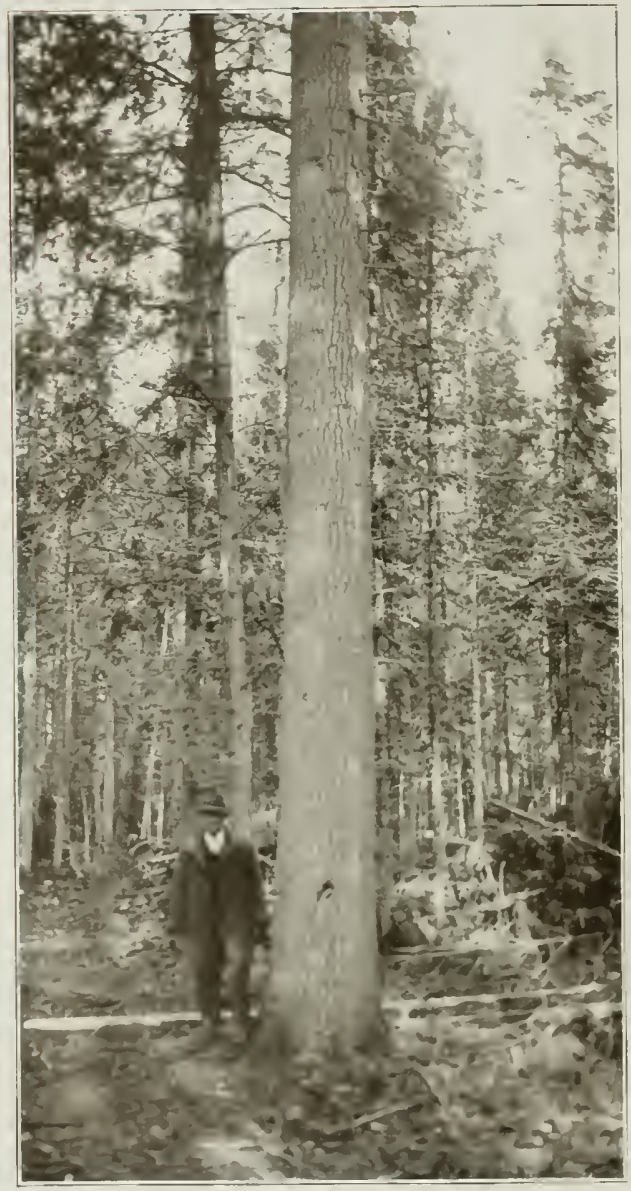

Wester.: White Pine 


\title{
WESTERN WHITE PINE
}

\author{
(Pinus Monticola)
}

$\mathrm{T}$ HE silvery luster of the needles of this tree gives it the name silver pine, by which many people know it. It appears in literature as mountain Weymouth pine, the reference being to the eastern white pine (Pinus strobus), which is sometimes called Weymouth pine. Finger-cone pine is a California name; so are mountain pine and soft pine. In the same state it is called little sugar pine, to distinguish it from sugar pine (Pinus lambertiana), which it resembles in some particulars but not in all. It is thus seen that California is generous in bestowing names on this tree, notwithstanding it is not abundant in any part of that state and is unknown in most parts.

The botanical name means "mountain pine," and that describes the species. It does best among the mountains, and it ranges from an altitude of from 4,000 feet to 10,000 on the Sierra Nevada mountains. Sometimes trees of very large size are found near the upper limits of its range, but the best stands are in valleys and on slopes at lower altitudes. Its range lies in British Columbia, Montana, Idaho, Washington, Oregon, and California. In the latter state it follows the Sierra Nevada mountains southward to the San Joaquin river.

This species has been compared with the white pine of the East of tener than with any other species. The weights of the two woods are nearly the same, and both are light. Their fuel values are about the same. The strength of the eastern tree is a little higher, but the western species is stiffer. The woods of both are light in color, but that of the eastern tree is whiter; both are soft, but again the advantage is with the eastern tree. The western pine generally grows rapidly and the annual rings are wide; but, like most other species, it varies in its rate of growth, and trunks are found with narrow rings. The summerwood is thin, not conspicuous, and slightly resinous. The small resin passages are numerous. The heartwood is fairly durable in contact with the soil.

The western white pine has entered many markets in recent years, but it is difficult to determine what the annual cut is. Statistics often include this species and the western yellow pine under one name, or at least confuse one with the other, and there is no way to determine exactly how much of the sawmill output belongs to caclı. The bulk of merchantable western white pine lumber is cut in Idaho and Montana. The stands are scldom pure, but this species frequently predominates over its associates. When pure forests are found, the yield is some- 
times very high, as much as 130,000 feet of logs growing on a single acre. That quantity is not often equalled by any other forest tree, though redwood and Douglas fir sometimes go considerably above it.

The western white pine's needles grow in clusters of five and are from one and a half to four inches long. The cones are from ten to eighteen inches long. The seeds ripen the second year. Reproduction is vigorous and the forest stands are holding their own. Trees about one hundred and seventy-five feet high and eight feet in diameter are met with, but the average size is one hundred feet high and from two to three feet in diameter, or about the size of eastern white pine.

The wood is useful and has been giving service since the settlement of the country began, fifty or more years ago. Choice trunks were split for shakes or shingles, but the wood is inferior in splitting qualities to either eastern white pine or California sugar pine, because of more knots. The western white pine does not prune itself early or well. Dead limbs adhere to the trunk long after the sugar pine would shed them. In split products, the western white pine's principal rival has been the western red cedar. The pine has been much employed for mine timbers in the region where it is abundant. Miners generally take the most convenient wood for props, stulls, and lagging. A little higher use for pine is found among the mines, where is it made into tanks, flumes, sluice boxes, water pipes, riffle blocks, rockers, and guides for stamp mills. However, the total quantity used by miners is comparatively small. Much more goes to ranches for fences and buildings. It is serviceable, and is shipped outside the immediate region of production and is marketed in the plains states east of the Rocky Mountains, where it is excellent fence material.

A larger market is found in manufacturing centers farther east. Western white pine is shipped to Chicago where it is manufactured into doors, sash, and interior finish, in competition with all other woods in that market. It is said to be of frequent occurrence that the very pine which is shipped in its rough form out of the Rocky Mountain region goes back finished as doors and sash. When the mountain regions shall have better manufacturing facilities, this will not occur. In the manufacture of window and hothouse sash, glass is more important than wood, although each is useless without the other. The principal glass factories are in the East, and it is sometimes desirable to ship the wood to the glass factory, have the sash made there, and the glazing done; and the finished sash, ready for use, may go back to the source of the timber.

The same operation is sometimes repeated for doors; but in recent years the mountain region where this pine grows has been supplied 
with factories and there is now less shipping of raw material out and of finished products back than formerly. The development of the fruit industry in the elevated valleys of Idaho, Montana, Washington, and Oregon has called for shipping boxes in large numbers, and western white pine has been found an ideal wood for that use. It is light in weight and in color, strong enough to satisfy all ordinary requirements, and cheap enough to bring it within reach of orchardists. It meets with lively competition from a number of other woods which grow abundantly in the region, but it holds its ground and takes its share of the business.

Estimates of the total stand of western white pine among its native mountains have not been published, but the quantity is known to be large. It is a difficult species to estimate because it is scattered widely, large, pure stands being scarce. Some large mills make a specialty of sawing this species. The annual output is believed to reach 150,000 ,000 feet, most of which is in Idaho and Montana.

Mexican White Pine (Pinus strobiformis) is not sufficiently abundant to be of much importance in the United States. The best of it is south of the international boundary in Mexico, but the species extends into New Mexico and Arizona where it is most abundant at altitudes of from 6,000 to $S, 000$ feet. The growth is generally scattering, and the trunks are often deformed through fire injury, and are inclined to be limby and of poor form. The best trees are from eighty to one hundred feet high, and two in diameter; but many are scarcely half that size. The lumbermen of the region, who cut Mexican white pine, are inclined to place low value on it, not because the rood is of poor quality, but because it is scarce. It is generally sent to market with western yellow pine. Excellent grades and quality of this wood are shipped into the United States from Mexico, but not in large amounts. An occasional carload reaches door and sash factories in Texas, and woodworkers as far east as Michigan are acquainted with it, through trials and experiments which they have made. It is highly recommended by those who have tried it. Some consider it as soft, as easy to work, and as free from warping and checking as the eastern white pine. In Arizona and $\mathrm{New}$ Mexico the tree is known as ayacahuite pire, white pine, and Arizona white pine. The wood is moderately light, fairly strong, rather stiff, of slow growth, and the bands of summerwood are comparatively broad. The resin passages are few and large. The wood is light red, the sapwood whiter. The leaves occur in clusters of five, are three or four inches long, and fall during the third and fourth years. The sceds are large and have small wings which cannot carry them far from the parent tree. 
Pinon (Pinus edulis). This is one of the nut pines abounding among the western mountains, and it is called pinon in Texas, nut pine in Texas and Colorado, pinon pine and New Mexican pinon in other parts of its range, extending from Colorado through New Mexico to western Texas. It has two and three leaves to the cluster. They begin to fall the third year and continue through six or seven years following. The cones are quite small, the largest not exceeding one and one-half inches in length. Trees are from thirty to forty feet high, and large trunks may be two and one-half feet in diameter. The tree runs up mountain sides to altitudes of 8,000 or 9,000 feet. It exists in rather large bodies, but is not an important timber tree, because the trunks are short and are generally of poor form. It often branches near the ground and assumes the appearance of a large shrub. Ties of pinon have been used with various results. Some have proved satisfactory, others have proved weak by breaking, and the ties occasionally split when spikes are driven. The wood's service as posts varies also. Some posts will last only three or four years, while others remain sound a long time. The difference in lasting properties is due to the difference in resinous contents of the wood. Few softwoods rank above it in fuel value, and much is cut in some localities. Large areas have been totally stripped for fuel. Charcoal for local smithies is burned from this pine. The wood is widely used for ranch purposes, but not in large quantities. The edible nuts are sought by birds, rodents, and Indians. Some stores keep the nuts for sale. The tree is handicapped in its effort at reproduction by weight, and the small wing power of the seeds. They fall near the base of the parent tree, and most of them are speedily devoured.

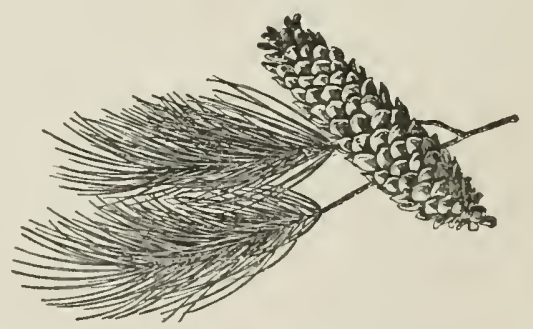


SUGAR PINE 


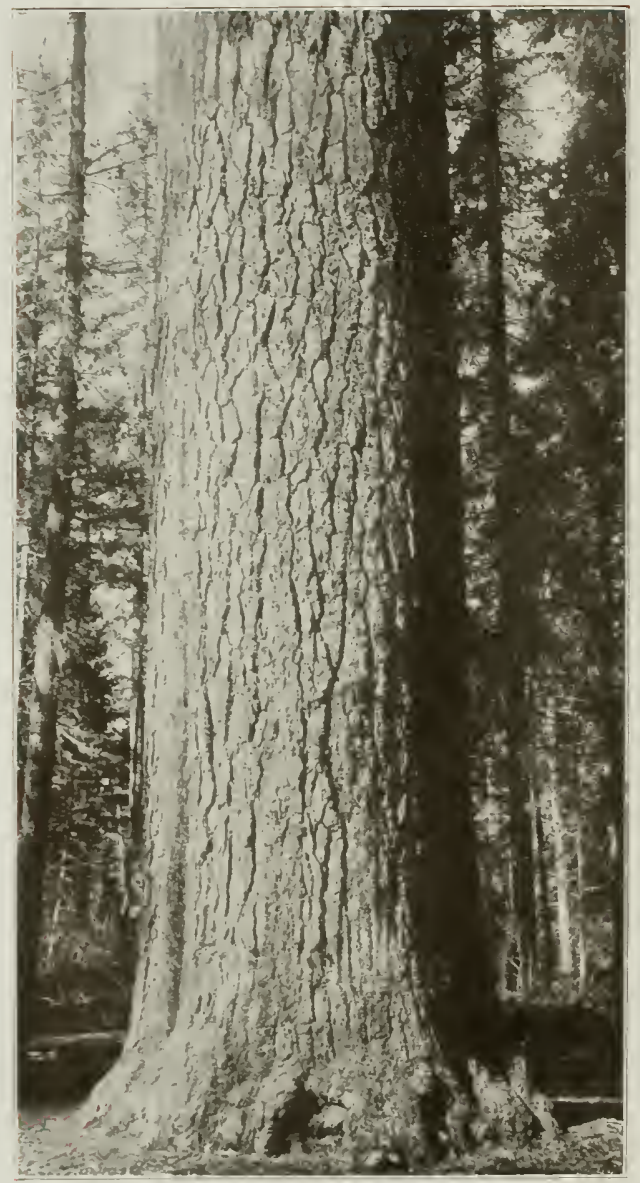

Stgar Pixe 


\section{SUGAR PINE}

\section{(Pinus Lambertiana)}

$\mathrm{T}^{\mathrm{n}}$ HIS is the largest pine of the United States, and probably is the largest true pine in the world. Its rival, the Kauri pine of New Zealand, is not a pine according to the classification of botanists; and that leaves the sugar pine supreme, as far as the world has been explored. David Douglas, the first to describe the species, reported a tree eighteen feet in diameter and 245 feet high, in southern Oregon. No tree of similar size has been reported since; but trunks six, ten, and even twelve feet through, and more than 200 high are not rare.

The range of sugar pine extends from southern Oregon to lower California. Through California it follows the Sierra Nevada mountains in a comparatively narrow belt. In Oregon it descends within 1,000 feet of sea level, but the lower limit of its range gradually rises as it follows the mountains southward, until in southern California it is 8,000 or 10,000 feet above the sea. Its choice of situation is in the mountain belt where the annual precipitation is forty inches or more. The deep winter snows of the Sierras do not hurt it. The young trees bear abundant limbs covering the trunks nearly or quite to the ground, and are of perfect conical shape. When they are ten or fifteen feet tall they may be entirely covered in snow which accumulates to a depth of a dozen feet or more. The little pines are seldom injured by the load, but their limbs shed the snow until it covers the highest twig. The consequence is that a crooked sugar pine trunk is seldom seen, though a considerable part of the tree's youth may have been spent under tons of snow. Later in life the lower limbs die and drop, leaving clean boles which assure abundance of clear lumber in the years to come.

The tree is nearly always known as sugar pine, though it may be called big pine or great pine to distinguish it from firs, cedars, and other softwoods with which it is associated. The name is due to a product resembling sugar which exudes from the heartwood when the tree has been injured by fircs, and which dries in white, brittle excrescences on the surface. Its taste is sweet, with a suggestion of pitch which is not unpleasaut. The principle has been uamed "pinite."

The needles of sugar pine are in clusters of five and are about four inches long. They are deciduous the second and third years. The cones are longer than cones of any other pine of this country but those of the Coulter pine are a little heavier. Extreme length of "22 inclies for the sugar pine cone has been recorded, but the average is from 12 to 15 inches. Cones open, shed their seeds the second year, and fall the third. 
The seeds resemble lentils, and are provided with wings which carry them several hundred feet, if wind is favorable. This affords excellent opportunities for reproduction; but there is an offset in the sweetness of the seeds which are prized for food by birds, beasts and creeping things from the Piute Indian down to the Douglas squirrel and the jumping mouse.

Sugar pine occupies a high place as a timber tree. It has been in use for half a century. The cut in 1900 was $52,000,000$ feet, in 1904 it was $120,000,000$; in $1907,115,000,000$, and the next year about 100,000 ,000 . Ninety-three per cent of the cut is in California, the rest in Oregon. Its stand in California has been estimated at $25,000,000,000$ feet.

The wood of sugar pine is a little lighter than eastern white pine, is a little weaker, and has less stiffness. It is soft, the rings of growth are wide, the bands of summerwood thin and resinous; the resin passages are numerous and very large, the medullary rays numerous and obscure. The heart is light brown, the sapwood nearly white.

Sugar pine and redwood were the two early roofing woods in California, and both are still much used for that purpose. Sugar pine was made into samed shingles and split shakes. The shingle is a mill product; but the shake was rived with mallet and frow, and in the years when it was the great roofing material in central and eastern California, the shake makers camped by twos in the forest, lived principally on bacon and red beans, and split out from 200,000 to 400,000 shakes as a summer's work. The winter snows drove the workers from the mountains, with from eight to twelve hundred dollars in their pockets for the season's work.

The increase in stumpage price has practically killed the shake maker's business. In the palmy days when most everything went, he procured his timber for little or nothing. He sometimes failed to find the surveyor's lines, particularly if there happened to be a fine sugar pine just across on a government quarter section. His method of operation was wastful. He used only the best of the tree. If the grain happened to twist the fraction of an inch, he abandoned the fallen trunk, and cut another. The shakes were split very thin, for sugar pine is among the most cleavable woods of this country. Four or five good trees provided the shake maker's camp with material for a year's work.

Some of the earliest sawmills in California cut sugar pine for sheds, shacks, sluiceboxes, flumes among the mines; and almost immediately a demand came from the agricultural and stock districts for lumber. From that day until the present time the sugar pine mills have been busy. As the demand has grown, the facilities for meeting it have increased. The prevailing size of the timber forbade the use of small 
mills. A saw large enough for most eastern and southern timbers would not slab a sugar pine log. From four to six feet were common sizes, and the lumberman despised anything small.

In late years sugar pine operators have looked beyond the local markets, and have been sending their lumber to practically every state in the Union, except probably the extreme South. It comes in direct competition with the white pine of New England and the Lake States. The two woods have many points of resemblance. The white pine would probably have lost no markets to the California wood if the best grades could still be had at moderate prices; but most of the white pine region has been stripped of its best timber, and the resulting scarcity in the high grades has been, in part, made good by sugar pine. Some manufacturers of doors and frames claim that sugar pine is more satisfactory than white pine, because of better behavior under climatic changes. It is said to shrink, swell, and warp less than the eastern wood.

Sugar pine has displaced white pine to a very small extent only, in comparison with the field still held by the eastern wood, whose annual output is about thirty times that of the California species. Their uses are practically the same except that only the good grades of sugar pine go east, and the corresponding grades of white pine west, and therefore there is no competition between the poor grades of the two woods. The annual demand for sugar and white pine east of the Rocky Mountains is probably represented as an average in Illinois, where $2,000,000$ feet of the former and $175,000,000$ of the latter are used yearly.

While there is a large amount of mature sugar pine ready for lumbermen, the prospect of future supplies from new growth is not entirely satisfactory. The western yellow pine is mixed with it throughout most of its range, and is more than a match for it in taking possession of vacant ground. It is inferred from this fact that the relative positions of the two species in future forests will change at the expense of sugar pine. It endures shade when small, and this enables it to obtain a start among other species; but as it increases in size it becomes intolerant of shade, and if it does not receive abundance of light it will not grow. A forest fire is nearly certain to kill the small sugar pines, but old trunks are protected by their thick bark. Few species have fewer natural enemies. Very small trees are occasionally attacked by mistletoe (Arceuthobium occidentale) and succumb or else are stunted in their growth.

Mexican Prion (Pinus combroides) is known also as nut pine, pinon pinc and stone-seed Mexican pinon. It is one of the smallest of the mative pincs of this country. The tree is fifteen or twenty feet high and a few inches in diameter, but in sheltered canyons in Arizona it sometimes at tains a height of fifty or sixty feel with 
a corresponding diameter. It reaches its best development in northern Mexico and what is found of it in the United States is the species' extreme northern extension, in Arizona and New Mexico at altitudes usually above 6,000 feet. It supplies fuel in districts where firewood is otherwise scarce, and it has a small place as ranch timber. The wood is heavy, of slow growth, the summerwood thin and dense. The resin passages are few and small; color, light, clear yellow, the sapwood nearly white. If the tree stood in regions well-forested with commercial species, it would possess little or no value; but where wood is scarce, it has considerable value. The hardshell nuts resemble those of the gray pine, but are considered more valuable for food. They are not of much importance in the United States, but in Mexico where the trees are more abundant and the population denser, the nuts are bought and sold in large quantities. Its leaves are in clusters of three, sometimes two. They are one inch or more in length, and fall the third and fourth years. Cones are seldom over two inches in length. The species is not extending its range, but seems to be holding the ground it already has. It bears abundance of seeds, but not one in ten thousand germinates and becomes a mature tree.

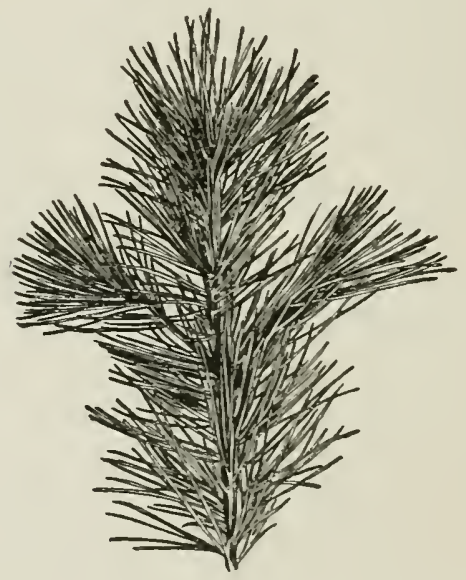


WHITEBARK PINE 


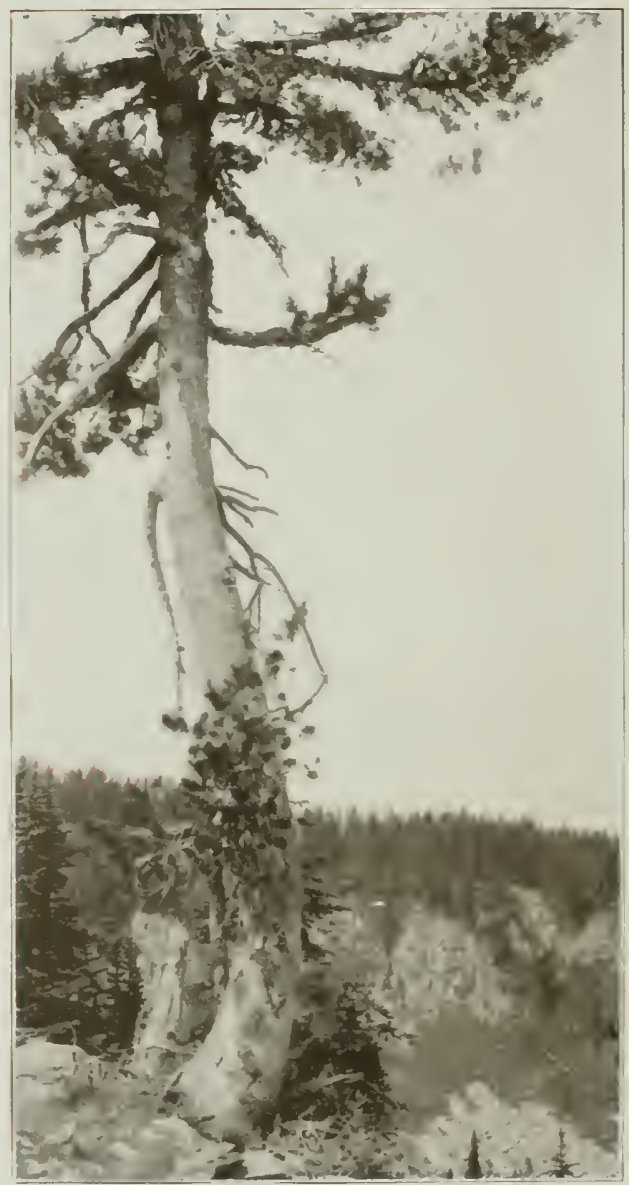

WHITEHARK PINE 


\section{WHITEBARK PINE}

\section{(Pinus Albicaulis)}

$\mathrm{T}$ HIS interesting and peculiar pine has a number of names, most of which are descriptive. The whiteness of the bark and the stunted and recumbent position which the tree assumes on bleak mountains are referred to in the names whitestem pine in California and Montana, scrub pine in Montana, whitebark in Oregon, white in California, and elsewhere it is creeping pine, whitebark pine, and alpine whitebark pine. It is a mountain tree. There are few heights within its range which it cannot reach. Its tough, prostrate branches, in its lof tiest situations, may whip snow banks nine or ten months of the year, and for the two or three months of summer every starry night deposits its sprinkle of frost upon the flowers or cones of this persistent tree. It stands the storms of centuries, and lives on, though the whole period of its existence is a battle for life under adverse circumstances. At lower altitudes it fares better but does not live longer than on the most sterile peak. Its range covers 500,000 square miles, but only in scattered groups. It touches the high places only, creeping down to altitudes of 5,000 or 6,000 feet in the northern Rocky Mountains. It grows from British Columbia to southern California, and is found in Montana, Idaho, Washington, Oregon, Nevada, Arizona, and California. Its associates are the mountain climbers of the tree kingdom, Engelınann spruce, Lyall larch, limber pine, alpine fir, foxtail pine, Rocky Mountain juniper, knobcone pine, and western juniper. Its dark green needles, stout and rigid, are from one and one-half to two and one-half inches long. They hang on the twigs from five to eight years. In July the scarlet flowers appear, forming a beantiful contrast with the white bark and the green needles. In August the seeds are ripe. The cones are from one and one-half to three inches long. The seeds are nearly half an inch long, sweet to the taste. The few squirrels and birds which inhabit the inhospitable region where the whitebark pine grows, get busy the moment the cones open, and few escape. Nature scems to have played a prank on this pine by giving wings to the seeds and rendering their use impossible. The wing is stuck fast with resin to the cone scales, and the seed can escape only by tearing its wing off. The heavy nut then falls plumb to the ground beneath the branches of its parent. It might be supposed that a tree situated as the whitebark pine is would be provided with ample means of seedflight in order to afford wide distribution, and give opportunity to survive the hardships which are inposed by surroundings; but such is not the case. The willow and the cottonwood 
which grow in fertile valleys have the means of scattering their seeds miles away; but this bleak mountain tree must drop its seeds on the rocks beneath. In this instance, nature seems more interested in depositing the pine nuts where the hungry squirrels can get them, than in furnishing a planting place for the nuts themselves-therefore, tears off their wings before they leave the cone. The battle for existence begins before the seeds germinate, and the struggle never ceases. The tree, in parts of its range, survives a temperature sixty degrees below zero. Its seedlings frequently perish, not from cold and drought, but because the wind thrashes them against the rocks which wear them to pieces. Trees which survive on the great heights are apt to assume strange and fantastic forms, with less resemblance to trees than to great, green spiders sprawling over the rocks. Trees 500 years old may not be five feet high. Deep snows hold them flat to the rocks so much of the time that the limbs cannot lift themselves during the few summer days, but grow like vines. The growth is so exceedingly slow that the new wood on the tips of twigs at the end of summer is a mere point of yellow. John Muir, with a magnifying glass, counted seventy-five annual rings in a twig one-eighth of an inch in diameter. Trunks three and onehalf inches in diameter may be 225 years old; one of six inches had 426 rings; while a seventeen-inch trunk was 800 years old, and less than six feet high. Such a tree has a spread of branches thirty or forty feet across. They lie flat on the ground. Wild sheep, deer, bear, and other wild animals know how to shelter themselves beneath the prostrate branches by creeping under; and travelers, overtaken by storms, sometimes do the same; or in good weather the sheepherder or the hunter may spread his blankets on the mass of limbs, boughs, and needles, and spend a comfortable night on a springy couch-actually sleeping in a tree top within two feet of the ground. In regions lower down, the whitebark pine reaches respectable tree form. Fence posts are sometimes cut from it in the Mono basin, east of the Sierra Nevada mountains. In the Nez Perce National Forest trees forty feet high have merchantable lengths of twenty-four feet. Similar growth is found in other regions. In its best growth, the wood of whitebark pine resembles that of white pine. It is light, of about the same strength as white pine, but more brittle. The annual rings are very narrow; the small resin passages are numerous. The sapwood is very thin and is nearly white. Men can never greatly assist or hinder this tree. It will continue to occupy heights and elevated valleys.

Bristlecone Pine (Pinus aristata) owes its name to the sharp bristles on the tips of the cone scales. It is known also as foxtail pine and hickory pinc. The latter name is given, not because of toughness, 
but on account of the whiteness of the sapwood. It is strictly a high mountain tree, running up to the timber line at 12,000 feet, and seldom occurring below 6,000 or $\overline{7}, 000$ feet. It maintains its existence under adverse circumstances, its home being on dry, stony ridges, cold and stormy in winter, and subject to excessive drought during the brief growing season. Trees of large trunks and fine forms are impossible under such conditions. The bristlecone pine's bole is short, tapers rapidly and is excessively knotty. The species reaches its best development in Colorado. Though it is seldom sawed for lumber, it is of much importance in many localities where better material is scarce. In central Nevada many valuable mines were developed and worked by using the wood for props and fuel. Charcoal made of it was particularly important in that region, and it was carried long distances to supply blacksmith shops in mining camps. Railways have made some use of it for ties. Though rough, it is liked for fence posts. The resin in the wood assists in resisting decay, and posts last many years in the dry regions where the tree grows. Ranchmen among the high mountains build corrals, pens, sheds, and fences of it; but the fibers of the wood are so twisted and involved that splitting is nearly impossible, and round timbers only are employed. The bristlecone pine can never be more important in the country's lumber supply than it is now. It occupies waste land where no other tree grows, and it crowds out nothing better than itself. It clings to stony peaks and wind-swept ridges where the ungainly trunks are welcome to the traveler, miner, or sheepherder who is in need of a shed to shelter him, or a fire for his night camp. In situations exposed to great cold and drying winds, the bristlecone pine is a shrub, with little suggestion of a tree, further than its green foliage and small cones. The needles are in clusters of five. They cling to the twigs for ten or fifteen years. The seeds are scattered about the first of October, and the wind carries them hundreds of feet. They take root in soil so sterile that no humus is visible. Young trees and the small twigs of old ones present a peculiar appearance. The bark is chalky white, but when the trees are old the bark becomes red or brown.

Foxtarl PrNe (Pinus balfouriana) owes its name to the clustering of its needles round the ends of the branches, bristling like a fox's tail. The needles are seldom more than one and one-half inches in length, and are in clusters of fives. They cling to the branches ten or fifteen years before falling. The cones are about three inches long, and are armed with slender spines. The tree is strictly a mountain species and grows at a higher altitude than any other tree in the United States, although whitebark pine is not much behind it. It reaches its best development near Mt. Whitney, California, where it is said to grow at an altitude of 15,000 feet above sea level. It has been officially reported at Farewell Gap, in the Sierra Nevada mountains, at an altitude of 13,000 . At high altitudes it is scrubby and distorted, but in 
more favorable situations it may be sixty feet high and two in diameter. On high mountains it is generally not more than thirty feet high and ten inches in diameter. It is of remarkably slow growth, and comparatively small trees may be 200 or 300 years old. The wood is moderately ligbt, is soft, weak, brittle. Resin passages are few and very small. The wood is satiny and susceptible of a good polish, and would be valuable if abundant. The seeds are winged and the wind scatters them widely, but most of them are lost on barren rocks or drifts of eternal snow. The untoward circumstances under which the tree must live prevent generous reproduction. It holds its own but can gain no new foothold on the bleak and barren heights which form its environment. The dark green of its foliage makes the belts of foxtail pines conspicuous where they grow above the timber line of nearly all other trees. Its range is confined to a few of the highest mountains of California, particularly about (but not on) Mt. Shasta and among the clusters of peaks about the sources of Kings and Kern rivers. Those who travel and camp among the highest mountains of California are often indebted to foxtail pine for their fuel. Near the upper limit of its range it frequently dies at the top, and stands stripped of bark for many years. The dead wood, which frequently is not higher above the ground than a man's head, is broken away by campers for fuel, and it is often the only resource.

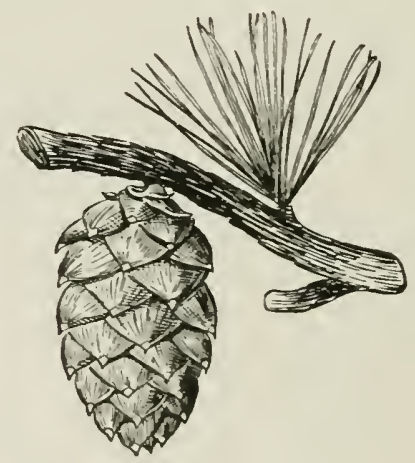


LONGLEAF PINE 


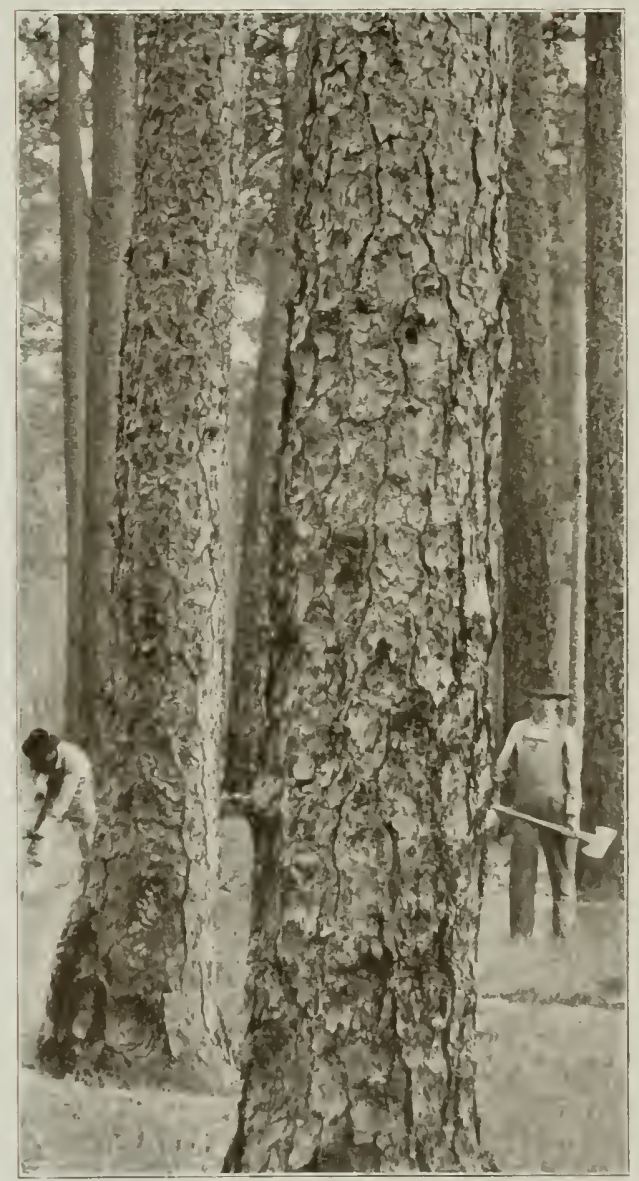

LONGLEAF PINE 


\section{LONGLEAF PINE}

\section{(Pinus Palustris)}

ONGLEAF is generally considered to be the most important member 1 of the group of hard or pitch pines in this country*. It is known by many names in different parts of its range, and outside of its range where the wood is well known.

The names southern pine, Georgia pine, and Florida pine are not well chosen, because there are other important pines in the regions named. Turpentine pine is a common term, but other species produce turpentine also, particularly the Cuban pine. Hard pine is much employed in reference to this tree, and it applies well, but it describes other species also. Heart pine is a lumberman's term to distinguish this species from loblolly, shortleaf, and Cuban pines. The sapwood of the three last named is thick, the heartwood small, while in longleaf pine the sap is thin, the heart large, hence the name applied by lumbermen. In Tennessee where it is not a commercial forest tree, it is called brown pine, and in nearly all parts of the United States it is spoken of as yellow pine, usually with some adjective as "southern," "Georgia," or "longleaf." The persistency with which Georgia is used as a portion of the name of this tree is due to the fact that extensive lumbering of the longleaf forests began in that state. The center of operations has since shifted to the West, and is now in Mississippi, Louisiana, and Texas. The tree has many other names, among them being pitch pine and fat pine. These have reference to its value in the naval stores industry. The name longleaf pine is now well established in commercial transactions. It has longer leaves than any other pine in this country. They range in length from eight to eighteen inches. The needles of Cuban pine are from eight to twelve inches; loblolly's are from six to nine; and those of shortleaf from three to five.

Longleaf pine's geographic range is more restricted than that of

*There is no precise agreement as to what should be included in the group of hard pines in the United States, but the following $t$ went $y-t$ wo are usually placed in that class: Longleaf Pine ( $P$ inus palustris), Shortleaf Pine ( $P$ inus echinata), Loblolly Pine (Pinus tada), Cuban Pine (Pinus hetcrophylla), Norway Pine (Pinus resinosa), Western Yellow Pine (Pinus ponderosa), Chihuahua Pine (Pinus chihuahuana), Arizona Pine (Pinus arizonica), Pitch Pine (Pinus rigida), Pond Pine (Pinus serotina), Spruce Pine (Pinus glabra), Monterey Pine (Pinus radiata), Knobcone Pine (Pinus altenuata), Gray Pine (Pinus sabiniana), Coulter Pine (Pinus coulferi), Lodgepole Pine (Pinus contorta), Jack Pine (Pinus dizaricata), Scrub Pine (Pinus virginiana), Sand Pine (Pinus clausa), Table Monntain Pine (Pinus pungcns) California Swamp Pine (Pinus muricata), Torry Pine (Pinus torrcyana.) 
loblolly and shortleaf, but larger than the range of Cuban pine. Longleaf occupies a belt from Virginia to Texas, following the tertiary sandy formation pretty closely. The belt seldom extends from the coast inland more than 125 miles. The tree runs south in Florida to Tampa bay. It disappears as it approaches the Mississippi, but reappears west of that river in Louisiana and Texas. Its western limit is near Trinity river, and its northern in that region is near the boundary between Louisiana and Arkansas.

Longleaf attains a height of from sixty to ninety feet, but a few trees reach 130. The diameters of mature trunks range from one foot to three, usually less than two. The leaves grow three in a bundle, and fall at the end of the second year. They are arranged in thick, broomlike bunches on the ends of the twigs. It is a tree of slow growth compared with other pines of the region. Its characteristic narrow annual rings are usually sufficient to distinguish its logs and lumber from those of other southern yellow pines. Its thin sapvood likewise assists in identification. The proportionately high percentage of heartwood in longleaf pine makes it possible to saw lumber which shows little or no saprrood. It is difficult to do that with other southern pines.

The wood is heavy, exceedingly har : for pine, very strong, tough, compact, durable, resinous, resin passages few, not conspicuous; medullary rays numerous, not conspicuous; color, light red or orange, the thin sapwood nearly white. The annual rings contain a large proportion of dark colored summerwood, which accounts for the great strength of longleaf pine timber. The contrast in color between the springwood and the summerwood is the basis of the figure of this pine which gives it much of its value as an interior finish material, including doors. The hardness of the summerwood provides the wearing qualities of flooring and paving blocks. The coloring matter in the body of the wood protects it against decay for a longer period than most other pines. This, in connection with its hardness and strength, gives it high standing for railroad ties, bridges, trestles, and other structures exposed to weather.

Longleaf pine is as widely used as any sof twood in this country. It serves with hardwoods for a number of purposes. It has been a timber of commerce since an early period, and was exported from the south Atlantic coast long before the Revolutionary war; but it was later than that when it came into keen competition with the Riga pine of northern Europe. It has since held its own in the European markets, and its trade has extended to many other foreign countries, particularly to the republics of South and Central America, Mexico, and the West Indies.

It did not attain an important position in the commerce of this 
country until after the Civil war, but it had a place in shipbuilding before that time, and it has held that place. The builders of cars employ large quantities for frames and other parts of gondolas, box cars, and coaches. Over 175,000,000 feet were so used in 1909 in Illinois. It is the leading car building timber in this country. Its great strength, hardness, and stiffness give it that place.

It is scarcely less important as an interior wood for house finish. It is not so much its strength as its beauty that recommends it for that purpose. Its beauty is due to a combination of figure and color. Splendid variety is possible by carefully selecting the material. Manufacturers of furniture, fixtures, and vehicles are large users of longleaf pine. In these lines its chief value is due to strength.

In the naval stores industry in this country, it is more important than all other species combined. For a century and a half it has supplied this country and much of the rest of the world. The principal commodities made from the resin of this tree are spirits of turpentine and rosin. These two articles are produced by distilling the resin which exudes from wounds in the tree. The distillate is spirits of turpentine, the residue is rosin. The manufacture of naval stores has destroyed tens of thousands of trees in the past; but better methods are now in use and loss is less. Georgia and South Carolina were once the center of naval stores production; but it has now moved to Louisiana and Florida.

The supply of longleaf pine has rapidly decreased during the past twenty years, and though the end is not yet at hand, it is approaching. Young trees are not coming on to take the place of those cut for lumber. They grow slowly at best, and a new forest could not be produced in less than a hundred years. Both protection and care have been lacking. Fire usually kills seedlings in their first or second year. The result is that many extensive tracts where longleaf pine once grew in abundance have few young and scarcely any old trees now. As far as can be foreseen, this valuable timber will reach its end when existing stands have been cut.

Cuban Pine (Pinus heterophylla). The Cuban pine has several local names; slash pine in Georgia, Florida, Alabama, and Mississippi; swamp pine in Florida, Alabama, and Mississippi ; meadow pine in Florida and Mississippi; pitch pine in Florida; and spruce pine in Alabama. Its range is confined to the coast region from South Carolina to Louisiana, from sixty to one hundred miles inlaud. It is the only pine in the extreme south of Florida. The wood is heavy, hard, very strong, tough, compact, durable, resinous, the resin passages few but conspicuous, rich dark orange color, the sapwood of ten nearly white. The annual 
ring is usually more than half dark colored summerwood. The Cuban pine grows rapidly, quickly appropriates vacant ground, and the species is spreading. Its needles, from eight to twelve inches long, fall the second year. The wood possesses nearly the strength, hardness, and stiffness of longleaf pine, and the trunks are as large. The two woods which are so similar in other respects differ in figure, owing to the wider annual rings of the Cuban pine. The sapwood of the latter species greatly exceeds in thickness that of longleaf pine. For that reason it is often mistaken for loblolly pine. Cuban pine never goes to market under its own name, but is mixed with and passes for one of the other southern yellow pines.

Sand Pine (Pinus clausa). This tree is generally twenty or thirty feet high, and eight or twelve inches in diameter. Under favorable conditions it attains a height of sixty or eighty feet and a diameter of two. The leaves are two or three inches long, and fall the third and fourth years. Its range is almost wholly in Florida but cxtends a little over the northern border. It grows as far south as Tampa on the west coast, and nearly to Miami on the east. It is not much cut for lumber because of its small size and generally short, limby trunk. In a few localities shapely boles are developed, and serviceable lumber is made. It is a poor-land tree, as its name implies. The cones adhere to the branches many years, and may be partly enclosed in the growing wood.

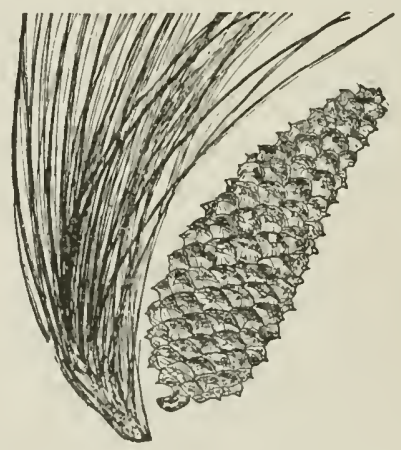


SHORTLEAF PINE 


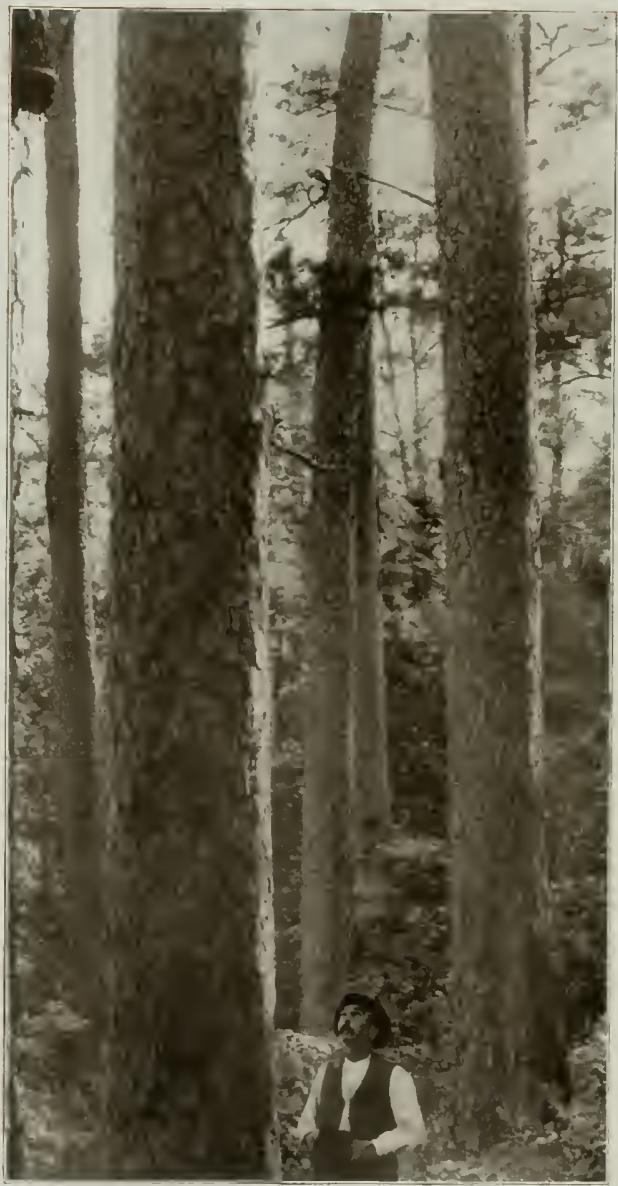

Shortleaf PiNe 


\section{SHORTLEAF PINE}

\section{(Pinus Echinata)}

$I^{\mathrm{N}}$ $\mathrm{N}$ the markets the lumber of this species is known as yellow pine, southern yellow pine, and sap pine, and in some localities the term shortleaf is used. The latter is descriptive, and can be easily understood when reference is made to the living tree, because its short needles distinguish it from its associates in the pine forest; but in speaking of lumber only, the reference to the leaves has less meaning, particularly to one who is not acquainted with the tree's appearance. Its wood so closely resembles that of Cuban and loblolly pine that they are not easily distinguished by sight alone. In the East the name Carolina pine or North Carolina pine is much used, but it is not often heard west of the Allegheny mountains. Referring to the manner and locality of its growth it is called slash pine in North Carolina and Virginia, old-field pine in Alabama and Mississippi, and poor-field pine in Florida. Its tendency to take possession of abandoned ground has given it these names. It is occasionally called pitch pine in Missouri. That name would not distinguish it in most parts of the South where several species of pitch pine grow. In some regions it is known as spruce pine, but the name is not based on any characteristic of the living tree or of its wood. In North Carolina and Alabama, and in literature, it is sometimes known as rosemary pine, but that name applies rather to fine timber cut from any southern yellow pine, than to this species in particular. In Delaware it is known as shortshat and in Virginia as bull pine. To those who are familiar with the tree's appearance, the name shortleaf pine is most accurate in definition.

The commercial range of shortleaf pine has contracted to a considerable extent since the settlement of the country. It once grew as far north as Albany, New York, and from fifty to a hundred years ago it was lumbered in Pennsylvania, Maryland, and West Virginia in regions where it has now ceased to exist, or is found only as scattered trees. Its geographical range is now usually given from New York to Florida, west to Missouri and Oklahoma and northeastern Texas. It is important in lumber operations in North Carolina and southward, and westward to the limits of its range. The tree reaches its largest size and attains its finest stands west of the Mississippi river. In average size it exceeds longleaf pine. It may reach a height above 100 feet and a trunk diameter of three or four. Squared timbers of large size were formerly exported from Virginia and North Carolina. Similar sizes cannot now be procured there. 
Shortleaf pine varies greatly in the quality and amount of sapwood. It is normally a thick sap tree, but midway between loblolly and longleaf. The young tree increases rapidly in size until it is from six to ten inches in diameter, and the yearly rings are wide. The rate of growth then decreases and during the rest of its life the rings are narrow. This feature is often of assistance in identifying southern yellow pine logs or large timbers which contain the heart and also the sap. Wide rings near the heart, followed by narrow ones, and a thick sapwood are pretty good evidence that the timber-if a southern yellow pine-is shortleaf pine. The rule is not absolute; for a high authority on timber has said that no infallible rule can be laid down for distinguishing by sight alone the woods of the four southern yellow pines-longleaf, shortleaf, Cuban, and loblolly.

The wood of shortleaf pine is strong, heavy, hard, and compact; very resinous, resin passages large and numerous; medullary rays numerous, conspicuous; color, orange, the sapwood nearly white. The thoroughly seasoned wood weighs thirty-eight pounds per cubic foot. It is about five pounds heavier than loblolly pine, five pounds lighter than longleaf, and nearly nine pounds lighter than Cuban pine. There is so great a variation in weight of shortleaf pine that only general averages have value.

Shortleaf pine is not as strong as longleaf, and is not so extensively employed in heavy structural work, but in certain other lines it has the advantage of longleaf. It is softer, and door and sash makers like it better. It is easier to work, and when manufactured into doors and interior finish many consider it superior to longleaf. The wide rings of annual growth in the heartwood show fine contrast in color, and when these are developed by stains and fillers, the grain or figure of the wood is very pleasing. Where hardness is not an essential, it is much used for floors. It is in great demand by builders of freight cars, but less for frames and heavy beams than for siding and decking. Car builders in Illinois bought $7 \bar{\tau}, 000,000$ feet of it in 1909 . That was nearly half of the entire quantity of this wood used in the state. The second largest users in Illinois were manufacturers of sash, doors, blinds, and general millwork. If the whole country is considered, this is probably the largest use of the wood. Makers of boxes and crates in the South employ large quantities.

The depletion of shortleaf forests has progressed rapidly, but in the absence of reliable statistics it is impossible to give figures by decades or years. In 1850 an estimate placed the amount west of the Mississippi at $95,000,000,000$ feet. That was probably less than half of the country's supply at that time. In 1911 the Commissioner of Corporations esti- 
mated that the combined remaining stand of loblolly and shortleaf pine in the South was $152,000,000,000$ feet. It is doubtful if half of it was shortleaf. In that case, there was less shortleaf pine in the entire South in 1911 than there was west of the Mississippi river thirty years before.

Rapid decrease in total stand of a species does not necessarily imply exhaustion. The cut will fall off as scarcity pinches. In the case of shortleaf pine, an influence is active which will bring good results in the future. This pine reproduces with vigor. Its small triangular seeds are equipped with wings which carry them into vacant areas where they quickly germinate if they fall on mineral soil. The seedling trees suffer much from fire, but their power of resistance is fairly good, and dense new growth is coming on in many localities. A good many years are required to bring a seedling to maturity, but it will reach sawlog size sometime, and there is no question but that the market will welcome it.

The shortleaf pine is peculiar among eastern softwoods in one respect. Stumps will sprout. That occurs of tener west of the Mississippi than east. However, the tree's ability to send up sprouts from the stump is of little practical value, since the sprouts seldom or never develop into merchantable trees. In that respect it differs from the other well-known sprouting sof twood of this country, the California redwood, whose numerous sprouts grow into large trunks.

Spruce Pine (Pinus glabra). This is one of the softest and the whitest of the hard pines of this country. Nothing but its scarcity stands in the way of its becoming an important timber tree. The best of it is a satisfactory substitute for white pine in the manufacture of doors. It grows rapidly, and the wide rings contain a high percentage of light colored springwood, though there is enough summerwood of darker color to give the dressed lumber a character. It weighs about the same as northern white pine, but is weaker. In South Carolina and Florida it is called white pine, but the name spruce is more general. It is known also as kingstree, poor pine, Walter's pine, and lowland spruce pine. Its range is restricted to southern South Carolina, northern Florida and southern Alabama and Mississippi, and northeastern Louisiana. Its leaves are from one and a half to three inches in length, grow two in a bundle, and fall the second and third years. Large and well-formed trunks attain a height of from eighty to 100 feet and a diameter from two to nearly three. It reaches its best development in northwestern Florida, and its light, symmetrical trunks have long been in use there as masts for small vessels. It is too scarce to attract much attention from lumbermen, but they are well acquainted with its good qualities, and some of them take pains to keep the lumber separate from associated pines, and sell it to manufacturers of doors and interior finish. The bark 
bears considerable resemblance to spruce, which probably accounts for the name of the tree.

Table Mountain Pine (Pinus pungens). The French botanist, Michaux the younger, has been criticized for the statement which he made more than a hundred years ago that this species was confined to a certain flat-topped mountain in the southern Appalachian ranges, and he called it table mountain pine. It lacked much of being confined within the narrow limits where it was discovered. It grows in New Jersey, Pennsylvania, Maryland, District of Columbia, Virginia, West Virginia, Kentucky, Tennessee, North Carolina, and Georgia. Its other names are prickly pine, bickory pine, and southern mountain pine. It supplies timber in all parts of its range, but, except in very restricted localities, it is not abundant. The lumber in the market is seldom distinguished from other pines, but some of the Tennessee mills sell it separately to local customers. The wood is medium light, rather strong (ahout like Pinus rigida, or pitch pine, which it resembles in other respects), is less stiff than white pine, and is resinous. The thick sapwood is nearly white, the heartwood brown. It is not a durable timber in contact with the ground. Its fuel value is low. Its needles grow in clusters of two, and are generally less than two inches long. The cones which are in clusters of from three to eight, and from two to three and a balf inches long, are armed with stout, curved hooks. The cones shed their seeds irregularly during two or three years, and sometimes hang on the trees for twenty years. In open ground this pine occasionally produces fertile seeds when only a few feet high. Its forest form and open-ground form are quite different. In thick woods the tree is tall, with good bole, but in open ground it is only twenty or thirty feet high, and is covered with limbs almost to the ground.

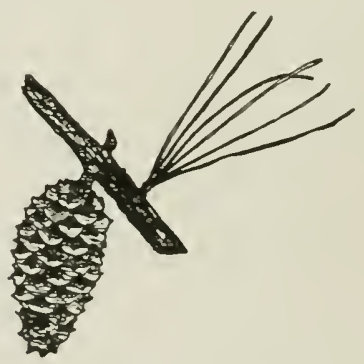


LOBLOLLY PIXE 


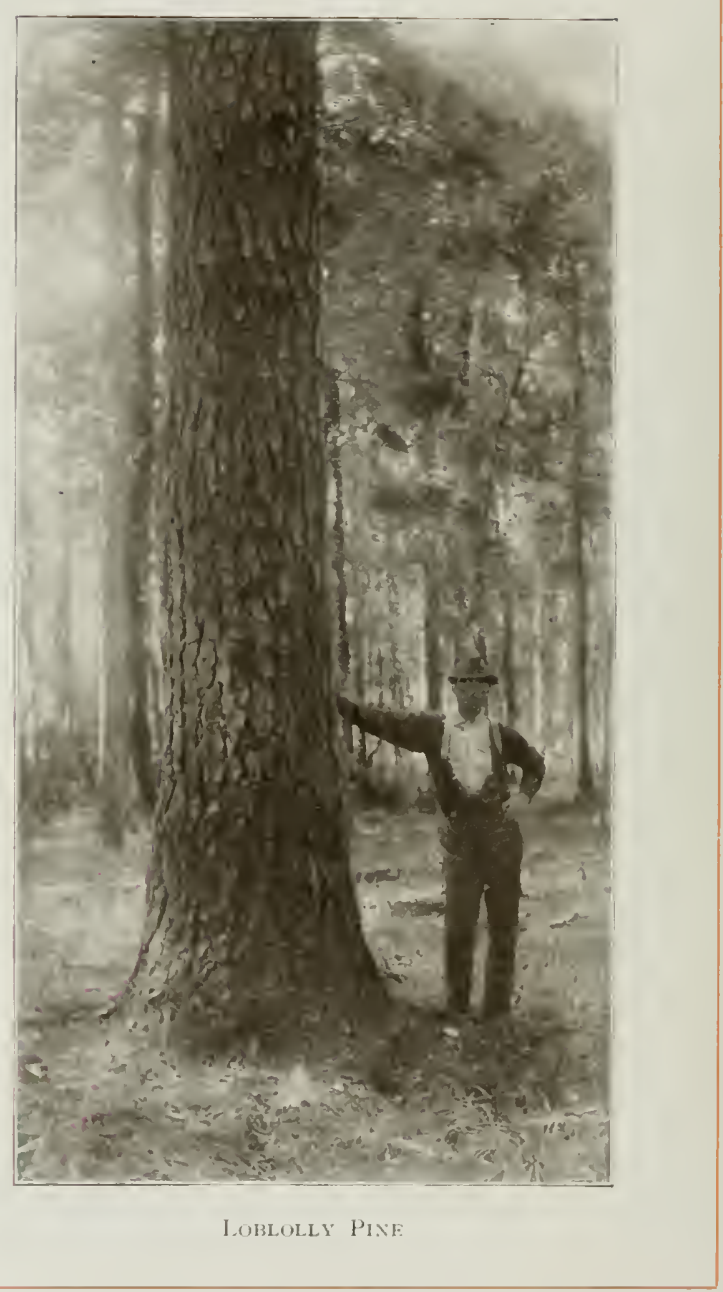




\section{LOBLOLLY PINE}

\section{(Pinus TRda)}

$\mathrm{F}$ EW trees have more names than this. The names, however, may be separated into groups, one group referring to the foliage, another to the situations in which the tree grows, and a third to certain characters or uses of the wood. Names descriptive of the leaves are longschat pine, longshucks pine, shortleaf pine, foxtail pine, and longstraw pine. The names which refer to locality or situation are loblolly pine, old-field pine, slash pine, black slash pine, Virginia pine, meadow pine and swamp pine. Names which refer to the character of the wood or of the standing tree are torch pine, rosemary pine, frankincense pine, cornstalk pine, spruce pine, and yellow pine. Not one of these names is applied to the tree in its entire range, and it has several names other than those listed. Sap pine is widely applied to the lumber, because the tree's sapwood is very thick, sometimes amounting to eighty per cent of a trunk. It has borne the name old-field pine for a hundred and fifty years in Virginia, and the name suggests a good deal of history. Some of the improvident early Virginia tobacco growers neglected to fertilize their fields, and the land wore out under constant cropping, and was abandoned. The pine quickly took possession, for the fields which were too far exhausted to produce tobacco or corn were amply able to grow dense stands of loblolly pine, and the farmers noticing this, called it old-field pine. It has been taking possession of abandoned fields in Virginia and North Carolina ever since, and the name still applies. The tree grows from New Jersey to Florida, west to Texas, north to Oklahoma, Tennessee, and West Virginia, but it does not cover the whole territory thus outlined. It is very scarce near its northern limit. There is evidence that the range of loblolly has extended in historic times, not into new or distant regions, but outside the borders which once marked its range. Since white men in Texas stopped the Indians' grass fires, the pine has encroached upon the prairie. Early writers in Virginia and North Carolina spoke of pine as scarce or totally wanting, except on the immediate coast. It is now found from one hundred to two hundred miles inland, and many sawmills now cut logs which have grown in fields abandoned since the Revolutionary war. This has occurred on the Atlantic coast rather than west of the Appalachian ranges of mountains. Virginia has more sawmills than any other state, and many of them are working on loblolly pine which has grown in the last hundred years.

The tree bears seeds abundantly and scatters them widely. It is vigorous, grows with great rapidity, and is able to fight its way if it finds 
conditions in any way favorable. Turpentine operators have not found the working of loblolly pine profitable, and this has relieved it of a drain which has done much to deplete the southern forests of longleaf pine.

Loblolly's leaves are from six to nine inches long, and fall the third year. This species, in common with other southern yellow pines, is disposed to grow tall, clear trunks, with a meager supply of limbs and foliage at the top. The lumber sawed from trunks of that kind is clear of knots. No other important forest tree of the United States comes as nearly being a cultivated tree as the loblolly pine. This is particularly true in the northeastern part of its range, in North Carolina, Virginia, and Maryland. Though nature has done the actual planting, men provided the seed beds by giving up old fields to that use; and many of the stands are as thick and even as if they had been planted and cared for by regular forestry methods. Trees are from eighty to one hundred feet tall, and from two to four in diameter, some very old ones being a little larger.

The annual rings of loblolly pine are broad, with good contrast between the spring and summer growth. The wood is light, not strong, brittle, not durable, very resinous, the resin passages are few and not conspicuous; medullary rays are numerous and obscure; color, light brown, the thick sapwood orange or nearly white. When this tree is of slow growth it is lighter, less resinous, and has thinner sapwood. It is sometimes known as rosemary pine.

The use of loblolly pine lumber was greatly stimulated when the custom of drying it in kilns bccame general. It is largely sapwood and dries slowly in air. Its market is found in all eastern and central parts of the United States, and it is exported to Europe and Central and South America. It is a substantial material for many common purposes and its use is very large on the Atlantic coast. In quantity it exceeds any other species in the wood-using industries of Maryland, and all others combined in North Carolina. It is not as often employed in heavy structural timbers as longleaf pine, but in the market of which Baltimore is the center, much use is made of it for that purpose. It is ten pounds a cubic foot lighter than longleaf, has about three-fourths of the strength, and nearly four-fifths of longleaf's elasticity. It is thus seen to be considerably inferior to it as a structural timber where heavy loads must be sustained; but builders use it for many purposes in preference to or on an equality with longleaf. It is fine for interior finish and doors. Railroads employ large quantities in building freight cars, much for crossties, and bridge builders find many places for it. It is not a long lasting wood when exposed to weather, unless it has been treated with creosote to preserve it from decay. It is one of the most easily treated woods. 
In North Carolina and Virginia loblolly tobacco hogsheads are common; and box factories within easy reach of it use much. A list of its uses, compiled from reports of factory operations in Maryland, will give an idea of the range it covers: Basket bottoms, beer bottle boxes, boats, cart bodies, crates, flooring, frames for doors and windows, fruit boxes, interior finish, nail kegs, oyster boxes, seats for boats, siding for houses, staves for slack cooperage, store fixtures, wagon beds, balusters, brackets, chiffoniers, mantels, molding, picture frames, stair railing, sash, scrollwork, sideboards, tables.

The amount of loblolly pine timber in this country is not known. No other important species comes so near growing as much as is cut from year to year. It covers 200,000 square miles with stands ranging from little or nothing in some parts to 20,000 feet per acre in others, or more in exceptional cases. The area of fully stocked loblolly pine is believed to be as large now as it ever was. Before the Civil war it was predicted that its period of greatest production was over; but large tracts are now being logged on which the pine seeds had not been sown in 1860 .

Pond Pine (Pinus serotina). Sargent's table of weights of woods shows this to be the heaviest pine of the United States; but, as his calculations were made from a single sample which grew in Duval county, Florida, further data should be secured before his figures, 49.5 pounds per cubic foot, are accepted as an average weight for the species. It is rated in strength about equal to longleaf and Cuban pine. Its structure shows a large percentage of dense summerwood in the yearly ring. The leaves are in clusters of three, rarely four, and are six or eight inches long, and fall in their third and fourth years. The name suggests that the cones are tightly closed, and that they adhere tenaciously to the twigs on which they grow. This is found true. The principal impression made on a person who sees the pond pine for the first time is that it is overloaded with cones, and that it must be a prolific seeder. Better acquaintance modifies the latter part of that impression. It is overloaded with cones, but most of them are many years old, and have lons been seedless, although most of the trees have the seed crops of tro years on the branches at one time. Enough seed is shed to perpetriate the species, but too little to insure an aggressive spread into surrounding vacant ground. The pond pine may reach a diameter of three feet and a height of eighty, but that is twice the average size. The wood is very resinous, and is brittle.

Scrub Pine (Pinus virginiana). This tree is often called Jersey pine because it is a prominent feature of the landscapes in the southern part of that state where it has spread extensively since the settlement of the country. Its short necdles have 
been responsible for several of its names, among them being shortshuck pine in Maryland and Virginia, shortshat pine in Delaware, shortleaved pine in North Carolina, and spruce pine and cedar pine in some parts of the South. In Tennessee it is known as nigger pine, and in some parts of North Carolina as river pine. The range is fairly well outlined by the above discussion of its names. It grows from New York to South Carolina, and west of the mountains it is found in northern Alabama and middle Tennessee, in Kentucky and West Virginia. It reaches its largest size in southern Indiana where it is sometimes 100 feet high and three in diameter. It is there a valuable tree for many purposes, but is not abundant. Its average size is small in the eastern states, usually not over fifty feet high, and often little more than half of that. Few trunks east of the Allegheny mountains are more than eighteen inches in diameter. The name scrub pine is an index to the opinions held by most people regarding this tree. It is often considered an encumbrance rather than an asset; yet statistics of wood-using industries hardly justify that view. Millions of feet of it are employed annually in each of the states of New Jersey, Maryland, Virginia, and North Carolina, for boxes, slack cooperage, and common lumber. The wood is moderately strong, but is not stiff. It is medium light, soft, brittle, with summerwood narrow and very resinous. Its color is light orange or yellow, the thick sapwood ivory white. The needles are from one and a half to three inches long, and fall in the third and fourth years. Cones are two or three inches long, and scatter their seeds in autumn. The wings are too small to carry the seeds far, yet the tree succeeds in quickly spreading into surrounding vacant spaces. Cones adhere to the branches three or four years. Tar makers and charcoal burners utilized scrub pine in New Jersey, northeastern Maryland and southeastern Pennsylvania a century and a half ago. The tree seems to be as abundant now as it ever was. Unless it occupies very poor land-which it generally does-the growth is liable to be suppressed and crowded to death by broadleaf trees before the stands become very old. As a species, it is weak in self-defense, and it owes its survival to its habit of retreating to poor soils where enemies cannot follow. It may be said of it as the Roman historian Tacitus said of certain men: "The cowards fly the farthest, and are the longest survivors.".

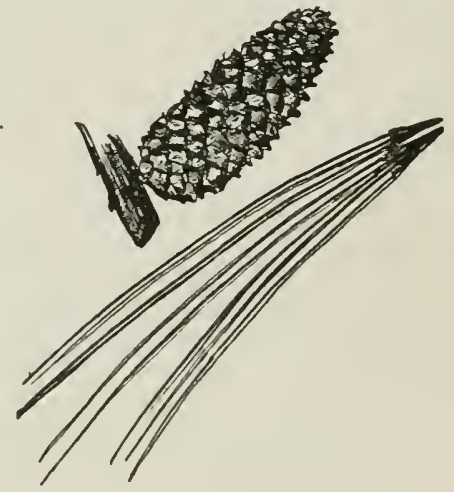


NORIIAT PINE 


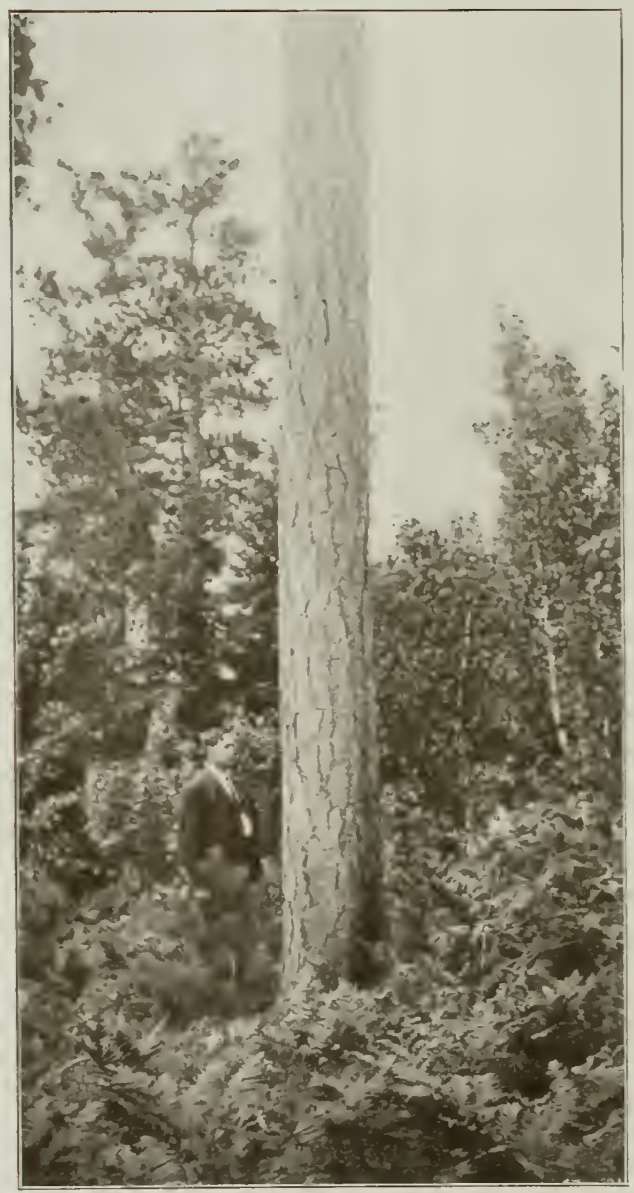

Nurway PINe 


\title{
NORWAY PINE
}

\author{
(Pinus Resinosa)
}

E ARLY explorers who were not botanists mistook this tree for Norway spruce, and gave it the name which has since remained in nearly all parts of its range. It is called red pine also, and this name is strictly descriptive. The brown or red color of the bark is instantly noticed by one who sees the tree for the first time. In the Lake States it has been called hard pine for the purpose of distinguishing it from the softer white pine with which it is associated. In England they call it Canadian red pine, because the principal supply in England is imported from the Canadian provinces.

Its chicf range lies in the drainage basin of the St. Lawrence river, which includes the Great Lakes and the rivers which flow into them. Newfoundland forms the eastern and Manitoba the western outposts of this species. It is found as far south as Massachusetts, Pennsylvania, northern Ohio, central Michigan, Wisconsin, and Minnesota. It conforms pretty generally to the range of white pine but does not accompany that species southward along the Appalachian mountain ranges across IVest Virginia, Virginia, Kentucky, and Tennessee. Where it was left to compete in nature's way with white pine, the contest was friendly, but white pine got the best of it. The two species grew in intermixture, but in most instances white pine had from five to twenty trees to Norway's one. As a survivor under adversity, however, the Norway pine appears to surpass its great friendly rival, at least in the Lake States where the great pineries once flourished and have largely passed away. Solitary or small clumps of Norway pines are occasionally found where not a white pine, large or small, is in sight.

The forest appearance of Norway pine resembles the southern yellow pines. The stand is open, the trunks are clean and tall, the branches are at the top. The Norway's leaves are in clusters of two, and are five or six inches long. They fall during the fourth or fifth year. Cones are two inches long, and when inature, closely resemble the color of the tree's bark, that is, light chestnut brown. Exceptionally tall Norway pines may reach a height of 150 feet, but the average is seventy or eighty, witl diameters of from two to four. Young trees are limby, but early in life the lower branches die and fall, leaving few protruding stubs or knots. It appears to be a characteristic that trunks are seldom quite straight. They do not have the plumb appearance of forest grown white pine and spruce.

The wood of Norway pine is medium light, its strengtl and stifiness 
about twenty-five per cent greater than white pine, and it is moderately soft. The annual rings are rather wide, indicating rapid growth. The bands of summerwood are narrow compared with the springwood, which gives a generally light color to the wood, though not as light as the wood of white pine. The resin passages are small and fairly numerous. The sapwood is thick, and the wood is not durable in contact with the soil.

Norway pine has always had a place of its own in the lumber trade, but large quantities have been marketed as white pine. If such had not been the case, Norway pine would have been much oftener heard of during the years when the Lake State pineries were sending their billions of feet of lumber to the markets of the world.

Because of the deposit of resinous materials in the wood, Norway pine stumps resist decay much better than white pine. In some of the early cuttings in Michigan, where only stumps remain to show how large the trees were and how thick they stood, the Norway stumps are much better preserved than the white pine. Using that fact as a basis of estimate, it may be shown that in many places the Norway pine constituted one-fifth or one-fourth of the original stand. The lumbermen cut clean, and statistics of that period do not show that the two pines were generally marketed separately. In recent years many of the Norway stumps have been pulled, and have been sold to wood-distillation plants where the rosin and turpentine are extracted.

At an early date Norway pine from Canada and northern New York was popular ship timber in this country and England. Slender, straight trunks were selected as masts, or were sawed for decking planks thirty or forty feet long. Shipbuilders insisted that planks be all heartwood, because when sapwood was exposed to rain and sun, it changed to a green color, due to the presence of fungus. The wood wears well as ship decking. The British navy was still using some Norway pine masts as late as 1875 .

The scarcity of this timber has retired it from some of the places which it once filled, and the southern yellow pines have been substituted. It is still employed for many important purposes, the chief of which is car building, if statistics for the state of Illinois are a criterion for the whole country. In 1909 in that state $24,794,000$ feet of it were used for all purposes, and $14,783,000$ feet in car construction.

For many years Chicago has been the center of the Norway pine trade. It is landed there by lake steamers and by rail, and is distributed to ultimate consumers. The uses for the wood, as reported by Illinois manufacturers, follow: Baskets, boxes, boats, brackets, casing and frames for doors and windows, crating, derricks for well-boring machines, doors, 
elevators, fixtures for stores and offices, foot or running boards for tank cars, foundry flasks, freight cars, hand rails, insulation for refrigerator cars, ladders, picture moldings, roofing, sash, siding for cattle cars, sign boards and advertising signs, tanks, and windmill towers.

As with white pine, Norway pine has past the period of greatest production, though much still goes to market every year and will long continue to do so. The land which lumbermen denuded in the Lake States, particularly Michigan and Wisconsin, years ago, did not reclothe itself with Norway seedlings. That would have taken place in most instances but for fires which ran periodically through the slashings until all seedlings were destroyed. In many places there are now few seedlings and few large trees to bear seeds, and consequently the pine forest in such places is a thing of the past. The outlook is better in other localities.

The Norway pine is much planted for ornament, and is rated one of the handsomest of northern park trees.

PITch PINE (Pinus rigida). The name pitch pine is locally applied to almost every species of hard, resinous pine in this country. The Pinus rigida has other names than pitch pine. In Delaware it is called longleaved pine, since its needles are longer than the scrub pine's with which it is associated. For the same reason it is known in some localities as longschat pine. In Mfassachusetts it is called hard pine, in Pennsylvania yellow pine, in North Carolina and eastern Tennessee black pine, and black Norway pine in New York. The botanical name is translated "rigid pine," but the rigid refers to the leaves, not the wood. Its range covers New England, New York, Pennsylvania, southern Canada, eastern Ohio, and southward along the mountains to northern Georgia. It has three leaves in a cluster, from three to five inches long, and they fall the second year. Cones range in length from one to three inches, and they hang on the branches ten or twelve years. The wood is medium light, moderately strong, but low in stiffness. It is soft and brittle. The annual rings are wide, the summerwood broad, distinct, and very resinous. Medullary rays are few but prominent; color, light brown or red, the thick sapwood yellow or of ten nearly white. The difference in the hardness between springwood and summerwood renders it difficult to work, and causes uneven wear when used as flooring. It is fairly durable in contact with the soil.

The tree attains a height of from forty to eighty feet and a diametcr of three. This pine is not found in extensive forests, but in scattered patches, nearly always on poor soil where other trees will not crowd it. Light and air are necessary to its cxistence. If it receives these, it will fight successfully against adversities which would be fatal to many other species. In resistance to forest fires, it is a salamander among trees. That is primarily due to its thick bark, but it is favored also by the situations in which it is generally found -open woods, and on soil so poor that ground hitter is thin. It is a useful wood for many purposes, and wherever it is found in sufficient quantity, it goes to market, but under its own name only in restricted localities. Its resinous knots were once used in place of candles in frontier homes. Tar made locally from its rich wood was the pioneer wagoner's axle grease, and the ever-present tar bucket and tar paddle swung from the rear axle. Torches made by tying splinters in bundles answered for lanterns in night travel. It was the best pine 
for floors in some localities. It is probably used more for boxes than for anything else at present. In I909 Massachusetts box makers bought 600,000 feet, and a little more went to Maryland box factories. Its poot holding power on spikes limits its employment as railroad ties and in shipbuilding. Carpenters and furniture makers object to the numerous knots. Country blacksmiths who repair and make wagons as a side line, find it suitable for wagon beds. It is much used as fuel where it is convenient.

TORrey PINE (Pinus torreyana), called del mar pine and Soledad pine, is an interesting tree from the fact that its range is so restricted that the actual number of trees could be easily known to one who would take the trouble to count them. A rather large quantity formerly occupied a small area in San Diego county, California, but woodchoppers who did not appreciate the fact that they were exterminating a species of pine from the face of the earth, cut nearly all of the trees for fuel. Its range covered only a few square miles, and fortunately part of that was included in the city limits of San Diego. An ordinance was passed prohibitirig the cutting of a Torrey pine under heavy penalty, and the tree was thus saved. A hundred and fifty miles off the San Diego coast a few Torrey pines grow on the islands of Santa Cruz and Santa Rosa, and owing to their isolated situation they bid fair to escape the cordwood cutter for years to come. Those who have seen this tree on its native hills have admired the gameness of its battle for existence against the elements. Standing in the full sweep of the ocean winds, its strong, short branches scarcely move, and all the agitation is in the thick tufts of needles which cling to the ends of the branches. Trees exposed to the seawinds are stunted, and are generally less than a foot in diameter and thirty feet high; but those which are so fortunate as to occupy sheltered valleys are three or four times that size. The needles are five in a cluster. The cones persist on the branches three or four years. The wood is light, soft, moderately strong, very brittle; the rings of yearly growth are broad, and the yellow bands of summerwood occupy nearly half. The sapwood is very thick and is nearly white.

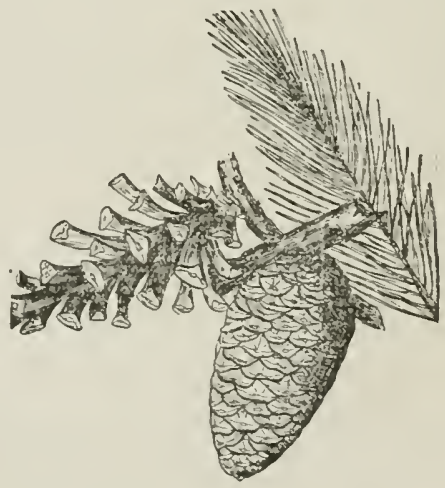


MESTERN YELL') PINE 


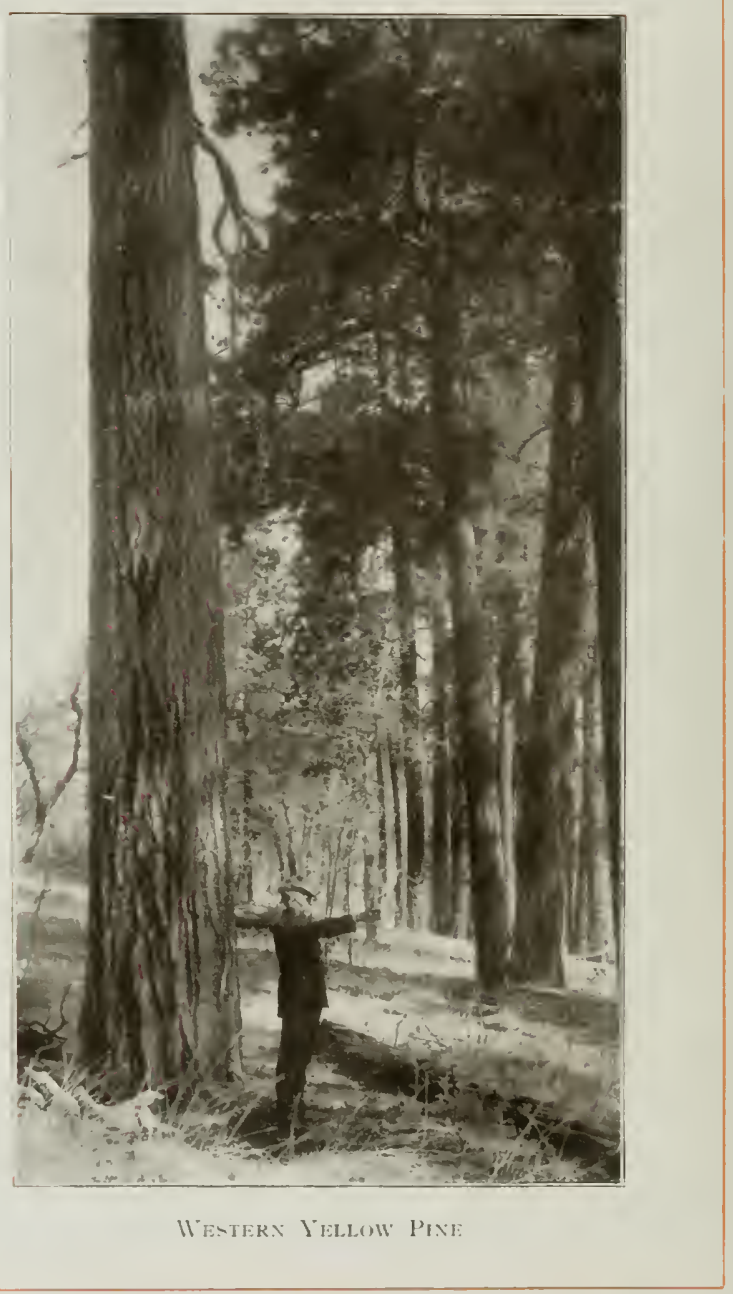




\section{WESTERN YELLOW PINE}

\section{(Pinus Ponderosa)}

$7 \mathrm{HE}$ range of western yellow pine covers a million square miles. Its eastern boundary is a line drawn from South Dakota to western Texas. The species covers much of the country between that line and the Pacific ocean. It is natural that it slould have more names than one in a region so extensive. It is best known as western yellow pine, but lumbermen often call it California white pine. The standing timber is frequently designated bull pine, but that name is not often given to the lumber. Where there is no likelihood of confusing it with southern pines, it is called simply yellow pine. The name heavy-wooded pine, sometimes applied to the lumber in England, is misleading. When well seasoned it weighs about thirty pounds per cubic foot, and ordinarily it would not be classed heavy. In California it is called heavy pine, but that is to distinguish it from sugar pine which is considerably lighter. The color of its bark has given it the name Sierra brownbark pine. The same tree in Montana is called black pine.

The tree has developed two forms. Some botanists have held there are two species, but that is not the general opinion In the warm, damp climate of the Pacific slope the tree is larger, and somewhat different in appearance from the form in the Rocky Mountain region. The same observation holds true of Douglas fir.

The wood of western yellow pine is medium light, not strong, is low in elasticity, medullary rays prominent but not numerous; resinous, color light to reddish, the thick sapwood almost white. The annual rings are variable in width, and the proportionate amounts of springwood and summerwood also vary. It is not durable in contact with the ground.

The wood is easy to work and some of the best of it resembles white pine, but as a whole it is inferior to that wood, though it is extensively employed as a substitute for it in the manufacture of doors, sash, and frames. It is darker than white pine, harder, heavier, stronger, almost exactly equal in stiffness, but the annual rings of the two woods do not bear close resemblance.

The tree reaches a height of from 100 to 200 feet, a diameter from three to seven. It is occasionally much larger. Its size depends much on its habitat. The best development occurs on the Sierra Nevada mountains in California and the best wood comes from that region, though certain other localities produce high-grade luruber.

Western yellow pine holds and will long hold an important place 
in the country's timber resources. The total stand has been estimated at $275,000,000,000$ feet, and is second only to that of Douglas fir, though the combined stand of the four southern yellow pines is about 100,000 ,000,000 feet larger. It is a vigorous species, able to hold its ground under ordinary circumstances. Next to incense cedar and the giant sequoias which are associated with it in the Sierra Nevada mountains, it is the most prolific seed bearer of the western conifers, and its seeds are sufficiently light to insure wide distribution. It is gaining ground within its range by taking possession of vacant areas which have been bared by lumbering or fire. In some cases it crowds to death the more stately sugar pine by cutting off its light and moisture. It resists fire better than most of the forest trees with which it is associated. On the other hand, it suffers from enemies more than its associates do. A beetle (Dendroctonus ponderosce), destroys large stands. In the Black Hills in 1903 its ravages killed 600,000,000 feet.

This splendid pine has run the gamut of uses from the corral pole of the first settler to the paneled door turned out by the modern factory: It has almost an unlimited capacity for usefulness. It grows in dry regions of the Rocky Mountains where it is practically the only source of wood supply; and it is equally secure in its position where forests are abundant and fine. It has supplied props, stulls, and lagging for mines in nearly every state touched by its range. Without its ties and other timbers some of the early railroads through the western mountains could scarcely have been built. It has been one of the leading flume timbers in western lumber and irrigation development. It fenced many ranches in early times and is still doing so. It is used in general construction, and in finish; from the shingle to the foundation sill of houses. It finds its way to eastern lumber markets. Almost 20,000,000 feet a year are used in Illinois alone. Competition with eastern white pine is met in the Lake States because, grade for grade, the western wood is cheaper, until lower grades are reached. The western yellow pine, in the eastern market, is confused with the western white pine of Idaho and Montana (Pinus monticola) and separate statistics of use are impossible.

The makers of fruit boxes in California of ten employ the yellow pine in lieu of sugar pine which once supplied the whole trade. It is also used by coopers for various containers, but not for alcoholic liquors.

The leaves are in clusters of twos and threes, and are from five to eleven inches long. Most of them fall during the third year. The cones are from three to six inches long, and generally fall soon after they reach maturity.

Covlter Pine (Pinus coulleri) is also known as nut pine, big cone pine, and long cone pine. It is a California species, searce, but of much interest because of its 
cones. They are larger than those of any other American pine and are armed with formidable curved spines from half an inch to an inch and a half in length. The cones are from ten to fourteen inches long. The tree is found on the Coast Range mountains from the latitude of San Francisco to the boundary between California and Mexico. It thrives at altitudes of from 3,000 to 6,000 feet. It never occurs in pure stands and the total amount is small. It looks like the western yellow pine, but is much inferior in size. Trunks seldom attain a length of fifteen feet or a diameter of two. There is no evidence that Coulter pine is increasing its stand on the ground which it already occupies, or spreading to new ground. The wood is light, soft, moderately strong, and very tough. The annual rings are narrow and consist largely of summerwood. The beartwood is light red, the thick sapwood nearly white. It is a poor tree for lumber, and it has been little used in that way, but has been burned for charcoal for blacksmith shops, and much is sold as cordwood. The leaves of Coulter pine are in clusters of three, and they fall during the third and fourth years.

California Swamp Pine (Pinus muricata) clearly belongs among minor species listed as timber trees. It meets a small demand for skids, corduroy log roads, bridge floors, and scaffolds in the redwood logging operations in California. It is scat tered along the Pacific coast 500 miles, beginning in Lower California and ending a hundred miles north of San Francisco. It is known as dwarf marine pine, pricklecone pine, bishop pine, and obispo pine. The last name is the Spanish translation of the English word bishop. The largest trees seldom exceed two feet in diameter, and a height of ninety feet. The average size is little more than half as much. The wood is very strong, hard, and compact, and the annual growth ring is largely dense summerwood. Resin passages are few, but the wood is resinous, light brown in color, and the thick sapwood is nearly white. The needles are in clusters of two, and are from four to six inches long. They begin to fall the second year. Some of the trees retain their cones until death, but the seeds are scattered from year to year. Under the stimulus of artificial conditions in the redwood districts this pine seems to be spreading. Its seeds blow into vacant ground from which redwood has been removed, and growth is prompt. The seedlings are not at all choice as to soil, but take root in cold clay, in peat bogs, on barren sand and gravel, and on wind-swept ridges exposed to ocean fogs. Its ability to grow where few other trees can maintain themselves holds out some hope that its usefulness will increase.

Monterey PINe (Pinus radiata). This scarce and local species is restricted to the California coast south of San Francisco, and to adjacent islands. Under favorable circumstances it grows rapidly and promises to be of more importance as a lumber source in the future than it has been in the past. It is, however, somewhat particular as to soil. It must have ground not too wet or too dry. If these requirements are observed, it is a good tree for planting. Its average height is seventy or ninety feet, diameter fron eighteen to thirty inches. Trunks six feet in diameter are occasionally heard of. The wood is light, soft, moderately strong, tough, annual rings very wide and largely of springwood; color, light brown, the very thick sapwood nearly white. The leaves are from four to six inches long, in clusters of two and three, and fall the third year. Cones are from three to five inclies long. The lumber is too scarce at present to have much importance, but its quality is good. In appearance it resembles wide-ringed loblolly pine, and appears to be suitable for doors and sash, and frames for windows and doors. Its present uses are confined chiefly to ranch timbers and fuel. If it ever anounts to much as a lumber resource, it will be as a planted pine, and not in its natural state.

JAck P1Ne (Pinus divaricata) is a far northern species which extends its range 
southward in the United States, from Maine to Minnesota, and reaches northern Indiana and Illinois. It grows almost far enough north in the valley of Mackenzie river to catch the rays of the midnight sun. It must necessarily adapt itself to circumstances. When these are favcrable, it develops a trunk up to two feet in diameter and seventy feet tall; but in adversity, it degenerates into a many-branched shrub a few feet high. The average tree in the United States is thirty or forty feet tall, and a foot or more in diameter. Its name is intended as a term of contempt, which it does not deserve. Others call it scrub pine which is little better. Its other names are more respectful, Prince's pine in Ontario, black pine in Wisconsin and Minnesota, cypress in Quebec and the Hudson Bay country, Sir Joseph Banks' pine in England, and juniper in some parts of Canada. "Chek pine" is frequently given in its list of names, but the name is said to have originated in an attempt of a German botanist to pronounce "Jack pine" in dictating to a stenographer. The tree straggles over landscapes which otherwise would be treeless. It is often a ragged and uncouth specimen of the vegetable kingdom, but that is when it is at its worst. At its best, as it may be seen where cared for in some of the Michigan cemeteries, it is as handsome a tree as anyone could desire. The characteristic thinness and delicacy of its foliage distinguish it at once from its associates. The peculiar green of its soft, short needles wins admiration. The wood is light, solt, not strong ; annual rings are moderately wide, and are largely composed of springwood. The thin bands of summerwood are resinous, and the small resin ducts are few. The thick sapwood is nearly white, the heartwood brown or orange. It is not durable.

Jack pine can never be an important timber tree, because too small; but a considerable amount is used for bed slats, nail kegs, plastering lath, barrel headings, boxes, mine props, pulpwood, and fuel. Aside from its use as lumber and small manufactured products, it has a value for other purposes. It can maintain its existence in waste sands; and its usefulness is apparent in fixing drifting dunes along some of the exposed shores of Lake Michigan and Lake Superior. It lives on dry sand and sends its roots several feet to water; or, under circumstances entirely different, it thrives in swamps where the watertable is little below the surface of the ground. It figbts a brave battle against adversities while it lasts, but it does not live long. Sixty years is old age for this tree. It grows fast while young, but later it devotes all its energies to the mere process of living, and its increase in size is slow, until at a period when most trees are still in early youth, it dies of old age, and the northern winds quickly whip away its limbs, leaving the barkless trunk to stand a few years longer.

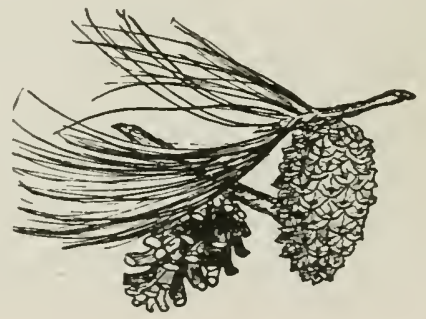


J()I)GEP(ILE PINE 


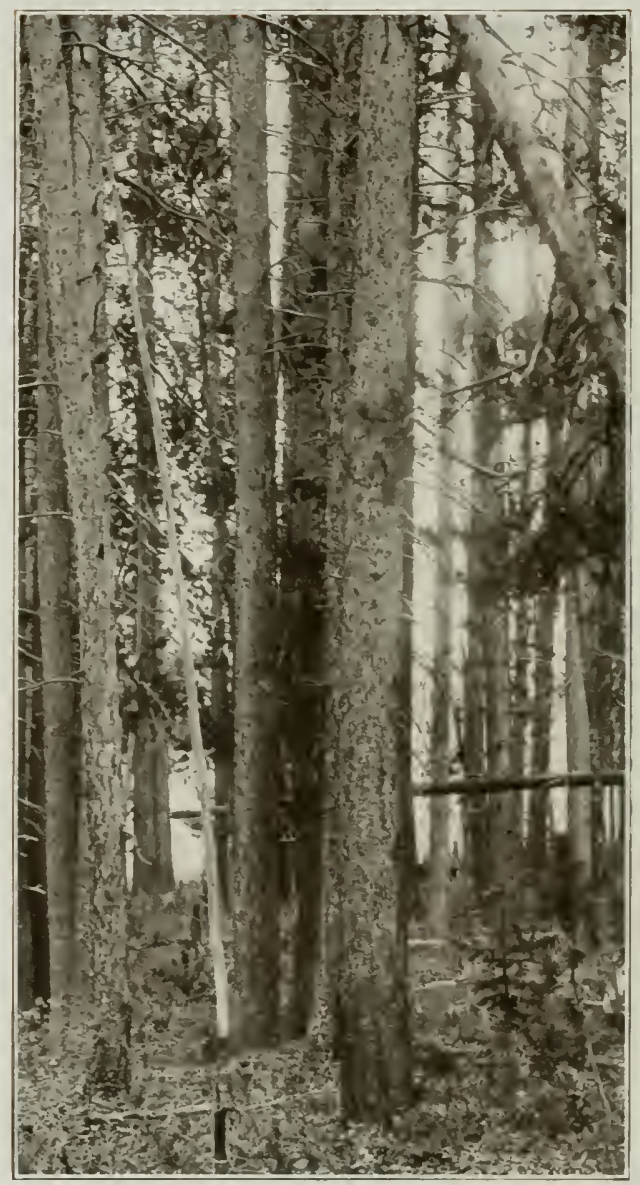

LOIMEPOLE PINE 


\section{LODGEPOLE PINE}

\section{(Pinus Contorta)}

$T$

$\mathrm{HE}$ common name of this tree was given it because its tall, slender, very light poles were used by Indians of the region in the construction of their lodges. They selected poles fifteen feet long and two inches in diameter, set them in a circle, bent the tops together, tied them, and covered the frame with skins or bark. The poles were peeled in early summer, when the Indians set out upon their summer hunt, and were left to season until fall, when they were carried to the winter's camping place, probably fifty miles distant. Tamarack is a common name for this pine in much of its range; it is likewise known as black pine, spruce pine, and prickly pine. Its leaves are from one to two inches long, in clusters of two. The small cones adhere to the branches many years-sometimes as long as twenty - without releasing the seeds, which are sealed within the cone by accumulated resin. The vitality of the seeds is remarkable. They don't lose their power of germination during their long imprisonment.

The lodgepole pine has been called a fire tree, and the name is not inappropriate. It profits by severe burning, as some other trees of the United States do, such as paper birch and bird cherry. The sealed cones are opened by fire, which softens the resin, and the seeds are liberated after the fire has passed, and wing their flight wherever the wind carries them. The passing fire may be severe enough to kill the parent tree without destroying or bringing down the cones. The seeds soon fall on the bared mineral soil, where they germinate by thousands. More than one hundred thousand small seedling trees may occupy a single acre. Most of them are ultimately crowded to death, but a thick stand results. Most lodgepole pine forests occupy old burns. The tree is one of the slowest of growers. It never reaches large sizepossibly three feet is the limit. It is very tall and slender. A hundred years will scarcely produce a sawlog of the smallest size.

The range of this tree covers a million square miles from Alaska to New Mexico, and to the Pacific coast. Its characters vary in different parts of its range. A scrub form was once thought to be a different species, and was called shore pine.

The wood is of about the same weight as eastern white pine. It is light in color, rather weak, and brittle, annual rings very narrow, sumnnerwood small in amount, resin passages few and small; medullary rays numerous, broad, and prominent. The wood is characterized by numerous small knots. It is not durable in contact with the ground, 
but it readily receives preservative treatment. In height it ranges from fifty to one hundred feet.

The government's estimate of the stand of lodgepole pine in the United States in 1909 placed it at 90,000,000,000 feet. That makes it seventh in quantity among the timber trees of this country, those above it being Douglas fir, the southern yellow pines (considered as one), western yellow pine, redwood, western hemlock, and the red cedar of Washington, Oregon, and Idaho.

Lodgepole pine has been long and widely used as a ranch timber in the Far West, serving for poles and rails in fences, for sheds, barns, corrals, pens, and small bridges. Where it could be had at all, it was generally plentiful. Stock ranges high among the mountains frequently depend almost solely upon lodgepole pine for necessary timber.

Mine operators find it a valuable resource. As props it is cheap, substantial, and convenient in many parts of Colorado, New Mexico, Wyoming, and Montana. A large proportion of this timber which is cut for mining purposes has been standing dead from fire injury many years, and is thoroughly seasoned and very light. It is in excellent condition for receiving preservative treatment.

Sawmills do not list lodgepole pine separately in reports of lumber cut, and it is impossible to determine what the annual supply from the species is. It is well known that the quantity made into lumber in Colorado, Wyoming, Montana, and Idaho is large. Its chief market is among the newly established agricultural communities in those states. They use it for fruit and vegetable shipping boxes, fencing plonk, pickets, and plastering lath.

Railroads buy half a million lodgepole pine crossties yearly. When creosoted, they resist decay many years. Lodgepole pine has been a tie material since the first railroads entered the region, and while by no means the best, it promises to fill a much more important place in the future than in the past. It is an ideal fence post material as far as size and form are concerned, and with preservative treatment it is bound to attain a high place. It is claimed that treated posts will last twenty years, and that puts them on a par with the cedars.

In Colorado and Wyoming much lodgepole was formerly burned for charcoal to supply the furnaces which smelted ore and the blacksmith shops of the region. This is done now less than formerly, since railroad building has made coal and coke accessible.

In one respect, lodgepole pine is to the western mountains what loblolly pine is to the flat country of the sonth Atlantic and other southern states. It is aggressive, and takes possession of vacant ground. Although the wood is not as valuable as loblolly, it is useful, and has 
an important place to fill in the western country's development. Its greatest drawback is its exceedingly slow growth. A hundred years is a long time to wait for trees of pole size. Two crops of loblolly sawlogs can be harvested in that time. However, the land on which the lodgepole grows is fit only for timber, and the acreage is so vast that there is enough to grow supplies, even with the wait of a century or two for harvest. The stand has increased enormously within historic time, the same as loblolly, and for a similar reason. Men cleared land in the East, and loblolly took possession; fires destroyed western forests of other species and lodgepole seized and held the burned tracts.

If fires cease among the western mountains, as will probably be the case under more efficient methods of patrol, and with stricter enforcement of laws against starting fires, the spread of lodgepole pine will come to a standstill, and existing forests will grow old without much extension of their borders.

Jefrrey Pine (Pinus jeffreyi) is often classed as western yellow pine, both in the forest and at the mill. Its range extends from southern Oregon to Lower California, a distance of 1,000 miles, and its width east and west varies from twenty to one hundred and fifty miles. It is a mountain tree and generally occupies elevations above the western yellow pine. In the North its range reaches 3,600 feet above sea level; in the extreme South it is 10,000 feet. The darker and more deeplyfurrowed bark of the Jeffrey pine is the usual character by which lumbermen distinguish it from the western yellow pine. It is known under several names, most of them relating to the tree's appearance, such as black pine, redbark pine, blackbark pine, sapwood pine, and bull pine. It reaches the same size as the western yellow pine, though the average is a little smaller. The leaves are from four to nine inches long, and fall in eight or nine years. The cones are large, and armed with slender, curved spines. The seeds are too heavy to fly far, their wing area being small. It is a vigorous tree, and in some regions it forms good forests. Some botanists have considered the Jeffrey pine a variety of the western yellow pine.

Gray PINE (Pinus sabiniana), called also Digger pine because the Digger Indians formerly collected the seeds, which are as large as peanuts, to help ekc out a living, is confined to California, and grows in a belt on the foothills surrounding the San Joaquin and Sacramento valleys. Its cones are large and armed with hooked spines. When green, the largest cones weigh three or four pounds. Leaves are from eight to twelve inches long, in clusters of two and three, and fall the third and fourth years. The wood is remarkable for the quickness of its decay in damp situations. It lasts one or two years as fence posts. A mature gray pine is from fifty to seventy feet high, and eighteen to thirty iaches in diameter. Some trees are much larger. It is of considerable importance, but is not in the same class as western yellow and sugar 
pine. The wood is light, soft, rather strong, brittle. The annual rings are generally wide, indicating rapid growth. Very old gray pines are not known. An age of $\mathbf{1 8 5}$ years seems to be the highest on record. The wood is resinous, and it has heiped in a small way to supply the Pacific coast markets with high-grade turpentine, distilled from roots. It yields resin when boxed like the southern longleaf pine. There are two flowing seasons. One is very early, and closes when the weather becomes hot; the other is in full current by the middle of August. It maintains life among the California foothills during the long rainless seasons, on ground so dry that semidesert chaparral sometimes succumbs; but it is able to make the most of favorable conditions, and it grows rapidly under the slightest encouragement. The seedlings are more numerous now than formerly, which is attributed to decrease of forest fires. The tree has enemies which generally attack it in youth. Two fungi, Peridermium harknessi, and Dadalia vorax, destroy the young tree's leader or topmost shoot, causing the development of a short trunk. The latter fungus is the same or is closely related to that which tunnels the trunls of incense cedar and produces pecky cypress.

Gray pine has been cut to some extent for lumber, but its principal uses have been as fuel and mine timbers. Many quartz mines have been located in the region where the tree grows; and the engines which pumped the shafts and raised and crushed the ore were often heated with this pine. Thousands of acres of hillsides in the vicinity of mines were stripped of it, and it went to the engine house ricks in wagons, on sleds, and on the backs of burros. In two respects it is an economical fuel for remote mines: it is light in weight, and gives more heat than an equal quantity of the oak that is associated with it.

Chrhuahoa PINe (Pinus chihuahuana) is not abundant, but it exists in small commercial quantities in southwestern New Mexico and southern Arizona. Trees are from fifty to eighty feet high, and from fifteen to twenty inches in diameter. The wood is medium light, soft, rather strong, brittle, narrow ringed and compact. The resin passages are few, large, and conspicuous; color, clear light orange, the thick sapwood lighter. The tree reaches best development at altitudes of from 5,000 to 7,000 feet. When the wood is used, it serves the same purposes as western yellor pine; but the small size of the tree makes lumber of large size impossible. The leaves are in clusters of three, and fall the fourth year. The cones have long stalks and are from one and a balf to two inches long.

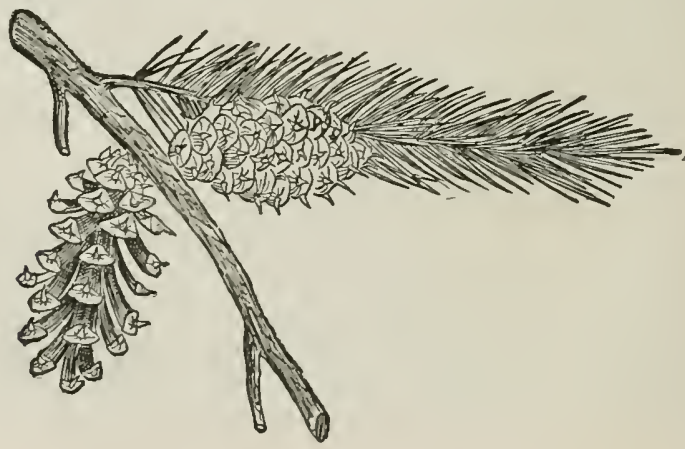


TAMARACK 


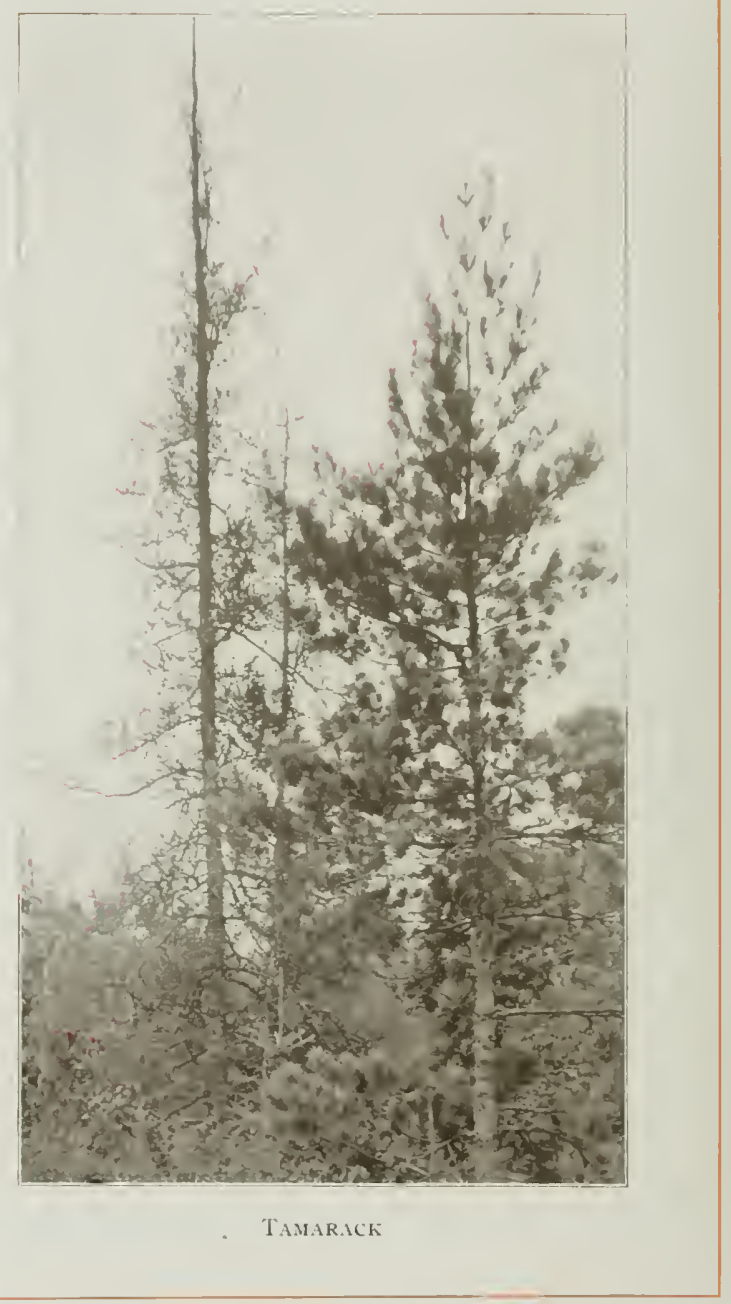




\section{TAMARACK}

\section{(Larix Laricina)}

$\mathrm{T}$

HERE are three species of tamarack or larch in the United States, and probably a fourth is confined to Alaska. One has its range in the northeastern states, extending south to West Virginia and northwestward to Alaska. Two are found in the northwestern states. Other species are native of the eastern hemisphere, and some of them have been planted to some extent in this country. A species of Europe is of much importance in that country. The tamaracks lose their leaves in the fall and the branches are bare during the winter. The name tamarack or larch should be applied only to trees of the genus larix. This rule is not observed in some parts of the West where the noble fir (Abies nobilis) is occasionally called larch by lumbermen. It is not entitled to that name, and confusion results from such use.

The larches are easily identified. They have needle leaves like those of pines and firs, but they are differently arranged. They are produced in little brush-like bundles, from twelve to forty leaves in each, on all the shoots, except the leaders. On these the leaves occur singly. The little brushes are so conspicuous, and so characteristic of this genus, including all its species, that there should be little difficulty in identifying the larches when the leaves are on. In winter, when the branches are bare, there are other easy marks of identification.

The little brushes are interesting objects of study. Botanists tell us that the excrescence or bud-like knob from which the leaves grow is really a suppressed or aborted branch, with all its leaves crowded together at the end. If it were developed, it would bear its leaves singly, scattered along its full length, as they occur on the leading shoots. The warty appearance of the branches in winter is a very convenient means of identification when the leaves are down.

The cones of larches mature in a single season, and often hang on the trees several years. They are conspicuous in winter when the branches are bare of foliage. The adhering cones are generally seedless after the first season, since they quickly let their winged seeds go. The male and female flowers are produced singly on branches of the previous year.

The eastern and northern larch (Larix laricina) has a number of names. It is commonly known as tamarack in the New England states and in New York, New Jersey, Pennsylvaria, Indiana, Illinois, Wisconsin, Micligan, Minnesota, Ohio, and in Canada. The name larcls is applied in practically all the regions where it grows, but it is not used as 
frequently as tamarack. Hackmatack, which was the Indian name for the tree in part of its eastern range, is still in use in Maine, New Hampshire, Massachusetts, Rhode Island, Delaware, Illinois, Minnesota, and Ontario. Nurserymen call it American larch to distinguish it from other larches on the market, particularly the European larch. Michaux, an early French botanist who explored American forests, called it American larch (Larix americana), and the name which he gave has been retained by many scientists to this day. In the Canadian provinces north of the Great Lakes, and also in Maine and New Brunswick, it is frequently called juniper, but without good reason, for it has little of the appearance and few of the qualities of the junipers. In some localities it is called black larch, and in others red larch. The first name refers to the color of its bark, the last to the lea ves when about to fall, for they then change to a brown or reddish color. They fall in the autumn, and the branches are bare until the next spring. Some of the New York Indians observed that peculiarity of the tree which they thought should be an evergreen like the balsam and pines with which it was often associated, and they named it kenehtens, meaning "the leaves fall". Indians did not, as a rule, give separate names to tree species, and when they did so, it was because of food value, or from some peculiarity which could not fail to attract the notice of a savage.

The tamarack's geographical range is remarkable. It is said to be best developed in the region east of Manitoba, but it extends southward into West Virginia and northward to the land of the midnight sun. It maintains its place almost to the arctic snows, and the willow is about the only tree that pushes farther north. It is found from Newfoundland and Labrador far down toward the mouth of the Mackenzie river, north of the arctic circle. It grows on dry land as well as wet, but is of tenest found in cold swamps, particularly in the southern part of its range. Silted-up lakes are favorite situations, and on the made-land above old beaver dams.

Tamarack forests frequently stand on ground so soft that a pole may be thrust ten feet deep in the mud. The moist, monotonous sphagnum moss generally furnishes ground cover in such places. A tamarack swamp in summer is cool and pleasant-provided there is not too much water on the ground-but in winter a more desolate picture can scarcely be imagined. The leafless trees appear to be dead, and covered with lifeless cones; but the first warm days bring it to life.

The average height of tamarack trees is from forty to sixty feet, diameter twenty inches or less. Leaves are one-half or one and a half inches long; cones one-half or three-quarter inches, and bright chestnut brown at maturity. They fall when two years old. The winged seeds 
are very small. The tree is neither a frequent nor abundant seeder. The foliage is thin, and is not sufficient to shut much sunlight from the ground.

The wood is heavy, hard, very strong, and is durable in contact with the soil. The growth is slow, annual rings narrow, summerwood occupies nearly half the ring, and is dark-colored, resinous, and conspicuous; resin passages few and obscure; medullary rays numerous and obscure; color of wood light brown, the sapwood nearly white.

The uses of tamarack go back to prehistoric times. The Indians of Canada and northeastern United States drew supplies from four forest trees when they made their bark canoes. The bark for the shell came from paper birch, threads for sewing the strips of bark together were tamarack roots, resin for stopping leaks was a product of balsam fir, and the light framework of wood was northern white cedar.

The roots which best suited the Indian's purpose came from trees which grew in soft, deep mud, where lakes and beaver ponds had silted up. Such roots are long, slender, and very tough and pliant, and may be gathered in large numbers, particularly where running streams have partly undermined standing trees.

White men likewise made use of tamarack roots in boat building, but the roots were different from what the Indians used. "Instep" crooks were hewed for ship knees. These were large roots, the larger the better. Trees which produced them did not grow in deep mud, for there the roots did not develop crooks. The ship knee operator hunted for tamarack forests growing on a soft surface soil two or three feet deep, underlaid by stiff clay or rock which roots could not penetrate. In situations like that the roots go straight down until they reach the hard stratum, and then turn at right angles and grow in a horizontal direction. The turning point in the root develops the crook of which the ship knee is made.

Tamarack is seldom of sufficient size for the largest ship knees. Such were formerly supplied by southern live oak; and in that case crooks formed by the union of trunk and large branches were as good as those produced by the union of trunk and large roots.

Tamarack is still employed in the manufacture of boat knees, but not as much as formerly. Steel frames have largely taken the place of wood in the construction of ship skeletons. Boat builders use tamarack now for floors, keels, stringers, and knees.

Tamarack has come into much use in recent years. Sawmills cut from it more than $125,000,000$ feet of lumber a year. Fourteen states contribute, but most of the lumber is produced in Minnesota, Michigan, and Wisconsin. Railroads in the United States buy $5,000,000$ or more 
tamarack ties a year, which reduced to board measure amount to over $150,000,000$ feet. Fence posts and telegraph poles come in large numbers from tamarack forests.

The wood is stiff and strong, its stiffness being eighty-four per cent of that of long leaf pine, and its strength about eighty per cent. Unusual variations in both strength and stiffness are found. One stick of tamarack may rate twice as high as another.

The wood-using factories of Michigan consume nearly 20,000,000 feet of this wood yearly. It is made into boxes, excelsior, pails, tanks, tubs, house finish, refrigerators, windmills, and wooden pipes for waterworks and for draining mines.

There is little likelihood that the supply of tamarack will run short in the near future. While it is not in the first rank of the important trees in this country, it is useful, and it is fortunate that it promises to hold its ground against fires which do grave injury to northern forests. In the swamps where the most of it is found the ground litter is too damp to burn. The tree does not grow rapidly, but it usually occupies lands which cannot be profitably devoted to agriculture, and it will, therefore, be let alone until it reaches maturity.

Tamarack is a familiar tree in parks, and it grows farther south than its natural range extends. It is not as desirable a park tree as hemlock, spruce, fir, the cedars, and some of the pines, because its foliage is thin in summer and wanting in winter. It is in a class with cypress. In the early spring, however, while its soft green needles are beginning to show themselves in clusters along the twigs, its delicate and unusual appearance attracts more attention than its companion trees which are always in full leaf and for that reason are somewhat monotonous.

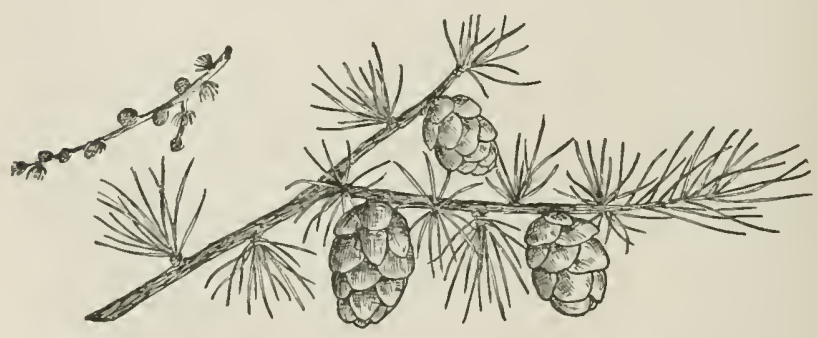


WESTERN LARCH 


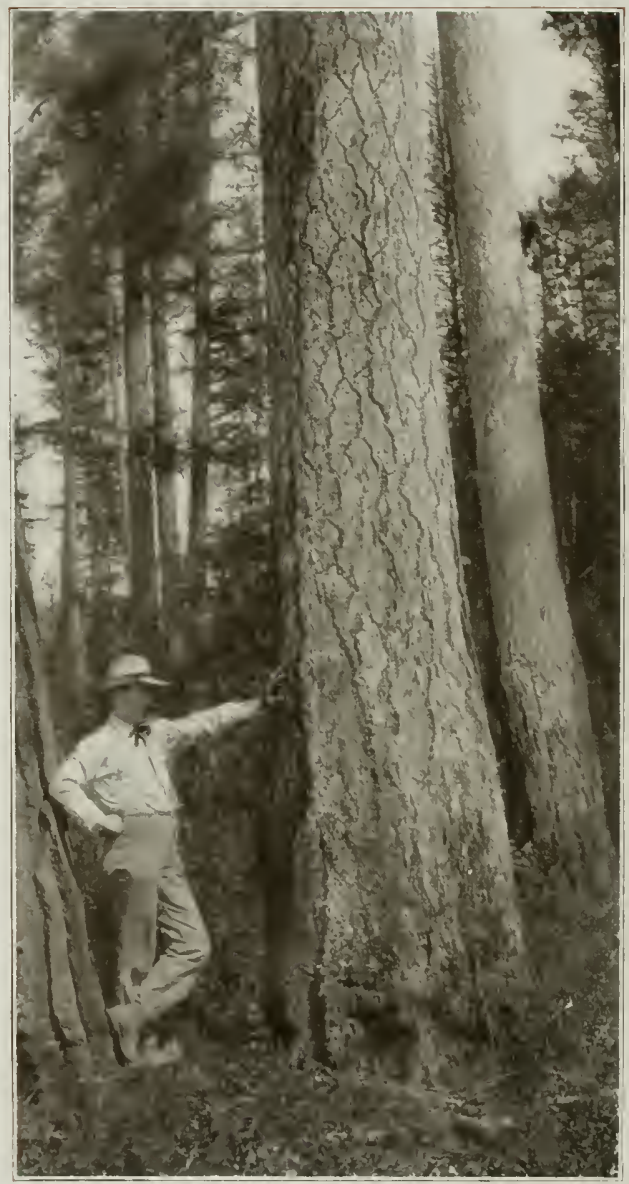

WESTERN LARCH 


\section{WESTERN LARCH}

\section{(Larix Occidentalis)}

$\mathrm{T}$ HIS is a magnificent tree of the Northwest, and its range lies principally on the upper tributaries of the Columbia river, in Idaho, Montana, and British Columbia, but it occurs also among the Blue Mountains of Washington and Oregon. It is the largest member of the larch genus, either in the old world or the new. The finest trees are 250 feet high with diameters of six or eight feet, but sizes half of that are nearer the average. The trunk is of splendid form. In early life it is limby, but later it prunes itself, and a long, tapering bole is developed with a very small crown of thin foliage. No other tree of its size, with the possible exception of old sequoias, has so little foliage in proportion to the trunk.

The result is apparent in the rate of growth after the larch has passed its youth. Sometimes such a tree does not increase its trunk diameter as much in seventy-five years as a vigorous loblolly pine or willow oak will in one year. The trunk of a tree, as is well known, grows by means of food manufactured by the leaves and sent down to be transformed into wood. With so few leaves and a trunk so large, the slowness of growth is a natural consequence. Though the annual rings are usually quite narrow, the bands of summerwood are relatively broad. That accounts for the density of larchwood and its great weight. It is six per cent heavier than longleaf pine, and is not much inferior in strength and elasticity. The leaves are from one to one and threequarter inches long, the cones from one to one and a half inches, and the seeds nearly one-quarter inch in length. They are equipped with wings of sufficient power to carry them a short distance from the parent tree.

The bark on young larches is thin, but on large trunks, and near the ground, it may be five or six inches thick. When a notch is cut in the trunk it collects a resin of sweetish taste which the Indians use as an article of food.

The western larch reaches its best development in northern Idaho and Montana on streams which flow into Flathead lake. The tree prefers moist bottom lands, but grows well in other situations, at altitudes of from 2,000 to 7,000 feet. The figures given above on the wood's weight, strength, and stiff ness show its value for manufacturing purposes. Its remoteness from markets has stood in the way of large use, but it has been tried for many purposes and with highly satisfactory results. In 1910 sawmills in the four western states where it grows cut $255,186,000$ feet. Mlost of this is used as rough lumber, but some is made into 
furniture, finish, boxes, and boats. The wood has several names, though larch is the most common. It is otherwise known as tamarack and hackmatack, which names are of tener applied to the eastern tree; red American larch, western tamarack, and great western larch.

Some of the annual cut of lumber credited to western larch does not belong to it. Lumbermen have confused names and mixed figures by applying this tree's name to noble fir, which is a different tree. If the fir lumber listed as larch were given its proper name, it would result in lowering the output of larch as shown in statistical figures. In spite of this, however, larch lumber fills an important place in the trade of the northern Rocky Mountain region.

There is little doubt that it will fill a much more important place in the future, for a beginning has scarcely been made in marketing this timber. The available supply is large, but exact figures are not available. Some stands are dense and extensive, and the trees are of large size and fine form. It is not supposed, however, that there will be much after the present stand has been cut, because a second crop from trees of so slow growth will be far in the future. Sudworth says that larch trees eighteen or twenty inches in diameter are from 250 to 300 years old, and that the ordinary age of these trees in theforests of the Northwest is from 300 to 500 years; while larger trees are 600 or 700 . Much remains to be learned concerning the ages of these trees in different situations and in different parts of its range. It is apparent, however, that when a period covering two or three centuries is required to produce a sawlog of only mederate size, timber owners will not look forward with much eagerness to a second growth forest of western larch.

The value of the wood of western larch has been the subject of much controversy. In the tables compiled for the federal census of 1880 , under direction of Charles S. Sargent, its strength and elasticity were shown to be remarkably high. The figures indicate that it is about thirty-nine per cent stronger than white oak and fifty-one per cent stiffer. This places it a little above longleaf pine in strength and nearly equal to it in stiffness or elasticity. Engineers have expressed doubts as to the correctness of Sargent's figures. They believe them too high. The samples tested by Sargent were six in number, four of them collected in Washington and two in Montana.

The wood of western larch is heavier than longleaf pine, and approximately of the same weight as white oak. It is among the heaviest, if not actually the heaviest, of softwoods of the United States. Sargent thus described the physical properties of the wood: "Heavy, exceedingly hard and strong, rather coarse grained, compact, satiny, susceptible of a fine polish, very durable in contact with the soil; bands of small 
summer cells broad, occupying fully half the width of the annual growth, very resinous, dark-colored, conspicuous resin passages few, obscure; medullary rays few, thin; color, light bright red, the thin sapwood nearly white." The wood is described by Sudworth: "Clear, reddish brown, heavy, and fine grained; commercially valuable; very durable in an unprotected state, differing greatly in this respect from the wood of the eastern larch."

The seasoning of western larch has given lumbermen much trouble. It checks badly and splinters rise from the surface of boards. It is generally admitted that this is the most serious obstacle in the way of securing wide utilization for the wood. The structure of the annual ring is reason for believing that there is slight adhesion between the springwood and that of the late season. Checks are very numerous parallel with the growth rings, and splinters part from the board along the same lines. Standing timber is frequently windshaken, and the cracks follow the rings.

All of this is presumptive evidence that the principle defect of larch is a lack of adhesion between the early and the late wood. If that is correct, it is a fundamental defect in the growing tree, and is inherent in the wood. No artificial treatment can wholly remove it. It should not be considered impossible, however, to devise methods of seasoning which would not accentuate the weaknesses natural to the wood.

The form of the larch's trunk is perfect, from the lumberman's viewpoint, and its size is all that could be desired. It is amply able to perpetuate its species, though it consumes a great deal of time in the process. Abundant crops of seeds are borne, but only once in several years. It rarely bears seeds as early as its twenty-fif th year, and generally not until it passes forty; but its fruitful period is long, extending over several centuries. The seeds retain their vitality moderately well, which is an important consideration in view of the tree's habit of opening and closing its cones alternately as the weather happens to be damp or dry. The dispersion of seeds extends over a considerable part of the season, and the changing winds scatter them in all directions. Many seeds fall on the snow in winter to be let down on the damp ground ready to germinate during the early spring. The best germination occurs on mineral soil, and this is often found in areas recently bared by fire. Lodgepole pine contends also for this ground; but the race between the two species is not swift after the process of scattering seeds has been completed; for both are of growth so exceedingly slow that a hundred years will scarcely tell which is gaining. In the long run, however, the larch outstrips the pine and becomes a larger tree. If both start at the same time, and there is not room for both, the pine 
will kill the larch by shading it. The latter's thin foliage renders it incapable of casting a shadow dense enough to hurt the pine. The best areas for larch are those so thoroughly burned as to preclude the immediate heavy reproduction of lodgepole pine.

Much of the natural ranges of larch and lodgepole pine lie in the national forests owned by the government, and careful studies have been made in recent years to determine the requirements, and the actual and comparative values of the two species. It has been shown that larch is one of the most intolerant of the western forest trees. It cannot endure shade. Its own thin foliage, where it occurs in pure stands, is sufficient to shade off the lower limbs of boles, and produce tall, clean trunks; but if a larch happens to stand in the open, where light is abundant, it retains its branches almost to the ground. It is more intolerant, even, than western yellow pine, which so of ten grows in open, parklike stands.

ALPINE LARCH (Larix lyallii) never grows naturally below an altitude of 4,000 feet, and near the southern border of its range it climbs to 8,000 , where it stands on the brink of precipices, faces of cliffs, and on windswept summits. It is too much exposed to storms, and has its roots in soil too sterile to develop symmetrical forms. It is found in Montana, Idaho, Washington, and Oregon. The finest trees are sometimes seventy-five feet high and three or four in diameter, but the average height ranges from forty to fifty, with diameters of twenty inches or less. Its leaves are one and a half inches or less in length; cones one and a half inches long, and bristling with hair; seeds one-eighth of an inch long with wings one-fourth inch; wood heavy, hard, and of a light, reddish brown color. It is seldom used except about mountain camps where it is sometimes burned for fuel or is employed in constructing corrals for sheep and cattle. It is impossible for lumbermen ever to make much use of it, because it is scarce and hard to get at.

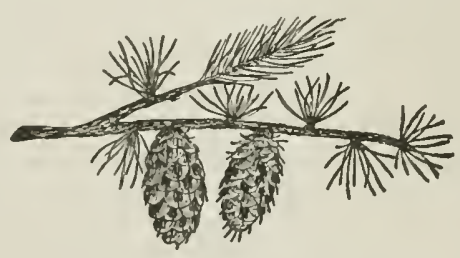


RED CEDAR 


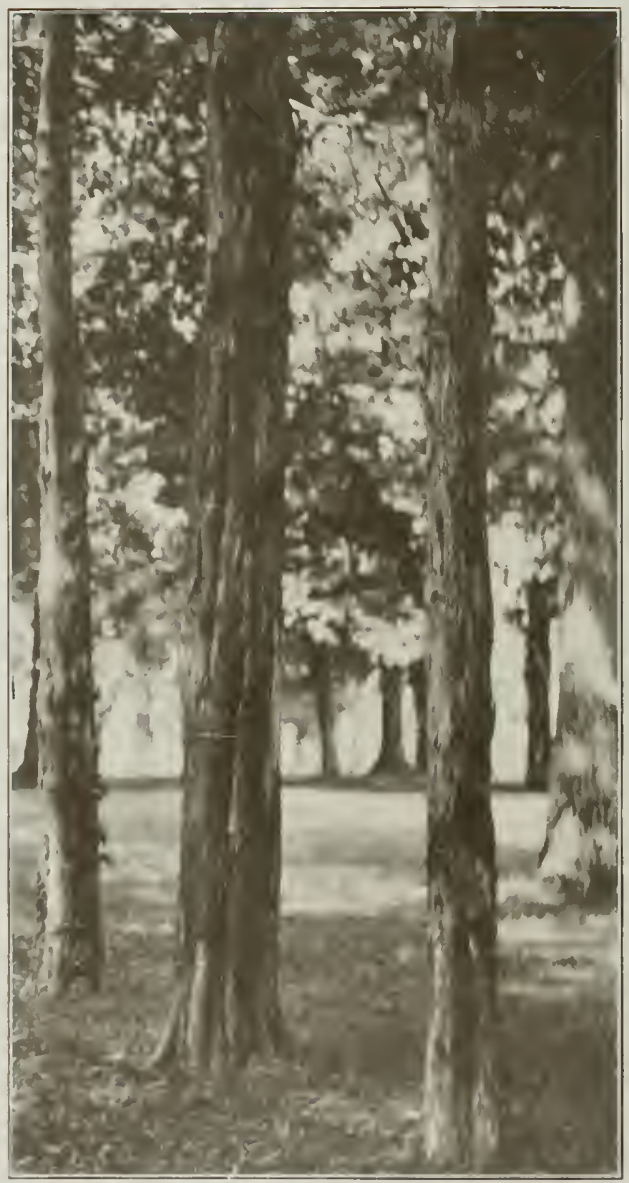

REI) CEDAR 


\section{RED CEDAR}

\section{(Juniperus Virginiana)}

7 HIS widely distributed tree is called red cedar in New Hampshire, 1 Vermont, Massachusetts, Rhode Island, New York, New Jersey, Pennsylvania, Delaware, West Virginia, North Carolina, South Carolina, Georgia, Florida, Alabama, Mississippi, Louisiana, Kentucky, Missouri, Illinois, Indiana, Wisconsin, Iowa, Michigan, Minnesota, Ohio, and Ontario; cedar in Connecticut, Pennsylvania, New Jersey, South Carolina, Kentucky, Illinois, Iowa, and Ohio; savin in Massachusetts, Rhode Island, New York, Pennsylvania and Minnesota; juniper in New York and Pennsylvania; juniper bush in Minnesota; cedre in Louisiana.

The names as given above indicate the tree's commercial range. It appears as scattered growth and in doubtful forms outside of that range, particularly in the West where several cedars closely resemble the red cedar, yet differ sufficiently from it to give them places as separate species in the lists of some botanists. They are so listed by the United States Forest Service; and the following names are given: Western Juniper, Rocky Mountain Juniper, One Seed Juniper, Mountain Juniper, California Juniper, Utah Juniper, Drooping Juniper, Dwarf Juniper, and Alligator Juniper. These species are not of much importance from the lumberman's viewpoint, yet they are highly interesting trees, and in this book will be treated individually.

The red cedar grows slowly, and thrives in almost any soil and situation except deep swamps. It is of ten classed as a poor-land species, yet it does not naturally seek poor land. That it is often found in such situations is because it has been crowded from better places by stronger trees, and has retreated to rocky ridges, dry slopes, and thin soils where competitors are unable to follow. The trees often stand wide apart or solitary, yet they can grow in thickets almost impenetrable, as they do in Texas and other southern states. It is an oldfield tree in much of its range. Birds plant the seeds, particularly along fence rows. That is why long lines of cedars may of ten be seen extending across old fields or deserted plantations.

The extreme size attained by this cedar is four feet in diameter. and one hundred in height, but that size was never common, and at present the half of it is above the average. That which reaches market is more often under than over eighteen inches in diameter. The reddish-brown and fibrous bark may be peeled in long strips. Stringiness of bark is characteristic of all the cedars, and typical of red cedar.

The wood is medium light and is strong, considering that it is very 
brittle. Tests show it to be eighty per cent as strong as white oak. The grain is very fine, even, and homogeneous, except as interfered with by knots. The annual rings are narrow, the summerwood narrow and indistinct; meduilary rays numerous but very obscure. The color is red, the thin sapwood nearly white. The heart and sap are sometimes intermingled, and this characteristic is prominent in the closely-related western species of red cedar. The wood is easily worked, gives little trouble because of warping and shrinking, and the heart is considered as durable as any other American wood. It has a delicate, agreeable fragrance, which is especially marked. This odor is disagreeable to insects, and for that reason chests and closets of cedar are highly appreciated as storage places for garments subject to the ravages of the moth and buffalo bug. An extract from the fruit and leaves is used in medicine, while oil of red cedar, distilled from the wood, is used in making perfume. Cedar has a sweet taste. It burns badly, scarcely being able to support a flame; it is exceedingly aromatic and noisy when burning and the embers glow long in still air. Some of the bungalow owners in Florida buy cedar fuel in preference to all others for burning in open fireplaces.

Its representative uses are for posts, railway ties, pails, sills, cigar boxes, interior finish and cabinet making, but its most general use is in the manufacture of lead pencils, for which its fine, straight grain and soft texture are peculiarly adapted. The farther south cedar is found, the softer and clearer it is. In the North, in ornamental trees, it is very hard, slow-growing, and knotty. It shows but a small percentage of clear lumber. In eastern Tennessee there were considerable quantities of red cedar brake that were for years considered of little value. About the only way the wood was employed a few years ago was in fence rails and posts, fuel, and charcoal. Of late people in localities where cedar grows in any abundance have awakened to its value, and cedar fences are rapidly disappearing, owing to the high prices now paid for the wood, and the excellent demand. On no other southern wood has such depredation been practiced. Because of its lightness and the ease with which it can be worked, it has been used for purposes for which other and less valuable woods were well adapted. On account of its slow growth, its complete exhaustion has often been predicted, but a second growth has appeared which, though much inferior to the virgin timber, can be used in many ways to excellent advantage. Instead of the huge piles of cedar flooring, chest boards, and smooth railings of the old days, one now sees at points of distribution great piles of knotty, rough poles, ten to forty feet long, which years ago would have been discarded. Today they represent bridge piling, the better and smoother among them being used for tclephone and telegraph poles. 
Middle Tennessee has produced more red cedar than any other part of the United States, but the bulk of production has been confined to a few counties, which produce a higher class and more aromatic variety of wood than that found elsewhere. A century ago these counties abounded in splendid forests of cedar. The early settlers built their cabins of cedar logs, sills, studding, and rafters; their smoke houses were built of them; their barns; even the roofs were shingled with cedar and the rooms and porches floored with the sweet-scented wood. Not many years ago trees three feet or more in diameter were often found, but the days are past when timber like that can be had anywhere.

Although the most general use at the present time is for lead pencils, few people who sharpen one and smell the fragrant wood, stop to wonder where it came from. One would smile were it suggested to him that perhaps his pencil was formerly part of some Tennessee farmer's worm fence. The best timber obtained now is hewn into export logs and shipped to Europe, particularly Germany, where a great quantity is converted into pencils. The red wood is made into the higher grades and the sap or streaked wood is used for the cheaper varieties and for pen holders. The smaller and inferior logs are cut into slats, while odds and ends, cutoffs, etc., are collected and sold by the hundred pounds to pencil factories. There are many such factories in the United States now, as well as in Europe, and pencil men are scouring the cedar sections to buy all they can. The farmer who has a red cedar picket or worm fence can sell it to these companies at a round price. Pencil men are even going back over tracts from which the timber was cut twenty-five years ago, buying up the stumps. When the wood was plentiful lumbermen were not frugal, and usually cut down a tree about two feet above the ground, allowing the best part of it to be wasted.

The German and Austrian pencil makers foresaw a shortage in American red cedar, and many years ago planted large areas to provide for the time of scarcity. The planted timber is now large enough for use, but the wood has been a disappointment. It does not possess the sof tness and brittleness which give so high value to the forest cedar of this country. As far as can be seen, when present pencil cedar has been exhausted, there will be little more produced of like grade. It grows so slowly that owners will not wait for trees to become old, but sell them while young for posts and poles.

One of the earliest demands for red cedar was for woodenware made of staves, such as buckets, kegs, keelers, small tubs, and firkins. Material for the manufacture of such wares was anong the exports to the West Indies before the Revolutionary war. The ware was no less 
popular in this country, and the home-made articles were in all neighborhoods in the red cedar's range. Scarcity of suitable wood limits the manufacture of such wares now, but they are still in use.

Cedar was long one of the best woods for skiffs and other light boats, and it was occasionally employed in shipbuilding for the upper parts of vessels. A little of it is still used as trim and finish, particularly for canoes, motor boats, and yachts.

The early clothes chest makers selected clear lumber, because it could be had and was considered to be better; but modern chest manufacturers who cannot procure clear stock, make a merit of necessity, and use boards filled with knots. The wood is finished with oils, but the natural colors remain, and the knots give the chest a rustic and pleasing appearance.

SOUTHERN RED JUNIPER (Juniperus barbadensis) so closely resembles the red cedar with which it is associated that the two were formerly considered the same species, and most people familiar with both notice no difference. However, hotanists clearly distinguish the two. The southern red cedar's range is much smaller than the other's. It grows from Georgia to the Indian river, Florida, in swamps. It is found in the vicinity of the Apalachicola river, forming dense thickets. Its average size is much under that of the red cedar, but its wood is not dissimilar. It has been used for the same purposes as far as it has been used at all. One of the largest demands upon it has been for lead pencils. Those who hought and sold it, generally supposed they were dealing in the common red cedar.

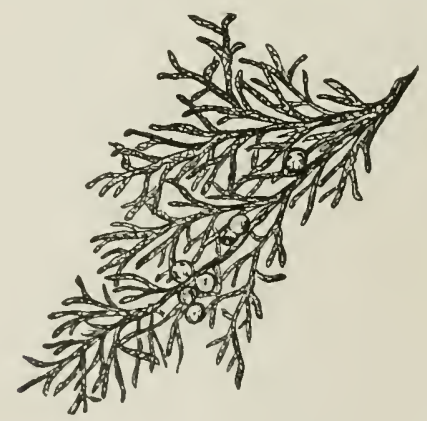


NORTHERN WHITE CEDAR 


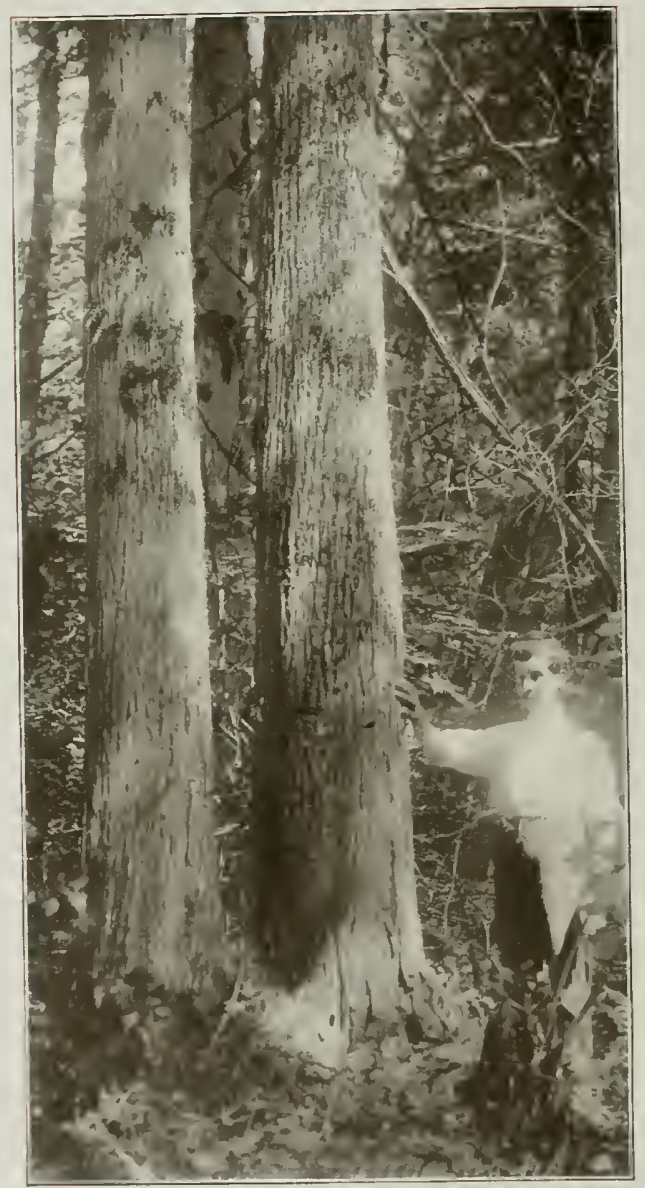

Northlern IHite Cendr 


\section{NORTHERN WHITE CEDAR}

\section{(Thuja Occidentalis)}

$T^{1}$ HIS tree is designated as northern white cedar because there is also a southern white cedar, (Chamecyparis thyoides) and the boundaries of their ranges approach pretty elosely. The name occidentalis, meaning western, applied to the northern white cedar is employed by botanists to distinguish it from a similar cedar in Asia, which is called orientalis, or eastern.

The American species has several names, as is usual with trees which grow in different regions. It is called arborvitæ in Maine, Vermont, Massachusetts, Rhode Island, Connecticut, New York, New Jersey, Pennsylvania, Delaware, Virginia, West Virginia, Indiana, Illinois, Wisconsin, Michigan, Minnesota, Ohio, and Ontario. White cedar is a name of ten used in Maine, New Hampshire, Vermont, Rhode Island, Massachusetts, New York, New Jersey, Virginia, North Carolina, Wisconsin, Michigan, Minnesota, and Ontario. In Maine, Vermont, and New York it is called cedar. In New York, and where cultivated in England, American arborvitæ is the name applied to it. The Indians in New York knew it as feather-leaf. In Delaware the name is abridged to vitæ.

The tree has been widely planted, and under the influence of cultivation it runs quickly into varieties, of which forty-five are listed by nurserymen. It is a northern species which follows the Appalachian mountains southward to North Carolina and Tennessee. It grows from New Brunswick to Manitoba, and is abundant in the Lake States.

The bark of arborvitæ is light brown, tinged with red on the branchlets; it is thin, and cracks into ridges with stringy, rough edges; the branchlets are very smooth.

In general appearance the tree is conical and compact, with short branches; it attains a height of from twenty-five to seventy fect, and a diameter of from one to three feet. It thrives best in low, swampy land, along the borders of streams.

The wood of arborvitæ is soft, brittle, light and weak; it is very inflammable. The fact that it is durable, even in contact with the soil, permits its use for railway ties, telegraph poles, posts, fencing, shingles and boats. However, the trunk is so shaped that it is seldom used for lumber, but oftener for poles and posts, the lower section being flattened into ties. A cubic foot of the seasoned wood weighs approximately nineteen pounds. The heartwood is light brown, becowing darker with exposure; the sapwood is thin and nearly white, with fine grain. 
The northern white cedar varies greatly in size and shape, depending on the soil, climate, and situation. Though it is usually associated with swamps in the North, it adapts itself to quite different situations. It grows in narrow, rocky ravines, on stony ridges, and it clings to the faces of cliffs, or hangs on their summits as tenaciously as the western juniper of the Sierra Nevada mountains. However, little good timber is produced by this species on rocky soils. Trees in such situations are short, crooked, and limby.

The wood of the northern white cedar possesses a peculiar toughness which is seen in its wearing qualities. A thin shaving, such as a carpenter's plane makes, may be folded, laid on an anvil, and struck repeatedly with a hammer, without breaking. It is claimed for it that it will stand a severer test of that kind than any other American wood. Toughness and wearing qualities combined make it an admirable wood for planking and decking for small boats. Its exceptionally light weight is an additional factor as a boat building material. The Indians knew how to work it into frames for bark canoes. Its lightness appealed to them; but the ease with which they could work it with their primitive tools was more important. It is a characteristic of the wood to part readily along the rings of annual growth. The Indian was able to split canoe ribs with a stone maul, by pounding a cedar billet until it parted along the growth rings and was reduced to very thin slats.

The property of this cedar which appealed to the Indians is disliked by the sawmill man. It is hard to make thin lumber that will hang togcther. The tendency to part along the growth rings develops wind-shake while the tree is standing. About nine trees in ten are so defective from shake that little good lumber can be made from them. It is a common saying, which probably applies in certain localities only, that a thousand feet of white cedar must be sawed to get one hundred feet of good lumber.

It is good material for small cooperage such as buckets, pails, and tubs, and has been long used for that purpose in the northern states.

It was once laid in large quantities for paving blocks. Hundreds of miles of streets of northern cities were paved with round blocks sawed from trunks of trees from five to ten inches in diameter. They were not usually treated with chemicals to prevent decay, but they gave service ranging from six to twelve years. They are less used now than formerly. Southern yellow pine has largely taken the cedar's place as paving material. Mluch northern cedar has been used in the manufacture of bored pipe for municipal watcrworks, shops, salt works, paper mills, and other factories.

The early settlers of New Jersey and eastern Pennsylvania made 
a rheumatism ointment by bruising the leaves and molding them with lard. This is probably not made now, but pharmacists distill an oil from twigs and wood, and make a tincture of the leaves which they use in the manufacture of pulmonary and other medicines.

There is little likelihood that northern white cedar will ever cease to be a commercial wood in this country. It will become scarcer, but its manner of growth is the best guarantee that it will hold its place. It lives in swamps, and the land is not in demand for any other purpose.

ONE-SEED JUNIPER (Juniperus monosperma) is also called naked-seed juniper. Its range lies in Colorado, New Mexico, Texas, Utah, and Arizona. It attains its greatest development in the bottoms of canyons in northern Arizona. It is a scrawny desert tree which lives in adversity but holds its ground for centuries, if fire does not cut its career short. Its growth is too scattered to attract lumbermen, and the form of its trunk is uninviting. It may reach a height of forty or fifty feet, and a diameter of three, but that is above the average in the best of its range. The desert Indians make the most of one-seed juniper. They weave its stringy bark into sleeping mats, rough blankets, and saddle girts. They make cords and ropes of it for use where great strength is not required, such as leashes for leading dogs, strands with which to tie bundles on the backs of their squaws, and cords for fastening their wigwam poles together. They likewise weave the bark into pokes and pouches for storing and carrying their dried meat and mesquite beans. The juniper berries are an article of diet and commerce with the Indians, who mix them with divers ingredients, pulp them in stone mortars, and bake them in cakes which become the greatest delicacy on their bill of fare. White men, when driven to it by starvation, have sustained life by making food of the berries. A small quantity of one-seed juniper reaches woodworkers in Texas. The lumber is short and rough. The numerous knots are generally much darker than the body of the wood. That is not necessarily a defect, for in making clothes chests, the striking contrast in color between the knots, and the other wood gives the article a peculiar and attractive appearance. The trunks are sharply buttressed and deeply creased. Sometimes the folds of bark within the creases almost reach the center of the tree. The sapwood is thin, the heartwood irregular in color. Some is darker than the heartwood of southern red cedar, other is clouded and mottled, pale yellow, cream-colored, the shade of slate, or streaked with various tints. The wood can be econornically worked only as small pieces. It takes a soft and pleasing finish. It is a lathe wood and shows to best advantage as halusters, ornaments, grill spindles and small posts, Indian clubs, dumb-bells, balls, and lodge gavels. It has been made into small game boards with fine effect, and it is an excellent material for small picture frames. Furniture makers put it to use in several ways, and it has been recommended for small musical instruments where the variegated colors can be displayed to excellent advantage. At the best it can never be more than a minor species, because it is difficult of access in the remote deserts, and it is not abundant.

Mountain JUnIPER (Juniperus sabinoides) is a Texas tree, occupying a range southward and westward of the Colorado river. It has several local names, rock cedar being a favorite. This name is due to the tree's habit of growing on rocky ridges and among ledges where soil is scarce. It is called juniper cedar, and juniper. Under the most favorable circumstances the tree may attain a height of 100 fcet and a diameter of two, but it nearly always grows where conditions are adverse, and its 
size and form change to conform to circumstances. It is often small and ragged. Its lead-colored bark is apt to attract attention on account of its woeful appearance, banging in strings and tatters which persistently cling to the trunk in spite of whipping winds. When the tree is cut for fuel, or for any other purpose, the ragged bark is occasionally pulled of and is tied in bales or bundles to be sold for kindling. When the mountain juniper is taken from its native wilds and planted where environments are different, it sometimes assumes fantastic forms. It has been planted for ornament on the low, flat coast in the vicinity of the Gulf of Mexico, and though it lives and grows, it often takes on a peculiar appearance. The trunks resemble twisted and interwoven bundles of lead-colored vines, buttressed, fluted, and gnarled. The branches lose their upright position, and hang in careless abandon; with drooping festoons. In winter the wind whips most of the foliage from them. The leaves become brittle and may be easily brushed from the twigs by a stroke of the hand. Some of the planted trees have trunks so deeply creased as to be divided in two separate stems. This very nearly happens with some of the wild trees among the western mountains. The sapwood of mountain juniper is very thin. The average tree cannot be profitably cut into lumber of the usual dimensions because of the oddshaped and irregular trunk. It lends itself more economically to the manufacture of articles made up of small pieces. Some of the wood is extremely beautiful, having the color and figure of French walnut; but there is great difference in the figure and color, and the wood of one tree is not a sure guide to what another may be. Boards a foot wide, or even less, may show several figures and colors. Some pieces suggest variegated marble; others are like plain red cedar; some are light red in color, others have a tinge of blue. It varies greatly in hardness, even in the same tree. Part of it may be soft and brittle enough for lead pencils; another part may be hard and tough. Clothes chests have been made of it, of most peculiar appearance-resembling crazy quilts of subdued colors. Sometimes the heartwood arid the,sapwood are inextricably mixed, both being found in all parts of the trunk from the heart out. On the whole, the tree can never have much importance as a source of lumber, but it is a most interesting member of the cedar group.

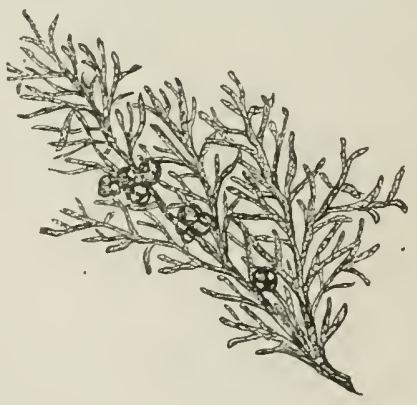


SOLTHERN WHITE CEIAR 


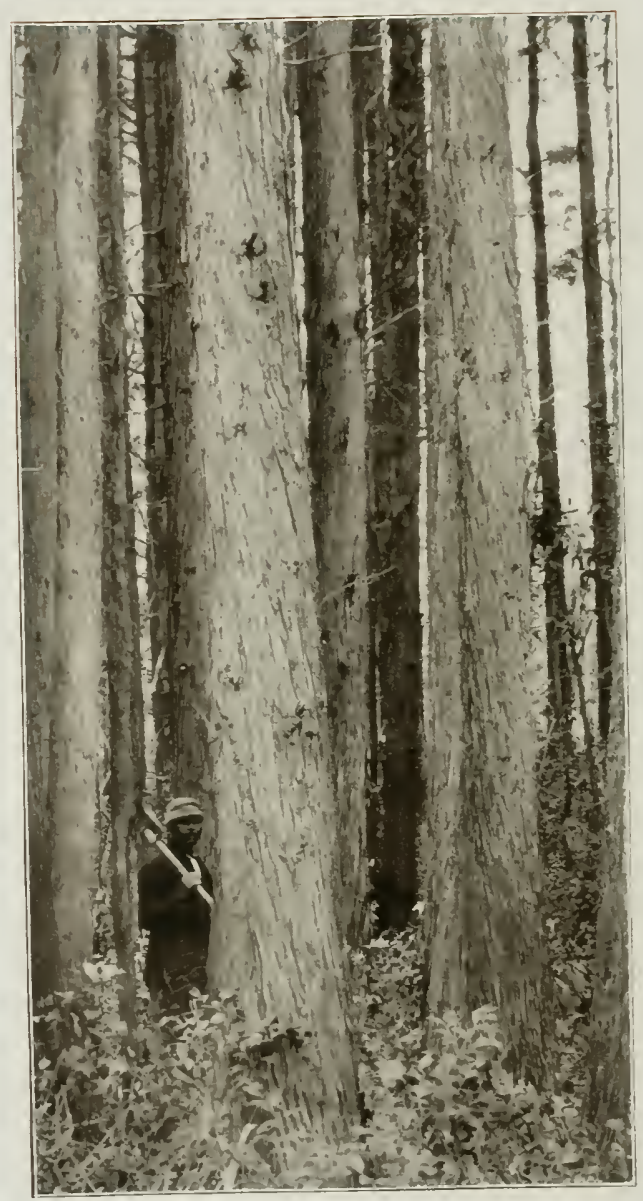

Sot'ther. White Cendr 


\title{
SOUTHERN WHITE CEDAR
}

\author{
(Chamacyparis Thjoides)
}

$\mathrm{T}$

HIS tree is called southern white cedar to distinguish it from northern white cedar or arborvitæ. When there is little likelihood of confusion, the name white cedar is applied locally in different parts of its range from Massachusetts to Florida. It is a persistent swamp tree and on that account has been called swamp cedar; but that name alone would not distinguish it from the northern white cedar, for both grow in swamps; but it does separate it from red cedar which keeps away from swamps. The ranges of the two are side by side from New England to Florida. Post cedar is a common name for it in Delaware and New Jersey, because of the important place it has long filled as fence material; but again, the name does not set it apart from red cedar or northern white cedar, for both are used for posts. The only name thus far applied, which clearly distinguishes it from associated cedars, is southern white cedar. Its range extends northward to Maine, but the tree's chief commercial importance has been in New Jersey and southward to North Carolina, very near the coast. Somehow, it seems to skip Georgia where no one has reported it for many years, though there is historical evidence that it once grew in that state. It grows as far west as Mississippi, but is scarce.

The small leaves remain green two years and then turn brown but adhere to the branches several years longer. The fruit is about one. fourth inch in diameter, and the small seeds are equipped with wings.

The wood is amorg the lightest in this country. It is only moderately strong and stiff. The tree usually grows slowly. Fifty years may be required to produce a fence post, but under favorable conditions results somewhat better than that may be expected. The summerwood of the yearly ring is narrow, dark in color, and conspicuous, making the counting of the rings an easy matter. The medullary rays are numerous but thin. When the sap is cut tangentially in very thin layers it is white and semi-transparent, presenting somewhat the appearance of oiled paper. The heartwood is light brown, tinged with red, growing darker with exposure. The wood is easily worked, and is very durable in contact with the soil. Fence posts of this wood have been reported to stand fifty years, and shingles are said to last longer. Trees reach a height of eighty feet and diameter of four; but such are of the largest size. Great numbers are cut for poles and posts which are little more than a foot in diameter. Few forest trees grow in denser stands than this. It of ten takes possession of swamps, crowds out all other trees, and develops 
thickets so dense as to be almost impenetrable. Southern white cedar is cut in ten or twelve states, but the annual supply is not known, because mills generally report all cedars as one, and the regions which produce this, produce one or more other species of cedar also. It has held its place nearly three hundred years, and much interesting history is connected with it. A considerable part of the Revolutionary war was fought with powder made from white cedar charcoal burned in New Jersey and Delaware. However, that was by no means the earliest place filled by this wood.

Two hundred years ago in North Carolina John Lawson wrote of its use for "yards, topmasts, booms, bowsprits for boats, shingles, and poles." It was cut for practically the same purposes in New Jersey at an earlier period, and 160 years ago Gottleib Mittelberger, when he visited Philadelphia, declared that white cedar was being cut at a rate which would soon exhaust the supply. But that prophecy, like similar predictions that oak and red cedar were about gone, proved not well founded. Seventy years after the imminent exhaustion of this wood was foretold, William Cobbett, an English traveler, declared with evident exaggeration that "all good houses in the United States" were roofed with white cedar shingles.

After boat building, the first general use of the southern white cedar was for fences and farm buildings, and doubtless twenty times as much went to the farms as to the boat yards. In all regions where the wood was convenient, little other was employed as fencing material, and many of the earliest houses in New Jersey and some in Pennsylvania were constructed almost wholly of this wood. Small trees which would split two, three, and four rails to the cut, were mauled by thousands to enclose the farms. The bark soon dropped off, or was removed, and the light rails quickly air-dried, and decay made little impression on them for many years. The larger trunks were rived for shingles or were sawed into lumber. About 1750 the use of round cedar logs for houses and barns began to give way to sawed lumber. It was an ideal milling timber, for the logs were symmetrical, clear, and easily handled. North Carolina sawmills were at work on this timber many years before the Revolution. It was acceptable material for doors, window frames, rafters, and floors, but especially for shingles which were split with frow and mallet, and were from twenty-four to twenty-seven inches long. They were known in market as juniper shingles and sold at four and five dollars a thousand. About 1750 builders in Philadelphia were criticized because they constructed houses with no provision for other than white cedar roofs; the walls being too weak for heavier material which would have to be substituted when cedar could be no longer 
procured. Philadelphia was not alone in its preference for cedar roofs. Large shipments of shingles were going from New Jersey to New York, and even to the West Indies earlier than 1750.

Southern white cedar is said to have been the first American wood used for organ pipes. The resonance of cedar shingles under a pattering rain suggested this use to Mittelberger when he visited America, and he tried the wood with such success that he pronounced it the best that he knew of for organ pipes.

Coopers were among the early users of white cedar. The "cedar coopers of Philadelphia" were famous in their day. They used this wood and also red cedar (Juniperus virginiana), and their wares occupied an important place in domestic and some foreign markets. Small vessels prevailed, such as pails, churns, firkins, tubs, keelers, piggins, noggins, and kegs. The ware was handsome, strong, durable, and light in weight. Oil merchants, particularly those who dealt in whale oil which was once an important commodity, bought tanks of southern white cedar. It is a dense wood and seepage is small.

A peculiar superstition once prevailed, and has not wholly disappeared at this day, that white cedar possessed powerful healing properties. It was thought that water was purified by standing in a cedar bucket, and even that a liquid was improved by simply running through a spigot of this wood. Some eastern towns at an early period laid cedar water mains, partly because the wood was known to be durable, and partly because it was supposed to exercise some favorable influence upon the water flowing through the pipes. It was even believed that standing trees purified the swamps in which they grew. Vessels putting to sea from Chesapeake bay, sometimes made special effort to fill their water casks with water from the Dismal swamp, where cedars grew abundantly in the stagnant logoons.

About 100 years ago it was found that whole forests of cedar had been submerged in New Jersey during prehistoric times, and that deep in swamps the trunks of trees were buried out of sight. No one knows how long the prostrate trees had lain beneath the accumulation of peat and mud, but the wood was sound. Mining the cedar became an important industry in some of the large swamps, and it has not ended yct. The wood is sound enough for slingles and lumber, though it has been buried for centuries, as is proved by the age of the forests which grew over the submerged logs. Sometimes a $\log$ which has lain under water hundreds of years, rises to the surface by its own buoyancy when pressure from above is removed. This is remarkable and shows how long a time this cedar resists complete waterlogging. The wood of green cedar has a strong odor, and that characteristic remains witl the submerged trunks. 
Experienced men who have been long engaged in mining the timber, are able to tell by the odor of a chip brought to the surface from a deeply submerged $\log$ whether the wood is sufficiently well preserved to be worth recovering and manufacturing. Trunks six feet in diameter have been brought to the surface. Few if any living white cedars of that size exist now.

Many of the early uses of southern white cedar have continued till the present time, but in much smaller quantities. Fence rails are no longer made of it; shingles and cooperage have declined. On the other hand, it now has some uses which were unknown in early times, such as telephone and telegraph poles, crossties, and piling for railroad bridges and culverts.

The supply of southern white cedar is not large, and it is being cut faster than it is growing. The deep swamps where it grows protect white cedar forests from fire, and for that reason it is more fortunate than many other species. Not even cypress can successfully compete with it for possession of water soaked morasses. It does not promise great things for the future, for it will never be extensively planted. Its range has been pretty definitely fixed by nature to deep swamps near the Atlantic coast. Within those limits it will be of some importance for a long time. Where it finds its most congenial surroundings, little else that is profitable to man will grow. This will save it from utter extermination, because much of the land which it occupies will never be wanted for anything else.

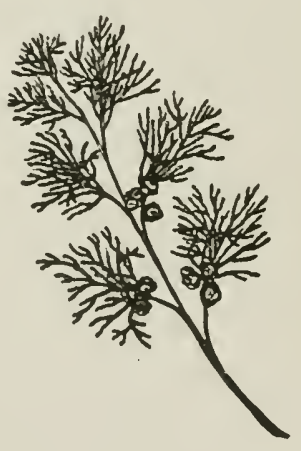


INCENSE (EEI)AR 


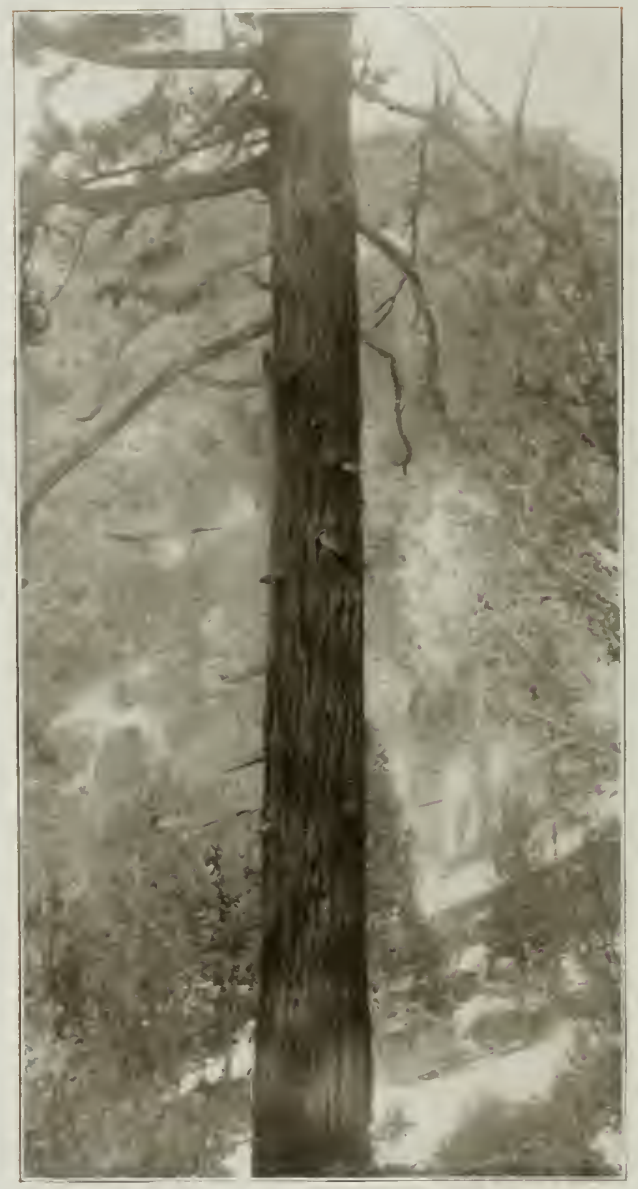

INCENSE CEIAR 


\section{INCENSE CEDAR}

\section{(Libocedrus Decurrens)}

N California and Oregon this tree is known as white cedar, cedar, and incense cedar; in Nevada and California it is called post cedar and juniper, and in other localities it is red cedar and California post cedar. It is a species of such strong characteristics that it is not likely to be confused with any other. Though different names may be applied to it, the identity of the tree is always clear.

Its range extends north and south nearly 1,000 miles, from Oregon to Lower California. It is a mountain species, and it faces the Pacific ocean in most of its range. In the North it occupies the western slope of the Cascade mountains in southern Oregon and northern California; and it grows on the western slope of the Sierras for five hundred miles, at altitudes of from 4,000 to 8,000 feet, where it is mixed with sugar pine, western yellow pine, white fir, and sequoias.

It is a fine, shapely tree, except that the butt is much enlarged. It has the characteristic form of a deep swamp tree, but it has nothing to do with swamps. Its best development is on the Sierra Nevada mountains, where swamps are few, and the incense cedar avoids them. It occupies dry ridges and slopes, but not sterile ones. It must have as good soil as the sugar pine demands. Its height when mature ranges from seventy-five to 125 feet, diameter four feet from the ground, from three to six feet, but some trees are larger. It is not a rapid grower, but it maintains its vigor a long time. As an average, it increases its diameter an inch in from seven to ten years.

The wood is dense. It contains no pores large enough to be seen with an ordinary reading glass. The medullary rays are so small as to be generally invisible to the naked eye, but when magnified they are shown to be thin and numerous. The summerwood forms about onefourth of the annual ring. The wood is nearly as light as white pine, is moderately strong, is brittle, straight grained, the heartwood is reddish, the thick sapwood nearly white. It is an easy wood to work, and in contact with the soil it is very durable.

The incense cedar is the only representative of its genus in the United States. It has many relatives in the pine family, but no near ones. Its kin are natives of Formosa, China, New Zealand, New Guinea, and Patagonia.

The name incense cedar refers to the odor of the wood rather than of the leaves. Those who work with freshly cut wood are liable to attacks of headache, due to the odor; but some men are not affected by it. 
The forest gromn tree is of beautiful proportions. Unless much crowded for room, it is a tall, graceful cone, the branches drooping slightly, and forming thick masses. In the Sierra Nevada mountains, within the range of this cedar, the winter snows are very heavy. It is not unusual for two or three feet of very wet snow to fall in a single day. The incense cedar's drooping branches shed the snow like a tent roof, and a limb broken or seriously deformed by weight of snow is seldom seen. Deer and other wild animals, when surprised by a heavy fall of snow, seek the shelter of an incense cedar, if one can be found, and there lie in security until the storm passes.

It is a tree which does fairly well in cultivation, and several varieties have been developed. It lives through the cold of a New England winter. Its cones are about three-fourths inch in length, and ripen in the autumn.

Incense cedar has filled an important place in the development of the great central valley of California, where it has supplied more fence posts than any other tree. Posts of redwood have been its chief competitor, but generally the region has been divided, and each tree has supplied its part. The redwood's field has been the coast, the cedar's the inland valley within reach of the Sierras. It has been nothing unusual for ranchmen to haul cedar posts on wagons forty or fifty miles.

The manufacture of posts from incense cedar has entailed an enormous waste of timber. The thick sapwood is not wanted, and in the process of converting a trunk into posts, the woodsman first sphts off the sap and throws it away. In trunks of small and medium size, the sapwood may amount to more than the heartwood, and is a total loss.

The tree's bark is thick and stringy, and it is generally wasted; but in some instances it is used as a surface dressing for mountain roads. It wears to pieces and becomes a pulpy mass, and it protects the surface of the roa. from excessive wear, and from washing in time of heavy rain.

Approximately one-half of the incense cedar trees, as they stand in the woods, are defective. A fungus (Dodalia vorax) attacks them in the heartwood and excavates pits throughout the length of the trunks. The galleries resemble the work of ants, and as ants of ten take possession of them and probably enlarge them, it is quite generally believed that the pits are due to ants. The excavations are frequently filled with dry, brown dust, sometimes packed very hard and tight. The cedar thus affected resembles "pecky cypress," and it is believed that the same species of fungus, or a closely related species, is responsible for the injury to both cypress in the South and incense cedar on the Pacific coast. It is not generally regarded by users of cedar posts that the honey-combed condition of the wood lessens the service which the post 
will give, unless by weakening it and causing it to break, or by rendering it less able to hold the staples of wire fences, or nails of plank and picket fences.

Post makers often prefer fire-killed timber. If a tree is found with the sapwood consumed, as is not unusual, it is nearly always free from fungous attack. The reason it stands through the fire which burns the sapwood off, is that the heart is sound-if it were not sound, the whole tree would be consumed.

The wood of the incense cedar is serviceable for many purposes. The rejection of the sapwood by so many users is the most discouraging feature. The heart, when free from fungus, is a fine, attractive material that does not suffer in comparison with the other cedars, though it may not equal some of them for particular purposes. Tests show it fit for lead pencils, and recent purchases of large quantities have been made by pencil makers. Clothes chests and wardrobes are manufactured from this wood on the assumption that the odor will keep moths out of furs and other clothing stored within. It has been used for cigar boxes, but has not in all instances proven satisfactory. The odor of the wood is objected to by some smokers. Another objection and a somewhat peculiar one, has been filed against incense cedar as a cigar box material. It is claimed that the boxes are attacked voraciously by rats which gnaw the wood, to which they are doubtless attracted by the odor.

Sawmills turn out incense cedar lumber which is worked into frames for doors and windows, and doors are made of it, and also interior finish. Shipments of inch boards are sold in New York and Boston, and exports go to London, Paris, and Berlin.

The long period during which incense cedar has been used and wasted, has reduced the supply in most regions, but there is yet much in the forest. It is never lumbered separately, but only in connection with pine and fir; but post makers have always gone about picking trees of this species and passing by the associated species.

Alligator Juniper (Juniperus pachyphloca) is so named from its bark which is patterned like the skin of an alligator. It is called oakbarked cedar in Arizona, mountain cedar in Texas, and checkeredbarked juniper in other places. Its range lies in southwestern Texas, about Eagle pass and Limpia mountains, and westward on the desert ranges of New Mexico and Arizona, south of the Colorado plateau, and among the mountains of northern Arizona. Its range extends southward into Mexico. It is one of the largest of the jumipers, but only wlien circumstances are wholly favorable. It is then sixty feet higl, and four or five feet in diameter; but it is generally small and of poor form for lumber, because of its labit of separating into forkes near the ground. 
It does best at elevations of from 4,000 to 6,000 feet in bottoms of canyons and ravines. The grayish green color of the foliage is due to the conspicuous white glands which dot the center of each leaf. The berries are small and blue, of sweetish taste which does not particularly appeal to the palate of civilized man, but the Indians of the region, whose normal state is one of semi-starvation, eat them with relish. The line separating heartwood from sap in alligator juniper is frequently irregular and vague, and like some of its kindred junipers of the West, patches of sap are sometimes buried deep in the heartwood, while streaks of heartwood occur in the sap. This heartwood is usually of a dirty color, suggesting red rocks and soil of the desert where it grows. Small articles which can be made of wood selected for its color are attractive. They may be highly polished, and the surface takes a satiny finish; but the wood does not show very well in panel or body work where wide pieces are used. The best utilization of alligator juniper appears to lie in small articles. It is fine for the lathe, and goblets, napkin rings, match safes, and handkerchief boxes are manufactured from the wood in Texas. Its rough uses are as fence posts and telephone poles. It is durable in contact with the soil.

CAlifornia Juniper (Juniperus californica) is called white cedar, juniper, sweet-fruited juniper, and sweet-berried cedar. Its range is in California south of Sacramento, among the ranges of the coast mountains, and the foothills of the Sierra Nevadas. Its height runs from twenty to forty feet, diameter one to two. The leaves fall in the second or third year. This tree is of poor form and size for lumber. Trunks frequently divide into branches near the ground. The wood resembles that of other western junipers, and usually the fine color which distinguishes the red cedar of the East is wanting, and in its stead is a dull brown, tinged with red. The wood is soft and durable, and is strongly odorous. The sapwood is thin and is nearly white. Fuel and fence posts are the most important uses of the California juniper. Indians eat the berries raw or dry them and pound them to flour.

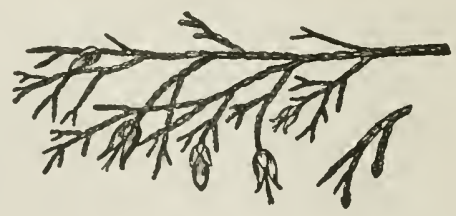


WESTERN RED CEDAR 


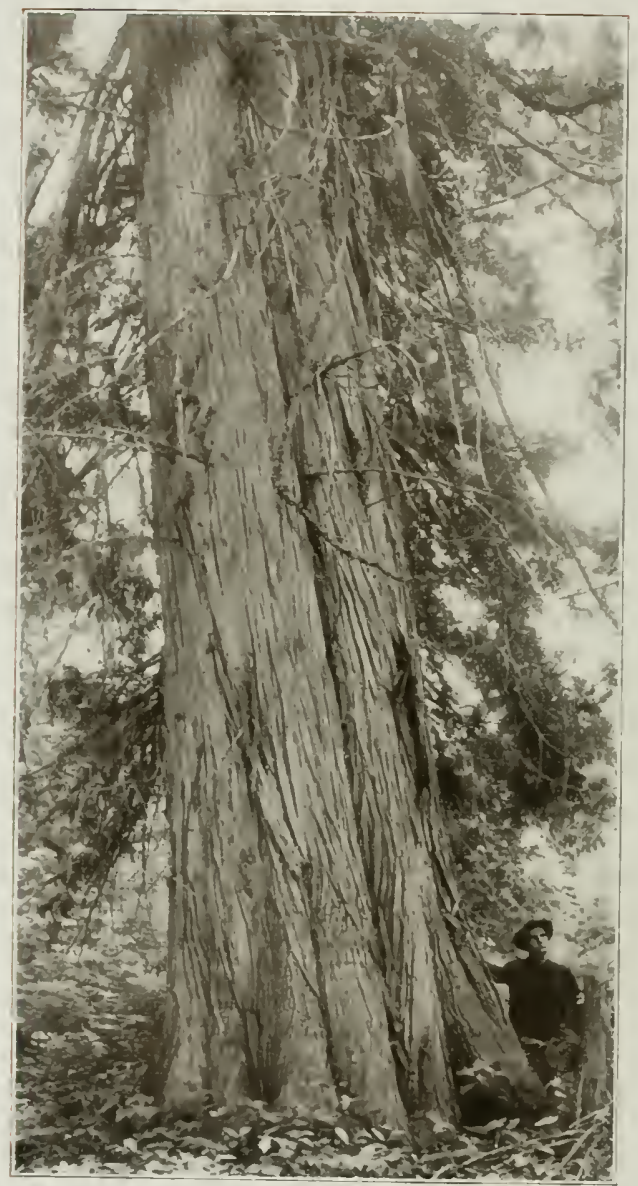

WEATERI REI CEIMR 


\title{
WESTERN RED CEDAR
}

\author{
(Thuja Plicata)
}

$I^{N}$ $\mathrm{N}$ the eastern markets the lumber from this tree is usually called western cedar without further description, but that name does not always sufficiently identify it. There are other western cedars, notably incense and yellow; but they have not generally appeared in eastern markets. Western red cedar is the name given it when the purpose is to separate it from other western cedars. It is the only red cedar in the far West, except the scarce junipers which are totally unknown as its competitors in lumber centers. Gigantic cedar is a name which takes size into account. It is the largest of American cedars. Trunks fifteen feet in diameter and 200 feet high are sometimes seen, but the usual size is 100 high, from two to four in diameter. Canoe cedar is a name bestowed upon this western tree for the same reason that canoe wood is one of the yellow poplar's names in the East. It is one of the best woods for dugout canoes. Botanists have called the tree giant arborvitæ, but the name never got beyond books. When the people of Washington and Oregon speak of cedar without a qualifying term, they mean this species. It is widely known as shingle wood or shingle cedar, because more shingles are made of it than of all other kinds of timber in the United States combined.

The western red cedar's range covers 300,000 square miles, not counting regions of small or scattered growth. For a timber tree, that range is large, but not nearly as large as some others. It exceeds onehundred fold the commercial range of redwood, and probably a thousand fold that of Port Orford cedar, but its range is not one-third that of the eastern red cedar, though in total quantity of available lumber it surpasses the eastern tree a hundred fold. Its range begins in Alaska on the north, and follows the coast to northern California, and extends eastward into Idaho. The best development occurs in the regions of warm, moist Pacific winds, but not in the immediate fog belts. The largest quantity of this wood, and probably the largest trees also, are in Washington. Abundant rainfall is essential to western red cedar's development. It would be difficult to approximate the amount of the remaining stand. This cedar does not form pure forests, and estimates of so many fect per acre or square mile cannot be based on fairly exact information as may be done with redwood, and some of the southern pines. Though the drain upon the cedar forests is heavy, it is generally believed there is cnougl of this species to meet demands for a long period of years.

Nature made ample provision for the spread and perpetuation of 
this tree. The seeds are fairly abundant, are light, have good wing power, and are great travelers in search of suitable places to germinate and take root. The tree's greatest enemy is fire. The cedar's bark is thin, even when trunks are mature, and a moderate blaze often proves fatal to large trees; but small ones, with all their branches close to the ground, have no chance when the fire burns the litter among them. Some tree seeds germinate readily on soil bared by fire-such as lodgepole pine, wild red cherry, and paper birch-but the western red cedar's do not, if the humus is sufficiently burned to lessen the soil's capacity to retain moisture. For that reason, this cedar seldom follows fire, and the result is that it constantly loses ground. Under normal conditions, it is not exacting in its requirements; but anything that disturbs natural conditions is more likely to harm than help this cedar. In that respect it is like beech and hemlock, which suffer when forest conditions are disturbed.

Trunks are large but not shapely. They are generally fluted, and greatly swelled at the base. These deformities develop rather late in the tree's life; at least, they are not prominent in young timber. Western cedar poles of large size are beautiful in outline; but when maturity approaches, the trunk grows faster near the ground than some distance above; the annual rings are wider near the base than twenty feet above, resulting in great enlargement near the ground. At the same time ribs and creases slowly develop, and by the time the tree is old, it is as ungainly as one of the giant sequoias. Its appearance is hurt by characteristics other than the swelled base and the buttresses. While the tree is small, the limbs ascend, and maintain a graceful upright position. Toward middle life they begin to droop, and the limbs of old trees hang down the trunks - the reverse of their attitude in early life.

The western red cedar lives to an old age, from 600 to 1,000 years. The oldest are liable to be hollow near the ground. The tree is remarkable for what happens after it falls. Often the trunk crashes down in a bed of moss, which in a few years buries it from sight. The moss holds so much water that the buried log is constantly too wet for fungous attack. Consequently decay does not take place. Fallen trees have lain for hundreds of years-as much as 800 having been claimed in one instanceand at the end of that time they are sound enough for shingles. The position of living trees growing upon buried logs furnishes the key to the length of time since the trunks fell. The long period during which the moss-buried wood has remained sound has led to the claim that western red cedar is the most enduring wood in America. Such is not necessarily the case. A good many others would probably last as long if protected in the same way. 
Western red cedar is strong and stiff but falls from twenty to thirty per cent below white oak in these factors. It is light, and the texture of the wood is rather coarse. The springwood and summerwood are distinct, the latter constituting one-half or less of the annual ring. The medullary rays are numerous and obseure. The wood's color is dull brown, tinged with red. The thin sapwood is nearly white.

The ease with which western red cedar may be worked led the Indians to use it in their most ambitious woodcraft. The gigantic totem poles which have exeited the curiosity and admiration of travelers near the coast in Alaska and southward have nearly all been of this wood. Some of them are the largest single pieces of wood carving in the world. Trunks three or four feet in diameter and forty or fifty feet long have been hewed and whittled in weird, uncouth, and fantastic forms, decorated with eagle heads, bear mouths, and with various creatures of the forest or sea, or from the realms of imagination. Before the northern Pacific coast Indians procured tools from white men they executed their carving by means of bone, stone, shell, and wooden tools, assisted by fire.

The making of canoes was in some ways a work more laborious for the Indians than the manufacture of totem poles. Their eanoes were dugouts of all sizes, from the small trough which carried one or two persons, to the enormous canoe which earried fifty warriors with all their equipment. Such a canoe, now in the National Museum at Washington, D. C., is fifty-nine feet long, seven feet, three inches deep at the bow, five feet three inches at the stern, and three feet seven inches in the middle, and eight feet wide. It was made on Vaneouver island, and is capable of carrying 100 persons. The capacity of the canoe is thirty-five tons. Civilized man has produced no vessel with lines more perfeet than are seen in some of these canoes made by savages; but all the canoes are not alike: some are crude and clumsy. It is claimed that large cedar canoes of Indian manufacture were early carried from the Pacific coast by fur traders, and New York and Boston shipbuilders took them as models in constructing the celebrated clipper ships which formerly sailed between New York and San Franciseo.

The Indians formerly made much use of western red cedar bark which they twisted into ropes and cords, braided for mats, wore for cloth, used in making baskets, roofing wigwams, constructing fish nets and bird snares, ladders for climbing cliffs, and they even pulped the inner bark by pounding it in mortars, and mixed it with their food.

White men have put western red cedar to many uses, as shingles, lumber, cooperage, poles, posts, piles, ear siding and roofing, boat building from skiffs to ships, and general furniture and interior finish. 
WESTERN JUNIPER ( Juniperus occidentalis) is a high mountain tree with all the characteristics belonging to that class of timber. The trunks are short and strong, the limbs wide-spreading, the wood of slow growth, and dense. The tree attains a diameter of ten inches in about 130 years. Trunks ten feet in diameter have been reported, but trees that large would be hard to find now. John Muir said that the western juniper lives 2,000 years, and that the tree is never uprooted by wind. The trunk is usually short, six or eight feet being a fair average, and very knotty. However, when a block of clear wood is found, it is high class, the heaviest of the cedars, straight grain, soft, compact, brittle. The summerwood is so narrow that it resembles a fine, black line. The medullary rays are numerous and very obscure. The wood is slightly aromatic, splits easily, works nicely, and in color is brown, tinged with red. In appearance, the sapwood suggests spruce. The average height of the trees is from twenty-five to forty-five feet, diameter two to four feet. The range of this tree is in Idaho, eastern Oregon, and through the Cascades and Sierras to southern California. It seldom occurs below an altitude of 6,000 feet, and ascends to 10,000 or more. On the highest summits it is deformed and stunted. Its fruit is eaten by Indians, and it furnishes fuel for mountain camps and ranches, timber for mines, and sometimes a little lumber. The crooked limbs and trunks are made into corral fences where better material cannot be had. The wood has been found suitable for lead pencils, but that of proper quality is too scarce to attract manufacturers. Other names for this tree are juniper, cedar, yellow cedar, western cedar, western red cedar, and western juniper. Some of these names are applied to other species of the same region.

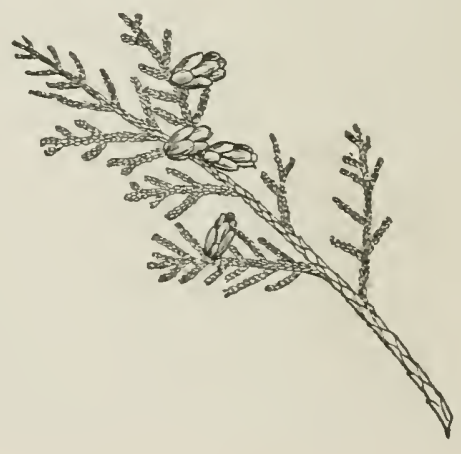


PORT URFURD CED.AR 


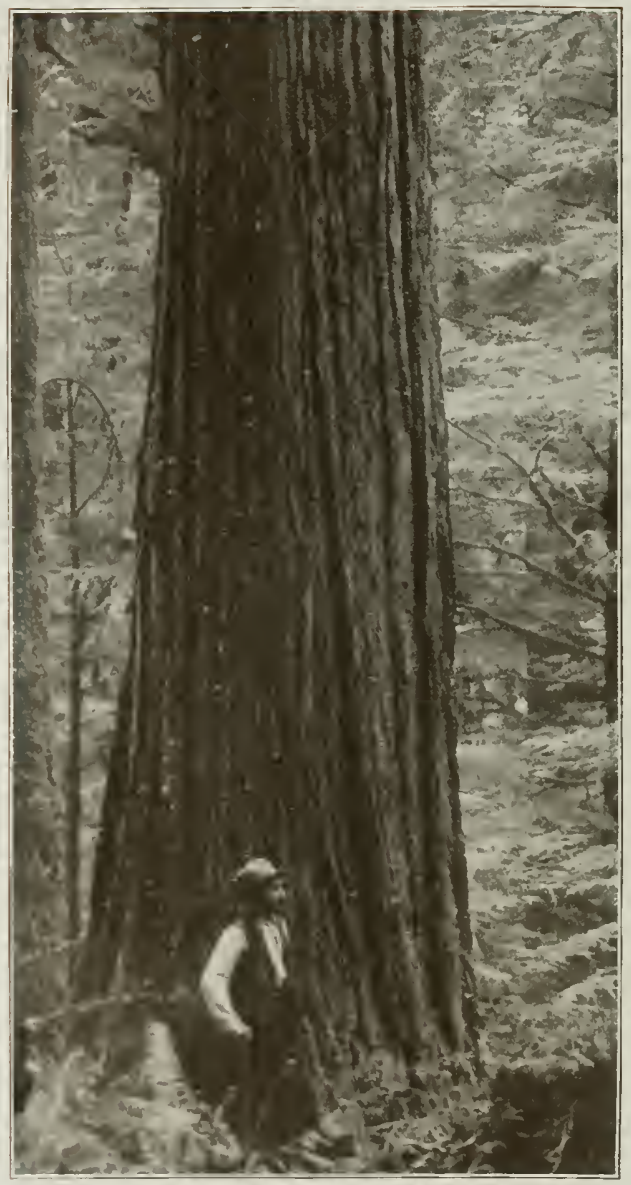

PORT ORFORI CEUAR 


\section{PORT ORFORD CEDAR}

\section{(Chamacyparis Lawsoniana)}

DORT Orford cedar of the northwestern coast is an interesting member of the cedar group with a very limited range. Specimens are found throughout an area of about 10,000 square miles, but the district moderately heavily timbered does not exceed 300 or 400 miles in area. It lies near Coos bay in southwestern Oregon. The tree is found as far south in California as the mouth of Klamath river, and it was once reported on M1. Shasta, but it is very scarce there if it exists at all. In the best of its range Port Orford cedar runs 20,000 feet to the acre, and a single acre has yielded 100,000 feet. Trees run from 135 to 175 feet in height and three to seven in diameter. The largest on record were about 200 feet high and twelve in diameter. Few trees of any species have smaller leaves. They of ten are only one-sixteenth of an inch in length. They die the third year and change to a bright brown. The cones are about one-third of an inch in diameter. Two or four seeds lie under each fertile cone scale, and ripen in September and October. The seeds are one-eighth inch in length, and are winged for flight. The bark of the tree is much thicker than of most cedars, being ten inches near the base of large trees. This ought to protect the trunks against fire but it falls short of expectations. About sixty years ago much of the finest timber was killed by a great fire which swept the region. Some of the dead trunks stood forty years without exhibiting much evidence of decay, and those that fell remained sound many years.

The whole history of this interesting tree, from its first announced discovery by white men until the present time, is embraced in the memory of living men. It had not been heard of prior to 1S55. Though fire and storm have destroyed large quantities, it has been estimated that $4,000,000,000$ feet of merchantable timber remain, an average of 15,000 feet per acre for an area of 400 square miles. The wood is moderately light, is nearly as strong as white oak, and falls only sixteen per cent below it in stiffness. The annual rings are generally narrow, but distinct. The summerwood is narrow, but dark in color in the heartwood. The medullary rays are numerous and obscure. The wood abounds in odorous resin. The odor persists long after the wood has ceased to be fresh. Workmen in mills where this cedar is cut, and on board of vessels freighted with it, are sometimes seriously affected by the odor. It is reputed to repel insects, and is made into clothes clicsts, wardrobes, and shelves, with the expectation that moths will be kept at a distance. Several other cedars bear similar reputations. 
One of the first uses to which the people of the Pacific coast put Port Orford cedar was boat building. The industry was important at Coos bay at an early day, and vessels constructed there sailed the seas thirty or forty years. Trunks of this cedar turn out a high percentage of clear lumber. The wood takes a good polish, and is manufactured into furniture, doors, sash, turnery, and matches. The latter article is esteemed by many persons for the peculiar odor of the burning wood. It has been found practicable to finish this cedar in imitation of mahogany, oak, and several other cabinet woods. In its natural state it sometimes bears some resemblance to yellow pine, and sometimes to spruce, there being considerable variation in the appearance of wood from different trees. When the visible supply of Port Orford cedar has been cut, the end will be reached, for not much young growth is coming on. Sixtyeight varieties of Port Orford cedar are recognized in cultivation.

Yellow CEDAR (Chamacyparis nootkatensis) describes this tree quite well. The small twigs are of that color, and so is the heartwood. Many give it the name yellow cypress. Others know it as Alaska cypress, Alaska ground cypress, Noctka cypress, or Nootka sound cypress. The name of the species, nootkatensis, was given it by Archibald Menzies, a Scotch botanist who discovered it on the shore of Nootka sound in Alaska.

Yellow cedar's geographic range extends from southeastern Alaska to Oregon, a distance of 1,000 miles. It does not usually go far inland, and consequently the range is narrow in most places. North of the international boundary the tree seldom reaches an altitude of more than 2,000 or 3,000 feet, but in Washington and Oregon it is occasionally met with at elevations of 4,000 and 5,000 feet. The species reaches its best development on the islands off the coast of southern Alaska and British Columbia, where the air is moist, the winds warm in winter, the rainfall abundant, and the snowfall of ten deep. Well developed trees under such circumstances are from ninety to 120 feet high, from two to six in diameter. The blue-green leaves remain active two years, and then die, but they do not usually fall until a year later. The presence of the dead leaves on the twigs tones down the general color of the tree crowns.

The cones are about half an inch long and have four, five, or six scales. From two to four seeds lie beneath each scale until September or October when they ripen and escape. Their wings are large enough to carry them away from the immediate vicinity of the parent tree, and reproduction under natural conditions is generally good. Yellow cedar is abundant within its range, but nature has circumscribed its range, and it shows no disposition to pass the boundary line. 
The bark is thin and exhibits cedar's characteristic stringiness. It is shed in thin strips.

The wood is moderately light, and is strong and stiff. It is probably the hardest of the cedars, and the grain is so regular that high polish is possible. Under favorable circumstances trees grow with fair rapidity, but when conditions are unfavorable, as on high mountains where summers are short and winters severe, growth is remarkably slow, and twenty years or more may be required for one inch increase in trunk diameter. The wood of such trees is hard, dense, and strong.

The grain of yellow cedar is usually straight. The bands of summerwood are narrow, the annual rings are indistinct, and an attempt to count them is often attended with considerable difficulty. The wood is easily worked, satiny, susceptible of a beautiful polish, and possesses an agreeable resinows odor. The heartwood is bright, clear yellow, and the thin sapwood is a little lighter in color. In common with all other cedars, yellow cedar resists decay many years. Logs which have lain in damp woods half a century remain sound inside the sapwood. Sometimes fallen timber in that region is quickly buried under deep beds of moss which preserves it from decay much longer than if the logs lie exposed to alternate dampness and dryness.

Statistics of sawmill operations in the Northwest do not distinguish between the different cedars, and the cut of yellow cedar is unknown. It is considerable, but of course not to be compared with the more abundant western red cedar. Statistics of uses are as meager as of the lumber output. In Washington the factories which use wood as raw material report only 7,500 feet of yellow cedar a year. Doubtless much more than that is used, but under other names. There is no occasion to disguise this wood under other names. It has a striking individuality and deserves a place of its own. In some respects it is one of the best woods of the Pacific Northwest. In nearly evcry situation where it has been tried, it has been found satisfactory. Its rich yellow presents a fine appearance in furniture and interior finish, and the polish which it takes surpasses that possible with any other cedar, with the probable exception of some of the scarce, high mountain junipers. It has becn used for pyrography and patterns, two hard places to fill, and for which few woods are suitable. Indians long ago in Alaska learned that it was the hest material for boat paddles which their forests afforded. It possesses the requisite stiffness and strength, and it wears to a smoothness almost like ebony. Boat factories have many uses for the wood, decking, railing, and interior finish being among the most important. It is said to be a satisfactory substitute for Spanish cedar in the manufacture of cigar boxes, but its use for that purpose is not yet large. 
It is said that occasional exports of this wood go to China where it is finished in imitation of scarce and expensive woods of that country.

Yellow cedar is a wood with a future. Its splendid properties cannot fail to give it a place of no small importance in factories and in general building operations. The supply has scarcely yet been touched, but it cannot much longer remain an undeveloped asset. It is apparently a high-class cooperage material, but it does not seem to have been used much if at all in that industry. The same might be said of it for doors. It is heavier than spruce, white pine, and redwood, but where weight is not a matter for objection, it ought to equal them in all desirable qualities.

In much of its range it is generally exempt from forest fire injury, because its native woods are nearly always too wet to burn.

Rocky Mountain JUNiper (Juniperus scopulonum) is scattered over the mountains from Dakota and Nebraska to Washington and British Columbia, and southward to western Texas, New Mexico, and Arizona. Except near the Pacific coast, it is usually found at altitudes above 5,000 feet. It clings closely to dry, rocky ridges where it attains a height of thirty or forty feet, and a diameter of three feet or less. The trunk usually divides near the ground into several stems. The bright blue berries ripen the second year. The wood resembles that of red cedar, and is used in the same way, as far as it is used at all. It is not a source of lumber. A little is sawed occasionally on mountain mills, and the lumber is used locally in house building, particularly for window and door frames; but sawlogs are short, and because of their poor form, the output of lumber is negligible. Some of it finds its way into Texas where it is manufactured into clothes chests and wardrobes, and these are sold as red cedar. A choice mountain juniper log, with large, sound heartwood, produces lumber with a delicate grain and is more at tractive than red cedar when made into chests and boxes. By habit of growth, it includes patches of white sapwood in the darker heartwood. When these are sawed through in converting the logs into boards, the islands of white wood scattered over the surface produce a unique effect not wanting in artistic value. Some of the other western junipers possess similar characteristics. Sometimes patches of bark are also found imbedded in the interoir of the trees.

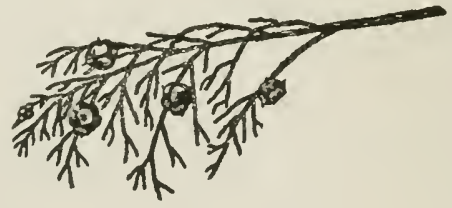


RED SPRLCE 


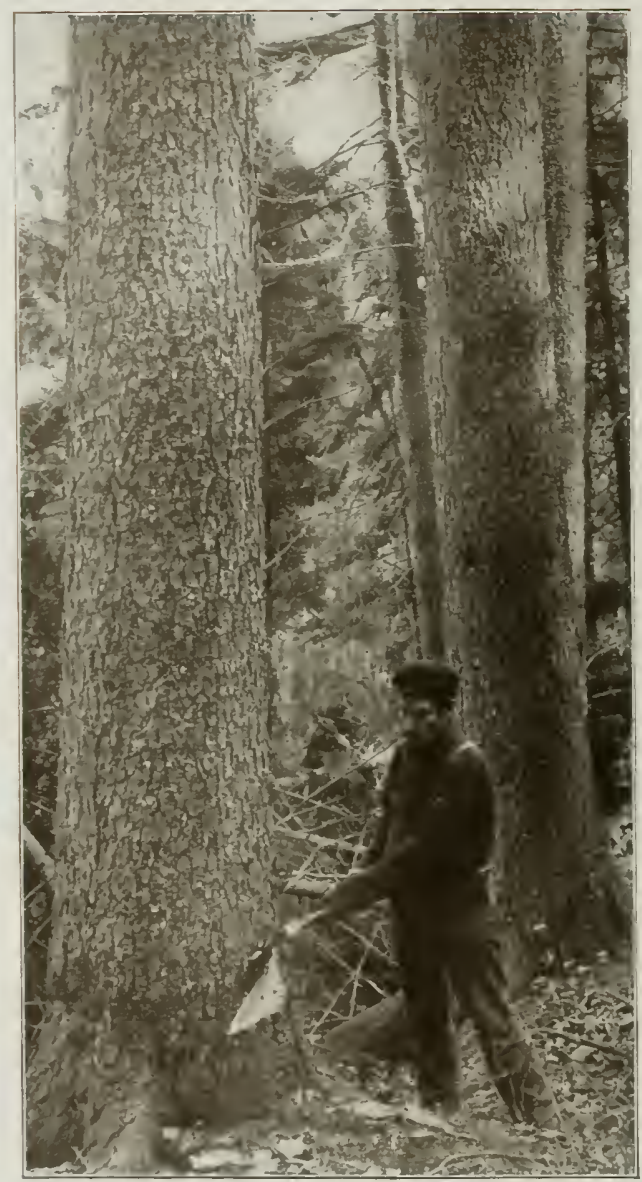

REI) SPRECE 


\section{RED SPRUCE}

\section{(Picea Rubens)}

I New York the tree is called yellow spruce, while in foreign literature It is known as North American red spruce. The tree is sometimes difficult to distinguish from black spruce (Picea nigra), the main points of difference in the appearance of the two trees being the size and shape of the cones and of the staminate blossoms. The cones of red spruce are larger than those of black, and they mature and drop from the branches during their first winter, while those of the latter named species frequently remain on the trees for several seasons. Certain eminent botanists incline to the belief that the two are different varieties of one species, inasmuch as even the timber of red spruce bears a close resemblance to that of the black spruce. Other botanists dispute this theory, saying that the trees are entirely different in appearance; that the red spruce is a light olive-green, while black spruce is inclined to a darker olive with perhaps a purplish tinge, so that when seen together they have no resemblance in point of color. They further say that the cones are not only different in size but that the scales are quite unlike in texture, those of black spruce being much thinner and more brittle. The same authorities maintain that the tiny twigs of red spruce are more conspicuous on account of their reddish tinge.

Generally speaking the principal spruce growth of northern New England and New York is black spruce, although interspersed with it in some localities is a considerable quantity of red spruce. On the contrary the chief stand of spruce in West Virginia, Virginia, western North Carolina, and eastern Tennessee and the other high altitudes over the South Carolina line, is largely red spruce. This botanical analysis of the two species of wood is based entirely on the authority of botanists, but from the viewpoint of the average lumberman there is absolutely no difference between red and black spruce and none in the physics of the two woods except that which rises from varying conditions of growth as soil, rainfall, altitude or latitude, or general environment. The larger spruce of West Virginia and the mountain region farther south, has certain qualities of strength and texture, combined with a large percentage of clear lumber that is not approximated by the spruce of New England and the British maritime provinces. In shape the tree is pyramidal, with spreading branches. It reaches a height of from seventy to a hundred feet. Its bark is reddish brown, slightly scaly. The twigs are light colored when young and are covered with tiny hairs. The leaves are thickly clustered along the branches, and are simple and 
slender, pointed at the apex. They become lustrous at maturity. The staminate flowers are oval, bright red in color; the pistillate ones are oblong, with thin rounded scales. The fruit of the red spruce is a cone, from one to two and a half inches in length; it is green when young, turning dark with age, and falling from the branches when thescales open. The seeds are dark brown, and winged.

Formerly spruce was littie thought of for lumber and manufacturing purposes in this country, though some use was made of it from the earliest settlements in the regions where it grew. White pine could generally be had where spruce was abundant, and the former wood was preferred. As pine became scarce, spruce was worked in for a number of purposes. The tree's form is all that a sawmill man could desire. The trunk has more knots than white pine, for the reason that limbs are a longer time in dying and in dropping off; but knots are small and generally sound. By careful culling, a moderate amount of clear lumber may be obtained. The wood is light, soft, narrow-ringed, strong in proportion to its weight, elastic, and its color is pale with a slight tinge of red, the sapwood whiter and usually about two inches thick. The contrast between heart and sapwood is not strong. The medullary rays are numerous, but small and obscure. The summerwood is thin and not conspicuous. It is the wood's red tinge which gives the tree its commercial name.

It is believed that the yearly cut of red spruce in the United States for lumber is about $500,000,000$ feet, one-half of which comes from West Virginia and southward, where this species reaches its highest development; and the pulpwood cut in the same region is about onetenth as much in quantity. The long fiber and white color of spruce make it one of the most satisfactory woods for pulp in this country. Red spruce is only one of several species of spruce which contribute to the supply. The total output of spruce pulpwood in the United States yearly is equivalent to about $1,000,000,000$ feet of lumber.

Red spruce lumber has a long list of uses. Much flooring is made of it, and it wears well, but not as well as hard pine from the South. It is more used for shipping boxes in the northeastern part of the United States than any other wood, except white pinc. Its good stenciling qualities recommend it. Manufacturers of sash, doors, and blinds find it excellent material, combining lightness, strength, and small tendency to warp, shrink, or swell. Coopers make buckets, tubs, kegs, and churns of it; manufacturers of refrigerators use it for doors and frames; and makers of furniture use it for many interior parts of bureaus, tables, and sideboards. Textile mills use spruce clothboards as center pieces round which to wind fabrics; and a further use in mills is for bobbins. It has 
many places in boat building, notably as spars and yards; and for window and door frames.

The makers of piano frames employ red spruce for certain parts; but as material for musical instruments its most important use is as sounding boards. All the commercial spruces are so used. Wood for this purpose must be free from defects of all kinds, and of straight and even grain. The sounding board's value lies in its ability to vibrate in unison with the strings of the instrument. Spruce has no superior for that place.

Red spruce bears abundance of seeds, the best on the highest branches. The seeds are winged, and the wind scatters them. They germinate best on humus. In spruce forests, clumps of seedlings are of ten seen where logs have decayed and fallen to dust. Seedlings do not thrive on mineral soil, and for that reason red spruce makes a poor showing where fires have burned. It does not spread vigorously in old fields as white pine does. It must have forest conditions or it will do little good. For that reason it does not promise great things for the future. It grows very slowly, and land owners prefer white pine, where that species will grow. If spruce is to be planted, most persons prefer Norway spruce (Picea excelsa) of Europe. It grows faster than native spruces. It is the spruce usually seen in door yards and parks.

BLACK SPRUCE (Picea mariana) grows much farther north than red spruce, but the two species mingle in a region of 100,000 square miles or more northward of Pennsylvania and in New England and southern and eastern Canada. Black spruce grows from Labrador to the valley of the Mackenzie river, almost to the arctic circle. It is found as far south as the Lake States where it constitutes the principal spruce of commerce. In some of the swamps of northern Minnesota and in the neighboring parts of Canada it is little more than a shrub, and trees three or four feet high bear cones. On better land in that region the tree is large enough for sawlogs. It passes under several names, among which are double spruce, blue spruce, white spruce, and water spruce. The common name black spruce probably refers to the general appearance of the crown. The small cones (the smallest of the spruces) adhere to the branches many years, and give a ragged, black appearance to the tree when seen from a distance. The wood is as white as other spruces. Trees vary greatly in size. The best are 100 feet high and two and a half feet in diameter; but the average size is about thirty feet high and twelve inches in diameter. That size is not attractive to lumbermen; but cutters of pulpwood find it valuable and convenient, and much of it is manufactured into paper. The wood weighs 28.57 pounds per cubic foot, and is moderately strong, and high in elasticity. It is pale yellow-white with thin sapwood In Manitoba, lumber is sawed from black spruce, and it is cut also in the Lake States, but it is preferred for pulp. It gives excellent service as canoe paddles. Spruce chewing gum is made of resinous exudations from this tree, and is an article of considerable importance. Spruce heer is another by-product wlich has long been manufactured in New England and the eastern Canadian provinces. It was made in Newfoundland three hundred years ago and has bcen bought and sold in the markcts of that region ever since. Fishing vessels carry supplics of the beverage on long voyages 
as a preventive of scurvy. The beer is made by boiling leaves and twigs, and adding molasses to the concoction which is allowed to pass through mild fermentation. Foresters will probably never pay much attention to hlack spruce because other species promise more profit. It is little planted for ornamental purposes, as it does not grow rapidly, is of poor form, and the accumulation of dead cones on the branches gives it a poor appearance. Besides, planted trees do not live long.

WHTTE SPRUCE (Picea canadensis) is of more importance in Canada than in the United States, because more abundant. It is one of the most plentiful timber trees of Alaska, and it is found west to Bering strait and north of the arctic circle. It is said to approach within twenty miles of the Arctic ocean. Its eastern limit is in Labrador, its southern in the northern tier of states from Maine to Idaho. A little of this species is cut for lumber in northern New England and in upper Michigan, and westward, just sonth of the Canadian line. The light blue-green foliage gives the tree its name. It is known by other names as well, single spruce, bog spruce, skunk spruce, cat spruce, double spruce, and pine. Some of its names are due to the odor of its foliage. The largest trees are 100 feet high and three in diameter, but most are smaller. Having a range so extensive, and in climates and situations so different, the tree naturally varies greatly in size and form. The wood of well-developed trees is white and handsome, the thin, pencil-like bands of summerwood having a slightly darker tone than the springwood. The two parts of the annual ring possess different degrees of hardness. The springwood is softer than the summerwood. The medullary rays are numerons, and the surface of quarter-sawed lumber has a silvery appearance, due to the exposed flat surfaces of the rays. In the markets, no distinction is made between white spruce lumber, and that cut from other species. The uses of the different species are much the same. As a pulpwood, white spruce is in demand wherever it is available. The largest output in the United States comes from northern New England. The tree is often planted for ornamental purposes in Erruope and in northern states. When grown in the open, the crown is pyramidal, like that of balsam fir. It does not thrive where summers are warm and dry.

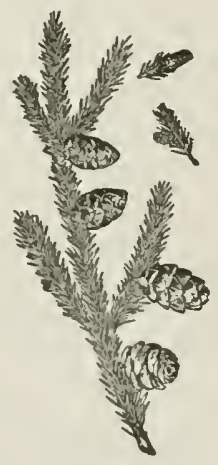


SITKA SPRUCE 


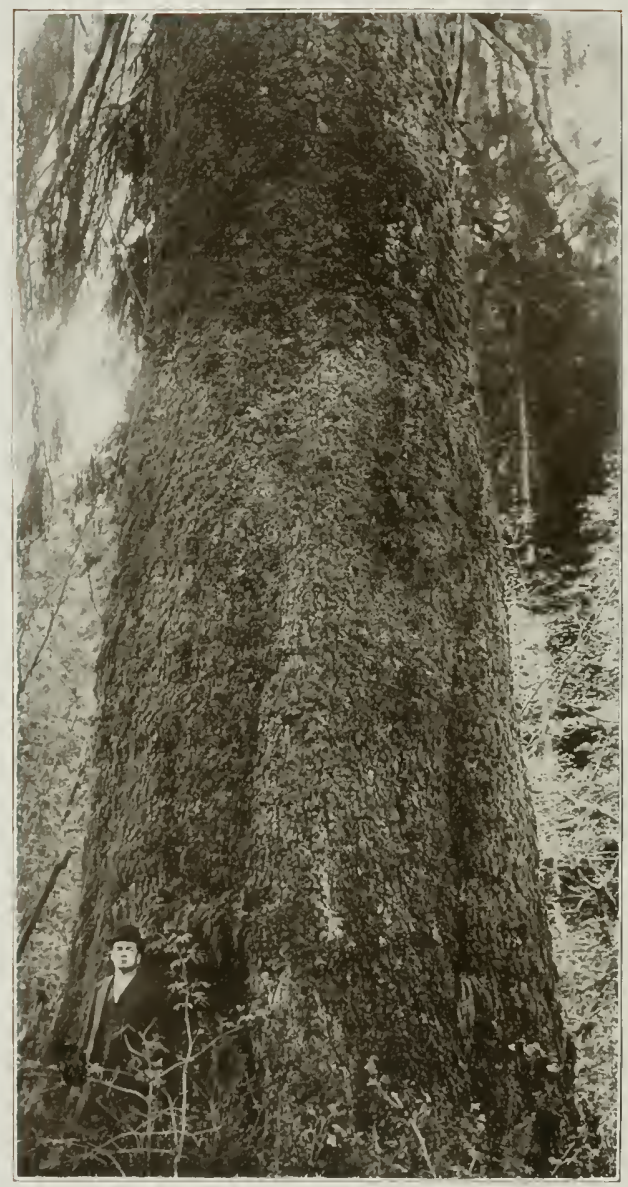

SITKA SHRT'Cl: 


\section{SITKA SPRUCE}

\section{(Picea Sitchensis)}

THIS is largest of the spruces. In height and in girth of trunk no other approaches it. The moist, warm climate of the north Pacific slope is its favorite home, though its range extends far northward along the islands and coast of Alaska. Toward the extreme limit of its habitat it loses its splendid form and size and degenerates into a sprawling shrub. The limit of the species southward lies in Mendocino county, California. Its range in a north and south direction is not less than 2,000 miles; but east and west the growth covers a mere ribbon facing the sea. It climbs some of the British Columbia mountains, 5,000 feet, but it prefers the low, wet valleys and flatlands, or the rainy and snowy slopes set to catch the sea winds. There it is at its best, and the largest trunks are 200 feet high, fifteen feet in diameter, and about $\$ 50$ years old. All sizes less than this are found. It is not easy to name an average size when variation runs from giants to dwarfs; but in regions where this spruce is cut for lumber, the average height of mature trees is about 125 feet, with a diameter of four feet.

Tideland spruce is one of its names. That has reference to its habit of sticking close to the sea. Its other names are Menzies' spruce, great tideland spruce, and western spruce. The last may be considered its trade name in lumber markets, for it is seldom called anything else when it is shipped east of the Rocky Mountains. The name is appropriate, except that other spruces grow in the West, and are equally entitled to the name. This applies particularly to Engelmann spruce of the northern Rocky Mountain region; but its lumber and that cut from Sitka spruce are not liable to be confused in the mind of anyone who is acquainted with the two woods. The name Sitka refers to the town of that name in Alaska.

The leaves of this species are usually less than one inch in length, and in color are light yellowish green. They stand out like bristles on all sides of the twigs. Cones are from two to four inches long, and hang by short stems, usually at the ends of twigs. They ripen the first year, release their seeds, which fly away on small but ample wings, and the cones drop during the fall and winter. Sitka spruce bark is generally less than half an inch in thickness. Trunks which grow in forests prune themselves well, and are usually clear of limbs from forty to eighty fcet. The bases of trees which grow on wet land are much enlarged like cypress and tupelo, and lumbermen frequently cut above the swell, leaving from 1,000 to 5,000 feet or more of lumber in the stump. Sitka 
spruce's characteristic root system is shallow; but on mountain sides where soil is dry, roots penetrate deep in search of moisture.

The wood of this spruce varies greatly in color, but it is usually a very pale brown, with the faintest tinge of red. It is a little heavier than white pine, considerably weaker, and with less elasticity. The size of the trunks, with their freedom from limbs, insures a high percentage of clear lumber when Sitka spruce is manufactured. The tree grows slowly, the annual rings are narrow, and the bands of summer growth are comparatively broad, to which fact the rather dark color of the wood of the spruce is due.

Sitka spruce is an important source of lumber. The total cut in Washington, Oregon, and California in 1910 was about 255,000,000 feet. It is below red spruce in quantity of sawmill cut, but above all other spruces in the United States. The people of the Pacific coast use much of it at home, but large quantities are shipped to markets in eastern states, and some to foreign countries. Nearly 4,000,000 feet were bought by Illinois manufacturers in 1909, in addition to what was used rough in the state. The commodities manufactured of this spruce in Illinois indicate with a fair degree of accuracy the uses made of the wood in most parts of the United States east of the Rocky Mountains and north of the Ohio river and the Potomac. Among articles so manufactured in Illinois are playground apparatus, porch and stair balusters, doors, blinds, sash and frames, poultry brooders, sounding boards for pianos and other musical instruments, parts of mandolins and guitars, pipes for organs, cornice brackets, store and office fronts, decking and spars for boats, wagon beds and windmill wheel slats, refrigerators and cold storage rooms, ironing boards and other woodenware.

Twenty times as much Sitka spruce is made into finished commodities in Washington as in Illinois. That is to be expected, since Washington is the home of the tree and the center of supply. A partial list of its uses in that state will show that the wood is liked at home. Douglas fir was the only wood bought in larger amounts by Washington manufacturers. They made $55,429,000$ feet of it into boxes, and coopers cmployed $12,000,000$ more. The next largest users were pulpmills, while $2,000,000$ feet went into sounding boards, many of which were for shipment abroad. Other users were basket makers, and the manufacturers of furniture, fixtures, finish, caskets, veneer, trunks, pulleys, vehicles, boats, and patterns. Sitka spruce decays quickly when exposed to rain and weather.

Sitka spruce can be depended upon for the future. Though it grows slowly it may be expected to keep growing. Its range lies in 
regions generally too wet for woods to burn, and it will suffer less from forest fires than trees of inland regions. It is an abundant seeder, and its favorite seedbed is moss, muck, decayed wood, and wet ground litter of various kinds. For the first few years seedlings are sensitive to frost, but not in later life.

Sitka spruce is often planted as an ornamental tree in western Europe, and occasionally in the middle Atlantic states. The New England climate is too severe for it.

Engelmann Spruce (Picea engelmanni) was named for Dr. George Engelmann. It has other names. In Utah it is called balsam, white spruce in Oregon, Colorado, Utah, and Idaho, mountain spruce in Montana, Arizona spruce farther south, while in Idaho it is sometimes known as white pine. That name is misleading, for Idaho has a species of white pine (Pinus monticola). In eastern markets the wood is known as western spruce; but that, also, is indefinite, for Sitka spruce is also a western species and is found in the same markets as Engelmann spruce. This tree's range extends from Yukon territory to Arizona, fully 3,000 miles. It is a mountain species and is found in elevated ranges. In the southern part of its habitat it ascends mountains to heights of nearly 12,000 feet. It grows in the Cascade mountain ranges in Washington and Oregon. The species' best development occurs in British Columbia. At its best, trees are 150 feet high and four or five in diameter; but every size less than that occurs in different parts of its range, down to a height of two or three feet for fully matured trees. Such are found on lofty and sterile mountains where frost occurs practically every night in summer, and winter snows bury all objects for months at a time. Though the stunted spruce trees may be only two or three feet high, their branches spread many feet, and lie flat on the rocks. Though such situations are exceedingly unfavorable to tree growth, the stunted spruces survive sometimes for two hundred years, and during that long period may not grow a trunk above five inches in diameter and four feet high. The Engelmann spruce is naturally a long-lived tree, and large trunks are 500 or 600 years old; and trees ordinarily cut for lumber are 300 or 400 years old. When the tree is young, its form is symmetrical, the longest branches being near the ground, the shortest near the top; but in crowded stands the trunk finally clears itself. Engelmann spruce lumber is usually full of small knots, each of which represents a limb which was shaded off as the tree advanced in age. The wood is lighter than white pine, and is the lightest of the spruces, the weight being 21.49 pounds per cubic foot. It is $110 t$ strong, and it rates low in elasticity. The wood is palc yellow, tinged with red. The thick sapwood is hardly distinguishable from the heart. 
It would be difficult to compile a list of this tree's uses, because in markets it hardly ever carries its right name. It is used for fuel and charcoal in the region of its growth; also as farm timber, and as props and lagging in mines. When it goes to market, it is manufactured into doors, window frames, sash, interior finish for houses, and for purposes along with other spruces. Large quantities of this wood will be accessible when lumbermen penetrate remote mountain regions where it grows. It may be expected to increase in importance. It is occasionally planted in eastern states as an ornament.

BLLE SPRLCE (Picer parryana) is found among mountains in Colorado, Utah, and $\mathrm{Wy}$ yoming, from 6,500 to 10,000 feet above sea level. It at tains a height of 150 feet and a diameter of three under favorable circumstances, but its usual size is little more than half ( $f$ that. Its name is given on account of the color of its foliage, but it has other names, among them being Parry's spruce, balsam, white spruce, silver spruce, Colorado blue spruce, and prickly spruce, the last name referring to the sharp-pointed leaves which are an inch or more in length. Cones are three inches long, and usually grow near the top of the tree. It is not unusual for blue spruce trees to divide near the ground in three or four branches. In its youth, particularly in open ground, blue spruce develops a conical crown. The wood is lighter than white pine, is soft, weak, and pale brown or nearly white in color. The sapwood is hardly distinguishable from the heart. This is a valuable tree for ornamental planting; but in later years it loses its lower limbs, and becomes less desirable.

IVEepticg SPRUCE (Picea breweriana) is of little commercial importance because of scarcity. It grows among the mountains of northern California and southern Oregon, at elevations of from 4,000 to 8,000 feet above sea level. The leaves are an inch or less in length, the cones from two to four inches long. They fall soon after they scatter their seeds. This tree is named on account of its drooping branchlets, some of which hang down eight feet. The wood seems not to have been investigated, but its color is pale yellowish to very light brown, and the annual rings are rather narrow. The tree ought to be valuable for ornamental planting, but nurseries have experienced much difficulty in making it grow. It grows on high and dry mountains where few ever see it, but refuses to become domesticated or to grace eastern parks.

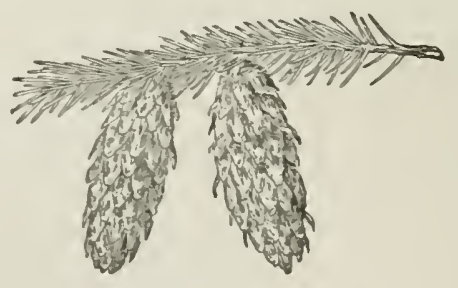


CYPRESS 


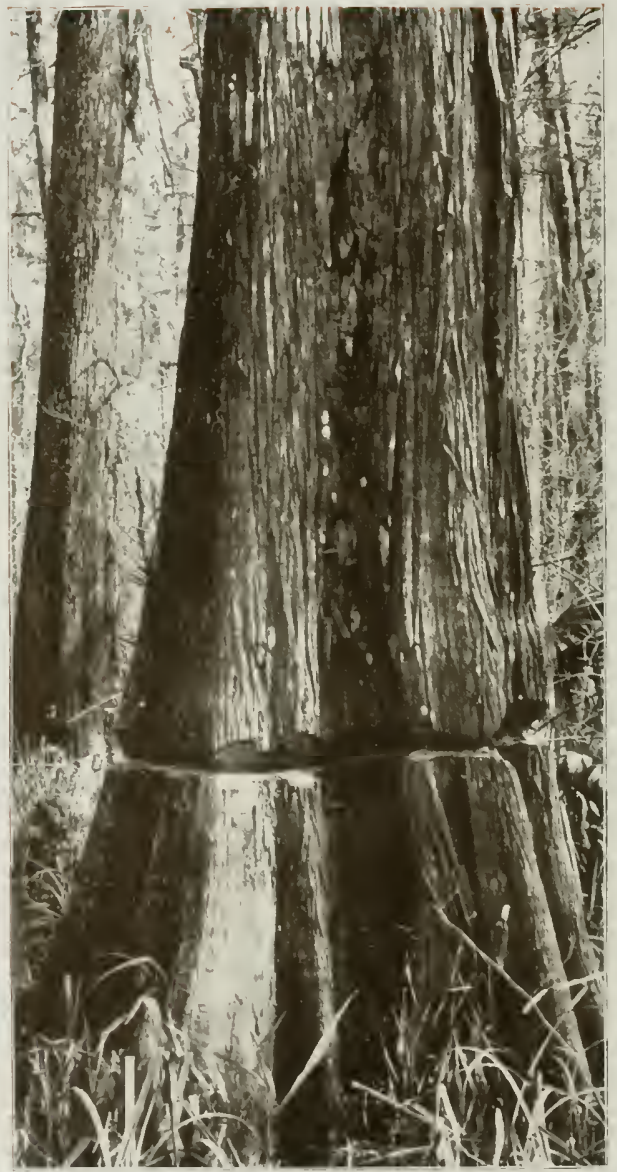

CIPRESS 


\section{CYPRESS}

\section{(Taxodium Distichum)}

$\mathrm{T}$ HE name cypress has been used quite loosely in this country and the old world, and botanists have taken particular care to explain what true cypress is. It is of no advantage in the present case to join in the discussion, and it will suffice to give the American cypresses according to the authorized list published by the United States Forest Service. Two genera, one having two and the other six species, are classed as cypress. These are Bald Cypress (Taxodium distichum), Pond Cypress (Taxodium imbricarium), Monterey Cypress (Cupressus macrocarpa), Gowen Cypress (Cupressus goveniana), Dwarf Cypress (Cupressus pygmaea) Macnab Cypress (Cupressus macnabiana), Arizona Cypress (Cupressus arizonica), and Smooth Cypress (Cupressus glabra). The first two grow in the southern states, and the others in the Far West. Bald cypress, which is generally known simply as cypress in the region where it grows, is more important as a source of lumber than are all the others combined. It probably supplies ninty-nine per cent of all cypress sold in this country. Its range is from southern Delaware to Florida, westward to the Gulf coast region of Texas, north through Louisiana, Arkansas, eastern Mississippi and Tennessee, southeastern Missouri, western Kentucky and sparsely in southern Illinois and southwestern Indiana. It is a deep swamp tree, and it is never of much importance far from lagoons, inundated tracts, and the low banks of rivers. Water that is a little brackish from the inwash of tides does not injure the tree, but the presence of a little salt is claimed by some to improve the quality of the wood. It is lumbered under difficulties. The deep water and miry swamps where it grows best must be reckoned with. Some of the ground is not dry for several years at a time. Neither felling nor hauling is possible in the manner practiced in the southern pineries. Owing to the great weight of the green wood, it will not float unless killed by being girdled for a year or more in advance of its being felled. In the older logging operations, cypress was girdled and snaked out to waterways and floated to the mills. Lately many cypress operations are carried on by the building of railroads through the swamps, which are largely' on piling and stringers, although occasionally earth fills are utilized. The usual size of mature cypress ranges from seventy-five to 140 feet in height and three to six in diameter.

The wood is light, soft, rather weak, moderately stiff, and the grain is usually straight. The narrow annual rings indicate slow growth. The summerwood is comparatively broad and is slightly resinous; 
medullary rays are numerous and obscure. The wood is light to dark brown, the sapwood nearly white. At one time specimens of the wood in the markets of the world were known as black or white cypress, according as they sank or floated. Much of the dark cypress wood is now known as black cypress in the foreign markets, where it is employed chiefly for tank and vat building. Individual specimens of the wood in some localities are tinted in a variety of shades and some of the natural designs are extremely beautiful.

The wood is reputed to be among the most durable in this country when exposed to soil and weather. Some of it deserves that reputation, but other does not. Well-authenticated cases are cited where cypress has remained sound many years-in some instance a hundred or morewhen subjected to alternate dampness and dryness. Such conditions afford severe tests. In other cases cypress has been known to decay as quickly as pine.

Historical cases from the old world are sometimes cited to show the wonderful lasting properties of cypress. Doors and statues, exposed more or less to weather, are said to have stood many centuries. The evidence has little value as far as this wood is concerned. In the first place, the long records claimed are subjects for suspicion; and in the second place, it was not the American cypress that was used-and probably no cypress-but the cedar of Lebanon.

Sound cypress logs have been dug from deep excavations near New Orleans, and geologists believe they had lain there 30,000 years. That would be a telling testament to endurance were it not that any other wood completely out of reach of air would last as long.

The estimated stand of cypress in the South is about $20,000,000,000$ feet. The annual cut, including shingles, exceeds $1,000,000,000$ feet. New growth is not coming on. The traveller through the South occasionally sees a small clump of little cypresses, but such are few and far between. It was formerly quite generally believed that cypress in deep swamps, where old and venerable stands are found, was not reproducing, and that no little trees were to be seen. It was argued from this, that some climatic or geographic change had taken place, and that the present stand of cypress would be the last of its race. More careful investigation, however, has shown that the former belief was erroneous. Seedling cypresses are found occasionally in the deepest swamps. Probably cypress which has not been disturbed by man is reproducing as well now as at any time in the past. The tree lives three or four centuries, and if it leaves one seedling to take its place it has done its part toward perpetuating the specics. Fire, the mortal enemy of forests, seldom hurts cypress, because the undergrowth is not dry enough to burn. 
The uses of cypress are so nearly universal that a list is impossible. In Illinois alone it is reported for seventy-eight different purposes. There is not a state, and scarcely a large wood-nsing factory, east of the Rocky Mountains which does not demand more or less cypress.

The tree is graceful when young, but ragged and uncouth when old. Though a needleleaf tree, it yearly sheds its foliage and most of its twigs. The fruit is a cone about one inch in diameter; and the seed is equipped with a wing one-fourth inch long and one-eighth inch wide.

When cypress stands in soft ground which most of the time is under water, the roots send up peculiar growths known as knees. They rise from a few inches to several feet above the surface of the mud, and extend above the water at ordinary stages. They are sharp cones, generally hollow. It is believed their function is to furnish air to the tree's roots, and also to afford anchorage to the roots in the soft mud. When the water is drained away, the knees die.

Cypress is widely planted as an ornament, and a dozen or more varieties have been developed in cultivation.

POND Cypress (Taxadium imbricarium) so closely resembles bald cypress with which it is associated that the two were once supposed to be the same. Pond cypress averages smaller and its range is more circumscribed. The name pond cypress, hy which it is popularly known in Georgia, indicates the localities where it is oftenest found. It is the prevailing cypress in the Okefenoke swamp in southeastern Georgia. The general aspect of the foljage and fruit is the same as of bald cypress. No detailed examination of the wood seems to have been made, but in general appearance it is like the other cypress. It is said that little of it ever gets to sawmills because it grows in situations where logging is inconvenient.

MoNTEREy Cypress (Cupressus macrocarpa). This tree has only one name and that is due to its place of growth on the shores of Monterey bay, California. Its range is more restricted than that of any other American softwood. It does not much exced 150 acres, though the trees are scattered in a narrow strip for two miles along the coast. They approach so close the hreakers that spray flies over them in time of storm. Trees exposcd to the sweep of the wind are gnarled and of fantastic shapes. Their crowns are broad and flat like an umbrella, but ragged and unsymmetrical in outline. That form offers least resistance to wits, and most surface to 1he sun. The trees take the best possible advantage of their opportunities. Tall crowns would be carried away by wind; and the flat tops, with a mass of grecin foliage, catch all the sunlight possible. They need it, for they grow in fog, and sunshine is scarce. Sheltered trees develop pyramidal tops. It is widely planted in this and other countries, and when conditions are favorable, it is graceful and symmetrical. The largest trees are from sixty to seventy feet tall, others are five or six in diameter; hut the tallest trees and the largest trutuks seldom go together. The cones are an inch or more in length, and each contains about 100 seeds. The leaves fall the third and fourth years. Wood is heavy, hard, strong, and durable, but is too scarce to be of value as lumber, even if the trunks were stuitable for sawlogs. The Monterey cypress is of peculiar interest to hotanists and also to physical geograpliers. The few trees on the shore of Monterey hay appear to be the last remnant of a species which was once more extensive. The ocean is eating away the coast at that point. 
Fragments of hills, cut sheer down from top to the breakers beneath, are plainly the last remnants of ranges which once extended westward, but have been washed away by the encroaching waves. No one knows how much of the former coast has been destroyed. Apparently the former range of the cypress was principally on land now swallowed up by the encroaching ocean. A mere fringe of the trees-a belt about 200 yards wide along the beach-remains, and the sea is undermining them one by one and carrying them down. So rapidly is the undermining process going on that many large roots of some of the trees are exposed to view.

ARIzona Crpress (Cupressus arizonica), as its name implies, is an Arizona tree. It forms considerable forests in the eastern, central, and southern parts of the state, and is found also in Mexico. It grows at elevations up to 6,000 feet. Because of the small population in the region where this cypress grows, it has never heen much used, hut the size of the trees and the character of the wood fit it for many purposes. Its growth is often quite rapid, and the timber is soft, light, and with well-defined summerwood. Its usual color is gray, but occasionally faint streaks of yellow appear. The leaves fall during the fourth and fifth years; cones are small and flat; and the small seeds are winged. It is believed by persons familiar with Arizona cypress that it will attain considerable importance when the building of railroads and the settlement of the country make the forests accessible. The wood is durable in contact with the soil.

Smooth Crpress (Cupressus glabra) ranges in Arizona and is not believed to have or to promise much importance as a source of lumber supply. Its name was given on account of the smoothness of the bark. It is one of the latest species to be given a place among the cypresses, and was described and named by George $B$. Sudworth of the United States Forest Service.

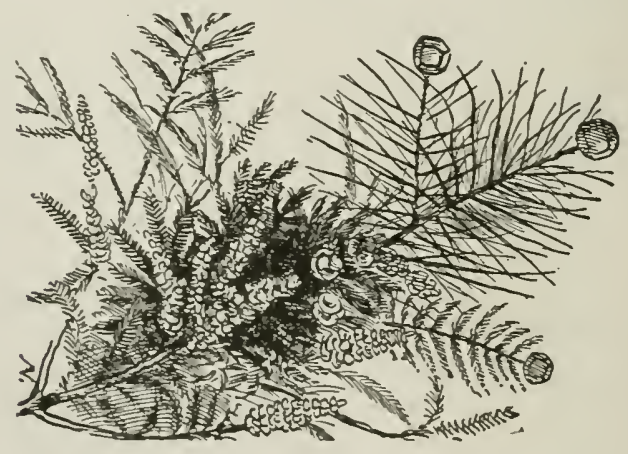


BAIAAM FIR 


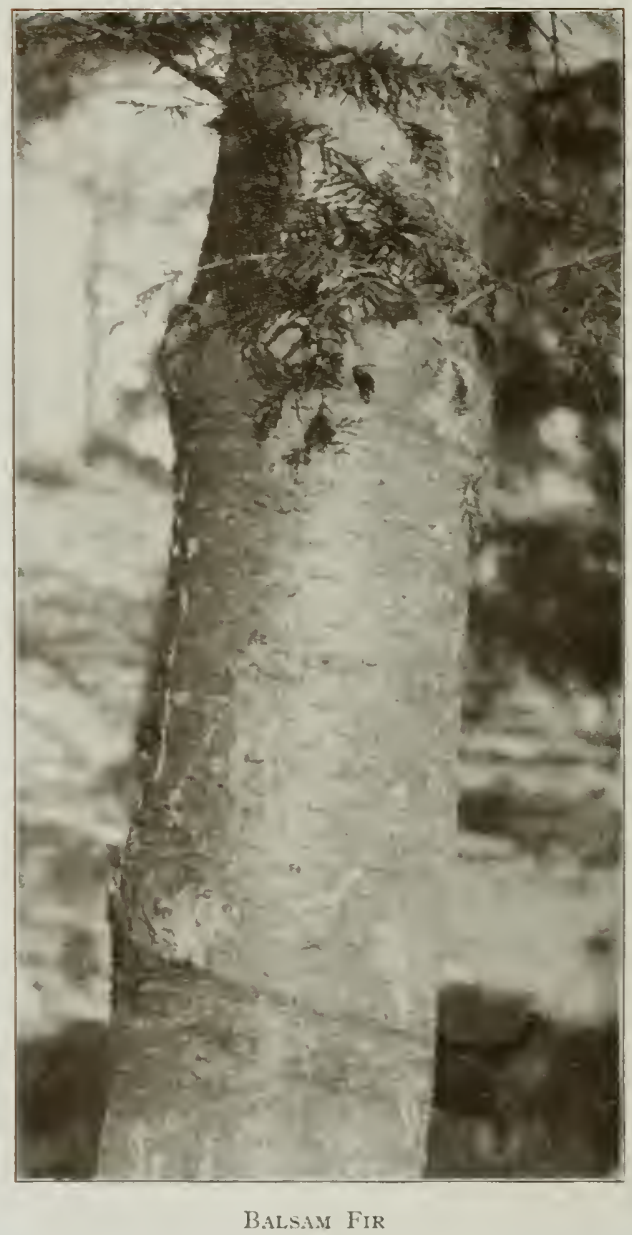




\section{BALSAM FIR}

\section{(Abies Balsamea)}

B ALSAM fir is the usual name applied to this tree in New England, New York, Pennsylvania, Michigan, Wisconsin, Minnesota, and Ontario. The shorter name balsam suffices in some parts of that region, and particularly in New York, New Hampshire, and Vermont. Because it is common north of the international boundary, the name Canada balsam has been given it in some regions. In Delaware it is known as balm of Gilead, but that name belongs to a tree of the cottonwood group, (Populus balsamifera) which is a broadleaf species. In New York and Pennsylvania a word of distinction is added, and it is called balm of Gilead fir. Toward the southern limit of its range it is spoken of as fir pine and blister pine. New York Indians knew the tree as blisters. They referred to the pockets under the bark of young trees and near the tops of mature trunks, in which resin collected. The name balsam refers to that characteristic also, as does the word balm. In some parts of Canada the tree is known as silver pine, and as silver spruce. The secretion of resin in bark blisters is a characteristic of several firs.

The list of names and the locality of their use indicate fairly well the geographical range of balsam fir. Its northern limit forms a line across eastern Canada from Labrador to Hudson bay. From Hudson bay its northern boundary trends northwestward and reaches the vicinity of Great Bear lake. In the United States it grows westward to Minnesota and southward to Pennsylvania. It is eut for lumber in eleven states.

In a range so large and including situations so various, it is natural that the tree should vary greatly in size. In the Lake States the common height is fifty or sixty feet, and the diameter is twelve or fifteen inches. Young balsam firs grow vigorously when the ground is suitable and their tops receive sufficient light. In lumbered regions in the Lake States, this fir gets a foothold in the shade of a dense growth of paper birch and other quickly-growing species; and in a few years the pointed, intensely grecn spires of the balsams may be seen piercing the canopy of other young tree tops, and shooting above into the light. This is accomplished after a struggle of some years in the shade; but the firs ultimately win their way upward, and in a few years they shade to death most of their broadleaf associates. If they are in competition with northern white cedar or tainarack, they are not always successful in winning first place.

The leaves of balsam fir are from one-half to one and one-fourth 
inches long. They are green and lustrous above and silver white below, the whiteness due to stomata on their undersides. On young twigs the leaves bristle out on all sides and are very numerous and crowded together, but on older branches the leaves are more scattered, due to the dropping of some of them. It is their habit to adhere to the stems about eight years.

The leaves of balsam fir possess a pleasing and characteristic odor which is turned to account in a practical way. The small needles are stripped from the branches in large quantities, cleaned, dried, and are used for stuffing sofa pillows, cushions, and other kinds of upholstery. The odor persists a long time. Much of the collecting of the needles is done in summer as a pastime by summer campers in the northern woods. The needles are sufficiently tough to stand much wear in pillows, and they are still odorous when long use has ground them to powder.

The cones of balsam fir follow the fashion of all species of fir, and stand erect on the branches. Seeds are one-fourth inch in length and are winged. The wood is of approximately the same weight as white pine, but it falls considerably below white pine in strength and stiffness. It is of moderately rapid growth when conditions are favorable, and the annual ring has a fair proportion of summerwood. The yearly rings are quit distinct. The medullary rays are numerous, and for a sof twood they are prominent. When a $\log$ is quarter-sawed, and the surfaces of the boards are planed, the wood presents a silvery appearance, but it is too monotonous to be very attractive. The heartwood is pale brown, streaked with yellow, the thick sapwood much lighter in color. It is perishable in contact with the soil.

Pulp manufacturers are the largest users of balsam fir. About three per cent of all the pulpwood cut in the United States in 1910 was from this species. Its use is on the increase, or appears to be; but recent statistics relating to this wood cannot be safely compared with returns for former years, because the custom of mixing fir with spruce and other pulpwoods formerly prevailed in New England, and it was then not possible to determine exactly how much fir reached the market. At the present time fir goes under its own name, and the output exceeds 132,000 cords, which is equivalent to $105,000,000$ feet, board measure, yearly.

Eleven states contribute to the balsam fir lumber cut, but most is supplied by Maine, Minnesota, Vermont, Michigan, and Wisconsin. The total for 1910 was $74,580,000$ feet. Much of it is employed in rough form for fences and buildings, while other is further manufactured by planing mills and factories. Car builders employ it in several ways. It serves as doors, siding, lining, and roofing for freight cars. It is not a 
durable wood when exposed to weather. The largest reported use of the wood in New England is by box makers. Massachusetts alone works nearly $15,000,000$ feet a year into crates and shipping boxes. Its uses in the Lake States are more varied. The makers of berry, fruit, and vegetable baskets draw supplies from the wood. Some of the product is of thin split slats, and other of veneer or sawed material.

The light weight and white color of balsam fir make it acceptable to the manufacturers of excelsior. The product is employed in packing merchandise for shipment, and to a small extent in upholstery. The wood fills a rather important place in the woodenware industry, where its white color and light weight constitute its most important recommendations. It is sawed into staves for pails and tubs.

Though balsam fir has little figure and its appearance is rather common, it finds its way to planing mills and woodworking shops where it is made into ceiling, newel posts, molding, railing, spindles, chairboards, and other interior finish.

The most widely known commercial product manufactured from this tree is Canada balsam. Strictly speaking, it is not a manufactured article except what is done in nature's laboratory, and the product is the resin stored under bark blisters. The resin is transparent, and is employed by microscopists in mounting objects for examination. Little machinery or apparatus is used in removing the viscid fluid from the pockets in the bark. With a knife the thin, soft blister is slit and the resin is scraped out. All kinds of claims of medicinal virtue are made for balsam resin in the region where the tree grows; but the treatment in most cases effects cures-if any cures are really effected-by appeals to faith and the imagination.

Balsam fir owes a large part of its importance to its abundance. It is not exactly a swamp tree, but it does best in damp situations where the ground is moist and cool in summer. Only in periods of protracted drought does the ground litter become sufficiently dry to burn fiercely, and to that fact is due much of the promise of future supply of balsam fir. That which grows on the dry uplands may fall prey to forest fires, but that in the damp flats, associated with northern white cedar and tamarack, will hold its ground and continue to supply demand.

Balsam fir has an importance which can not be wholly measured in feet, pounds, cords, or dollars. Many of the choicest Christmas trees which in December go by tens of thousands to the cities, are of this tree. Its form is almost perfect, being conical, broad near the bottom, and running to a sharp apex. The deep green of the needles, which retain their color from two weeks to a month after the trunk is severed, gives balsam Christmas trees much of their popularity. The trees are cut 
from Maine to Michigan, and many are shipped across the international boundary from Canada. The custom of cutting Christmas trees is often condemned as a waste of resources. It has been argued that the destruction in one month of $1,000,000$ young trees is equivalent to the destruction of $500,000,000$ feet of lumber, because, if allowed to reach maturity, they would yield that much lumber. That argument does not take into consideration the fact that not one of the young trees in ten would reach maturity if left to the course of nature.

When Gifford Pinchot was United States forester, a protest against the cutting of Christmas trees was formally laid before him. It was generally believed that he would declare that the waste ought to be stopped and would set his disapproval on the practice; but he did nothing of the sort. He declared that the forests are for the use of the people and that they can serve in no better way than by supplying every child in the land with a Christmas tree once a year.

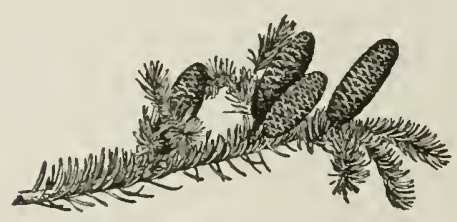


FRASER FIR 


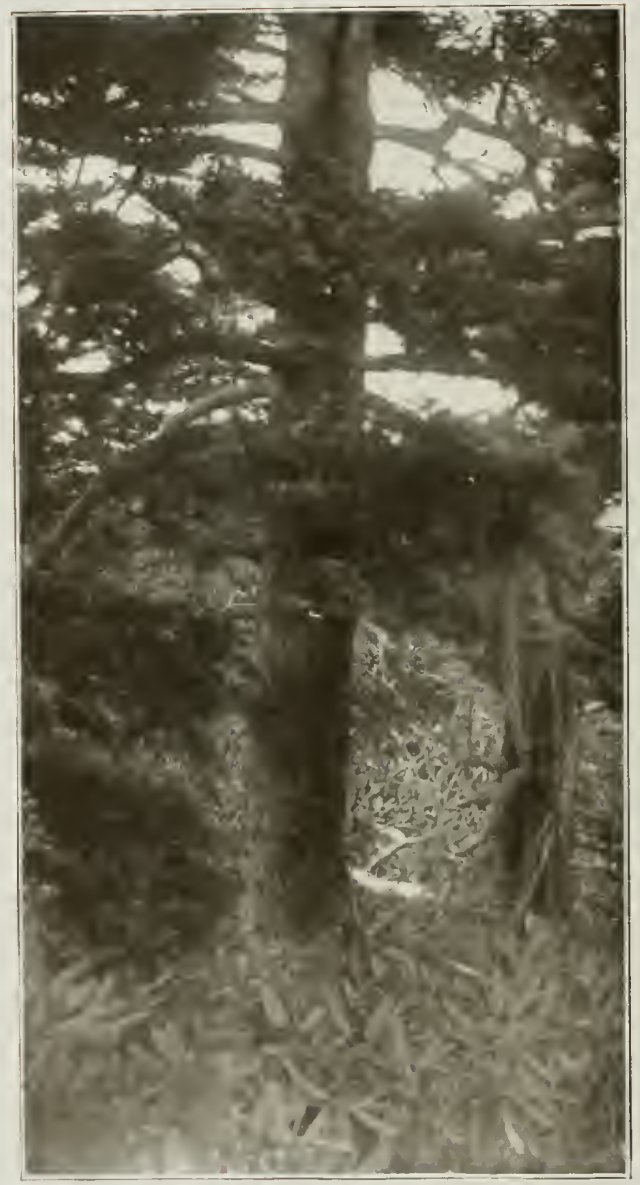

IRASIR FIR 


\section{FRASER FIR}

\section{(Abies Fraseri)}

$\mathrm{T}$

$\mathrm{HE}$ people who are acquainted with this interesting and somewhat rare tree have seen to it that it does not want for names. Some of these names are both definitive and descriptive, whilc others are neither. Tennessee, North Carolina, and West Virginia furnish the names. Within the tree's range in Tennessee and North Carolina it is often known as balsam without any qualifying word, and that is quite sufficient, for no other fir or balsam grows within its range. In the same region it is called balsam fir. That is the common name of its northern relative, but there is little likelihood of confusing the two species, for their ranges do not overlap much, if they touch at all, which they probably do not. In Tennessee the name is reversed and instead of balsam fir it is fir balsam. It is likewise known as double fir balsam, but why "double" is added to the name is not clear. Similar mystery attaches to the name "single spruce," which is applied to the balsam fir in the interior of British America. The southern Appalachian tree is called she balsam and she balsam fir. These names have no scientific basis, and they appear to have originated in a desire to distinguish this tree from the red spruce with which it is associated. The spruce is called "he balsam." Artificial names like these are not necessary to distinguish red spruce from Fraser fir, as very slight acquaintance should enable anybody to tell one from the other at sight, and to see clearly that they are not of the same species. Mountain balsam, a North Carolina name for this fir, is well taken, for it is distinctly a mountain species. The name healing balsam is given in acknowledgment of the supposed medicinal properties of the resin which collects in blisters or pockets under the bark of young trees and near the tops of old. In West Virginia, where this tree reaches the northern limits of its habitat, it is called blister pinc, on account of the resin pockets. In the same region it is called stackpole pine, because farmers who mow mountain meadows use straight, very light poles cut from this fir round which to build haystacks.

This tree is decidedly an inhabitant of the high, exposed localities, being found entirely in the upper elevations of the southern Appalachian mountains, either forming extensive pure stands or growing in the company of red spruce (Picea rubens), with a scattering of various stunted hardwoods, as birch, mountain ash, cherry and usually with an undergrowth of rhododendron.

Fraser fir's range extends from the high mountains of Nortl Carolina, where it grows 6,000 feet above sea level, uorthward into 
West Virginia, within a few miles of the Maryland line, at an altitude of 3,300 feet. The tree is not found in all regions between its northern and southern limits. Its best development is in the southern part of its range.

On the upper limits of its habitat the tree presents a decidedly picturesque appearance, being gnarled and twisted and plainly showing the results of its long struggle for life and development. It is always noticeable that on the exposed side the limbs are so short as to be almost missing and on the opposite side they grow out straight and long, appearing to fly before the wind. These limbs are sometimes of as great a girth for five or six feet of their length as any part of the main stem, and have a singular look, seeming to be all out of proportion to the rest of the tree. The older trees are vested in a smooth, yellowish-gray, mossy bark, which is quite different from that of the balsam fir. The bark is thin, about one-fourth of an inch on young trunks, and half an inch near the ground on old ones. The leaves are usually half an inch long, sometimes one inch, and their lower sides are whitish, which tint is due to abundant white stomata. In that respect they resemble leaves of balsam fir and hemlock.

The cones, like those of other species of fir, stand erect on the branches, and average about two and a half inches in length. They are smoother than the cones of most pines. They mature in September. The winged seeds average one-eighth inch in length, and are fairly abundant. The Fraser fir grows as tall as balsam fir, from forty to sixty feet, and the trunk diameter is greater, being sometimes thirty inches, though half of that is nearer an average. When of pole size, that is, from five to eight inches in diameter, Fraser fir is of ten tall, straight and shapely. Its form, however, depends upon the situation in which it grows. If in the open, it develops a relatively short trunk and a broad, pyramidal crown. This fir differs from balsam fir in its choice of situation. The latter, though not exactly a swamp tree, prefers damp ground, while Fraser fir flourishes on slopes and mountain tops.

On the mountains of western North Carolina fir grows in mixture with red spruce. Sometimes the fir is fifty per cent of the stand, but usually it is less, and frequently not more than fifteen per cent. Few fir trees in that locality are two feet in diameter. They grow with fair rapidity in their early years, but decline in rate as age comes on. It may be observed in traveling through the stands of mixed spruce and fir among the high ranges of the southern Appalachian mountains that the proportion of spruce is much higher in old stands than in young. That is due to the greatcr age to which spruce lives. Trees of that species continue to stand after the firs have died of old age. On the other hand, 
fir outnumbers spruce in many young stands. That is because fir reproduces better than spruce, and grows with more vigor at first. In stands of second growth the fir often predominates. It depends to some extent upon the conditions under which the second growth has its start. Fir does not germinate well if the ground has been bared by fire and the humus burned. Consequently, old burns do not readily grow up in fir. The best stands occur where the natural conditions have not been much disturbed further than by removing the growth. Fortunately conditions on the summit and elevated slopes of the southern Appalachians do not favor destructive forest fires. Rain is frequent and abundant, and the shade cast by evergreen trees keeps the humus too moist for fire. To this condition is due the comparative immunity from fire of the high mountain forests of fir and spruce. Sometimes, however, fires sweep through fine stands with disastrous results. The destruction is more serious because no second forest of evergreens is likely on tracts which have been severely burned.

A report by the State Geological Survey on forest conditions in western North Carolina, issued in 1911, predicted that spruce aud fir forests aggregating from 100,000 to 150,000 acres among the high mountain ranges, will become barren tracts, because of the destructive effect of fires stripping the ground of humus.

The cutters of pulpwood in the southern Appalachian mountains take Fraser fir wherever they find it, mix it with spruce, and the two woods go to market as one. Statistics show the annual cut of both, but do not give them separately. The output of spruce, including fir, south of Pennsylvania, in 1910 was 115,993 cords, equivalent to about 80 ,000,000 feet, board measure. Mlost of it was red spruce, but some was fir, and in North Carolina probably twenty-five per cent was of that species. The total pulpwood cut in that state was 14,509 cords of the two woods combined, and probably 3,800 cords were Fraser fir.

The wood of Fraser fir is very light. An air dry sample from Roan mountain, N. C., weighed 22.22 pounds per cubic foot. That is lighter than balsam fir, which is classed among the very light woods. It is stronger than balsam fir by twenty-five per cent. The wood is soft, compact and the bands of summerwood in the annual rings are rather broad and light colored and are not conspicuous. The medullary rays are thin but numerous. The color is light brown, the sapwood mostly white.

This wood is not of much commercial value except for pulp. It is not abundant, and it is not suited to many purposes. It is suitable for boxes, being light in weiglst and moderately strong; but other woods which grow in the same region are as good in all respects and are 
more abundant, and will be used in preference to fir for that purpose. The decrease in area on account of fires, and in quantity because of pulpwood operations, indicates that forest grown Fraser fir has seen its best days. On the other hand, the United States Forest Service has acquired tracts of land on the summits of the mountains where this species has its natural home, and the growth will be protected from fires and from destructive cutting, and there is no danger that the species will be exterminated.

It is an interesting tree. It contributes to the pleasure of tourists and carmpers among the southern mountains. The fragrance of its leaves and young branches add a zest to the summer camp. The traveler who is overtaken in the woods by the coming of night, prepares his bed of the boughs of this tree and of red spruce and sleeps soundly beneath an evergreen canopy. Pillows and cushions stuffed with fir needles carry memories of the mountains to distant cities.

In one respect this tree of the high mountains is like the untamed Indians who once roamed in that region: it refuses to be civilized. The tree has been planted in parks in this country and in Europe, but it does not prosper. Its form loses something of the grace and symmetry which it exhibits in its mountain home, and its life is short. Those who wish to see Fraser fir at its best must see it where nature planted it high on the southern mountains.

Arizona Cork Frr (Abies arizonica) very closely resembles forms of the alpine fir, and may not be a separate species. Sudworth was unable to distinguish its foliage and cones from those of alpine fir, but the bark is softer. Its range is on the San Francisco mountains in Arizona. It is very scarce, and only local use of its wood is possible.

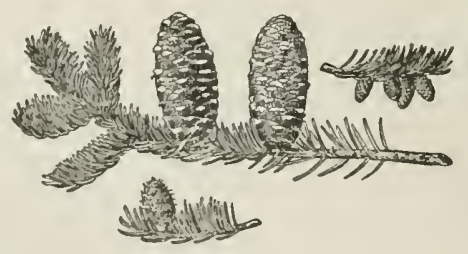


NOBLE FIR 


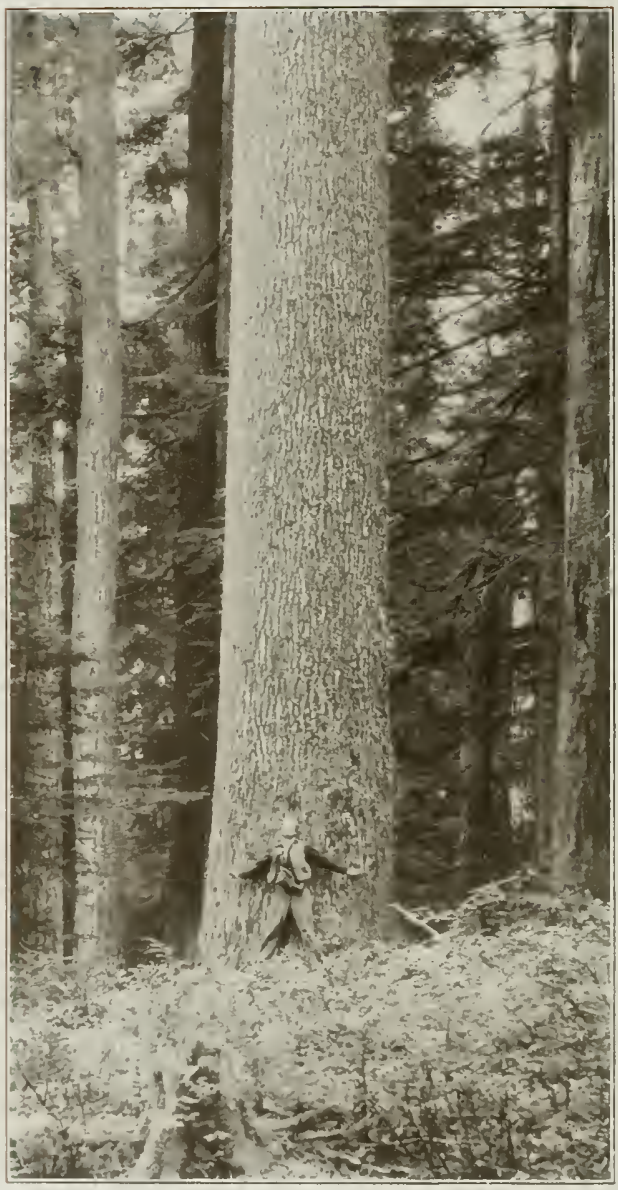

Noble Fir 


\section{NOBLE FIR}

\section{(Abies Nobilis)}

THIS tree's name is justified by its appearance when growing at its 1 best in the forests of the northwest Pacific coast. It is tall, shapely, and imposing. It often exceeds a height of 250 feet, and a trunk diameter of six feet. It is sometimes eight feet in diameter. No tree is more shapely and symmetrical. When grown in dense stands the first limb may be 150 feet from the ground, and from that point to the base there is little taper. It over-reaches so many of its forest companions that it is sometimes designated locally as bigtree; but it is believed that lumber is never so spoken of, and that the name applies to the standing tree only. The Indians of the region where it grows call it tuck-tuck, but information as to the meaning of these words is not at hand. In northern California, and probably still farther north, this species is often called red fir, feather-cone red fir, or bracted red fir. The color of the heartwood and the appearance of the cone, doubtless are responsible for these names. There is a tendency in the fir-growing regions of the West to call all firs either white or red, depending upon the color of the heartwood. There are ten or more species of fir west of the Rocky Mountains, and to the layman they all look much alike, but to botanists they are interesting objects of study.

The range of noble fir covers parts of three states, but the whole of no one. Its northern limit is in Washington, its southern in northern California, and it follows the mountains across western Oregon. It often forms extensive forests on the Cascade mountains of Washington. It is most abundant at elevations of from 2,500 to 5,000 feet in southwestern Washington and northwestern Oregon. On the eastern and northern slopes of those mountains it is of smaller size and is less abundant. Like several other of the extraordinarily large western trees, it keeps pretty close to the warm, moist coast of the Pacific.

The shining, blue-green color of the leaves is a conspicuous characteristic of noble fir as it appears in the forest. They vary in length from an inch to an inch and a half. They usually curl, twist, and turn their points upward and backward, away from the end of the branch which bears them. The cones, following the fashion of firs, stand upright on the twigs, and are conspicuous objects. They are four or five inches in length, which is rather large for firs, but not the largest. The seeds are half an inch long, and are winged. They are well provided with the means of flight, but many of them never have an opportunity to test their wings, for the dextrous Douglas squirrel cuts the cones from 
the highest trees, and when they fall to the ground he pulls them apart with his feet and teeth, and the seeds pay him for his pains. If cones ripen on the trees and the released seeds sail away, there are birds of various feather waiting to receive them. Consequently, the noble fir plants comparatively few seeds. Their ratio of fertility is low at best, but that is partly compensated for by the large numbers produced.

Thick stands of noble fir are not common. It generally is found, a few trees here and there, mixed with other species. Sawmills find it unprofitable to keep the lumber separate from other kinds. It does not pay to do so for two reasons. Extra labor is required to handle it in that way, and there is a prejudice against fir lumber. It does not appeal to buyers. For that reason some operators have called this timber Oregon larch, and have sent it to market under that name. That is a trick of the trade which has been put into practice many times and with many woods. The purpose in the instance of noble fir was to pass it for the larch which grows in the northern Rocky Mountain region. The two woods are so different that no person acquainted with one would mistake it for the other. A recent government report of woods used for manufacturing purposes in Washington does not list a foot of noble fir. The inference is that it must be going to factories under some other name, for it is incredible that this wood should be put to no use at all in the region of its best development.

Noble fir is of slow growth, and the large trunks are very old, the oldest not less than $\$ 00$ years. The summerwood forms a narrow, dark band in the annual ring. Medullary rays are numerous, but very thin and inconspicuous. The wood possesses little figure. It weighs twentyeight pounds per cubic foot, which is four pounds less than the average Douglas fir. It is very low in fuel value, as softwoods usually are which have little resin. It is very weak, and it bends easily. It is soft, easily worked, and polishes well. This is one of its most valuable qualities. It is deficient in a number of properties which are desirable in wood, but partly makes up for them in its ability to take a smooth finish. It is pale brown, streaked with red, the sapwood darker. In that particular it is unusual, for most softwoods have sap lighter in color than the heart.

It has been already pointed out that difficulty is met when an attempt is made to list the uses of noble fir, because it loses its name before it leaves the sawmill yard and takes the name of some other wood, and those who put it to use of ten do so without knowing what the wood really is. It is known that some of it is manufactured into house siding. It works nicely and looks well, but since it is liable to quick decay it must be kept well painted when it is exposed to weather. It serves as interior finish, and this seems to be one of its best uses. It is 
so employed for steamboats and for houses, and many shipments of it have been made to boat builders on the Atlantic coast. It is used for shipping boxes, and its light color fits it for that purpose, as the wood shows painting and stenciling to good advantage.

European nurseries have propagated noble fir with success, but it does not do so well in the eastern part of the United States, though it lives through winters as far north as Massachusetts. It is not known to have been planted for other than ornamental purposes. Unless it would grow much faster in plantations than in its wild state, it will be too long in maturing to make it attractive to the timber planter.

WHITE FrR (Abies concolor). The whiteness of the wood and the silver color of the young branches give this species its name, but it is not the sole possessor of that name, but shares it with three other firs. In California, Idaho, and Utah it is called balsam fir. The branches and upper parts of the trunk where the bark is thin, are covered with blisters which contain white resin. In Utah it is known as white balsam, as silver fir in some parts of California, and as black gum in Utah. The reason for that name is not apparent, unless it refers to the black bark on old trees. It has several other names which are combinations of white and silver with some other term. Its range is mostly in the Sierras and in the Rocky Mountain ranges, extending from southern Colorado to the mountains of California, north through Oregon, and south throngh New Mexico and Arizona. The immense proportions are reached only in the Sierra growth, those trees in the Rockies being hardly above ordinary size. In its free growth the tree is reputed to be the only one of its genus found in the arid regions of the Great Basin, and similar localities in Arizona and New Mlexico. It is not distinguished by all botanists from the similar species, Abies grandis.

White fir attains a height of 250 feet and a diameter of six in some instances, but the average size of mature trees among the Sierra Nevadas is 150 feet tall and three or four in diameter. In the Rocky Mountain region the tree is smaller. It grows from 3,000 to 9,000 feet above sea level. The leaves are long for the fir genus, and vary from two to three inches. The tree's bark is black near the base of large trunks but of less somber color near the top. Near the base of large trees the bark is sometimes six inches thick. The wood of this species is light and soft. Carpenters consider it coarse grained, by which they mean that it does not polish nicely. It is brittle and weak. The rings of annual growth are generally broad, with the bands of darker colored summerwood prominent. In lumber sawed tangentially, rings produces distinct figure, but it is not generally regarded as pleasing. The medullary rays are prominent for a softwood, but quarter-sawing does not add much to the wood's appearance. It decays quickly in alternate wet and dry situations. Trees are apt to be affected with wind shake, and the wood's disposition to splinter in course of manufacture has prejudiced many users against it. However, it has some good qualities. The wood is free from objectionable odor, and this qualifies it as box material. Fruit shippers can use it without feat of contaminating their wares. It is light in color, and stenciling looks well on it. Its weight is likewise in its favor.

Trees of this species seldom occur in pure stands of large extent, but are scattered among forests of other kinds. Sawrrills cut the fir as they come to it, but seldom go much out of their way to get it. The United States ccnsus for 1910 showed that 132,327,000 feet of white fir lumber were cut in tlie whole country, but as several species pass by that name it is not possible to determine how much belonged 
to the one under discussion, but probably about half, as that much was credited to California where this tree is at its best. The fir does not suffer in comparison with trees associated with it. Its trunk does not average quite as large as the pines, yet larger than most of the cedars; but in height it equals the best of its associates, and in symmetrical form, and beauty of color of foliage, it must be acknowledged superior. The dark intensity of its green crown when thrown against the blue summer skies of the Sierras forms a picture which probably no tree in the world can surpass and few can equal. Its cones suffer from the depredations of the ever-hungry Douglas squirrel which is too impatient to wait for nature's slow process to ripen and scatter the seeds; but he climbs the trunks which stand as straight as plummet lines two hundred feet or more, and clinging to the topmost swaying branches, clips the cone stems with his teeth, and the cone goes to the ground like a shot. A person who will stand still in a Sierra forest in lste summer, where firs abound, will presently hear the cones thumping the ground on all sides of him. If his eyes are good, and he looks carefully, he may see the squirrels, silhouetted against the sky on far-away tree tops, seeming so small in the distance that they look the size of mice; yet the Douglas squirrel is about the size of the eastern red squirrel. He does not always let the cones fall when he cuts their stems, but sometimes carries them down the long trunk to the ground, then goes back for another. The squirrel hoards the cones for winter, but does not neglect to fully satisfy his appetite while about the work. A single hoardcarefully covered with pine needles as a roof against winter snow-may contain five or ten bushels of cones, which are not all fir cones, but these predominate in most hoards.

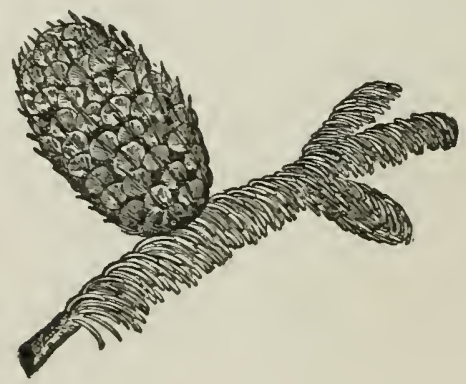


GRAND FIR 


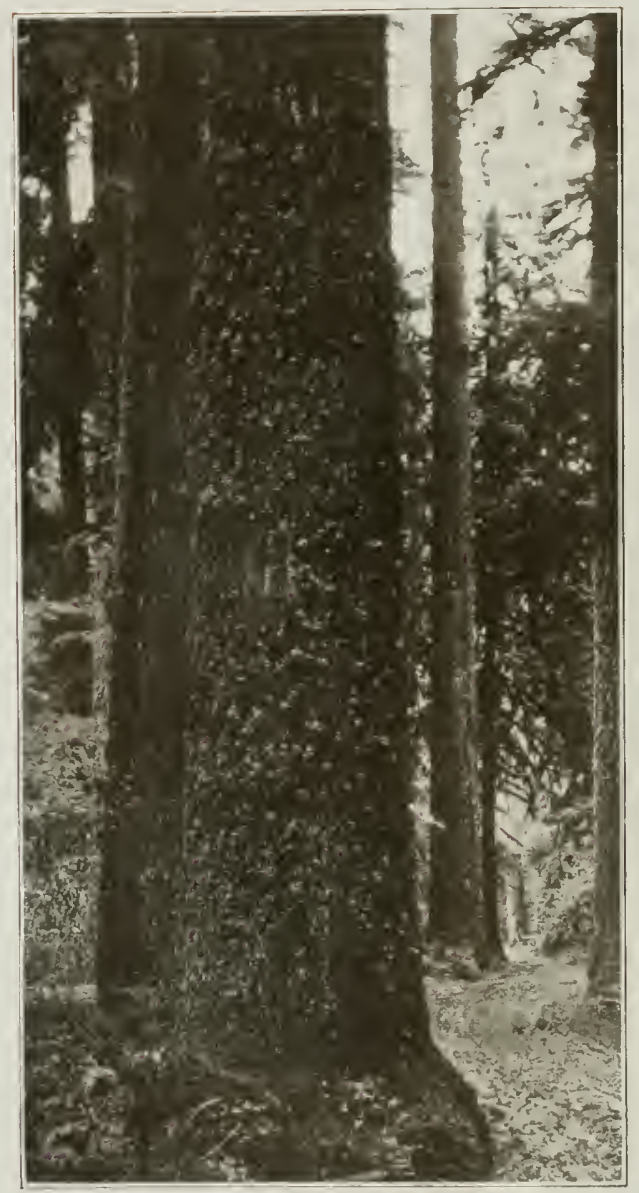

GRAND FiR 


\section{GRAND FIR}

\section{(Abies Grandis)}

N California, Oregon, and Idaho this tree is called white fir, but it has several other names, silver fir and yellow fir in Montana and Idaho. In California some know it as Oregon fir, western white fir, and great California fir. Grand fir is more a botanist's than a lumberman's name.

The range extends from British Columbia to Mendocino county, California, and to the western slopes of the continental divide in Montana. The coastal growth lies in a comparatively narrow strip. In the mountains an altitude of 7,000 feet is sometimes reached, the soil and moisture requirements, however, being the same. The largest trees are found in bottom lands near the coast where trunks 300 feet tall and six feet in diameter are found, but the average is much less. In mountain regions at considerable altitudes a height of 100 feet and a diameter of two or three is an average size. The leaves are about an inch and a half in length, occasionally two and a half. They are arranged in rows along the sides of the long, flexible branches. Cones are from two to four inches long, and bear winged seeds three-eighths of an inch long, the wings being half an inch or more in length. The bark of old trunks may be two inches thick, but generally is thinner. It is unfortunate that the wood of the large western firs lacks so many qualities which make it valuable. It is generally inferior to the woods of Douglas fir, western hemlock, Sitka spruce and the western cedars, sugar pine, and western yellow pine. The wood of grand fir is light, soft, weak, brittle, and not durable in contact with the soil. Its light color and the abundance of clear material in the giant trunks are redeeming features. These ought to open the way for much use in the future. It cannot find place in heavy construction, because it is not strong enough. That shuts it from one important place for which it is otherwise fitted. Box makers find it suitable, as all fir woods are, and large demand should come from that quarter. Trunks that will cut from 15,000 to 20,000 feet of lumber that is practically clear, and of good color, and light in weight, are bound to have value for boxes and slack cooperage. Trees grow witlı fair rapidity. Annual rings are usually broad, and the bands of summerwood are wide and distinct. This guarantees a certain figure in lumber sawed tangentially, but it is not a figure to compare in beauty with some of the hardwoods, or even with Douglas fir, or the southern yellow pines. It ought to be a first class material for certain kinds of woodenware, particularly for tubs, pails, and small stave vessels, and as far as it has been used in that way it has been satisfactory. It cannot be recom- 
mended for outside house finish, such as weather-boarding, cornice, and porch work, because of its susceptibility to decay; but it meets requirements for plain interior finish, and tests have shown it to be good material for cores or backing over which to glue veneers of hardwood.

While the eastern states have not yet wakened up to the fact that this tree is of value in ornamental planting, its decorative qualities in open stands have been recognized for some time in eastern Europe, where trees of considerable size, promising to attain almost primeval proportions, are already flourishing.

RED FIR (Abies magnifica) is the largest fir in America. At its best it attains a height of 250 feet and a diameter of ten, but that size is rare. It has several names, magnificent fir, which is a translation of its botanical name; redbark fir, California red fir, and golden fir. The reference to red which occurs in its several names, is descriptive of its heartwood. Its range lies on the Cascade mountains of southern Oregon, and along the entire length of the western slope of the Sierra Nevadas in California. It is common in southern Oregon and sometimes forms nearly pure forests at elevations of 5,000 or 7,000 feet. It is plentiful in the Sierra Nevada ranges at altitudes of from 6,000 to 9,000 feet. In southern California it ascends 10,000 feet. On old trees the limbs, regularly whorled in collars of five, are usually pendulous or down-growing and are regularly and precisely subdivided into branches and twigs, the short, stiff blue-green leaves, which persist for ten years, closely covering the upper side of the latter. Its cones are the largest of the firs, are dark purple in color and grow erect on the branches.

The cones are six or eight inches long, and three or four in diameter. They present a fine appearance as they stand erect on the branches. The seeds are large, but their strong wings are able to carry them away from the immediate presence of the parent tree. The wings are extremely beautiful, and flash light with the colors of the rainbow. Old trees are protected by hard, dark-colored bark five or six inches thick. A forest fire may pass through a stand of old firs without burning through the bark, but young trees are not so protected, and are liable to be killed.

A study of the wood of the red fir reveals rather more favorable qualities than the other firs afford. Sap and heartwood are more easily distinguished than in the other species, the sapwood being much lighter in color than the reddish heart. Contrary to the general rule among the firs, this wood possesses considerable durability, especially when used for purposes which bring it in contact with the soil. It is, however, light, soft and weak, but has a close, fine grain and compact structure. Seasoning defects, such as checking and warping, are liable to occur unless properly guarded against. It weighs 29.30 pounds per cubic foot, or 
nearly three pounds less than Douglas fir. It is used for rough lumber, packing boxes, bridge floors, interior house finish, and fuel.

SHASTA RED FIR (Abies magnifica shastensis) is pronounced by George B. Sudworth to be only a form of red fir (Abies magnifica) and not a separate species. The principal difference is in the cones. The Shasta form was discovered on the mountain of that name in northern California in 1890 by Professor J. G. Lemmon. It was supposed to be confined to that locality, but was subsequently found on the Cascade mountains in Oregon, and also at several points in northern California. It was later found in the Sierras five hundred miles south of Mount Shasta.

LOVELy Fir (Abies amabilis) is known by a number of names, red fir, silver fir, red silver fir, lovely red fir, amabilis fir, and larch. The last name is applied to this tree by lumbermen who have discovered that fir lumber sells better if it is given some other name. The range of this species extends from British Columbia southward in the Cascade mountains through Washington to Oregon. It is the common fir of the Olympic mountains and there reaches its best development, sometimes a height of 250 feet and a diameter of five or six; but the average, even in the best part of its range, is much under that size, while in the northern country, and high on mountains, it is a commonplace tree, averaging less than I00 feet high, and scarcely eighteen inches in diameter. When this fir stands in open ground, the whole trunk is covered with limbs from base to top; but in dense stands, the limbs drop off, and a clean trunk results.

Some of the largest trees rise with scarcely a limb 150 feet, and above that is the small crown. The bark of young trees is covered with blisters filled with resin. The bark is thin and smooth until the tree is a century or more old, after which it becomes rougber, and near the base may be two and a half inches thick. It is of very slow growth, and a century hardly produces a trunk of snall sawlog size. The leaves are dark green above, and whitish below. They are much crowded on the twigs, those on the underside rising with a twist at the base, and standing nearly erect. They are longer than those on the twig's upper side. The purple cones are conspicuous objects on the tree, are from three and a half to six inches long, and bear abundance of seeds which are well dispersed by wind. However, the reproduction of this tree is not plentiful. The species holds its own, and not much more. When artificial reforestation takes place in this country, if that time ever comes, lovely fir will receive scant consideration, because of its discouragingly slow growth. It ranks with lodgepole pine in that respect. Nature can afford to wait two hundred years for a forest to mature, but men will not plant and protect when the prospect of returns is so remote. The wood is light, weak, moderately stiff and hard. The heartwood is pale brown, the sap nearly white. The summerwood appears in thin but well-marked bands in the annual rings, and the medullary rays are large enough to show slightly in quartersawed lumber. Growing as it does, interspersed with really valuable woods, the lovely fir is not highly thought of from a commercial standpoint. However, it is exploited in conjunction with the other species and turned into lumber and general structural material. A considerable quantity finds a market as interior finish and wher millwork. It has many of the properties which fit it for the manufacture of packing boxes, particularly those intended for dried fruit and light merchandise. It bears considerable resemblance to spruce. The utilization of this and similar species 
of western fir for pulp bas been suggested, but little has been done. It has been planted ornamentally in parts of Europe, but there is no comparison between the decorative appearance of this fir and its associated species, the others which are in cultivation being much superior. Removal from the old habitat militates greatly against its natural beauty and reduces it to the level of the ordinary.

ALP1NE FIR (Abies lasiocarpa) is so called because it thrives on high mountains and in the far North. It grows in southern Alaska, up to latitude $60^{\circ}$, and southward to Oregon and Colorado. Its other names are balsam, white balsam, Oregon balsam, mountain balsam, white fir, pumpkin tree, down-cone, and downy-cone subalpine fir. It grows from sea level in Alaska up to 7,000 feet or more in the South. It is not abundant, and not very well known. However, its slender, spirelike top distinguishes it from all associates and it may be recognized at long distances by that characteristic. It endures cold at 40 degrees below zero, and summer climate at 90 degrees. Trees are usually small, and the trunks are covered with limbs to the ground. On high mountains the lower limbs often lie flat on the ground, and the twigs sometimes take root. Under very favorable circumstances this fir may reach a height of 160 feet and a diameter of four, but the usual size is less than balf of it, even when conditions are fair, while on bleak mountains mature trees may be only three or four feet bigh, with most of the limbs prostrate. The sprawling form of growth makes the tree peculiarly liable to be killed by fire. The bark is thin, smooth, and flinty; and in color it is ashy gray or chalky white. Leaves are one and a balf inches or less long; the purple cones from two to four inches. Trees bear cones at about twelve years of age. The seeds are equipped with violet or purplish wings, and they fly far enough to find the best available places to plant themselves. The wood is narrow-ringed, light, soft, and in color from pale straw to light yellowishbrown. It is fairly straight grained, and splits and works easily; but trunks are very knotty. Its best service in the past has consisted in supplying fuel to mining camps and mountain stock ranges.

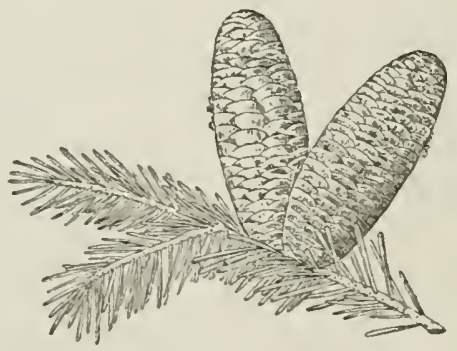


DOLGLAS FIR 


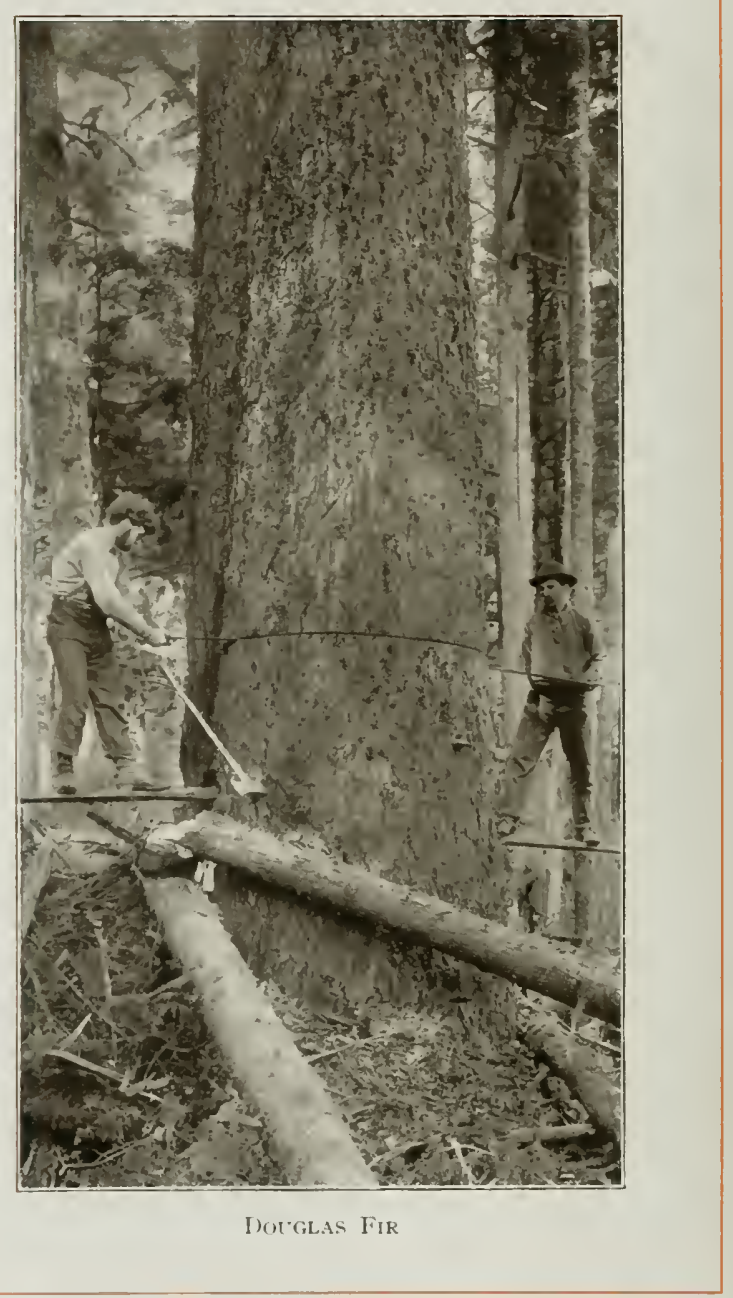




\title{
DOUGLAS FIR
}

\author{
(Pseudotsuga Taxifolia)
}

URING one hundred and ten years, from 1803 until the present time, botanists and others have proposed and rejected names for this tree. It has been called a fir, pine, and spruce, with various combinations, but the name now seems to be fixed. Laymen have disputed almost as much as botanists as to what the tree should be named. It has been called red fir, Douglas spruce, Douglas fir, yellow fir, spruce, fir, pine, red pine, Puget Sound pine, Oregon pine, cork-barked Douglas spruce, and Douglas tree. More than a dozen varieties are distinguished in cultivation.

The range of Douglas fir covers most of the Rocky Mountain region in the United States and northward to central British Columbia; on the coast from the latitude of southern Alaska to the Sierra Nevada mountains in central California. It reaches its maximum development in western Washington and Oregon, particularly between the Cascade mountains and the Pacific ocean. In these Cascade forests, stands are found which yield from 50,000 to 100,000 feet per acre, and mills in that region cut the longest timbers in the world, some two feet square and 100 feet long.

Two forms of Douglas fir are recognized by botanists, not essentially different except in size and habit of growth. One is the finely developed form on the Pacific coast where the climate is warm and the air moist. The other is the Rocky Mountain form which is smaller and shows the effect of cold, dryness, and other adverse circumstances. When the seeds of the two forms are planted in nurseries, where they enjoy identical advantages, the coast form outgrows the other in Europe, but the Rocky Mountain form thrives best in the eastern part of the United States.

Douglas fir needles are from three-quarters to one and a quarter inches long, and of a dark, yellow-green color. They remain on the twigs about eight years. Coner are from two to four and a half inches long, and are borne on long stems. The seeds, which ripen in August, are of light, reddish-brown color with irregular white spots on the lower side; are about a quarter of an inch long, and are provided witlı wings. Trees of this species in the moist climate of the Pacific slope average much larger than those in the mountains farther east. The largest are 300 feet high, occasionally more, and from eight to ten in dianeter. The average among the Rocky Mountains is from eighty to 100 feet high, and two to four in diameter. Young trecs are slender with crowded 
branches. In thick stands the lower limbs die and the trunks remain bare, except an occasional small branch. Douglas fir at its best grows in thick stands; with crowns forming a canopy so dense that sunlight can scarcely reach the ground. The result of this is that other species have little show where Douglas fir prevails.

The bark of large trunks attains a thickness of eight or ten inches near the base. Young bark contains blisters filled with resin, similar to those of balsam and other species of fir.

The wood is light red or yellow, the sap much whiter. Lumbermen recognize two kinds of wood, yellow and red. The former is considered more valuable. Both may come from the same trunk, and the season for the difference in color and quality is not well understood. It cannot be attributed to soil or climate, or to the age of the tree, and it does not seem to depend upon rate of growth. The bands of summerwood are broad and quite distinct. A few scattered resin ducts are visible under a magnifying glass of low power. The medullary rays are numerous, rather large, frequently yellow, conspicuous when wood is split radially. The wood's average weight is given by Sargent at 32.14 pounds per cubic foot, yet some specimens exceed forty pounds. It is hard, strong, and stiff. In mechanical properties it rates about the same as longleaf pine of the South. Elaborate tests have been made to determine which of these woods is the better for heavy construction, and neither appears to win over the other. In one respect, however, Douglas fir has a clear advantage over its southern rival: it may be had in much larger pieces. No other commercial wood of the worlci equals it in that particular. The Douglas fir flagstaff at the Kew gardens in England was 159 feet long, eight inches in diameter at the top, more than three feet at the base. The extraordinary size of squared beams cut from this species has led to great demand for it for heavy construction in Europe and this country. The pines from the Baltic sea region of northern Europe, which held undisputed place in heavy work during centuries, has now yielded that place to Douglas fir and longleaf pine.

No other single species in the United States or in the world equals the annual sawmill cut of Douglas fir. The four species of southern yellow pines, if counted as one, surpass it; but singly, not one comes up to it. In 1910 the lumber cut from this fir amounted to $5,203,644,000$ feet, which exceeded one-eighth of the total lumber cut in the United States. The importance of such a timber tree can scarcely be estimated. The available supply in the western forests is very large and will last many years, even if the demand for more than $5,000,000,000$ feet a year continues to be met.

The timber is exported to practically every civilized nation in the 
world. Shipbuilding creates a heavy demand. Some of the leading European nations use it as deck lining for battleships, and except mahogany and teak, it is said to have no equal for that purpose. Its cheapness gives it a decided advantage over those woods.

Every important lumber market in the United States handles Douglas fir, and its uses are so many that it would be easier to list industries which do not use it than those which do. It is manufactured into more than fifty classes of commodities, in Illinois alone. Among these are boats, railroad cars, electrical apparatus, farm machinery, laundry supplies, ladders, refrigerators, musical instruments, fixtures for offices, stores, and banks, and sash, doors, and blinds. This list of uses shows that its place in the country's industries includes much more than rough construction. It may be stained in imitation of valuable foreign and domestic woods, including walnut, mahogany, and oak. The natural grain and figure of the wood may be deepened and improved by stains, and this is much done by manufacturers of interior finish, panels, and store and office fixtures. There is practically no limit to the size of panels which may be cut in single pieces. It is easy to procure planks large enough for whole counter tops.

The best grain of Douglas fir is not brought out by quarter-sawing. The figures desired are not those produced by the medullary rays, but by the rings of annual growth. Therefore, the sawyer at the mill cuts his best logs-if intended for figured lumber-tangentially, as far as possible. In the state of Washington, which leads all other states in the production of Douglas fir, its chief use as a manufactured product is for doors, sash, and blinds, and the annual consumption in that industry exceeds $50,000,000$ feet. It is cut in veneers, and it is likewise used as corewood to back veneers. Crossarms for telegraph and telephone poles demand $35,000,000$ feet yearly in Washington alone, and many thousands of poles are of this wood. It is third among the crosstie woods of the United States, the combined cut of oaks standing first, and the pine second. It is rapidly taking high position as material for large water pipes and for braces, props, stulls, and lagging in mines and for paving blocks for streets.

BRISTLECONE FIR (Abies venusta) is pronounced by George B. Sudworth to be "the most curious fir tree in the world." It is found almost exclusively in Monterey county, California, but a few trees grow outside of that circumscribed arca. It has been called Santa Lucia fir, because it was once supposed to exist only in canyons of Santa Lucia mountains, but its range is now known to be more extensive. Montercy county, California, is of peculiar interest to dendrologists. Three species of trees are either confined to that area, or liave their best devclopment there. They are Monterey cypress (Cupressus macrocor $p a$ ), Monterey pine ( $P$ inus radiata), and bristlecone fir. All are peculiar trees: the cypress because of its ragged form and ex- 
tremely limited range, the pine because of its exceedingly rapio growth when given a chance, and the fir, hecause of its peculiar form of crown, odd appearance of cone, and extraordinary weight of wood. No reason is apparene why that particular point on the California coast should have brought into existence-or at least should have gathered to itself-three peculiar tree species. Bristlecone fir is well named from the bristles an inch long covering the cone. The leaves, too, are peculiar, bearing much resemblance to small willow leaves. Their upper sides are deep yellow-green and the under sides silvery. The largest leaves are two inches long, cones three inches. They ripen in August, and soon afterwards scatter their seeds. The tree is not a prolific seeder, and it is believed that its range is becoming smaller. Bristlecone's form of crown has heen compared to an Indian club, the large end on the ground and the handle pointing upward. Trees from sixty to eighty feet high have such "handles" twenty or thirty feet long. That peculiarity of shape makes the tree recognizable among associated species at a distance of several miles. The recorded weight of the wood is 42.27 pounds per cubic foot, which is nearly twice the weight of some other firs. The wood is moderately soft, but very firm. Few uses for it have been reported. Trunks are very knotty, and are too few in number to be of importance as a source of lumber. The tree has been planted successfully for ornament in the south of Europe.

Brgcone SpRuce (Pseudotsuga macrocarpa) is of the same genus as Douglas fir and bears much resemblance to it, but is smaller, and its range lies wholly outside that of its northern relative. It is a southern California species, occupying mountain slopes and canyons in Santa Barbara and San Diego counties. It is found from 3,000 to 5,000 feet above sea level. Trees average forty or fifty feet in height and $t w o$ or three in diameter. The leaves are approximately of the same size as those of Douglas fir; but the cones are much larger, hence the name by which the tree is known. It is called hemlock as often as spruce. The cones are from four to seven inches long, hang down, and usually occupy the topmost branches of trees. The winged seeds are half an inch long. The bark is six inches or less in thickness. The wood is inferior in most ways to that of Douglas fir, lighter, weaker, and less elastic. Its color is reddish brown. It has never contributed much lumber to the market and never will. Its range is local and the form of the tree is not of the best. An occasional log reaches a sawmill, but the principal demand is for fuel.

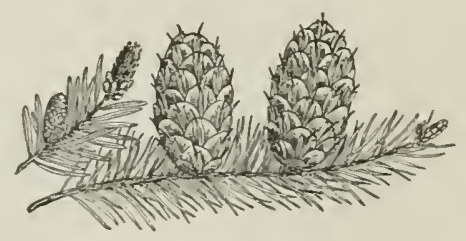


BICTREE 


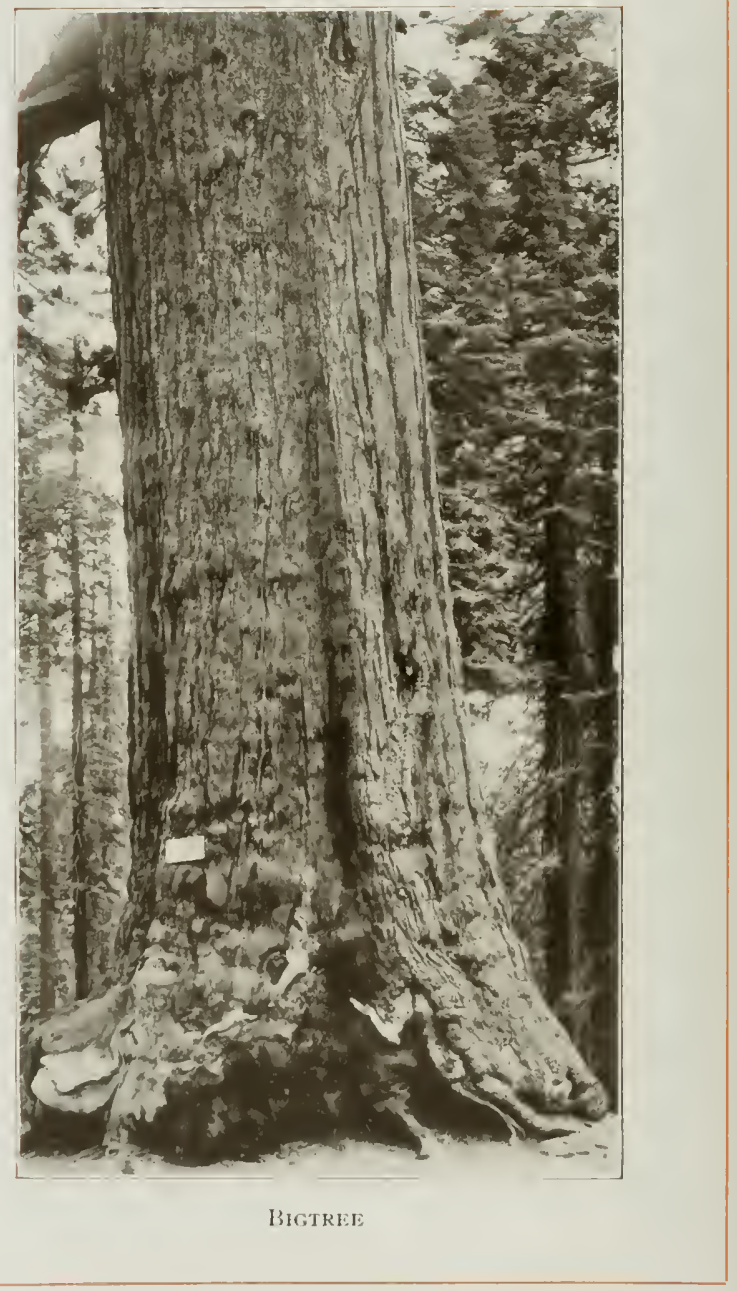




\section{BIGTREE}

\section{(Sequoia Washingtoniana)}

$\mathrm{B}^{\mathrm{o}}$ OTANISTS have had a hard time giving this tree a Latin name which will meet the requirements of technical classification, but an English name acceptable everywhere was early found for it-bigtree. No fewer than a dozen names have been proposed by botanists. Most of them attempt to express the idea of vastness or grandeur; but the simple English name comes directly to the point and ends the controversy as far as the common name is concerned.

Everything connected with this tree is interesting. Geologically, it is as old as the yellow poplar. There were five species of sequoias in the northern hemisphere, in Europe and America, before the ice age. They grew in the North, nearly to the Arctic circle, at a time when the climate of those regions was milder than it is now. The later advance of the ice southward overwhelmed three species of bigtrees, and pushed two survivors into the region which is now California. These are the bigtree and the redwood. It is not known how long ago it was that the ice sheet did its destructive work, but it antedated human history, and the gigantic trees have been in California since that time.

Long after the ice age ceased generally in North America it continued among the high Sierras of California, and the bigtrees to this day give a hint of it in the peculiar outlines of their range. They are scattered north and south along the face of the Sierra Nevada mountains in California, a distance of 260 miles, and at elevations from 4,500 to $\$, 000$ feet.

The aggregate of the total areas is about fifty square miles. The stand is not continuous, but consists of "groves," that is, isolated stands with wide intervals between, where no trees of this species are found. The arrangement suggests that the bigtree forest was cit in sections by glaciers which descended from the high mountains to the plains, a distance of one hundred miles or more, crossing the belt of sequoias at right angles. The glaciers withdrew thousands of years ago, and their tracks down the mountain slopes have long been coveied by forests; but the bigtree groves, for some unknown reason, never spread into the intervening spaces, but today are separated by wide tracts in which not a seedling or an old trunk or $\log$ of that species is to be found. This is one of the mysteries which add interest to those wonderful treeswhy they cannot extend their range beyond the circumscribed limits which they occupied thousands of years ago.

It was claimed for a long time and was quite generally believed that 
bigtrees were not reproducing, that there "were no little bigtrees." That was conclusively disproved by Fred G. Plummer, geographer of the United States Forest Service, who made a scientific study of a small grove, measured the trees, and actually counted and classified them. His work showed that there were in the area which he investigated:

Trees containing 100,000 to 120,000 feet each.......... 2

Trees containing $S 0,000$ to 100,000 feet each ......... 13

Trees containing 60,000 to 80,000 feet each ......... 49

Trees containing 40,000 to 60,000 feet each $\ldots \ldots \ldots \ldots . \quad 112$

Trees containing 20,000 to 40,000 feet each ......... 251

Trees containing less than 20,000 feet each .......... 353

"Little bigtrees" ......................... 2,6S2

Total. . . . . . . . 3,462

Bigtree is distantly related to southern cypress, and the shapes of very old trees of both species bear some resemblance. Bigtree leaves do not fall annually as those of bald cypress do. They are from oneeighth to one-fourth of an inch long, and on the leading shoots they may be half an inch in length. Cones are from two to three and a half inches long, and they ripen their seeds the second year, but the empty cones may adhere to the branches several years. The seeds are a quarter of an inch long, and have wings sufficient to carry them a hundred yards or more. The trees bear abundance of seeds, in proportion to the small number of branches. Though shapely and well clathed with limbs when young, the crown contracts with age, and consists of a few enormous, crooked limbs, almost destitute of twigs and small branches. One of these trees may actually bear more twigs when the trunk is only a foot in diameter than will be on the same trunk when it is fifteen or twenty feet in diameter. The old tree trunks are of ten without limbs to a height of 100 or 150 feet.

The Douglas squirrel is the bigtree's greatest enemy. In proportion to size, this little creature probably eats ten times as many tree seeds as the most ravenous hog that roams the forest. One of the first things that impresses a visitor in a grove of bigtrees is the rich brown of the bark of some of the trunks. All are not brown alike, or at all seasons. The trees on which the seed harvest is ready are the brownest, thanks to the sharp claws, the tireless energy, and keen appetite of the Douglas squirrel. He goes up and down the trunks for three square meals a day among the clusters of cone-bearing branches two hundred or three hundred feet above, and makes several extra trips for exercise: and at each scratch of his briery foot he kicks off scales of bark, until the whole trunk is "scratched raw." The detached scales of bark accumulate in a 
mound about the base of the tree, where they have been so accumulating for centuries. It is fortunate that those old trees have bark from one to two feet thick. They can afford to be scratched for a month or two each year.

These are the heaviest trees in America, notwithstanding their wood is light. It weighs less than northern white cedar. The largest bigtree trunks weigh more than $2,000,000$ pounds. In order to stand at all, they must stand plumb. It is a provision of nature that the old trees are almost branchless, otherwise the wind would force them out of plumb and they would go down. It has been claimed that the overthrow of one of these giants is always brought about by one of two causes. The development of larger limbs on one side than on another unbalances them; or the wash of gullies undermines the roots on one side, and draws the tree that way. It is currently believed that no bigtree ever dies from natural causes.

A good deal of pure fiction has been published regarding the size and age of the largest of these trees. They are old enough and large enough without drawing upon the imagination. The tree's base is greatly enlarged, but tapers rapidly the first few feet. There is little doubt that some of the trunks are over forty feet in diameter, one foot above ground, but that is not a fair measurement. The point should be five or six feet at least. Measured thus, about twenty-five feet inside the bark would represent the largest. With the bark added, the diameter would be nearly thirty feet. Probably not one tree in fifty, taking them as they occur in the whole range and counting veterans only, is fifteen feet in diameter five feet from the ground.

There is also some extravagant guessing as to height. Too many tourists measure with the unaided eye, or accept a guidebook's figures. An authentic height of 365 feet-the measurement of a fallen trunk-is probably the greatest. Very few reach three hundred feet. Many unreliable figures have been published concerning the age of bigtrees. One thing can be accepted without question; size is no proof of age, in comparing one tree with another; neither is the number of annual rings in a block cut from the side of a tree a reliable factor to determine age. The only sure way to determine the age of one of these trees is by counting all the rings from the pith to bark. Care should be taken not to count the same ring twice, as may be done when the wood is curly. John Muir counted 4,000 rings in a bigtree stump. It is believed that no higher age is backed by the evidence of yearly rings. It was twentyfour feet in diameter. The count of another of like size made it 2,200 years old; and of still another of the same size placed its age at 1,300 years. The Forest Service has made accurate measurement and record 
of every ring of growth in a tree that was over twenty-four feet in diameter, and it is shown that during certain periods of years the tree grew three or four times as rapidly as during other periods.

The wood of bigtree is very light, soft, moderately strong, brittle, summerwood thin and dark rendering the rings of annual growth easily seen; the medullary rays are thin, numerous, and very obscure. The wood is light to dark red, the thin sapwood nearly white; it works easily, splits readily, and polishes well. It is very durable in contact with the soil. Trunks lie in the woods long periods before decay seriously attacks them; but forest fires hollow them, and finally burn them up. Enormous depressions are found in the forest where logs once lay, but which disappeared long ago, judging by the size of trees which have since grown in the depressions. The interior of some large trunks which have been worked up on sawmills showed the scars of forest fires centuries ago. The annual rings which covered one such scar showed that the burning took place 1,700 years ago.

Not much can be said for the commercial uses of bigtree. Many a species of insignificant size is much more useful. Considerable quantities have been cut by sawmills. The waste is great, heavy trunks crushing badly in fall. Logs are so large that many of them are split with gunpowder to facilitate handling them. Some of the wood has been exported for lead pencils; other has been used for fence posts, shingles, and grapevine stakes, while the soft bark has been worked into novelties.

MACNAB Cypress (Cupressus macnabiana) is a California tree of limited range and little commercial value. It grows in Napa, Lake, Mendocino, and Trinity counties; is often little more than a branching shrub, but the largest specimens may be thirty feet high and fifteen inches in diameter. The wood is light, soft, and usually of slow growth. The medullary rays are numerous but thin, and the bands of summerwood are distinct. The cones are generally less than one inch long, and the seeds have narrow wings. The foliage is grayish which is due to white glands in the leaves. Forest foliage is fragrant. The tree is known as white cedar, Shasta cypress, and California mountain cypress.

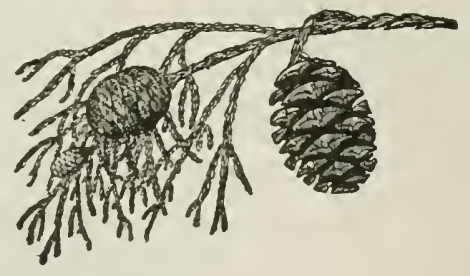


REDWOOD 


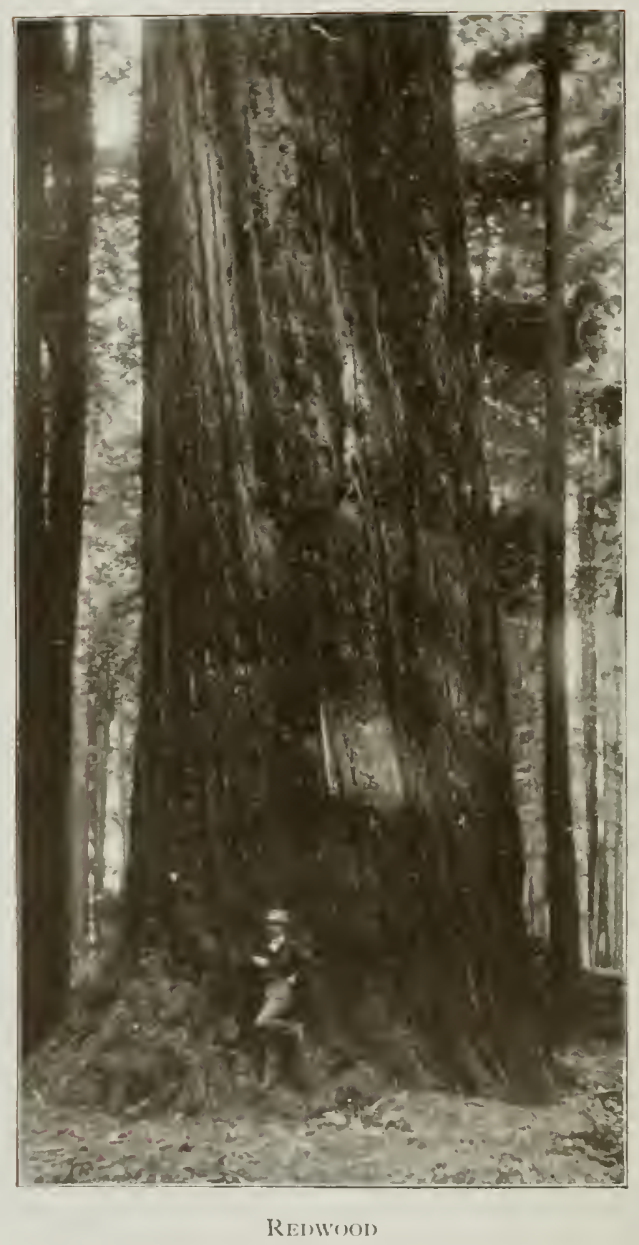




\section{REDWOOD}

\section{(Sequoia Sempervirens)}

$\mathrm{T}$ HIS tree's color is responsible for its name. It is sometimes spoken of as coast redwood to distinguish it from bigtree which grows in the interior of California. In European markets it is known as California redwood to distinguish it from other redwoods growing in distant parts of the world. Its botanical name, Sequoia sempervirens, means evergreen sequoia. The other species of sequoia is also evergreen. In reality, the coast redwood is less of an evergreen than the bigtree is, because the leaves of redwood turn brown two years before they fall, but there are always plenty of green leaves on the branches. "The leaves are from one-quarter to one-half inch in length.

The geographical range of redwood covers about 6,000 square miles, but the commercial range is scarcely one-fifth as mucl. The redwood belt extends 500 miles along the Pacific coast from southern Oregon to central California. It varies from ten to thirty miles in width. It is strictly a fog belt tree, and grows poorly outside the region of ocean fog, which seldom reaches an altitude more than 2,800 feet above sea level. Where fog is thick and frequent, and soil is moist and otherwise suitable, redwood forests have grown in such luxuriance that no species in this country exceeds it. Stands running much over 100,000 feet per acre are frequent, and it is said 1,000,000 feet have been cut from a single acre.

Redwood cones are one inch or less in length. They ripen in one season. Seeds are quite small, and are equipped with wings. The bark is thick, but is much thinner than the bark of bigtrees, though it is in gleat ridges like the bark of that species. The habits of the two species, as to form of crown, are similar. Young redwoods, particularly if they grow in the open, develop symmetrical and conical crowns which they retain until the trunks are a foot or more in diameter. Lower limbs die and fall off after that, and old trees have crowns so small that it would seem impossible that they could supply the wood-building material for trunks so large. That the growth should be slow under such circumstances is to be expected. The ages of mature trees vary from 500 to 800 years, but an extreme age of 1,373 years is on record. The average is, therefore, considerably below that of bigtrees.

Redwoods grow as tall as bigtrees, but do not equal them in diameter of trunk, though trees twenty feet in diameter occur.

A noticeable feature of the forests is that, in a given stand, nearly all trees are of the same height, irrespective of size of truuk. The crowns go up to the light and when they reach the common level 
of others, and secure a share of light, they show no disposition to go higher. The doctrine which they silently put into practice is to live and let others live. That habit makes it possible for redwoods to grow in very dense stands, which they could not do if a few trees domineered over the others, and appropriated the light to themsel ves.

When old age overtakes the giant redwoods, they exhibit the first symptoms of weakened vitality by dying at the top. Most trees over five hundred years old are "stag-headed." From that period they die slowly, but usually survive two or three hundred years after the visible signs of approaching death strike them.

Redwood has an advantage over nearly all other needle-leaf trees in that it propagates by both seeds and sprouts. Few softwoods send up sprouts from stumps or roots. Redwoods of large size are produced that way, and the stumps of very old trees send up many vigorous shoots. Sometimes a ring of large trees surrounds a depression in the ground where the parent tree grew, died, and decayed.

Sprouts are of course confined to the immediate proximity of the parent tree, but redwood seeds are scattered by the wind over vacant spaces. This results in dense stands where other conditions are favorable, but the species has never been able to establish itself far inland or high on mountains.

In 1880 the Federal census made a rough estimate of the available redwood, and placed it at 25,825,000,000 feet. More than twenty years later, with heavy cutting all the time, private estimates placed the remaining stand at orer $50,000,000,000$ feet. The second estimate was unquestionably nearer correct than the first. The stand of no important timber tree in this country is more easily estimated than redwood. The forests are compact, the trees large, the trunks similar in form, and the well-timbered area is comparatively small. Redwood has been called the most important timber tree of the Pacific coast. The title probably confers too much, though the tree's importance is beyond question. The annual cut of Douglas fir is nearly ten times as large as of redwood, and the supply still in the forests is much greater than that of redwood. The cut of western yellow pine likewise exceeds the output of redwood, and the remaining supply is larger. The cut of western red cedar, including shingles, is about the same, and the remaining stand of cedar is very large. Western hemlock, too, exists in large quantity, and its importance as a source of timber supply may be equal to redwood.

Redwood is frequently referred to as one of the lightest in this country. Its weight per cubic foot, oven-dry, is 26.2 pounds. On the same basis, white pine is $2 t$, southern white cedar 20.7 , northern white 
cedar 19.7, and bigtree 18.2. There are woods in Florida lighter than any of these. Redwood is very soft, yet it dulls tools quickly. It is moderately strong, a little below white pine; it is brittle, again ranking below white pine; it splits and works easily and polishes well. Few, if any woods surpass this one in splitting properties. Boards twelve feet long and a foot wide may be rived from selected logs, and they present surfaces nearly as smooth as if cut with a saw. However, curly and wavy redwood is not uncommon, and that, too, splits well, but the surface is not smooth. The width of annual rings varies, usually wide in young timber and narrow in old. The bands of summerwood are narrow and clearly defined. The surface of redwood lumber absorbs water quickly, yet, for some reason, creosote and other preservatives can be forced into the wood only with the greatest difficulty. Fortunately, it is not necessary to treat this timber to revent decay, for, in almost any position, it wears out before it rots. Shingles, and window and door frames of the old barracks buildings at Eureka, California, remained in place until fifty years of wind and driven sand wore them away. Railroads use the wood for ties until they wear out, not until they rot out. Farmers near some of the California railroads gather up the rejected worn ties by thousands and use them for fence posts. When redwood is employed as city paving blocks it is wear and not decay that puts them out of commission.

The medullary rays of redwood are thin and very obscure, but numerous. Few woods show them to less advantage in quarter-sawing. The lack of luster in the surface of polished panels is well known. The wood's beauty is in its sameness and richness of color. Except curly specimens and burls, the wood may be said to have no figure, though in planks cut tangentially, the contrast of spring and summerwood displays some figure in a modest way. It is possible to wash much of the coloring matter out of the wood, if it is first chipped fine. It washes from the surface by ordinary exposure to weather. Red rainwater runs from a roof of new redwood shingles, and weatherboarding, posts, and picket fences fade perceptibly in a few months. This coloring matter when washed out in large amounts in the process of paper making has been manufactured into fuel gas.

A complete list of the uses of redwood is not practicable, for this material goes into most of the large wood-using factories of this country, and much is exported-nearly $60,000,000$ feet annually going to foreign countries. It has been much employed in California cities and towns for picket fences, and as posts for wire and plank fences. It is, next to western red cedar, the most important shingle wood of the Pacific coast. One western railroad alone had in its tracks $12,000,000 \mathrm{red}$ wood 
ties at one time. Builders of tanks, flumes, and water pipes procure some of their best material, and large quantities of it, from redwood sawmills. Few woods are more universally found in furniture factories.

Gowen Cypress (Cupressus goveniana) follows the California coast from Mendocino county, California, to San Diego, and ascends mountains to the height of 3,000 feet in some localities. At its best it is fifty feet iigh and two feet in diameter; but it extends as a shrub over many sandy tracts. Specimens no more than a foot high sometimes bear cones. The Gowen cypress sheds its leaves the third and fourth years. Cones are from one-half to one inch long, and each bears about 100 seeds. The wood is light, soft, weak, light brown in color, the thick sapwood nearly white. The medullary rays are numerous but obscure. The wood is used for posts and other ranch purposes. Woodpeckers attack tie trunks, picking holes through the bark to suck the juice from the cambium lajer beneath.

DWARF CyPress (Cupressus pygmaa) was formerly supposed to be a stunted form of Gowen cypress. The ranges of both lie in the same region, on the coast of California in Mendocino county. The avcrage height of dwarf cypress is from ten to twenty feet, with trunk diameter from six to twelve inches; but in peat swamps and on sterile sands it may not exceed three or four feet in height. It bears abundant cones at that size, and sometimes a tree no more than a foot high has mature cones. They ripen the second year, but remain a long time on the branches. The trees thrive in the most forbidding places, and are sometimes the only occupants of bogs or sand dunes. The rood is necessarily of little value, because of the small size of trees. There seems to be no record of a dwarf cypress over sixty years of age; but it is believed that much older trees have fallen victims to fire.

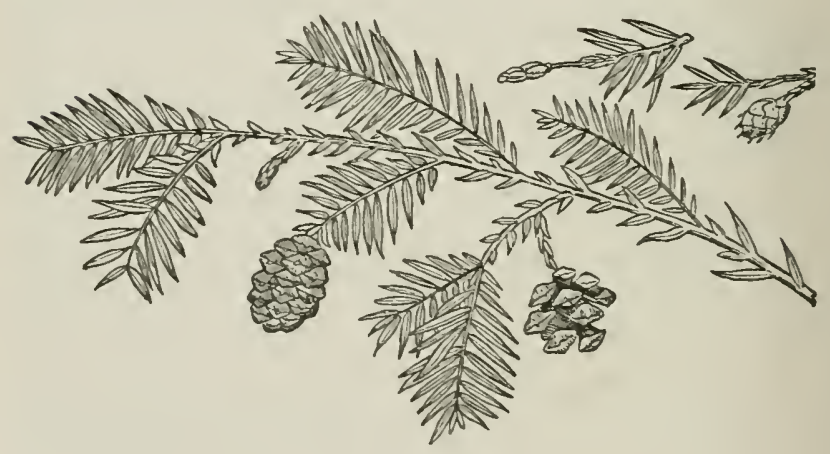


HEMLOCK 


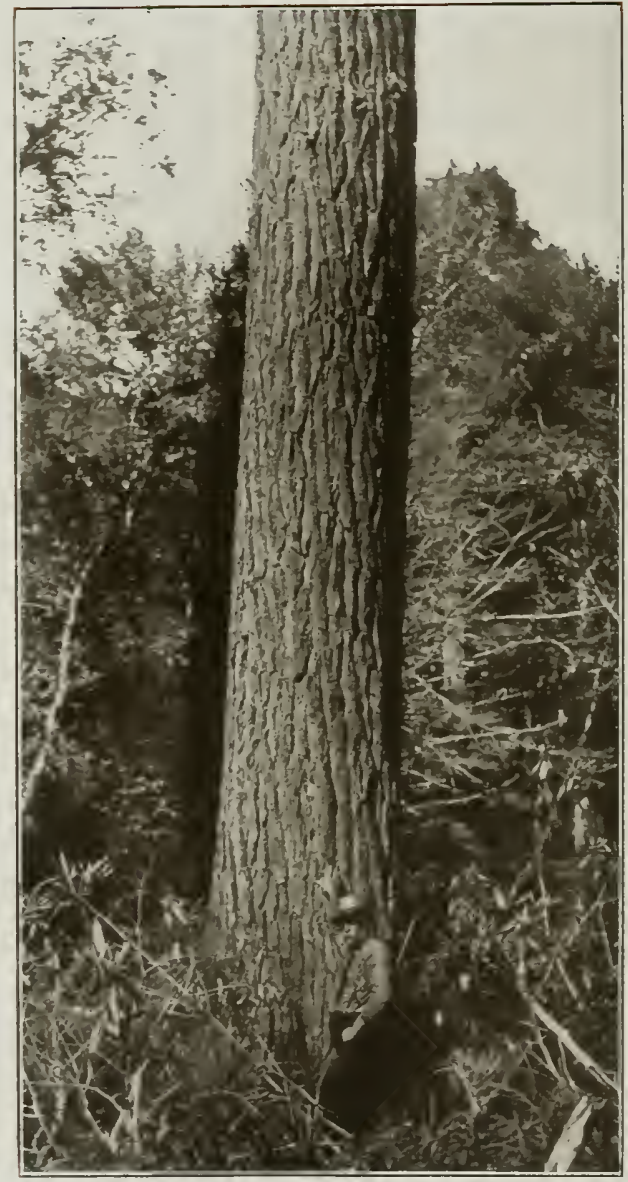

HEMLOCK 


\section{HEMLOCK}

\section{(Tsuga Canadensis)}

GEVEN hemlocks are known in the world, four of them in America. Two of these are in the East, two in the IVest. The eastern species are the Canadian and Carolinian. The former is Tsuga canadensis, the latter Tsuga caroliniana. The western species are, mountain hemlock (Tsuga mertensiana), and western hemlock (Tsuga heterophylla). The word tsuga is Japanese and means hemlock.

The hemlock lumber in eastern markets is practically all from one species, which is known as hemlock in Maine, New Hampshire, Vermont, Massachusetts, Rhode Island, Connecticut, New York, New Jersey, Pennsylvaria, Delaware, Virginia, North Carolina, South Carolina, Kentucky, Wisconsin, Michigan, Minnesota, Ohio, Ontario. In Vermont, Rhode Island, New York, Pennsylvania, New Jersey, West Virginia, North Carolina, South Carolina; in England it is called hemlock spruce; spruce tree in Pennsylvania and West Virginia; spruce pine in Pennsylvania, Delaware, Virginia, North Carolina, Georgia; to the New York Indians it was known as oh-neh-tah, which being interpreted means "greens on the stick."

The range of hemlock extends east and west more than fifteen hundred miles, from Nova Scotia to western Wisconsin; sonth to Delaware and southern Michigan, and along the Appalachian monntains to northern Alabama and Georgia. The original quantity of timber was enormons, for large areas were covered with dense stands. The largest trees are found near the southern part of its range, among the monntains of Tennessee and North Carolina; but the bulk of the timber has always been in the North. It thrives best in well drained soil, but it likes cool situations and often develops dense forests on northern slopes or in deep ravines; but it maintains a foothold on ridges, on the banks of streams, and around the borders of swamps.

The cones are very small, about a half inch in length, growing singly from the lower side of the branchlet. Their scales are rounded and thin, light brown in color. Tle seeds are winged and even when ripe the cones do not spread apart perceptibly. The seeds escape, however, slowly during the winter following their maturity. They are very small, and their wings distribute them a hundred feet or more. The seeds germinate best on leaf mold, but the seedling takes sevcral years to thrust its roots deep into the mineral soil. During that time, growth is very slow. A seedling five years old may not exceed five inclies in height; but when its roots have developed, growth is fairly rapid. The 
distribution of seeds is often facilitated by the activities of red squirrels, and perhaps other small mammals, which climb the trees in winter and tear the cones apart to get at the seeds. Many of the seeds are devoured, but more escape and fly away on the winter winds.

Hemlock leaves are narrow and about half an inch long. Examined closely, particularly with a magnifying glass, rows of white dots extend from end to end on the under side. Small as these white points are separately, when seen in the aggregate they change the color of the whole crown of the tree. This is illustrated by looking at a hemlock from a distance-the upper sides of the leaves on the drooping twigs being then visible and the tree's aspect dark green. Approach the tree, and look up from its base-the under side of the leaves being then visibleand the dark color changes to a light silvery tint. The whiteness is due to the white spots on the leaves. The spots are stomata (mouths), and are parts of the chemical laboratory which carriers on the tree's living processes. All tree leaves have stomata, but all are not arranged in the same way and are not visible alike. Few trees have them as prominent as the hemlocks.

Hemlock attains a height from sixty to 100 feet and a diameter from two to four. When it grows in the open, it is one of the handsomest and most symmetrical evergreens of any country. Its dark, dense foliage will permit scarcely any sunlight to filter through. When forestgrown, it loses its lower limbs. In the forester's language, they are "shaded off," and long, smooth trunks are developed; but the stubs from which the branchesfall remain buried deep inside the smoothest bole, and the saws will find them when the logs are converted into lumber.

Reference has been made to hemlock's slow growth during the seedling's first four or five years. That takes place in the dense shade of the hemlock forest. If the seed falls on open ground, in full sunlight, the chance is that it will not germinate; but if it does, the seedling is doomed to an early death. It cannot endure strong light. This fact is of great importance, for it means the end of hemlock forests. When a stand is cut and the sunshine reaches the ground, no seedlings bring on a new forest. White pine seeds grow in open ground, in old fields, in burnt woods, wherever they reach soil, but hemlock must scatter its seeds in cool, deep shade or they will do little good. Strong, vigorous, and healthy as hemlock trees are, they are killed more easily than almost any other. Cut a few trees from the center of a mature hemlock clump, and the chance is that several trees next to the open space thus made will die. The unusual light proves too much for their roots which had always been cool and damp; but when young hemlocks are protected until they get a start, they thrive nicely in the open. 
The wood of hemlock is light, soft, not strong, brittle, coarse and crooked grained, difficult to work, liable to windshake, splinters badly, not durable. The summerwood of the annual ring is conspicuous; and the thin medullary rays are numerous. The color of hemlock heartwood is light brown, tinged with red, often nearly white. The sapwood is darker. Lumbermen recognize two varieties, red and white, but botanists do not recognize them.

The physical characters of hemlock are nearly all unfavorable, yet it has become a useful and widely used wood. It is largely manufactured into coarse lumber and used for outside work-railway ties, joists, rafters, sheathing, plank walks, laths, etc. It is rarely used for inside finishing, owing to its brittle and splintery character. Clean boards made into panels or similar work and finished in the natural color of ten present a very handsome appearance, owing to the peculiar pinkish tint of the wood, ripening and improving with age.

With the growing scarcity of white and Norway pine, hemlock has become the natural substitute for these woods for many purposes. It has never been conceded that hemlock possesses the intrinsic merit of either of the northern pines for structural purposes, but it has proven a suitable substitute for a variety of uses, notably for framing and sheathing of medium priced structures.

In 1910 hemlock lumber was cut in twenty-one states, the total output exceeding 2,500,000,000 feet. Only four species or groups of species exceeded it in amount. They were southern yellow pines, Douglas fir, the oaks, and white pine. The principal cut of hemlock lumber was in the following states in the order named: Wisconsin, Michigan, Pennsylvania, West Virginia, New York, Maine, Vermont, Virginia, New Hampshire, Tennessee, and North Carolina. Ten other states produced smaller amounts.

Hemlock possesses remarkable holding power on nails and spikes, and that is one reason for its large use for railroad ties. It does not easily split, and there is no likelihood that spikes will work loose; but the wood decays quickly in damp situations, and unless given preservative treatment, hemlock ties do not last long. They are pretty soft anyway, and where trafic is heavy, rails cut them badly.

Manufacturers of boxes and crates use much hemlock. The annual use for that purpose in Massachusetts is about 27,000,000 feet, in Michigan practically the same quantity, in Illinois $34,000,000$, and varying quantities in many other states. Michigan converts nearly $100,000,000$ feet a year into flooring and other planing mill products, and Wisconsin and other hemlock states follow it in lesser amounts. The wood is employed by car builders, slack coopers, manufacturers of retrigerators, 
silos, and farm implements; but the largest demand comes from those who use the rough lumber.

Hemlock bark is the most important tanning material in this country. It has long been used by leather makers who generally mix it with some other bark or extract because leather tanned with hemlock alone has a redder color than is desired.

Large areas of hemlock forests have been cut for the bark alone. Formerly the wood was of so little value that it was cheaper to leave it in the forest than to take it out. The peelers worked in early summer, cutting trees and removing the bark in four-foot lengths, which was measured by the cord, though often sold by weight. Care was taken that the bark be removed from the slashings before the dry weather of autumn, for fire was to be expected then, and anything combustible in the woods at that time was likely to be lost. The tracts on which bark peelers worked were called "slashings," and they were fire traps of the worst kind with their tangled masses of tops and branches.

Large quantities of hemlock bark are still peeled every summer, but the practice is less destructive than formerly. The trunks are worth taking out, and when the fire comes late in the season it consumes little valuable hemlock. A permanent decline in the annual production of this wood has not yet begun, but it must soon set in, for the demand cannot be indefinitely met.

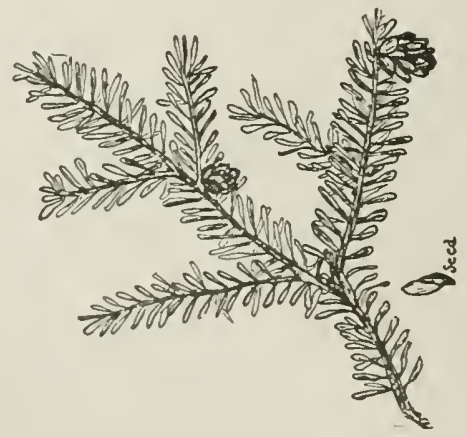


WESTERN HEILOCK 


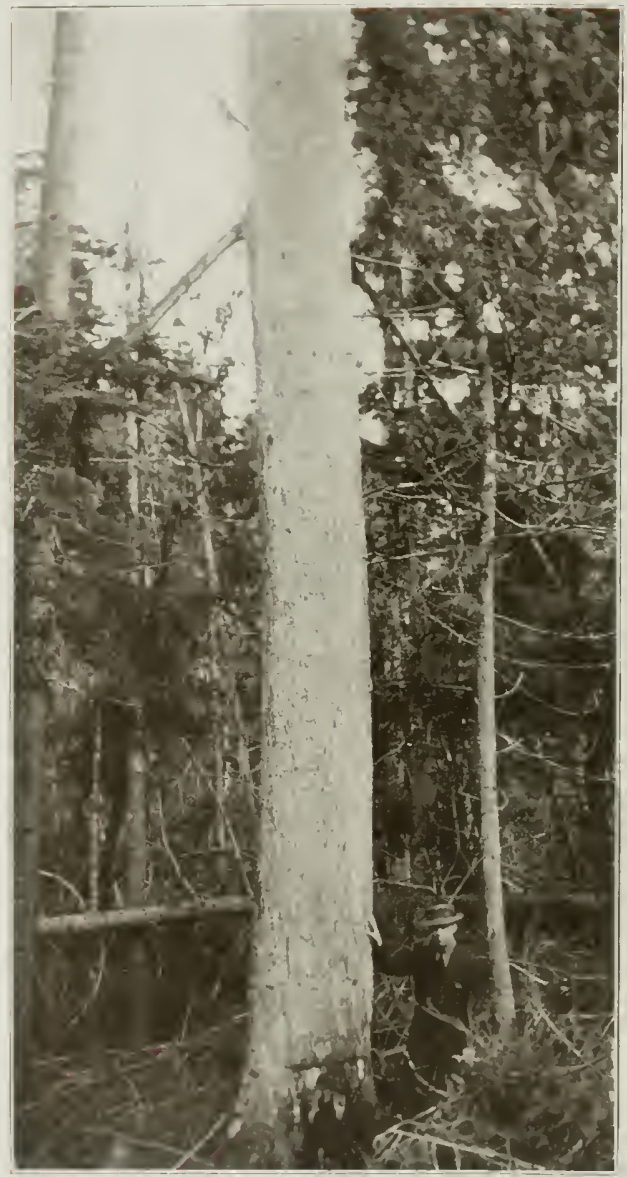

Westery HeMlock 


\title{
WESTERN HEMLOCK
}

\author{
(Tsuga Hetcrophylla)
}

W

$\mathrm{HEN}$ this wood began to go to market, its promoters found difficulties in securing a trial for it in eastern states, because of its name. The eastern hemlock was known to be a substantial wood, but a rough one with many faults linked with its virtues. It was naturally supposed that the western hemlock had all the faults of its eastern relative with possibly some of the good qualities left out; and there was general hesitancy to put the new comer to a trial. That caused a movement among western lumbermen to sell their hemlock under some other name. They were confident the wood had only to be given a trial and it would win its way, after which the name would make little difference. Accordingly, it was started to market under the name of Alaska pine, although Alaska has no pine large enough for good lumber. Other lumbermen thought it advisable to choose a name less likely to excite suspicion, and they called it Washington pine. Others designated it as spruce, and still others as fir. It was more likely to pass for fir than for pine or spruce.

The lumber is now generally known as western hemlock, but in California some call it hemlock spruce or California hemlock spruce. In Idaho, Washington, and Oregon the name hemlock usually suffices; while western hemlock spruce, and western hemlock fir, and Prince Albert's fir are names used in speaking of lumber and of the tree in the forest.

Western hemlock's range extends rorth and south a thousand miles, from southern Alasia to California south of San Francisco. It grows from the Pacific coast eastward to Montana, five hundred miles or more. It ascends to altitudes of 6,000 feet, but it is not at its best on high mountains, but in the warm, damp region near the coast in Washington and Oregon. Trees 200 feet high and eight or ten in diameter are found, but the average size is much less.

The leaves of western hemlock are dark green and very lustrous above. The flowers are yellow and purple. Cones are one inch or less in length, and the small seeds are equipped with wings which carry them some distance from the base of the parent tree. The seeds will germinate and develop a root system without touching mineral soil. Their ability to do so assists them greatly in maintaining the tree's position in the damp climate where this hemlock reaches its best development. The ground in the forest, with all objects that lie upon it, is often covered with wet moss a foot or more thick. The seeds of most trees would 
inevitably perish if they fell upon such a bed of moss; but the seeds of western hemlock germinate, and the rootlets strike through the moss until they reach the soil beneath, and seedling trees are soon growing vigorously. Seeds often germinate in the moss on logs and stumps, but the roots strike for the ground, and generally reach it. In this habit the western hemlock resembles the yellow birch of the East whose seeds seem to germinate best on mossy logs and stumps.

Western hemlock has one of the bad habits of its eastern relative: it does not prune itself very well, even in dense forests, and the lumber is apt to be knotty, but the knots are usually sound, though dark in color.

The wood of western hemlock is moderately light, but twenty per cent heavier than eastern hemlock; stronger than the wood of other American hemlocks, and nearly twenty-five per cent stronger than the eastern commercial species, and nearly fifty per cent stiffer. It is tough and hard, but has little of the flinty texture of other hemlocks. Its color is pale brown, tinged with yellow, the thin sapwood nearly white. It is fairly durable in contact with the soil. Its growth is usually rapid, and trees live to a great age. Some of the largest are said to reach 800 years. The summerwood often constitutes half of the yearly ring, and is dark yellow. The medullary rays are numerous and rather prominent. When cut radially, the appearance, size, and arrangement of the exposed medullary rays suggest those of sugar maple when exposed in the same way.

The annual sawmill output of western hemlock is about $170,000,000$ feet. The largest market for it is in the region where it grows, and it is used as rough lumber for ranch purposes and for buildings in towns; but a considerable quantity is further manufactured. About one-fourth of the entire sawmill output goes to the factories of Idaho, Washington, and Oregon. A list of the wood's principal uses in those states shows its intrinsic value. The largest quantity is demanded by box factories. The wood's nail-holding power commends it for that use, but of no less importance is its strength. Eighty-three per cent of all the wood used for boxes in Washington is western hemlock. Cooperage calls for much of this wood also. Fruit and vegetable barrels are made of it. Its place in furniture manufacture corresponds to that of the other hemlock in the East. The pulp business is not very extensive on the Pacific coast, but western hemlock is a respectable contributor. It is suitable for burial boxes, and probably ranks about third among the woods within its range, those used in larger amounts being Sitka spruce and western red cedar. It is coming into use as interior finish, particularly as door and window frame material. Fixture manufacturers employ it for drawers and shelves. It is made into flooring, ceiling, molding, and 
wainscoting. Door makers use a little of it as core material over which to glue veneers. It is made into veneer, but of the cheaper sorts, such as are suitable for crates and berry boxes.

The Pacific coast is so abundantly supplied with excellent softwoods that only those of good quality have any chance in the local markets. The fact that western hemlock has won and is holding an important place in active competition with such woods as western red cedar, yellow cedar, Sitka spruce, and Douglas fir, is proof that it is valuable material. It is winning its way in the central part of the United States also, but not as rapidly as it has won in the West.

The bark of western hemlock is rated high as a tanning material. The bark on young trees is thin, but as the trunks increase in size and age the bark thickens. It is richer in tannin than the bark of eastern hemlock, but is not so extensively used because the demand is less on the Pacific coast.

The future of the western hemlock is fairly well assured. Its range is extensive and varied, and lumbermen will be a long time in cutting the last of the present stand. Reproduction is satisfactory. It will be important in future forestry, when people will grow much of the timber they need; but this tree will stick pretty close to the range where nature planted it.

Mountain Hemlock (Tsuga mertensiana) is a near relative of western hemlock, and occupies the same geographical ranges but higher on the mountains. Near Sitka, Alaska, it occurs at sea level, but southward it rises higher until on the Sierra Nevada mountains in California it is 10,000 feet above sea level. It is one of the timber line trees in many parts of its range, though it is nowhere above all others. It is a difficult matter to state what its average size is. That depends upon the particular region considered. At its best it is 100 feet high or even more; at its poorest it sprawls on the rocks like a shrub. Specimens of fair size are from twenty-five to sixty feet high, and ten to twenty inches in diameter. Cones vary in size fully as much as the trunks. Some are one-half inch in length, others are three inches. The leaves vary no less, some being a one-twelf th inch long, others one inch. The leaves stand out on all sides of the twig, and fall during the third and fourth years. They are bluish-green. The seeds fall in September and October, and are provided with large wings. The wood is light in weight, soft, and pale reddish-brown. The mountain hemlock is nearly always spoken of as spruce by persons who are not botanists. The arrangement of the leaves on the twigs gives the impression that it is a spruce, and among the names by which it is known in its native recion are Williamson's spruce, weeping spruce, alpine spruce, hemlock spruce. 
Patton's spruce, and alpine western spruce. There is little prospect that this tree will ever become important as a source of lumber. It is nowhere very abundant, and what timber there is generally stands so remote from mills that little of it will ever be taken out. Botanists and mountain travelers who have made the acquaintance of the mountain hemlock in the wildness of its natural surroundings have spoken and written much in its praise. It has been called the loveliest cone-bearing tree of the American forest. That praise, however, applies only when the tree is at its best, with its broad, pyramidal crown, balanced and proportioned with geometrical accuracy, outlined against a background of rocks, peaks, snow, or sky. Its other form, prostrate and angular where the tree occurs on cold, bleak mountains, has never inspired praise from anybody, though its defiance of the elements and its persistence in spite of adversity, cannot but challenge the admiration of all who like a fair and square fighter. There are many intermediate forms. On mountains facing the Pacific, and at altitudes of 6,000 or 7,000 feet, the young hemlocks are buried under deep snow weeks or months at a time. They are pressed down by the weight of tons, and it might be supposed that not a whole branch would be left on them, and that the main stems would be deformed the rest of their lives. But when the early summer sun melts the snow, the young trees spring back to their former faultless forms, without a twig missing or a twisted branch.
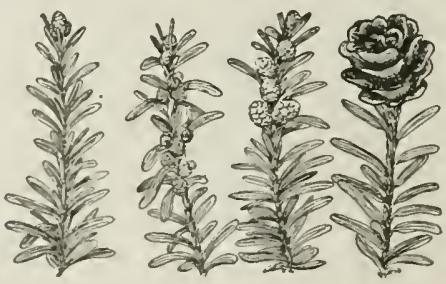
WESTERN YEW 


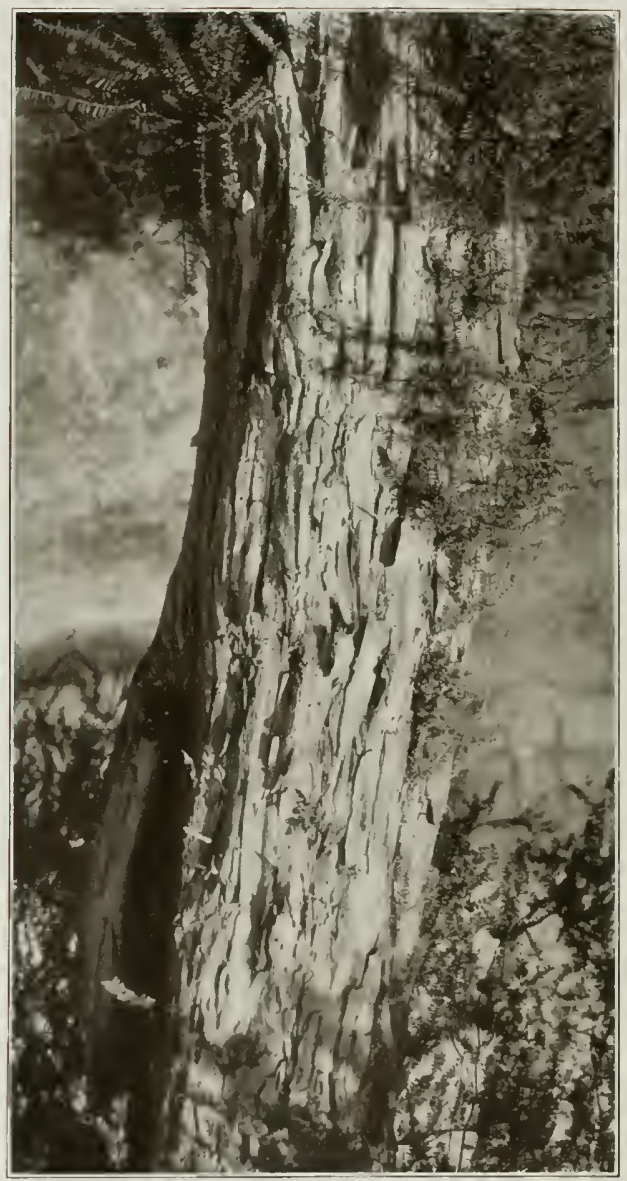

WESTERN YEW 


\title{
WESTERN YEW
}

\author{
(Taxus Brevifolia)
}

$\mathrm{T}$

HE Pacific yew is an interesting tree, useful for many minor purposes, but it is not procurable in large quantities. Its north and south range covers more than $I, 000$ miles, from Alaska to central California; while the species occurs from the Pacific coast eastward to Montana. It approaches sea level on some of the Alaskan islands, and toward the southern part of its range it reaches an altitude of 8,000 feet.

In Idaho it is called mountain mahogany, but apparently without good reason. Its color may bear some resemblance to that wood, but it is different in so many particulars that the name is not appropriate. The names western yew and Pacific yew are used interchangeably. Sometimes it bears the simple name yew; but since there is a yew in Florida, and another in Europe, it is well to give the western species a name which will distinguish it from others. The northwestern Indians called it "fighting wood," which was the best description possible for them to give. They made bows of it, and it was superior to any other wood within their reach for that purpose. In fact, if they could have picked from all the woods of the United States they could scarcely have found its equal. It is very strong, though in elasticity its rating is under many other woods. It is of interest to note that five hundred or more years ago, the European yew (a closely related but different species) had nearly the same name in England that the northwestern Indians gave the western yew. It was called "the shooter yew," because it was the bow wood of that time, and "bow staves," which were rough pieces to be worked out by the bow makers, were articles of commerce. The search for it was so great, and so long-continued, that yew trees were well-nigh exterminated in the British Isles. It was, next to oak, and possibly above oak, the most indispensable wood in England at that time. It is instructive to observe that Indians who used the bow found the western yew as indispensable in their life as the English armies found the European yew at a time when the bow was the best weapon.

The northwestern Indians put this remarkable wood to other uses. They made spears of it, and sometimes employed them as weapons of war, but generally as implements of the chase, particularly in harpooning salmon which in summer ascend the northwestern rivers from the Pacific ocean in immense schools. The Indians whittled fishhooks of yew before they were able to buy steel hooks from traders. Some of those unique hooks are still in existence, and speak well of the inventive genius of the wild fisherman of the wilderness. A proper crook was 
selected where a branch joined the trunk, and serviceable fish hooks were made without any cross grain. They were strong enough to hold the largest fish that ascended the rivers. Sometimes a bone barb was skillfully inserted. The Indians found a further use for this wood as material for canoe paddles. It is so strong that handles can be made small and blades thin without passing the limit of safety. The manufacture of boat paddles from yew continues.

More is used for fence posts than for any other one purpose. It is one of the most durable woods known where it must resist conditions conducive to decay. The name yew is said to be derived from a word in a north Europe language meaning everlasting. Yew fence posts are not named in statistics, and it is impossible to quote numbers. Their use is confined to the districts where they grow.

The manufacturers of small cabinets draw supplies from this wood, but the fact is not mentioned in Pacific states wood-using statistics. It is particularly liked for turnery, such as small spindles used in furniture and in grill work. It takes an exceptionally fine polish, and the wood's great strength makes the use of slender pieces practicable. Experiments have shown that this wood may be stained with success, but its natural color is so attractive that there is little need of staining unless the purpose is to imitate some more costly wood. If stained black it is an excellent substitute for ebony.

Western yew figures little in lumber output. It is not listed in the markets. The few logs which reach sawmills are never again heard of, but probably most of the lumber is disposed of locally to those who need it. The tree is not of good form for saw timber. Burls are said to make beautiful veneer. Trunks are seldom round, but usually grow lopsided. Most of them are too small for sawlogs. The largest are seldom two feet in diameter, and generally not half that large. They are short and branched, the tree often dividing near the ground in several stems. The average tree is scarcely thirty feet high, but a few are twice that. Its growth is very slow. A six-inch trunk is seventyfive or 100 years old, and the largest sizes are from 200 to 350 years. It is evident, therefore, that efforts to grow western yew for commercial purposes will be few. Wild trees will be occasionally cut as long as they last, and they will probably last as long as any of their associates, for they are scattered sparingly over several hundred thousand square miles of country, and some of it rough and almost inaccessible. The best development of the species is in western Oregon, Washington, and British Columbia.

The leaves of western yew are one-half or five-eighths inch long. The fruit consists of red pulp enclosing a hard seed. Birds devour it 
eagerly. The fruit is not poisonous, as the yew berries of the Old World are. It ripens in September and falls in October. The wood is fine grained, clear rose red, becoming gradually duller on exposure. It weighs 39.83 pounds per cubic foot. Its fuel value is high.

FLORIDA YEW (Taxus floridana) is extremely local in its range, and small in size. Few trees are more than twenty-five feet high and one foot in diameter. They are bushy and of poor form for manufacturing. The only reported use is as fence posts. The wood's durability fits it for that place. The species is found in Gadsden county, Florida. The leaves are one inch or less in length; flowers appear in IIarch, and the fruit ripens in October. The wood is moderately heavy, hard, and narrow-ringed, for the trees grow slowly. Its color is dark, tinged with red, the thin sapwood being whiter. There is little prospect that the wood of this yew will ever be more important than it is now. It is often spoken of locally as savin, which name is likewise given to the red cedar (Juniperus virginiana), which is abundant in this yew's range.

CAlifornia NutMeg (Tumion californieum) is an interesting tree which ranges over a considerable portion of California, but is at its best in Mendocino county and the coast region north of San Francisco. It occurs also on the western slope of the Sierra Nevada mountains, in central California, at altitudes up to 5,000 feet. It receives its name from the resemblance of its seeds to nutmegs. Their surface is shriveled, but they do not have the nutmeg odor. The wood and the leaves, when bruised, give off an odor not altogether pleasing. On account of this, the tree has been called stinking cedar. In some localities it is called yew, and in others California false nutmeg, and coast nutmeg. Trees are generally small, with trunks of irregular form. The crown is open and usually extends to the ground; but in crowded situations, a rather shapely bole is developed, and the crown is small. The usual size of the tree does not exceed a height of fifty feet and a diameter of twenty inches. More trees are below than above that size; but in extreme cases the tree may reach a height of eighty-five feet and a diameter of four. The leares in form and size resemble the foliage of yew, but their points are stiff and sharp, and if approached carelessly they will wound like cactus thorns. The fruit is an inch or more in length, a pulpy substance surrounding the seed. The wood possesses properties which ought to make it valuable, though reported uses are strictly local, such as small cabinet work and skiff making. It is bright lemon, yellow, rather hard, takes good polish, is of slow growth, with bands of summerwood thin but distinct, and medullary rays small, numerous, and obscure. Its weight is 29.66 pounds per cubic foot; it is not stiff or strong. It cannot attain high place as a manufacturing material, because it is too scarce, but it 
possesses a beauty which must bring it recognition as a fine furniture, finish, and novelty wood. A few sawlogs go to mills in the region north of San Francisco, but the lumber is probably mixed with other kinds and it goes to market without a name. It ought to be put to a better use.

Florida TORREYA (Tumion taxifolium) is often called Chattahoochee pine in the region where it grows. That name is generally given to the tree when planted for ornament in yards, parks, and along streets of towns in northwestern Florida. It is known also as stinking cedar, stinking savin, and fetid yew. These names are generally applied to the forest-grown tree, particularly by those who cut it for fence posts, which is its principal use. Its range is local, being confined largely, if not wholly, to Gadsden county, Florida, where it grows on limestone soil. It can never have much importance as a commercial timber, because it is too scarce. In fact, it is in danger of extermination. Post cutters never spare it, and its range being so limited, there is not much hope for it. The interesting and beautiful tree is making a game fight for life. Many seedlings appear in the vicinity of old trees, while stumps, and even prostrate trunks, send up sprouts which, if let alone, grow to tree size. Sprouts on logs and stumps send roots to the ground as the seedling yellow birch does in damp northern woods. The yew-like leaves of Florida torreya are one and a half inch or less in length. The tree blooms in March and April, and the drupe-like fruit, an inch or more in length, is ripe by midsummer. The tree is from forty to sixty feet in height, and one to two feet in diameter. It is clothed in whorls of limbs, beginning near the ground, and tapering to the top. The wood is clear, bright yellow, the thin sapwood of lighter color; soft, easily worked, and susceptible of fine polish. It is very durable in contact with the soil. The green wood, and the bruised leaves and branches give off an odor suggestiug the tomato vine. The texture and color of the wood indicate that it is well suited for fine cabinet work, but it is not a figured wood.

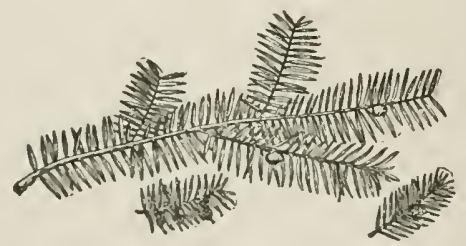


WHITE OAK 


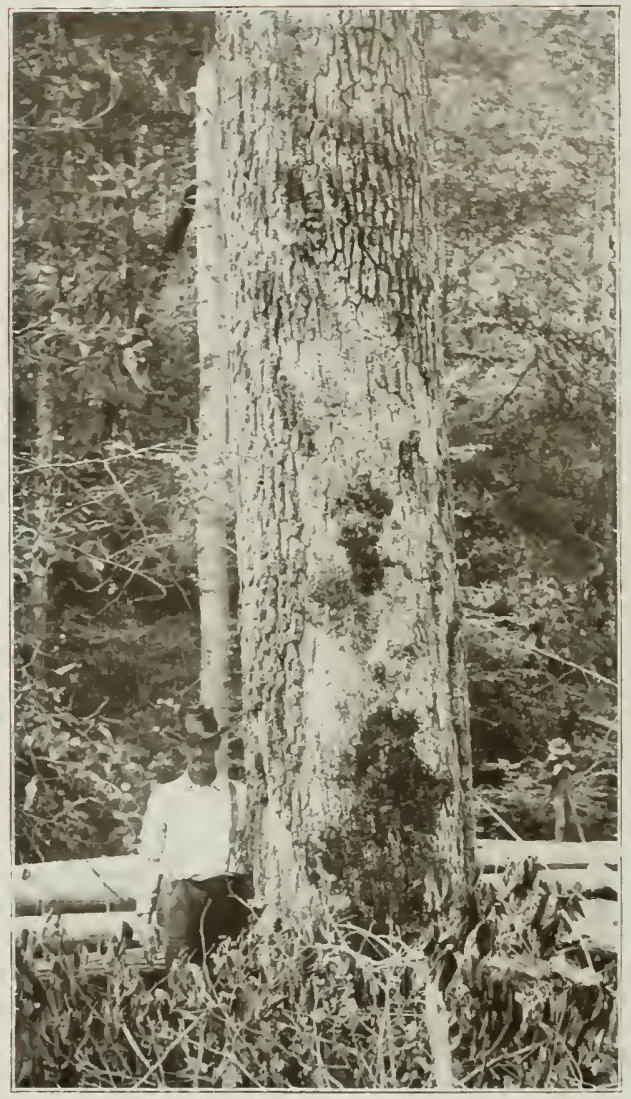

WHITE (MK 


\section{WHITE OAK}

(Quercus Alba)

$\mathrm{O}$ AKS belong to the beech family, that is, the "foodtrees," though most acorns are too bitter and contain too much tannin to be edible; some may be eaten, and for that reason the ancients classed them among the food trees. "Quercus," which is the name of the genus, means oak in the language of northwestern Europe. The name white oak nearly always suffices, but in Arkansas it is often called stave oak because it is the best stave timber in that region. It could with equal reason be called stave oak nearly anywhere, for it is excellent material for tight cooperage. Formerly it was sometimes called Baltimore oak, because many of the staves of export were shipped from that city. That name, however, belonged more to post oak (Qucrcus minor) than to white oak, because the fine staves which went out of Chesapeake bay in the export trade, were largely post oak. It matters little now, for the name Baltimore oak is not much used, and white oak may be said to have only one trade name. After the wood is dressed, it has different names referring to the style of finish and not to the wood itself.

White oak grows in all the states east of the Mississippi river, and it crosses that stream two or three hundred miles in some places. It

*The oaks of this country, which number more than fifty species, have been classified in different ways, depending upon the purpose in view. In the present treatment they will be divided in two general groups, white oaks and black oaks. No effort will be made to draw hard and fast lines, because it is not necessary. Oaks which ripen their acorns in one year are listed as white oaks; those with two year acorns, as black oaks. This is a botanicai rather than a lumberman's classification; yet lumbermen recognize it in a general way. White oak (Quercus alba) is clearly entitled to bead the list of white oaks, and red oak (Quercus rubra) should occupy a similar position with regard to the black oak group. In numbers, the white oaks and black oaks are nearly equally divided, one authority giving twenty-seven species of white oak and twenty-five of black oak in the United States; but botanists differ as to exact numbers of each. The following species are usually classed as white oaks: White oak (Quercus alba), valley oak (Quercus lobata), Brewcr oak (Quercus breweri), Sadler oak (Quercus sadleri), Pacific post oak (Qucrcus garryana), Gambcl oak (Quercus gambclii), post oak (Quercus minor), hapman oak (Qucrcuschapmam), bur oak (Quercus macrocarpa) overcup oak (Quercus lyrata), swamp white oak (Quercus platanoides), cow oak (Quercus michauxii), chestnut oak (Quercus prinus), chinquapin oak (Quercus acuminata), dwarf chinquapin oak (Quercus prinoides), Durand oak (Quercus breviloba), Rocky Mountain oak (Quercus undulata), California bluc oak (Quercus douglasi i), Engelmann oak (Quercus engclmanni), Rocky Mountain blue oak (Quercus oblongifolia), Arizona white oak (Quercus arizonica), Toumey oak (Quercus toumeyi), netleaf oak (Quercus reticulata), California scrub oak (Quercus dumosa), live oak (Quercus virginiana), Emory oak (Qucrcus emoryi). 
reaches eastern Nebraska and eastern Kansas, and runs southward through Ollahoma to the Brazos river, Texas. It is scarce in the northern parts of Michigan, Wisconsin, and Minnesota. Its total range covers an area of more than $1,000,000$ square miles. Like all other important timber trees, it has regions where the species is best developed. The finest original stands of white oak were found in the upper Ohio valley, beginning in Indiana. The timber in many other districts was, and in some still is, very good, such as southern Michigan, eastern Arkansas, some of the Appalachian valleys and slopes, and in certain places along the upper tributaries of streams flowing into the Atlantic ocean.

This tree is in the very front rank in economic importance, and it has held that place since the earliest settlements in this country. No forest tree was more evenly distributed than white oak over the eastern half of the United States. It did not form pure forests of large extent, as some of the pines did, but white oaks were within reach of almost every part of the country. Conditions have greatly changed. The establishment of farms where woods originally occupied the whole country, lessened the abundance of oak long before lumbermen made it a commodity; and since then, the cutting of billions of feet of it has depleted or exhausted the supply in many regions. Still, white oak is as widely dispersed as ever. It has not been completely exterminated in any extensive region. White oak of as high grade goes to market now as ever in the past, but in smaller amounts, and the lower grades go in proportionately larger quantities. In other words, prime white oak has passed its best day. A hundred years of use and abuse in states west of the Alleghany mountains, and two hundred years in some of the regions east, have reduced original forests to remnants. But with all that, white oak remains undisputed king of American hardwoods.

At its best, white oak attains a height of 125 feet and a diameter of six, but that size is unusual. A diameter of three feet and a height of 100 is above the average. The leaves are peculiar in that they hang on the branches until late winter, sometimes dropping only in time to give place to the new crop. They turn brown after the first hard frost. In some sections of the Appalachian region white oak coppice (sprout growth) is known as "red brush," because of the adherence of the brown leaves during winter. The leaves of some other species have the same habit.

The wood of white oak is very strong, stiff, heavy, and durable when exposed in all kinds of weather. Scarcely any other wood which can be had in mcrchantable quantities equals white oak in these qualities. It rates high in fuel value, and 6,000 pounds of dry wood when burned, leaves about 245 pounds of ashes. The color of the heartwood is light 
brown; the sapwood is thin; medullary rays are numerous and large; pores large; summerwood broad and dense.

The medullary rays of no wood in this or any other country are more utilized to commercial advantage than those of white oak. Quarter-sawing is for the purpose of bringing them out. They are the bright streaks, clearly visible to the naked eye in the end of an oak log, radiating from the center outward like the spokes of a wheel. Many are too thin to be visible without a magnifying glass. By quarter-sawing, the rays are cut edgewise and appear as bright streaks or patches, often called "mirrors," on the surface of boards. The woodworker knows how to finish the boards and treat them with fillers to bring out the figures.

White oak is a porous wood. Some of the pores are large enough to be visible without a glass, and twenty times as many more can be seen only when magnified. The direction of the pores is up and down the trunk of the tree, and they are seen to best advantage in the end of a stick, although they are always more or less visible on the side of a board when the cutting is a little across the grain. The pores thus cut diagonally across are taken advantage of by the finisher who works stains and fillers into them, and changes their natural color, thereby accentuating the wood's figure.

The possibilities of white oak are almost infinite. It is good for nearly anything for which any wood is used. It is not the best for everything, but does well for most. Hickory is more resilient, ironwood is stronger, locust more durable, white pine warps and checks less; but white oak has so many good qualities in a fair degree that it can afford to fall below the highest in some, and still rank above competitors on general averages. It ranks high in shipbuilding, general construction, furniture manufacturing, finish and fixtures, the making of agricultural implements, car building, vehicle stock, cooperage, and many more.

It is one of the most important of American veneer woods. It is sawed very thin, and is glued upon cores of other wood, thus becoming the covering or outside part. The purpose of using oak veneer instead of the solid wood is twofold. First, it goes farther, and second, a wellbuilt article with veneer outside and a core of other woods which stand well, is superior to a solid oak article, except in cases where great strength is the object sought, or where deep carving is desired.

The continued use of white oak is assured. It is not necessary to seek new uses for it. The demand is as great as the supply can meet, but the supply is not assured for the distant future. There will always be some white oak in the country; but the best has been or is being cut. The tree grows slowly, and good quarter-sawed white oak cannot be cut 
from young trees. An age of about 150 years is necessary. Most good white oak lumber today is cut from trees 200 or more years old. When the present supply of venerable oaks has been exhausted, prime oak lumber will be largely a thing of the past. Fortunately, that time has not yet arrived. About eighty years are required to grow a white oak of crosstie size. Those who will grow oak for market in the future will probably not wait much longer than eighty years to cut their trees, and the result will be a scarcity of mature trunks for lumber and veneer.

DuRAND OAK (Quercus breviloba). In some parts of Alabama, Mississippi, and Louisiana this tree goes to the lumber yard as white oak, and no one is injured by the substitution, for it is heavy, hard, and strong, and is of good color. The wood weighs 59.25 pounds per cubic foot, which places it above the average weight of white oak. It is said to be less tough than white oak. The tree varies greatly in different parts of its range which extends from central Alabama across Texas and into Mexico. It is known as white oak, Texas white oak, shin oak, pin oak, and basket oak. Its best development is in the eastern part of its range where trees eighty or ninety feet high are common; but in Texas the average is scarcely thirty feet high and one in diameter. Westward in Texas it becomes shrubby, and forms extensive thickets of brush.

Chapman OAK (Qucrcus chapmani) is put to little use, because trunks are too small. They are seldom more than a foot in diameter, and are often little more than shrubs. The tree grows in the pine barrens near the coast from South Carolina to Florida, and it is found also in great abundance, but generally of small size, on the west coast of Florida from Tampa to the Apalachicola river.

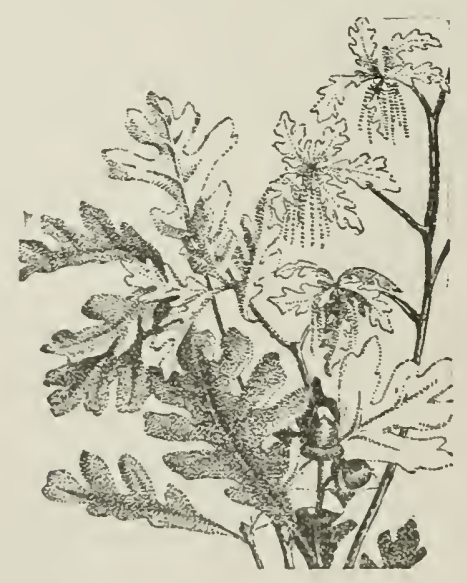


BUR OAK 


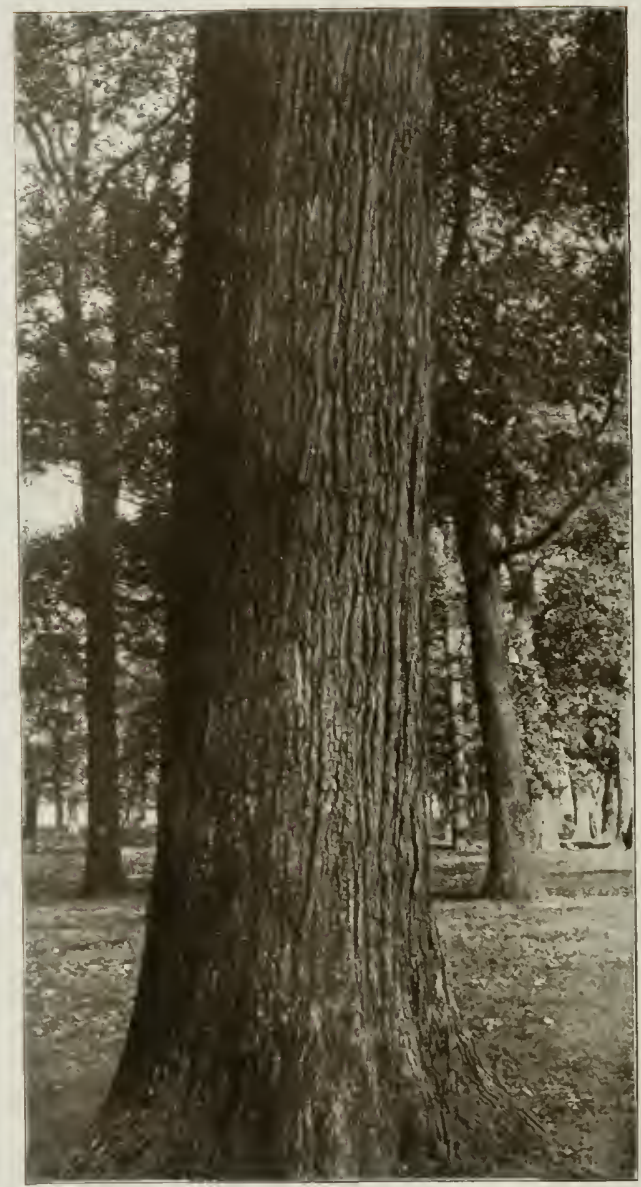

BLR OAK 


\section{BUR OAK}

\section{(Quercus Macrocarpa)}

$\mathrm{T}$ HIS splendid oak was naned by Michaux, a French traveler and botanist who visited many parts of eastern and southeastern United States more than a century ago. The botanical name macrocarpa, means "large fruit." The bur oak bears small acorns in the North, and very large ones in the South. They are sometimes two inches long and one and a half inches wide, and "large-fruit" oak is an appropriate name for the tree in the South, but would not be near the northern limit of its range.

It is known in different regions as bur oak, mossy cup oak, overcup oak, scrub oak, and mossy cup white oak. Bur oak is a name suggested by the acorn which has a fringe round the cup like a bur. This is the oak which gave name to James Fenimore Cooper's book, "Oak Openings" a romance of early days in Michigan. Oak openings were areas where fires had killed the old timber, and a young growth had sprouted from stumps and roots, or had sprung up from seeds buried in the ground beyond the reach of the fire. Some of those tracts were very large, and they were not confined to any one state. They existed in Michigan, Wisconsin, Minnesota, Dakota, and elsewhere. Bur oak, because it is a vigorous species, was able to take possession of such burned areas, to the exclusion of most others.

Few American oaks have a wider range. It extends from Nova Scotia to Manitoba, and in the United States is found in most states east of the Rocky Mountains. It extends farther west and northwest than any other commercial oak of the Atlantic states. In a range of so great geographical extent the bur oak finds it necessary to adapt itself to many kinds of land. It prefers low tracts where water is sufficient but not excessive, but it grows well in more elevated situations, provided the soil is fertile. It is not a poor-land tree. In the primeval forests it attained largest size in Indiana and Illinois. The largest trees were from 150 to 170 feet high and four to seven in diameter. Sizes varied from that extreme down to the other extreme near the outskirts of its range where the growth was stunted. Large quantities of very fine logs have been cut from trunks from two to four feet in diameter, and forty to sixty feet to the limbs.

The leaves of bur oak are from six to twelve inches long, simple and alternate; the petioles are thick with flattened and enlarged bases; the leaves are wedge-shaped at the base, and have from five to seven long, irregular lobes, the terminal one very large and broad. They are dark 
green in color, and are smooth and shiny above, silvery white and pubescent below. The edge of the leaf is notched somewhat like chestnut, but the teeth or notches are not so sharp.

The twigs are provided with corky wings, or flattened keels of bark, along their sides. Some of the wings are an inch or more wide. They are apt to escape notice when the tree is in leaf, but in the winter the bare twigs look rough and ragged.

The weight of bur oak is approximately the same as white oak, and the two woods are much the same in strength and elasticity. The bands of summerwood are broad and dense, and the springwood is filled with large pores. The medullary rays are broad, but not numerous in comparison with white oak. They are sufficiently conspicuous to show well in quarter-sawing.

Bur oak nearly always goes to market as white oak, or simply as oak, and it is difficult to ascertain all the uses found for it. Some factories which make furniture, finish, vehicles, and other articles that figure in the country's trade, attempt to identify the woods they use. That is done as carefully in Michigan as anywhere else, though comparatively few of the factories carry out the plan even in that state where many of the best wood-using establishments of the country are located. In a report issued in 1912 which gave statistics collected from more than eight hundred Michigan factories, bur oak received separate consideration. The uses there are doubtless representative, and will hold throughout the country wherever bur oak is fairly abundant. It is listed as baseboards, billiard tablerims, bookcases, clay working machines, filing cabinets, furniture, hand sleds, hay balers, interior finish, molding, tinplate boxes, wagon sills, work benches. The amount of wood used in the state was nearly 900,000 feet, according to the reports; but it certainly does not include all. What it does show, however, is that bur oak is one of the substantial woods of that region, and that it possesses properties which fit it for many important places in the country's industries.

Bur oak contributes to the output of cooper shops. Slack coopers class it with many other hardwoods for the manufacture of barrels for vegetables and various other commodities, while the makers of barrels for liquids put bur oak in with white oak.

The future of bur oak does not promise much after the trees which now remain have been cut. That does not mean that the species will become extinct, for that is improbable; but when the mature trees which developed during two or three hundred years of forest conditions have passed away, there is not much prospect of others being left to grow to the age and size which will make them valuable as lumber. Woodlot 
owners will not wait much longer than the seventy-five or one hundred years required to grow trees of crosstie size. Railroads pay good prices for this wood, for it lasts well, holds spikes in a satisfactory manner, and is strong and hard. As far as can be seen, bur oak will fare in the future about like white oak; that is, few trees will be left standing long enough to attain large size, because it will pay better to cut them while comparatively small.

Californta BluE OAK (Quercus douglasii) receives its name from the color of its foliage in spring and early summer in the valleys and on the rolling foothills of central California. Later in the summer, when the dry season is on, the leaves lose some of their blue, on account of age, but more from an accumulation of dust; but even then the form of the tree, from its habit of growing in open formation like an old apple orchard, presents an attractive picture. It is of ten associated with the valley oak, which is larger and more stately, but the blue oak loses nothing by the contrast. It is occasionally called rock oak, but for what reason is not clear. It is known, too, as moun tain white oak, or simply white oak, and as blue oak, Its range covers central Cahifornia from Mendocino to the Hojave desert, and from the immediate coast inland through the valleys to the Sierras, and upward to an altitude of 4,000 feet where the tree degenerates into a shrub which has neither beauty nor utility. The species reaches its best development in the Salinas valley from twenty to sixty miles from the coast. There the largest trees are found, and also some that have assumed peculiar forms. In positions exposed to the never-ceasing sea winds which sweep up the valleys, the blue oaks lie prone like logs, their tops pointing away from the wind. They grew in that unnatural position, having been pressed flat by the wind since they were seedlings. This oak's ashen gray bark harmonizes well with the dry summer grass and dull sand and gravel which surround it during the hot period. The branches are often covered with green-gray lichens which somewhat modify the aspect of the tree under close inspection. The leaves are irregular in form. Some closely resemble leaves of the eastern white oak, while others are almost or quite without lobes. During the growing season the acorns are deep green, but when approaching maturity they change to a chestnut-brown. They vary in shape as much as the leaves. Some are almost eggshaped, bulging out above the cup which seems too small; but all of them do not assume that form, but may be short and symmetrical, or very long and slender. Woodpeckers store these acorns in large numbers, and they search out peculiar places for their hoards. A knot hole in the weatherboarding of an old barn, granary, or school house is considered ideal, though when the acorns are so disposed of, they are out of reach of the woodpecker forever. Another method is to peck holes just large enough for an acorn in fence posts or dead tree trunks, and hammer the acnrns tightly in, small end first. The surfaces of dead trees are sometimes absolutely covered with such holes, each with its acorn. The woodpecker's purpose is to wait until the acorns become infested with larvæ. He has no intention of eating the acorn itself.

California blue oaks range in height from shrubs to trees of ninety feet, witls diameters of three or four feet. The average height is about forty-five and the diameter two or less. The trunk frequently divides a few feet from the ground into large limbs. That form excludes the wood from sawmills, and only in rare cases docs any of it find its way there. The lumber is of poor quality, brittle, black, and otherwise defective. The sapwood is white and thick. A cubic foot weighs 55.64 pounds, or nearly ten more than eastern white oak. It is weak, and is low in elasticity. The 
annual rings are of ten nearly invisible, because the pores are scattered evenly and do not form bands. The medullary rays are broad, in the heart black, in the sapwood white. If the wood were otherwise suitable, pleasing effects might be produced by quarter-sawing, but as far as known, no attempts have been made to do this. Now and then a suitable log might be found. The importance of this oak lies in its fuel value. It rates above white oak in theoretical tests, but it is heavier in ash, and in practice it hardly measures up to white oak. It grows slowly and is destined to disappear as a source of fuel supply. Reproduction has nearly ceased in most parts of its range, due largely to the perseverance of hogs in eating the acoms. Cordwood cutters have stripped the last tree from large areas where much once grew. This oak never forms forests. The trees seldom grow as close together as apple trees in an orchard.

G.AMBEL OAK (Quercus gambelit) was destined by nature to occupy an inferior place in the country's timber resources. It occupies a region of stunted vegetation among the dry mountains and plateaus of the Southwest, and except where it grows in better situations than usual, it is too small to be properly called a tree. It is at its best among the mountains of southeastern Arizona where it grows in canyons that can maintain a little damp soil. There it occasionally reaches a height of thirty feet and a diameter of a foot or less. In most other parts of its range it is simply a tangled, sprawling thicket of brush, covering the dry, rocky mountain ridges, and along the bases of cliffs. It is found from Colorado to western Texas, and westward into Utah, Nevada, and Arizona. The leaves are small, thick, firm, and hairy, typical of desert foliage which must husband the scant water supply. The acorns are pretty large for a tree so stunted, and they are tempting bait for birds and rodents of the region. The acoms are sweet. If this oak's reproduction depended on acoms alone it is doubtful if it would hold its ground in the face of perpetual adversity; but its roots send up distorted and stunted sprouts which cover the ground, affording hiding places for the few acorns which escape their hungry enemies. Man puts this oak to few uses. It affords a pretty good class of fuel for camp fires, but cordwood cutters cannot make much out of it. In rare instances frontier ranches use a few of the unshapely poles for corral fences, but only as a case of last resort. The names bestowed upon the tree by those who know it best are uncomplimentary. They call it shin oak, pin oak, scrub oak, mountain oak, and Rocky Mountain oak.

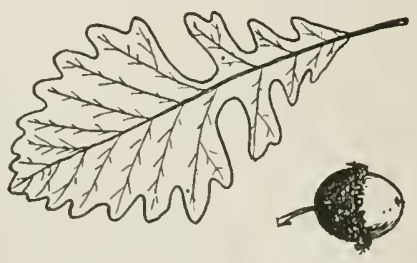


FORKED-LEAF WHITE OAK 


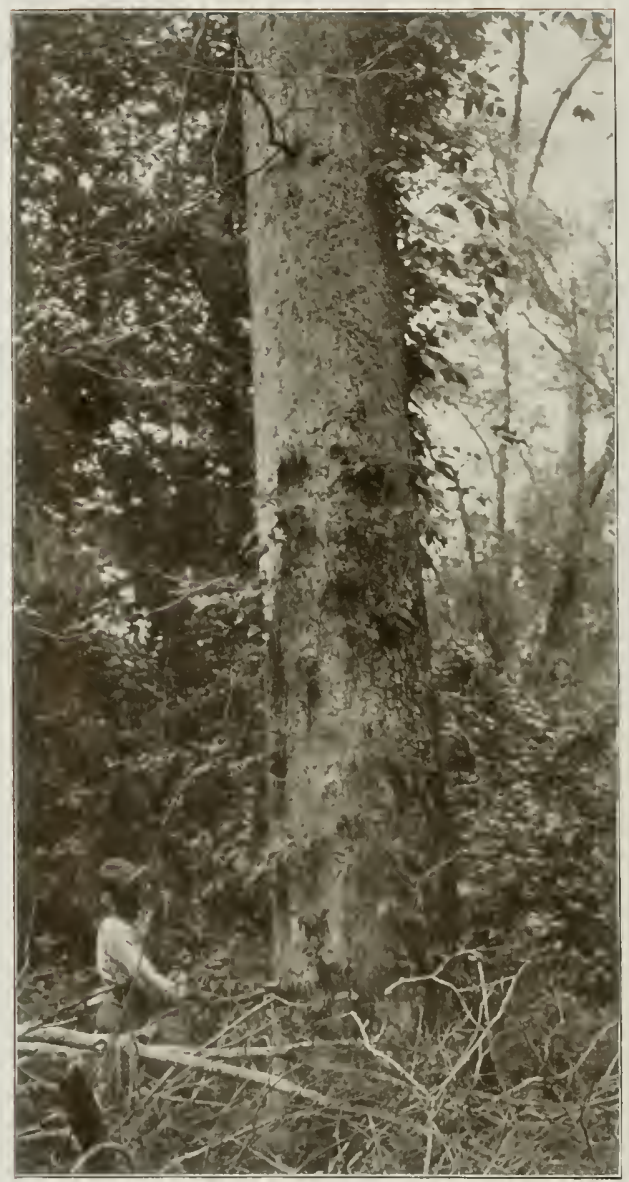

FORKED-ILAF IWHTE OAK 


\section{FORKED-LEAF WHITE OAK}

(Quercus Lyrata)

$\mathrm{T}$ HE leaf gives this tree its name in the best part of its southern range. The tree bears much resemblance to the bur oak on the one hand, and swamp white oak on the other. The names by which it is known in different regions indicate as much.

In North and South Carolina, Georgia, Florida, Alabama, Mississippi, Louisiana, Texas, Arkansas, and Illinois it is commonly known as overcup; in Alabama, South Carolina, Mississippi, Louisiana, and Missouri it is called the swamp post oak; the name water white oak is applied to it in Mississippi and parts of South Carolina; swamp white oak in Texas; forked-leaf white oak among lumbermen in several of the southern states. The last name scarcely describes the leaf, for no one is apt to notice any fork, unless his attention is called to it. The fact is, the name forked-leaf oak is applied of tener to the turkey oak (Quercus catesbai) than to this one. However, since the ranges of the two species are not the same, misunderstandings in practice are not apt to arise as to which is meant when the forked leaf is referred to. The fact that turkey oak belongs in the black oak group, ripening its acorns in two years, and this one is a white oak with one year acorns, is of further assistance in keeping the species separate.

The range of the forked-leaf white oak is from Maryland, along the Potomac river near the District of Columbia, southward to parts of Florida; westward through the Gulf states to the Trinity river in Texas; throughout Arkansas, sections of Missouri, central Tennessee, southern Illinois and Indiana.

It shows preference for river swamps, and small deep depressions in rich bottom lands where moisture is always abundant. It has never amounted to much in the Atlantic states, and its best development is found in the moist, fertile valley of Red river in Louisiana, and in certain parts of Arkansas and Texas. Its geographical range is pretty large, but as a timber tree it is confined to a comparatively restricted region west of the Mississippi. Good trees are found in other parts of its range. Lumbermen do not find it in extensive forests or pure stands, but isolated trees or small groups occur with other hardwoods.

This species of oak grows occasionally to a height of 100 feet, though its average is about seventy feet. It has a trunk two to three feet in diameter, which spreads out after attaining a height of fifteen or 'twenty feet, into small, often pendulous branches, forming a symmetrical round top. The branchlets are green, slightly tinged with red; covered 
with short hairs when first appearing, becoming grayish and shiny during their first winter, eventually turning ashen gray or brown.

The bark is three-quarters or one inch thick, light gray in color, shedding in thick plates, its surface being divided into thin scales. The winter buds are about one-eighth of an inch long and have light colored scales. The staminate flowers grow in long, slender, hairy spikes from four to six inches long; the calyx is light yellow and hairy. The pistillate flowers are stalked and are also covered with hairs.

The fruit of forked-leaf white oak is often on slender, fuzzy stems, sometimes an inch or more in length, but is often closely attached to the twig that bears it; the acorn is about one inch long, broad at the base, light brown and covered with short, light hairs, and usually almost entirely enclosed in the deep, spherical cup, which is bright reddishbrown on its inside surface, and covered on the outside with scales; thickened at the base, becoming thinner and forming an irregular edge at the margin of the cup. The cup often almost completely envelopes the acorn. The fruit then looks somewhat like a rough, nearly spherical button.

This oak's leaves are long and slender, and are divided in from five to nine lobes. When the leaves unfold they are brownish green and hairy above and below; at maturity they are thin and firm, darker green and shiny on the upper surface, silvery or light green and hairy below; from seven to eight inches long, one to four inches broad; in autumn turning a beautiful bright scarlet or vivid orange.

Commercially this wood is a white oak, and it is seldom or never sent to market under its orrn name. There are no statistics of cut at the mills or of stand in the forests. Lumbermen take the tree when they come to it in the course of their usual operations, but never go out of their way to get it. Though rather large stands occur in certain southern regions, and scattering trees are found in large areas, the total quantity in the country is known to be too small to give this tree an important place as a source of lumber. Neither is there expectation that the future has anything in store for this particular member of the tribe of oaks. The wood rates high in physical properties; is strong as white oak, if not stronger, tough, stiff, hard, and heavy. In contact with the ground it is very durable. The heartwood is rich, dark brown, the sapwood lighter.

It may be said, generally, that since it goes to market as white oak, and its buyers never object, it possesses the essential properties of that wood, and is used in the same way as far as it is used at all.

ARIzONA WHITE OAK (Quercus arizonica) is the common and most generally distributed white oak of southern New Mexico and Arizona 
where it covers the hillsides and occurs in canyons at altitudes from 5,000 to 10,000 feet above sea level. It occasionally ascends nearly or quite to the summits of the highest peaks. The form of the tree varies greatly, as might be expected from a range extending from one to two miles above sea level. On the dry, windswept summits the tree degenerates into a shrub, with stiff, harsh branches. Lower down, in canyons and in other situations where moisture may be had and the soil is fertile, trunks are fifty or sixty feet high and three or four in diameter; but these are not the usual sizes even in the best of the tree's range, for it cannot be classed as a timber tree.

The hardships of the desert have stunted it, and its form is rough. It is important for fuel, and this has been its chief use. The region where it occurs is thinly settled, and demand for lumber is small, but stockmen build corrals and fences to enclose sheep and cattle, and the Arizona white oak supplies some of the rough poles and posts for that purpose. The wood is heavy, hard, strong, and the heartwood is almost black, but the sapwood is lighter. The grain and figure of the wood are not attractive, and what little may be sawed into lumber in the future will be rather low-grade. The branches are crooked and when cut into cordwood the ricks are so open that it is a common saying in the region that "you can throw a dog through." The wood burns well, and the demand for fuel is large, in proportion to the population of the country.

The leaves of this oak are sometimes slightly lobed, and are sometimes nearly as smooth as willow leaves. They are light red and covered with hair when they unfold in the spring, but when mature they are dark green, and shiny. Acorns are one inch or less in length, and rather slender. They are very bitter, and wild animals are inclined to let them alone, unless pressed by hunger, and then eat them sparingly. This insures good reproduction, provided other conditions are favorable. Though cordwood cutters may strip the large trees from the hills and canyons, scrub growth may be expected to continue, particularly on high mountains, and in ravines where roads cannot be built.

NETLEAF OAK ( $Q$ uercus reticulata) will never attract lumbermen in this country, but sometime they may send to the Sierra Madre mountains of Mexico to procure it. In that region it is a tree large enough for lumber; but the portion of its range overlapping on the United States lies in southern Arizona and New Mexico among mountains from 7,000 to 10,000 feet above sea level. Conditions are unfavorable and the netleaf oak shows it by its stunted size and rough form. The wood is hard, heavy, dark brown in color, with lighter sapwood. The medullary rays are numerous and very broad. The tree seldom exceeds forty feet in height and one foot in diameter. The leaf is netted somewhat like that of the elm. The acorn is usually not more than half an inch in length.

Rocky Mountain OAK (Quercus undulatu) bears acorns which nuy be eaten like chestnuts, and not much more may be said for the tree in the way of usefulness 
to man, though it is the salvation of some of the small mammals of the bleak Texas and New Mexico hills where there is little to eat and few places for concealment from hawks and other enemies. The tree is also called scrub oak and shin oak. It grows in Colorado, New Mexico, western Texas, Arizona, Nevada, and Utah. At its best it rarely exceeds thirty feet high and a foot in diameter, and it often forms a jungle of shrubs through which the traveler must wade waist deep or go miles out of his way to pass round it. Its leaf is one of the smallest of the oaks, and is notched much like the chestnut leaf.

ALVORD OAK (Quercus alvordiana) is little known and will probably never be of much importance. It grows in the region of Tehachapi mountains, the northern border of the Mojave desert, in California, and was named for William Alvord of that state. The leaf is toothed, and the acorn smooth. No record has been found of any use of the wood, and when Sudworth compiled his book, "Forest Trees of the Pacific Slope," he was unable to procure enough leaves, flowers, and fruit to enable him to give a botanical description. It may therefore be regarded as one of the scarcest oaks in the United States, which fact gives it a certain interest.

SADLER OAK (Quercus sadleriana) is one of the minor oaks of the Pacific coast, and is popularly and properly called scrub oak by those who encounter it on high, dry slopes of northern California and southern Oregon mountains, from 4,000 to 9,000 feet above the sea. It forms dense thickets, and passes for an evergreen. Its leaves remain on the branches only thirteen months. The leaves are tootbed like those of chestnut. The acorns are matured in one season. The name Sadler oak was given it in honor of a Scottish botanist. Trees are too scarce and too small to have much value, except as a ground cover.

BREWER OAK (Quercus breweri) grows on the west slope of the Sierra Nevada mountains in California, from Kaweah river northward to Trinity mountains. It is often little more than a shrub, and its usefulness to man lies less in the quantity of wood it produces than in the protection the dense thickets, with their network of roots, afford steep billsides. Gullying in time of heavy rain cannot take place where this oak's matted masses of roots bind the soil. Sprouts rise freely from the roots, and thickets are reproduced in that way rather than from acorns, although in certain years crops of acorns are bountiful. The trunks are too small to make any kind of lumber, but are capable of supplying considerable quantities of fuel.

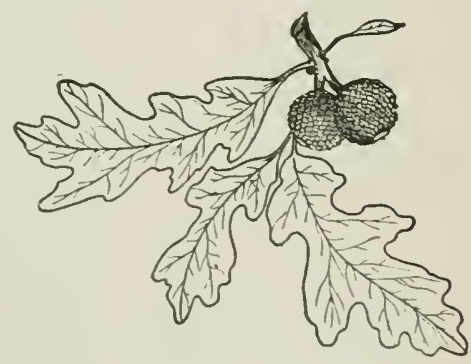


POST OAK 


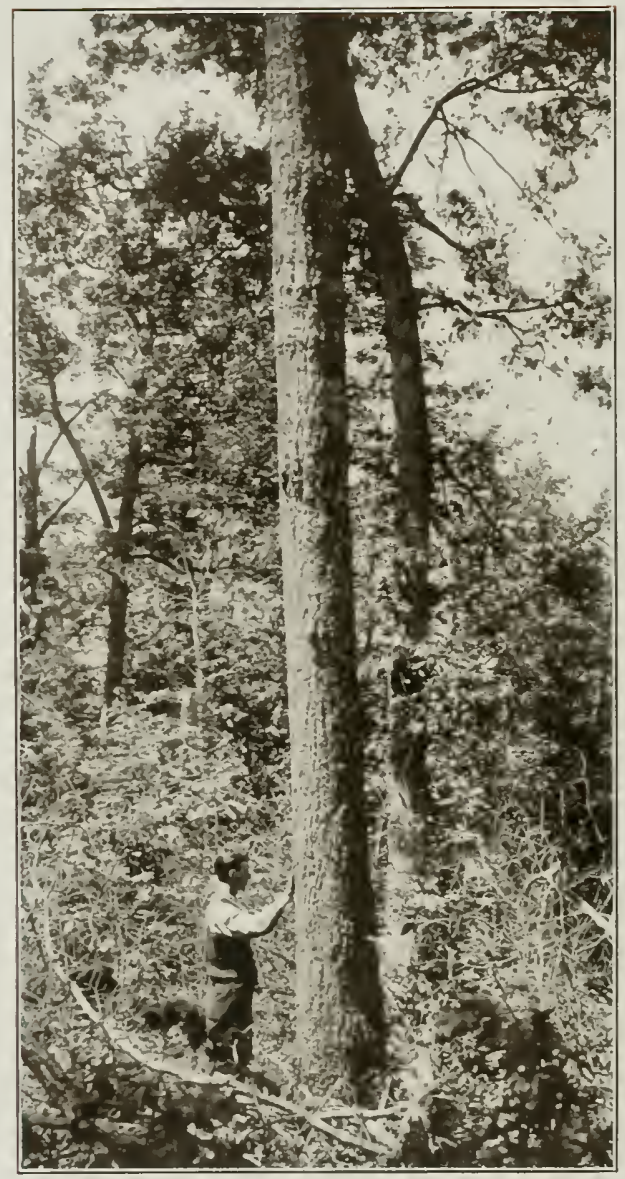

POST OAK 


\section{POST OAK}

\section{(Quereus Minor)}

DOST oak is the most common name for this tree but various sections of its range have given it their own names which probably have local significance. The following names are in use in the localities denoted : post oak in the eastern and Gulf states, Connecticut to Texas, and in Arkansas and West Virginia; box white oak in Rhode Island; iron oak in Delaware, Mississippi and Nebraska; chêne étoile in Quebec; overcup oak in Florida; white oak in Kentucky and Indiana; box oak and brash oak in Maryland.

Toward the northern portion of the range of this tree it is small, and in early times it was little used except for fence posts. Its durability fitted it for that use, and it is said the common name was due to that circumstance. The name iron oak was used by shipbuilders who sometimes bought small knees made of this wood. Baltimore oak was an early name which is not now in use. It was generally applied to white oak, but it included some post oak shipped from the Chesapeake bay region.

Post oak is botanically and commercially a white oak and is seldom distinguished from the true white oak, Qucrcus alba, in commerce. It is seen at its best in the uplands of the Mississippi basin and in the Gulf states west of the Mississippi, where it attains a considerable size. In the northeastern states and in Florida it is small, becoming shrubby in some localities, and more or less of local growth. Limestone uplands or dry, sandy or gravelly soils seem to offer the best conditions for its existence, where it grows in company with black jack, red and white oak, sassafras, dogwood, gums, and red cedar.

The range of growth of post oak extends from New Brunswick south through the Atlantic states into Florida; west through the Gulf states and throughout the Mississippi river system, growing west brokenly to Montana. It is the common oak of central Texas but in the North it is rather scarce, becoming more plentiful in the lower Appalachians.

The broad, dense, round-topped crown of the post oak with its peculiar foliage make it very noticeable in the woods, even to the casual observer. Its dark green looks almost black at a distance. The tree has an average height of sixty or eighty feet and is about two feet in diameter, but in exceptional cases it reaches one hundred fcct in hcight and has a diameter of three feet. It has a moderately thick, dark brown bark with a reddish tinge and deep fissures, the broad ridges being 
covered with thin scales. On the branches it becomes much thinner, and lighter in color, the branchlets being unfissured and glabrous in the second year, although fuzzy at first. They are rather heavy and rounded and terminate in short round buds with conspicuous scales. A noticeable feature of the tree is the peculiar branching. The limbs are heavy and crooked, separating often, with wide angles, forming knees which when big enough, have a commercial value.

When the tree is in foliage the tufted appearance of the leaves grouped on the ends of the twigs gives it a distinctive look. They bear some resemblance to a star, and for that reason some botanists have named the species stellata. The leaves are five or seven inches long usually, but in some cases, especially on young specimens, they are ten or more inches long. They are dark, shiny-green and on a short petiole, the veins and midrib being heavy and conspicuous. The identification of these leaves is easy as they are heavy in texture, are bilaterally developed with a large, obtuse lobe on each side about in the middle, giving them a maltese cross effect. They are very persistent, staying on the tree until the new leaves push them off in the spring.

The form of post oak is not ideal from the lumberman's viewpoint. The tree does not prune itself well. Straggling limbs adhere to the trunk and prevent the clean bole which often makes white oak so attractive.

The wood weighs 52.14 pounds per cubic foot. The name iron oak referred to the weight as well as the strength of the wood. It is rather difficult to season, and is inclined to check badly. The medullary rays are broad and numerous, and checking is apt to develop along the rays. The summerwood occupies about half of the annual ring, and is dense and dark colored. Large pores are abundant in the springwood, and smaller ones in the summerwood.

Formerly this tree was known in some sections as turkey oak, though the name is no longer heard, but is now applied to another oak in the South. The acorns are small enough to be eaten by turkeys, and when those game birds were wild in the woods they frequented parts of the forests where post oaks grew, and hunters knew where to find them. The uses of post oak for building and manufacturing purposes are the same as for white oak as far as they go, but post oak is not so extensively employed.

The earliest railroads in America were built in the region where post oak of excellent quality grew, and it saw service from the first as crossties, and car and bridge timbers. It is still used for those purposes. Its other important uses are as furniture material, both as solid stock and veneer; interior finish and fixtures for offices, banks, and stores; musical instruments, including frames, braces, and veneers; baskets, 
crates, and shipping boxes; vehicles, particularly tongues, axles, and hounds of heavy wagons; flooring, stair work, balusters.

Post oak will do well on land too gravelly and thin to sustain good white oak growth. To that extent the two species are not competitors for ground, and post oak is assured a place in future woodlots, but it cannot be expected ever to equal white oak in commercial importance, while as an ornamental tree it is not usually favored because the shape of its crown is not altogether pleasing. Its very dark foliage, however, is admired by many and gives the tree an individuality.

SWAmp White OAK (Quercus platanoides). This tree's botanical name means "broadleaf oak," and that is a good description as far as it goes, but it does not apply solely to this species. The characteristic which fixes it best in the minds of most people is its preference for low, wet soil. Its two common names are swamp oak and swamp white oak, yet it is not really a swamp tree, such as the northern white cedar, southern white cedar, cypress, and tupelo are. It does not associate with any of those trees. It prefers river banks, and does not object to a good deal of water about its roots, though it grows nicely in situations out of reach of all overflow, and often side by side with silver maple, hickory, ash, and several other oaks. The leaf resembles that of chestnut oak, and the bark is somewhat like chestnut oak, but the wood passes in market for white oak, and is a good substitute for it, though the resemblance is not so close that one need be mistaken for the other. The tree averages about seventy feet high with a diameter of two feet, but much larger trunks are common. The famous "Wadsworth oak," which stood on the bank of the Genesee river in western New York, about a mile from the village of Geneseo, was a swamp white oak. It had a trunk diameter of nine feet, but it was not tall in proportion. It met its overthrow by the undermining of the river bank in time of flood. That is a common fate for this tree, because of its preference for river banks. Its range is from Maine to Wisconsin and Iowa. It follows the mountains to northern Georgia; and west of the Mississippi it grows as far south as Arkansas. The species is best develofed in western New York, northwestern Pennsylvania, and along the southern shores of Lakes Erie and Michigan.

Trees do not clear themselves of branches on their lower trunks very early in life, and lumber more or less knotty results. It is possible, however, to cut a fairly large proportion of clear boards. The wood is of about the same weight as white oak, and is hard, strong, and tough. Its color is light brown, and the thin sapwood is hardly distinguishable from the heart. The medullary rays are as large as those of white oak, but are few. For that reason, swamp white oak does not give very 
satisfactory results when quarter-sawed. The bright patches are too scarce. Neither does it show as many of these rays as chestnut oak. The wood is very porous, but the large pores are confined to the springwood, while the broad bands of summerwood are dense. The contrast between the two parts of annual rings forms a strong, but not particularly handsome figure when the lumber is sawed tangentially-that is, from the side of the $\log$. The wood finisher can improve this oak's natural appearance by employing fillers and stains to lighten shades or deepen tints. The uses of this oak are numerous. It is excellent fuel, and is rather low in ash; it is weaker and more brittle than white oak; but it is quite satisfactory for railroad ties, car building, house finish, furniture, some parts of heavy vehicles, certain kinds of cooperage, and for farm implements.

Rocky Mountaix BleE OAk (Quercus oblongifolia) is named from the blue color of its foliage, though what little lumber is cut from it, is bought and sold as white oak. It is of little importance, yet in the almost timberless mountains of western Texas it supplies some of the urgent wants of a scattered population. It bears willow-like leaves one or two inches long, and less than an inch wide; but on vigorous shoots they are larger. The acorns are very small. Trees seldom exceed thirty feet in height, and a diameter of twenty inches; and often the trunk is divided near the ground in three or four stout, crooked forks. Ordinarily, it is an impossible tree to lumber, but sometimes a few logs find their way to sawmills and a little passable lumber is produced. The wood weighs 58 pounds per cubic foot. It is strong, but when it breaks, it snaps short. The heartwood is darker than in most oaks, and the sapwood is brown. The tree is useful for fuel. Charcoal for local blacksmith shops is manufactured from the wood. It is abundant on many of the sterile slopes and mesas of New Mexico and Arizona, but usually in the form of brush about the heads of canyons.

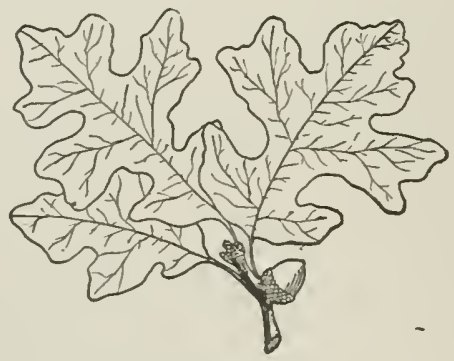


COII OAK 


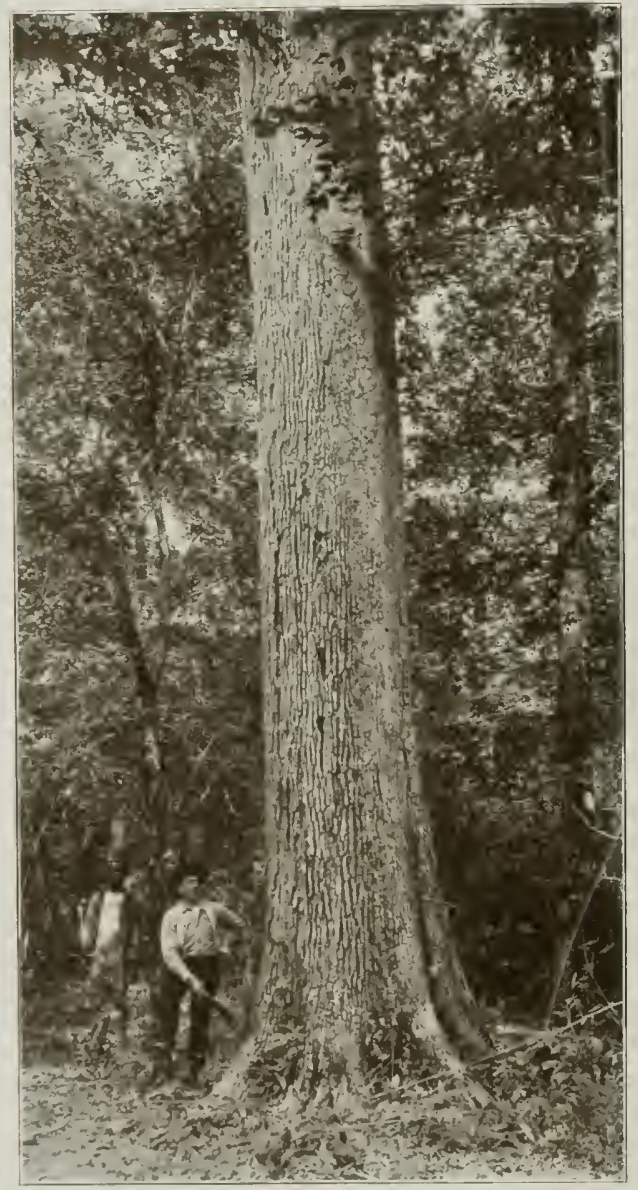

Cow OAK 


\section{COW OAK}

(Quercus Michauxii)

$\mathrm{T}$ HIS oak's acorns are remarkably free from the bitterness due to tannin and are therefore pleasant to the taste. Herbivorous animals eat them when they are to be had, and the eagerness with which cattle gather them in the fall is doubtless the reason for calling the tree cow oak. Hogs and sheep are as eager hunters for the acorns as cattle are, and the half-wild swine in the southern forests become marketable during the two months of the acorn season. Children know the excellency of the cow oak acorns, and gather them in large quantities during the early weeks of autumn in the South. The tree is widely known as basket oak, and the name refers to a prevailing use for the wood in early times, and a rather common use yet. Long before anyone had made a study of the structure of this wood, it was learned that it splits nicely into long, slender bands, and these were employed by basket weavers for all sorts of wares in that line. Tens of thousands of baskets were in use before the war in the southern cottonfields, and they have not gone out of use there yet. It is safe to say that millions of dollars worth of cotton has been picked and "toted" in baskets made of this oak. It was natural, therefore, that the name basket oak should be given it. Large, coarse baskets are still made of splits of this wood, and china and other merchandise are packed in them; while baskets of finer pattern and workmanship are doing service about the farms and homes of thousands of people.

When the structure of wood became a subject of study among dendrologists, the secret of the cow oak's adaptability to basket making was discovered. The annual rings of growth are broad, and the bands of springwood and summerwood are distinct. The springwood is so perforated with large pores that it contains comparatively little real wood substance. The early basket maker did not notice that but he found by experimenting that the wood split along the rings of growth into fine ribbons. The splitting occurs along the springwood. Ribbons may be pulled off as thin as the rings of annual growtl, that is, from an eighth to a sixteenth of an inch thick. These are the "splits" of which baskets are made. When subjected to rough usage, such as being dragged and hauled about cornfields and cotton plantations, such a basket will outlast two or three of willow.

The tree is sometimes called swamp white oak, and swamp chestnut oak. It bears some resemblance to the swamp white oak (Qucrcus platanoides) and some people believe that both are of one species, but of 
slightly different forms. It is not surprising that there should be a conflict of names and confusion in identification. The leaf resembles that of the chestnut oak, and to that fact is due the belief which some hold that the chief difference between the trees is that the chestnut oak (Quercus prinus) grows on dry land and cow oak in damp situations. Botanists make a clear distinction between cow oak and all other species, though it closely resembles some of them in several particulars.

From the northern limits of its growth in Delaware, where it is not of any considerable size, it extends south through the Atlantic states and into Florida, west in the Gulf states to the Trinity river in Texas, and up the Mississippi valley, including in its range Arkansas, eastern Missouri, southern Indiana and Illinois and western Kentucky and Tennessee. It is distinctly of the South and may be considered the best southern representative of the white oak group. It does best in swampy localities where it is found in company with water hickory, sweet magnolia, planer tree, water oak, willow oak, red maple, and red and black gum.

In general appearance the tree gives the impression of massiveness and strength, offset by the delicate, silvery effect of the bark and the lining of the foliage. The usual height is sixty or eighty feet, but it of ten exceeds a hundred feet, the bole attaining a diameter of as high as seven feet and showing three log lengths clear. The characteristic light gray, scaly, white oak bark covers trunk and heavy limbs, which rise at narrow angles, forming a rounded head and dividing into stout branches and twigs. The winter buds are not characteristic of white oak, being long and pointed rather than rounded. They are about a half inch in length, scaly, with red hairs and usually in threes on the ends of the twigs. The general texture of the leaves is thick and heavy, their upper surfaces being dark, lustrous green and the lower white and covered with hairs. They are from five to seven inches long with petioles an inch in length and of the general outline of the chestnut leaf. Their rich crimson color is conspicuous in the fall after turning.

The wood of cow oak is hard, heavy, very tough, strong, and durable. The heartwood is light brown, the sapwood darker colored. It weighs 50.10 pounds per cubic foot, and is not quite up to white oak in strength and elasticity. In quarter-sawing it does not equal white oak, because the medullary rays, though broad, are not regularly distributed, and the surface of the quarter-sawed board has a splotchy appearance, and it is not as easy to match figures as with white oak.

Cow oak is one of the most important hardwoods of the South. Its uses are much the same as those for white oak farther north. The custom of calling it white oak when it goes to market renders the collec- 
tion of statistics of uses difficult. Sawmills seldom or never list cow oak in making reports of cut. Factories which further manufacture lumber, after it leaves the mill, sometimes distinguish between cow oak and other oaks. It has been found suitable material in the South for canthook handles where it takes the place of hickory which is more expensive. It is reported for that use in considerable quantity in Louisiana. The handles are subjected to great strain and violent shocks. The billets are split to the proper size, because if they are sawed they are liable to contain cross grain which is a fatal defect. The wood is cut in dimensions for chair stock and furniture, the better grades usually going to furniture factories. Defective logs, short lengths, and odds and ends may be worked into chair stock which contains a large proportion of small pieces. The making of large plantation baskets of this wood is still a fairly large business in Louisiana and Mississippi. Braided bottoms of cheap chairs are of the same workmanship as baskets.

Vehicle makers in the South are large users of this wood. It is employed in heavy wagons chiefly, and is worked into many parts, including axles, bolsters, felloes, hubs, hounds, tongues, reaches, spokes, and bedbottoms.

This tree is classed as white oak by coopers who accept it as stave material. The amount used is much less than of the true white oak, but the exact quantity taken yearly by barrel makers is not known because statistics do not list the different white oaks separately. Cow oak rives well when a trunk is found clear of knots. The trees are usually smaller and less perfect than true white oak in the North.

Railroads accept crossties of this species and they give as long service as white oak, are as hard, and hold spikes as well. The wood is accepted by car shops for use in repairs and in new work. Trunks are split or sawed into fence posts and are used in probably larger numbers than any other southern oak.

This tree's future seems fairly well assured. It will further decline in available supply, because it is cut faster than it is growing. That is the status of all the timber oaks of this country. This one has advantage over some of the others in that it occupies wet land which will not soon be in demand for agricultural purposes, and young growth will be left to develop.

EXGELMANN OAK (Quercus engelmanni) occupies a restricled range in southwestern California where it is generally spoken of as a desert tree; but its rate of growth appears to be much more rapid than is usual with trees in arid situations. It occupies a narrow belt in San Diego county and its range extends into Lower California. It forms about one-third of the stand in Palomar mountains, and is much scarcer in the Cuyamaca mountains. The tree seldom attains a height greater than 
forty or fifty feet, or a diameter more than twenty or thirty inches. The largest trees are of small value for lumber and in rare instances only, if at all, do they go to sawmills. The trunks fork and each branch forks, until a fairly large bole near the ground is divided among numerous limbs. The tree's chief value is as fuel. It rates high as such. The leaves are bluish-green and are thick with sharp points on their margins. The leaves vary greatly in size, and are largest on young shoots. They remain a year on the tree, and are classed as evergreen. The acorns ripen in one year. This interesting species was named for Dr. George Engelmann, whose name is borne also by Engelmann spruce. The wood is among the heaviest of the oaks, exceeding white oak by more than twelve pounds per cuhic foot. It is brittle and weak, and very dark brown. The green wood checks and warps badly in seasoning. The medullary rays are numerous and large, but are so irregularly dispersed that quarter-sawing promises no satisfactory results, even if logs of suitable size could be found. The annual rings are indistinct, owing to no clear line of separation between springwood and summerwood. Pores are numerous, diffuse, and some of them large. The species is entitled to recognition only because it is found in a region where forests are scarce and scrubby, and every trunk has value as fuel, if for nothing else. It affords a cover for hills which otherwise would be barren, and it frequently occurs iu fairly dense thickets.

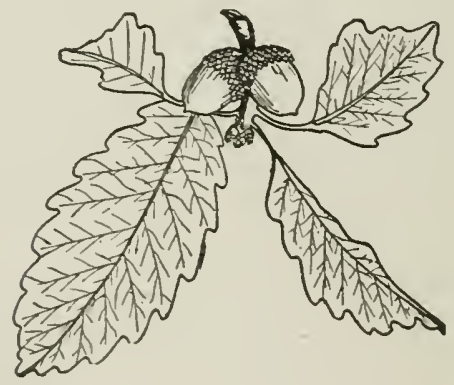


PACIFIC POST OAK 


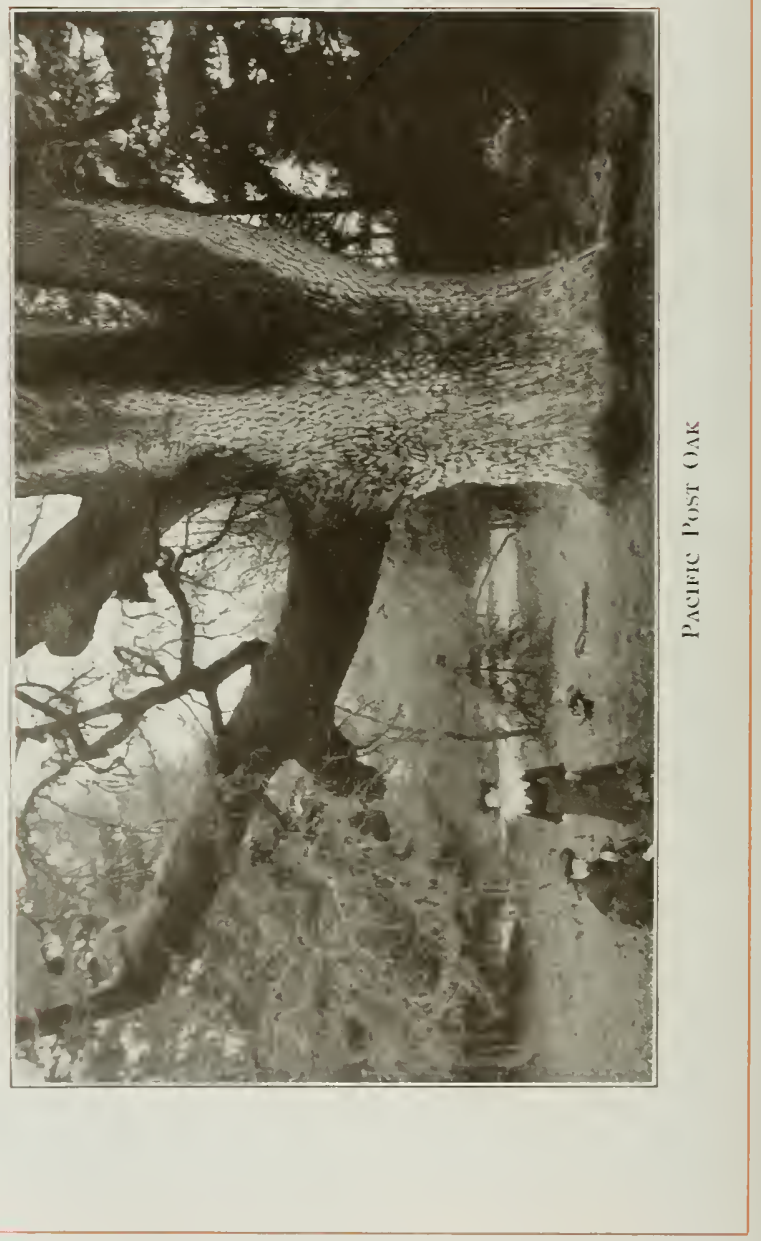




\title{
PACIFIC POST OAK
}

\author{
(Quercus Garryana)
}

$\mathrm{D}$

AVID Douglas named this tree the Garry oak, in honor of Nicholas Garry of the Hudson Bay Company, who furnished valuable assistance to botanists and other explorers of early times in the northwestern parts of America. This tree is best developed in the neighborhood of Puget Sound, the present state of Washington, and at the period of explorations in that region by Douglas, who was a Scotchman, the country was a sort of "no man's land." It was claimed by both England and the United States, and Russia had cast covetous eyes on it as a southern extension of her Alaska holdings. England at that time put a good deal of dependence in the Hudson Bay Company to get possession of and to hold as much country as possible, and Garry's help given to explorers was part of a well-laid plan to possess as much of the northwestern country as possible. Douglas doubtless had that in mind when he named the oak in honor of Garry. It was a witness and perpetual reminder that the Hudson Bay Company's strong arms had been stretched in that direction.

The people in California and Oregon of ten speak of the tree simply as white oak, but it is sometimes called Oregon white oak, and more often Oregon oak without a qualifying word. When it is spoken of as western white oak, which frequently is the case, it is compared with the well-known eastern white oak. It bears more resemblance to the eastern post oak (Quercus minor) and for that reason it has been named Pacific post oak. The leaves and twigs, particularly when they are young, resemble post oak.

The northern limit of the tree's range crosses southern British Columbia. It is found in the lower valley of Frazer river and on Vancouver island. It is the only oak tree of British Columbia. Its range extends southward to the Santa Cruz mountains in California, but near the southern limit of its range it is found chiefly in valleys near the coast. It is best developed in western Washington and Oregon. It occurs of good size on dry gravelly slopes of low hills; and it ascends the Cascade mountains to considerable elevations, but becomes stunted and shrubby. It is abundant in northwestern California.

The tree has a height from sixty to a hundred feet; sometimes it attains a diameter of three and one-half feet. It carries a broad and compact crown, especially when the tree is surrounded by young coniferous growth as is the case in its best habitat where natural pruning gets rid of the lower limbs and causes an outward and later a pendulous 
growth of the upper part. The limbs are strong and heavy as are the branches and twigs. The bark is a grayish-brown with shallow fissures, the broad ridges being sometimes broken across forming square plates which are covered with the grayish flakes or scales. The buds are long and acute, and are coated with a red fuzz. The leaves are from four to six inches long and are bilaterally developed, having seven or nine coarse round lobes; the sinuses being rounded or rather shallow. The color is a dark lustrous green and the texture leathery.

The acorn is rather large being about an inch and a quarter in length and usually about half as broad as long; has a shallow cup covered with pointed sometimes elongated scales.

This oak is one of the most important hardwoods of the far Northwest. It is of ten compared with the eastern white oak, but its physical properties fall below that species in some important particulars. The two woods weigh about the same, but the eastern species is stronger and more elastic, and is of better color and figure. All oaks season somewhat slowly, but the Pacific post oak is hardly up to the average. It is a common saying that it must remain two years on the sticks to fit it for the shop, but that time may be shortened in many instances. Checking must be carefully guarded against.

Some of this oak is exceedingly tough, and when carefully sorted and prepared it is excellent material for heavy wagons; but the best comes from young and comparatively small trees. When they attain large size they are apt to become brash. The tree usually grows rapidly, and is not old in proportion to the size of its trunk. An examination of the wood shows broad bands of summerwood and narrow, very porous springwood. The medullary rays are broad and numerous, and ought to show well in quarter-sawed stock; but it does not appear that much quarter-sawing has been done.

Practically all of this species cut in the United States is credited to Oregon in the census of sawmill output in 1910 . The cut was $2,857,000$ feet, and was produced by fourteen sawmills, while in Washington only one mill reported any oak, and the quantity was only 4,000 feet. On the northwest Pacific coast it comes in competition with eastern oak and also with Siberian or Japanese oak.

Basket makers put this wood to considerable use. Young trees are selected on account of their toughness. The wood is either split in long, thin ribbons for basket weaving, or it is first made into veneer and then cut in ribbons of required width. The largest users are furniture makers, but boat yards find it convenient material and it takes the place of importcd oak for frames, keels, ribs, sills, and interior finish. It is durable, and it may be depended upon for long service in any part of boat 
construction. Its toughness fits it for ax, hammer, and other handles. It is far inferior to hickory, but on the Pacific coast it can be had much cheaper. Its strength and durability make it one of the best western woods for insulator pins for telephone and telegraph lines. It is worked into saddle trees and stirrups.

The scarcity of woods on the Pacific coast suitable for tight cooperage gives this oak a rather important place, because barrels and casks made of it hold alcoholic liquors. Available statistics do not show the quantity of staves produced from this wood, but it is known to be used for staves in Oregon.

Much Pacific post oak is employed as rough lumber for various purposes. Railroads buy crossties, hewed or sawed from small trunks, and country bridges are occasionally floored with thick planks which wear well and offer great resistance to decay.

The quantity of this oak growing in the Northwest is not known. It falls far below some of the softwoods of the same region, and the area on which it is found in commercial amounts is not large. It is holding its ground fairly well. Trees bear full crops of acorns frequently, and if they fall on damp humus they germinate and grow. The seedlings imitate the eastern white oak, and send tap roots deep into the ground, and are then prepared for fortune or adversity. It happens, however, that trees which bear the most bountiful crops of acorns do not stand in forests where the ground is damp and humus abundant, but on more operi ground on grass covered slopes. Acorns which fall on sod seldom germinate, and consequently few seedlings are to be seen in such situations. Open-grown trees are poorly suited for lumber, on account of many limbs low on the trunks, but they grow large amounts of cordwood.

CAlifornta SCRL'B OAK (Quercus dumosa) has been a puzzle to botanists, and a hopeless enigma to laymen. Some would split the species into no fewer than three species and three varieties, basing distinctions on forms of leaves and acorns and other botanical differences; but Sudworth, after a prolonged study of this matter, recognized only one species and one variety, but admitted that "California scrub oak unquestionably varies more than all other oaks in the form and size of its leaves and acorns." He thought it might possibly be equalled in that respect by Qucrcus undulata of the Rocky .Iountains. Some of the leaves of California scrub oak are three-fourths of an inch long and half an inch wide, while others may he four inches long. The edges of some leaves are as briery as the leaves of holly, others are comparatively smooth. The shapes and sizes of acorns vary as much as the leaves. Some are long and slcnder, others short and stocky. This peculiar oak is found only in Catifornia, but it shows a disposition to advance as far as possible into the sea, for it has gained a foothold on islands lying off the California coast, and it there finds its most acceptable habitat. It reaches its largest size in sheltered canyons on the islands, and attains a height of twenty or twenty-five feet, and a diameter of a foot or lcss. It is not large cnnugh to win favor with lumbermen but in its scrubby form it is abundant in many localities. It is scattered over several thousand square miles, from nearly sea level up to $\vec{\imath}, 000$ 
feet in the mountains of southern California. It is found scattered through the coast range and the Sierra Nevadas from Mendocino county to Lower California, 700 miles or more. It grows from sprouts and from acorns. The leaves adhere to the twigs thirteen months, and fall after the new crop has appeared. The wood is light brown, hard, and brittle. No use is made of it, except to a small extent for fuel. On the mountains it grows in thickets scarcely five feet high, but they cover the ground in dense jungles, and the roots go deep in the ground. The species is valuable chiefly: for protection to steep slopes which would otherwise be without much growth of any kind. Being low on the ground, forest fires are particularly destructive to this oak; but its ability to send up sprouts repairs the damage to some extent.

EMORY OAK (Quercus emoryi) grows among the mountains of western Texas, New Mexico, and Arizona, attains a height from thirty to seventy feet, and a diameter from one to four. The largest size is found only in sheltered canyons, while on high mountains and in exposed situations the tree degenerates to a shrub. It always has a crop of leaves. The old do not fall until the new appear. In shape, the leaves somewhat resemble those of box elder. The acorns ripen from June to September, the exact time depending upon the tree's situation. Trunks large enough for use are not scarce, but the wood is not of high class. Stair railing and balusters have been made of it in Texas, but the appearance is rather poor. The grain is coarse, the figure common, the color unsatisfactory. The heart is very dark, but the tones are not uniform, and flat surfaces, such as boards and panels, show streaks which are not sufficiently attractive to be taken for figure. Trunks are apt to be full of black knots which mar the appearance of the lumber. The medullary rays are numerous and broad, and in quarter-sawing, the size and arrangement of the "mirrors" are all that could be desired, but they have a decidedly pituk color which does not contrast very well with the rest of the wood. The weight of this oak exceeds per cubic foot white oak, by more than ten pounds; but it has scarcely half the strength or half the elasticity of white oak. The springwood is filled with large pores, the summerwood with smaller ones. It rates high as fuel, and that is its chief value. Large quantities are cut for cordwood. Railroad ties are made of it, and more or less goes into mines as props and lagging. Stock ranches make fences, sheds, and corrals of this oak, and live stock eats the acorns. The human inhabitants likewise find the Emory oak acorn crop a source of food. Mexicans gather them in large quantities and sell what they can spare. The market for the acorns is found in towns in northwestern Mexico.

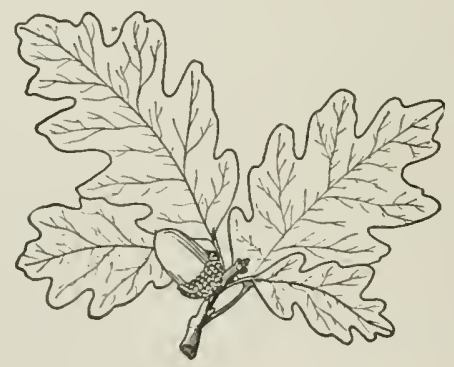


CHESTNUT OAK 


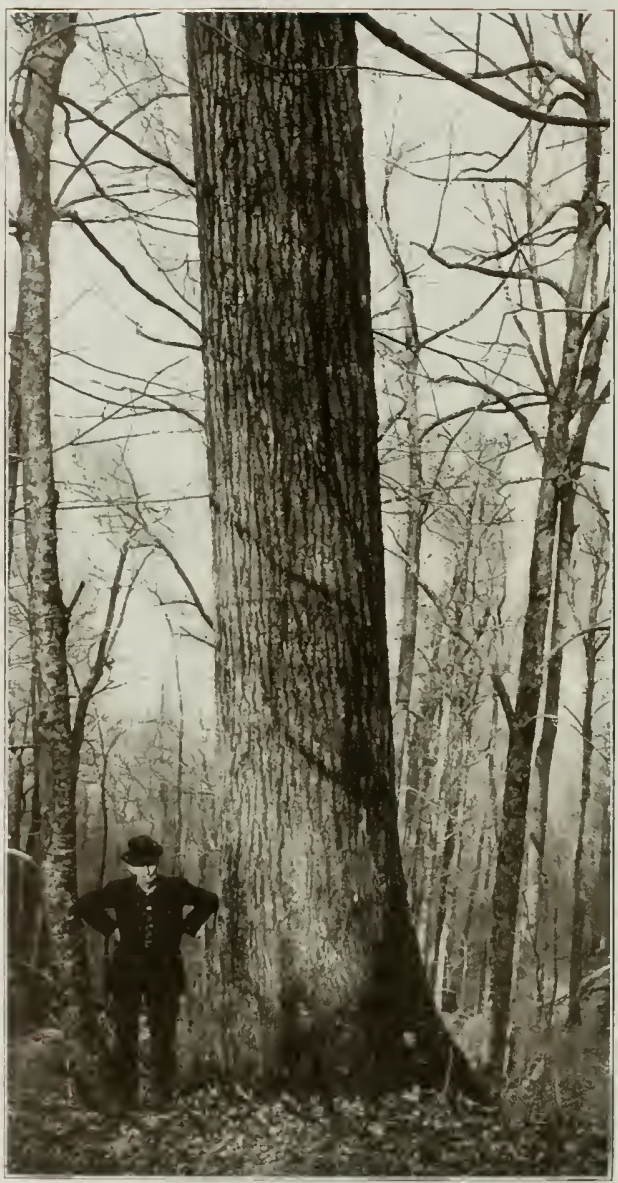

CHESTNIT OAK 


\section{CHESTNUT OAK}

\section{(Quercus Prinus)}

7 HIS tree is known as rock oak in New York; as rock chestnut oa! 1 in Massachusetts and Rhode Island; as rock oak and rock chestrust oak in Pennsylvania and Delaware; as tanbark oak and swampy chestnut oak in North Carolina and as rock chestnut oak and mountain oak in Alabama.

There is a pretty general disposition to call this tree rock oak. The name refers to the hardness of the wood, and is not confined to this species. Other oaks are also given that name, and the adjective "rock" is applied to two or three species of elm which possess wood remarkable for its hardness. Cedar and pine are likewise in the class. In all of these classes "rock" is employed to denote hardness of wood. Iron as an adjective or ironwood as a noun is used in the same way for a number of trees. The name swampy chestnut oak as applied in some parts of the South to this tree, is hardly descriptive, for it is less a swamp tree than most of the oaks, though it does often grow along the banks of streams.

Its distribution ranges from the coast of southern Maine and the Blue Hills of eastern Massachusetts southward to Delaware and the District of Columbia; along the Appalachian mountains to northern Georgia and Alabama; westward to the shores of Lake Champlain and the valley of the Genesee river, New York; along the northern shores of Lake Erie and to central Kentucky and Tennessee. It is rare and local in New England and Ontario, but plentiful on the banks of the lower Hudson river and on the Appalachian mountains from southern New York to Alabama. It reaches its best development in the region from West Virginia to North Carolina, pretty high on the ridges flanking the mountain ranges.

Leaves are alternate, from five to nine inches long, with coarse teeth rounded at the top. At maturity, they are thick and firm, yellowgreen and rather lustrous on the upper surface, paler and usually hairy beneath. In the autumn before falling, they turn a dull orange color or rusty-brown.

The flowers appear in May and are solitary or paired on short spurs. The fruit or acorn is solitary or in pairs, one or two and one-half inches long, very lustrous and of a bright chestnut-brown color. The acorn cup is thin, downy-lined and covered with small scales. The kerncl is sweet and edible. The bark of the chestnut oak is thin, smooth, purplishbrown and often lustrous on young stems and small branches, becoming 
a thick, dark, reddish-brown, or nearly black on old trunks, and divided into broad rounded ridges, separating on the surface into small, closely appressed scales. The bark of the tree is so dark in color and so deeply furrowed that it has often been mistaken for one of the black oak group, although its wavy leaf margins and annual fruit clearly differentiate it from those species. The bark of the chestnut oak is thicker and rougher on old trunks than on any other oak.

The bark of chestnut oak has long been valuable for tanning. There is tannin in the bark of all oaks, and several of them contain it in paying quantities, but chestnut oak is more important to the leather industry than any other oak. In richness of tannin the tanbark oak of California occupies as high a place, but it is not supplying as much material as the eastern tree. Statistics showing the annual consumption of tanbark and tanning extracts in the United States, do not list the oaks separately, but it is well known that chestnut oak far surpasses all others in output. Hemlock bark is peeled in large quantities, but tanneries occasionally mix chestnut oak bark with it to lighten the deep red color imparted to leather when hemlock bark is the sole material employed.

Large quantities of chestnut oak timber have been destroyed to procure the bark. Fortunately, it is a practice not much indulged in at present, because the wood now has value, but it formerly had little. It was then abandoned in the forest after the bark was peeled and hauled away. The same practice obtained with hemlock years ago. Much chestnut oak is still cut primarily for the bark, but the logs are worth hauling to sawmills, unless in remote districts.

The chestnut oak is a vigorous tree and grows rapidly in dry soil, where it of ten forms a great part of the forest. It is not as large as the white oak or red oak, but is a splendid tree, its bole being very symmetrical and holding its size well. It grows usually to a height of from sixty to seventy feet and sometimes 100 feet, with a diameter of from two to five feet and occasionally as large as seven feet.

The form of the tree shows great variation, depending upon the situation in which it grows. Trees in open ground often divide into forks or large limbs, and the trunks are short and of poor form. Opengrown trees show a decided tendency to develop crooked boles, and unduly large branches. No such objection can be urged against it when it grows under forest conditions. Trunks are straight and are otherwise of good form.

The wood of chestnut oak differs little from that of white oak in weight, strength, and stiffness. It is hard, rather tough, durable in contact with the soil, and is darker in color than white oak. It has few 
large, open pores, and requires less filler in finishing than most oaks. There are many pores, however, and those in the springwood are arranged in bands. The summerwood is broad and distinct, usually constituting three-fourths of the annual ring. The medullary rays are as broad and numerous as in the best furniture oaks. They are regularly arranged, and spaces between them do not vary much in width. The wood quarter-saws well.

The wood has the fault of checking badly in seasoning, unless carefully attended to. In recent years, these difficulties have been largely overcome, both in air seasoning and in the drykiln.

Chestnut oak has a wide range of uses. It is classed as white oak in many markets, but few users buy it believing it to be true white oak. It is coming year by year to stand more on its own merits. Some sawmills which formerly piled it and sold it with other oaks, now keep it separate, and some factories which once took it only because it came mixed with other oaks, now buy it for special uses, and make high-class commodities of it. One of these is mission furniture, which has become fashionable in recent years. Chestnut oak possesses good fuming properties, and this constitutes much of its value as furniture material.

The wood is found in factories where general furniture is made. It is largely frame material for furniture though some of it is for outside finish. It is employed as frames in Maryland in the construction of canal boats, and the annual demand for that purpose is about a quarter of a million feet in that state.

One of the most important places for chestnut oak is in the shop which makes vehicles. It goes into sills for both heavy and light bodies, bolsters, and wagon bottoms. It has become a favorite wagon wood in England and in continental Europe, and there passes as white oak, though dealers well know that it is not the true white oak. There is no indication that demand for it will lessen, for it possesses many characters which fit it for vehicle making.

In Michigan more chestnut oak is reported by car builders than by any other class of manufacturers, though wagon makers buy it. Car shops use about 220,000 feet a year, and work it into hand cars, pusl cars, track-laying cars, and cattle guards.

The large remaining area of timber growth in which chestnut oak appears is the Appalachian range through eastern Tennessee and western North Carolina, and the fact that it is comparatively plentiful in the forests of the Appalachian range will tend to bring it more and more into prominence as a factor in the making of wagons, cars, boats, staves, and furniture as the other oaks become scarcer.

The probable future of chestnut oak is an interesting problem for 
study. Few steps have yet been taken looking toward providing for generations to come. Chestnut oak has been left to take care of itself. The trees, produced in nature's way, have been ample to supply all needs in the past, and they will be for the near future. Chestnut oak possesses some advantages over most of the other oaks. Large trees will grow on very poor soil, where most other oaks are little more than shrubs. Trees so growu are little more susceptible to disease than if produced in good soil, though they develop more slowly and are smaller. There are many poor flats and sterile ridges in the chestnut oak's range, and they will produce timber of fairly good kind, if the chestnut oaks are permitted to have them. Nature gave this tree facilities for taking possession. Its acorns will grow without being buried. They do not depend on blue jays to carry them to sunny openings or squirrels to plant them; but they will sprout where they fall, whether on hard gravelly soil or dry leaves; and they at once set about getting the tap roots of the future trees into the ground. In many instances the chestnut oak's acorns do not wait to fall from the tree before they sprout. Like the seed of the Florida mangrove, they are often ready to take root the day they touch the ground. The large acorn is stored with plantfood which sustains the growing germ for some time, and the ground must be very hard and exceedingly dry if a young chestnut oak is not soon firmly establisked, and good for two or three hundred years, if let alone.

The forester who may undertake to grow chestnut oaks must exercise great care in transplanting the seedlings, or the tap roots will be broken and the young trees will die. The best plan is to drop acorns on the ground where trees are expected to grow, and nature will do the rest, provided birds and beasts leave the acorns alone.

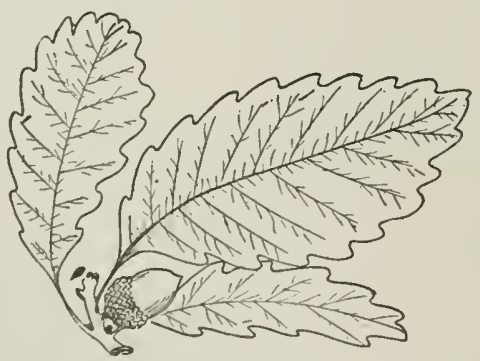


CHINQUAPIN OAK 


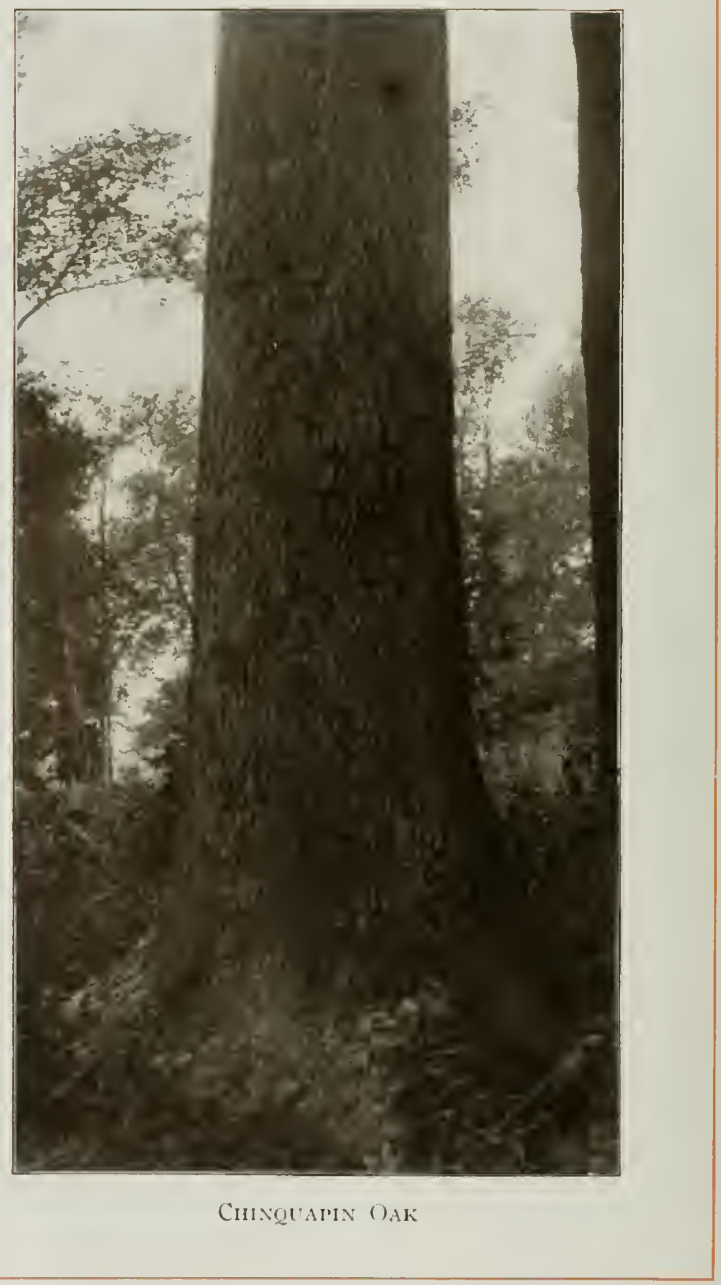




\section{CHINQUAPIN OAK}

\section{(Qucrcus Acuminata)}

$T$ HIS tree is known as yellow chestnut oak, chinquapin oak, chestnut oak, pin oak, yellow oak, scrub oak, dwarf chestnut oak, shrub oak, and rock oak. It should not be confused with Qucrcus prinus, the true chestnut oak, although it is commonly known in so many sections of the country by the latter name; the names yellow oak, pin oak, and scrub oak are likewise applied to many species, so that the only way to accurately designate members of this great family is to employ their botanical names. However, this species should always be known as the chinquapin oak, which is a distinctive term, and not applied to any other.

The bark of this tree is light gray and is broken into thin flakes, silvery-white, sometimes slightly tinted with brown, rarely half an inch thick. The branchlets are marked with pale lenticels.

The leaves of the chinquapin oak are from five to seven inches long, simple and alternate; they have a taper-pointed apex and blunt, wedgeshaped or pointed base; are sharply toothed. When unfolding they show bright bronze-green above, tinged with purple, and are covered underneath with light silvery down; at maturity they become thick and firm, showing greenish-yellow on the upper surface and silvery-white below. The midrib is conspicuous and the veins extending outward to the points of the teeth are well-defined. In autumn the leaves turn orange and scarlet and are very showy. The leaves are narrow, hardly two inches wide, and more nearly resemble those of the chestrut than do any other oak leaves. In their broadest forms they are also similar to those of the true chestnut oak, although the difference in the quality and color of the bark, and of the leaves, would prevent either tree from being mistaken for the other. They are crowded at the ends of the branches and hang in such a manner as to show their under surfaces with every touch of breeze. This characteristic gives the chinquapin oak a peculiar effect of constantly shifting color which is one of its most attractive features and which puts the observer in mind of the trembling aspen, although the shading and coloring of the oak is much more striking.

This tree's range extends from northern New York, along Lake Champlain and the Hudson river westward through southern Ontario, and southward into parts of Nebraska and Kansas; on its eastern boundary it extends as far south as the District of Columbia and along the upper Potcmac; the growth west of the Alleghany mountains reaches 
into central Alabama and Mississippi, through Arkansas and the northern portion of Louisiana to the eastern part of Oklahoma and parts of Texas even to the canyons of the Guadaloupe mountains, in the extreme western part of that state. It is a timber tree of much importance in Texas, and in 1910 manufacturers reported the use of $1,152,000$ feet in that state, largely for making furniture and vegetable crates.

The chinquapin oak is named from the form of its leaf. Its acorn bears no resemblance to the nut of chinquapin. Trees average smaller in size than white oak, but when all circumstances are favorable they compare well with any of the other oaks. In the lower Wabash valley, trees of this species were found in the original forests 160 feet high and four or five in diameter. When it grows in crowded stands it develops a tall, symmetrical trunk, clear of limbs; but it is shorter in open growth. The base is often much buttressed.

The wood is very heavy, hard, strong, stiff, and durable. In color the heartwood is dark, the sapwood lighter. The springwood is narrow and filled with large pores, the summerwood broad and dense. Medullary rays are less numerous and scarcely as broad as in chestnut oak, which this wood resembles. It checks badly in drying, both by kiln and in the open air; but when properly seasoned it is an excellent wood for most purposes for which white oak is used. It shows fewer figures when quarter-sawed than white oak shows, but it is satisfactory for many kinds of furniture, particularly when finished in mission style.

Railroads throughout the region where this species is found have laid chinquapin oak ties in their tracks for many years and they give long service, because they resist decay and are hard enough to stand the wear of the rails. In early times in the Ohio valley it helped to fence many a farm when the material for such fences was the old style fence rail, eleven feet long, mauled from the straightest, clearest timber afforded by the primeval forest. It had for companions many other oaks which were abundant there, and it was on a par with the best of them. In the first years of steamboating on the Ohio river, when the engines used wood for fuel, they provided a market for many an old rail fence. The rails were the best obtainable fuel, and the chinquapin oak rails in the heaps were carefully looked for by the purchasers, because they were rated high in fuel value. It is now known that chinquapin oak in combustion develops considerably more heat than an equal quantity of white oak.

When southern Indiana and Illinois were furnishing coopers with their best staves, chınquapin oak was ricked with white oak, and no barrel maker ever complained. The pores in the wood seem large, but in old timber which is largely heartwood, the pores become clogged by 
the processes of nature, and the wood is made proof against leakage. That is what gives white oak its superiority as stave timber. It has as many pores as red oak, but upon close examination under a magnifying glass, they are found to be plugged, while red oak's pores are wide open. The result is that red oak barrels leak through the wood; those made of white oak do not. Chinquapin oak possesses the same properties, which account for its reputation as stave material.

The future for chinquapin oak is not quite as promising as that of chestnut oak. The former's choice growing place is on rich soil and in damp situations. These happen to be what the farmer wants, and he will not leave the chinquapin oak alone to grow in nature's method, nor will he plant its acorns in places where the trees will interfere with his cornfields and meadows. Consequently, the tree is apt to receive scant consideration after the original forests have disappeared; while its poor cousin, the chestnut oak, will be left to make its way on sterile ridges, and may even receive some help from the forester and woodlot owner.

VALLEY OAK (Quercus lobata) is of ten considered to be the largest hardwood of the Pacific coast. Trunk diameters of ten feet have been recorded, and heights more than 100; but such measurements belong only to rare and extraordinary individuals. The average size of the tree is less than half of that. The most famous tree of this species is the Sir Joseph Hooker oak, near Chico, California, though it is not the largest. It is seven feet in diameter and $100 \mathrm{high}$. It was named by the botanist Asa Gray in $18 i 7$. This species is commonly called California white oak, which name would be unobjectionable if it were the only white oak in California. A more distinctive name is weeping oak, which refers to the appearance of the outer branches. It is called swamp oak, but without good reason, though the ground on which it grows is often swampy during the rainy season. The name valley oak is specially appropriate, since its favorite habitat is in the hroad valleys of central California. Its range does not go outside that state, neither does the tree grow very high on the mountains. Its range begins in the upper Sacramento valley and exiends to Tejon, south of Lake Tulare, a distance north and south of about five bundred miles, while east and west the tree is found from the Sierra foothills to the sea, 150 or 200 miles. 1 ts characteristic growth is in scattered stands. It does not form forests in the ordinary sense. Two or three large trees to the acre are an average, and often many acres are wholly missed. The form of trees, and the wide spaces between them, resemble an old apple orchard, though few apple trees live to attain the dimensions of the valley oak of ordinary size. The best stands were originally in the Santa Clara valley and in the central part of the San Joaquin valley in the salt grass region north of Lake Tulare in Kings and Fresno counties. IIost of the largest trees were cut long ago.

The leaves are lobed like white oak (Quercus alba) but are smaller, seldom more than four inches long and two wide. The acorns are uncommonly long, some of them being two and a half inches, sharp pointed, with shallow cups. The wood or this oak is brash and breaks easily. It is far below good eastern oak in strength and elasticity. It weighs 46.17 pounds per cubic foot. The tree grows rapidly, and its wide, clearly defined annual rings are largely dense summerwood. The springwood is perforated with large pores. The color of the wood is light brown, the sapwood 
lighter. Except as fuel, the uses found for valley oak hardly come up to what might be expected of a tree so large. It is not difficult, or at least was not difficult once, to cut logs sixteen feet long and from three to five in diameter. Such logs ought to make good lumber. The medullary rays indicate that the wood can be quartersawed to advantage; yet there is uo account that any serious attempt was ever made to convert the valley oak into lumber. The wood has some objectionable properties, but it bas escaped the sawmill chiefly because hardwood mills have never been numerous in California, and they have been especially few in the regions where the best valley oaks grow. The tree has been a great source of fuel. It usually divides twenty or thirty feet from the grouud into large, wide-spreading branches, tempting to the woodchopper. In central California, twenty or thirty years ago, it was not unusual to haul this cordwood twenty-five miles to market. Stockmen employed posts and rails split from valley oak to enclose corrals and pens on the open plains for bolding cattle, sheep, and horses. The acorns are edible, and were formerly an article of food for Indians who gathered them in considerable quantities in the fall and stored them for winter in large baskets which mere secured high in the forks of trees to be out of reach of all ordinary marauders. The baskets were made rain proof by roofing and wrapping them with grass. When the time came for eating the acorns, they were prepared for use by hulling them and then pounding them into meal in stone mortars. The hulling was done with the teeth, and was the work of squaws. The custom of eating the acorns has largely ceased with the passing of the wild Indians from their former camping places; but the stone mortars by hundreds remain in the vicinity of former stands of valley oak.

This splendid tree is highly ornamental, but it has not been planted, and perhaps it will not become popular. Nature seems to have confined it to a certain climate, and it is not known that it will thrive outside of it. It will certainly disappear from many of the valleys where the largest trees once grew. The land is being taken for fields and rineyards, and the oaks are removed. Some will remain in canyons and rough places where the land is not wanted, and one of the finest species of the United States will cease to pass entirely from earth. The largest of these oaks have a spread of branches covering more than one-third of an acre.

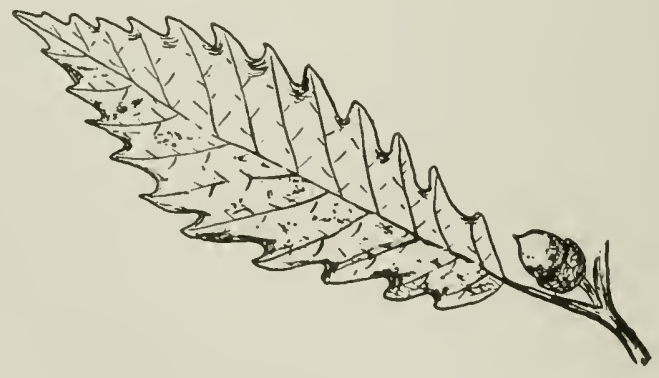


LIVE OAK 


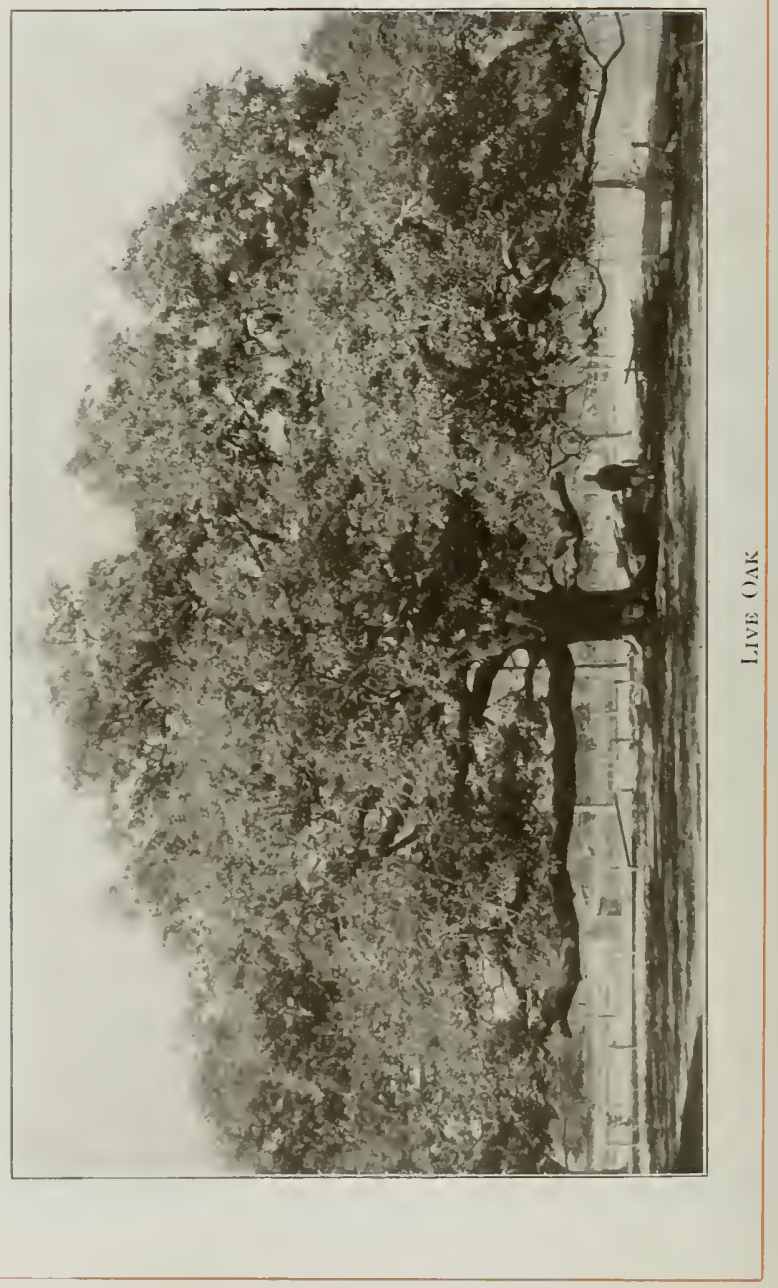




\section{LIVE OAK}

(Quercus Virginiana)

$\mathrm{T}$ HE history of this live oak is a reversal of the history of almost every other important forest tree of the United States. It seems to be the lone exception to the rule that the use of a certain wood never decreases until forced by scarcity. There was a time when hardly any wood in this conntry was in greater demand than this, and now there is hardly one in less demand. The decline has not been the result of scarcity, for there has never been a time when plenty was not in sight. A few years ago, several fine live oaks were cnt in making street changes in New Orleans, and a number of sound logs, over three feet in diameter, were rolled aside, and it was publicly announced that anyone who would take them away could have them. No one took them. It is doubtful if that could happen with timber of any other kind.

The situation was different 120 years ago. At that time live oak was in such demand that the government, soon after the adoption of the constitution, became anxious lest enough could not be had to meet the requirements of the navy department. The keels of the first war vessels built by this government were about to be laid, and the most necessary material for their construction was live oak. The vessels were to be of wood, of course; and their strength and reliability depended upon the size and quality of the heavy braces used in the lower framework. These braces were called knees and were crooked at right angles. They were hewed in solid pieces, and the largest weighed nearly 1,000 pounds. No other wood was as suitable as live oak. which is very strong, and it grows knees in the form desired. The crooks produced by the junction of large roots with the base of the trunk were selected, and shipbuilders with saws, broadaxes, and adzes cut them in the desired sizes and shapes.

When the building of the first ships of the navy was undertaken, the alarm was sounded that live oak was scarce, and that speculators were buying it to sell to European governments. Congress appropriated large sums of money and bought islands and other lands along the south Atlantic and Gulf coast, where the best live oak grew. In Louisiana alone the government bonght 37,000 live oak trees, as well as large numbers in Florida and Georgia. In some instances the land on which the trees stood was bought.

Ship carpenters were sent from New England to hew knees for the first vessels of the navy. The story of the troubles and triumphs of the contractors and knee cutters is an interesting one, but too long for even a summary here; suffice it that in due tine the vessels wcre finished. The 
history of those vessels is almost a history of the early United States navy. Among their first duties when they put to sea was to fight French warships, when this country was about to get into trouble with Napoleon. They then fought the pirates of North Africa, and there one of the ships was burned by its own men to prevent its falling into the hands of the enemy. "Old Ironsides," another of the live oak vessels, fought fourteen ships, one at a time, during the war of 1812, and whipped them all. Another of the vessels was less fortunate. It was lost in battle, in which its commander, Lawrence, was killed, whose last words have become historic: "Don't give up the ship." Another came down to the Civil war and was sunk in Chesapeake bay.

The invention of iron vessels ended the demand for live oak knees. The government held its land where this timber grew for a long time, but finally disposed of most of it. Part of that owned in Florida was recently incorporated in one of the National Forests of that state.

Live oak is a tree of striking appearance. It prefers the open, and when of large size its spread of branches often is twice the height of the tree. Its trunk is short, but massy, and of enormous strength; otherwise it could not sustain the great weight of its heavy branches. Some of the largest limbs are nearly two feet in diameter where they leave the trunk, and are fifty feet long, and some are seventy-five feet in length. Probably the only tree in this country with a wider spread of branches is the valley oak of California. The live oak's trunk is too short for more than one sawlog, and that of moderate length. The largest specimens may be seventy feet high and six or seven feet in diameter, and yet not good for a sixteen-foot log. The enormous roots are of no use now. When land is cleared of this oak, the stumps are left to rot.

The range of live oak extends 4,000 miles or more northeast and southwest. It begins on the coast of Virginia and ends in Central America. It is found in Lower California and in Cuba. In southern United States it sticks pretty closely to the coastal plains, though large trees grow 200 or 300 feet above tide level. In Texas it is inclined to rise higher on the mountains, but live oak in Texas seldom measures up to that which grows further east. In southern Texas, where the land is poor and dry, live oak degenerates into a shrub. Trees only a foot high sometimes bear acorns. In all its range in this country, it is known by but one English name, given it because it is evergrcen. The leaves remain on the tree about thirteen months, following the habit of a number of other oaks. When new leaves appear, the old ones get out of the way.

The wood is very heavy, hard, strong, and tough. In strength and stiffness it rates higher than white oak, and it is twelve pounds a cubic 
foot heavier. The sapwood is light in color, the heartwood brown, sometimes quite dark. The pores in the sapwood are open, but many of them are closed in heartwood. The annual rings are moderately well defined. The large pores are in the springwood, and those of the summerwood are smaller, but numerous. The medullary rays are numerous and dark. Measured radially, they are shorter than those of many other oaks. They show well in quarter-sawed lumber, but are arranged peculiarly, and do not form large groups of figures; but the wocd presents a rather flecked or wavy appearance. The general tone is dark brown and very rich. It takes a smooth polish. When the wood is worked into spindles and small articles, and brightly polished, its appearance suggests dark polished granite, but the similitude is not sustained under close examination. Grills composed of small spindles and scrollwork are strikingly beautiful if displayed in light which does the wood justice. Composite panels are manufactured by joining narrow strips edge to edge. Selected pieces of dressed live oak suggest Circassian walnut, but would not pass as an imitation on close inspection. It may be stated generally that live oak is far from being a dead, flat wood, but is capable of being worked for various effects. Its value as a cabinet material has not been appreciated in the past, nor have its possibilities been suspected. It dropped out of notice when shipbuilders dispensed with it, and people seem to have taken for granted that it had no value for anything else. The form of the trunks makes possible the cutting of short stock only; but there is abundance of it. It fringes a thousand miles of coast. Many a trunk, short though it is, will cut easily a thousand feet of lumber. Working the large roots in veneer has not been undertaken, but good judges of reneers, who know what the stumps and roots contain, have expressed the opinion that a field is there awaiting development.

Published reports of the uses of woods of various states seldom mention live oak. In Texas some of it is employed in the manufacture of parquet flooring. It is dark and contrasts with the blocks or strips of maple or some other light wood. It is turned in the lathe for newel posts for stairs, and contributes to other parts of stair work. In Louisiana it is occasionally found in shops where vehicles are made. It meets requirements as axles for heary wagons. Stone masons' mauls are made of live oak knots. They stand nearly as much pounding as lignumvitae. More live oak is cut for fuel than for all other purposes. It develops much heat, but a large quantity of ashes remains.

The live oak is the most highly valued ornamental tree of the South. though it has seldom been planted. Nature placed these oaks where they are growing. Many an old southern lomestead sits wcll back in 
groves of live oak. Parks and plazas in towns have them, and would not part with them on any terms. Tallahassee, Florida, is almost buried under live oaks which in earlier years sheltered the wigwams of an Indian town. Villages near the coasts of both the Gulf and the Atlantic in several southern states have their venerable trees large enough for half the people to find shade beneath the branches at one time. Many fine stands have been cut in recent years to make room for corn, cane, and rice.

Many persons associate the live oak with Spanish moss which festoons its branches in the Gulf region. The moss is no part of the tree, and apparently draws no substance from it, though it may smother the leaves by accumulation, or break the branches by its weight. Strictly speaking, the beard-like growth is not moss at all, but a sort of pine apple (Dendropogon usenoides) which simply hangs on the limbs and draws its sustenance from water and air. It is found on other trees, besides live oak, and dealers in Louisiana alone sell half a million dollars worth of it a year to upholsterers in all the principal countries of the world.

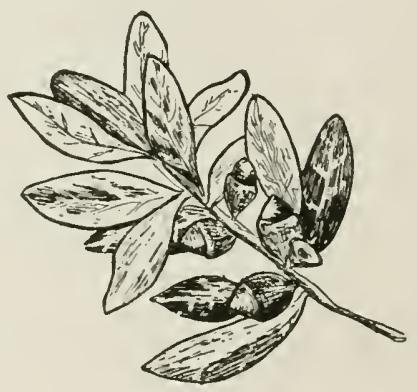


RED OAK 


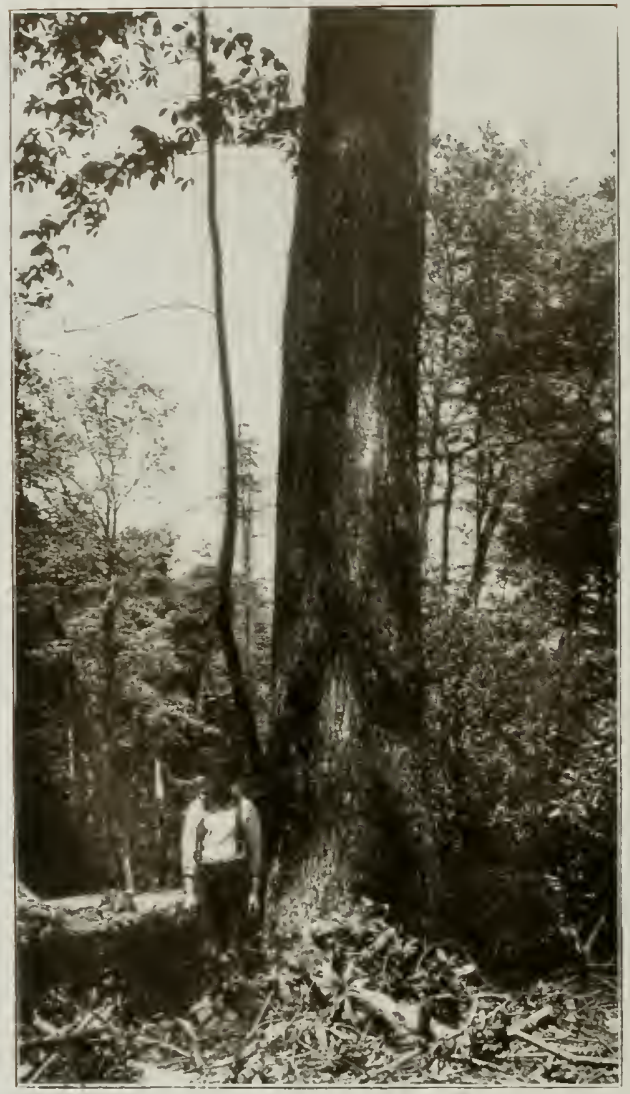

REI OAK 


\section{RED OAK*}

(Quercus Rubra)

W

HEN a lumberman speaks of red oak he may mean any one of a good many kinds of trees, but when a botanist or forester uses that name he means one particular species and no other. For that reason there is much uncertainty as to what species is in the lumberman's mind when he speaks of red oak. It means more to him than a single species, depending to a considerable extent upon the part of the country where he is doing business. If he is in the Gulf states, and has in mind a tree which grows there, he does not refer to the tree known to botanists as red oak. He may mean the Texan or southern red oak (Quercus texana), or the willow oak (Quercus phellos), or the yellow oak (Qucrcus velutina), or any one of several others which grow in that region; but the typical red oak does not grow farther south than the mountains of northern Georgia; and any one who is cutting oak south or southwest of there, is cutting other than the true red oak. That does not imply that he is handling something inferior, for very fine oak grows there; but in an effort to separate the commercial black oaks into respective species, it is necessary to define them by metes and bounds of ranges as well as to describe them by characteristics of leaves, acorns, and wood. The time will probably never come in this country when the sawmill man will pile each species of oak separately in his yard, and sell separately; but the tendency is in that direction. The twenty-five or more black oaks in this country all have some characteristics in common; but they are by no means all valuable alike, or all useful for the same purposes. For that reason, the demands of trade require, and will require more and more as higher utilization is reached, that certain kinds of red oak or black oak be sold separately.

What lumbermen call red oaks, speaking in the plural, botanists

*Red oak belongs to the black oak group. Other species usually listed as black oaks are Pin oak (Quercus palustris), Georgia oak (Quercus georgiana), Texan red oak (Quercus texana), Scarlet oak (Quercus coccinea), Yellow oak (Qucrcus velutina), California black oak (Quercus californica), Turkey oak (Quercus catesbcez), Spanish oak (Quercus digitata), Black Jack oak (Quercus marilandica), Water oak (Quercus nigra), Willow oak (Quercus phellos), Laurel oak (Qucrcus laurifolia), Blue Jack oak (Quercus brevifolia), Shingle oak (Quercus imbricaria), Whiteleaf oak (Quercus hvpoleuca), Highland oak (Quercus wislizen $)$, Myrtle oak (Qucrcus myrtifolia), California live oak (Quercus agrifolia-sometimes classed with white oaks), Canyon live oak (Qucrcus chrysolepis), an evergreen oak with no English name, (Quercus tomentella), Price oak (Qucrcus pricei), Morehus oak (Qucrcus morchus), Tanbark oak (Quercus densiflora), Barren oak (Quercus pumila). 
prefer to call black oaks. The difference is only a difference in name for the same group of trees. The general dark color of the bark suggests the name to botanists, while the red tint of the wood appeals more to the lumberman, and he prefers the general name red oaks for the group. They mature their acorns the second year, while the trees belonging to the white oak group ripen theirs the first year. There are other differences, some of which are apparent to the casual observer, and others are seen only by the trained eye--often aided by the microscope-of the dendrologist. Several of the black oaks have leaves with sharp pointed lobes, ending in bristles. This helps to separate them from the white oaks, but not from one another, for the true red oak, the scarlet oak, the yellow oak, the pin oak, and others, have the sharp-pointed lobes on their leaves; while the willow oaks have no lobes or bristles on theirs, yet are as truly in the black oak group as any of the others. The identification of tree species, particularly when they are as much alike as some of the oaks are, is too difficult for the layman if he undertakes to carry it along the whole line; but it is comparatively easy if confined to the leading woods only. An understanding of the geographical range of a certain tree often helps to separate it from others. The knowledge that a tree does not grow in a particular part of the country, is proof at once that a tree in that region resembling it must be something else. If that principal is borne in mind it will greatly lessen mistakes in identifying trees. In accounts of the black oaks in the following pages, a careful delimiting of ranges will be attempted in the case of each.

The range of red oak extends from Nova Scotia and southern New Brunswick through Quebec and along the northern shore of Lake Huron, west to Nebraska. It covers the Ohio valley and reaches as far south as middle Tennessee. It runs south through the Atlantic states to Virginia, while among the Appalachian mountains the range is prolonged southward into northern Georgia. That is the tree's extreme southern limit. It reaches its largest size in the region north of the Ohio river, and among the mountain valleys of West Virginia, and southward to Tennessee and North Carolina. It is a northern species. Toward its southern limit it meets the northern part of the Texan red oak's range (Quercus texana). There is some overlapping, and in many localities the two species grow side by side.

The red oak is known by that name in all parts of its range, but in some regions it is called black oak, and in others Spanish oak. The latter name properly belongs to another oak (Quercus digitata) which touches it along the southern border of its range.

The average size of red oak in the best part of its range is a little under that of white oak, but some specimens are 150 feet high and six 
feet in diameter. Heights of seventy and eighty feet are usual, and diameters of three and four are frequent. The forest grown tree disposes of its lower limbs early in life, and develops a long, smooth trunk, with a narrow crown. The bark on young stems and on the upper parts of limbs of old trees is smooth and light gray. All leaves do not have the same number of lobes, and they are sharp pointed, and fall early in autumn.

The acorns are bitter, and are regarded as poor mast. Hogs will leave them alone if they can find white oak acorns, and squirrels will do likewise. The best red oak timber grows from acorns, though stumps will send up sprouts. The sprout growth may become trees of fairly large size, but they are apt to decay at the butt. The acorn-grown tree is as free from defects as the average forest tree. Cracks sometimes develop in the trunk, extending up and down many feet. Unless the logs are carefully sawed, a considerable loss occurs where these cracks cross the boards. Trunks are occasionally bored by worms, as all other oaks may be.

Red oak grows rapidly. It will produce small sawlogs in the lifetime of a man. It is a favorite tree for crossties, and railroads have made large plantings for that purpose. The ties do not last well in their natural state, but they are easy to treat with preservatives by which several years are added to their period of service. It has been a favorite tree with European planters for the past two hundred years; but the most of the plantings beyond the sea have been for ornament in parks and private grounds.

The principal interest in red oak in this country is due to its value for lumber. That interest is of comparatively recent date. Some red oak has always been used for rails, clapboards, slack cooperage, and rough lumber; but while white oak was cheap and plentiful, sawmill men usually let red oak alone. It had a poor reputation, which is now known to have been undeserved.

Red oak is lighter than white oak, and it is generally regarded as possessing less strength and stiffness. The wide rings of annual growth, and the distinct layers of springwood and summerwood, give the basis for good figure. To this may be added broad and regular medullary rays which are nicely brought out by quarter-sawing. The tone of the wood is red, to which fact the uame red oak is due. It las large, open pores. A magnifying glass is not required to see them in the end of a stick. It is said that smoke may be blown through a piece of red oak a foot in length. These open pores disqualify the wood for use in tiglit. cooperage. Liquids will leak through the pores. Statistics of sawmill output in this country do not separate the white and black oaks, and the 
quantity of lumber sawed from any one species is not known. Manufacturers are disposed to separate them. Some furniture makers use red oak exclusively for certain purposes, and the same rule is followed by makers of other commodities.

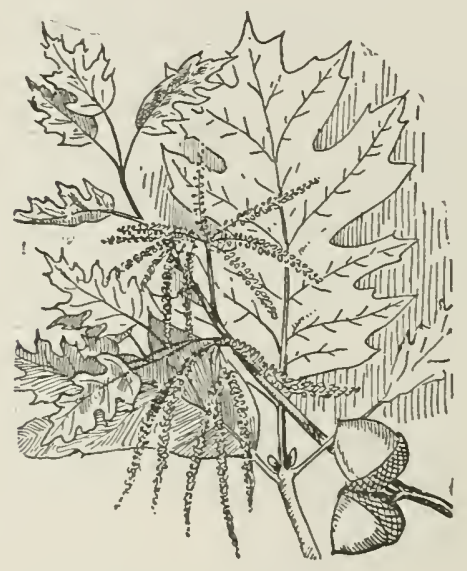


TEXAN RED OAK 


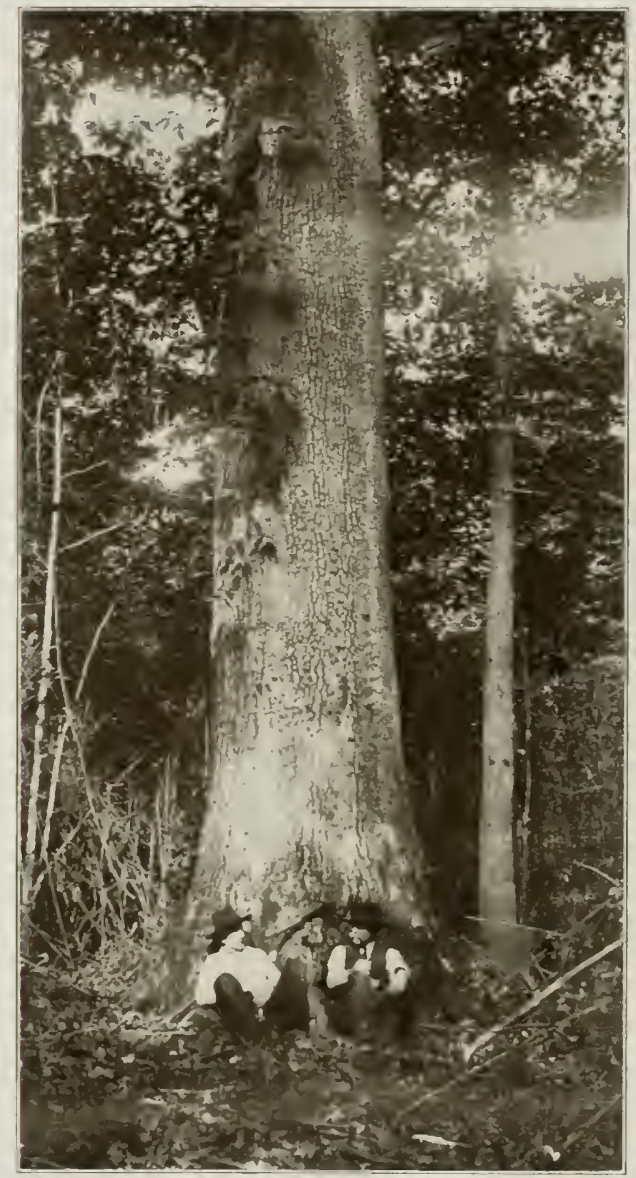

TEXAX RED OAK 


\section{TEXAN RED OAK}

\section{(Qucrcus Texana)}

$\mathrm{T}^{\mathrm{s}}$ HE line between red oak (Qucrcus rubra) and Texan red oak is closely drawn by botanists, but lumbermen do not recognize much difference except toward the extreme ranges of each. Some call one simply red oak and the other southern red oak, but that leaves doubtful the timber on a large area occupied by both species. Their ranges overlap two or three hundred miles in the Ohio valley and on the southern tributaries of the Ohio river in Kentucky and Tennessee. A large amount of red oak from that region goes to market, and no one knows, and few care, whether it is of the northern or southern species. It is usually a mixture of both. But outside of the common zone where both trees grow, the woods of the two are kept fairly well separate. Thirty years ago Texan red oak received slight recognition from botanists. When Charles S. Sargent compiled in 1880 a volume of over 600 pages, "Forest Trees of North America," for the United States government, and which was published as volume 9 of the Tenth Census, he did not so much as accord this tree the dignity of a species, but called it a variety of the common red oak. Its range and its great importance were little understood at that time. Sargent thus described its range: "Western Texas, valley of the Colorado river with the species and replacing it south and west, extending to the valley of the Neuces river and the Limpia mountains."

Compare that restricted range with that given by the same author twenty-five years later in his "Manual of the Trees of North America." He gives it thus: "Northeastern Iowa and central Illinois, through southern Illinois and Indiana and western Kentucky and Tennessee, to the valley of the Apalachicola river, Florida, northern Georgia, central South Carolina, and the coast plains of North Carolina, and through southern Missouri, Arkansas, and Louisiana to the mountains of western Texas; most abundant and of its largest size on the low bottom lands of the Mississippi basin, of ten forming a considerable part of lowland forests; less abundant in the eastern Gulf states; in western Texas on low limestone hills and on bottom lands in the neighborhood of streams."

This quotation is given in full because it shows loow scientific men change their opinions to conform to new evidence. The range of that particular species was as wide in 1880 as in 1905 , but botanists liad not yet worked it out. Thus knowledge increases constantly, and year by year the resources of American forests are better understood. In this 
instance, what in 1880 was supposed to be a rather insignificant varicty, occupying a restricted area in Texas, was found by 1905 to be a separate species, covering sixteen states in whole or in part. Similar progress concerning the forests has been made all over the country, not only by botanists but by lumbermen. Trees which were formerly considered so nearly alike that no distinctions were made, are now recognized to be quite different.

The Texan red oak is frequently called spotted oak. The appearance of the bark suggests the name. Large, irregular, whitish patches cover the trunks. That peculiarity is not noticeable everywhere and on all trees, but is common west of the Mississippi river. The tree is sometimes known as Spanish oak in the southwestern part of its range, but the name is ill-advised, for the true Spanish oak (Quercus digitata) occurs in the same region. The most usual name for this species, in nearly all parts of its range, is simply red oak.

The Texan red oak varies greatly in size of trees, as is natural in so wide a geographical range. Trees have been reported 200 feet high and eight feet in diameter; but sizes like that are extraordinary and attempts to locate anything approaching them at this day have not been successful. The average in the lower Mississippi valley is eighty or ninety feet in height, and two or three in diameter. In Texas this size is seldom reached, the average not much exceeding half of it.

The leaves of Texan red oak are about half the size of those of the northern species. That alone will not serve to separate them, because of such great variation. It applies only to averages. The southern trees' leaves are from three to six inches long, two to five wide; the northern species bears leaves from five to nine inches long and four to six wide. The acorns of the two species do not show so much difference in size. The states which use Texan red oak in largest amounts are Alabama, Mississippi, Louisiana, Texas, and Arkansas, though some of this wood finds its way to northern markets where it passes as red oak without any questions. That condition renders very difficult the task of separating the woods. It is not so difficult further south where the true red oak is seldom seen. Shipments go north, not south. The two red oaks mingle in the lumber yards north of the Ohio river, but seldom south of the Tennessee river.

Investigations made by the Forest Service of the utilization of woods in various states slow that factories report the annual use of Texan red oak as follows: Louisiana 1,777,000 feet, Mississippi 2,400,000, Texas 2,814,000, Alabama 5,500,000, and Arkansas 39,301,000. This does not include lumber or other forest products used in the rough, or lumber shipped out of the respective states. 
Texan red oak is heavier than its northern relative, hard, light, reddish-brown, much of it of rapid growth, with wide, clearly defined annual rings. The medullary rays are prominent, and show well in quarter-sawing. The best of the wood is as strong as red oak, and compares favorably with it in physical properties.

One of the most exacting uses of wood is for fixtures, such as counters in stores, bars in saloons, partitions in banks and counting rooms, and standing desks in offices. Extra wide and long pieces are required, and they must show satisfactory figure, and be finished to harmonize with the interior of the room where they are placed. Texan red oak is selected by builders in many southern cities for that class of fixtures, and it meets the requirements. It is used also for interior finish and furniture, and stair work.

Like most members of the black oak group, the wood is inclined to rot quickly in damp situations, but it measures well up to the average of the group to which it belongs. It is often employed in the South as bridge material, particularly as flooring for wagon bridges, where the wood's hardness is its chief recommendation. Much is converted into flooring for halls, houses, and factories.

The available supply of this valuable wood in the forests of the South is not known, but there is little doubt that it exists in larger quantities than any other species of oak within its range. Perhaps in total quantity it exceeds red oak (Quercus rubra) in the whole United States. It is quite generally distributed over an area exceeding 300,000 square miles, and toward the western part, it is the prevailing oak. The future of this oak is assured. It is now cut at a rapid rate, and doubtless the annual growth falls short of the yearly demand; but it occurs in a range so extensive that scarcity will not come for a long period. If the time ever comes in the South when planted timber must be depended upon to meet the needs of the people, this oak will fill an important place in woodlots. It does not grow as rapidly as willow oak, but its range is more extensive, and it possesses certain desirable properties not found in willow oak. The acorns are rather poor mast, and this is in the tree's favor, for the seed will be left to grow instead of being devoured by hogs and small animals of the woods. In that respect it has an advantage over cow oak and the other white oaks which occupy parts of its range. Their acorns are sought as food by domestic and wild animals. Texan red oak prunes itself well when it grows in close stands, but is low and limby when it occupies open ground. The trunks vary in form, but are inclined to enlarge at the base, particularly when they grow in low, damp situations, as many of the best do in the South.

GEORGIA OAK (Quercus georgizna) is one of the minor oaks of the South and 
has not been found outside of Georgia. It grows in the central part of the state on Stone mountain and on a few other granite hills. Whether the species originated there and was never able to work its way down to the more congenial valleys below, or whether it once grew lower down and was crowded to its last retreat by other species, is not known. But an interest attaches to it from the very fact that its range is so restricted and that its babitat is on the sterile summits. Lumbermen care nothing about this tree. Few of them ever saw it or heard of it. The trunk is small, the acorns only from one-third to half an inch long, and the leaves are of a form midway between those of pin oak and turkey oak. The characters of the wood have not been reported, but since there is not enough of it to have any commercial value, the matter is not very important.

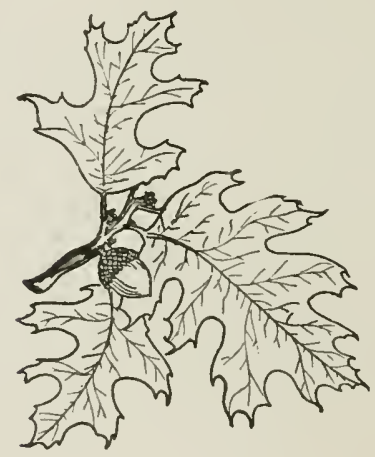


YELLOW OAK 


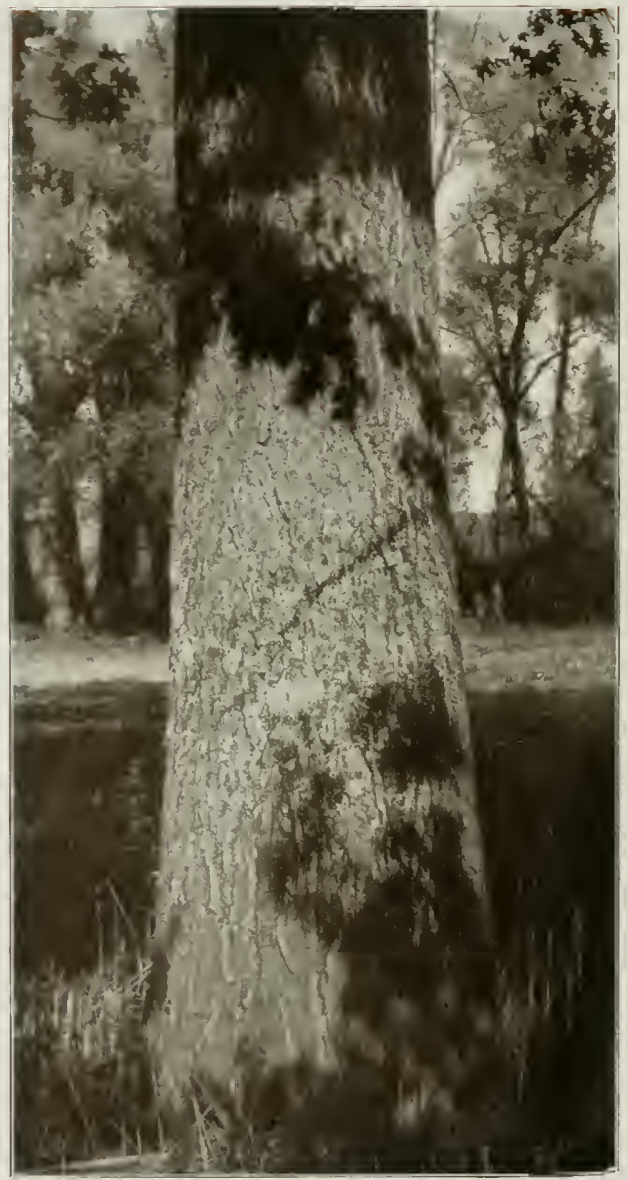

\ELLOW ()AK 


\section{YELLOW OAK}

\section{(Quercus T'elutina)}

$T^{\mathrm{H}}$ HIS tree is known as black oak in Vermont, Massachusetts, Rhode Island, New York, New Jersey, Pennsylvania, Delaware, Virginia, IVest Virginia, North Carolina, South Carolina, Georgia, Alabama, Florida, Mississippi, Louisiana, Texas, Ohio, Illinois, Iowa, Kansas, Nebraska, Michigan, IVisconsin, Minnesota and Ontario; quercitron oak in Delaware, South Carolina, Louisiana, Kansas and Minnesota; yellow oak in Rhode Island, New York, Illinois, Texas, Kansas and Minnesota; tanbark oak in Illinois; yellow-bark oak in Minnesota and Rhode Island; spotted oak in Missouri; dyer's oak in Texas; and yellow butt oak in Mississippi.

Those who call this tree black oak have in mind the bark which is usually quite dark, though all members of this species do not present the same appearance in that respect. Some trunks are gray, and in color do not greatly differ from white oaks, but would hardly be mistaken for them. Tanbark oak, a name occasionally given to this tree, is not applied in the region where chestnut oak grows, because it is much inferior to chestnut oak as tanning material. It is not only poorer in tannin, but the coloring matter associated with the inner bark is troublesome to the tanner who is compelled to remove it or neutralize it unless he wants his leather given a yellow tone. Dyer's oak is a name which refers to the value of the bark for coloring purposes. The botanical name velutina refers to the velvety texture of the inner bark.

This oak is one of the easiest to identify. The inner layer of the bark is yellow. The point of a knife easily reaches it ; cutting through a deep crack in the bark, and no mistake is possible, for no other oak has the yellow layer of bark. The tree may be identified by leaves, flowers, and fruit, but the process is not always easy, for other members of the black oak group bear more or less resemblance to this one.

The yellow oak's range extends over nearly or quite a million square miles. It exceeds the limits of most oaks in its geographical extension. It endures severe winters and hot summers. The northern limit of its range lies in Maine; it grows westward across southern Canada to Minnesota; it extends two hundred miles west of the Mississippi into eastern Nebraska and Kansas, and follows that meridian south into Texas. It reaches the Gulf of Mexico east of the Mississippi, and is found in many localities in all the southern states, and along the footlills of the Appalachian ranges. It attains its largest size in the lower Ohio valley. The average height is seventy or eighty feet, and its diameter two or 
three feet. In some localities the trees are scrubby and produce little merchantable timber.

The growth rings are only moderately wide in the typical yellow oak; the ring is divided nearly evenly between springwood and summerwood. The former contains two or three rows of large, open pores. The medullary rays are fewer and smaller than those commonly found in oaks. A general average of the properties of the wood is somewhat difficult to give, because of remarkable variation in trees which grow under different conditions. In some instances, where the soil is fertile and climate favorable, the yellow oak produces a large, clear trunk, with sound wood, of good color, and equal to that of red oak; but the reverse is often the case-trunks are small and rough, wood hard and brittle, color not satisfactory, and strength not up to standard. Sometimes first class yellow oak passes without question as good red oak in the finish and furniture business, but that is not its usual course. Well developed wood is heavy, hard, strong, bright brown, tinged with red, with thin, lighter colored sapwood. Its weight is 43.9 pounds per cubic foot.

The uses of yellow oak follow red oak pretty closely, but are not so extensive. Figures cannot be given to show the total annual cut of yellow oak, but the output is likely much below red oak, though it is found over a wider area, and some of it gets into the lumber yards in all regions where it grows. It is made into furniture from Maine to Louisiana. In cheaper grades of furniture, it may be the outside material, but its place is usually as frame stock, to give strength, but is not visible in the finished article. An exception to this is found in chairs where yellow oak is one of several species which go regularly to the sawmills which cut chair stock. Massachusetts snow plow makers use it, but of course it fills no such place in the South. In Mississippi, Louisiana, and Texas it is bought by manufacturers of agricultural machinery. It is worked into cotton gins in Mississippi. Some extra fine stands of this oak occur in the Delta region of Mississippi. Frames of freight cars are made of it in Louisiana and Texas, and warehouse and depot floors are occasionally laid of this lumber. It is floor material in Michigan also, but that is of a better class than is required for warehouses. It is not infrequently sold as red oak for flooring and interior finish. Throughout the whole extent of yellow oak's range it finds its way to wagon shops. It is less tough than white oak, but in many places, such as bolsters, sandboards, and hounds, it serves as well. Warehouse trucks and push cars are of this wood in many instances.

Slack coopers convert this wood into their wares in many regions. The pores are too open to permit its use as tight cooperage, where 
liquids are to be contained, but for barrels and kegs of many kinds, as well as for boxes, baskets, and crates, it meets all requirements. It is good fuel. Many burners of brick and pottery show it preference, and charcoal burners make a clean sweep of it when it occurs in the course of their operations; though when it is desirable to save the by-products of charcoal kilns or retorts, yellow oak is considered less valuable than birch, beech, and maple.

The bark of this tree is employed less now than formerly for dyeing purposes. Aniline dyes have taken its place. In pioneer times the bark was one of the best coloring materials the people had, and every family looked after its own supply as carefully as it provided sassafras bark for tea, slippery elm bark for poultices, and witch hazel for gargles. The oak bark was peeled, dried, and pounded to a powder. The mass was sifted, and the yellow particles, being finer than the black bark, passed through the screen, and were set apart for the dye kettle, while the screenings were rejected. Various arts and sciences were called into requisition to add to or take from the natural color which the bark gave the cloth. Salts of iron were commonly employed to modify the deepness of the yellow.

The acorns of this oak are bitter, and escape the mast hunters. Old stumps have little need to send up sprouts, for acorns keep the species alive. Yellow oaks are in no immediate danger of extermination. Nature plants gener ously, and the tree can get along on poor soil where the farm hunter is not apt to molest it. It has a fairly thick bark, and is able to take care of itself in a moderate fire, except when the seedlings are quite small. The young tree's tap root is much developed, and goes deep for moisture, and the growing sappling flourishes on ground where some other species would suffer for water.

WHITELEAF OAK (Quercus hypoleuca). The beauty of this small evergreen oak of the mountains of western Texas, New Mexico, and Arizona, is in its foliage rather than its wood. Large trunks - that is, those twenty inches or more in diameter -are apt to be hollow, but the sound wood is employed in repairing wagons in local shops, and in rough ranch timbers. Its importance will nevcr extend beyond the region where it grows, but in that region it will continue to be used where nothing better can be obtained. The largest trees are sixty feet high, and two in diancter, but few reach those dimensions. It is an arid land oak. It grows at from 4,000 to 6,000 feet elevations on mountains and plateaus. The leaves remain thirteen months on the twigs. They are of the willow form, ranging from two to four inches in length and one-half to one in width. The acorns are snzall and bitter. The strength of this oak is remarkable, if it may be judged by the figures given by Sargent. Two samples of wood procured by himself and Dr. Engelmann on a dry, gravelly gronnd among the Santa Rita r.ountains in Arizona, showed breaking strength sixty-onc per cent greater than the average given by the same author for white oak. The stifiness of the specimens was a little above white oak, and the weight three pounds more per cubic 
foot. It should be borne in mind, bowever, that results derived from a test of only two samples are not a safe basis for concluding that the wood generally will average of so great strength. The annual rings of growth are not clearly marked. The wood is porous, but the pores are not generally arranged in bands, although they occasionally follow that arrangement. The medullary rays are broad and abundant, but are rather short, measured along the radial lines. They are of pink color, a characteristic not unusual with oaks in semi-arid regions. The foliage is doubtless the most valuable characteristic of whiteleaf oak. The leaves are silver white below, and dark green above. When they are agitated by wind the flashing of the different tones and tints in the sunshine presents an attractive picture. It belongs to the willow oak branch of the red oak group, and bears two-year acoras.

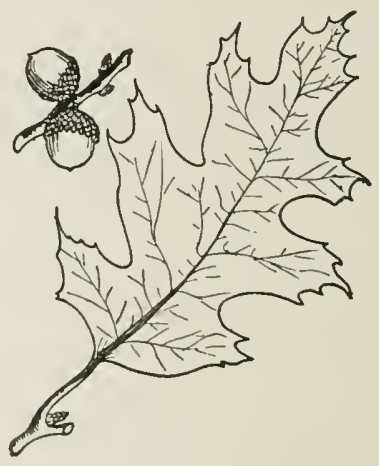


SCARLET OAK 


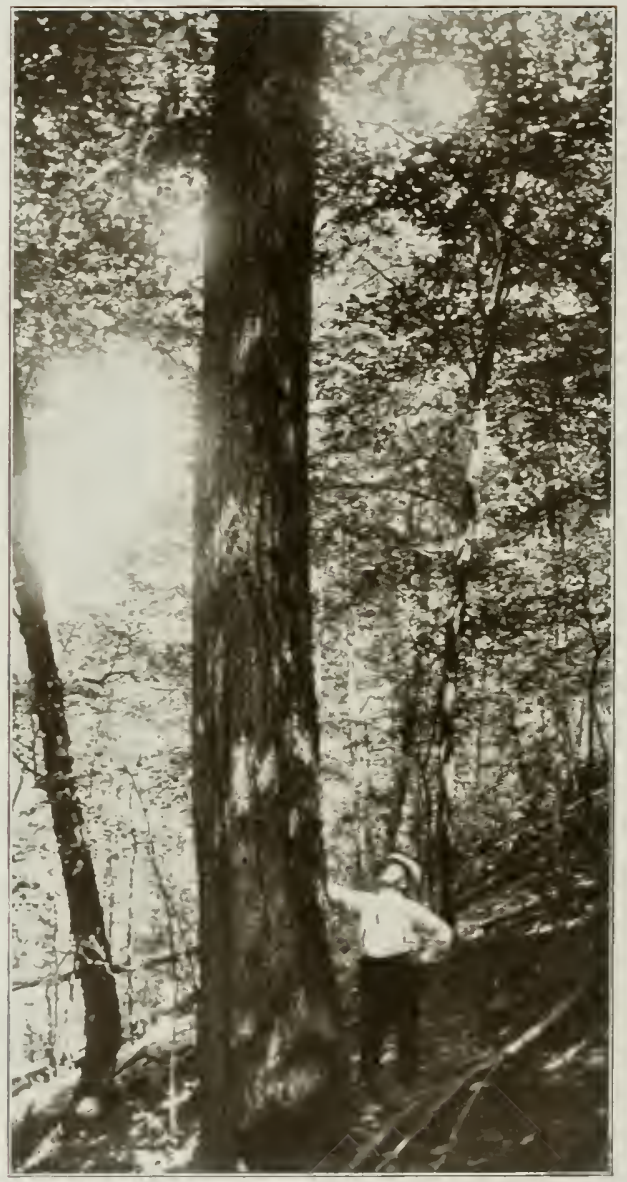

SLARIET O.AK 


\section{SCARLET OAK}

\section{(Quercus Coccinea)}

$\mathrm{T}$ HE name of scarlet oak is in use in Vermont, Massachusetts, Rhode Island, Connecticut, New York, New Jersey, Pennsylvania, Delaware, North Carolina, Missouri, Illinois, Indiana, Wisconsin, Minnesota, Michigan, Nebraska, Iowa, and Ontario; red oak is the name in North Carolina, Alabama, Wisconsin, Nebraska, and Minnesota ; black oak in Nebraska, Illinois, Iowa, and Wisconsin, and Spanish oak in North Carolina.

The name is descriptive of the autumn leaves. Artists dispute among themselves whether the leaves are scarlet, red, or crimson. In their opinion a good deal of difference exists between these colors, rendering it quite incorrect to give one color the name of another. As for the artists, they are probably correct in their analysis of colors, but the general public knows the tree as scarlet oak, and it will doubtless be called by that name by most people who speak of the tree in the woods, while those who refer to the wood after it is sawed will speak of it as red oak.

The leaves of scarlet oak are rather persistent, and remain on the twigs late in the season. The brilliancy of this tree is rendered doubly conspicuous, when it is contrasted with the surrounding sombre, winter colors.

In appearance the tree is striking for its delicacy of foliage and twigs. The crown is always narrow and open, and in forest growth is compressed. The height, in good specimens, is about one hundred feet, but it often exceeds that size. In diameter it grows as large as four feet. The mature bark is dark in color and broken into broad, smooth ridges and plates, edged with red. It shows a reddish inner bark when cut and this may be relied upon to identify the tree. The leaves are four or five inches long; deeply sinused, three or four on a side; long, bristle-toothed lobes, broad at the base; acorns bitter, mature in two years; sessile, brown; cup closely drawn in at the edge.

Its range comprises the northeastern quarter of the United States. Beginning in southern Maine, New Hampshire and Vermont, it grows through middle New York, Michigan, Wisconsin, and Iowa to eastern Nebraska. Southward it extends along the coast through Virginia and inland along the mountains to South Carolina and Gcorgia. The growth is abundant over most of the range, the favorite liabitat being dry, gravelly upla11ds. It seews to be most abundant aloug the northern part of the Atlantic coast from Massachusetts to New Jersey, 
and is less common in the interior, and on the prairies skirting the western margins of the eastern forests. The average size of the tree is from seventy to eighty feet high and two or three in diameter. In many regions it is much smaller, while no very large trees have been reported.

The wood is heavy, strong, hard; the layers of annual growth are strongly marked by several rows of large, open ducts; the summerwood is dense and occupies half the yearly ring; the medullary rays are much like those of red oak, though scarcely as broad. They run in straight lines radially, and show well in quarter-sawing. The color of the wood is light brown or red, the thin sapwood rather darker.

This wood is practically of the same weight as white oak; but it is rated considerably stronger and stiffer. A number of writers have listed scarlet oak low in fuel value. Theoretically, the fuel values of woods are proportionate to their weights, except that resinous woods must be compared with resinous, and non-resinous with non-resinous. In practice, however, every fireman who feeds a furnace with wood knows that different woods develop different degrees of heat, though they may weigh the same. Results are modified by various circumstances and conditions, and for that reason theory and practice are of ten far apart in determining how much heat a given quantity of wood is good for.

It is difficult to procure exact information regarding the uses of scarlet oak. It never goes to market under its own name. An examination of wood-using reports from a dozen states within scarlet oak's range does not reveal a single mention of this wood for any purpose. It is certain, nevertheless, that much goes to market and that it has many important uses. It loses its identity and is bought and sold as red oak. Under the name of that wood it is manufactured into furniture, finish, agricultural implements, cars, boats, wagons and other vehicles, and many other articles. One of the most important markets for scarlet oak is in chair factories. Its grain is attractive enough to give it place as outside material, and its strength fits it for frames and other parts which must bear strain. Chair stock mills which clean up woodlots and patches of forest where scarlet oak grows in mixture with other species of oak, take all that comes, without being particular as to the exact kind of oak. Slack coopers follow much the same course. A wood strong enough to meet requirements, is generally acceptable. Scarlet oak is usually considered unsuitable for tight cooperage, on account of the large open pores of the wood, which permit leakage of liquids. It meets considerable demand in the manufacture of boxes and crates, particularly the latter.

The size and quality of logs which a tree may furnish to a sawmill is no measure of its full value. Scarlet oak is far better known as an 
ornamental tree than for its wood. It has been planted in this country and in Europe. Its brilliant foliage is greatly admired. No other oak equals it, and it compares favorably with sugar maple, black gum, and dogwood. It is an ornament to parks and private grounds, though the brilliancy of its foliage is seldom exhibited to as good advantage in cultivation as in the native forest where contrasts are more numerous, and nature does its work unhindered by man. The scarlet oak is not a rapid grower, and the form of the tree is not perfectly symmetrical. The spring leaves are red, the summer foliage bright, rich green, the autumn scarlet-a variety not equalled by many forest trees.

WrLlow OAK (Quercus phellos) is named for its leaves which look like those of willow. There is a group of such oaks with leaves similar, and they are known collectively as willow oaks. The one here described may be considered typical of the group.

This oak is apt to present rather a surprising appearance to those who have seen nothing but those oaks whose leaves are lobed or cleft. It belongs to the red oaks. Like others of this division it has a tendency to hybridize, several varieties being known. Willow oak is a denizen of the southern Atlantic and southeastern states and favors rich, moist soil, either on uplands or on bottoms, along the margins of streams or swamps. It does not go inland as far as the foothills of the ranges and is found most abundantly in the basin of the lower Mississippi. Beginning in New York, the range extends southward into Florida, along the Gulf states, touching Texas, up through Arkansas, touching Missouri and Kentucky, down through western Tennessee and southern Georgia rounding the southern end of the Appalachians.

Young trees have a slender delicate pendant appearance of twigs and foliage more typical of the willow than of oak; but in time they become more rugged, although the branching and foliage are always more delicate than is usual with oaks. The tree attains a height of eighty feet and a diameter up to four feet, but usually is about half of this. It is clothed in a smooth, brown bark, ridged only in older trees. The leaves are about five inches long and narrow in proportion, are of shiny, leathery texture, dark above and pale below. The acorns are on short stalks, solitary or in pairs, and ripen in two years, are short and rounded and in shallow cups.

The weight of willow oak is approximately the same as white oak. It is slightly stronger but less elastic. Its annual rings contain broad bands of small open ducts parallel to the thiu, dark, medullary rays. The wood is reddish-brown in color, the thick sapwood darker brown. The fuel value is rated the same as white oak, but the wood contains more ash. 
Willow oak is much used in the South, but usually under the name red oak. Lumbermen seldom speak of it as willow oak. The species is as highly developed in Louisiana as anywhere else, and the uses found for the wood in that state will probably be found for it wherever the tree grows in commercial quantities. A report on the manufacture of wooden commodities in Louisiana, published in 1912, listed the following uses for willow oak: Agricultural implements, balustrades, bar tops, bedsteads, bottoms for wagon beds, bridge approaches and floors, chairs, church pews, cot frames, doors, floors, frames, interior finish, molding, newel posts, pulpits, railing, screens, slack cooperage, stairwork, store fixtures, wagon axles, and other vehicle parts.

These uses coincide nearly with those of red oak, and indicate the important position occupied by willow oak in the country's industries. Those who handle the wood complain that its seasoning qualities are poor, and that care is necessary to bring satisfactory results. It works nicely and stands well after the seasoning is accomplished.

Willow oak grows rapidly. It is doubtful if any oak in this country surpasses it. It wants damp, rich soil and a warm climate, to do its best. Some of the bottom lands in the lower Mississippi valley have produced splendid stands of willow oak, the trunks being tall and clear of limbs, and the wood sound.

The willow oak is much planted for ornamental purposes in the southern states. It manages to keep alive when planted as far north as Massachusetts, but the grace of its form is not fully developed much north of the Potomac river. It is a common street tree in the South, and its airy foliage forms a pleasing contrast with the heavy, dark-green of the magnolia.

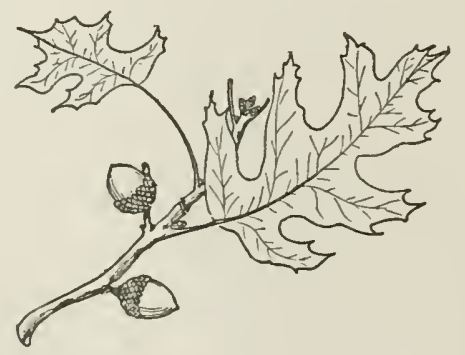


TURKEY OAK 


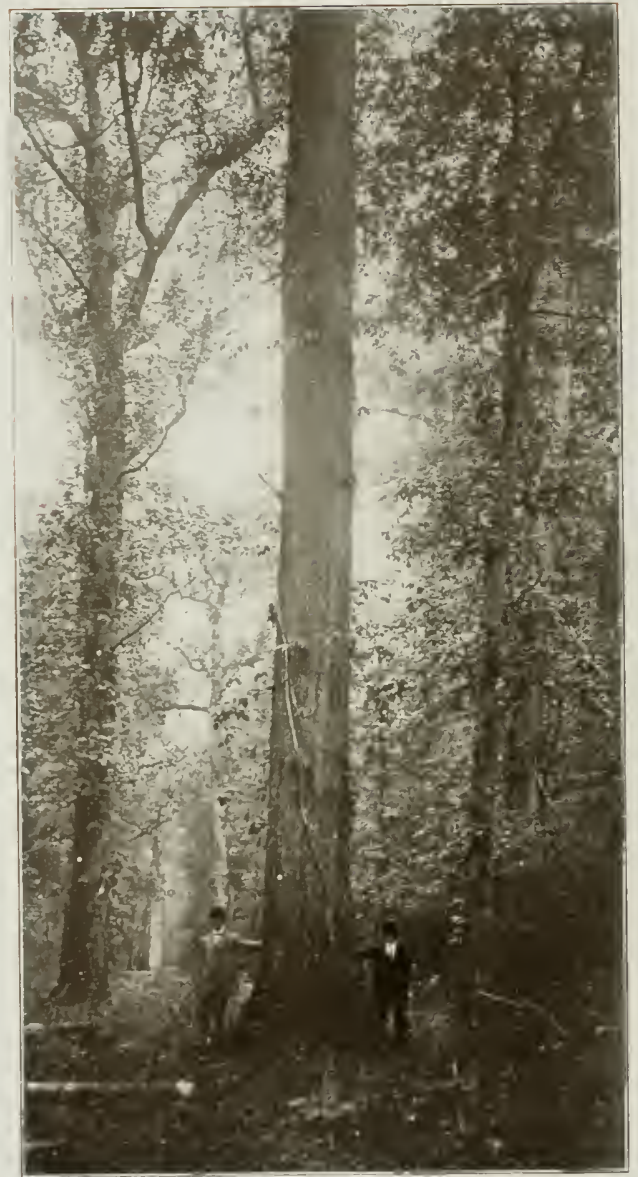

TURKEY OAK 


\section{TURKEY OAK}

\section{(Quercus Catesbici)}

$T$ $\mathrm{HE}$ claim that this tree is called turkey oak because turkeys feed on the acorns, is not well founded. In common with nearly all members of the black oak group, to which this species belongs, the acorns of turkey oak are bitter, and unless animals are pressed by hunger they do not eat them. It is evident that the shape of the leaves gives this tree its name. They bear considerable resemblance to the foot of a turkcy. There is at least enough similitude to suggest the name, and it is not inappropriate. Many people now use the term without thinking of its origin, and if asked their opinion say that fondness of turkeys for the acorns led to the name.

The tree has other names in different regions. In North Carolina, South Carolina, Mississippi, and Florida it is known as scrub oak. The name fits it well in certain places, for when it grows on poor soil and in adversity, it degenerates into a low, straggling thicket, frequently not trees at all, but shrubs. It is called black jack in South Carolina but the name belongs to another species (Quercus marilandica). In the same state it is known as barren scrub oak, because it is very small and is found on poor lands popularly known as barrens. Some call it forked-leaf black jack, but the name is usually shorter, and forked-leaf, or forked-leaf oak, is a name well understood among lumbermen, and the people generally over much of the tree's range. Some of the leaves show clearly-defined three forks, the middle one longer than the others; but in other leaves, often from the same tree, the forks are not so regularly outlined. This tree, like many other oaks, exhibits considerable variation in the forms of leaves.

There is nothing peculiar in the form and appearance of the acorns. They average about one inch long and three-quarters of an inch wide, and sit in shallow cups. They mature the second year. The bark of old trees is black near the ground, rather rough, and an inch or more thick.

It is difficult to name an average size for turkey oak. The largest trunks are three or four feet in diameter and eighty feet high, but the trees cut for sawlogs are only fifty or sixty feet high and two in diameter, in most of the regions. As previously stated, much of the stand is stunted and some of it is only brush. All sizes are found, from large, first rate trunks down to shrubs. Large trees which grow in forests, prune themselves well and their trunks compare favorably with red oaks.

The tree's range has its northeastern limit in North Carolina, and 
extends to Peace Creek, Florida. It is found westward to Louisiana where fair-sized timber grows, but in small quantities. It is usually considered that its best development is in South Carolina and Georgia, but good trees are likely to be found in any part of its range. It is distinctly a tree of the South. It was named by Michaux, the wellknown French botanist who visited the southern states early in the nineteenth century, and he named it in honor of Mark Catesby who explored the region much earlier and wrote concerning its trees and other natural history.

Turkey oak is one of the little-known trees of the South, as far as lumbermen are concerned. They know it well enough in the woods, but not at sawmills. When cut into logs it ceases to be turkey oak and becomes red oak, and under that name it goes to the lumber yard, and later to market. Users of red oak lumber do not object to the occasional piece of turkey oak mixed with it-if they cver find it out, which few of them do. Nevertheless, the consensus of opinion among sawmill men is that turkey oak ought to rate below red oak.

Tests of the wood to determine its character and qualities do not justify so low an estimate of turkey oak. Sargent found it stronger and more elastic than white oak, while a little lighter in weight. It is nearly equal to white oak in fuel value. It is hard, compact, and the rings of annual growth are marked by several rows of large, open ducts. The medullary rays are broad and conspicuous. The color is light brown, tinged with red, the sapwood somewhat lighter.

A special investigation of the uses of turkey oak in one of the southern states brought out the fact that it meets requirements well and fills a place in several woo.-using industries in that region. Vehicle makers find it satisfactory in a number of places. It is made into bottoms of wagon beds, felloes, bolsters, axles, hubs, hounds, tongues, spokes, standards, sandboards, and reaches. These constitute nearly all parts of heavy vehicles. The wood is made into telegraph brackets, but apparently not in large quantities. Car builders employ it for frames and floors. It is made into ordinary matched flooring and goes in with other oaks. It is used as a general furniture wood, both as outside material, and inside frames. It may be quarter-sawed to advantage. It is employed also as interior finish, which demands lumber of practically the same grades as go into furniture. Mantels of this wood compare favorably with those of red oak. Chair makers cut stock from turkey oak. It is not abundant anywhere, otherwise it would be of much importance.

The forests of the United States contain so many valuable oaks that a scarce and geographically restricted species like turkey oak cannot be 
expected to attract much attention in the future. Nevertheless, it is a strong, interesting tree. It takes advantage of every opportunity to develop. When an acorn germinates in good soil, and receives sufficient light and moisture, it produces a merchantable tree; but in poor soil and under unfavorable circumstances it becomes a stunted bush only. Woodlots of turkey oak planted in fertile land would probably do as well as most of the southern red oaks under like conditions. The tree is not apt to get justice, because of the prejudice against it.

California Black OAK (Quercus californica) ranges from central Oregon southward through the coast region of California nearly to the Mexican boundary. It occurs also on the western slope of the Sierra Nevadas in California. It is not found on the plains or near the sea, but occurs on mountain slopes, low summits, elevated valleys, and in canyons. In the North, it ranges from 1,500 to 3,000 feet and in the South it ascends to 9,000 feet. This far western oak bears more resemblance to the yellow oak (Qucrcus velutina) of the East than to any other. Trees have been reported 100 feet high and four in diameter, but they are scarce. Seventy-five feet high and two or three feet in diameter are usual dimensions of mature timber. The trees are inclined to be angular in the outlines of their crowns. The leaves fall in autumn, but the acorns persist two years. They sit deep in their rough cups. The trunk is habitually crooked. It leans out of plumb, and lacks the nicely balanced poise which adds to the attractiveness of some oaks. The large boles are usually hollow, dead at the tops, or otherwise defective. That condition is apparently due to old age. Trees stand long after they pass maturity and start on their decline. They die by inches, and not infrequently they decay and crumble by piecemeal both at the bottom and at the top. At best the trunk of this oak is of poor form for saw timber. It divides into large limbs ten or twenty feet from the ground. It is of slow growth, and it reaches old age-possibly as much as 350 years in extreme cases. The wood is very porous, but the pores are not in rows. The medullary rays are thin and distinct. It is not known that any quarter-sawing has been attempted, and it would hardly be profitable. The wood is pale red, exceedingly brittlc, firm, light for oak, and it lias a distinct odor of tannin with which both the wood and the bark are heavily charged. The principal uses to which this oak is put in California and Oregon are as fuel and ranch timbers, the latter being of the simplest and roughest sort. Its fuel value is high, comparcd witl other woods of the region. Some use was made of the bark for tanning purposes years ago on the Pacific slope, but it does not appear to go to market now.

BLUE JACK OAK (Qucrcus brevifolia) bears several names, upland willow oak, 
to distinguish it from other willow oaks which grow in swamps, sand jack, referring to the land on which it grows, bigh-ground willow oak, turkey oak, shin oak and cinnamon oak. No reason is known for the last name which is not used outside of Florida. The tree grows in a narrow strip along the coast from North Carolina to Texas, crossing northern Florida. The blue jack oak sometimes attains a height of fifty feet and a diameter of twenty inches; but that is its best. It is usually fifteen or twenty feet high and a few inches in diameter. The leaves are from two to five inches long and quite narrow, closely resembling those of willow. The acorns are abundant, but small. The tree is of so little value that it does not interest the lumberman. It occupies waste land, and may produce a little fuel without crowding more valuable trees, but is in every way inferior to the black jack oak (Quercus marilandica), which overlaps its range a little, but is a torthern species. The wood of blue jack oak is hard, strong, light brown in color, with darker-colored sapwood.

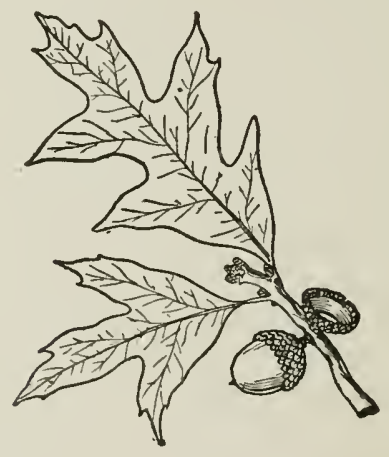


SPANISH OAK 


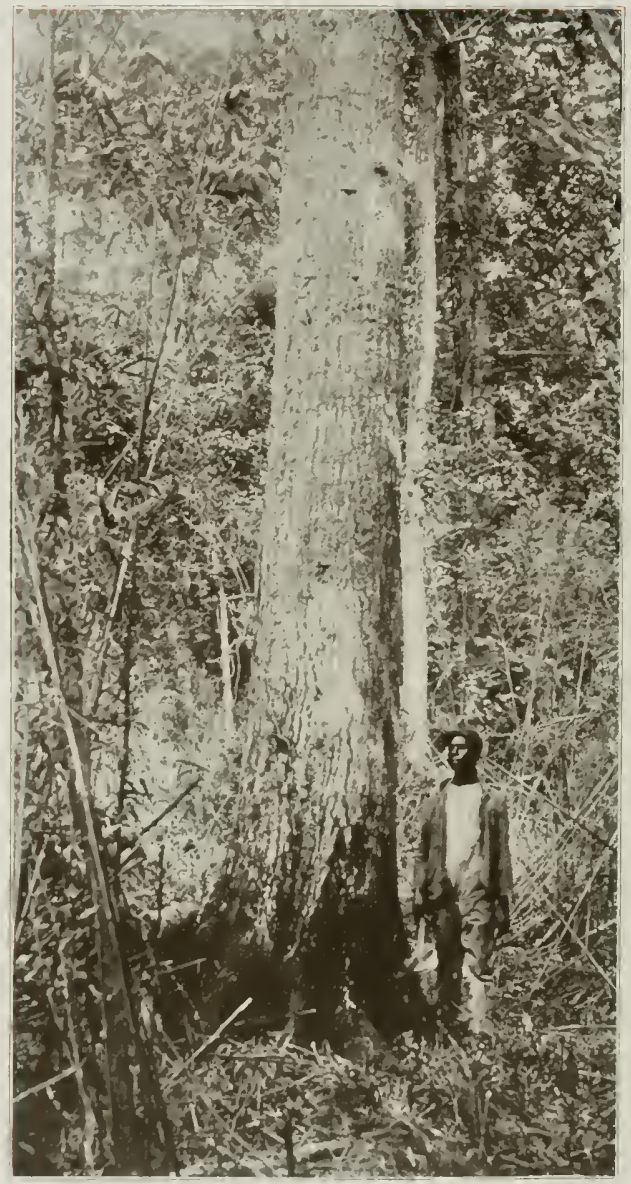

SPANISH OAK 


\title{
SPANISH OAK
}

\author{
(Quercus Digitata)
}

$\mathrm{O}$ NE of the first difficulties in an attempt to clear up the misunderstandings regarding Spanish oak is to confine the name to the species to which it belongs. That is no easy task, because the name has been applied to numerous oaks in various parts of the country, and without any apparent reason. Some of these bear little resemblance to Spanish oak and grow almost wholly outside its range. It is not a case of mistaking one for the other, for there is no mistake. Some speak of the common red oak as Spanish oak, others bestow that name on yellow oak, others on black jack oak, or scarlet oak, or anyone of several others. It appears, however, that the name is not applied to any member of the white oak group.

It is said that Spanish oak and Norway pine were named by the same process. Each got its name hecause it was supposed to be similar to a species in the old country-the pine like an evergreen of north Europe, and the oak like a broadleaf tree of Spain. It was learned later that both the American species were different from those of Europe which they resembled.

The peculiar drooping foliage of Spanish oak gives the tree a character which impresses a person who sees the full-leafed crown for the first time. The leaves are six or seven inches long and four or five wide. Their forms vary within wide limits, and their shapes change from week to week while growing. Some have no lobes or sinuses, others have them in rudimentary form only, while in still others they are well developed.

The tree is often called red oak, particularly by lumbermen who cut it and send it to market with red oak. In Louisiana it is known as Spanish water oak, there being much resemblance between it and water oak (Quercus nigra) with which it is associated. Its range covers more than 200,000 square miles, beginning at the north in New Jersey and following down the coast regions to central Florida. It extends westward into Texas to the valley of the Brazos river; northward to Missouri and southern Indiana and Illinois. It does not grow far inland from the coast in the north Atlantic states, but furtler south it is common on the coast plain between the sea and the base of the mountains. It is often found on dry sand hills in that region. The largest Spanish oaks on record grew in the lower Ohio valley, particularly along the Wabash river. It is usually of medium size and large trunks are seldom seen. The average height is seventy or eighty feet, dianneter two or three. In 
the open, the crown is broad and low, but in forests the trunk prunes itself fairly well, and makes good saw timber, as far as form and size are concerned. The acorns ripen in two years, and are bitter. The bark is rich in tannin, but tanneries do not use much of it.

The tree is not generally abundant. Some large areas within its range have little, and thick stands are unusual anywhere. It is one of the oaks which lumbermen neither reject nor seek. They cut it in course of operations, and saw it and sell it under the common name, red oak.

The wood is heavy, very hard, and strong. It is reputed to decay more rapidly than most oaks, and it checks badly in seasoning. The annual rings of growth are broad, and the springwood is marked by several rows of large open pores. The medullary rays are few but conspicuous; color light red, the sapwood lighter. The wood weighs about three pounds less than white oak per cubic foot, and its fuel value is less.

It is not easy to compile an account of the uses of Spanish oak by the various industries of this country, for the reason that other oaks pass by its name and it is known by names which should not be applied to it. It is shown, however, where special studies of its utilization have been made that it is a useful wood for many purposes. It is a useful furniture material, and though statistics do not give separate figures for it, evidently the total quantity consumed yearly runs into many millions of feet. It is much employed in the manufacture of tables, chiefly for frames, but occasionally as the outside material. It may be quartersawed, if good logs are selected. The chair factories in North Carolina use about $44,000,000$ feet of oak yearly, and Spanish oak supplies a rather large share of the material. It is employed as interior finish in that state, and also for mission furniture, brackets for telegraph and telephone poles, refrigerators, and kitchen safes. Slack coopers and manufacturers of boxes and crates find the wood suitable for their wares; but its open pores stand in the way of its use for tight cooperage.

Similar uses of the wood occur in Mississippi, Louisiana, and Texas, and it may be assumed that they occur also in all other portions of Spanish oak's range. It goes to wagon shops in Texas where it is substituted for red oak. It is employed also in the manufacture of rice hullers and cotton gins. Lumbermen in northern Louisiana use log trucks with axles, felloes, and other heavy parts of Spanish oak, and it is frequently preferred for stone wagons.

In practically all large shipments of southern red oak to the North, some Spanish oak is mixed. It could not be otherwise, since this wood is cut in the forest with other red oaks, is sawed and stocked with them, and goes with them to market. 
BLACK JACK OAK (Quercus marilandica) is one of the scrub trees of this country, and few good words are ever heard for it; yet it has redeeming qualities. Lumbermen have not paid much attention to it and never will, for only when at its best is the trunk large enough for any kind of sawlog, and there has been little inclination to use it for anything else. It attains size fitting it for fence posts, and sometimes it performs service along that line; but the small trunks are nearly all sapwood, and decay strikes them quickly. The bark is black, hence the name, and it is exceedingly rough, and is broken in squares. The leaves are large and pear-shaped, with the broad end opposite the stem. Some are slightly lobed. A vigorous black jack oak, standing in open ground, presents a fine appearance. The crown is wide and is frequently conical, the limbs small, and are set in the trunk on nearly horizontal lines. The range of this unloved species covers 600,000 or more square miles, beginning in New York, running west to central Nebraska, south through Texas nearly to the Rio Grande, and in Florida to Tampa. It is not an aggressive tree and has permitted itself to be crowded off the good land until it has formed the habit of occupying geographical left-overs in the form of sand banks and wornout fields. In the northeastern part of its range it is often associated with scrub pine (Pinus virginiana), because the two have similar habits and are content to live in perpetual poverty on dry gravel or thin sand. Large trunks are not possible under such circumstances, and first-class wood is unusual. Black jack oak at its best may attain a height of fifty feet and a diameter of eighteen inches, but it is oftener twenty feet high and six inches through. It grows with moderate rapidity and does not live long.

The annual rings are often indistinct. The wood is hard, heavy, and strong, and checks badly in seasoning. The medullary rays are broad and conspicuous, the wood dark brown in color, the sapwood lighter. This oak is very high in ash contents, more than one per cent of the dry weight of wood going to ashes when burned. The tree reaches its best development in the lower Mississippi valley, and in eastern Texas. Comparatively few uses for it have been found. Cordwood cutters find it valuable where it abounds in sufficient quantity, and it has been burned for charcoal for iron foundries and blacksmith shops. Small amounts are occasionally found in wood-using factories in Texas, but only when logs with considerable heartwood can be procured. The sap is characterless and seems to be utterly rejected at the factory. Sometimes the rich brown of the heartwood is attractive, but more frequently the wood is ringed and splotched with different colors, not distributed in a way to give any artistic effect. When a satisfactory stick is found, it can be worked into balusters and small spindles which 
show grain well. It is also worked into broad panels made up of narrow, quarter-sawed strips, which exhibit the dark flecks of the wood to good advantage.

TRIDENT OAK (Quercus tridentata) is remarkable for its extreme scarcity, and is of no commercial importance. It was formerly found in Missouri-a single treewhich was afterwards destroyed. It occurs in Washtenaw county, Michigan. It appears that no report showing the character of the wood has been made.

LEA OAK (Quercus leana), which is believed to be a hybrid between yellow oak (Quercus velutina) and shingle oak (Quercus imbricaria), is interesting but not important. Trees are apt to stand alone, and far apart. They occur from District of Columbia to Missouri, and south to North Carolina. The range is imperfectly known.

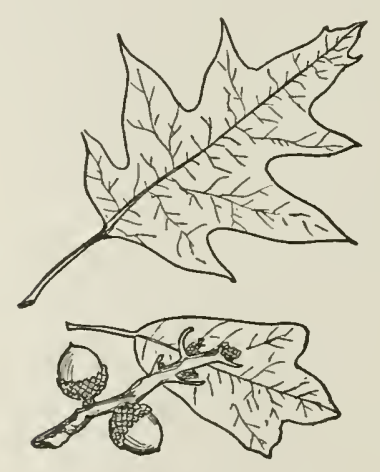


LAUREL OAK 


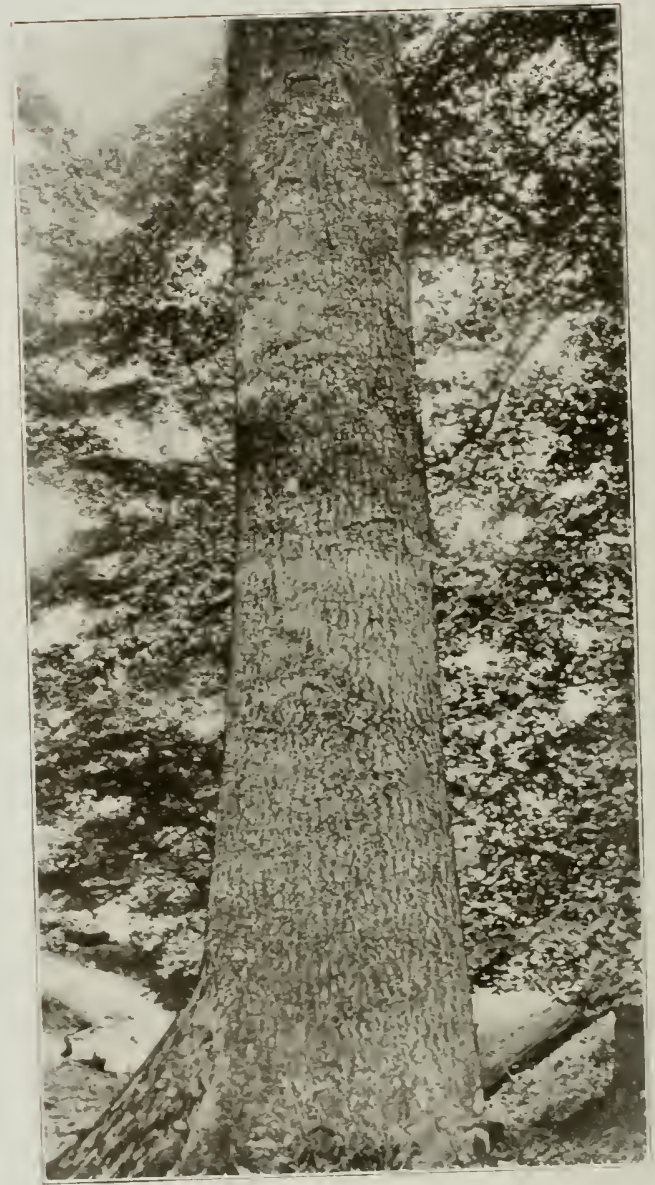

LALREL OAK 


\section{LAUREL OAK}

\section{(Quercus Laurifolia)}

$T$ HIS representative of the black oak group is found nowhere except in the southeastern states, and only in their borders. It never ranges far inland, but sticks to wet localities and the margins of swamps where its associates are tupelo, southern white cedar, cypress, magnolias, and, near its southern limit, myrtle and other semi-tropical trees and shrubs. It is sometimes utilized as an ornament, but that is not its usual function. It is not a successful competitor as a shade tree with willow oak and water oak.

Beginning at the border of the Dismal Swamp in Virginia as the northern limit of growth, this interesting tree ranges southward along the coast to Cape Romano in Florida and westward in the lower Gulf states to southeastern Louisiana. It is seen at its best in eastern Florida. It puts forth a vigorous growth on the hummock land in the southern part of that state, where it develops a shapely trunk when in crowded stands. It grows well in very rocky ground.

Although the common name laurel oak is prompted by its foliage, the tree bears various other sectional names. It is known as laurel oak in North Carolina, South Carolina, Alabama, and Florida; Darlington oak in South Carolina; willow oak in Florida and South Carolina; water oak in Georgia. The latter name has a tendency to confuse it with another species which is properly called water oak (Quercus nigra).

The ornamental qualities of this tree are due to the tall stately bole, its shapely and symmetrical round-topped head and slender branches and twigs. It sometimes attains the dignity of one hundred feet in height with a proportionate diameter of three or four feet. The bark is firm, of dark, reddish-brown color, and usually is not fissured but finely broken into small close, scale-like plates. On old trees, especially at the butt, deep fissures divide it into broad ridges. The buds are shiny brown, and they narrow abruptly to an acute point. The acorns are either sessile or have short stalks, and they usually grow alone. They are short and broad, and are incased in shallow, thin cups. In the flowering season hairy aments add to the attractiveness of the tree. The leaves are dark green above and lighter on the lower surface and are grouped rather closely on the twigs. They attain a length of four inches or less, and fall gradually after turning yellow.

Laurel oak seems to be little used. It is occasionally referred to as rather inferior to other members of the black oak group, but it is not apparent why it bears that reputation. It may be on account of its 
poor seasoning qualities. Like other southern oaks, it is very heavy when green, and it is inclined to shrink and warp while in the process of parting with its moisture. If this can be successfully overcome, the wood ought to be valuable. Tests made on four samples cut on St. John's river, Florida, recorded in Sargent's tables, show remarkable results. The wood is 34 per cent stronger and 37 per cent stiffer than white oak, and is only one pound heavier per cubic foot of dry wood. If these values are fairly representative of the wood of laurel oak, it should be exceptionally valuable in vehicle making. It would fall considerably below hickory, but would stand very high among other woods, and could be recommended for wagon axles, tongues, and other parts of heavy vehicles.

It should be borne in mind, however, that tests alone, and particularly when the number of samples is small, are not sufficient to decide a wood's place as a manufacturing material. It must be tried in actual practice, and that has not yet been done in the case of laurel oak as a wagon wood. When tried out it may exhibit defects, or undesirable qualities, which are not apparent in samples employed in laboratory tests.

There is little exact information available in regard to the supply of laurel oak in the South. It is not abundant in the sense that willow oak and Texan red oak are. Neither are the trees generally of good form for lumber. Little has ever been cut, because the land where it grows is not demanded for agriculture. It occupies out-of-the-way places, and the hunter and fisherman are better acquainted with it than the lumberman.

Highland OAK (Quercus wislizeni) is a California evergreen with leaves commonly shaped like holly, but sometimes their edges are smooth with no sign of teeth. The foliage remains longer on this tree than is usual with evergreen oaks. Old leaves generally fall within a month after the new crop appears; but those of highland oak remain several months longer, gradually falling during the second summer. When the tree is at its best it is a splendid representative of the vegetable kingdom. Its form does not please lumbermen, for the trunk is short and rough; but the crown rises seventy or eighty feet, is symmetrical, the foliage dark green, and the general appearance is that of an enormous holly tree. Trunks are sometimes five or six feet in diameter. The name highland oak is somewhat misleading, though the species ascends to an altitude of 6,000 feet or more. It is described as a highland tree to distinguish it from the California live oak (Quercus agrifolia) which grows in the vicinity of the sea in California. The highland oak ranges from northern Caliiornia to the international boundary, following the foothills of the mountain ranges. It occurs in dry river bottoms and 
washes and in desert mountain canyons. It is not choice as to soil but will grow in loam, sand, gravel, or among rocks. It is not abundant.

When it gruws zear the sea it is apt to lose its tree form and become a shrub. It assumes that form on Santa Cruz and Santa Rosa islands off

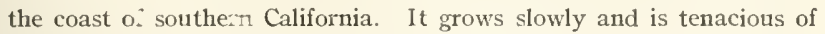
life. When it has once secured a foothold it hangs on with determination, though exposed to severe storms and inhospitable conditions. The acorns do not mature until late in the autumn of their second year. They are sometimes an inch and a half long, and scarcely a third of an inch thick. The wood of this oak possesses some good qualities which are locally appreciated by wagon makers who use it for repair work. It is extensively cut for fuel, and it burns about like eastern white oak, but leaves more ashes. The dry wood weighs 49 pounds per cubic foot. It is considerably weaker than white oak and is less elastic. The summerwood constitutes a large part of the annual growth ring. It is very porous, the rows of pores running parallel with the medullary rays. This part of the wood structure is midway between that of deciduous and the evergreen oaks. The medullary rays are broad but short. When exposed on a tangential surface, they are from one-fourth to one-half inch long, and give the wood a flecked appearance. Exposed in cross section, they are from one inch to four inches in length. This applies, of course, only to large rays, easily seen with the naked eye. In quarter-sawed lumber, the rays have a pinkish color and glossy luster which are not pleasing. This tree belongs in the class with those which are in no danger of being extirpated by human agencies. It occupies land which man does not need and will never want.

MYRTLE OAK (Quercus myrtifolia) associates with the laurel oak in some parts of South Carolina, Georgia, and Florida, and closely resembles it, though it is smallet, and gives little promise of ever becoming important in a commercial way. It is clearly in the scrub oak class, and does not approach the dignity of even a small tree in most of its range. Few specimens can be found exceeding a height of twenty feet and a diameter of five or six inches. Trees approaching that size grow in western Florida in the region of the Apalachicola river. Generally this oak covers dry, sandy ridges and islands, and is shrubby. It forms thickets on some of the islands off the coast of Alabama and Mississippi, and extends its range westward to the low, southern parts of Louisiana where the dwarf trees are almost hidden by tall reeds and grass. Its name refers to the leaf it bears. It is impossible that man can ever make much use of this tree.

MOREHUS OAK (Quercus morehus) can never be important in the lumber industry, but it fills a few places in California where the ground needs a cover. Its range is in the northern coast range and the Sierra foothills, extending as far south as Kings river. The edges of the leaves bear bent hooks like saw teetl. The foliage falls in late winter. Trees are occasionally a foot or more in diameter. The wood has not the appearance of possessing much value, and is too scarce to be important. The most interesting thing connected with this tree is that it is supposed to be a 
hybrid-a cross between highland oak and California black oak. It was first found in 1863 , and a considerable range has since been established for it.

It is the opinion of some investigators that new tree species have their origin in crosses between existing species. Of the countless thousands of such crosses a few, at long intervals of time, may develop characteristics which enable them to maintain their existence and to spread into new territory. If that occurs, a new kind of tree has appeared on earth and is ready to take its place among the established forests of the region. Cross-fertilization among trees and plants is very common, but so many adverse conditions are encountered, that few hybrids ever amount to anything,

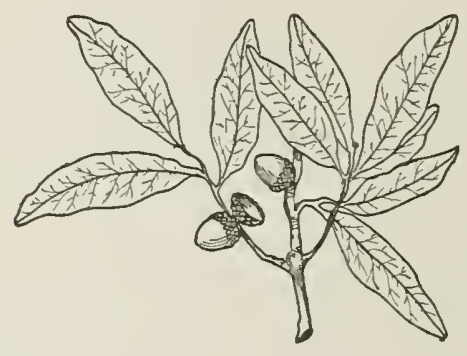


PIN OAK 


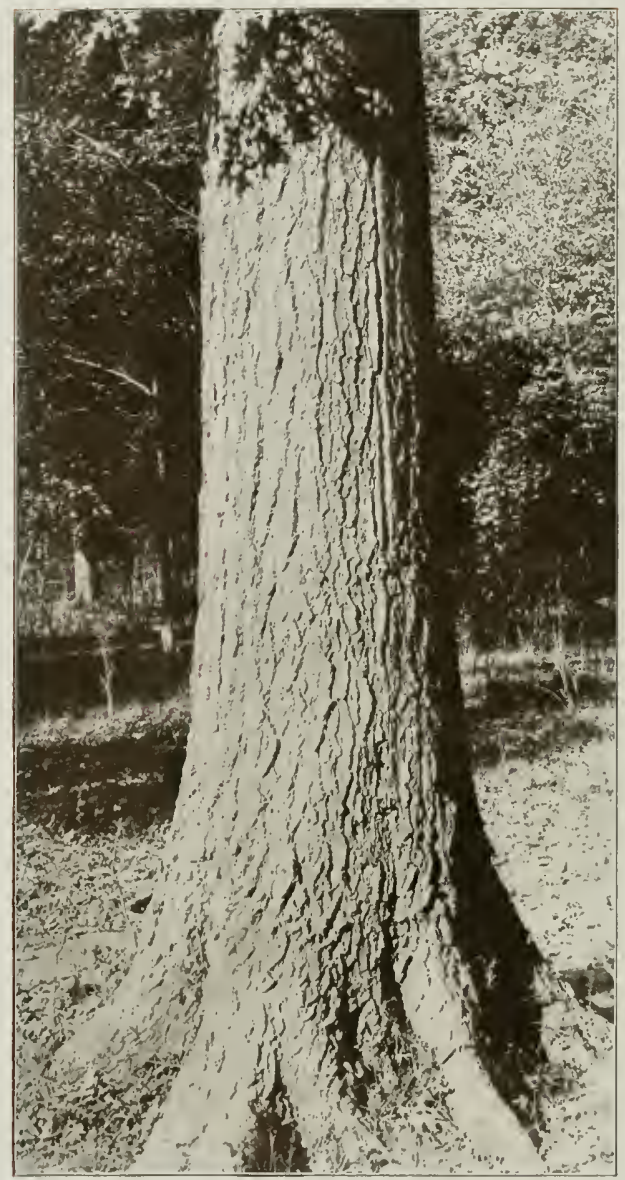

PIN OAK 


\section{PIN OAK}

\section{(Quercus Palustris)}

DIN oak ranges from certain sections of Massachusetts, notably the Connecticut river valley, and near Amherst, westward as far as the sontheastern part of Missouri; on the south it is found along the lower Potomac river in Virginia, in Kentucky, Arkansas, and Oklahoma.

It is known as pin oak in Massachusetts, Connecticut, Rhode Island, New York, Pennsylvania, Delaware, Virginia, Maryland, Arkansas, Missouri, Illinois, Wisconsin, Iowa, and Kansas; in Arkansas and Kansas it is called swamp Spanish oak; in Rhode Island and Illinois it is often known as water oak; in Pennsylvania, Ohio, and Kansas as swamp oak; in Arkansas as water Spanish oak.

The name pin oak is said to belong to this tree because of a peculiarity of its branches. They leave the trunk and the larger limbs at nearly right angles, and criss-cross in all directions, resembling pins thrust into the wood, and bristling outward at every angle. The crowding to which they are subjected kills many of them as the tree reaches middle age, but the stubs do not drop quickly, and as many of the characteristic pins appear to be present as ever. Such is the usual explanation given to account for the name, and the facts fit the theory; but the fact that several other species are called pin oaks is not accounted for. The habit of the branches of all of them is not the same. The Gambel oak in its Arizona range has that name. So has the chinquapin oak in Arkansas and Texas, but that is apparently a shortening of its true name, the last syllable only being used. They call the Durand oak pin oak in Texas, but without any known reason.

The botanical name palustris, belonging to this species, refers to the tree's habit of growing in swamps and damp land along river bottoms. It is not a swamp tree as cypress is, but is more like swamp white oak, and finds its most congenial surroundings on the borders of streams and on fairly well drained lowland where roots readily reach water.

The leaves are three or five inches long, are simple, and alternate. They are broad, and have from five to nine lobes which are toothed, and bristle-tipped on the ends. The sinuses are broad and rounded, and extend well toward the midrib, which is stout, and from which the veins branch off conspicuously. In color the leaves are bright green above and lighter below when young, becoming thin, firm and darker grecn at maturity; late in autumn they turn a ricl, deep scarlet. They are coated below with pubescense, and lave large tuits of pale lairs in the axils of the veins. 
The fruit of pin oak is a small acorn which grows either sessile or on a very short stem; sometimes in clusters, and sometimes singly. In shape the acorns are nearly hemispherical, and measure about a half incl in diameter; they are enclosed only at the base, in a thin, saucer-shaped cup, dark brown, and scaly.

The bark of a mature tree is dark gray or brownish-green; it is rough, being full of small furrows, and frequently cracks open and shows the reddish inner layer of bark. On small branches and young trunks, it is smoother, lighter, and more lustrous.

Pin oak is smaller than red oak. Average trees are seventy or eighty feet high and two or three in diameter. Specimens 120 feet high and four feet in diameter are heard of but are seldom seen. Near the northern limit of pin oak's range large trees are not found, nor are small trees plentiful. This holds true in all parts of New England and northern New York where the species is found growing naturally. South of Pennsylvania, along the flood plains of rivers which flow to Chesapeake bay, a better class of timber is found. The best development of the species is in the lower Ohio valley.

It grows rapidly, but falls a little short of the red oak. When young growth is cut, sprouts will rise from the stumps and flourish for a time, but merchantable trees are seldom or never produced that way. The acorn must be depended on. It has been remarked that pin oak does not prune itself well, but it does better in dense stands than in open ground. In the latter case the limbs are late in dying and falling.

Pin oak has proved to be a valuable street and park tree. It possesses several characteristics which recommend it for that use. It grows rapidly, and it quickly attains a size which lessens its liability to injury by accidents. Its shade is tolerably dense; the crown is shapely and attractive; the leaves fall late; and it seems to stand the smoke and dust of cities better than many other trees. It is easily and successfully transplanted if taken when small. Many towns and cities from Long Island to Washington, D. C., have planted the pin oak along streets, avenues, and in parks. Several thoroughfares in Washington are shaded by them.

Considerable planting of pin oak has been done by railroads which expect to grow ties. Trees of this species when cut in forests and made into crossties do not all show similar resistance to decay. Some ties are perishable in a short time, while others give satisfactory service. The best endure well without preservative treatment, but all are lenefited by it. Ii the experimental plantings turn out well, it may be expected that pin oak will fill an important place in the crosstie business.

Because of numerous limbs, lumber cut from pin oak is apt to be 
knotty, and the percentage of good grades small. The annual rings are wide, and are about evenly divided between spring and summerwood, though the latter often exceeds the former. Its general appearance suggests red oak, but it is more porous in trunks of thrifty growth. The springwood is largely made up of pores. The medullary rays are hardly as prominent as those of red oak, but in other ways resemble them. The wood weighs $43.2 t$ pounds per cubic foot, which is a little above red oak. It is hard and strong, dark brown with thin sapwood of darker color. The lumber checks and warps badly in seasoning.

The uses to which pin oak is put must be considered in a general way because of the absence of exact statistics. The wood is not listed by the lumber trade under its own name, but goes along with others of the black oak group. Its uses, however, are known along a number of lines. Lumbermen cut it wherever it is found mixed with other hardwoods. Sometimes vehicle manufacturers make a point of securing a supply of this wood. That occurs oftener with small concerns than large. It is made into felloes, reaches, and bolsters. Furniture makers use it, and well selected, quarter-sawed stock is occasionally reduced to veneer. The articles produced pass for red oak, and it would be very difficult to detect the difference between pin oak and true red oak when finished as veneer. Some highly attractive mission furniture is said to be of pin oak.

More goes to chair stock mills than to factories which produce higher classes of furniture. Chairs utilize very small pieces, and that gives the stock cutter a chance to trim out the knots and produce the maximum amount of clear stuff. Chair makers in Michigan reported the use of 60,000 feet of pin oak in 1910. Slack coopers work in much the same way as chair mills, and pin oak is acceptable material for many classes of barrels and other containers. Sinall tight knots are frequently not defects sufficient to cause the rejection of staves. Tight coopers do not find pin oak suitable, because the wood is too porous to hold liquids, particularly liquors containing alcohol. The wood is mixed at mills with red oak and other similar species and is manufactured into picture frames, boxes, crates, interior finish for houses, and many other commodities requiring strength or handsome finish. In early years when the people manufactured by hand what they needed, and obtained their timber from the nearest forest or woodlot, they split fence rails, pickets, clapboards, and shingles of pin oak.

Oak-apples or galls are the round excrescences formed on the limbs by gallflies and their eggs. They seem particularly fond of this species and specimens are often seen which are literally covered with them. The worms which live inside seem to flourish particularly well on the 
food they imbibe from pin oak. The primitive school teachers three or four generations ago turned these oak galls to account. They are rich in tannin, and were employed in manufacturing the local ink supply. The teachers were the ink makers as well as the pen cutters when the pens were whittled from quills. The process of making the ink was simple. The galls were soaked in a kettle of water and nails. The iron acted on the tannin and produced the desired blackness, but if special luster was desired, it was furnished by adding the fruit of the wild greenbrier (Smilax rotundifolia), which grew abundantly in the woods. It was well that steel pens were not then in use, for the schoolmaster's oak ink would have eaten up such a pen in a single day.

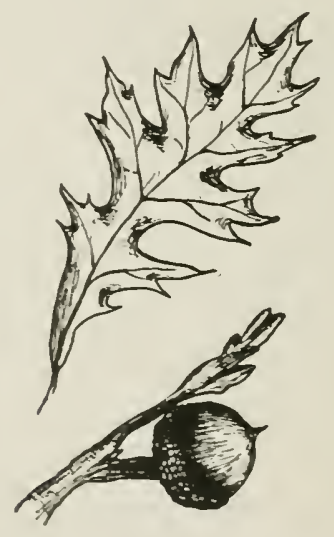


CALIFURIIA LIVE OAK 


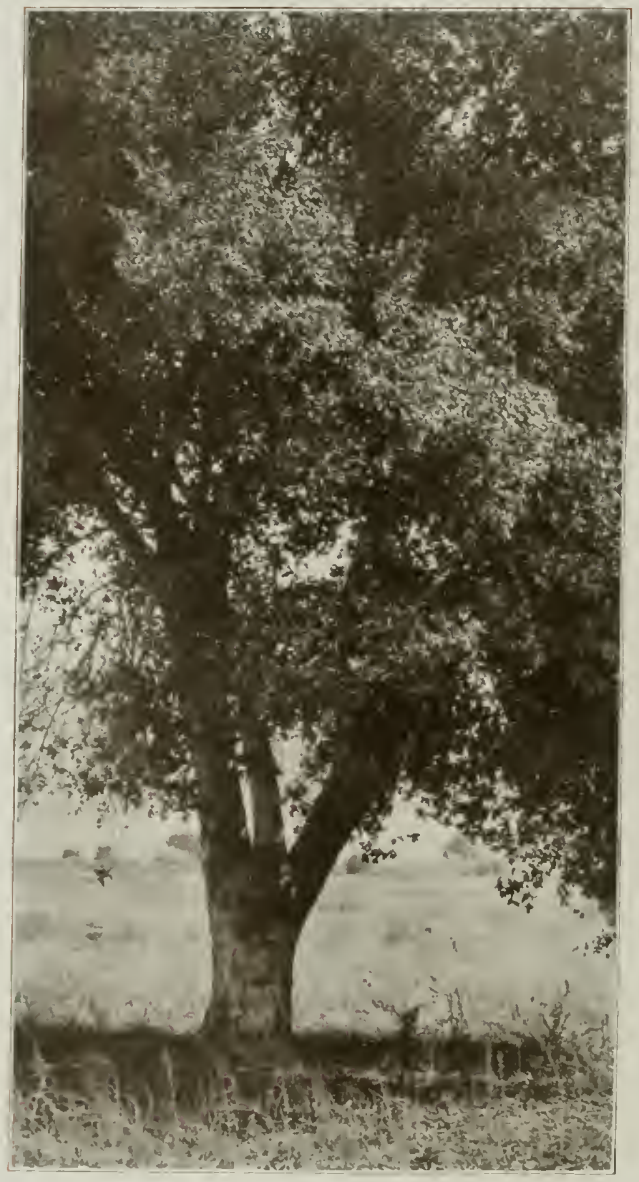

Califoria Live OAK 


\title{
CALIFORNIA LIVE OAK
}

\author{
(Quercus Agrifolia)
}

THIS fine western tree belongs to the black oak group, yet its acorns 1 mature in one year, like those of white oaks. It is the only known black oak with that habit. It is properly classed with canyon live oak which has many characteristics of white oak, yet matures its acorns the second year. The two oaks with freakish fruit belong in California, and to some extent occupy the same range. California live oak is apparently making an effort to conform to the habit of other black oaks by producing two year acorns. It has not yet succeeded in doing so, but flowers occasionally appear in the fall, and young acorns set on the twigs. They drop during the winter, and it is not believed that any of them hang till the second season.

The range of this tree covers most of the California coast region but does not reach the great interior valleys. The tree is very common in the southwestern part of the state. It is called an evergreen, and some individuals deserve that reputation, but the leaves never remain long after the new crop appears. Frequently the old leaves do not wait for the new, and when they drop, the branches remain bare for a few weeks. The form of the leaf is not constant. Some have smooth margins, but the typical leaf is toothed like holly. One of the early names by which the tree was known was holly-leaved oak. The bark looks much like the bark of chestnut oak. It is bought for tanning purposes, but its principal use is to adulterate the bark of another oak (Quercus densiflora). Trees range in height from twenty-five to seventy-five feet, and from one foot to four in diameter. The trunks are very short, and seldom afford clear lengths exceeding eight feet, and often not more than four. Trees generally grow in the open, but when in thickets, the boles lengthen somewhat. They are of slow growth and live to old age.

The wood is hard and brittle. A cubic foot weighs 51.43 pounds when thoroughly dry. The wood of mature trees is reddish-brown; but young and middle aged trunks are all sapwood, and are white from bark to center. When sapwood is exposed to the air a considerable time it changes color and becomes very dark brown. The medullary rays of this oak are broad, fairly numerous, and are darker than the surrounding wood. When the $\log$ is quarter-sawed, the exposed flecks of bright surface are the darkest parts. To that extent, it resembles quarter-sawed sycamore, but the woods do not look alike in any other particular. This oak is very porous, and the pores-as is usual with live 
oaks-are arranged in rows running from bark to center rather than parallel with the annual rings. No clear line is distinguishable between spring and summerwood.

Cordwood constitutes the most important use for California live oak. It rates high in fuel value, and the many large and crooked limbs make the tree an ideal one, from the cordwood cutter's viewpoint. By carefully ricking the wood, with the crooks and elbows in every possible direction-at which some cordwood cutters are very proficient-a cord of wood may be constructed in the forest, which, when sold and delivered in the buyer's shed, contracts like an accordion.

CANYON LIVE OAK (Quercus chrysolepis). This splendid California oak bears many names. It is an evergreen, and therefore is called live oak. It is hard when thoroughly seasoned, and this has won for it the name iron oak. Wagon makers often so designate it. It is called Valparaiso oak, but for what reason is not apparent. Black live oak doubtless refers to the dark color of the foliage. The most shapely trees grow in the bottoms of canyons, and the name, canyon live oak, refers to that circumstance. Hickory oak is not an appropriate name, though it doubtless implies that the wood possesses the toughness of hickory. It is about as tough as white oak. The name golden cup oak is a translation of its botanical name which, in Greek, means "golden scale," a reference to a yellow tomentum or wool which covers the cups of the acorns. The wood's hardness qualifies it to serve as mauls, hence the naine maul oak.

The northern limit of its growth is in southern Oregon. It goes south from there on the coast ranges of California and the western slopes of the Sierra Nevadas to the highlands of southern California. Its growth on the mountains of southern Arizona and New Mexico is always shrubby. The lowest limit of its range is about 1,000 feet above sea level, the best specimens occurring at low altitudes in the sheltered canyons of the coast ranges of California. Gradually diminishing in size, it grows to the very tops of many of the high mountains, sometimes reaching 9,000 feet, heing not more than a foot high at the upper limits of its range. In appearance this tree resembles the eastern live oak (Quercus virginiana), having the same majestic wide-spreading crown, except in the high altitudes where it forms dense thickets covering large areas.

When in its favorite habitat, the massive proportions and majestic appearance of this tree are imposing, the crown sometimes being 150 feet across, the bole short and thick, and the great branches long and horizontal. It is not clothed in the somber Spanish moss that is often present on the great live oaks of the southeastern states, but there is a similarity of appearance in the drooping slender twigs. One hundred and fifty feet across is cited as an unusual width of crown, one hundred feet being a good average size, and forty or fifty feet the usual height, although it sometimes reaches 100 . The bole is vested in a gray-brown, reddish-tinged bark, about an inch thick, and broken into numerous scales which in old age become flaky and pliable and fall off.

The bark is light colored, and has the stringy character of white oak. The tree would readily pass for a white oak were it not for its two-year acorns which class it in the black oak group. The wood resembles white oak, and weighs 52.93 pounds per cubic foot.

Few oaks, if any, retain their leaves a longer time than this. They remain on the branches three or four years. Most evergreen oaks shed theirs at the beginning 
of the second year. The leaves of this tree are pcculiar in another way. They assume various forms. That in itself is not unusual and occurs with many species; but the canyon live oak has one pattern of leaf for the young tree, another for the old. One form has a margin with sharp, hooked teeth; another has smooth-margined leaves, and there are varions intermediate forms. Sizes vary no less than shapes of both acorns and leaves. Some acorns are half an inch in length, others two inches.

The canyon live oak is believed to be long-lived, but further information is desirable. The massive trunks represent centuries. They usually occur in sheltered places which are measurably secure from the ordinary perils which beset trees, notably the woodsman's ax and the periodic forest fire. The bot toms of canyons where this oak makes choice of situation do not usually burn fiercely, and trees sheltered there escape. Cordwood cutters are the most constant peril to good fuel trees in California; but many a canyon is safe from their invasions, because of lack of roads. There the most magnificent oaks rear their crowns in security, while trees of inferior size and character, which grow on exposed slopes and flats, fall before the cordwood cutter, and go to the ricks in village woodyards.

The wood of canyon live oak is superior to that of any other oak in its range. It is of light brown color, and is tough, strong, stiff, and heavy. The trunks are generally unsuitable for sawlogs, being too short, but when a chance tree is found that may be cut into lumber, it is considered a prize. Trunks are seldom good for more than one sawlog. In that respect this oak may be compared with the sonthern live oak. The scarcity of good hardwoods on the Pacific coast adds to the value of what may be found there. If the canyon live oak grew in the East, and developed a trunk of the same size and shape as it has in its present home, it would attract no more attention from the users of hardwoods than the live oak in the South attracts now. But place makes great difference.

Factories in California do not report the use of much of this oak, yet considerable quantities of it are in service. The most important place found for it is in country and village blacksmith shops, where wagons are repaired. Nearly every piece of wood which goes into a wagon, except the bed, may be this oak. Many persons consider it the best wagon timber on the Pacific coast, and it is particularly valued for tongues, not only for wagons, but for heavy log trucks which are operated by several yoke of oxen. The wood is likewise made into singletrees. It has always been in use in California for pack saddles. That article is small, but many saddles were formerly made, and the pack saddle is still an important article in the mountains. Trains of mules, horses, and burros thread the narrow paths, where wheeled vehicles cannot go, and deliver supplies to camps and mines in remote districts. The pack saddle's strength is frequently all that intervenes between the load and destruction; for the snapping of a piece of wood may let the pack go over a precipice beyond recovery. The pack trains are slowly passing out of use in the West, as they long ago disappeared from the "bridle paths" of eastern monntains and forests; but they are still to be seen among the fastnesses of the Sierra Nevadas, as in the days when a western poet lourst into inspired song of the long pack trains going

"Up and down o'er the mountain trail

With one horse tied to another's tai]."

Hu'CKLEBERRY OAK (Quercus chry'solepis vaccinifolia) is a variety of canyon live oak, and is never large enough to supply wood for any purpose, but is valuable as a covering to the ground on exposed mountains. It is usually a shrub, and specimens no more than a foot high are mature and bear acorns enormously out of projortion to the size of the tree. If the canyon live oak of largest size in the low hills bore acorns 
proportionately as large, they would be the size of barrels. The huckleberry oak's acorns are set in their golden cups. The name huckleberry is applied because of a fancied resemblance of the leaves to those of huckleberries. They are generally less than one inch in length, sometimes not half an inch. This unique variety of oak ranges on elevated slopes and ridges of the Sierra Nevada mountains, and the traveler in climbing to the peaks is often grateful for the privilege of pulling himself up the steep slopes by grasping in his hands the tops of full grown trees.

PALMER OAK (Quercus chrysolepis palmeri) is considered a variety of canyon live oak by some, but Sudworth believes it is a distinct species, and draws his conclusion from forms of leaves, flowers, and fruit. It forms large thickets on foothills and plateaus near the southern boundary of California, eighty miles or more east of San Diego. The trees do not attain sufficient size to give them commercia! importance.

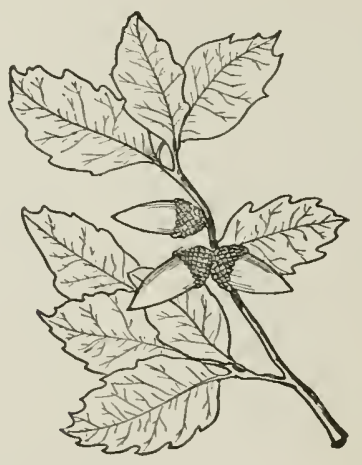


CALIFORNIA TANRARK OAK 


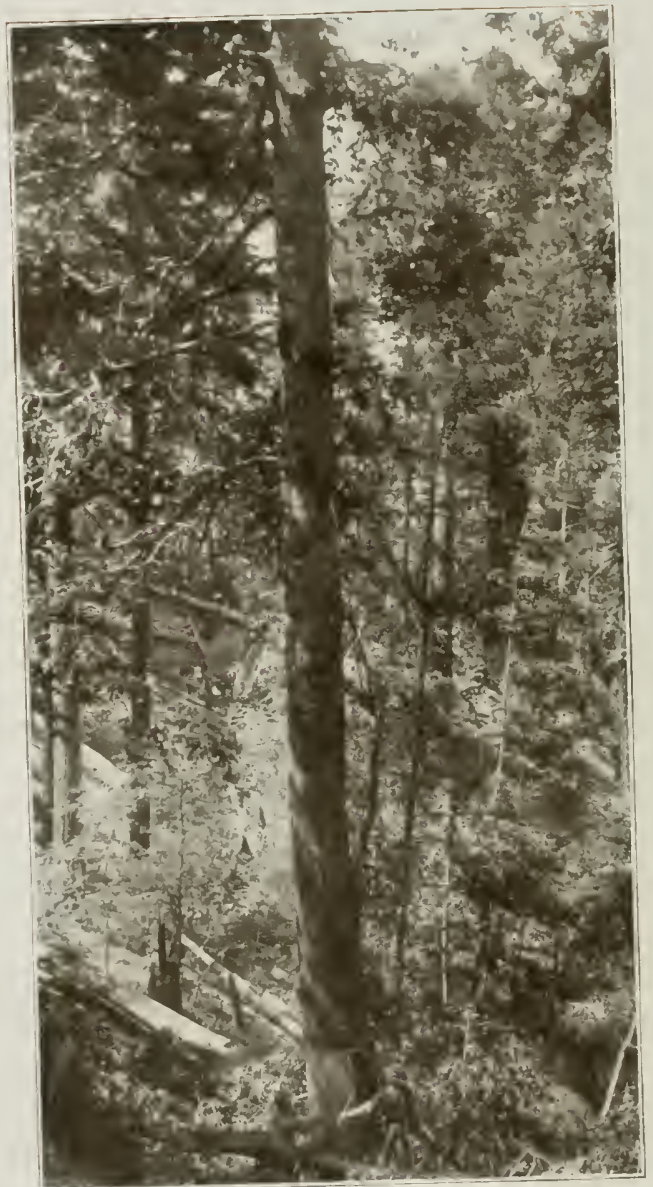

CALIFORNIA TANBARK OAK 


\section{CALIFORNIA TANBARK OAK}

\section{(Qucrcus Dcnsiflora)}

$\mathrm{B}$ OTANISTS dispute the right of this tree to the name of oak, and some of them refuse to call it an oak. It is admitted that it possesses characters not found in any other oak, but these are important to the botanist only, while laymen have never considered the tree anything but an oak. It has been variously called tambark oak, chestnut oak, California chestnut oak, live oak, and peach oak. The trunk, branches, and foliage look much like chestnut. The leaf is like the chestnut's, but it is evergreen. There are three or four crops on the tree at one time, and none fall until they are three or four years old. Young leaves are remarkably woolly, but late in their first summer they get rid of most of the fuzz, and become thick in texture.

Tanbark oaks are of all sizes, from mere shrubs on high mountains in the northern Sierra Nevadas to fine and symmetrical timber in the damp climate of the fog belt between San Francisco and the Oregon line. The average height of mature trees is from seventy to 100 feet, with diameters up to six feet in rare cases, though more trunks are under than over two feet in diameter.

The range of this oak reaches southern Oregon on the north, and runs southward three or four hundred miles along the Sierra Nevada mountains, to Mariposa county, and six hundred miles through the Coast range to Santa Barbara county. The tree is affected by climatic conditions, and where surroundings do not suit, it is small and shrubby, often less than ten feet high. It does best in the redwood belt where fogs from the Pacific ocean keep the air moist and the ground damp. It sometimes associates with Douglas fir, and at other times with California live oak. If it grows in dense side shade it loses its lower branches and develops a long, clean trunk; but in open ground it keeps its limbs until late in life.

This is the most important source of tanbark on the Pacific coast, and up to the present it has been procurable in large quantities. The annual output is nearly 40,000 tons, and it commands a higher price than the bark of any other oak or of hemlock. The absence of other adequate tanning materials on the Pacific coast gives this tree much importance. Its range covers several thousand square miles, and the stand is fairly good on much of it. But on the other hand, the destruction of timber to secure the bark has been excessive. What occurred with chestnut oak and hemlock in the East, is occurring with tanbark oak in the West. Trees are cut and peeled, and are lcft by thousands 
to rot in the woods, or to feed fires and make them more destructive. The bark peelers do their principal work in the California redwood region, because there the oak is at its best. Economic conditions make the salvage of the trunks impossible. The bark can be hauled to market, but the wood is unsalable at living prices, after the long haul. It has, therefore, been usually abandoned, and becomes a total loss. It cannot even be sold for fuel, because the country within reach of it is thinly settled, and wood is plentiful on every side.

Large oaks are felled, because the bark san not be stripped from the trunks in any other way, and small trees are not spared. The peelers often do not take the trouble to cut them down, but strip off the bark as high as a man can reach, and leave them standing. A future tree is thus destroyed for the sake of a strip of bark a few feet long. Such trees live a year or two, sometimes several years, before yielding to the inevitable. Usually, as a last expiring effort, they bear an abnormally large crop of acorns. That performance, in the language of the bark peelers, is "the last kick." A tanbark slashing, when the peelers are ready to abandon it, is a sorry spectacle. The barkless and sun-cracked trunks strew the ground, the tops and limbs are piled in windrows, the small peeled trees stand dying, and the last ricks of bark have been sledded down the tote roads, marking the close of operations in that district. A few months later, when fire runs through, the end of the tanbark oak on that tract is accomplished.

Within recent years commendable efforts have been made to use the wood as well as the bark. One of the first steps in that direction was to overcome the prejudice against the wood. It was long considered to be valueless. That belief was founded on the single fact that this oak is difficult to season. Few woods in this country check as badly as this, when it is left exposed to sun and wind after the bark has been removed. It checks both radially and along the annual rings. The medullary rays are broad and extend much of the distance from the center to the outside. These are natural lines of cleavage when the log begins to scason and the internal stresses develop. It must be admitted that the prospect of making anything out of timber of that character is discouraging; but it has been accomplished, and tanbark oak is now a material of considerable value.

The wood has about the strength and stiffness of white oak, while it is four pounds lighter per cubic foot. The structure is similar to that of California live oak, but the pores of tanbark oak are smaller. They run in rows from center to circumference. The medullary rays are broad enough to show well in quarter-sawing, but the wood's appearance when so worked is not wholly satisfactory. The exposed flat surfaces 
of the rays show a faint purplish or violet tinge which is considered objectionable. But when the wood is worked plain it is dependable and substantial. It makes good flooring, fairly good furniture, finish, vehicles, and agricultural implements. It is perishable when placed in damp situations, and this detracts somewhat from its value as railway ties; but the wood's porous nature indicates that it will readily yield to preservative treatment.

Since the value of the wood is coming to be understood it is to be expected that less of it will be destroyed than formerly, and that second growth will be given opportunity to hold the ground when old stands are cut. The tree is a prolific seeder, but not every year, and seedlings come up abundantly in sheltered places. Sprouts rise from stumps and grow to vigorous trees. It would seem, therefore, that the tanbark oak will hold at least part of the ground where nature planted it.

TOUMEY OAK (Quercus toumeyi). No oak in this country has smaller leaves than this. They are usually less than three-fourths of an inch long and half an inch wide, and they hang on petioles one-sixteenth inch long. The leaves have no lobes or notches. They remain all winter and fall in the spring in time to make room for the new crop. The acorns are nearly as long as the leaves and ripen in June of the first year. Few persons ever see this oak, for its known range is restricted to Mule mountain, in Cochise county, southeastern Arizona. It attains a height of twenty-five or thirty feet, and a diameter of six or eight inches. The trunk is not only small, but is of form so poor that it can never be of value for anything but fuel. It divides near the ground into crooked branches. The heart of the tree is light brown, the thick sapwood is lighter.

Woolıy OAK (Quercus tomentella) has apparently been crowded off the American continent and has taken refuge on islands off the southern California coast. As far as known, not a single tree stands on the mainland, but several groves, with a few isolated specimens, are found on Santa Cruz, Santa Rosa, and Catalina islands, where they are huddled together in the hot torns of sheltered canyons. The leaves are thick, leathery, and are toothed like holly. The trees are evergreen. The acorns do not mature until the second season. They are generally more than an inch long. The scarcity of this oak relegates it to an unimportant place among commercial woods. This seems unfortunate, for the appearance of the wood indicates that it possesses excellent properties. No other oak looks like this wood. It is decidedly yellow, and is dense and firm. The medullary rays are different from those of any other oak. When seen in cross section they are arranged in short, wavy lines, broadest in the middle and tapering toward both ends. The pores are arranged hetwcen the rays, and follow wavy lines also. Trees grow with fair rapidity, and the largest on the islands are seventy-five feet high and two in diameter.

BARREN OAK (Quercus pumila) is called dwarf black oak, or simply scrub oak. Its habit of growing on barren land is responsible for its common name which some people shorten to "bear" oak. It is one of the poorest oaks of the East, and it scidom 
grows more than twenty-five feet high and a few inches in diameter. Its range follows the Atlantic coast southward from Mount Desert Island, Maine, to North Carolina. It is probably more abundant on the pine barrens of New Jersey than elsewhere. The trunks are too small to be of use for anything but fuel.

PRICE OAK (Quercus pricei) is a California tree, supposed to be very local in its range, since it has not been found outside the drainage basin of a small stream in Monterey county. That locality on the coast of California appears to be the starting place or principal abiding place of several tree species, among which are Monterey cypress and Monterey pine. The Price oak attains a height of twenty-five or thirty feet, and a diameter of twelve inches or less; consequently it is too small to be of value to lumbermen, even if it were abundant. The leaves resemble those of California live oak, and are believed to remain two summers on the tree. The acorns mature the second season.

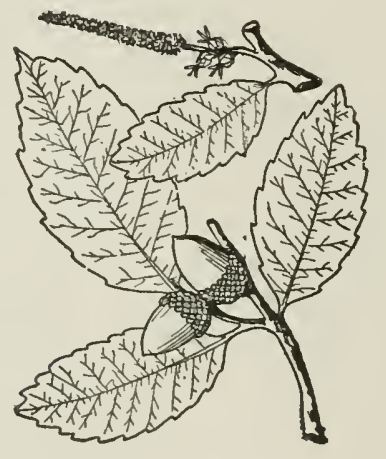


SHINGLE OAK 


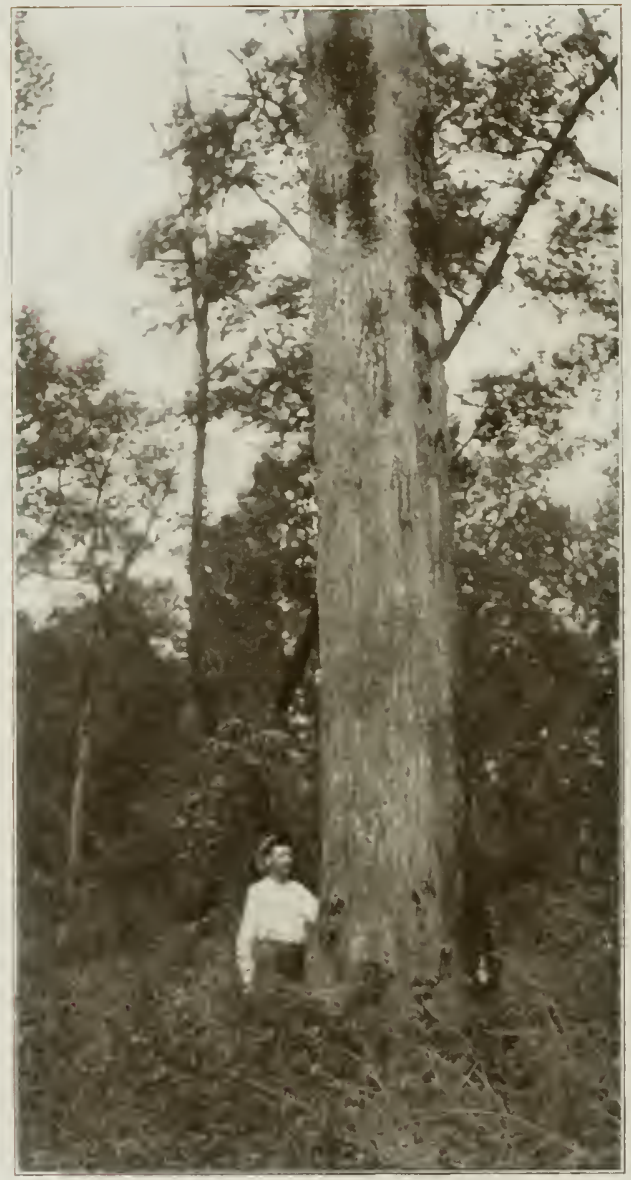

SHINGLE OAK 


\section{SHINGLE OAK}

\section{(Quercus Imbricaria)}

T HE origin of this tree's name has been the subject of considerable controversy. According to one account the name was first used by the French colonists at Kaskaskia, Illinois, nearly 150 years ago. They found that the wood rived well and it was abundant in the vicinity of their settlement. They split it for shingles and covered their cabins. It was the best wood obtainable for the purpose in that region, and they designated the tree shingle oak, a name translated into Latin by the botanist Michaux and still retained as the tree's botanical name. The story of the name appears to be well authenticated, but the fact cannot be denied that as much reason exists for another theory. A person who sees a shingle oak tree in full leaf, particularly if it stands in open ground where its foliage has had opportunity to develop along natural lines, will at once notice the peculiar and characteristic overlapping of the leaves. They suggest the courses of shingles nailed on a roof. No other oak has that arrangement. The similitude is so striking that it would be surprising if the name shingle oak were not applied.

It is not a one-name tree, but following the fashion, it carries several names. It is called laurel oak in some regions. The form and appearance of the leaf give the name. The oak looks like a mammoth laurel tree more than like its own species. The shingle oak is known as jack oak in some parts of Illinois. That is a name liable to be applied to any tree when its real name is not known. In North Carolina they call the tree water oak, which name, like jack oak, is of ten used to conceal ignorance of the true name. Another southern species (Quercus nigra) is properly named water oak.

Shingle oak requires good soil for growth but is not partial either to uplands or bottoms. It is found at its best in the lower Ohio river basin and in Missouri, but is comparatively rare in the East. From middle Pennsylvania its range extends southward along the Alleghanies to northern Georgia, Alabama, Tennessee, and west Arkansas. It is found in Michigan, Wisconsin, and westward to Kansas.

It manifests a strong tendency to hybridize with other oaks, and it readily crosses with black jack oak, pin oak, and yellow oak. It is believed that a cross between yellow oak and shingle oak produced the species known as lea oak.

A mature tree may be one hundred feet high and three or four feet in diameter. It has a round or pyramidal attractive crown composed of many slender branches and twigs. The foliage is distinctively 
grouped at the ends of the twigs in star-like clusters. The leaves are four or six inches long, with wedge-shaped or rounded bases, and are deep green and shiny on the upper side, but lighter below. The acorns are short, stubby, and rounded, covered one-third of the way with thin shallow cups.

Shingle oak grows rapidly, and it is often sold by nurseries which deal in ornamental forest trees. It is hardy as far north as Massachusetts. Although it bears great abundance of leaves, they are so arranged that the crown seems open. One may see through the branches of a large shingle oak, and it suggests an airiness not common with oaks.

Differences of opinion exist concerning the value of shingle oak for commercial purposes. It belongs in the black oak group, and its wood goes to market as red oak, and apparently is never listed as anything else. It is never named in market reports; shops and factories never report it, and it has been pronounced inferior to red oak in strength and seasoning properties. Tests have been made of some of its physical properties, and the results do not indicate that the wood belongs with inferior timbers. Its breaking strength is given at 39 per cent greater than white oak, and its stiffness at 28 per cent greater. However, these values, which are calculated from Sargent's tables, are based on tests of only a few specimens of the wood, and fuller investigation might make revision necessary.

The wood is heavy, hard, and is said to check badly in drying. The pores are large and are arranged in rows; medullary rays are broad and conspicuous. The wood is light brown, tinged with red, the sapwood much lighter. The broad medullary rays, running radially, give the wood its good splitting qualities.

The tree is fairly abundant in different parts of its range, and is cut and manufactured with other oaks and hardwoods. Slack coopers use it for barrels; box makers employ it for crates; chair mills saw dimension stock and ship it to factories to be finished; some goes to furniture factories; some is turned for spindles for grills, and for balusters for stairs; other fills various places as interior finish and molding. But it all goes to market and passes through factories under names other than its own.

WATER OAK (Quercus nigra) has several names, some of them bestowed with little apparent reason. It is called possum oak and duck oak, but these names are neither descriptive nor definitive. Punk oak is another name. It may refer to a decayed condition of the wood, but this tree is no more affected by decay than others of the same region. In Texas it is sometimes known as spotted oak. It thrives in wet situations though not actually in swamps. It prefers margins of ponds, 
banks of rivers, and low swales where the ground water is just below the surface, but it is not confined to such situations. It does well, within its range, wherever willow oak flourishes, but willow oak has a wider range. The leaves take on various forms, and they change shape as they increase in size. Some have smooth margins, others are lobed. Some are wedge-shaped, others coffin-shaped. Their typical form, if it may be said of them that they have a typical form, is narrow at the stem end and wide at the other. To this is usually added rudimentary lobes, which are sometimes nearly as well developed as in any other oak. Their typical form is like the leaf of the black jack oak; but they are not half as large, and are thin and delicate, while the black jack's leaf is thick and leathery.

The range of water oak begins in Delaware and follows the Atlantic coastal plain south to central Florida, and through the Gulf States to Texas. It grows as far north as Kentucky and Missouri. It keeps clear of the Appalachian mountain region, and other hilly districts. It is plentiful in some parts of its range, and trunks three feet in diameter and long enough for two or three logs are not unusual, yet large numbers of water oaks may be seen in the South which are not fit for sawlogs because they stand in open ground and are limby down to ten feet of the ground. Many have been planted for shade trees in streets and in parks, and are justly admired. They grow rapidly and are extremely graceful. Their leaves are deciduous, but adhere to the branches most of the year. South of the belt of severe frost, the old leaves frequently hang until the buds for the new crop are opening. The acorns are bitter, and even the southern pine hog passes them by until the pinch of famine edges up bis appetite.

Water oak possesses value as a source of lumber, but it belongs with the large class of oaks which lose their names and their identity when they pass the threshold of the sawmill. They come out red oak. Only in rare instances is water oak called by its own name in the factory and lumber yard. Wagon makers employ it for bolsters, axles, spokes, tongues, sandboards, hounds, felloes and reaches. Entire dump carts, except the iron, are constructed of this wood. Furniture manufacturers use it as frame inaterial, but seldom as the outside visible parts, though no reason for not doing so is offered. Objection is made to its seasoning qualities, but the same objection applies to most red oaks. A considerable amount of water oak is cut in the South into thick planks for bridge floors. It is strong and hard, and satisfactorily resists decay in that place; though, in common with the black oaks generally, it is liable to decay when exposed to dampness. The wood weighs a little less than white oak, and is not 
quite as strong or as stiff. It is porous, but the pores are small, except one or two rows in the springwood. The medullary rays are thin and not numerous, but they are conspicuous, and the rood may be successfully quarter-sawed. The lumber has the appearance of red oak, though the reddish color is not so pronounced.

BARTRAM OAK (Quercus heterophylla). This interesting but commercially unimportant oak was named by Michaux from a single tree found in a field belonging to John Bartram near Philadelphia more than a century ago. A few trees have since been found in widely scattered districts as far south as North Carolina and as far west as Texas. Botanists believe it is a hybrid, one parent being the willow oak (Quercus phellos) and the other yellow oak (Quercus velutina). It is probable that here may be witnessed the origin of a tree species. The leaves seem to be a compromise between the deeply cut foliage of yellow oak and the entire leaf of willow oak. The new species is so scarce that few people have ever seen it.

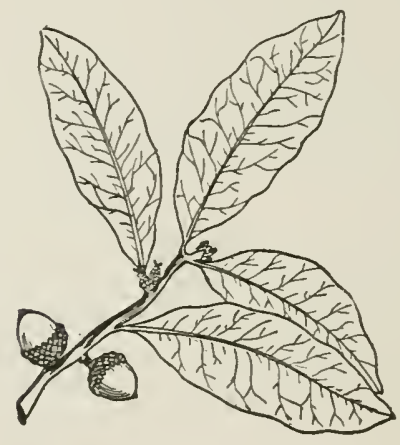


RED GUM 


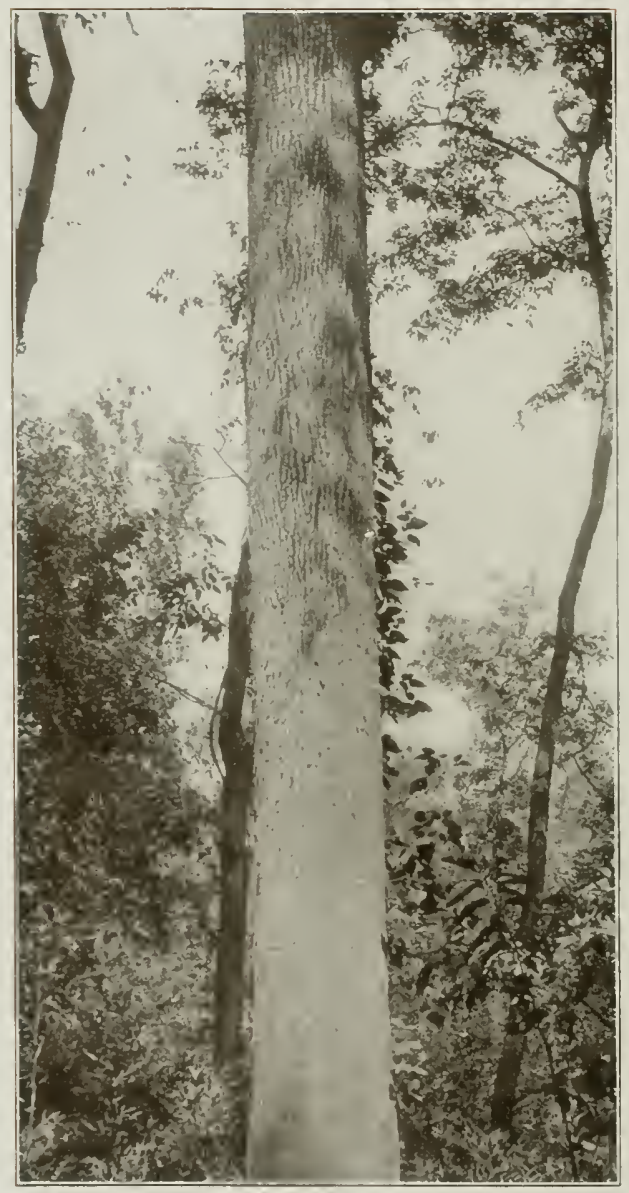

RED G(Y) 


\section{RED GUM \\ (Liquidambar Styracifua)}

$\mathrm{T}$ HIS tree does not belong to the same group as black gum and tupelo, which are in the dogwood family, while red gum is of the witch hazel family. If a tree is to be judged and named by its character, red gum is more entitled to the name "gum" than any other tree of this country, because it exudes a yellow resin from wounds in the bark. The botanical name recognizes that fact. Storax is procured from a closely related tree is Asia, and has been known in commerce for many centuries. The other popular names of red gum are sweet gum, liquidamber, gum, gum tree, alligator wood, bilsted, starleaved gum, and satin walnut.

The last name originated in England where it was desirable to avoid the name gum when applied to the wood of this tree. Though botanically it is about as distantly related to walnut as any tree can be, the figure of the wood often suggests walnut. The name sweet gum refers to the pleasant odor of the resin which is sometimes used in France, and probably elsewhere, to perfume gloves. Alligator wood is descriptive of warty excrescences on the bark of some trees, but they are not common to all. Starleaved gum relates to the leaf. It is a lopsided star-a six point star with one point missing.

This tree's range in the United States extends from Connecticut to Texas and as far northwest of the Alleghanies as Missouri and Illinois. It reaches its greatest size in the lower Mississippi valley in rich bottom land which is subject to repeated inundation. It is not, however, as purely a swamp tree as tupelo and cypress. It grows well on land which is never inundated, but it needs plenty of moisture. 'The largest specimens exceed a height of 120 feet and a diameter of four; but logs from eighteen inches to three feet are the usual sizes. The tree's range extends southward through Mexico into Central America.

The rise of red gum lumber into prominence forms an interesting chapter in the industry. It was formerly considered so difficult to season that few mills cared to deal with it, but that difficulty has been largely overcome. In the past, gum, having no market value, was left standing after logging; or, where the land was cleared for farming, was gircled and allowed to rot, and then felled and burned. Not only were the trees a total loss to the farmer, but, from their great size and the labor required to handle them, they were so serious an obstruction as often to preclude the clearing of valuable land. Now that there is a market for the timber, it is profitable to cut gum with otlicr hardwoods, 
and land can be cleared more cheaply. This increase in the value of gum timber will be of great benefit to the South in many ways.

Throughout its entire life red gum is intolerant of shade. As a rule seedlings appear only in clearings or in open spots in the forest. It is seldom that an overtopped tree is found, for the gum dies quickly if suppressed, and is consequently nearly always a dominant or intermediate tree. In a hardwood bottom forest, the timber trees are all of nearly the same age over considerable areas, and there is little young growth to be found in the older stands. The reason for this is the intolerance of most of the swamp species.

Red gum reproduces both by seed and by sprouts, fairly abundantly every year, but about once in three years there is a heavy production. In the Mississippi valley the abandoned fields on which young stands of red gum have sprung up are, for the most part, being rapidly cleared again. The second growth here is considered of little worth in comparison with the value of the land for agricultural purposes.

A large amount of red gum growing in the South can be economically transported from the forests to the mills only by means of the streams, owing to the expense of putting in railroads solely for handling the timber. Green red gum, however, is so heavy that it scarcely floats and, to overcome this difficulty, various methods of driving out the sap before the logs are thrown into the river have been tried. One method is to girdle the trees and leave them standing a year. That partly seasons them, but does not give time for the sapwood to decay. The logs from such trees float readily, and the swamps and streams are utilized to carry the logs to the mills.

Some years ago that method of seasoning red gum was extensively advertised in England by contractors who sold paving blocks of this wood. It was claimed that the common defects of red gum were thus overcome. Large sales of paving material were made, particularly in London, and red gum was popular for a time, but it finally lost its hold as a paving wood in competition with certain Australian woods. The theory that by girdling a tree and allowing it to die, the amount of heartwood will be increased has been abandoned. In selecting trees for cutting, those with doty tops, rotten stumps, and heavy bark, indications of an old tree which contains a very small proportion of sapwood, are now chosen. These are found mainly in the drier localities. In low, wet places the trees have more sapwood and are smaller. The heartwood forms while the tree is living, not after it dies.

The rapidity with which red gum has come into use in this country and elsewhere is the best evidence of the wood's real value. Its range 
of uses extends from the most common articles, such as boxes and crates, to those of highest class, like furniture and interior finish. It is only moderately strong and stiff, and is not a competitor of hickory, ash, maple, and oak in vehicle manufacturing and other lines where strength or elasticity is demanded; but in ncarly all other classes of wood uses, red gum has made itself a place. It has pushed to the front in spite of prejudice. As soon as the difficulties of seasoning were mastered, its victory was won. Its annual use in Michigan, the home and center of hardwood supply, exceeds $20,000,000$ feet in manufactured articles, exclusive of what is employed in rough form. In Illinois, the most extensive wood-manufacturing state in the Union, red gum stands second in amount among the hardwoods, the only one above it being white oak. In Kentucky, only white oak and hickory are more important among the factory woods, while in Arkansas, where the annual amount of this wood in factories exceeds $I 00,000,000$ feet, it heads the list of hardwoods.

As a veneer material, it is demanded in four times the quantity of any other species. The veneer is nearly all rotary cut, and it goes into cheap and expensive commodities, from berry crates to pianos.

The wood weighs 36.83 pounds per cubic foot. It is straightgrained, the medullary rays are numerous but not prominent, the pores diffuse but small, and the summerwood forms only a narrow band, like a line. The annual rings do not produce much figure, but wood has another kind of figure, the kind that characterizes English and Circassian walnuts, smoky, cloudy, shaded series of rings, independent of the growth rings. They have no definite width or constant color, but the color is usually deeper than the body of the wood. This figure is one of the most prized properties of red gum. It is that which makes the wood the closest known imitator of Circassian walnut.

All red gum is not figured, and that which is figured may be worked in a way to conceal or make little use of the figure. It shows best in rotary cut veneer and tangentially sawed lumber. Various woods are imitated with red gum. It is stained or painted to look like oak, cherry, mahogany, and even maple.

Some trees have thin sapwood, and others are all sapwood. This peculiarity sometimes leads to misunderstandings in lumber transactions. A buyer specifies red gum, expecting to get red heartwood, but the seller delivers lumber cut from the red gum tree, though light colored sapwood may predominate. Properly speaking, the name is applied to the tree as a whole and does not refer to any particular color of wood in the tree. The term "red" is said to have referred originally to the color of autumn leaves, and not to the wood. 
The fruit of red gum is a bur, midway in appearance and size between the sycamore ball and the chestnut bur. It hangs on the tree until late in winter. The resin which exudes from wounds in the bark is of much commercial importance and is shipped from New Orleans and Mexican ports. Near the northern limit of the species' range the trees yield little resin, but it is abundant farther south. In the southern states it is used locally as chewing gum. It is known commercially as copalm balm.

WrTch HAZEL (Hamamelis virginiana) is a cousin to red gum, but there is small resemblance. It is known as winter bloom, snapping hazel, and spotted alder. Its range extends from Nova Scotia to Nebraska, Texas, and Florida. It reaches its largest size among the southern Appalachian mountains where the extreme height is sometimes forty feet, with a diameter of eighteen inches; but few people have ever seen a witch hazel that large. It is usually fifteen or twenty feet high and three or four inches in diameter. The wood is much like that of red gum, being diffuseporous with obscure medullary rays, and a thin line of summerwood. It is of little commercial use; in fact, no report has been found that a single foot of it has ever been used for any purpose. Yet it is a most interesting little tree. It blooms in the fall, sometimes as late as the middle of November. Its rusty summer foliage turns yellow in autumn, and as the leaves begin to fall, the tree bursts into delicately-scented golden flowers, the inost visible part of each consisting of four petals which float out like streamers. At the same time that flowers are scenting the air, the seeds are discharging. A full year is required to ripen them; and when dry, cold weather comes, the contraction of their envelopes shoots them with sufficient force to send them fifteen or twenty feet. They depend on neither wings, birds, nor squirrels to scatter them. The origin of the name witch hazel is disputed; but the person who examines the open-topped button which holds the black seeds, and notes the fantastic resemblance to a weasen face, will feel satisfied that he can guess the origin of the name. The tree's bark is used for medicine, in extracts and gargles.

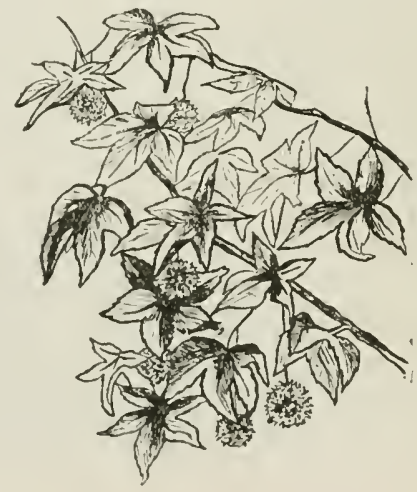


BLACK GUM 


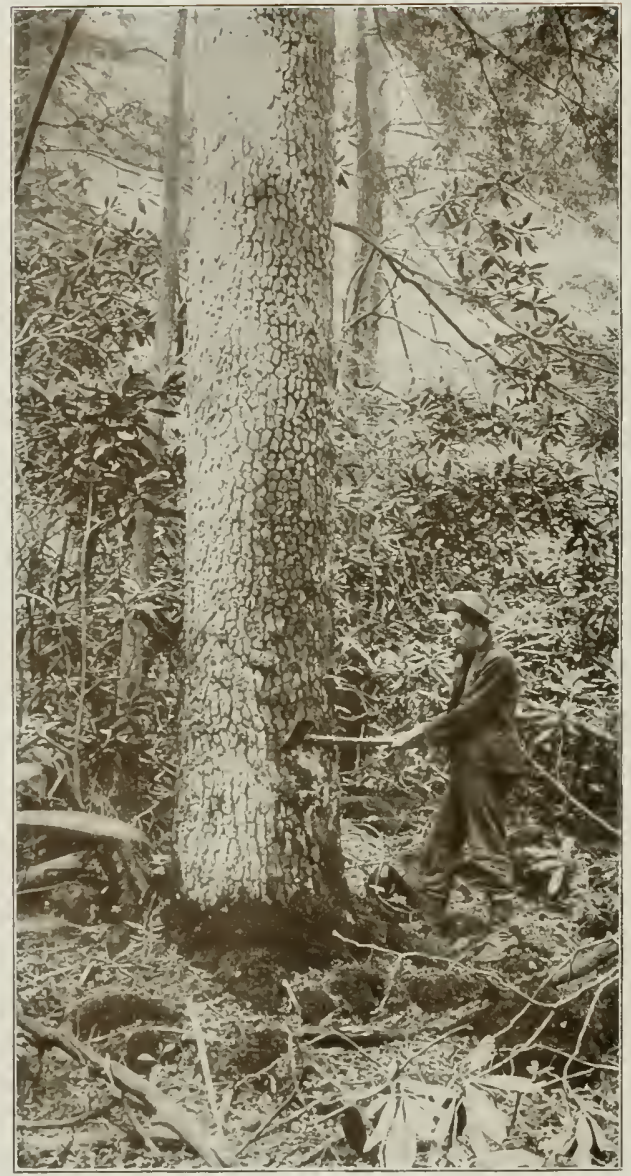

Black Gum 


\section{BLACK GUM}

\section{(Nyssa Sylvatica)}

$\mathrm{B}^{\mathrm{i}}$ LACK gum grows from the Kennebec river in Maine to Tampa bay, Florida; westward to southern Ontario and southern Michigan; southward through Missouri, as far as the Brazos river in Texas. The names by which it is known in different regions are black gum, sour gum, tupelo, pepperidge, wild pear tree, gum, and yellow gum.

The leaves of black gum are simple and alternate; not serrate. They are attached by very short petioles, which are fuzzy when young; they are a rich, brilliant green above and lighter below; rather thick, with prominent midrib. As early as the latter part of August the leaves commence to turn a gorgeous red. The flowers are greenish and inconspicuous, growing in thick clusters, the staminate ones small and plentiful, the pistillate ones larger. They bloom in April, May or June. The fruit of black gum is a drupe about one and a half inches long; inside of it is a rough, oval pit; the pulp is acrid until mellowed by frost.

The bad name given to black gum by early settlers of this country has stayed with it, though the faults found with it then, should hold no longer. The pioneers were nearly all clearers of farms. They went into the woods with ax, maul, mattock, wedges and gluts, and made fields and fenced them. The fencing was as important as the clearing, for the woods were alive with hogs, cattle, and horses, and the crop was safe nowhere except behind an eight-rail staked and ridered fence. The farmer mauled the rails from timber which he cut in the clearing, and there it was that he and black gum got acquainted. The oak, chestnut, walnut, cherry, yellow poplar, and red cedar were split into rails and built into fences; but black gum never made a fence rail. No combination of maul, wedge, glut, determination, and elbow grease ever split a black gum log within the borders of the American continent. An iron wedge, driven to its head in the end of a rail cut, will not open a crack large enough to insert the point of a pocket knife. In fact, it is as easy to split the $\log$ crosswise as endwise. Consequently, the early farmers heaped their anathemas and maranathas on black gum and passed it by.

Nevertheless, the tree had its virtues even in the eyes of the railsplitters; for, though it was unwedgeable, it helped along the fence rail industry in a very substantial way by furnishing the material of which mauls were made. It drove the wedges and gluts which opened other timbers. About the only maul that would beat out more rails than one of black gum was that made of a chestnut oak knot. The oak beetle's 
only advantage over gum was that it was harder and wore longer. So involved and interlaced are the fibers of black gum, that they cross one another not only at right angles, but at every conceivable angle. This can be seen in examining very thin pieces with a magnifying glass.

The wood is not hard, but is moderately strong, and stiff. It has been compared with hickory, but it is so inferior in almost every essential that no comparison is justified.

Black gum weighs 39.61 pounds per cubic foot. It is very porous, but the pores are too small to be seen by the naked eye, and are diffused through the wood and form no distinct lines or groups. The summerwood is a thin dark line, not prominent enough to clearly delimit the yearly rings of growth. The medullary rays are numerous, but very thin. In quarter-sawed wood they produce a luster, but the individual rays are practically invisible. The wood is not durable in contact with the soil.

The standing tree is apt to fall a victim to the agencies of decay. Hollow trunks, mere shells, are not uncommon. The entire heartwood is liable to fall away. The pioneers cut these hollow trees, and sawing them in lengths of about two feet, made beehives of them. They called them gums because they were cut from gum trees. Larger sizes, used in place of barrels, were also called gums, but these were usually made from sycamores. The black gum is not usually large. Individuals have been measured that were five feet in diameter and more than a hundred in height, but an average of sixty feet high and two in diameter is probably too much, except in the southern Appalachian mountains where the species attains its largest size.

It is a tree which will always be easily recognized after it has been seen and identified once. Its general outline, particularly when leaves are off, is different from other trees associated with it. It might possibly be mistaken for persimmon uniess looked at closely; but there are easily-recognized points of difference. Its branches are very small, slender, and short. Its bark is rougher than that of any other gum, and is much darker in color. It is the bark's color that gives the tree its name. The leaves have smooth edges. In the fall they change to gorgeous red, and one of their peculiarities is that half a leaf may be red while the other half remains green. Toward the end of the season, the green disappears. The dark blue drupes ripen in October. They do not seem to be food for any living creature.

Sawmills include black gum with tupelo in reporting lumber cut, and generally call both of then gum without distinction. The woods are quite different, and neither the standing tree nor the lumber of one need be mistaken for the other. The range of black gum is much more 
. extensive than that of tupelo. Gum lumber cut north of the Ohio and Potomac rivers may be safely classed as black gum, though a little of both red and tupelo gum is found north of those streams. In the South, the species cannot be separated by regions, for all the gums grow from Texas to Virginia. The total annual output of black gum is not known, but some operators estimate it at about $20,000,000$ feet a year, or nearly one-fourth as much as tupelo.

The bulk of black gum lumber is used in the rough, for floors, sheathing, frames, and scaffolds; but a considerable portion is further manufactured. The amounts thus used annually have been ascertained for a few states, and furnish a basis for estimates for the whole country: Mississippi, 7,000 feet; Maryland, 85,000; Illinois, 120,000; Louisiana, 120,000; Missouri, 190,000; Texas, 360,000; Massachusetts, 475,000; Alabama, 4S6,000.

The uses are general, except that the wood is not employed where attractive figure is required, for black gum is as plain as cottonwood. It is not displeasing in its plainness, for the surface finishes nicely with a soft gloss which, except that it lacks figure, suggests the sap of red gum. It is specially useful in situations where noncleavability is required. Black gum mallets for stone masons and woodworkers are in the market. Mine rollers require a much larger amount. The entire $\$ 5,000$ feet reported in Maryland was made into such rollers. They furnish the bearing for the rope that hauls the car up the incline out of the coal pit. Its toughness qualifies it for wagon hubs, but it is sometimes objected to because its sof tness causes the mortises to wear larger where the spokes are inserted, and the wheel does not stand as well as when the hubs are of good oak. Early farmers and lumbermen preferred black gum for ox yokes, and some are still seen where oxen are used; but many other woods are as strong and equally as serviceable for yokes. Rollers of this wood for glass factories are common. It is made into hatters' blocks where a wood is wanted which, when thoroughly seasoned, will hold its shape. It is less popular for this purpose than yellow poplar. One of the best places for black gum is in the manufacture of bored water pipe. The wood's interlaced fiber prevents splitting under the internal stress due to hydrostatic pressure. The shell of such pipes can be thimer than with most woods. A drawback is found in the won-durable qualities of black gum. However, the internal pressure of water keeps the wood thoroughly saturated, and prolongs its life when uscd as pipes.

The makers of firearms employ black gum as gunstocks and pistol grips. The wood is stained to make it darker. It is cut by the rotary process into cheap veneer and is made into baskets and berry crates. Less trouble with the veneer, on account of breaking, is expcrienced 
than might be expected of a wood so cross-grained. It is sawed into thin lumber for boxes for shipping coffee and other groceries. It is a substitute for cottonwood and yellow poplar in the manufacture of certain lines of woodenware, notably, ironing.boards, rolling pins, potato mashers, and chopping bowls. It is made into interior finish for houses; and furniture manufacturers find many places where it is a serviceable material. Musical instrument makers employ it, particularly as trusses for pianos, and in frames of pipe organs. In Louisiana it is converted into excelsior, and in Mississippi into broom handles, and parts of agricultural implements, particularly hoppers and seedboxes.

All gums are hard to season, and this one is no exception. It checks badly, but the checks are usually very small.

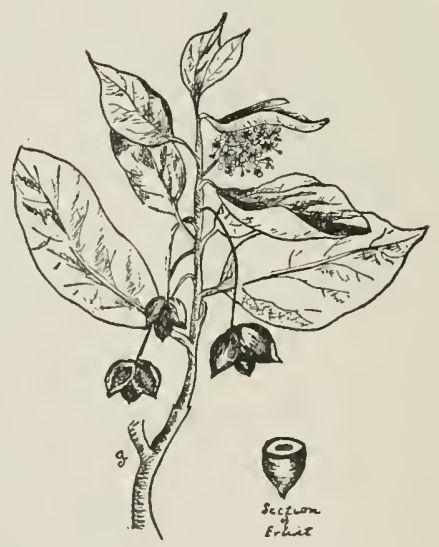


TUPELO 


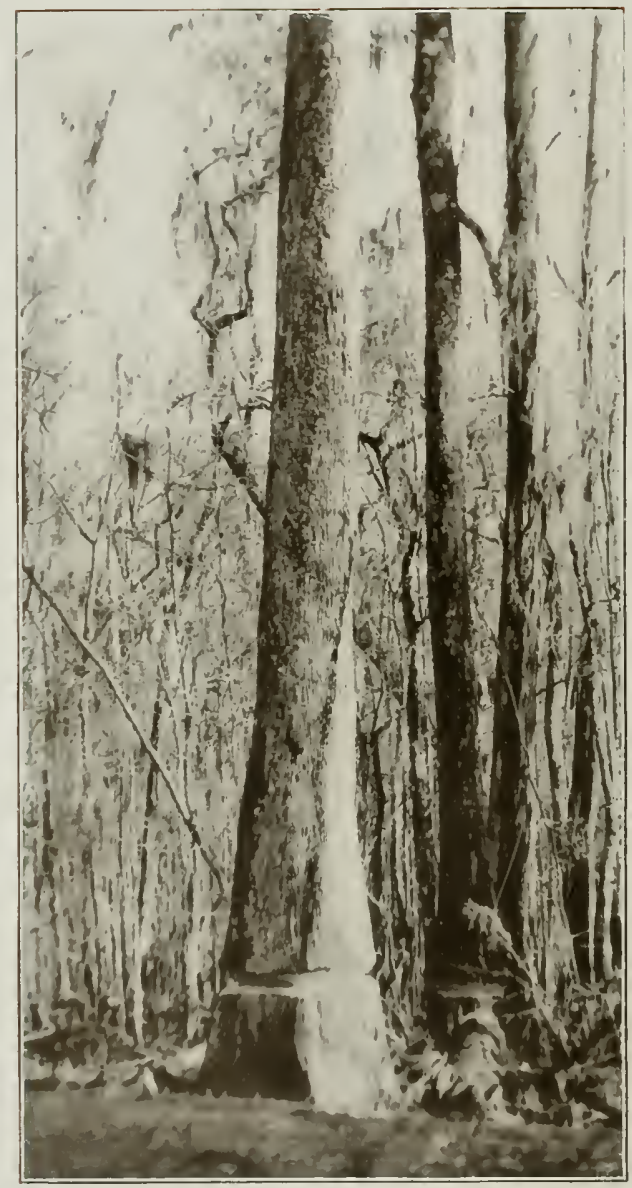

TIPELLO 


\section{TUPELO}

\section{(Nyssa Aquatica)}

$\mathrm{T}$ UPELO is said to be an Indian name. White men have applied it to three species of gum, all of the same genus, namely, black gum (Nyssa syliatica), sour tupelo (Nyssa ogeche), and tupelo (Nyssa aquatica). Probably, the name tupelo applies as well to one as to the other, for it is said to refer to the drupe-like fruit; but custom confines the name to the species now under consideration. It is largest of the three species, most abundant, and most important. Sour gum is heard in Arkansas and Missouri, swamp tupelo in South Carolina and Louisiana, cotton gum in the two Carolinas and Florida, wild olive tree in Louisiana, and olive tree in Mississippi.

The range of tupelo extends from Virginia along the coast to Florida, northward in the Mississippi valley to southern Illinois, and westward to Arkansas and Texas. It prefers swamps and attains largest size in low ground which is subject to frequent overflow. The tree will stand in several feet of water the greater part of the year without injury. It is closely associated with cypress, the planer tree, and other species which grow in deep swamps.

Tupelo has not figured much in tree literature outside the books of botanists. Travelers and local writers have paid it little attention. It has not been remarkable for anything in the past, and has escaped observation to a large extent because it grows in swamps and along bayous, remote from the usual routes of travel. Its flowers attracted no attention, its fruit was worthless, and the early settlers did not put themselves to trouble to procure the wood for any purpose. That was the situation from the early settlement of the country where this species is found up to a very recent period when economic conditions began to bring tupelo into notice.

It first attracted attention in the markets as a substitute for yellow poplar. That was brought about by an attempt to pass it as poplar. The growing scarcity of that wood in the region about Chesapeake bay led to the trial of tupelo. It was sold as bay poplar, and the purcliaser was left to infer that it was poplar cut in the region tributary to Chesapeake bay. Probably few buyers were deceived, but they found the wood a fair substitute for the yellow poplar whicl they had been purchasing in the Baltimore and Norfolk markets. It is known as bay poplar yet in many localities. It goes to England as such. One of its most important uses in that country is as casing for electric wire fittings. It has, however, many other important uscs in England and on the 
continent. It is claimed that it may be stained to imitate Circassian walnut in the manufacture of furniture. This is possible, but most probably tupelo has been confused with red gum which is a well-known substitute for Circassian walnut.

Tupelo trees attain a height from seventy to a hundred feet, and a diameter of two to four feet above the swelled base. The general appearance of the bark suggests both yellow poplar and red gum. Trees have a habit of forking near the tops. The leaves are five or seven inches long, sometimes with smooth margins, and often with a few sharp points. Flowers appear in March and April, and fruit ripens early in Autumn. It is a dark purple, tough-skinned drupe, about an inch long.

The wood weighs 32.37 pounds per cubic foot. It is soft, and has about three-fourths the strength and little more than half the stiffness of white oak. It is not well suited to places where strength and rigidity are required. The fibers are interwoven, making the wood difficult to split. The heart is brown, often nearly white; the sapwood is very thick; and the annual rings are not clearly defined, because of the similarity between the springwood and summerwood. The pores are small but numerous, and are scattered evenly through the whole annual ring. The wood of roots differs from that of the trunk more than is usual with hardwoods. It is very light, and has been long employed in the South as a substitute for cork as floats for fish nets.

Tupelo is often logged with cypress. The two trees grow in close association in deep swamps. The butt cuts of tupelo are so heavy that they float deep, or even go to the bottom. It was formerly customary, and still is to some extent, to girdle trees whose trunks were to be floated to the mills. In the course of one season the standing trees dry sufficiently for the logs to float. At other times, trees are cut green, the logs are skidded and allowed to dry some months before they are rafted or floated to the mills. The sapwood is liable to decay, even in the brief period while the logs are on the skids. The wood may be protected against decay to some extent by smearing the ends of the logs with tar or some other substance which prevents the spores of decay-producing fungus from entering.

The seasoning of tupelo was formerly a problem exceedingly vexatious to the lumberman. The wood is full of water, and warping was one of the troubles which was constantly encountered. Finally experience gained the mastery, and seasoning troubles are fewer now. Shrinkage of four or five per cent is not unusual in passing lumber from the green to dry state.

Tupelo is like hickory in one respect-factories use more wood 
than the sawmills cut. The shops and manufacturing plants of ten states use as much tupelo as is cut by all the sawmills in the United States. These states are Alabama, Arkansas, Illinois, Louisiana, Maryland, Michigan, Mississippi, Missouri, North Carolina, and Texas. The reason for factory use exceeding the sawmill cut is that much reaches factories, in the form of veneer, which does not pass through a sawmill. The lumber output of most of the timber trees of this country is from one-third to one-half greater than the factory use. The difference represents the rough lumber used, and which never goes to a factory.

Tupelo lately entered the general market, but the yearly demand now exceeds $100,000,000$ feet. Its uses range from boxes and cheap handles to interior finish and material for musical instruments. It is particularly liked for containers for berries and small fruits, on their way to market. Its whiteness and clean appearance fit it for that use.

Higher grades of shipping boxes are also made. Wholesale grocers order largely of this wood for spice, coffee, and tea boxes. These commodities are exacting in their requirements because their odor, which is often regarded as the criterion of their value, must not be impaired. A wood with an odor of its own is immediately ruled out. Cigar box makers use tupelo, sometimes as thin lumber for the whole box, but usually as backing over which to lay a thin veneer of Spanish cedar. Plug tobacco boxes are also made of tupelo.

In Illinois and Michigan tupelo is listed among woods manufactured into pianos, organs, mandolins, and guitars. In Maryland they make scows and barges of it. In Arkansas and Louisiana it is worked into excelsior and slack cooperage stock. It is a favorite wood in Mississippi for pumplogs and broom handles. Its leading reported use in Texas is for porch columns. In Missouri it is manufactured in to laundry appliances, such as washboards, clothes racks, and ironing boards. In nearly all manufacturing centers of the country it is made into furniture and interior finish. It is frequently substituted for yellow poplar in panels, not only in furniture and cabinet work, but in carriage bodies.

The supply of tupelo in southern forests is fairly large, and will meet demand for some years, but it is a tree of slow growth, and when present stands are cut, a new supply will probably never come.

SOUR TupELo (Nyssa ogeche) appears to be the only member of the gum growp whose fruit is of any value to man, and it is not very important. The large, dull red drupes ripen in July and August, and sometimes hang on the trees until late fall, allowing ample time for gathering them. They are very sour, for which reason the tree is ealied sour gum. The fruit is put through a pickling process which renders it palatable and it is not an infrequent article on southern pantry shelves. The range of the tree is eonfined to the region near the coast from the southern border of South Carolina, through the Ogeechee river valley in Georgia, to northern and western 
Florida. The botanical name refers to the river along whose course the trees are most abundant. Local names are gopher plum, Ogeechee lime, and wild lime. The tree is sixty or seventy feet high,one or two in diameter, and is often divided in several stems. Its wood is lightest of the gums, weighing only 28.75 pounds per cubic foot. It is diffuse-porous, and the springwood is scarcely distinguishable from the summerwood. The annual rings of growth are indistinct, and the medullary rays are thin and inconspicuous. The wood is weak, soft, tough, and white, and little difference is apparent between heart and sapwood. The flowers are rich in honey and are valuable to bee keepers. It appears that no reports exist of the use of this nood for any purpose. It is not abundant anywhere.

WATER GuM (Nyssa biflora) is a member of the gum group, and is of small importance. Trees above thirty feet high are unusual, and the trunk is of poor form, owing to its greatly enlarged base. This gum is found on the margins of small ponds in the pine barrens from North Carolina to the Gulf coast. The leaves turn purple and red in the fall, and are then conspicuous objects. The fruit is a blue drupe about a third of an inch long. The woor is light, tough, and difficult to split.

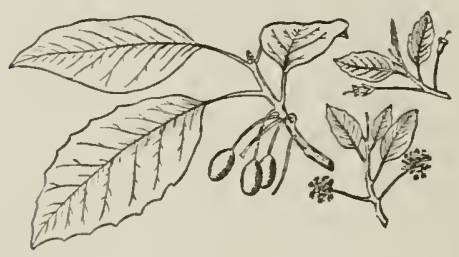


BLACK WALNUT 


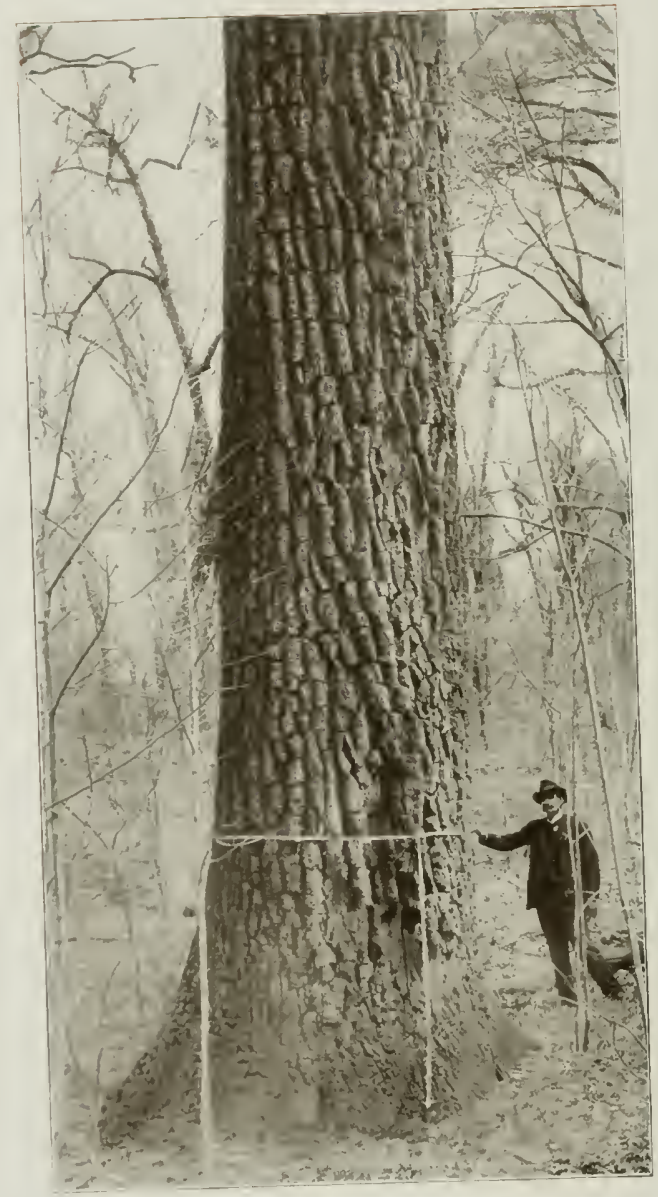

BLACK IVALNTT 


\title{
BLACK WALNUT
}

\author{
(Juglans Nigra)
}

T HIS tree has few names. It is called walnut, black walnut, and walnut-tree. The color of the wood and bark is responsible for the word black in the name, though some people use the adjective to distinguish the tree from butternut which is often known as white walnut. The natural range of black walnut covers 600,000 or 700,000 square miles, and it has been extended by planting. Its northern limit stretches from New York to Minnesota, its southern from Florida to Texas. It is difficult to say where the species found its highest development in the primeval forests, for very large trees were reported in New York, among the southern Appalachian monntains, in the Ohio valley, and beyond the Mississippi in Arkansas, Oklahoma, Missouri, and Kansas. The wood cut in Ohio and Indiana has been of greater commercial importance than that from any other portion of its range, but that has been due, in part, to the fact that it came into market before the best of the forest growth had been destroyed in those states, and instead of burning it or mauling it into rails, as eastern farmers did in early times, the farmers of the Ohio valley sold their walnut. Early in the history of black walnut lumbering, Indiana and Ohio came to the front as the most important sources of supply, and they still hold that position, notwithstanding the original forests of those states were supposed to be nearly exhausted long ago. The states cutting most black walnut in 1910 , in the order named, were Ohio, Indiana, Illinois, Kentucky, Tennessee, Missouri, West Virginia, Virginia, Pennsylvania, and Iowa.

During the period from 1860 to 1880 black walnut was in much demand for furniture, and the largest yearly cut was $125,000,000$ feet. It was during that period of twenty years that operators pushed into all of the ont-of-the-way places in search of the timber. Logs were hanled on wagons long distances to bring them out of remote valleys and slopes where no timber buyer had ever gone before. The walnut buyers made such a thorough canvas of the country that it was generally supposed no merchantable tree from Kansas to Virginia wonld escape. Many a dooryard giant whose wide branches had shaded the family roof for generations, fell before the ax of the contractor who was willing to pay fifty dollars for a single trunk, though it miglıt be twenty miles from the nearest railroad or navigable stream. In spite of the thoroughness of the search, many a walnut tree was spared. Logs have been going to market ever since, and still they go. They will continue to go for years, generations, and centuries; for walnut trees grow with rapidity. 
The trunk's value increases with age. The dark colored heartwood only is merchantable, and young trees have little heartwood. The thick, white sap constitutes most of the trunk until long after the tree has reached small sawlog size. Then the transformation to the dark, valuable heartwood goes on with fair rapidity, and the outer shell of sapwood becomes thinner as the heart increases, and in time a trunk is produced which is fit for good logs. Value comes only with age. The quarter or half a century which has passed since the country was so diligently ransacked for merchantable walnut, has been sufficient to develop many a tree which was then rejected by the purchasers. Many a tree now a foot in diameter had scarcely sprouted then. In a region of 700,000 square miles, walnut trees do not need to grow very close together to produce a yearly cut of $30,000,000$ or $40,000,000$ feet.

Black walnut is valuable for its color, figure, and the fine polish it takes. It is stronger than white oak, weight for weight, but it is eight pounds lighter per cubic foot. The figure of the wood is due wholly to the annual rings, as its medullary rays are invisible to the naked eye. The wood is very porous, and the pores are diffused in all parts of the annual rings, except in the thin, pencil-like mark representing the outward boundary of the summerwood. When sapwood changes to heartwood, some of the pores disappear, but those which remain are abundantly sufficient to absorb any stains or fillers which the wood finisher may wish to apply.

The aunual sawmill cut of black walnut in the United States is from $35,000,000$ to $40,000,000$ feet, but much goes to foreign countries in the $\log$, and a considerable quantity goes to veneer mills-about $2,500,000$ feet a year-and a quantity finds its way to various factories where it is worked up without any statistical record being made of it.

Black walnut is never used as rough lumber. It all goes to factories of some kind to be converted into finished commodities. It is not possible to say where it all goes, for statistics of manufacture are fragmentary in this country. It may be of interest to know that demand for walnut by factories in the following states was $11,6+1,137$ feet in 1910 : Alabama, Arkansas, Illinois, Kentucky, Maryland, Massachusetts, Missouri, North Carolina, and Texas. The wood served so many purposes that a list of them would be monotonous. In Illinois the largest users are the sewing machine and the musical instrument industries; in Michigan the makers of automobiles and of musical instruments; in Kentucky the manufacturers of coffins, furniture, and musical instruments; in Massachusetts, the makers of furniture and of firearms. These uses probably afford a fairly accurate index for the whole country. During the Civil war the largest demand for walnut came from gunstock 
makers. Doubtless the largest use from 1865 to 1885 was for furniture.

Much of the best black walnut is exported. The logs are flattened on the four sides to make them fit better in ships and cars, and also to be rid of most of the sapwood which is valueless. The ends are painted with red lead or some other substance to lessen liability to check. Sometimes export walnut is sawed in thick planks.

Large quantities of old-time walnut furniture have been resurrected in recent years from granary and garret where it was stored long ago to have it out of the way. Some of the old beds, lounges, cupboards, and chairs were of heavy, solid walnut, the kind not made now. Some of it has been furbished, re-upholstered, and set among the heirlooms; other pieces have been sold to furniture makers who saw the solid wood in veneers, and use it again.

The search for old walnut did not stop with dragging antique furniture from cubbyholes and attics, but two-inch lumber has been pulled from floors of old barns, and mills. Many old fence rails were made into gun stocks during the Civil war. Later, walnut stumps were pulled from field and wayside, and went to veneer mills. Some finely figured wood comes from stumps where roots and trunk join.

An occasional walnut tree develops a large burl which is valued for its figured wood. Sometimes the burl is the form of a door knob, with the tree trunk growing through the center. The burl sometimes has a diameter three or four times as great as the trunk. The origin of such burls is supposed to be a mass of buds which fail to break through the bark.

Black walnut has a compound leaf from one to two feet long, with from fifteen to twenty-three leaflets, each about three inches long and an inch or two wide. The nuts ripen in the fall, and are valuable. They are borne chiefly by trees growing in open ground; forest trees do not bear until old, and then only a few nuts. The walnuts which germinate are usually those buried by squirrels, and forgotten.

Within the past twenty or thirty years plantations have been made in states of the Middle West. Many young planted trees have been cut for fence posts, with disappointing results. It was known that old walnut is durable, and it was supposed young trunks would be, when used for posts; but young trees are nearly all sapwood which rots quickly.

Forest grown walnut trees vary in size from a diameter of two feet and a height of fifty, to a diameter of six or more and a height of 100 or 120. Trunks which grow in the shade are tall, clear, and symmetrical; those in the open are shorter, with more taper.

PALE-LEAF HickORY (Hicoria villosa) is a smalt tree but large enough to he 
useful wherever it exists in sufficient quantity. The largest specimens attain a height of fifty feet and a diameter of eighteen inches. The tree bears nuts when very small, and the kernel is sweet. The bark of this hickory is rough but not shaggy. The range extends from New Jersey to Florida and west to Missouri and Texas. It is most abundant in the lower Appalachian ranges. The wood possesses the common characteristics of the hickories, and it is cut with them wherever it is found, but is seldom or never reported separately in lumber operations.

Smal, Pignut Hickory (Hicoria odorata) is considered a species by some botanists while others regard it as a variety. It is called small pignut in Maryland, and occasionally little shagbark. This last name refers to the ronghness of the bark which resembles the bark of elm. The range of the tree extends from Massachusetts to Missouri and south to the Ohio and the Potomac rivers. The wood differs little from that of pignut hickory, and the uses are the same. No distinction is made between them at the shop and factory. This tree is by some botanists believed to be a hybrid between shagbark and pignut. It is sometimes called false sbagbark. The aut is edible.

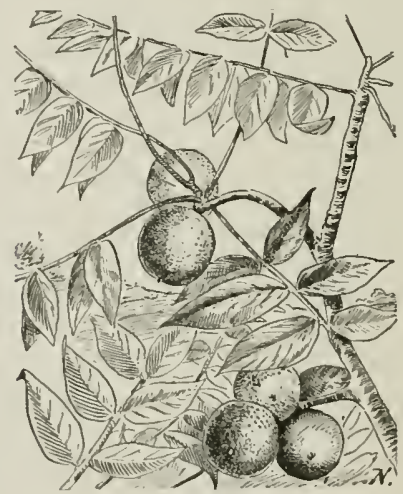


BLTTERNUT 


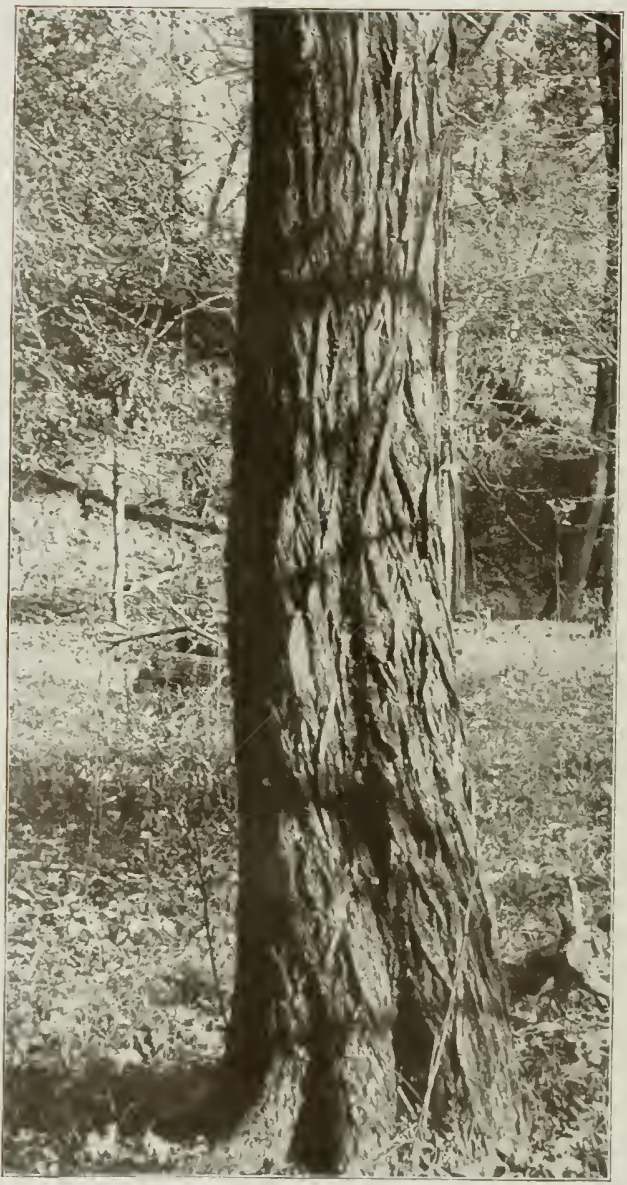

BetTERNe l 


\title{
BUTTERNUT
}

\author{
(Juglans Cinerea)
}

$\mathrm{T}$ HIS tree is known as butternut or as white walnut in all parts of its range. Butternut is in reference to the oily kernel of the nuts, and white walnut is the name given by those who would distinguish the tree from black walnut. Persons acquainted with one of the species in its native woods are usually sure to be acquainted with the other, for their ranges are practically co-extensive, except that black walnut extends farther southwest, butternut farther northeast. Butternut grows from New Brunswick to South Dakota, from Delaware to Arkansas, and along the Appalachian highlands to northern Georgia and Alabama.

Butternut resembles black walnut in a good many ways and differs from it in several. They are very closely related botanically-as closely as are brothers in the same household. Black walnut is larger, stronger, better known, and has always dominated and eclipsed the other in usefulness and public esteem; yet butternut is a tree both useful and interesting. No person acquainted with both would ever mistake one for the other, winter or summer. Botanists tell how to distinguish butternut from black walnut by noting minor differences. The person who is not a botanist needs no such help. He knows them at sight, and there is no possibility of mistaking them.

Butternut in the forest may attain a height of eighty or 100 feet, and a diameter of three, but few persons ever see a specimen of that size, and never in open ground. In shade, the butternut does its best to get its crown up to light and sunshine, but it is weak. It often gives up the struggle and remains in the shade of trees which overtop it. In that situation its crown is small, thin, and appears to rest lightly in the form of a small bunch of yellowish-green leaves on the top of a tall, spindling bole, which is seldom straight, but is made up of slight, undulating curves. The pale, yellowish tinge of the bark suggests a plant deprived of sunshine.

When butternut grows in open ground where light falls upon its crown and on all sides, it assumes a different form and presents another figure. The trunk is nearly as short as that of an apple tree. It divides in large branches and limbs, and these spread wide; leaves are licalthy, yet the crown of a butternut always looks thin compared with that of the black walnut. Tests show that butternut wood, when thoroughly dry, is somewhat stifier than black walnut; but it is light and weak. It is about two-thirds as heavy and two-thirds as strong as black walnut. The growing tree betrays the wood's weakness. Large limbs snap in 
storms. Trees become lopsided, and a symmetrical, well-proportioned butternut crown is an exception. The broken branches leave openings for the entrance of decay, and butternuts nearly always die of disease rather than of old age.

Leaves are compound, and from fifteen to thirty inches in length. Few trees of this country have larger leaves. There are from eleven to seventeen leaflets. They are hairy and sticky. Hands that handle them are covered with mucilage-like substance. The nuts, which grow in clusters of three or five, are of the same color as the leaves and covered with the same sticky fuzz. The nuts are two inches or more in length, and are borne abundantly when trees stand in open ground. Size rather than age appears to determine the period when trees commence to bear. Those of extra vigor produce when ten or twelve years old. The nuts are salable in the market. They fall with the leaves, immediately after the first sharp frost, and all come down together. A single day frequently suffices to strip the last leaf from a tree, though some of the nuts may hang a little longer. The kernels are very rich, when the nuts are dry, and are apt to cloy the appetite; but they are improved by freezing where they lie on the ground among the leaves; but they must be used quickly after they thaw, or they will spoil. Nuts nearly full-grown but not yet hard are made into pickles, but the fuzz must first be washed off with hot water.

Butternut bark has played a rather important role in the country's affairs. Doctors in the Revolutionary war made much of their medicine of the roots and bark of this tree. Drugs were unattainable, and physicians were forced to betake themselves to the woods for substitutes, and their pharmacopoeias were enriched by the butternut tree. Housewives dyed cloth a brown color with this bark long before aniline dyes found their way into this country. Whole companies of Confederate soldiers from the mountain regions in the Civil war wore clothes dyed in decoctions of butternut bark, and popularly known as "butternut jeans."

The annual output of butternut lumber is placed at a little more than 1,000,000 feet a year. It is widely used, but in small amounts. In Maryland it is made into ceiling and flooring; in North Carolina into cabinet work, fixtures for stores and offices, and into furniture; in Michigan its reported uses are boat finish, interior finish for houses, molding, and screen frames. In Illinois it is used for all the purposes listed above and also for church altars and car finish. These uses are doubtless typical, and hold good in all parts of the country where any use is made of butternut.

The wood has figure similar to that of black walnut, but the color 
is lighter. It is nearer brown than black. The pores are diffused through the annual ring, but are more numerous and of larger size in the inner than in the outer part. The springwood blends gradually with the wood of the latter part of the season, without sharp distinction, but the ring terminates in a black line which is the chief element of contrast in the wood's figure.

The future value of butternut will be less in the lumber than in the nuts. The tendency in that direction is now apparent. When land is cleared, the trees which would formerly have gone to the sawmill, are now left to bear nuts. The averaged price paid by factories in North Carolina for butternut is $\$ 40$ a thousand feet. It is cheaper in the Lake States.

Mexican WaLnut (Juglans rupestris) will never amount to much as a timber tree, though it is by no means useless. It is known by several names, among them being western walnut, dwarf walnut, little walnut, and California walnut. The last name is applied in Arizona through a misunderstanding of the tree's identity. It is there confused with the California walnut which is a different species. The Mexican walnut's range extends from central Texas, through New Mexico to Arizona, and sonthward into Mexico. It prefers the limestone hanks of streams in Texas where it is usually shrubby, seldom attaining a height above thirty feet. It reaches its largest size in canyons among the mountains of New Mexico and Arizona where it reaches a height of sixty feet. Trunks are sometimes five feet in diameter. The wood weighs 40.85 pounds per cubic foot, is dark in color, but the tone is not as regular as that of black walnut; neither is it as strong and stiff. It polishes well, and is said to he durable in contact with the soil. It finds its way in small amounts to local mills, shops, and factories where it is made into various commodities. It is particularly liked for the lathe, and is suited better for turnery than for any other purpose. It is made into gavels, cups, spindles, parts of grills; and it is also worked into picture frames, handles, and small pieces of furniture. It does not appear that lumber sawed from this walnut ever gets into the general market, but the whole output, which is small, is consumed locally. Trees do not occur in pure stands and the whole supply consists of isolated trees or small groups, with few trunks large enough for sawlogs. The nuts are dwarfs. All are not the same size, but none are as large as a hickory nut. Many that grow on the diminutive trces along the water courses in western Texas are not as large, husks and all, as a nutmeg, and the nut itself is ahout half the size of a nutmeg, and not dissimilar in appearance. The kernels of such a nut are too small to have any commercial value, but they are rare morsels for the native Mexicans and Indians who pick them by pocketfuls. Trees in the stony canyon of Devil's river, in Texas, are in full hearing when so small that a man can stand on the ground and pick walnusts from their highest branches. The Mlexican walnut is occasionally cultivated in the eastern part of the United States and in Europe. It is hardy as far north as Massachusetts.

Californta Walnut (Juglans californica) is a small trec confined to California, and pretty close to the coast, though it grows in Eldorado county. It is most ahundant within twenty or thirty miles of tidewater. In the southern part of the state it ascends to an elevation of 4,000 feet. It prefers the banks of streams and the bottoms of canyons where the soil is 1noist, but it will grow in dry situations. Trees occur singly or in snall groups. Their average size is fiftecn or twenty feet high, and 
eight or ten inches in diameter; but trees occasionally are sixty feet high and eighteen inches through. The leaves are small, measuring from six to nine inches in length, with from nine to seventeen leaflets. Nuts are about half the size of eastern black walnuts. The kernel is edible. The wood is heavier than black walnut, and somewhat lighter in color. Otherwise the two woods are much alike, except in strength and stifiness. In these the California wood is inferior. It has not been reported for any use, but it is suitable for a number of purposes, provided logs of sufficient size could be had. The trunk, in addition to being small, is usually short. The tree is intolerant of shade, and is not often found in forests. It grows rapidly and will attain a diameter of fifteen inches in twenty years or less; but it apparently does not live long. Its principal usefulness in California is as a shade tree, and as a stock in nurseries on which to graft English walnut.

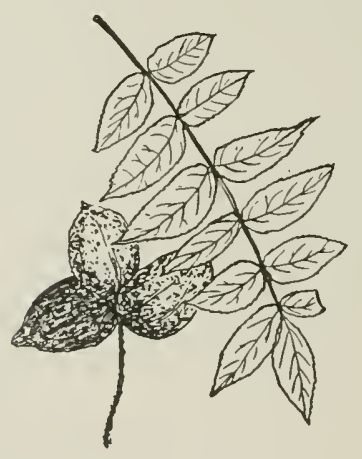


SHAGBARK HICKORY 


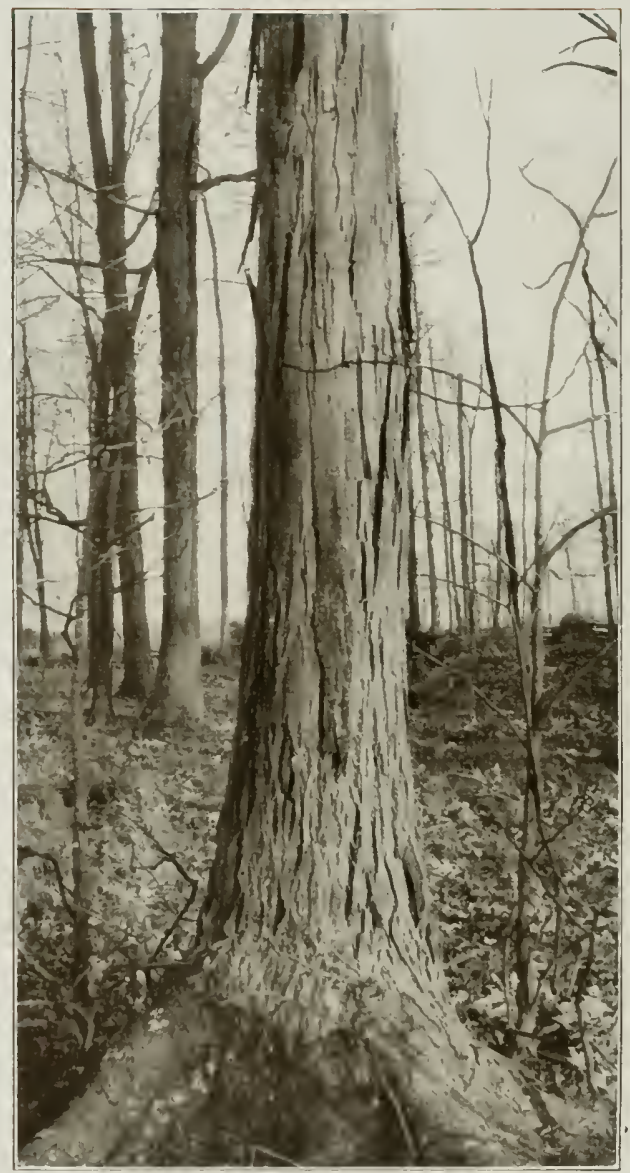

SHAGBARK Hickory 


\title{
SHAGBARK HICKORY
}

\author{
(Hicoria Ovata)
}

$\mathrm{T}$ WELVE species of hickory grow in the United States, all east of the Rocky Mountains. None grow anywhere else in the world, as far as known. They were widely dispersed over the northern hemisphere in prehistoric times. The records of geology, written by leaf prints in the rocks, tell of forests of hickory in Europe, and even in Greenland, probably a hundred thousand or more years ago, and certainly not in times that can be called recent. No records there later than the ice age have been found. This leads to the presumption that the sheet of ice which pushed down from the North and covered the larger portions of Europe and North America, overwhelmed the hickory forests, and all others, as far as the southern limit of the ice's advance.

In Europe the hickory was utterly destroyed, and it never returned after the close of the reign of ice; but America was more fortunate. The ice sheet pushed little farther in its southward course than the Ohio and Missouri rivers, and forests south of there held their ground, and they slowly worked their way back north as the ice withdrew. Hickory recovered part but not all of its lost ground in America, for it is now found no farther north than southern Canada, which is more than a thousand miles from its old range in Greenland.

The early settlers in New England and in the South at once came into contact with hickory. It was one of the first woods named in this country, and the name is of Indian origin, and is spelled in no fewer than seventeen ways in early literature relating to the settlements. It is probable that John Smith, a prominent man in early Virginia and New England, was the first man who ever wrote the name. He spelled it as the Indians pronounced it, "powcohiscora," and it has been trimmed down to our word hickory. The Indian word was the name of a salad or soup made of pounded hickory nuts and water, and was only indirectly applied to the tree itself.

The first settlers along the Atlantic coast nearly always called this tree a walnut, and the name white walnut was common. They were unacquainted with any similar nut-bearing tree in Europe, except the walnut, and most people preferred applying a name with which they were already familiar. Hickories and walnuts belong to the same family, and have many points in common.

Although there are twelve hickories in the United States, and in many respects they are similar, all are not of equal value. Some are very scarce, and the wood of others is not up to standard. From a 
commercial standpoint, four surpass the others. These are shagbark (Hicoria ovata), shellbark (Hicoria laciniosa), pignut (Hicoria glabra), and mockernut (Hicoria alba). The wood of some of the others is as good, but is scarce; and still others, particularly the pecans, are abundant enough, but the wood is inferior. It is impossible in business to separate the hickories. Lumbermen do not do it ; manufacturers cannot do it. In some regions one is more abundant than the others, and consequently is used in larger quantities, but in some other region a different species may predominate in the forest and in the factory. It cannot be truthfully asserted that one hickory is always as good as another, or even that a certain species in one region is as good as the same species in another region. All parts of the same tree do not produce wood of equal value.

Along certain general lines, hickories have many properties in common. The wood is ring-porous, that is, the inner edge of the yearly growth ring has a row of large pores. Others are scattered toward the outer part of the ring, generally decreasing in number and size outward. There is no distinct division between spring and summerwood. The medullary rays are thin and obscure. The unaided eye seldom notices them. The sapwood is white in all species of hickory, and is usually very thick. The heartwood is reddish. Common opinion has long held that sapwood is tougher and more elastic than heartwood, and therefore to be preferred for most purposes. Tests made a few years ago by the United States Forest Service ran counter to the long-established opinion of users, by showing that in most respects the redwood of the heart was as good as the white sapwood. However, where resiliency is the chief requisite, as in slender handles, many manufacturers still prefer sapwood.

Hickory is very strong, probably the strongest wood in common use in this country. The statement that one wood is stronger than all others is hardly justified because averages of strength should be taken, and not isolated instances. Satisfactory averages have not yet been worked out for a large number of our woods; but, as far as existing figures may be accepted, hickory is at the head of the list for strength, toughness, and resiliency. Choice samples of certain woods may exceed the average of hickory in some of these particulars. Sugar maple, hornbeam, and locust occasionally show greater strength than hickory, but they lack in toughness and resiliency - the very properties which give hickory its chief value for many purposes.

Considerable misunderstanding exists as to second growth hickory. Some suppose it consists of trees of commercial size developed from sprouts where old trees have been cut. That is not generally correct. 
When small hickory trees are cut, the stumps often sprout, but hoop poles are about the only commodity made from that kind of hickory. If sprouts are left to grow large, the trees produced are generally defective. Good hickory grows from the nut. The term "second growth" means little, unless it is explained in each instance just what conditions are included. In one sense, all young, vigorous trees are second growth, and that is often the idea in the mind of the speaker. Some would restrict it to trees which have come up in old fields or partial clearings, where they have plenty of light, and have grown rapidly. Their trunks are short, the wood is tough, and there is little red heartwood. The larger a pine, oak, or poplar, provided it is sound, the better the wood; but not so with hickory. Great age and large size add no desirable qualities to this wood.

Shagbark is largest of the true hickories. The pecans are not usually regarded as true hickories from the wood-user's viewpoint. Some shagbarks are 120 feet high and four feet in diameter, but the average size is about seventy-five tall, two in diameter. There is confusion of names among all the hickories, and shagbark is misnamed and over-named as often as any of the others. Many persons do not know shagbark and shellbark apart, though the ranges of the two species lie only partly in the same territory. Shagbark is known as shellbark hickory, shagbark hickory, shellbark, upland hickory, hickory, scaly bark hickory, white walnut, walnut, white hickory, and red heart hickory. Most of the names refer to the bark, which separates into thin strips, often a foot or more long, and six inches or more wide; and this remains more or less closely attached to the trunk by the middle, giving the shaggy appearance to which the tree owes its common name.

The leaf-buds are large and ovate, with yellowish-green and brown scales. The leaves are compound and alternate; they lave rough stalks containing five or seven leaflets; they are sessile, tapering to a point and having a rounded base. The lower pair of leaflets is markedly different from the rest in shape; sharply serrate and thin; dark green and glabrous above; lighter below. The flowcrs do not appear until the leaves have fully matured. They grow in catkins; the staminate ones are light green, slender, and grow in groups of three on long peduncles; the pistillate ones grow in spikes of from two to five flowers. The fruit grows within a densc, green husk, shiny and smootl on the outside, opening in four parts. The nut is nearly white, four-angled, and flattened at the sides. The kernel is sweet and of a strong flavor.

This tree'srange is not much short of $1,000,000$ square miles, but it is not equally abundant in all parts. It grows from southern Maine to western Florida; is found in Minnesota and Nebraska, and southward 
beyond the Mississippi. It is most common and of largest size on the western slopes of the soutbern Appalachian mountains and in the basin of the lower Ohio river. Its favorite habitat is on low hills, or near streams and swamps, in rich and moderately well drained soil.

The hickories have long tap roots, and they do best in soils which the tap roots can penetrate, going down like a radish. The root system makes most hickories difficult trees to transplant. Early in life they do a large part of their growing under ground, and when that growth is interrupted, as it must be in transplanting, the young tree seldom recovers. Those who would grow hickories for timber, nuts, or as ornaments, should plant the seed where the tree is expected to remain. Most of the planting of hickory in the forest is done by squirrels which bury nuts, with the apparent expectation of digging them up later. Occasionally one is missed, and a young tree starts.

The uses of this wood are typical of all the other hickories. Handles and light vehicles consume most of it. The markets are in all parts of this country, and in manufacturing centers in many foreign lands.

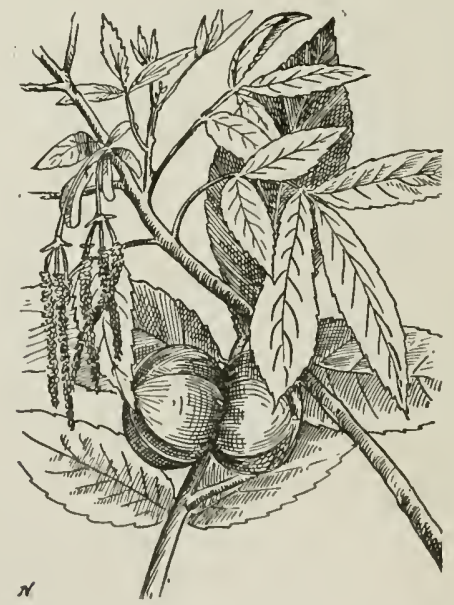


BITTERNLT HICKORY 


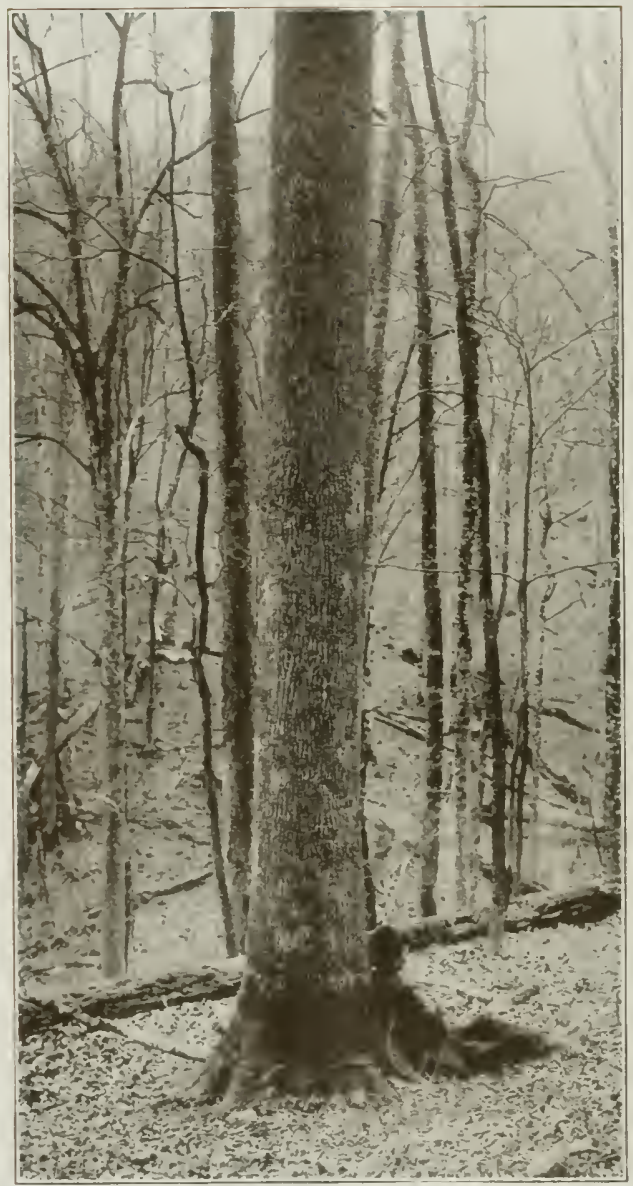

BITTERNIT HICKORY 


\title{
BITTERNUT HICKORY
}

\author{
(Hicoria Minima)
}

$\mathrm{T}$ HE tannin in the thin shelled nuts which grow abundantly on this tree gives the name bitternut. The name is truly descriptive. Gall itself scarcely exceeds the intense bitterness of the kernel, when crushed between the teeth. The sense of taste does not immediately detect the bitterness in its full intensity. A little time seems to be necessary to dissolve the astringent principal and distribute it to the nerves of taste. When this lias been accomplished, the bitterness remains a long time, seeming to persist after the last vestige of the cause has been removed. In that respect it may be likened to the resin of the incense cedar of California which is among tastes what musk is among odors, nearly everlasting. The bitterness of this hickory nut has much to do with the perpetuation of the species. No wild or tame animal will eat the fruit unless forced by famine. Consequentiy, the nuts are left to grow, provided they can get themselves planted. That is not always easy, for small quadrupeds which bury edible nuts for food, and then occasionally forget them, show no interest whatever in the unpalatable bitternut. It is left where it falls, unless running water, or some other method of locomotion, transports it to another locality. This happens with sufficient frequency to plant the nuts as widely as those of any other hickory. It is believed that this is the most abnndant of the hickories.

The tree bears names other than bitternut. It is called swamp hickory, though that name is more applicable to a different species, the water hickory. Pig hickory or pignut are names used in several states, but without good reason. Hogs may sometimes eat the nuts, but never when anything better can be found. Besides, pignut is the accepted name of another species (Hicoria glabra). In Louisiana they call it the bitter pecan tree. Bitter hickory is a common name in many localities. In New Hampshire it is known as pig walnut, in Vermont as bitter walnut, and in Texas as white hickory. The names are so many, and so often apply as well to other hickories as to this, that the name alone is seldom a safe guide to identification. It has two or three characters which will help to pick it out from among others. Its leaves and bark bear considerable resemblance to ash. The leaves are the smallest among the hickories, and the bark is never shaggy. The small branches always carry yellow buds, no matter what the season of the year. The compound leaves are from six to ten inches long, and consist of from five to nine leaflets, always an odd number.

Bitternut hickory's range covers pretty generally the eastern part 
of the United States. It is one of the largest and commonest hickories of New England, and is likewise the common hickory of Kansas, Nebraska, and Iowa. It grows from Maine through southern Canada to Minnesota, follows down the western side of the Mississippi valley to Texas, and extends into western Florida.

Hickory is often lumbered in ways not common with other hardwoods. It is not generally found in ordinary lumber yards, and is not cut into lumber as most other woods are. It is in a class by itself. The person who would consult statistics of lumber cut in the United States to ascertain the quantity of hickory going to market, would utterly fail to obtain the desired information. The statistics of lumber cut in the United States for the year 1910 listed the total for hickory at 272,252,000 feet, distributed among 33 states, and cut by 6,349 mills. Reports by users of this wood in a number of states show that probably twice as much goes to factories to be manufactured into finished commodities, as all the sawmills cut. This means that much hickory goes to factories without having passed through sawmills to be first converted in tolumber. It goes as bolts and billets, and as logs of various lengths. Some sawmills in the hickory region cut dimension stock and sell it to factories to be further worked up; but that is a comparatively small part of the hickory that finds its way to factories of various kinds. Many sawmills refuse to cut hickory, claiming that it does not pay them to specialize on a scarce wood. Scattered trees occur among other timber, but these are left when the other logging is done. Special operators go after the hickory, and distribute it among various industries which are in the market for it. That method of ten results in much waste, because the man who is specializing in one commodity, such as wagon poles, ax handles, sucker-rods, wheel stock, or the like, is apt to cut out only what meets his requirements, and abandon the rest. Some of the hickory camps where such stock is roughed out are spectacles of carelessness and waste, with heaps of rejected hickory which, though not meeting requirements for the special articles in view, are valuable for many other things. Few woods contribute to the trash heap more in proportion to the total cut than hickory; but the waste nearly all occurs before the factories which finally work up the products are reached. These factories are often hundreds of miles from the forests where the hickory grows.

Hickory was not a useful farm timber in early times, as oak and chestnut were. It decayed quickly when exposed to weather, and was not suitable for fence rails, posts, house logs, or general lumber. It was sometimes used for barn floors, but when seasoned it was so hard to nail that it was not well liked. The pioneers were not able to use this wood to advantage, because it is a manufacturer's material, not a farmer's or 
a villager's standby. It can be said to the credit of the pioneers, however, that they knew its value for certain purposes, and employed as much of it as they needed.

Fuel was the most important place for hickory on the farm. All things considered, it is probably the best furewood of the American forest. The yawning fireplaces called for cords of wood every month of winter in the northern states. Enough to make a modern buggy would go up the chimney in a rich red blaze in an hour, and no one thought that it was waste; and it was not waste then, because farms had to be cleared, and firewood was the best use possible for the hickory at that time. Every cord burned in the chimney was that much less to be rolled into logheaps and consumed in the clearing for the new cornfield.

Hickory has always been considered the best material for smoking meat. More than 30,000 cords a year are now used that way. It was so used in early times, when every farmer smoked and packed his own meat. Hickory smoke was supposed to give bacon a flavor equalled by no other wood; and in addition to that it was believed to keep the skippers out.

The nuts were made into oil which was thought to be efficacious as a liniment employed as a remedy against rheumatism to which pioneers were susceptible because their moccasins were porous and their feet were often wet. The oil was used also for illuminating purposes. It fed the flame of a crude lamp.

No other wood equalled hickory for "split brooms," the kind that swept the cabins before broom corn was known or carpet sweepers and vacuum cleaners were invented. The toughness, smoothness, and strength of hickory made it the best oxbow wood, and the same property fitted it for barrel hoops. Thousands of fish casks in New England and tobacco hogshead in Maryland and Virginia were hooped with hickory before George Washington was born. The wood's value for ax handles was learned early. The Indians used it for the long, slender handles of their stone hammers with which they barked trees in their clearings, and broke the skulls of enemies in war.

Bitternut hickory has about ninety-two per cent of the strength of shagbark, and seventy-three per cent of its stifiness. It yields considerably more ash when burned, and is rated a little lower in fuel value.

Mocker Nut Hickory (Hicoria alba) has many names. It is called mocker nut in Massachusetts, Rhode Island, New York, New Jersey, Delaware, Alabama, Mississippi, Louisiana, Texas, Arkansas, Illinois, Iowa, and Kansas; white hearl hickory, Rhode Island, New York, Pennsylvania, Delaware, North Carolina, Texas, Illinois, Ontario, Iowa, Kansas, Minnesota, and Nebraska; black hickory, Texas, Mississippi, Louisiana, Missouri; big bud and red hickory, Illorida; hardback hickory, Illinois; white hickory, Pennsylvania, South Carolina; hig hickory nut, West Virginia: hognut, Delaware. The name mocker nut is supposed to refer to the thick shcll and 
disappointingly small kernel within. The range is not as extensive as some of the other hickories. Beginning in southern Ontario, it extends west ward and southward to eastern Kansas and the eastern half of Texas. The region of its most abundant growth is in the basin of the lower Ohio and in Arkansas, the best specimens appearing in fertile uplands. This is said to he the only hickory that invades the southern maritime pinebelt, growing on the low country along the Atlantic and Gulf coasts in abundance. The leaves are fragrant with a powerful, resinous odor; they have five or seven leaflets with hairy petioles or stems. The bark resembles that of bitternut, and is not scaly like that of shagbark. The wood weighs 51.21 pounds per cubic foot. It is hard, strong, tough, flexible. It has about uinety-four per cent of the strength of shagbark, and eighty per cent of its stiffness. Certain selected specimens of this species are probably as strong as any hickory; but, as is the case with all woods, there is great difference between specimens, and general averages only are to be relied upon. G. W. Letterman, who collected woods for Sargents' tests, procured a sample of this hickory near Allenton, Missouri, which showed strength sufficient to sustain 20,000 pounds per square inch, and its measure of stiffness was the enormous figure of $2,208,000$ pounds per square inch.

The uses of mocker nut hickory do not differ from those of other hickories. The tree is ferquently nearly all sapwood, to which the name white hickory is due. Some persons suppose that the heartwood is white, but that misconception is due to the fact that some pret ty large trees have no heartwood, but are sap clear through.

The term "black hickory" is sometimes applied to three species with darkcolored bark which bears some resemblance to the bark of ash. They are bitternut (Hicoria minima), pignut (Hicoria glabra), and mocker nut (Hicoria alba). When the word black is thus used, it refers to the bark and the general outward appearance of the tree, and not to the wood, which is as white as that of any other hickory.

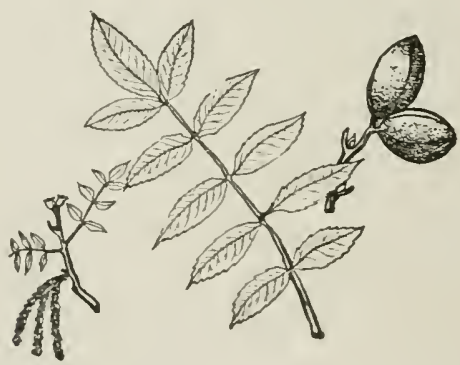


PIGNUT HICKORY 


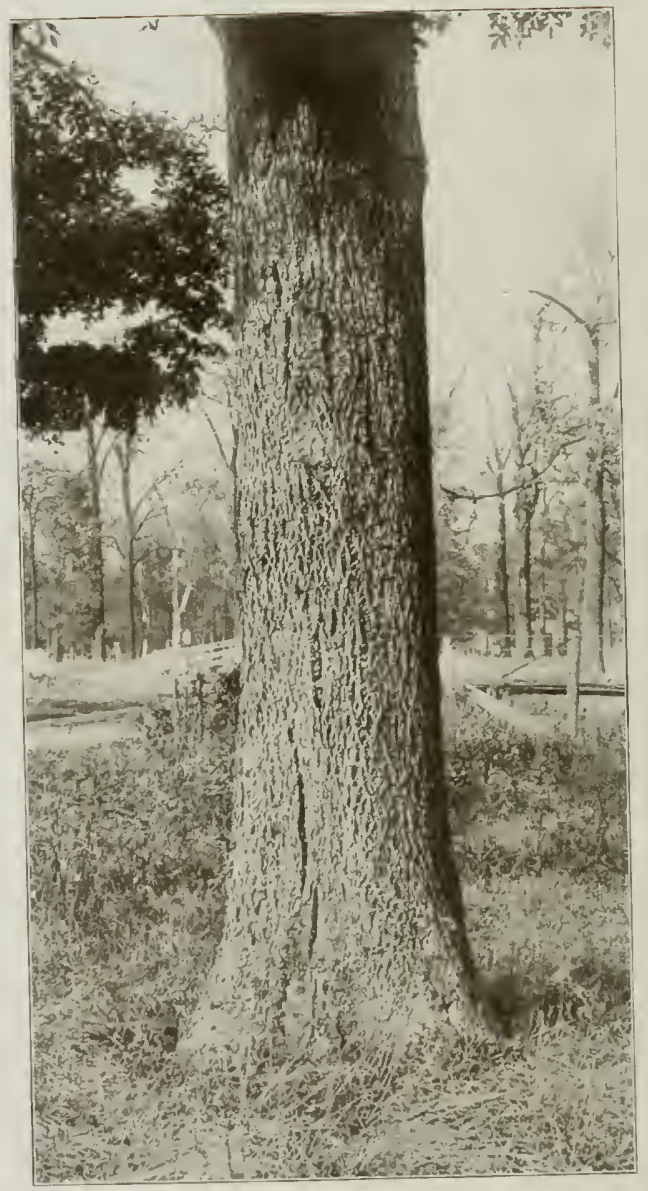

PIGNTT HICKORV 


\section{PIGNUT HICKORY}

\section{(Hicoria Glabra)}

7 HE name of this tree is unfortunate, although so far as the nuts are concerned, no injustice is done. It is one of the best hickories in the quality of its wood, and also as an ornamental tree. It is likewise abundant in many parts of its range, which extends from Maine to Kansas, Texas, Florida, and throughout most of the territory enclosed by the boundary lines thus delimited.

The name pignut is common in New England, New York, New Jersey, Pennsylvania, Delaware, West Virginia, North Carolina, South Carolina, Florida, Alabama, Mississippi, Louisiana, Texas, Arkansas, Kentucky, Missouri, Illinois, Indiana, Ohio, Iowa, Kansas, Nebraska, and Minnesota; bitternut in Arkansas, Illinois, lowa, and Wisconsin; black hickory in Mississippi, Louisiana, Arkansas, Missouri, Iowa, and Indiana; broom hickory in Missouri; brown hickory in Mississippi, Delaware, Texas, Tennessee, Minnesota; hardshell in West Virginia; red hickory in Delaware; switch bud hickory in Alabama; and white hickory in New Hampshire and lowa.

The nuts are generally bitter, but some trees bear fruit which is not very offensive to the taste. The avidity with which swine feed upon it gives the common name. This tree is doubtless confused many times with bitternut, though their differences are enough to distinguish them readily if they grow side by side. As far as the woods of the two species are concerned, there is little occasion to keep them separate. The pignut is a forked tree more frequently than any other species of hickory; and the nuts vary in shape and size more than those of any other. The tree is more remarkable for its variations than for its regularity. In one thing, however, it is pretty constant: the limbs and branches are smooth and clean, hence the botanical name glabra. As a name for this tree, smooth hickory would be preferable to pignut. Trunks attain a height of eighty or ninety feet and a diameter of three or four, but the extreme sizes are rare. The largest specimens are found in the lower Olio valley, and the species is most common in Missouri and Arkansas. It grows farther south and farther west than any other hickory except pecan. Its southern limit is in Florida and its western in Texas.

The uses of hickory fall into general classes. More is manufactured into vehicles than into any other single class of commodities, but not more than into all other articles combined. The second largest uscrs of hickory are the manufacturers of handles. The third largest demand comes from makers of agricultural implements and farm tools. Large 
amounts are required for athletic goods, meat smoking, and various miscellaneous purposes. The total amount used yearly in this country, and exported to foreign countries, is not accurately known, but it probably exceeds $500,000,000$ feet, board measure. About half of this passes through sawmills in the usual manner, and the other half goes directly from the forest to the factory or to the consumer.

The superiority of American buggies, sulkies, and other light vehicles is due to the hickory in their construction. No other wood equals this in combination of desirable physical properties. Though heavy, it is so strong, tough, and resilient that small amounts suffice, and the weight of the vehicle can be reduced to a lower point, without sacrificing efficiency, than when any other wood is employed. It is preëminently a wood for light vehicles. Oak, ash, maple, and elm answer well enough for heavy wagons where strength is more essential than toughness and elasticity. Hickory is suitable for practically all wooden parts of light vehicles except the body. The slender spokes look like frail dowels, and seem unable to maintain the load, but appearances are deceptive. The bent rims are likewise very slender, but they last better than steel. The shafts and poles with which carriages and carts are equipped will stand severe strains and twists without starting a splinter. The manufacturing of the stock is little less than a fine art. In scarcely any other wood-using industry-probably excepting the making of handles-is the grain so closely watched. Hickory users generally speak of the annual growth rings as the grain. The grain must run straight in spokes, rims, shafts, and poles. If the grain crosses the stick, a break may occur by the simple process of splitting, and the hickory in that case is no more dependable than many other woods.

Handle makers observe the same rule, and must have straight grain. The more slender the handle, the more strictly the rule must be followed. A cross grained golf club handle would fail at the first stroke. An ax handle, if it has cross grain, will last a little longer, but it will speedily split. Many of the best slender handles are of split hickory. The line of cleavage follows the grain, but a saw does not always do so. Heavy handles, like those for picks and sledges, are not so strictly straight grained, because they are made strong enough to stand much more strain than is ever likely to be put on them. Red heartwood is frequently used in handles of that kind. Peavey and canthook handles are generally split from billets, because the grain must be straight. Though they are among the largest and heaviest of handles, breakage must be guarded against with extra care, for the snap of a peavey handle at a critical moment might cost the operator his life by precipitating a skidway of logs upon him. 
The hickory which goes into agricultural implements fills many places, among the most important being connecting rods. It is often made into springs to take up or check oscillation. It is used for that purpose as picker sticks in textile mills.

Furniture makers could get along without hickory, and they do not need much. It is oftenest seen in dowels, slender spindles, and the rungs of chairs. The makers of sporting and athletic goods bend it for rackets, hoops, and rims, or make vaulting poles, bats, or trapezes.

SHELLBARK HickoRy (Hicoria laciniosa) is often mistaken for shagbark. The ranges of the two species coincide in part only. Shagbark grows farther east, north and south than shellbark. The latter occupies an island, as it were, inside the shagbark's range. Shellbark is found from central New York and eastern Pennsylvania, westward to Kansas, and southward to North Carolina and middle Tennessee. The species is at its best in the lower Ohio valley and in Missouri. The largest trees are $\mathbf{1 2 0}$ feet high and three in diameter, and are often free from branches half or two-thirds of the length. The species prefers rich, deep bottom lands, and does not suffer from occasional inundation from overflowing rivers. The average tree is not quite as large as shagbark. The leaves are larger than those of any other hickory, ranging in length from fifteen to twenty-two inches. There are from five to nine leaflets, usually seven. The upper ones are largest, and may be eight or nine inches long and four or five wide. In the autumn the leaflets drop from the petioles which adhere to the branches and furnish means of identifying the tree in winter. The nuts including the hulls are as large as small apples. When ripe, the hulls open and the nuts fall out; but the hulls fall also. The nuts are as large as shagbark nuts, but the two are seldom distinguished in market, though the shagbark's are a little richer in flavor. The bark's roughness gives the tree its name. Strips three or four feet long and five or six inches wide curl up at the lower ends-sometimes at both ends - and adhere to the trunk several years. The species has other nanles. It is known as big shellbark in Rhode Island, Pennsylvania, West Virginia, Kentucky, Missouri, Illinois, and Kansas; bottonn shellbark in Illinois; western shellbark or simply shellbark in Rhode Island and Kentucky; thick shellbark in South Carolina, Indiana, and Tennessee; kingnut in Tennessce.

The wood weighs 50.53 pounds per cubic foot, and is very hard, strong, tough, and flexible. The lieartwood is dark brown, the sapwood nearly white. This hickory usually has less sapwood in proportion to heart than other members of the species; but the wood is not kept separate from the others when it goes to market, and its uses are as extensive as the other hickories'. It is believed by some foresters that 
shellbark hickory is worth cultivating for its nuts, as it is a vigorous bearer; but little planting has been done. East of the Alleghanies, particularly in Virginia, some planting has been carried out on old plantations for ornamental purposes. On account of its long taproot, the tree is difficult to transplant, and the nuts should be planted where the trees are expected to remain.

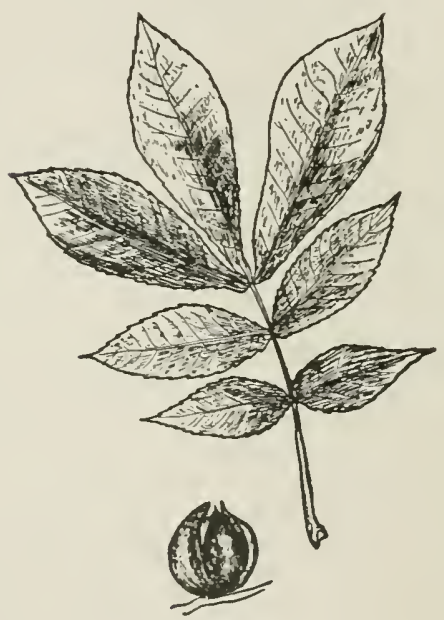


PECAN 


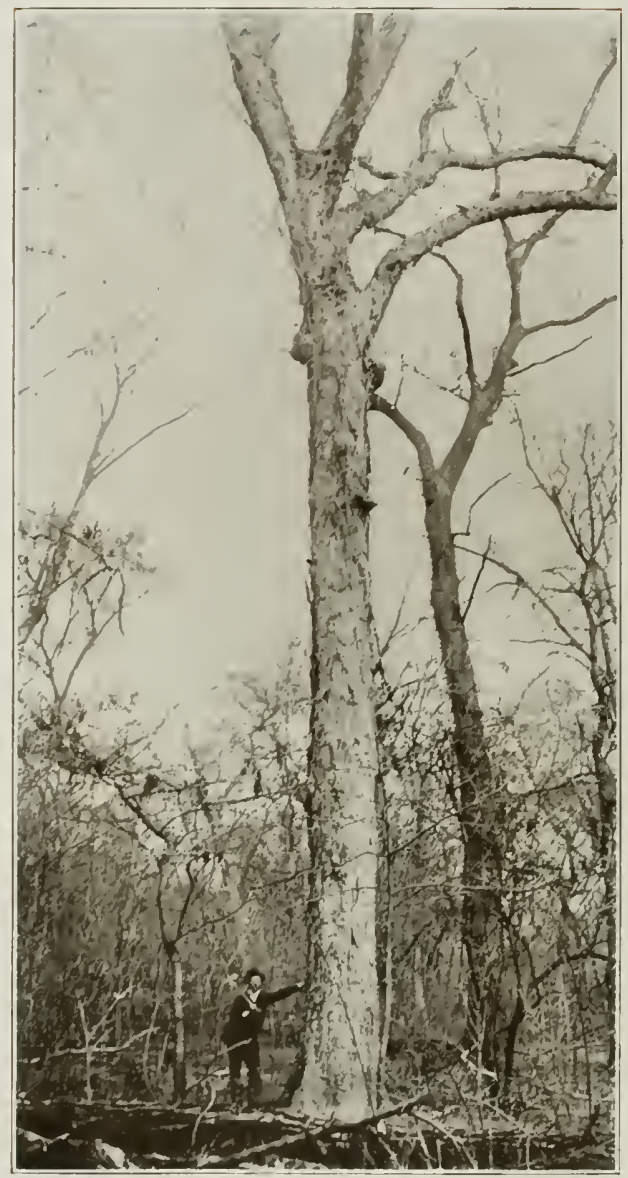

Prean 


\section{PECAN}

(Hicoria Pecan)

$\mathrm{T}$ HE name is pecan in Virginia, North Carolina, South Carolina, Alabama, Mississippi, Texas, Arkansas, Missouri, Illinois, Indiana, Iowa, and Kansas; pecan nut and pecan tree in Louisiana. The name is of Indian origin, and means walnut. The tree's natural range is smaller than the present area in which the tree is found, for it has been extensively planted in recent years. It is found as far north as Iowa, south to Texas, and east to Alabama and Kentucky. The highest development of the wild tree is in the lower Ohio valley. Forest trees were once found there which were said to be six feet in diameter and 170 high. Specimens that large would be hard to find now.

The pecan is a hickory. As to wood, it is the poorest of the hickories, and as to nuts it is the best. Its compound leaves are from twelve to twenty inches long with from nine to seventeen leaflets. The latter are from four to eight inches in length, and from one to three wide. The first pairs on the petiole are smallest. The fruit grows in clusters of from three to eleven, the number exceeding any other hickory. The nuts are four-angled, and long for their width.

The wood of pecan has disappointed those who have attempted to use it like other hickories. It does not differ much from them in appearance, but it falls low in mechanical tests. In strength, toughness, and stiffness it is inferior to the poorest of the other hickories. It has less than half the strength and half the stifiness of shagbark hickory. It is a fairly good fuel, but is high in ash.

The inferior quality of the wood has saved many a pecan tree from the sawmill and the wagon shop. Irine trunks stand near public highways, along river banks, and in fields, while al! merchantable hickories of other species have been sent to market. The uses of the wood are few. If some of it goes to wagon shops or to factories where agricultural vehicles are made, it is employed for parts which are not required to endure strain or sustain sudden jars.

Fortunately it is a tree with a value of another kind. It is the most important nut tree of the United States at this time, and it promises to remain so. The forest-grown pecans were an article of food for Indians who once lived in the region, and though white settlers who succeeded the Indians as occupants of the land, depended less upon forest fruits than the red men had done, yet the pecan was often of supreme importance in the early years of settlement. The nuts have constituted an article of commerce ever since the region had markets. 
Nurserymen were not slow to recognize the value of the pecan tree for planting purposes, and nursery grown stock has been on the market many years. Extensive orchards have been planted in Texas, Louisiana, Florida, and other southern states, and some of the earliest of these orchards are now in bearing. However, by far the largest part of pecans on the market is wild fruit from the forests. Many are shipped in from Mexico, but most grow in the rich woods of southern states. They are gathered like chestnuts in northern woods. The people who pick them sell to local stores at low prices, often taking pay in merchandise. Buyers collect the stock from country and village merchants, and put it on the general market, often at three or four times the price paid to the gatherers of the nuts.

One of the most important matters connected with pecan is the large number of horticultural varieties which have been produced by cultivation and selection. More than seventy have been listed in nursery catalogues and special reports. Some of the nuts are twice the size of those of the forest, and shells have been reduced in thinness until some of them are really thinner than they should be to stand the rough usage which comes to them in reaching markets.

Dealers occasionally polish pecans to impart the rich, brown color which is supposed to give them the appearance of being fresh and of high grade. The polishing is produced by friction, when the nuts in bulk are shaken violently. Last year's stock takes on as bright a polish as fresh stock, and the color and smoothness alone are not sufficient to prove that pecans are fresh from the trees.

The planted pecan tree grows rapidly and is as easily raised as fruit trees. The wild tree is long-lived, and the cultivated varieties will probably be like it.

Nutmeg Hickory (Hicoria myristiceformis) is so named because the nut has the size and the wrinkled surface of a nutmeg, though the shape is different. The husk enclosing the nut is almost as thin as paper. The only other name by which it is known is bitter waternut, in Louisiana. The name scarcely applies, for the kernel is said not to be bitter. The range of nutmeg hickory extends from the coast of South Carolina to Arkansas. It is rather abundant in Arkansas, but scarce in most other parts of its range. The tree has several interesting features. It was partly discovered a long time before the discovery was complete. In 1802 Andre F. Michaux saw the nut and to that extent the species was discovered, but many years passed before a full description was given to the world by a competent botanist. The wood rates among the strongest and stiffest of all the hickories, according to present information; but the calculations were based on too few tests to be considered final. Two samples of wood procured near Bonneau's depot, South Carolina, by WV. H. Revenel, showed the remarkable breaking strength of 19,822 pounds per square inch, and the measure of stiffness exceeded $2,000,000$ pounds to the square inch. That strength is sixteen per cent above shagbark. The weight of nutmeg hickory is 46.96 pounds to the cubic foot. The wood is hard, tough, and compact. The structure, including pores, 
medullary rays, annual rings, springwood and summerwood, is similar to the wood of other hickories. Trees grow best in sandy soil but near swamps and rivers where there is plenty of water. The largest trunks are eighty or one hundred feet in height and two in diameter. When use is made of this hickory it serves the same purposes as the wood of other trees of the group. It is never reported separately in statistics of wood utilization. It is too scarce to be important as a timber tree. It apparently has a future as an ornament, though it bas not yet been widely planted. It has proved a success in the Carolinas and it thrives in the climate of Washington, D. C. The luster of its foliage makes it the most beautiful of the hickories. 1n common with other members of the genus, its long taproot renders the transplanting of nursery stock difficult.

WATER Hickory (Hicoria aquatica) is known as swamp hickory in South Carolina, Florida, Mississippi, and Louisiana; 1 bitter pecan in Mississippi and Louisiana, and water bitternut in Tennessee and South Carolina. The northern limit of this species is in Virginia near IIobjack bay, the southern limit in the Caloosa valley, Florida, west to the Brazos river, Texas, and north to southern Illinois. The wood is hard, heary, strong, but rather brittle; the sapwood is thick and of ten is nearly white, while the heartwood is dark brown. It is the most porous of the hickories, and the pores are distributed generally through the annual rings of growth. In other hickories they are largely restricted to the inner part of each ring, though a few are dispersed through all parts. In swamp hickory there is little difference in appearance between the wood grown early in the season and that produced later. The tree is a rapid grower. It is an inhabitant of deep swamps, and if the land is inundated a considerable part of the year, the tree seems to grow all the better. At its best it may attain a height of 100 feet, and a diameter of two, but that size is unusual. The nut is small and wrinkled, and when broken open, pockets of red bitter powder are frequently found inside the shell. Usually the nuts are too bitter to be eaten, but it is said that near the western limit of the tree's range, nuts are sometimes edible.

The only reported uses for the wood are fuel and fencing. It is poor fence material, because, like other hickories, it decays in a short time when exposed to weather. The wood of this genus is rich in foods on which decay-producing fungi feed. Fungus is a low order of plant life which sends its hair-like threads into the wood cells and consumes the material found there; but numerous insects bore into wood to procure food. Few woods suffer from such attacks more than hickory: Even after it is seasoned and manufactured into commodities, it is frequently attacked by varions species of powder post beetles, and much injury results. Water hickory while yet standing is often greatly damaged by the larva of certain moths which find their way into the soft wood just under the bark and tunnel minute galleries which subsequently fill with brown substance. According to R. B. Hough, these brown streaks in water hickory are hard enough to turn the edge of steel tools. They not only damage the structure of the wood but spoil its appearance.

Butter Pecaxi (Hicoria texana) is a Texas species which has not been reported elsewhere. The average size of the tree is from fifteen to twenty-five feet in height and eight to ten inches in diameter; but in rich bottom land, particularly along the Brazos river, specimens sometimes attain a cliameter of three feet and a height of 100 . The leaves are from ten to twelve inches in length, with from seven to eleven leatlets. The nuts are very bitter, but are of approximately the same size and shape as edible pecans. The shells are thin and very brittle. The tree's range cxtends inland 100 or 150 miles from the Texas coast. 
North Carolina Shagbark Hickory (Hicoria carolineseptentrionalis) is found in the neighboring parts of the four states: North Carolina, Georgia, Tennessee; and Alabama. In the best land this tree is occasionally eighty feet high and two or three in diameter, but when it occurs on dry hillsides its average height is twenty or thirty feet, and its diameter about a foot. The compound leaves are from four to eight inches long, with usually three, but occasionally five leaflets. The sweet nuts are small and brown. The bark separates into thick strips a foot or more in length and three or four inches wide. The rough trunk resembles the northern shaghark hickory. The wood is very tough, strong, and hard, the heart light reddish-brown, the thin sapwood nearly white. It is not distinguished from the other hickories in commerce, and it has the same uses when any use is made of it.

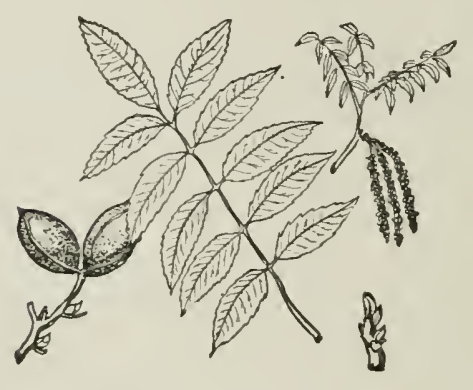


WHITE ELW 


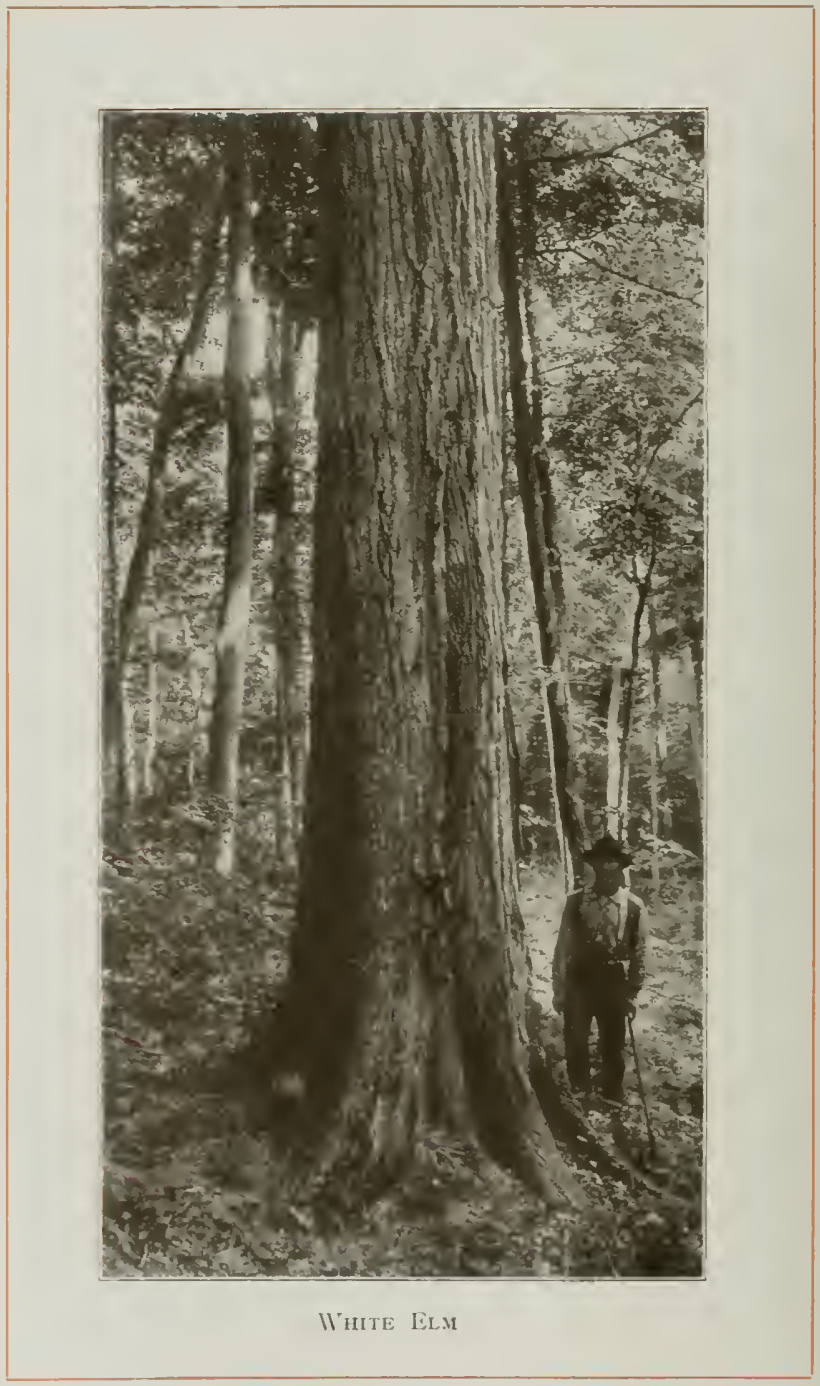




\section{WHITE ELM}

(Clmus.Americana)

SIX species of elm occur in the Lnited States, not counting the planer $S$ tree as an elm, though lumbermen usually consider it as such.* The white elm is the most common, is distributed most widely, and is commercially the most important. More of it is used as lumber, slack cooperage, and other forms of forest products, than all other elms of this country combined. The statistics of sawmill output collected annually by the United States census are not compiled in a way to show the elms separately. All go in as one. The annual lumber cut of elm in the whole country is about $265,000,000$ feet, distributed over thirty-four states, with Wisconsin leading, followed in the order named by Nichigan, Indiana, Ohio, Missouri, Arkansas, New York, and Minnesota. In addition to lumber, elm furnishes about $130,000,000$ slack cooperage staves yearly.

The elms, taken as a class, are much alike. There is more resemblance between the species than between species of oaks or pines, yet some difference exists between elms. This holds not only between different species, but between individuals of the same species. Climate, situation, and soil have much to do with the character of the wood of the same species. So great is the difference at times that fairly good judges of timber are deceived as to the species. A tree growing on dry, rocky soil produces wood quite different from one on rich, deep, wellwatered soil. Not only is the wood of one difierent from that of the other, but the appearances of the standing trees are not alike. The differences may not show in leaves, flowers, and fruit as much as in the shapes and sizes of trees, and the habit of the branches.

White elm is by common consent the type of the genus, the standard by which the other species are measured. It is proper to compare certain properties and characters of other elms with white elm, in order that a general view of all may be had. The dry weights, per cubic foot, of wood are as follows: White elm 40.54 pounds, slippery elm 43..35, cedar elm 45.15, cork elm 45.26, and wing elm 46.69. Figures which show the weight of the southern red elm (Ulmus scrotina) are not available. White elm is thus shown to be lightest of the group.

Its breaking strength averages $12,15 \mathrm{~S}$ pounds per cubic inch, under

*The elms are white elm (Llmus americana), eork elm (Llmus racemosa), slippery elm (Ulmus pubescens), cedar elm (Ulmus crassifolia), wing elm (Llmus alata), and red elm (Ulmus serotina). They are all eonfined to the region east of the Rocky Mountains. 
the usual tests by which the strength of woods is determined. Reduced to everyday language that means that 12,158 pounds would just break a white elm stick, 25 inches square, and resting on supports twelve inches apart. That is the meaning of "breaking strength," or "modulus of rupture," as the term is used in engineering text books relating to woods. The following figures for the breaking strength of other elms make comparisons with white elm easy: Cedar elm 11,000; wing elm 11,162; slippery elm 12,342; cork elm (often called rock elm) 15,172. It is shown that two elms are stronger and two weaker than white elm. This wood rates very little below white oak in strength.

The different species of elms vary considerably in stiffness, or the ability to spring back when bent. This factor is expressed by engineers in high figures, is purely technical, and is based on a wood's ability to stretch and regain its former position. The only service which the figures can render to the layman is to furnish a basis for comparing one wood with another. The stiffer a wood, the greater its resistance to an effort to stretch it lengthwise. White elm's measure of stiffness (modulus of elasticity) is $1,070,000$ pounds per square inch; wing elm 853,000 ; cedar elm 981,000; slippery elm 1,318,000; cork elm 1,512,000. It is shown here, as was shown in the figures representing the strength of the elms, that two species rate above and two below white elm in stiffness.

White elm is known by several names. The color of the bark is responsible for the name gray elm among lumbermen and woodworkers of the Lake States. American elm is a translation of its botanical name, and is neither descriptive nor definitive, because there are other elms as truly American as this one. White elm distinguishes its wood from the redder wood of slippery elm, but it would often be difficult if not impossible to identify the elms, or any one of them, by the color of the wood alone. Some persons who call this elm white doubtless refer to the color of the bark, as is the case with those who speak of it as gray elm. $1 \mathrm{t}$ is known as water elm in several states, but that name is applied indiscriminately to any elm that frequents river banks, as most of them do in some part of their range. It is called rock elm when it is found on stony uplands, and swamp elm on low wet ground. In some parts of the Appalachian mountain ranges it is called astringent elm to distinguish it from slippery elm.

White elm surpasses the others in extent of range. Its northern boundary stretches from Newfoundland, across Canada to the eastern base of the Rocky Mountains, a distance of nearly 3,000 miles. It runs south through the Atlantic states to Florida, a distance of 1,200 miles or more. Its southwestern limit is in Texas. The area thus bounded is 
about 2,500,000 square miles. A few other trees have ranges as large, but none much exceed it. It covers so much of America, and is so important in many parts of its range, that it is clearly the leading elm in this country. It is entitled to first place among elms for other reasons.

It is not easy to give any sure features or characteristics by which the layman may always distinguish this elm from others with which it is associated; however, by carefully observing certain features, the identity of white elm is generally easy to establish.

The leaves have teeth along the margins like beech and birch. They have straight primary veins running from the midrib to the points of the teeth. Before falling in autumin the leaves turn yellow. The foliage is not very thick, and most of it is near the ends of the limbs. The bloom comes early in the spring, ahead of the leaves, and the seeds are ripe and ready for flight before the leaves are grown. Sometimes the seeds are ripe almost before the leaves are out of the buds. The seeds are oblong, and about the size of a small lentil. The wing entirely surrounds the seed, and is about balf an inch long. The flight of elm seeds is an interesting phenomenon. The individual seeds are so small that they are not easily seen as they sail away from the tall tree top but when they go in swarms, in fitful pufis of wind, they are not hard to see. It is chiefly by their fruits that they are known, that is, by the multitudes of seedlings that appear a few weeks later. If one seedling elm in a thousand should reach maturity, there would be little besides elms in the whole country. They spring up by highways and hedges, in gutters, fields, and even between cobbles and bricks of paved streets; but in a few days they have crowded one another to death, or have perished from other causes, and those which manage to live to maturity do not much more than make up for old trees which perish from natural causes.

The botanist Michaux pronounced the white elm "the most magnificent vegetable of the temperate zone." A number of trees are larger, though this reaches great size. Sargent sets the limit of the tree at 120 feet high and eleven feet in trunk diameter. That size is, of course, unusual, but it has been surpassed at least in height. A tree in Jefferson county, Pennsylvania, was 140 feet high, and although forest grown, it had a spread of crown of seventy-six feet. It was sent to the sawmill where it made $\$, \$ 20$ feet of lumber. That trunk was only five feet in diameter.

Some of the finest forest grown elms in this country have been cut in Michigan. Their trunks were as tall, straight, and shapely as yellow poplars, and their crowns surpassed those of poplars. It was formerly not unusual for sawlogs to be cut from elin limbs which branched from the trunk fifty or more feet from the ground. The best of the forest 
grown elm of this country has been cut; but it is still lumbered throughout the whole eastern half of the United States.

The finest elms of this country, and doubtless the finest in the world, are the planted trees in some of the New England villages. The largest of them have been growing for two hundred years, and in many instances they still show the vigor of youth. Trunks six or seven feet through are not uncommon, but the glory of the trees is not alone in the trunks. Their spread and form of crown are magnificent. The largest are 150 feet across, and some of the splendid branches, rising in parabolic curves, are fully 100 feet long, from the junction with the tree to the tips of the twigs. The most apt comparison for that form of elm is the spray of a fountain. The upward jet of water corresponds to the trunk of the tree; the upward, outward, and downward curves of the spray represent the crown of the elm. Trees which take that form are grown in open ground where sunlight and air reach every side. Forest grown trees are less symmetrical, but even in dense woods, the elm frequently rises clear above the canopy of other trees, and develops the fountain form of crown. The new England street and park elms surpass those farther west only because they are older. The splendid trunks and crowns are the work of centuries.

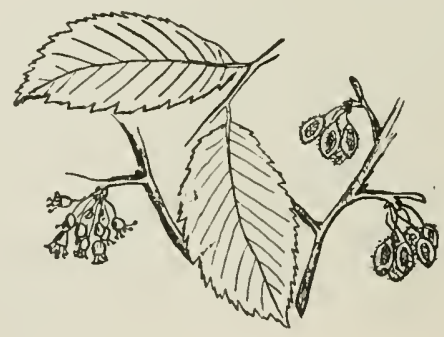


CORK ELM 


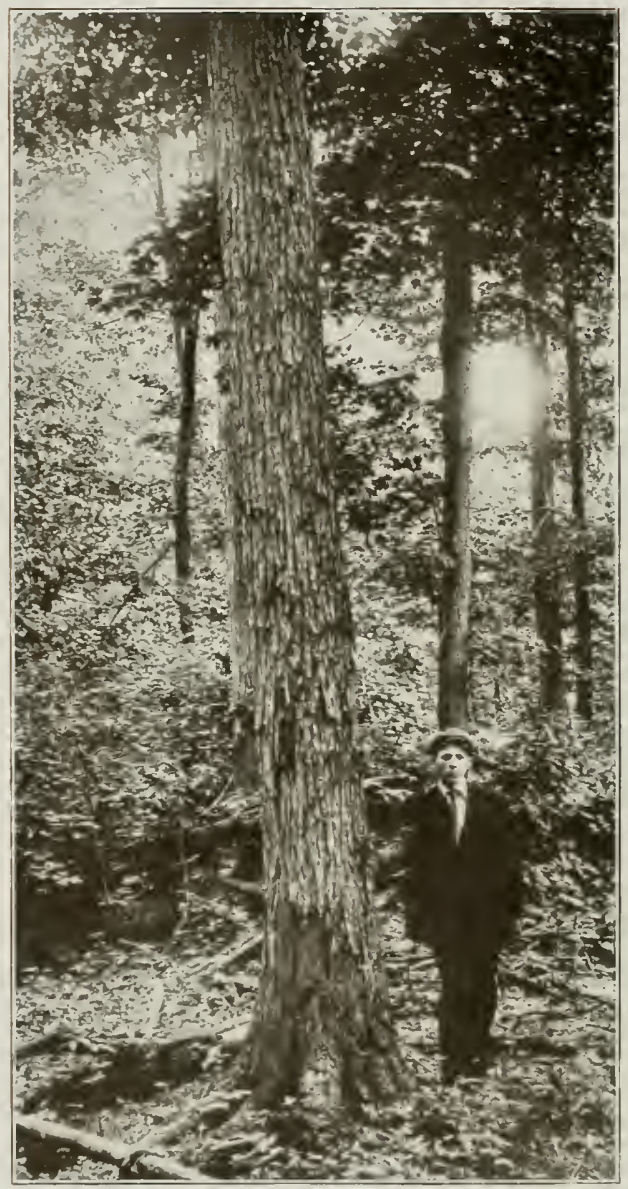

CORK ELM 


\section{CORK ELM}

\section{(Ulmus Racemosa)}

$\mathrm{T}$ HIS tree is called cork elm in Vermont, Massachusetts, Rhode Island, New York, New Jersey, Arkansas, Kentucky, Missouri, IVisconsin, Michigan, Iowa, and Ohio; rock elm in Rhode Island, Kentucky, West Virginia, Missouri, Illinois, Wisconsin, Iowa, Michigan, Nebraska; hickory elm in Missouri, Iowa, Illinois, and Indiana; white elm in Ontario; Thomas elm in Tennessee; northern cork-barked elm in Tennessee; corkbark elm, New York; northern cork elm, Vermont; wahoo, Ohio; cliff elm in $\mathrm{W}$ isconsin.

Cork elm is the natural name. It is a descriptive term which a stranger would be apt to apply on seeing the tree for the first time. The bark of the branches, after it has attained an age of three or four years, becomes rough by the growth of ridges and protuberances. This feature is sometimes so prominent that it at once attracts attention, particularly when the branches are bare of leaves; hence the name cork eim.

Lumbermen insist on naming the tree rock elm. They refer to the hardness of the wood, or they may have in mind the dry, stony situations where tough, strong elm grows. The latter is often the case, because the name is applied also to slippery elm and white elm if they grow on stony ground. A wide-spread opinion prevails that wood which grows among rocks is harder, tougher, stronger, and more durable than that produced by deep, fertile soil. It is possible to cite much evidence to support that view, and the case might be considered proved, but for the fact that an equal, or greater amount of evidence, in every way as trustworthy, may be cited on the other side. The strongest hickory, ash, and oak do not come from stony land. It sometimes happens that a species with tough, strong wood, is found on rocks, but it is not tough because it is there, but in spite of being there.

The name cliff elm which this tree bears in Wisconsin is but another form of the name rock elm, and clearly has reference to the situation where the tree grows in that part of the country. Hickory elm, on the other hand, a name applied to this tree much farther south, is a recognition of the woods toughness.

In some particulars it does not fall much below hickory in toughness, but is not as strong, elastic, or capable of as smooth polish. The latter property is one of the recommendations of hickory when uscd for handles. It is very smooth to the touch; cork elm is less so. In the northern woods, elm ax handles are in use, aud some axmen prefer them 
to hickory. Such is probably the case when the best cork elm and a medium or poor quality of hickory are in competition.

The fibers of cork elm are interlaced, rendering the splitting of the wood difficult. For uses in which that is a desirable property, it is preferable to hickory. It is better for hubs for large wagons, and that is a very important use for this elm.

The wood of all the elms is ring-porous; that is, the springwood, or inner part of the annual ring, consists of one or more rows of large ducts. The summerwood contains pores in large numbers, but they are small, and are usually arranged in short curved lines. The medullary rays are not prominent in the wood of any of the elins, and quarter-sawing adds no beauty to the lumber. The wood is practically without figure, on account of either annual rings or medullary rays; but it may be stained, polished, and made very attractive. That is done of tener with white elm than with any other.

The strength of cork elm created demand for it in boat building at an early day. The tree is and always was scarce in the vicinity of the Atlantic sea board, and the earliest boat builders seem not to have been acquainted with the wood. It was most abundant in the forests of Michigan, though it extended westward to Nebraska. It was plentiful in the province of Ontario, and the timbers from that region acquainted English shipbuilders with the merits of the wood. They sent contractors into Michigan to buy cork elm, long before the other hardwoods of that region had attracted the attention of the outside world. The most convenient supplies of cork elm on the Lower Michigan peninsula thus passed through Canada to ship yards on the other side of the sea. The wood is reputed to be more durable than any of the other elms.

It is generally understood that the country's supply of cork elm is rumning short, but there are no statistics which show how much is left or how much has been cut. It is doubtful if the original forests, including the whole country, had one tree of cork elm to twenty of white elm. The average size of cork elm is sixty feet high and two in diameter. The trunks are well shaped, if forest grown. They develop small crowns in proportion to the size of trunks; and the crowns are less graceful than those of white elm - lacking the long, sweeping curves of the latter. The general contour of the tree has been compared to white oak.

Cork elm grows well when planted on the Pacific coast, in environments quite different from its native habitat. In the forest it increases in size slowly; when planted it makes much better headway. It has a disagreeable habit of sprouting which puts it out of favor as a park tree.

The wood of the different elms is largely used for manufacturing purposcs. They are sometimes kept separate, but generally not. The 
particular place where cork elm is preferred is in the manufacture of vehicles and boats, but it is by no means confined to those commodities.

The state of Michigan alone sends 50,000,000 feet of elm a year to its factories to be converted into articles of general utility. Furniture makers take over $2,000,000$ feet of it, though elm is not classed as a furniture wood. In certain places it is superior to almost every other wood. No matter how discolored it becomes by weathering and the accumulation of foreign substances, a vigorous application of soap, water, and a scrubbing brush will whiten it. It is liked in certain parts of refrigerators which need constant scrubbing. Elm to the extent of $8,000,000$ feet goes into refrigerators in Michigan alone.

The strength and toughness of elm make it suitable for frames of tables. When thus used, it is generally out of sight, but not infrequently it is made into table legs as well as frames. Statistics show that more than a million feet are manufactured yearly into handles in Michigan alone. All three of the northern elms-white, cork, and slippery-are listed in the handle industry.

Many millions of feet of elm are yearly converted into automobile stock-3,000,000 in Michigan. Horse-drawn vehicles take more. The most common place for it is the hub, but it serves also as shafts, poles, reaches, and even as spokes for wagons of the largest size.

The important place in the slack cooperage industry held by elm is well known. It is a flour barrel wood, but is employed for barrels of many other kinds. It stands high as veneer, not the kind of which the visible parts of furniture are made, but the invisible interior, built up of veneer sheets glued together. A similar kind of veneer forms the boxes or frames of trunks-the part to be covered by metal, leather, or cloth. The slats which strengthen the outside of trunks are frequently of elm.

This wood is not in favor for one important purpose, hardwood distillation. It has escaped pretty generally also from being employed as a farm material, on account of its poor lasting qualities. Some slippery elm was mauled into fence rails in the pioneer days of Ohio, Indiana, and southern Michigan, but that was only because it was plentiful and convenient. Cork elm probably never made a fence rail, because it is so unwedgeable that no rail splitter would have anything to do with it. At the best, it is but a temporary makeslift as fence posts, but by applying creosote and other preservative treatments to lessen decay, it measures up with most other post woods.

The elms are not indispensable woods in this country, but their exhaustion, should it ever come, will leave many places hard to fill. As far as known, no woodlots of any species of elm have been planted in this country, and there is little prospect that any will be planted, because 
the slow growth of the trees discourages foresters. A century or two is a long look ahead.

However, the exhaustion of no species of the elms in this country need be expected soon. The most apparent peril lies ahead of cork elm, because it never was abundant, and demand, which has been large for a long time, is still strong. The species is scattered over more than 200,000 square miles, and a long time must elapse before the last cork elm finds its way to the sawmill. The situation of white elm is more promising. It may be among the last trees of the American forests to take its final departure. Its wide range and its bounteous seed crops insure a supply, though not necessarily a large one, for a long time. The greatest peril to elms, as well as to many other forest trees, is that, when weakened by depletion, some disease will attack them and destroy the remnants. Experience in New England and elsewhere has shown that elm has no great resisting power when a strong attack is made upon it.

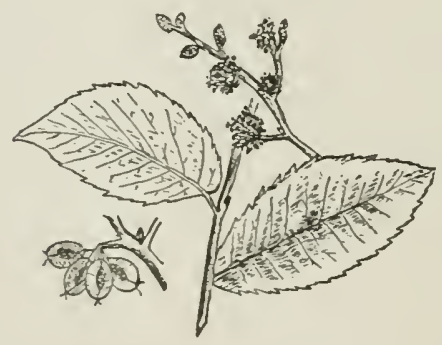


SLIPPERY EIM 


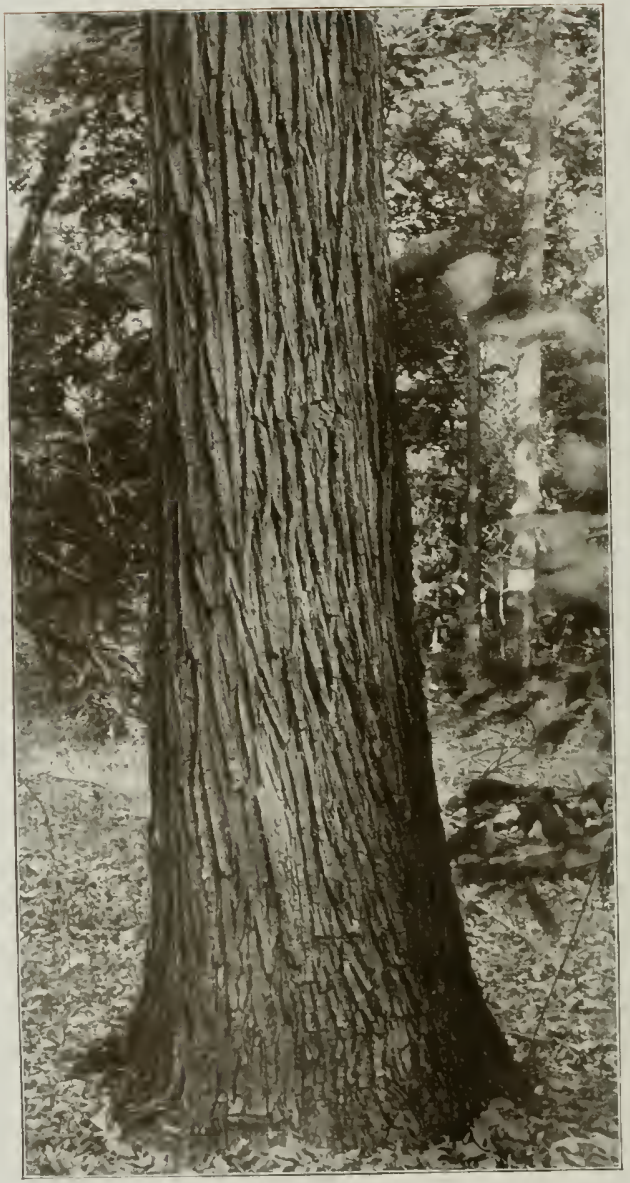

Slipperi Elm 


\title{
SLIPPERY ELM
}

\author{
(Ulmus Pubescens)
}

$\mathrm{T}$ HIS tree is known as slippery elm in every state where it grows, thirty or more; but in some localities it has other names also. It is doubtful if any person who is acquainted with the tree would fail to recognize it by the name slippery elm, though some who are acquainted with the lumber only night not know it by that name. Those who call it red elm have in mind the color of the heartwood which is of deeper red than the wood of any other elin, or they may refer to the tawny pubescence on the young shoots in winter. The botanical name describes that characteristic.

In the North, the slippery elm is sometimes known as moose elm. It furnishes forage in winter for the moose and other herbivorous animals when ground plants are covered with snow. The moose is able to eat branches as thick as a man's thumb. The principal food element in the twigs is the nucilaginous inner bark. It is this which gives the tree its name slippery elm. The value of the bark as a food has been questioned. It is agreeable to the taste of both man and beast, but it is claimed that a human being will starve to death on it, though it will prolong life several days. The lower animals, however, seem able to derive more benefit from eating the bark. An incident of the IVar of 18 I2 appears to prove this. The army under General Harrison, operating in the vicinity of Lake Erie, kept the horses of the expedition alive by feeding them on slippery elm bark, stripped from the trees and chopped in small bits.

The inner bark has long been used for medicinal purposes. It is now ground fine and is kept for sale in drug stores, but formerly it was a household remedy which most families in the country provided and kept in store along with catnip, mandrake, sage, dogwood blossoms, and other rural remedies which were depended upon to rout diseases in the days when physicians were few. The slippery elm bark was peeled from the tree in long strips, the rough outer layers were shaved off, leaving the mucilaginous inner layer. That was from an eighth to a quarter of an inch thick. It was dried and put away for use. When needed it was pounded to a pulp, moistened with water, and applied as a poultice, if an external remedy was wanted. If a medicine was needed, a decoction was drunk as tea. There is no question that the remedy often produced good results when no doctor was within reach. A well-known medical writer said three-quarters of a century ago that the slippery elm tree was worth its weight in gold. 
The range of slippery elm extends from the lower St. Lawrence river through Canada to North Dakota. It is found in Texas as far west as the San Antonio river, and its western limit is generally from 200 to 300 miles west of the Mississippi river. Its range extends south nearly to the Gulf of Mexico. It is not this tree's habit to grow in thick stands, but it occurs singly or in small groups on the banks of streams or on rich hillsides.

The average size is scarcely half that of white elm. Few trees exceed a height of seventy feet and a diameter of two. It grows rapidly at first, but does not live to old age. The crown lacks the symmetry and beanty so conspicuous in white elm. The limbs follow no law of regularity, but leave the trunk at haphazard. The fruit is mature before the leaves are half grown. The seeds have more wing area than those of white elm; and, like those of white elm, the wing surrounds the flat seed on all its edges. The leaves are rough to the touch, and when crumpled in the hand, the crunching sensation is unpleasant.

Next to white elm, slippery elm appears to be more abundant than any other member of the group; but statistics do not give the basis for close estimates. The factories of Michigan use 3,700,000 feet of slippery elm a year, and $14,000,000$ of white elm. The proportion of slippery to white is larger in the factories of Illinois.

The uses are the same as for other elms. The wood is rated more durable than the others, but it is not in much demand for outdoor work where resistance to decay is an important consideration. It is sometimes set for fence posts, but the results are scarcely satisfactory, particularly for round posts which are largely sapwood. Posts sawed from the heartwood of large trees would do better. The deeper red of the heartwood gives it an advantage over the other elms for furniture and finish where natural colors are shown; but this is not important because no elm's natural color stands for much in the estimation of users of fine woods. The more common use of slippery elm is for boxes and cooperage. Next to red gum, it is employed in larger quantities for cooperage in Illinois than any other wood.

The supply is rapidly decreasing. The cut for lumber is the chief drain, but a not inconsiderable one is the peeling of trees for bark. This goes on all over the species' range and much of it is done by boys with knives and hatchets. It is often hard to find slippery elms within miles of a town, because all have succumbed to bark hunters.

CEDAR ELM (Ulmus crassifolia) appears to bear this name because it is often found associated with red cedars on the dry limestone hills of Texas. There is little in the form and appearance of the tree to suggest the 1all, tapering conical crown of cedar. There is still less in the wood. In some parts of Texas the species is called red elm, on account of the color of the wood, while in Arkansas, which is ncar the 
northern boundary of its range, it is locally known as basket elm, because hasket makers find desirable qualities in its wood. It is a species of rather limited range, hut it is abundant in cert ain regions. It is found as far east as Sunflower river, Mississippi, north into Arkansas, west to Pecos river, Texas, and south into Mexico. It is confined to three states, this side the Rio Grande. Trees on dry hills are inclined to be shruhhy, hut in damp valleys where soil is fertile, specimens attain a beight of eighty feet and a diameter of three, hut the average is not nearly so large. The leaves are small but numerous. The flowering habits of this elm are somerhat erratic. The usual time for bloom to appear is August, and a month or six weeks afterwards the small seeds are ready for flight; but occasionally, as if not satisfied with its first effort, the tree blooms again in October, and ripens a second crop late in the fall. The seeds are poorly supplied with wings, which are reduced to narrow margins surrounding the seed. It does not appear, however, that the species is in any way handicapped in securing reproduction. The small shoots are equipped with flat, corky keels, similar to but much smaller than those of the wing elm.

This tree is important for the lumber it produces. It is the common and most abundant elm of Texas, and it is found in a large part of that state. The wood is the weakest of the elms, and is likewise quite brittle; but in the region where it is most abundant it compares favorably with any other. The best is cut from the largest trees, which grow in valleys where moisture is abundant. The growth found on the dry hills is of poor quality, and is worth little, even for fuel. The highest development in Texas, and also the highest in the species' range, is in the valleys of Trinity and Guadalupe rivers. In Texas this wood is employed in furniture factories as inside frames, to be covered by other woods, but it is not employed as outside parts of furniture, unless in very cheap kinds. It is suitable for drain boards and floors of refrigerators where it is wet much of the time. Under such circumstances it is more easily kept clean than most other woods. It whitens with repeated scrubbings. One of its most common uses in Texas is for wagon hubs. Some wheelwrights pronounce it next to the best native wood for that purpose, the first place being accorded Osage orange. The tree is often planted for shade along the streets of Texas towns, and develops thick crowns and satisfactory forms.

RED ELM ( Ulmus serotina) is a lately discovered member of the elm family. It so closely resembles the cork elm that it was supposed to be of the sattie species, and the close scrutiny of a botanist was required to discover that it was a separate species. Sargent ohserved the flowers opening in September while those of cork elm appear in early spring. The seeds ripen in Novemher, while cork elm's are ripe early in the summer. The tree was named red elm, the wood heing reddish-brown. That name is widely applied to slippery elm, but it is improbable that much confusion will result. The red elm's range is quite restricted and in that area the slippery elm is not important. Red elm occurs on limestone hills and river banks from central Kentucky to northern Georgia and Alabama. It attains a height of fifty or sixty feet and a dianeter of two or three. The leaves are from two to four inclies in length, and one or two wide, with margins toothed like the other elms. The midrih is ycllow, and in the autumn the leaves change to an orange yellow before falling. Branches which are two or three years old develop corky wings, two or three in number.

It is not known that mechanical tests of the wood have been made in a regular way to determine its physical properties, but superficial examination indicates that it is hard, tough, and strong, apparently about the same as cork clm. Special lists of uses for this wood have not been compiled for the reason that lumbermen and operators of sawmills have never distinguished it from other elms of the 
region. Since it has never been left standing in districts where other elms are cut, it is evident that it has been regularly put to use for vehicles, agricultural implements, boxes, crates, and slack cooperage, because such articles have been manufactured in the region. The red elm has been occasionally planted as a shade tree along strects of torns in northern Georgia and Alabama.

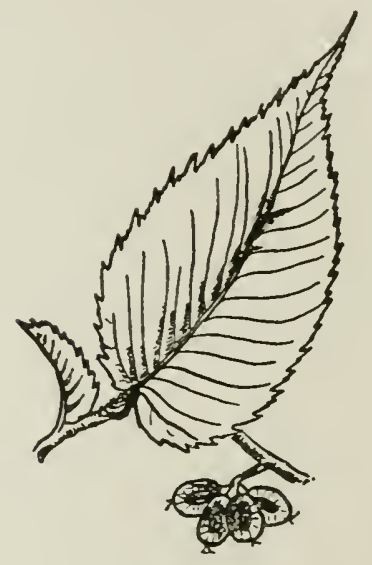


PLANERTREE 


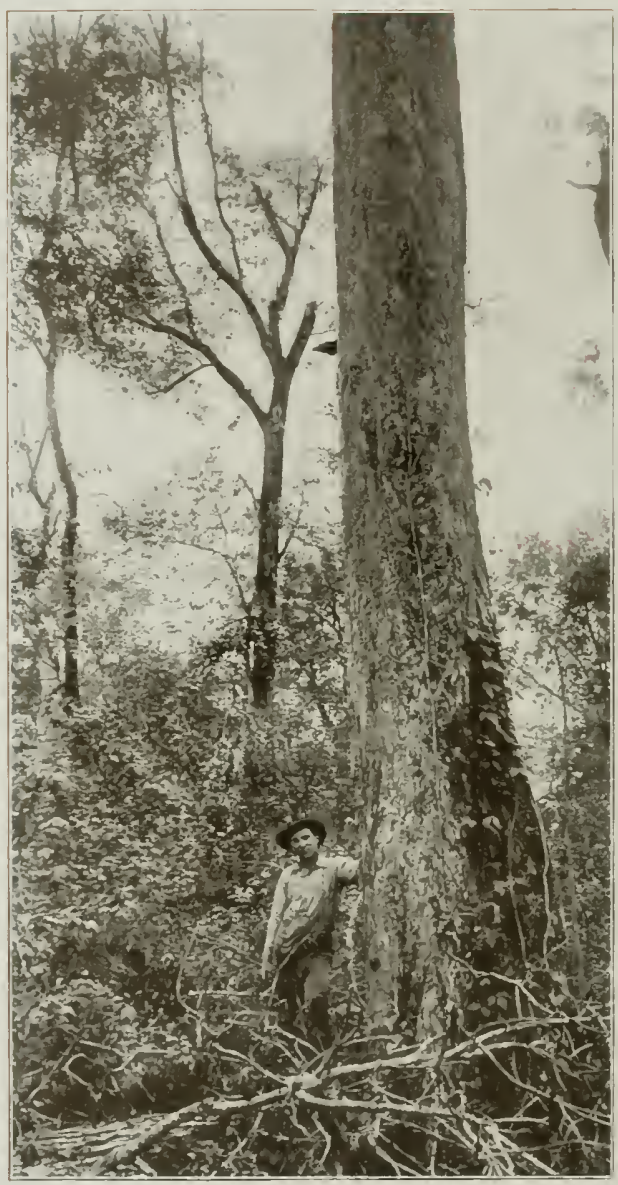

Planertree 


\title{
PLANERTREE
}

\author{
(Planera iquatica)
}

T HIS tree is a first cousin of the elms, but it is no more an elm than a hackberry is an elm. It is a member of the family but is of a different genus, and it is the sole representative of its genus in the known world. There is only one kind of planertree, with no nearer relatives than the elms on one side and hackberry, sugarberry, and palo blanco on the other. Except those kinsfolk, it is alone on earth. The name is in honor of Johann Jacob Planer, a German botanist whose efforts did much for science nearly two hundred years ago. The name of the species aquatica, recognizes the tree's habit of growing where water is abundant. It is a swamp species, or rather, it prefers situations subject to periodic overflow. It looks like an elm, and that has led people to call it water $\mathrm{elm}$. That is the name by which it is usually known in Florida. In Alabama it is called the American planertree, which is an unnecessary restriction, since there is no planertree except this one. The Louisiana French gave it the name plene, and the abridgement of its name is yet heard in that state. In North Carolina it has acquired the name sycamore, but without good reason. It does not look in the least like sycamore.

It has the leaf of an elm, and it resembles that tree in bark, and somewhat in general form. The layman detects the first important difference when he exannines the seeds. Those of the elms have wings, but the planertree's are without those appendages, and they would be useless if it had them, unless they were as large as the parachute of the basswood seed. The planertree bears a sort of nut, a third of an inch long, and too heavy to be transported far on the ordinary membranous wings of tree seeds. Water is doubtless the principal agent in carrying the seeds from place to place. Probably few of them are transported iar, because the water about the trees is generally stagnant; and, besides, the species does not seem to be extending its range or increasing in numbers.

The planertree has a history. If the terms which the Roman historian Tacitus applied to people, could be applied to trees, it might be said of this species, as he said of certain tribes: "The cowards fiy the farthest and are the last survivors." The planertree is now found only in certain southern swamps, from North Carolina to Florida, and west to Missouri and Texas. In former periods, as is shown by the records of geology, there were several species, and they had a wide range over portions of the nor thern hemisphere. They appear to have been a strong 
group of trees, able to hold their ground with the best inhabitants of the forest. They were in the Rocky Mountains, and far north in Alaska. They were in Europe also, or were represented there by some very similar species.

For some reason which is not definitely known, they lost ont when competition with other trees became keen, and in the course of long periods of time they disappeared from their former ranges in the North and W'est. They took to the swamps, just as the tribes of which Tacitus spoke, took to the morasses when they could no longer face their enemies on open ground. It was a far cry from Alaska to the Chattahoochee swamps in Florida, yet that was where $A$. H. Curtis and Charles Mohr went to procure typical planertree specimens for the tests which Sargent made of American woods.

It has been suggested that tree species which have lost out in competition for ground, have been those which were at some decided disadvantage in the matter of getting their seeds properly scattered and planted. The case has not been proved, because there are as many facts and as much argument against that hypothesis as for it. The bigtrees of California are a noted example of a species which lost ont and retreated to a corner, yet their seeds fly like birds. Plainly, something besides winged seeds is needed to keep the species in the fight. However, it is not difficult to see that the planertree, with wingless seeds and of so little use as food that no bird or rodent will carry them or bury them, has been much handicapped in the long contest which has crowded it from the arctic circle to the cotton belt.

It lias the habits of the subdued and conquered tree. It has adapted itself to swamps where few species can grow, and where competition for light and room is reduced to a minimum. Yet, even there, it is content to take the leavings of more ambitious species. The crowns make little effort to rise up to the light, for which many other trees battle during their whole existence. The planertree's low, broad top of contorted branches places it perpetually in the shade of any other trees which overtop it.

The wood of the planertree is lighter in weight, poorer in fuel value, weaker, and more brittle than the poorest of the elms. The annual ring lacks the rows of large open pores common in all the elms, but it has many small pores scattered througls the whole year's growth. It is not easy to note a difference between the springwood and that which grows later. The wood is soft, light brown in color, and the nearly white sapwood is thick. It is often, perhaps generally, a tree of fairly rapid growth, and since it does not reach large size, it is probably short-lived, but exact information along that line is lacking . 
The tallest trees seldom exceed a height of forty feet and a diameter of two. It is evident that a tree of that size and form does not tempt the lumberman to much exertion to procure it. An examination of reports of sawmill operations and of the utilization of woods by shops and factories in the southern states has failed to find a single instance where the planertree has been reported in use for any purpose whatever. Doubtless, trees are sometimes cut and the lumber gets into the market, but not under its own name. The species is interesting for reasons other than that it ever has had or ever can have a place in the country's lumber industry.

Wra Els (L'mus alata), which is the smallest of the elms, is plentifully supplied with names, but in most parts of its range it is known as wing or winged elm. It is also called wahoo or wahoo elm, and the West Vriginians have named it witch elm; the North Carolinans refer to it often as simply elm; from Florida to Texas some call it cork elm; in Alabama it is water elm; in Arkansas mountain elm; while in other regions it is corky elm, small-leaf elm, and red elm. Some of these names are self-explanatory. Wing elm does not relate to a winged seed, but to winged twigs. That characteristic of the tree is very prominent. The wings consist of flattened keels along opposite sides of the branches. A twig no more than a quarter of an inch in diameter may be decorated with wings half an inch or more wide, making the twig four or five times as wide as it is thick. As the twig enlarges, the wings do not broaden in proportion. The lowest branches and those nearest the trunk are most generously furnished with wings. They appear to be entirely ornamental, for it is not known that they serve any useful purpose. The growth is different from those which give cork elm its name. The latter occur on the large branches, often in the form of isolated protuberances, but the wings are fairly continuous for a foot or more, except that they terminate abruptly at the nodes, but recommence immediately after. Branches less than a year old seldom have wings. The name wahoo appears to have lost its etymology if it ever had any. Dictionaries tell what it means, but they shy at its origin. It is a southern word which is applied to this elm, and also to other trees, and occasionally it means a fish instead of a tree. Some would trace it to the cry of an owl, others to a name in Gulliver's Travels, with a slight change in spelling.

Ting elm at its best is about fifty feet high and two in diameter; but much of the stand is small. The best occurs west of the Mississippi river. The range extends from Texas to Virginia, south to Florida, and north to Illinois. In Texas it is a fairly important wood in furniture factories, the annual supply being about a million feet. It is used by turners for table legs. In an investigation of the uses of the wood, the same difficulty is encountered that makes difficult a study of the uses of all the clmsconflict and uncertainty of names. There are few regions in the hardwond areas of this country which produce one elm and no more; and after all practical means of identification are resorted to, there is often doubt and uncertainty concerning the exact species of elm lumber found in use. Fortunately, it generally makes little difference, because anyone of them is good enough for ordinary use. Wing clm is extensively planted for shade along the streets of towns in the lower Mississippi valley, but more frequently on the west side of the valley. When the trees grow in the open they develop broad crowns, and the branches, even of comparatively small trees, are long enough to reach well over the sidewalks, and cast satisfactory shade. 
The dark-colored winged twigs add much to the ornamental value of the street trees.

FREMONTIA (Fremontodendron californicum) is not botanically in the elm family, but it is popularly known as slippery elm in the region where it occurs, and for that reason it is here given place among the elms. It is known also as leatherwood. It is a California species, ranging among the lower mountains and higher foothills in dry, gravelly soils, from the Mexican boundary five hundred miles northward in the state. The mucilaginous inner bark tastes like that of the true slippery elm. The shape of the leaf much more resembles sycamore than elm; and it is an evergreen. It bears a bright yellow, roselike flower, and the seeds are small, reddish-brown. The wood is fine grained, clear reddish-brown, with thick, whitish sapwood. It is very soft. The tree attains its largest size among the foothills of the Sierra Nevada mountains, but even there it is too small to have much economic value, seldom exceeding thirty feet in height and a foot in diameter. Its most important use is as a forage plant for cattle and sheep. In that particular it resembles slippery elm in northern woods. The tree is occasionally planted in the eastern states and in Europe for ornament. In its native range it grows slowly.

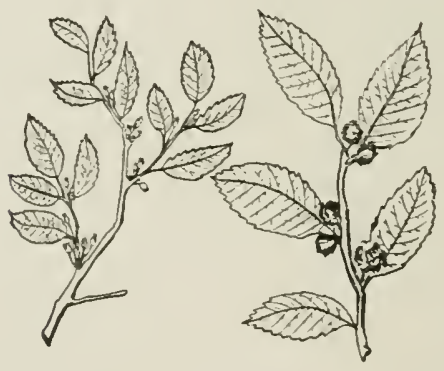


HACKBERRI 


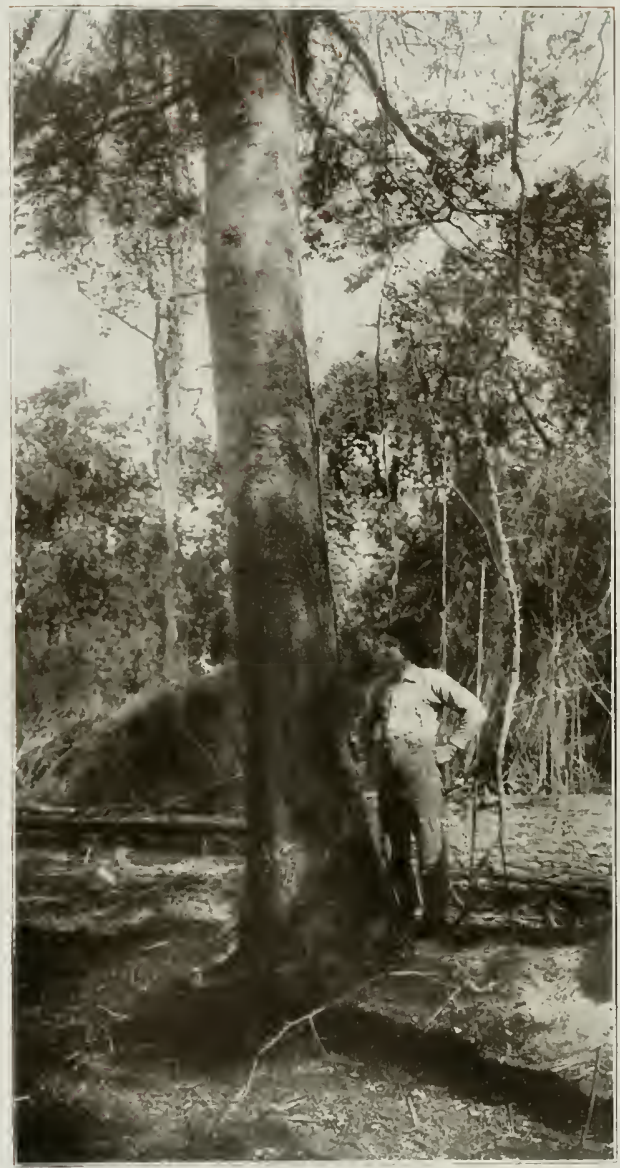

HACKBERRI 


\section{HACKBERRY}

\section{(Celtis Occidentalis)}

$\mathrm{H}^{\prime}$ ACKBERRY is a common name for this tree in nearly all parts of its range, but it has other names. It is sometimes confused with sugarberry (Celtis mississippiensis). They call it nettle tree in Rhode Island, Massachusetts, Delaware, and Michigan, and in Tennessee it is known as American nettle-tree. In Vermont it is hoop ash; in Rhode Island one-berry; hack-tree in Minnesota, and juniper tree in New Jersey.

The name hackberry is not of American origin. It dates far back in the languages of western Europe and is believed to have the same origin as the word haw, which, in its turn meant hedge. If that etymology is correct, the word really means hedge berry, which is not an inappropriate name for the tree. The name is sometimes applied to a small bird cherry in Europe. The new Jersey name juniper-tree is in recognition of the resemblance of the berries to those of red cedar or red juniper. No reason has been assigned for the name nettle-tree.

Its range covers about $2,000,000$ square miles in the United States besides part of Canada. It grows from the Atlantic on the coast of New England to the tide water of the Pacific on Puget sound; in southern Florida and in Texas. It is not found in pure stands, but often as single trees far apart. This is the case in the northeastern part of the United States in particular where probably not more than one tree might be found in a whole county. Frequently the people in the neighborhood do not know what the tree is, and suppose it is the last representative on earth of some disappearing species.

It is far from being a disappearing tree. Not only is it widely dispersed over the United States, but related species are scattered through many countries of the old world, from Denmark to India. There are said to be between fifty and sixty species, only two of which are in the United States.

It has been claimed by scholars that the lotus referred to by ancient writers was the hackberry. It was reputed to cause forgetfulness when eaten, but the claim was fictitious, for the fruit does not produce that effect. It is not now regarded as human food. Tennyson deals with the fiction very beautifully in the poem "Lotus Eaters," but he took liberties with botany when he represented fruit and flowers on the same branch; for, though the berries hang several inonths, they drop before the next season's flowers appear.

The hackberry belongs to the elm iamily, being of the same relation 
as the planertree. The leaves resemble those of the elm, but are more sharply pointed. The fruit is usually classed as a berry. It ripens in September and October, but remains on the tree several months, becoming dry. It is about one-fourth inch long, dark purple, with a tough, thick skin, and with flesh dark orange. Most of the pale brown seeds are eaten by birds.

The tree varies greatly in size. In some remote corners of its immense range it is little more than a shrub, while at its best it may attain a height of 100 feet and a diameter of three or four. Its average size is about that of slippery elm. The bark varies as much in appearance as the tree in size. Sometimes it has the smooth surface and pale bluish-green appearance that suggest the bark of beech; again it is darker and rougher, like the elm. It frequently exhibits the harsh warty bark which is peculiar to the hackberry, and when present it is a pretty safe means of identification. The warts may be conical, oblong, or sharp-pointed, and probably an inch in height. When closely examined, most of them are found to consist of parallel strata of bark which may usually be pulled off without much difficulty. The warts are a decided disadvantage to the tree in some of the low swampy districts of Louisiana where Spanish moss is a pest. This moss (which is not a true moss), is propagated principally by tufts and strands which are carried by wind until they find anchorage among the branches of trees where they increase and multiply at a rapid rate until they finally smother or break down the unfortunate tree which supplied a lodging place. The hackberry's warts catch and hold every flying strand of moss that touches them, and hundreds, perhaps thousands of pounds of it may accumulate on a single tree. The grayish-green color of the moss often exactly matches the hue of the tree's bark.

The reported annual cut of hackberry lumber in the United States is less than $5,000,000$ feet. That can be only a fraction of the total output. Few mills report it separately, but list it as asl. The wood looks more like ash than elm. It is heavy, but only moderately hard and strong. Its color is more yellowish than ash, but the annual rings of growth resemble that wood. The sapwood is thick, and growth is rapid where conditions are favorable.

It is doubltess used by industries in thirty states or more, but comparatively few factories report it. In Texas it is listed in the box and crate industry. In Louisiana it rises to more importance, for that is the region where the tree attains its best. Slack coopers make kegs, tubs, and barrels of it; vehicle manufacturers convert it into parts of buggy tops and the running gears of wagons; it serves for furniture and interior finish; and it takes the place of ash for hoe handles and parts of 
agricultural implements. The uses are nearly the same in Mississippi, but it is used there for rustic seats and other outdoor furniture. In Missouri it is found suitable for cart axles, saddle trees, stitching horse jaws, and wagon beds. In Arkansas it goes with ash into flooring, and interior finish for houses. Illinois builders work it into fixtures for stores. In Michigan it serves the same purposes as in Texas, baskets, boxes, and crates. These examples doubtless are representative of its uses wherever the tree is found in commercial quantities. The word is not durable in contact with the soil. It is also liable to attack by boriag insects if logs are allowed to retain their bark.

The hackberry has been planted to a small extent as a street tree in the southern towns, but it is not as popular as the elms and oaks. It will never occupy a more important position in the country's lumber industry than it holds at present. It is a tree which, for some reason, inspires little enthusiasm in anybody; but nature takes care of it fairly well, and the small sweet drupes which it bears are a guarantee that the species will not want for seed carriers as long as birds continue to have access to its branches in winter.

SugARBERRY (Celtis mississippiensis) is frequently mistaken for hackberry even by persons who onght to be able to distinguish them. Botanists formerly confused the two, and probably some insist still that sugarberry is only a variety of hackberry. The leaves generally have smooth margins, and that would differentiate the tree from the hackberry were it not that sometimes the sugarberry has serrate leaves. The drupes are bright orange red and are usually smaller than the purple fruit of hackberry. As for the wood of the two species, it is not easy to tell one from the other. The sugarberry's range is not one-third as extensive as hackberry's, but covers some hundreds of thousands of square miles in the sontheastern quarter of the United States. Its northern limit is in Illinois and Indiana where it occupies rich bottom lands and the banks of streams. It reaches its largest size in the lower Ohio river basin, grows sonthward into Florida and west into Texas, Arkansas, and Missouri. It crosses the Rio Grande into Mexico, appearing to outstrip the hackberry in that direction. It outstrips it in another direction also, for it is found in the Bermuda islands. The French of Louisiana called it bois inconnu, or the unknown wood.

This tree shows a marked tendency to run into varieties, and cultivation would probably develop the tendency. The differences betwreen the species and the varicties are plain enougl to the systematic botanist, but are such that the lumberman or other ordinary observer would scarcely notice them. The variety which has been named 
Celtis mississippiensis reticulata, but without any English name except sugarberry, is a tree forty or fifty feet high, covered with blue-gray bark, very rough. It ranges from Dallas, Texas, to the Rio Grande and westward into New Mexico, Arizona, and Utah, and into southern California and Lower California. In eastern Texas it is found on dry limestone hills, but westward only in mountain canyons in the vicinity of water. In the southern part of Texas this tree is usually known as palo blanco, but those who apply that name have no idea that it is a variety of sugarberry but suppose it is a tree peculiar to their region. In Cameron and Hidalgo counties, Texas, either because an extra good quality grows there, or because some opinion exists in its favor, it is liked for wagon material, and occasionally is turned for table legs and other parts of furniture. It is quite common in that part of Texas as an ornamental tree in yards and along streets of small towns. The whiteness of the bark is the most striking feature.

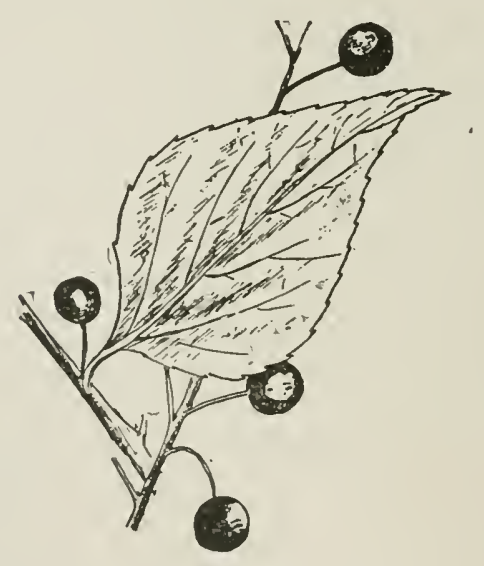


VIHITE ASH 


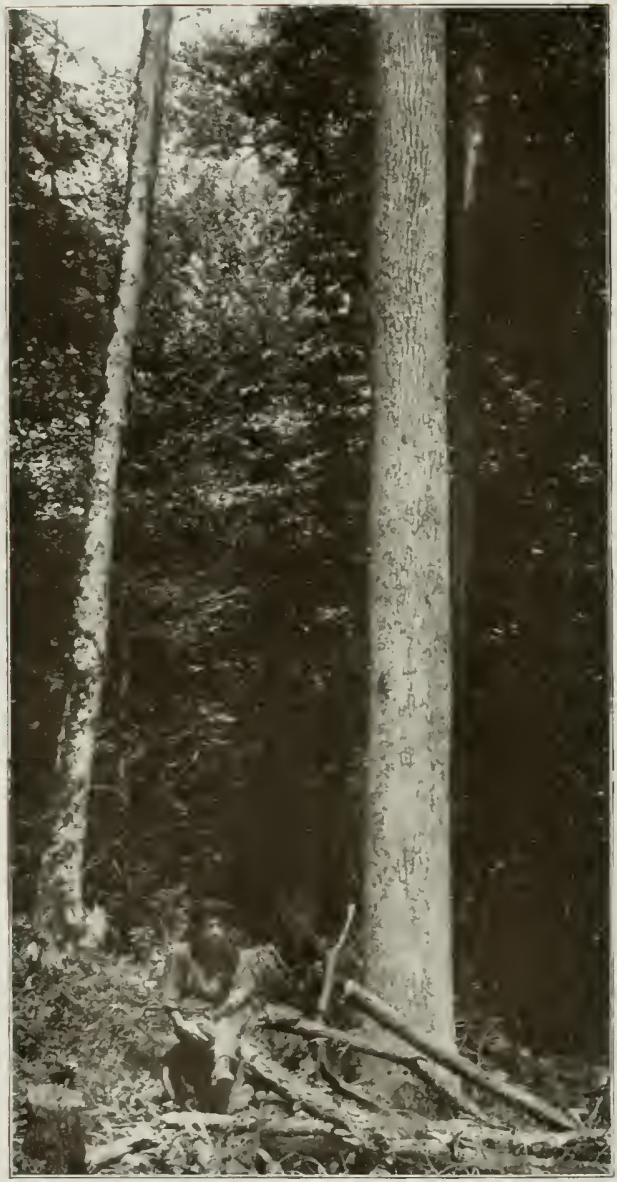

VIIITE . ISH 


\section{IVHITE ASH}

\section{(Fraxinus Americana)}

$\mathrm{T}$ HIS tree is generally called white or gray ash, or simply ash. American ash is a translation of its botanical name and is not of ten used in business transactions in this country. In some parts of the South the term cane ash is occasionally employed, but there seems to be no agreement among those who use the name as to what it means. This is the common ash in the lumber trade. There are more than a dozen species in the United States, but white ash goes to market in larger amounts than all others togrether. This is known in a general way, but exact figures cannot be given, because statistics of the cut of different species of ash are not kept separate.

The range of this tree covers at least a million square miles, and all or part of every state east of the Mississippi river and west of it from Nebraska to Texas. It is reported cut for lumber in thirty states. The various ashes are lumbered in thirty-nine states. Ash does not occur in pure stands but is seattered in forests of other species, sometimes growing in small clumps. It is difficult to name an average size for the tree, because climate and soil control the growth over a large area where conditions vary. Trees 120 feet high and six feet in diameter are said to have stood in the primeval forests in the lower Ohio valley; but logs four feet through are seldom seen now. Trees seventy or eighty feet high and three in diameter are above the average in any region where this tree is now lumbered. Some of the old planted trees of New England are five or six feet through, and are finely proportioned, but growing as they do in the open, they have larger crowns than are found in forest trees.

All species of ash have compound leaves, and those of white ash are from eight to twelve inches long. The under sides of the leaflets are white, and some persons have this fact in mind when they call the species white ash, while others refer to the bark, and still others to the wood. It is a characteristic of the tree that most of the leaves grow near the ends of the limbs. For that reason the crown appears open when viewed from below, and the larger limbs and branches are naked. The leaves demand light, and they arrange themselves on the extremities of the limbs to get it. When the tree is crowded, it sheds its lower limbs and its crown rises rapidly until it reaches abundance of light. This produces long trunks in forests.

The boles are often not quite straight, but liave several slight crooks, yet keep close to a general perpendicular line. That form is due 
to a peculiarity of growth. The leading shoot of a growing ash has more than one terminal bud. If a side bud pushes ahead, the stem leans a little in that direction; next, a bud on the other side may gain the ascendancy, producing a slight lean for a few years in that direction; or two side buds may develop simultaneously, causing a forked trunk. Mlature trees of ten carry the history of these peculiarities of growth.

The seeds of white ash are equipped for moderate flight. The wing is large, but the seed attached to the end of it is heavy enough to give it a sharp tilt downward when it begins its flight through the air, and it generaily shoots at a steep angle toward the ground. It is not apt to whirl through the air with a gliding motion line a maple seed. Consequently, ash seeds are not great travelers. They are dispersed with economy, however, for all do not come down at once, but many hang on the tree for months, and a few go with every strong wind, thus getting themselves scattered in every direction. Their power of germination is low, and only about forty per cent of seeds are fertile. This is due to the fact that pistillate and staminate flowers do not grow on the same tree, and fertilization is imperfect.

The importance of ash in the industries of the country does not depend on the quantity but the quality of the wood. Although the various species are produced in thirty-nine states, as shown by mill statistics, the total yield is less than $250,000,000$ feet a year. That is exceeded by several woods, among them hickory, elm, beech, basswood, chestnut, and even larch.

The wood of asly which has grown rapidly is generally considered superior to that of slow growth. The reason is found in the fact that trees of slow growth do most of their growing early in the season, and the wood is porous; but trees of rapid growth lay summerwood on abundant$1 y$, and it is dense. Few species show a sharper line between spring and summerwood thau ash, for which reason the annual rings are clear-cut and distinct. IThat figure ash has is produced by the growth rings, and not by medullary rays. Quarter-sawing brings out no additional beauty. Slight crooks in many logs produce a moderate cross grain in lumber, which gives to finislied ash its characteristic figure or grain. When straight-grained wood is wanted, as when it is for tool handles and oars, logs without crooks are selected.

The wood of white ash is lieary, hard, strong, elastic, but rather brittle. It lacks the toughness of hickory. The medullary rays are numerons, but small and obscure. The color is brown, the sapwood much lighter, often nearly white. It is not durable in contact with the soil. Notwithstanding its name, the wood rates low in ash, and its fuel value is under that of white oak. The states which produce the largest 
yearly cut of this species are, ranging downward in the order named: Arkansas, Ohio, Wisconsin, Kentucky, Indiana, Michigan, and Tennessee.

The uses of white ash] are so numerous that they can be presented conly in classes. It goes into almost every wood-using industry, but in different sections of country certain uses lead. Thus in Illinois the makers of butter tubs take more of it than any other industry; in Michigan automobiles lead, and in Arkansas the handle factories are largest buyers; in Louisiana boat oars consume most; in Alabama and Missouri car construction is in the lead; in Texas boxes and crates; in North Carolina wagons; in Kentucky handles; in Maryland musical instruments; and in Mlassachusetts furniture. The utilization of ash in these states, scattered over the eastern half of the United States, indicates fairly well the wood's most important lines of usefulness. A considerable quantity is made into flooring and interior finish. It is classed among sanitary woods, that is, it does not stain or taint food products by contact.

The total quantity of merchantable white ash in the country is not known, but there is still enough to meet demand, and the extent of the tree's range makes supplies convenient in nearly all manufacturing states. The species grows rather rapidly, and trees a hundred or a hundred and fifty years old yield logs of good size.

Texas AsH (Fraxinus texensis) has been regarded by some as a variety of white ash, while others, inclinding Sudworth and Sargent, consider it a distinct species. It is often called mountain ash where it occurs among the mountains of western Texas. Its range lies wholly in that state, and extends from the vicinity of Dallas to the valley of Devil's river. The compound leaves are smaller than those of white ash, and are usually composed of five leaflets. The winged seeds ripen in Mlay, and are an inch or less in length. The largest trees are fifty feet high and two or three in diameter; but generally the trees are much smaller. The wood is strong, heavy, and hard. The anmual rings are marked by one or more rows of open ducts, and the medullary rays are inconspicuous. The heartwood is light brown, the sapwood lighter. This ash is cmployed within its range for various purposes, but it is not of sufficient abundance to constitute an important commodity. In market it is not distinguished from white asl.

GREGG AsH (Fraxinus greggii) has some pectliarities which make it worthy of mention as one of the minor species. Its range is in the dry mountains of western Texas where a 1111mber of aslies seem to have put in an appearance as members of the thinly-peopled regetable kingdown of that region. The compound leaves of Cregg ash are seldom three inches long, and the leaflets are often lialf an inch long and less 
than a quarter of an inch wide. The petioles are winged like the twigs of wing elm. The undersides of the leaves have small black dots. The winged seeds are as proportionately small as the leaves. The flowers have not been described by botanists, for the species is not well known. The largest trees are scarcely twenty-fire feet high and eight inches in diameter. More frequently they are shrubs from four to twelve feet tall. The wood is heavy, hard, brown in color and of slow growth.

DWARF ASH (Fraxinus anomala) might be mistaken for some other species were its telltale winged seeds missing. It has lost the leaflets from its compound leaf, and a single one remains. Occasionally, however, a stem bearing three leaflets is found. The seeds are equipped with wide, oblong wings. It is a desert species, and the desolate surroundiugs of its habitat explain why nature has dispensed with as much foliage as possible. It is found in southwestern Colorado, in southern Utah, and on the western slopes of the Charleston mountains in southern Nevada. Trees are small and the wood is not of much use for other than fuel, but a few small ranch timbers are made of it where other kinds are scarce. Trunks are usually not more than six or seven inches in diameter. The wood is heavy, hard, and light brown in color.

FrIsGe ASH (Fraxinus cuspidata) has some difficulty in proving that it is entitled to be called a tree in the United States, thongh southward in Mexico its right to that title is unquestioned. It is very small where its range extends over the dry ridges and rocky slopes of southwcstern Texas and southern New Mexico and Arizona. It compound leaves are five or seven inches long, and the leaflets which number from threc to seven have long, slender tips. The trowel-shaped fruit is about one inch long. The wood resembles white ash, but irunks of considerable size are not found. The name refers to the flowers, and they give this small tree its value for ornamental purposes. The flowers appear in April and are extremely fragrant.

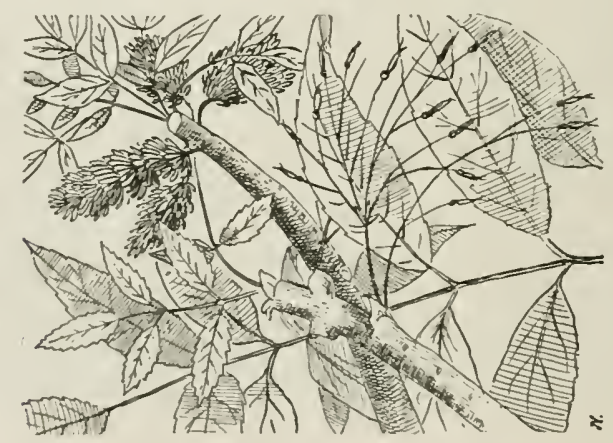


BLACK ASH 


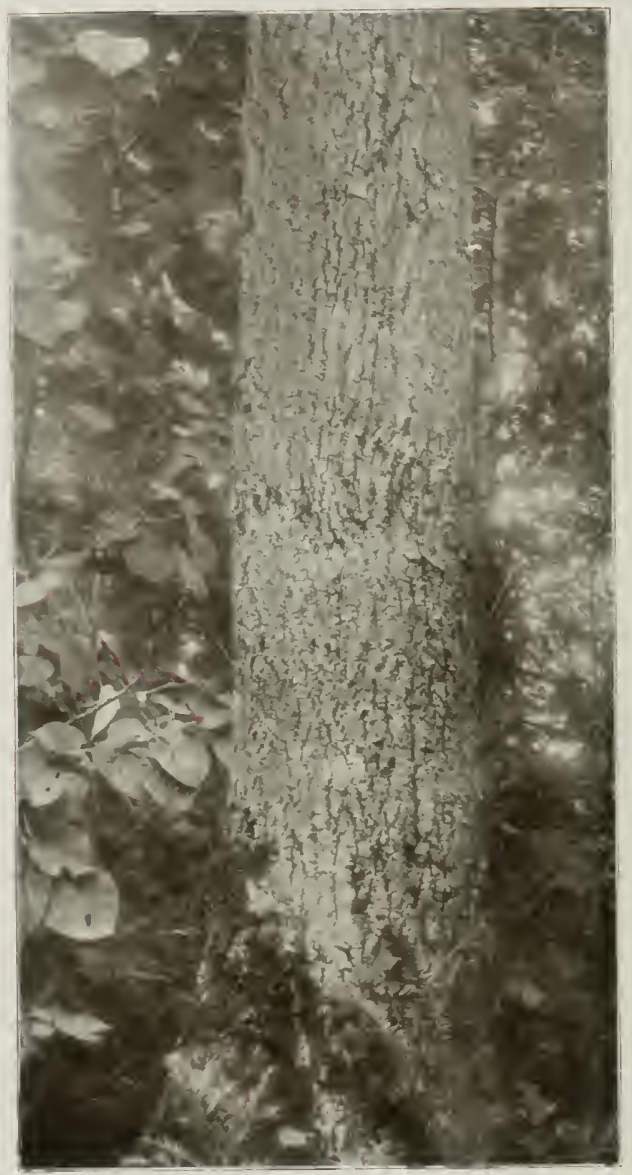

BLACK ASH 


\title{
BLACK ASH
}

\author{
(Fraxinus Nigra)
}

W

HEN George Washington was a surveyor locating land on the upper waters of the Potomac river, and westward on the Kanawha and Ohio rivers, he always spoke of this ash as "hoop tree" when he marked it with two or with three "hacks," depending upon whether it designated a "corner" or a "line," or a "pointer" in the system of surveying then in use. Trees were used then as landmarks, and were duly recorded in the surveyor's field notes, and were described in the deeds when the title to the land passed from one party to another. It was not unusual, if subsequent litigation came up, to cut blocks from marked trees to prove that such a corner was at such a place. The "hacks" or ax marks, were sometimes healed over and invisible at the bark, but were found deep in the wood. The rings of growth curering the ax marks afforded an admissible record of the years that had passed since the surrey was made. The selection of the black ash as a landmark was one of the few instances in which II'ashington showed poor judgment; because it is a tree of short life, and might be expected to die before a great many years.

The name hoop ash is applied to this tree yet. It has always been good material for barrel hoops, because it splits into thin pieces, and is sufficiently tough. It is known as basket ash for the same reason. The New England Indians were making fish baskets of it when the first white people landed on those shores, and settlers speedily learned the art from the children of the wilderness. Those untutored savages knew little of wood technology, but they were able to take advantage of a peculiarity in the structure of black ash wood, which the white man's microscope has revealed to him. The Indians doubtless discovered it accidentally. The springwood in the annual ring of black ash is made up of large pores, crowded so closely together that there is really very little actual wood substance there. In other woods, the springwood is chiefly air spaces. The result is, that billets of blark ash are easily separated into thin strips, the cleavage following the weak lines of springwood. A little beating and bending causes the annual rings to fall apart. In some way the Indians found that out, and utilized their knowledge in manufacturing baskets in which to carry fish, aconss, lickory nuts, and other forest and water commodities.

The white people extended the scope of application to include chairs and other furniture in which splits are minipulated. It is worthy of note that Indians made a similar discovery with northern white cedar 
or arborvitæ, which separates into thin pieces by beating and bending. Barrel makers took advantage of the splitting properties of black ash to make hoops of it, hence the name hoop ash, or hoop tree as Washington called it. The name basket ash has a similar origin.

The names swamp ash and water ash refer to situations in which the tree grows best. It is one of the thirstiest inhabitants of the forest. Its aggressive roots ramify through the soil and drink up the moisture so voraciously that if water is not abundant, neighboring trees and plants may find their roots robbed, and the functions of healthy growth will be interfered with. This has led to a general belief that black ash poisons trees that it touches. It simply robs their roots. Carolina and Lombardy poplars will sometimes do the same thing.

The name black ash by which this tree is now known in most regions where it grows refers to the color of the large, prominent, shiny, blueblack buds in late winter and early spring; to the very dark green leaves in summer-which at a distance resemble the foliage of post oak-and, to some extent, to the dark brown color of the heartwood, though the wood is not always a safe means of identification if judged from superficial appearance only. The form of the tree assists in identifying it; for it is the slimmest of the ashes, in proportion to its height. Trunks three feet through are heard of, but few persons have ever seen one much over twenty inches, and many are about done growing when they are one foot in diameter. Yet the trunks of such are very tall, perhaps seventy or eighty feet. Their appearance has been likened to tall, slender columns of dark gray granite. They often stand so straight that a plummet line will not reveal a deviation from the perpendicular.

The tree has been called elder-leaved ash. The form of the foliage has something to do with that name, but the odor more. Crush the leaves, and they smell like elder. The compound leaves are from twelve to sixteen inches long; the leaflets range from seven to eleven in number, and the side leaflets have no stalks. The leaves appear late in spring, and they fall early in autumn. They drop with the butternut leaves, and like them, all at once. The seed is winged, and the wing forms a margin entirely round the seed.

The wood of black ash is rather soft, moderately heavy, tough, but only moderately strong, not durable in contact with the soil, dark brown in color with sapwood whiter. The species ranges farther north than any other ash, and grows in cold swamps and on the low banks of streams and lakes from Newfoundland to Winnipeg, and southward to Virginia, southern Illinois, southern Missouri, and Arkansas.

Black ash fills many important places in the country's wood-using industries, but the total quantity is not large. In 1910 Michigan manu- 
facturers reported the annual quantity in that state at $9,110,432$ feet, and in Illinois the total was $9,936,000$ feet. The uses for the wood in Michigan may be regarded as typical of the whole country. The reported uses were, auto seats, baskets, boat finish, butter tubs, candy pails, carriage seats, crating, church pews, fish nets, office fixtures, flooring, furniture, ice chests, interior finish, jelly buckets, kitchen cabinets, lard tubs, piano frames, putty kegs, racked hoops, spice kegs, tin plate boxes, veneer, washboards, and woven splint boxes.

Black ash burls are characteristic excrescences on the trunk. They begin as small lumps or knobs under the bark, and never cease growing while the tree lives. They may reach the dimensions of wash tubs, but most do not exceed the size of a gallon measure. The grain of the wood is exceedingly distorted and involved. The burls are sliced or sawed in veneers which are much prized by cabinet makers. Early New Englanders made bowls of them, which seldom checked or split during generations of service. The burls are believed to be due to adventitious buds; that is, buds wlich originate deep in the wood, but are never able to force their way through the bark. The internal structure of the ash burl indicates that the buried bud grows, branches, and sends shoots in various directions, but all of them are hopelessly enmeshed in the wood substance, and never are able to free themselves and burst through the bark. A constantly enlarging excrescence is the result.

Blue AsH (Fraxinus quadrangulata) is named from a blue dye procured from the inner bark. The botanical name relates to the square shape of the young twigs, particularly the twigs of young trees, and was given by $\mathrm{A}$. F. Michaux who found the species growing in the South. It reaches its best development on the lower M'abash river in Indiana and Illinois and on the Big Smoky nountains in Tennessee. Its northern limit reaches southern Michigan, its western is in Missouri. It is not abundant, if found at all, east of the Appalachian mountains. Trees may reach a height of 100 feet and a diameter of three, but about seventy is the average height, with a diameter of two feet or less. The leaves resemble those of black ash in form, but the foliage when secn in mass is ycllow-green instead of dark green like that of black ash. The seeds look like those of black ash. The tree bears perfect flowers, and in that respect differs from most other species of ash.

The wood is heavier than that of any other nember of the ash group, except Texas ash. It weighs about the same as wlite oak, which is six pounds per cubic foot more than white ash weighs. In general appearance the wood resembles white ash, but it is usually considered stronger and more springy. The trunks of young trees are largely or entirely sapwood. Sometimes no heartwond is formed until an age of 
seventy or eighty years is reached. Many manufacturers of ash tool handles prefer this species to any other ash, because of its thick, white sapwood. It is of ten made into handles for hoes, rakes, shovels, pitchforks, spades, and snaths for scythes. Makers of vehicles draw liberally upon this wood within its range, as do furniture makers and the mant1facturers of flooring. It is regarded as harder than white ash, and consequently better flooring material.

LEATHERLEAF Asil (Fraximus velutina) changes its velvety leaves to a leathery condition, hence the conflict in the meanings of its two names. lelutina means velvetlike. The compound leaves are seldom six inches long, often not three, and they are made up of from three to nine leaflets. The small seeds are equipped with wings. The tree is small and would be without any commercial importance except that it grows in an arid region where any wood is welcome. It is made into ax, hammer, and pick handles, and wagon makers are often glad to get it. It is found among the mountains and canyons of western Texas, in New Mexico, Arizona, southern Nevada, and southeastern California, near the shores of Owen's lake. The largest trees are scarcely forty feet high and eight inches in diameter. The wood is not hard or strong, and is of slow growth. The largest trunks are apt to be hollow. Sapwood is comparatively thick.

Berlandier Asn (Fraxinus berlandieriona) may not be entitled to a place among native species of the United States. Some suppose it was introduced from Mexico by early Spanish settlers in western Texas. It now grows wild there along Nueces and Blanco rivers where specimens thirty feet high and a foot in diameter are found. Southward in Mlexico it is a popular street tree, and trunks reach six or eight feet in diameter. The wood is soft and is used only locally and in very small quantities.

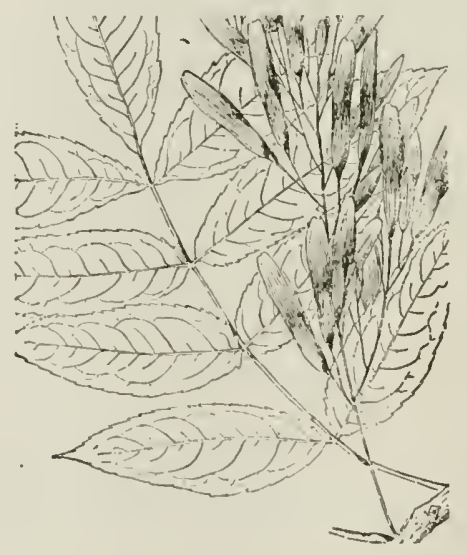


OREGON ASH 


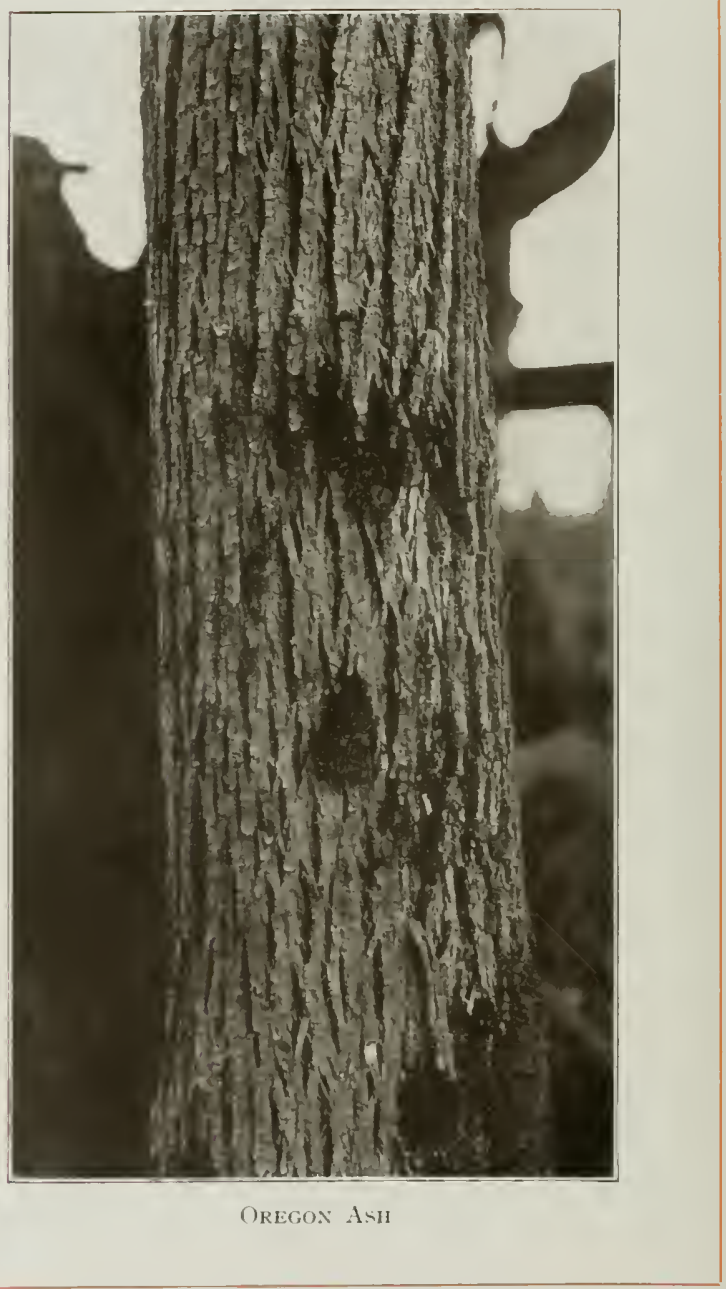




\section{OREGON ASH}

\section{(Fraximus Oregona)}

T HIS tree is unusual in that it has only one common name, and that is a translation of its botanical name which was given it by Nuttall who visited the Pacific coast several years before the discovery of gold.

The moist bottom lands of southwestern Oregon are best suited to its growth, and here the best individuals and most abundant stands are found. Moist soil and climate are essential to proper development of this tree, and in suclr environment it is found from Puget Sound southward along the coast to San Francisco. A little further from the coast it grows along the foothills of the Sierra Nevada mountains, to the low mountains in San Diego and San Bernardino counties, California, in the southern extension of its range occupying a rather dry region.

The trunk grows to a height of eighty or $100 \mathrm{fect}$, and is often three feet in diameter. It is covered with a gray-brown bark, exfoliating in flaky scales. The leaves are from five to fourteen inches long, and have five or seven firm, light-green leaflets, finely toothed and bluntly pointed. The flowers appear in April and May and are in compact panicles; the fruit in clusters, broadly winged and round pointed, and from one to two inches long.

The scarcity of good hardwoods on the Pacific coast gives this ash more importance than it otherwise would have, and the importance which it possesses has been frequently overstated. It is not abundant of form and size fitting it for lumber. It has long been cui in small quantities, but never in large. The census returns for 1910 show that less than 400,000 feet per year are reported in its entire range. Threefourths of this is sawed in Oregon, the remainder in Washington. Though the species has a range of 800 miles north and south through California, no sawmill reported a foot of it. However, it is probable that census returns fail to do this wood full justice; for it is well known that considerable quantities are manufactured into articles without passing through sawmills. Chief among such commodities is slack cooperage. Butter tubs of Oregon ash are common. Much goes to wagon shops, and some of it without aid of sawmills.

Little or none of this wood is shipped outside its range, and its use is local. Boat builders work it into finish for cabius and upper parts, and some serves as ribs. It is often seen as handles for picks, shovels, spades, pitchforks, and rakes. A little finds place, combined with other woods, in office and store fixtures. Its grain resembles that of white ash. It is not as heavy, and it is not believed to be as strong. It is 
hard, brittle, brown in color, with thick, lighter-colored sapwood. Furniture makers list it as shop material, and such is its largest reported use in Washington. A moderate amount is made into saddletrees and stirrups, and much is used as fuel.

Oregon ash has been planted for shade and ornament in both this country and Europe. It grows rapidly and develops a symmetrical crown. The habit it has of coming into leaf late in the spring and throwing its foliage down early in autumn is held by some as a serious objection to it as an ornamental tree; but it has compensating habits. It is remarkably free from disease, and, though leaves come late and go early, while its foliage is on, it is healthy and vigorous. Reproduction is satisfactory in the tree's wild state, and there is no danger that the species will disappear. No movement has yet been made to plant this ash for commercial timber growing.

GREEN ASH (Fraxinus lanceolata) has been given that name on account of the bright color of its foliage. It has other names, however, which indicate that its greenness is not always preeminently prominent. In Iowa and Arkansas they call it blue ash; in Kansas and Nebraska white ash; in some regions it is known as water ash, and elsewhere swamp ash. Some botanists do not regard it as a separate species but call it a variety of red ash, but the concensus of opinion is that it is a distinct species, though there appear to be connecting forms grading from red ash into green ash. Certain it is that the two are distinct enough in certain parts of the country. The range of green ash is more extensive than that of any other ash in this country. Beginning in Vermont it passes southward to Florida; northwestward to the Saskatchewan river several hundred miles north of the international boundary line; along the base of the Rocky Mountains and over the ranges to Arizona, and through Texas. This includes more than half of the area of the United States. Notwithstanding a range so extensive, the total quantity of green ash timber in the country is not large. No pure forests or extensive stands exist. Trees are widely dispersed, and when lumbermen cut them, the wood is sold as some other, usually as white ash. The wood has the general characters of red ash. It weighs about fortyfour pounds per cubic foot of dry wood; is moderately strong, fairly stiff and elastic, and, like other species of ash, it is not durable in contact with the soil.

Green ash is more planted than any other in the cold and dry regions of the West and Northwest. It is a prairie tree and is found along highways and in door yards from Kansas northward into British America. It stands drought better than any other ash, and resists cold fully as well, and yet it endures the warm weather and the rains of the 
South and flourishes there. It is not a large tree, but of sufficient size for use as furniture, finish, and vehicle making. It is seldom listed in statistics of woods which go to sawmills, yet it is known that a good many logs find their way to mills, while wagon makers and slack coopers employ it in producing their commodities. The tree is an abundant seeder, and the seeds continue to fall during most of the winter.

RED ASH (Fraxinus pennsylvanica) is neither a large tree nor very abundant, yet it has a wide range and is put to use wherever lumbermen find it convenient. The lumber generally passes in the market as white ash, and for most purposes it is as good, but is rated lower than that wood in elasticity. It is ealled brown ash in Maine, black ash in New Jersey, river ash in Rhode Island. The last name is bestowed because the tree prefers moist land near rivers and ponds, and largest speeimens are found in such situations, where it is often an associate of black ash and is frequently mistaken for it, though it should not be difficult to tell the species apart. A slight reddish tinge sometimes shows on the outer bark; the inner layer of bark is reddish; the small twigs and the under sides of leaves are clothed with hairs which sometimes suggest redness; and the heartwood is reddish-brown. Persons who speak of the tree as red ash probably bave one or more of those characteristics in mind. As a tree it bas no striking peculiarities. Its usual height is forty or sixty feet; its diameter from fifteen to twenty inches; its compound leaves ten or twelve inches long, with seven or nine leaflets; its seeds one or two inches in length, narrow, and sharply pointed, with slender, graceful wing.

The range of red ash is from New Brunswick to Dakota, and from Florida to Alabama, with all of the included region of a million square miles. It attains its best development in the north Atlantic states, while it is ustually inferior west of the Alleghany mountains. It develops a broad crown in open ground, but even there its lower limbs die and drop, while in forests the trunk grows tall and the crown is reduced. It is planted for shade and ornament, but it seems to have no superiority over white ash for that purpose. Some of the Michigan manufacturers list red ash separately in their factories, and apparently this is not done elsewhere in the country. About three-quarters of a million feet a year are used in that state, and since uses there are doubtless typical of uses in the country generally, the list possesses importance: Automobile frames, boxes, butter tubs, crates, eveners, flooring, furniture, interior finish, neck yokes, singletrees, wagon poles. Farther east in early times red ash was occasionally split for fence rails, but that use is important now only as history.

PUMpkin Ash (Fraxinus profunda) is a tree of peculiar interest. It was unknown before 1893, though the region had been settled over a hundred years. It has the largest leaves, largest fruit, and largest swelled base of all American ashes. Notwithstanding that, it remained so deeply hidden in swamps that it eseaped discovery. The hotanical name refers to the deep swamps in which the tree chooses its habitation. Its great, swelled base enables it to stand on the soft mud of lagoon bottoms, and the abnormal swelling is ribhed like a pumpkin, hence the only English name the tree has ever had. These are not the only remarkable things conneeted with this ash. Its range ineludes three or four deep swamps, far apart. One is in southern Missouri, New Madrid country, another near Varney, Arkansas, and a third, in a vast morass on the Apalachicola river, Florida. It is believed to have heen originally a Florida species, and by some freak of nature it reached the Missouri and Arkansas swamps. Certain other Florida plants accompanied it, one of which was corkwood (Leitncria floridana). It is cxpected that pumpkin ash will be found else- 
where in deep swamps intermediate between the extremes of its range. The uses of this wood are few, because it is scarce, and the trees are difficult of access on account of being nearly always surrounded by water. Lumbermen who operate in swamps occasionally bring out a few ash logs with cypress and tupelo. No tests seem to have been made of the wood. Trees are sometimes 120 feet high and three in diameter above the swelled bases.

WATER AsH (Fraxinus caroliniana) is much lighter in weight than any other American ash, and the wood is also lighter in color. It is weaker and less elastic than any other, and is lower in fuel value. It weighs less than white pine. It grows in deep swamps from southern Virginia to Florida and westward in swamps to Texas. Some have confused it with pumpkin ash, but the two are quite distinct. This tree is also called poppy ash. The leaves are from seven to twelve inches long, with five or seven leaflets which are much blunter than most other ash leaves. The seeds are nearly in the center of the broad, long wing, and are better flyers than most ash seeds. The tree seldom exceeds forty feet in height, or twelve inches in diameter. It is not known that the wood is ever used. Its scarcity will keep it from becoming important, though its uncommon lightness may lead to its employment for certain purposes.

BıLTMORE Asu (Fraxinus biltmoreana) is named from Biltmore, N. C., where the tree attains its best development, a height of forty or fifty feet and a foot or less in diameter. Its range extends from northern West Virginia southward along the foothills of the Appalachian mountains to Georgia, Alabama, and middle Tennessee. The seed wings are slender, and only slightly narrowed at the end. The leaf is ten or twelve inches long, with seven or nine leaflets. The twigs of young trees are hairy. An occasional log doubtless goes to sawmills, but no report has been made of uses of the wood.

FLORIDA AsH (Fraxinus floridana) is a deep swamp tree, thirty or forty feet high, and a few inches in diameter. It is found in the valley of St. Mary's river, southern Georgia, and along the lower Apalachicola river, Florida. The compound leaves are five or more inches long with three or five leaflets. The seeds are small but their wings are wide and long. No report has been made concerning the quality of the wood, nor has it been used, as far as known. The supply is very small.

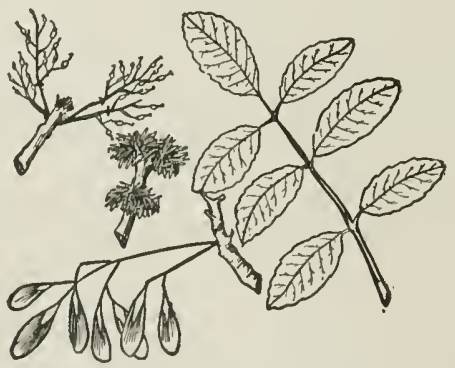


STGAR MAPIEE 


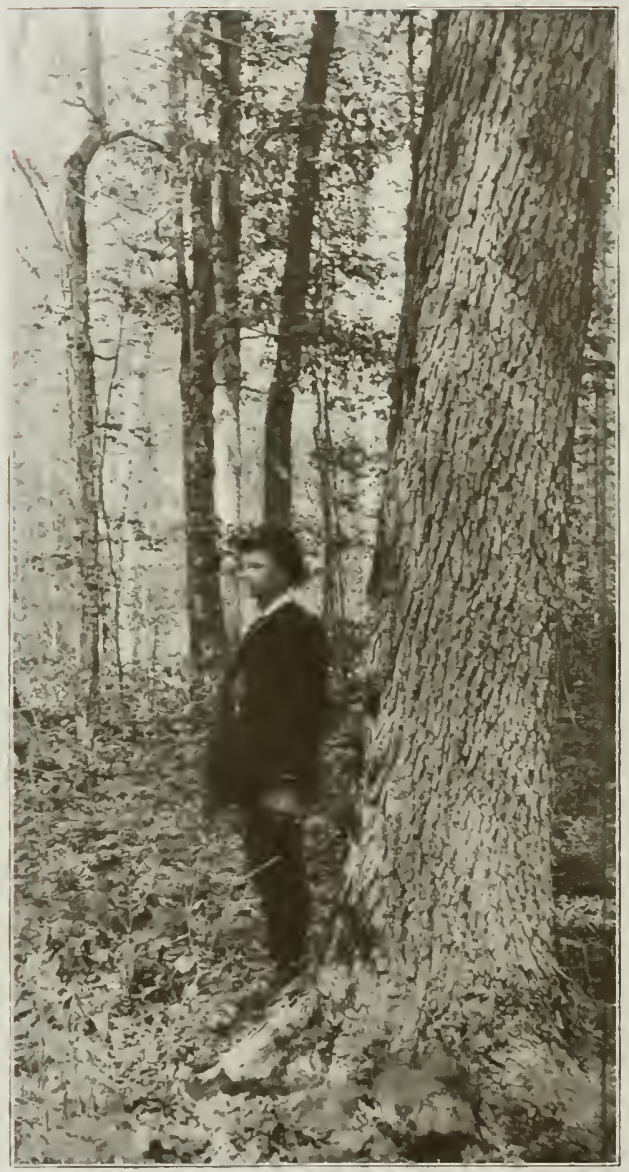

Sigar Maple: 


\section{SUGAR MAPLE}

(Acer Saccharum)

$\mathrm{T}$

HE makers of sugar in the North call this tree sugar maple, but lumbermen and users of wood nearly always speak of it as hard maple. All maples - and there are nearly a clozen-are tolerably hard, and sugar may be obtained from most of them; but this speeies is liardest of all, and the most prolific sugar maker, hence the two names are appropriate. It is often called rock maple, which name refers to its hard wood. In some regions the name most heard is sugar tree.

Its range extends from Newfoundland through Canada to Lake of the Woods, southward through Minnesota, Iowa, Kansas, and Arkansas to Texas. It is found in every state east of the Mississippi, but it is not abundant in the South. Its best development is found from New England across the northern states to Michigan. Sonne very fine sugar maple is found in fertile valleys and on slopes among the Appalachian ranges from Pennsylvania southward. The largest lumber eut of maple is in the following states, ranging in the order given: Michigan, Wisconsin, Pennsylvania, West Virginia, New York, Ohio, Indiana, and Vermont. Since the different species of maple are not reported separately in statisties, there is no way of determining how mucl each of the maples supplies. It is well known that sugar maple greatly exceeds all others.

At its best this tree may exceed a height of 100 feet and a diameter of three; but the average for mature timber in the best part of its range is sixty or eighty feet in height, and two in diameter. The flowers appear with the leaves in early spring, but the seeds do not ripen until autumn, when they are bright red. They are winged, and usually two grow together, but they sometimes become detached, in which case each is eapable of flight with its single wing. It is eharacteristic of maple seeds to whirl rapidly while falling, and if a moderate wind is blowing, they glide considerable distances. They usually fly farther than the seeds of ash although their wings are no larger. The imnense numbers of seeds borne by the sugar maple insure abundant reproduction in the vicinity of parent trees. The seeds sprout readily, but of ten so closely crowded together that most of them die the first few weeks. Not one in ten thousand can even become a large tree, ant yet large trees are exceedingly abundant in extensive regions. They often form nearly pure stands, crowding to deatl all rivals that try to obtain a foothold. ()n the other hand, this maple often contents itself with a place anongr other forest trees. 
It is one of the most vigorous and dependable of trees. It does not grow fast, but it keeps steadily at it a long time, and enjoys unusually good health. Its worst enemy is coal smoke, but fortunately, most sugar maple forests are out of reach of that disturber, though shade trees near factory towns and in the vicinity of coke ovens often suffer. Woodlots of sugar maple, occupying corners of farms in the northern states from Minnesota to Maine, present pictures of health, vigor, cleanliness, and beauty which no forest tree surpasses. The intense green and the density of the crowns in summer make the trees conspicuous in any landscape where they occur, while their brilliant colors in autumn are the chief glory of the forest where they abound.

The wood of this tree is hard, strong, and dense. It is three pounds lighter per cubic foot than white oak, and theoretically it rates a little lower in fuel value, but those who use both woods as fuel consider maple worth more. It is thirty per cent stronger than white oak, and fifty-three per cent stiffer. The wood is diffuse-porous, that is, the pores are not arranged in bands or rows, as they usually are in oaks, but are scattered in all parts. They are too small to be seen with the naked eye, but under a magnifying glass they are visible in large numbers. The yearly ring is not very distinct, because of the slight contrast between spring and summerwood. The medullary rays are numerous but small. In wood sawed along radial lines, from heart to sap, small silvery flecks are numerous. These are the medullary rays. They add something to the appearance of quarter-sawed maple, but cot enough to induce mills to turn out much of it.

Such figures as maple has are brought out best in tangential sawing - that is, cut like a slab off the side of the log. Three distinct figures are recognized in sugar maple, and to some extent they belong to other maples. These forms of wood are known as birdseye, curly, and blister maple. They are accidental forms and exist in certain trees only. Students of wood structure are not wholly agreed as to the cause of these forms, but one of them, the birdseye effect, is belicved to be due to adventitious buds which distort the wood in their vicinity. These buds start near the center of the tree when it is small, but never succeed in forcing their way out. They remain just beneath the bark during most or the whole of the tree's life. A pin-like core, resembling a fine thread, connects the birdseye with the tree's pith. This thread is the pith of the embryonic branch formed by the bud which never breaks through the bark. When the wood is sawed tangentially, small, darkbrown points or dots show the center of the buds, or the pith line connecting it with the tree's center. Curly maple and blister maple are not believed to be formed in the same way as birdseye. 
The uses of sugar maple are nearly universal, where a hard, white wood is wanted. Many large trees contain little colored heart, and trees are generally fifty years old before they have any. More maple is worked into flooring than into any other one commodity. Mills in Michigan alone, in 19 10, made 185,611,662 feet of maple flooring. It was shipped to practically every eivilized country in the world. Many builders consider it the best wooden floor that ean be laid. In a test made in a large store in Philadelphia some years ago, a marble floor wore through sooner than maple, when the same wear was on both.

Nearly all kinds and classes of furniture have places for maple, either as outside material or inside frames, drawer bottoms, or partitions. Vehicle manufacturers employ it for heavy axles, running gear, parts of automobiles, sleigh runners and frames, and hand sleds. It is made into handles from gimlet sizes to eant hooks. Gymnasium apparatus owes much to the whiteness, smoothness, and strength of maple. Woodenware from toothpicks to ironing boards; from buteher blocks to butter molds; from door knobs to die blocks, is dependent on maple for some of its best material. It is largely used for boxes, in both solid and veneer form. Only two woods are now employed in larger amounts for veneers in the United States than maple. They are red gum and yellow pine.

Maple is one of the three woods most largely employed in hardwood distillation in this country; beech and birch are the others. Maple sugar is a product of this tree almost exclusively, and the business is large. In some parts of New England it is claimed that a grove is worth more for sugar than the land is wortls for agrieulture.

Silver MAPLE (Acer saccharinum) is generally called soft maple by lumbermen. It is known aiso as white maple, river maple, silver-leaved maple, swamp maple, and water maple. The sinuouses of the leaves are very deep. The lighter color of $\mathrm{its}$ bark and the pale green of the leaves distinguish soft maple at a glance from sugar maple when both are in full leaf. The grecnish-yellow flowers open in early spring, and the seads are ripe in April or May, depending on the season and region. The seeds have large wings and fly well. They germinate in a few days after llicy find sutable soil, and before the end of the summer the seedlings have grown several leaves. The vigor thus displayed continues until the tree is large. It is a fast grower, and for that rcason has been extensively planted as a street and park tree. The wisdom of doing so is doubtful, for this maple throws otst long limbs which are often broken by wind. The trunk is subject to disease, and a row of old soft maples nearly always presents a ragged, unkept, neglected appearance. As to beanty of form and crown, there is littie comparison between it and the planted sugar maple. Soft maples in forests range frum sercnty-five to 120 feet in height, and two to fon in diamerer; that is, they attain atrout the same size as sugar maples. The species covers a million square miles, practically the whole comntry east of the Mississippi, sume west of that river, and must of eastern Canadia.

Ic is a usefut wood for many purposes. The custom of mixing this with sugar maple makcs it impossible to clearly separate the two woods afterwards. It is the 
opinion of some well-inforned mannfacturers that abont five per cent of the total maple cut in the United States is soft maple. The ratio is less in the North and more in the sunth. The wood is hard, strong, rather brittle, easily worked, pale brown with thick, white sapwood. Some rather large trunks have no sapwood. It is in general use, but not for as many purposes as sugar maple. The largest places found for it are as flooring and woodenware, though furniture and boxes, particularly veneer boxes, consume much. Its weight is three-fourths that of sngar maple. The largest trees and the best wood grow in the lower Ohia valley.

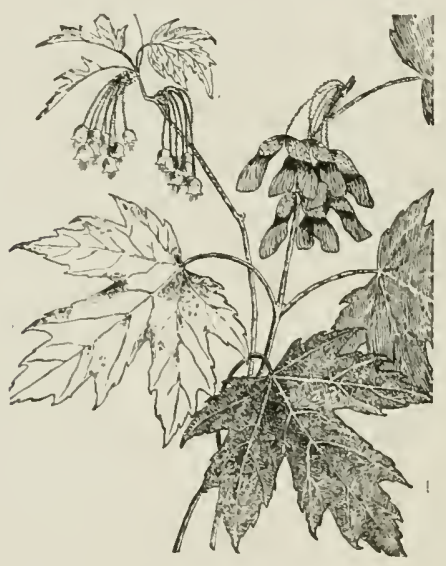


RED MAPLE 


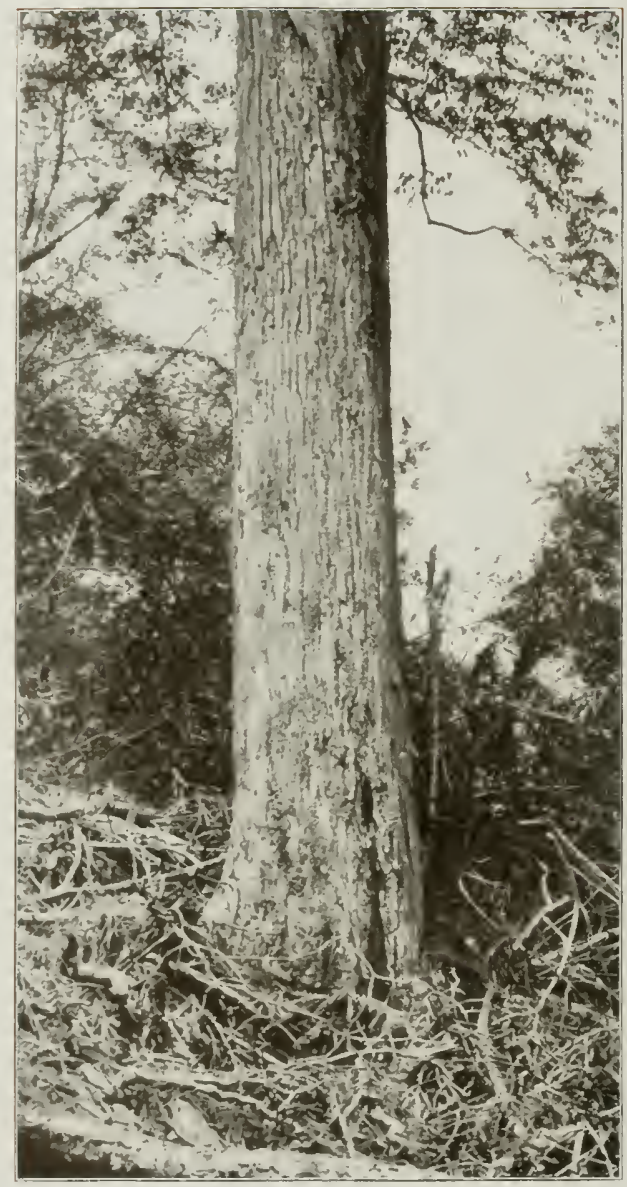

REI) MAPLE 


\section{RED MAPLE}

\section{(Acer Rubrum)}

T

HIS tree's names describe it. Some refer to color of leaves, flowers, and fruit, others to situation where it grows best. It is known as red maple and swamp maple; also as water maple, white maple, scarlet maple, and shoepeg maple. New York Indianas called it ah-we-hotkwah, which meant red flower. Most trees looked alike to Indians, and when they gave a name, it was descriptive.

The redness of this maple is so marked that it cannot escape notice. The flowers, fruit, twigs, and leaves all possess the property at one time or another during the season. The flower comes before the leaf, during the first warm days of spring. That is pretty early in the South, and later in the North. The flowers are briglit scarlet, and very conspicuous, growing in umbel-like, drooping clusters. The staminate and pistillate ones frequently grow on different trees, and always in separate clusters.

The fruit ripens quickly, and is sometimes almost mature before the Isaves appear. Tlie date of ripening depends upon latitude. The tree's range north and south exceeds a thousand miles and that nukes much difference in climate. In the South the fruit ontstrips the leaves and has about reaclied maturity before the unfolding leaves are large enough to hide it ; but in New England and New York the leaves are large before the fruit is mature. The seed is the characteristic maple key, with a wing to carry it. The fruit-and by that term the seed with its attached wing is meant - is bright red, and a tree loaded with the vivid clusters is a beautiful spectacle. Two seeds are generally fast together, and they make surprising fliglits in that condition, passing with whirling motion through the air. Gravity spins them, but wind carries them forward, and the random of their flight depends on the strength of the wind, which happens to be blowing when they sever their connection with the tree.

The seeds germinate quickly when they light on damp soil. If they do not find such situations, they soon perish; because they do not retain their vitality long. By the niddle of summer the young trees have several leaves, and from that time on the struggle is nainly anong themselves for space and moisture, because they stand so thick that it is a survival of the fittest.

The young twigs are generally red in spring, but they do not present as conspicuous a mass as the flowers and fruit do. The leaves are simple, with long reddish petioles. They have three or five lobes, the lower pair often entirely missing, and small if present. Each lobe has a pointed 
apex, and is irregularly serrate. The base of the leaf is rounded; also the sinuses, which extend far into the body of the leaf. The upper surface of the leaf is bright green, the lower a silvery-white. In the fall this tree is entitled to the name scarlet; for then the brilliant hues of the leaves are remarkably fine.

The range of red maple covers more than a million square miles, and touches every state east of the Mississippi river, and west of that stream it extends from South Dakota to Texas. It prefers rather swampy ground, but wants fertile soil. It is frequently found on the banks of creeks and rivers, and rarely on hillsides. It is most abundant in the South, particularly in the lower Mississippi valley, while trees of larger size are found in the valley of the lower Olio. In the North it takes more to low wet swamps where it sometimes grows in such thickets as almost to exclude other species.

The best red maple trees attain a height of 100 feet or more, and a diameter of four feet or less. The average size is seventy feet high and two in diameter. The form of the tree, like that of all other maples, depends much upon the situation in which it grows. Good saw timber is not often cut from this species near the outer borders of its range.

The wood is about three-fourths as strong as hard maple, and is five pounds lighter per cubic foot, but is about six pounds heavier than soft or silver maple. It may, therefore, be considered that in some important points red maple is midway between hard and soft maple. In color it is light brown, slightly tinged with red. The sapwood is thick and lighter in color than the heart. The tree is usually not of rapid growth. The contrast between the springwood and summerwood is not strong. The wood is very porous, but the pores are so small that the unaided eye cannot discern them. The medullary rays are numerous, but thin, and are seldom considered in working the lumber.

Mills which saw this maple do not separate the lumber from other maples. The woodsman knows the difference, but the lumberman does not consider it worth while to pile the sawed stock separately. It sometimes goes to market as hard maple, sometimes as soft, but nerer under its own name. Consequently, it has no uses which are not also common to other maples. Lumbermen cut it when they find it mixed with other hardwoods where they are carrying on logging operations.

Red maple is made into flooring, interior finish, and veneer box material. Veneers are also made for furniture. These are the most important uses for the wood, but the manufacturers of woodenware employ it for numerous commodities, such as trays, bowls, ironing boards, grain scoops, snow shovels, clothes racks, garment hangers, and clothes pins. This species shows birdseye effect similar to that of sugar maple, 
but less of the stock goes to market. Logs with birdseye wood are generally reduced to veneer by the rotary process. Curly and wavy grains also occur in this maple. The wavy grain was much sought after by the early hunters who equipped their long rifles with stocks. Having found a piece of timber with the desired wavy grain, the hunter proceeded to shave and whittle until the stock was fitted to the barrel, and the gun was complete. Some of the stocks made with no tools but an $\mathrm{ax}$, drawing knife, and a pocket knife, were works of art which are worthy of preservation in museums.

Occasionally some unknown rural Stradivari made a violin and selected the curly wood of red maple for the neck and sides. A few of these instruments are floating about the country, but an age of fifty or a hundred years has not yet imparted classic value to them, but the wood is unsurpassed in delicacy of grain and figure.

Sugar may be manufactured from red maple, but in smaller quantity than from sugar maple. In the days when every frontier settlement did its own manufacturing, inks and dyes were made from the bark of this tree. The tannin boiled from the bark was treated with sulphate of iron, and it became ink; when alum was added it became black dye; when the sulphate of iron was omitted, and alum alone was put in, a cinnamon-colored dye resulted.

Red maple is one of the most desirable trees for planting in parks and by roadsides. Nurserymen complain that seedlings are more cifficult to manage than silver maples; nor do they grow as rapidly, but the trees are worth much more when once established. They have shorter and stronger branches than silver maple; are less liable to be attacked by disease; are more handsome in every way; but they demand damper soil, and succeed poorly in any other. That drawback tends to restrict the artificial planting of this tree.

Mountain MAPLE (Acer spicatum) is known also as moose maple, low maple, and water maple. It is a small tree at its best, seldom more than twenty-five fect high and eight inches in diameter, while in most parts of its range it is only a shrub. Its best growth is on mountain slopes of eastern Tennessee and western North Carolina. It likes moist, rich billsides, and does not object to shade. The flowers come late, but within a month or six weeks after the bloom appears, the fruit is full grown, but it remains on the tree till autumn. The tree's bark is smooth and very thin. The absence of stripes distinguishes this tree from striped maple, which has nearly the same range. Mountain maple grows from Maine to Ninnesota, southward to Mich. igan, and along the mountains 10 Georgia. The wood is light, soft, brown tinged with red. The small size of the trunk forbids its conversion into ordinary lumber. The only commercial use reported for it is in Pennsylvania where it is cut along with other hardwoods for destructive distillation.

FLORIDA MAPLE (Acer fioridanum) is a species according to some, and according to others is a variety of the lard maple. Its range is limited, and the available 
quantity of the wood is small. It is found in the swamps of southern Georgia and western Florida, and westward to Texas, Louisiana, and southern Arkansas. Near the southwestern limits of its range in Texas and Mexico, it is often a shrub; but in the best part of its range it becomes a tree fifty or sixty feet high and two or three in diameter. The wood passes for hard maple when sawed into lumber, but it is not often sent to sawmills. The makcrs of bent wood rustic furniture in some of the southern towns, particularly in Louisiana, have found the slender branches of Florida maple well suited to that purpose.

DRummond Maple (Acer rubrum drummondii) is a variety of red maple, not a separate species. Its range lics in the coastal plain of Alabama and Georgia, western I.ouisiana, eastern Texas, southwestern Tennessee, and southern Arkansas. It grows in deep swamps, and has three-lobed leaves, and large-winged fruit, ripening in April and May. The wood is too scarce to be important in the lumber trade, but where it can be had it is used. Violin makers have procured some finely curled wood of this maple in Union Parisl, Louisiana. Some of the wood from that district has been made into gunstocks also.

WHTEBARK MIAPLE (Acer leucoderme) has been classed as a variety of sugat maple, and also as a separate species. It is named from the light gray color of the oark of young stems; but the color turns dark with age. The tree is usually twenty or thirty feet high with a liameter of a foot or more. The wood is of good quality, but no uses, except fuel, have been reported. Trees are not abundant, but the range covers parts of North Carolina, Tennessee, Georgia, Alabama, Louisiana, and Arkansas. It is occasionally planted as a shade tree along the streets of towns of Georgia and Alabama.

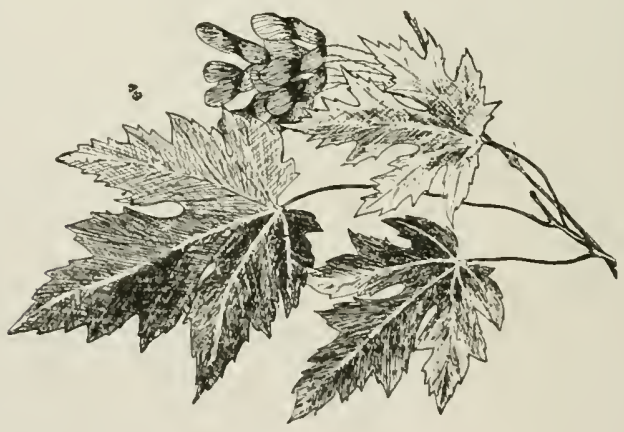


OREGON MAPLE 


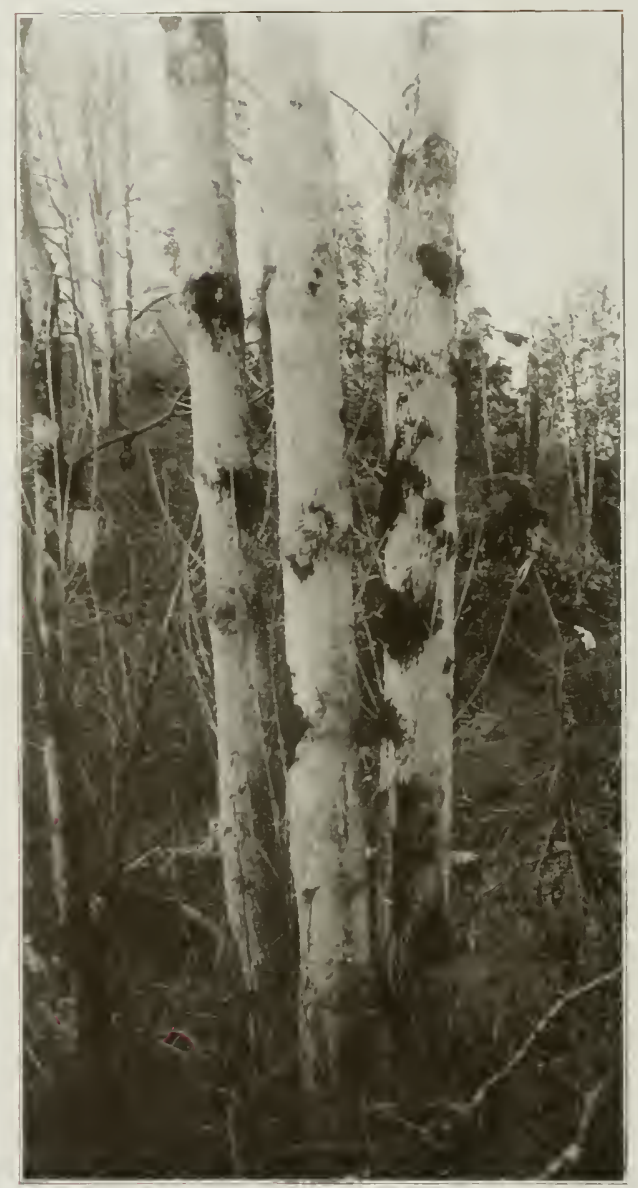

()REGON M.WILE 


\section{OREGON MAPLE}

(Acer Macrophyllum)

B OTANISTS prefer to call this tree broadleaf maple. The name is not inappropriate, as its extraordinarily broad leaves constitute the most striking feature of the tree where it stands in the woods. The leaf is usually wider than it is long. Some exceed a foot in both measurements. Bigleaf maple is not an uncommon name for the tree in Oregon, where it attains its highest development in damp valleys where the soil is good. The name white maple is not particularly descriptive of any feature of the tree, though the name is applied in both Oregon and Washington. In California it is known simply as maple. There is small likelihood in that region that it will be confused with any other member of the maple household; nor is there much danger of such a thing in any part of the Pacific coast, for, though four species of maple occur there, no one of them bears close enough resemblance to this one to be mistaken for it.

The Oregon maple's range north and south covers twenty degrees of latitude. In that particular it is not much surpassed, if surpassed at all, by any maple of this country. Its northern limit lies in Alaska, its southern close to the Mexican boundary, in San Diego county, California. Its range east and west is restricted. It has a width of about one hundred and fifty miles in California, where it grows from the coast to the foothills of the Sierra Nevada mountains. An altitude of 5,600 feet appears to be the limit of its range upward. It attains altitudes above 5,000 feet at several points in the Sierra Nevada range. It descends nearly to sea level. Its geographical range is similar to the ranges of several other Pacific coast species which occupy long ribbons of territory stretching north and south parallel with the coast of the Pacific ocean.

This maple's leaves change to a clear reddish-yellow before falling. Flowers appear after the leaves are grown, and the seeds ripen late in autumn. Some of them hang until late in winter, but the habit varies in different parts of the range, as is natural in view of its great extension north and south. The trees which stand in open ground are very abundant seeders, but those in dense stands produce sparingly, in that particular following the habit of most trees. This maple often grows in dense, nearly pure stands in Oregon and Waslington where soil and other conditions are favorable.

The sizes and forms of Oregon maple vary greatly. John Muir spoke of forests whose trees were eighty or one hundred fect high, so 
dense with leaves and so abundantly supplied with branches that moss and ferns formed a canopy with foliage and limbs high over head, like an aerial garden; while George B. Sudworth described it in certain situations as a short-stemmed, crooked tree from twenty-five to thirty feet high and under a foot in diameter.

This maple has been called the most valuable hardwood of the Pacific coast, but that claim is made also for other trees. Some persons rate it with the hard maple of the East, in properties which commend it for use. It is doubtful if the claim can be substantiated. According to Sargent's figures for strength, stiffness, weight, and fuel value, it lacks much of equalling the eastern tree. It is twelve pounds per cubic foot lighter; has not three-fourths the fuel value; and is little more than half as strong or as stiff. The comparison is more in favor of the western tree when color of wood and appearance of grain are considered. The wood is light brown with pale tint of red. The rings of annual growth are tolerably distinct, with a thin, dark line separating the summerwood of one year from the springwood of the next. The pores are scattered with fair evenness in all parts of the ring. They are small and numerous. The medullary rays are thin and abundant. In quarter-sawed wood they show much the same as in hard maple, but are rather darker in color. The mirrors are decidedly tinged with brown. The wood is reported poor in resisting decay when in contact with the soil.

The largest use of Oregon maple appears to be for furniture, second, for interior finish, and following these are numerous miscellaneous uses. Statistics of the cut of this wood, as shown by sawmill reports, are unsatisfactory. Census returns include it with all other maples of the country, without figures for species. The cut of maple for all the western states seems too small to give this wood justice. The amount reported used in Washington, Oregon, and California exceeds the total reported sawmill cut in the West.

Oregon maple is an important handlewood. The smooth grain appeals to broom makers. The wood is made into ax handles, but for that use it is much below hickory, or ever hard maple or white oak. It is converted into pulleys in Washington, also into saddle trees, and tent toggles. Boat makers employ it for finish material, in which capacity it fills the same place, and must meet the same requirements as in interior finish for houses. Curly or wavy wood is occasionally found and this is worked into finish and also into furniture. The figure is as handsome as in eastern maple, but birdseye is less frequent. Counter tops for storcs and bar tops for saloons are sometimes made of figured maple. It is seen also in grill work and show cases, but in order to show the figured wood to the best advantage it should be worked in flat surfaces. 
Oregon maple is converted into flooring of the ordinary tongued and grooved kind, and also into parquet flooring. Rotary veneers are made into boxes and baskets. Solid logs are turned for rollers of various sizes and kinds. Mill yards use them for offbearing lumber, and house movers find them about the best local material to be had. This maple has been successfully stained in imitation of mahogany, and is said to pass satisfactory tests where the color is the principal consideration

The amount of this species available in the Northwest is not definitely known, but it is a relatively scarce wood. No attention has ever been given to planting it as a commercial proposition. It is not of very rapid growth, and unless it is in dense stands, it develops a short trunk and large crown. It is better suited for shade and ornament, and is to be seen as a street tree in some western towns. It does not flourish in the eastern states, but has found the climate of western Europe more congenial and is occasionally found as an ornamental tree there.

The relative importance of this maple in the state of Washington is indicated by the amount used annually compared with certain other hardwoods. In 1911 the consumption of willow was 2,000 feet, vine maple 10,000, Oregon ash 58,000, Oregon oak 197,000, western birch 315,000 , Oregon maple 932,500 , red alder $1, \$ \$ 1,500$, and black cottonwood $32,572,200$.

Vine MAPLE (Acer circinatum) is sometimes called mountain maple, though the name is misleading. It may grow among mountains, but always near streams. It is found at various altitudes from near sea level to 5,000 feet above. It ranges from the coast region of British Columbia southward through Washington and Oregon to Mendocino county, California. This tree is more useful than might be inferred from its name, or even from a study of it in its usual form. Only an occasional tree is good for the wood user. A height of twenty feet and a diameter of six inches are above the average. It is called vine maple because of its habit of sprawling on the ground like a vine. The trunk lacks sufficient stiffness to hold it erect. It grows upward to a certain point, then leans over and the branches lie on the ground. Some of them take root and in course of time what was first a single stem becomes a thicket of branches and stems. The winter snow often has much to do with bending the trunk, which appears to have no power to get back to the perpendicular when once bowed down. The damp situation where this tree thrives best, induces a luxuriant growth of moss and mold which help to bury the branches that lie on the ground.

The tree prospers in deep shade. The young leaves are rose red, and in the fall become yellow or scarlet. The fruit is the characteristic maple key. The wing becomes rose-red before falling in autumn. 
Though this tree is more a curiosity than a lumberman's asset, it is not without value. Handle makers use 10,000 feet of it a year in the state of Washington. It is shaved and turned for ax and shovel handles. It has two-thirds the strength and less than half the stiffness of eastern hard maple. The tree grows slowly and the annual rings are very narrow and indistinct. Seventy or eighty years are required to produce a trunk five inches in diameter. The wood is hard, and checks badly in seasoning. The bark is very pale brown-suggesting the color of a potato sprout that has grown in a dark cellar. The Indians liked the wood for fish net bows, though there appears to have been no very good reason why they preferred it to other woods of the region. Its most extensive use at present is as fuel, but it is not particularly sought after. The tree's future is not promising. Under domestication it does not take on its fantastic, moldy, moss-grown form, and its forest growth will never be encouraged by lumbermen.

DWARF MAPLE (Acer glabrum) is one of the smallest of the maples, but in a north and south direction its range is equal to that of any other. Its southern limit is among the canyons of Arizona, and its northern on the coast of Alaska within six or seven degrees of the Arctic circle. It extends to Nebraska, and is found east of the continental divide far north in British America. It reaches its largest size on Vancouver island and on the Blue mountains in Oregon. It here is large enough to make small sawlogs, but it is usually shrubby in other parts of its range. It grows from sea level in Alaska to 9,000 feet altitude among the Sierra Nevada mountains of California. Two forms of leaf occur. One is three-lobed; the other is a compound leaf, the lobes having formed separate leaves. The bright upper surface of the leaf gives the species its botanical name. The seeds have large, wide wings. It cannot be ascertained that the wood of this maple has ever been used for anything.

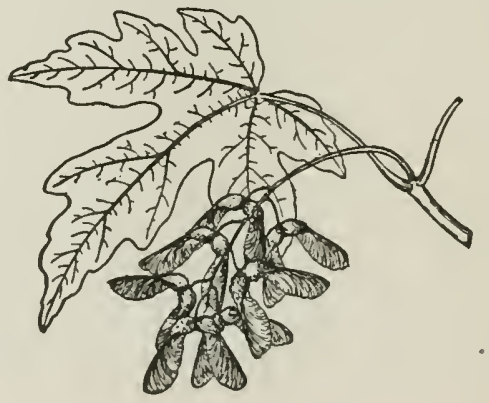


BOA ELDER 


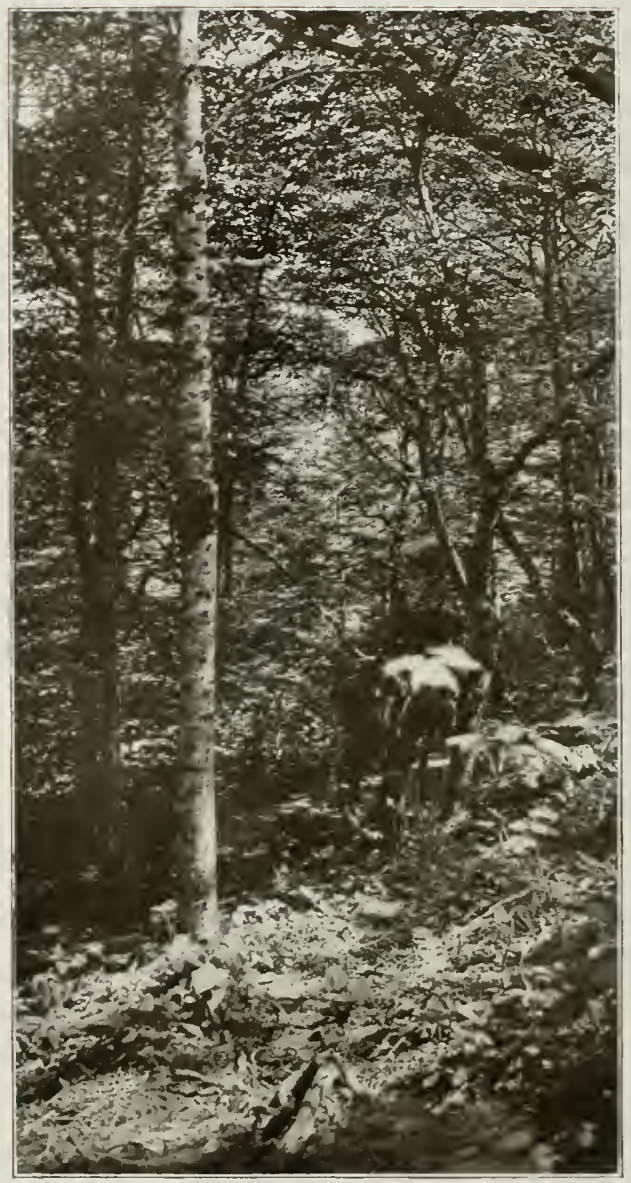

BOX ELDER 


\section{BOX ELDER}

\section{(Acor Negundo)}

A

T'ENPTS to ascertain the meaning of the word negundo which botanists apply to this species have not been crowned with entire success. It is known to be a word in the Malayalam language of the Malabar coast of India, and is there applied to a trce, apparently referring to a peculiar form of leaf. The name was transferred to the box elder by Moench, and has been generally adopted by botanists, although at least seven other scientific names have been given the tree. It bears ten or more English names in different regions. Among these names are asli-leaved maple, known from Massachusetts to Montana and Texas; cut-leaved maple in Colorado; three-leaved maple in Pennsylvania; black ash in Tennessee; stinking ash in South Carolina; sugar ash in Florida; water ash in the Dakotas; and box elder wherever it grows.

The trec's geographical range does not fall much short of 3,000,000 square miles, and is equalled by few species of this country. It extends from New England across Canada to Alberta, thence to Arizona, and includes practically all the United States cast and south of those lines. It thrives in hot and cold climates, and ligh and low elevations; in regions of much rain, and in those with little. That fact has been turned to account by tree planters, particularly in the years when the western plains were being settled by homesteaders. The box elder was the chief tree on many a timber claim where the letter of the law rather than the spirit was carried out. It afforded the earliest protection against scorching summer sun and the keen winds of winter about many a frontiersman's cabin on the plains. It was the earliest street tree in many western towns. The people planted it because they knew it would grow, and they were not so sure of a good many other trees. Green ash was often its companion in pioneer plantings on the plains. Many towns which set box elders along the streets when they did not know of anything better, still have the trees, though they would willingly exchange then for something else. They are not ideal street and park trees; do not produce shapely trunks and crowns; and drop leaves all summer and seeds all winter. The tree is reputed to be short lived, yet some of those planted a generation or two ago show no symptoms of decline.

There is no good reason why this tree should be called an elder. or an ash, except that its leaves are compound. If that is a reason, it might be called a hickory or a walnut, since they hear compound leaves. It is clearly a maple. Its fruit shows it to be so, and Indians of the far 
Northwest who had no other maple, formerly manufactured sugar from this tree, collecting the sap in wood or bark troughs and boiling it with hot stones.

The compound leaf does not necessarily take it out of the maple group. It requires no great exercise of imagination to understand how a lobed leaf, by deepening the sinuses between the lobes, might become a compound leaf in the process of evolution. There may be no visible evidence that the box elder's leaf reached its present form by that process, but there is another maple which is at the present time developing a compound leaf in that way, or seems to be doing so. It is the dwarf maple (Accr glabrum) of the Northwest coast. Lobed leaves and compound leaves may occur on the same tree.

The seeds of box elder resemble those of other maples. They ripen in the fall, and are blown off by wind, few at a time, during several months. The trees are from fifty to seventy feet high, and from one and a half to three feet in diameter. The trunk is apt to divide near the ground in several large branches, and is not of good form for sawlogs, being often crooked as well as short. The small branches, particularly those less than a year old, are usually nearly as green as the leaves. This fact may assist in identifying the tree when the leaves are off. The bark bears more resemblance to ash and basswood than to maple.

The wood is lightest of the maples. It weighs less than twentyseven pounds to the cubic foot; has less than half the strength and about forty per cent of the stiffness of sugar maple; and is much inferior to it in most mechanical properties. It is equal, if not superior to most maples in whiteness. The pores are small, numerous, and scattered through all parts of the growth ring, as is characteristic of maple wood. The tree grows rapidly. The summerwood is a thin, dark line, separating one annual ring from another. The medullary rays are many and obscure, but when wood is sawed or split along a radial line, they are easily seen, and show the true maple luster.

The uses of box elder are similar to those of soft maple. The wood is seldom reported under its own name. In fact, an examination of woodusing reports of various states, shows that in only two states, Michigan and Texas, has box elder been listed separately. Its uses in the former state were for boxes, crates, flooring, handles, woodenware, and interior finish, whilc in Texas it was made into furniture. The tree is of commercial size in at least thirty states, and is cnt and marketed in all of them. Tests of the wood for pulp are said to be satisfactory, and it finds its way in rather large amounts to cooper shops where it is made iuto slack barrels. It is cut as acid wood along with other maples, beech, and birch, and is converted into charcoal and other products of distillation. 
It may be expected that box elder will exist in the United States as long as any other forest tree remains. It is willing to be crowded off good land into low places, which are almost swamps, and there it grows free from disturbance; but if given the opportunity it will appropriate the most fertile soil within reach of it; and by scattering seeds during four or five months of the year, it manages to do much effective planting.

CAL1Fornia Box ELDER (Acer negundo californicum) is a variety of box elder, and not a separate species. As the name implies, it is a California tree, and it occurs in the valleys and among the Coast liange mountains from the lower Sacramento valley to the western slopes of the San Bernardino mountains. The tree is from twenty to filty leet high and from tea to thirty inclies in diameter. The leaves and young twigs are hairy, in that respect differing from the eastern box elder. The seeds are scattered during winter. The wood is very pale lemon-yellow or creamy-white, the heart and sapwood hardly distinguishable. The wood is soft and brittle, but is suited to the same purposes as the eastem box elder. No reports of its uses appear to have been made. It is found on the borders of streams and in the bottoms of moist canyons. It is believed to be a short-lived tree.

STRIPED MAPLE (.Acer pennsylvanicum) is usually thirty or forty feet high, and eight or ten inches in diameter. Its range extends from Quebec to northern Georgia, westward to Minnesota, and is of largest size on the slopes of Big Smoky mountains of Tennessee, and the Blue Ridge in North and South Carolina. It grows best in shade, but maintains itself in open ground, is generally shrubby in the northern part of its range. The name refers to the bark. The stripes are longitudinal and are caused by the parting of the outer bark and the exposure to view of the lighter colored inner layers. The bark of small trees is greenish, but later in life the color is darker, and the stripes largely disappear. Among its names are moosewood, so ealled because it is good browse for moose and other deer; goosefoot maple, a reference to the form of the leaf; whistlewood, an allusion to the ease with which the bark slips from young branches in spring when boys with jack-knives are on the search for whistle material. The names mountain alder and striped dogwood are based on misunderstanding of the tree's family relations.

The young leaves are rose colored when they unfold, and when full grown are six inches wide. The wood is light and soft, and light brown in color, the thick sapwood lighter. The wood is liable to contain small brown pith flecks, which in longitudinal sections appear as brown streaks an inch or less in length and as thick as a pin, and in cross section they are brown dots. They are not natural to the wood but are cansed by the larva of certain moths which burrow into the cambium layer, or soft inner bark, and excavate narrow galleries up and down the trunk. The galleries afterwards fill with dark material. The insects sometimes attack other maples, the birches, service, and other trees. The wood of striped maple is little used, because of the small size of the trees. The species is planted for ornament in this country and Europe.

BLACK MAPLe (Acer nigrum) has been by some considered a varicty of sugar or hard maple, and by others a separate species. It is as large as the sugar maple and its range is much the same, but it is more abundant in the western part of its range than in the East. The name refers to the color of the bark of old trunks. If thic name had considered the bark of young twigs it would have been yellow or orange maple, because the twigs are of that color. In summer the peculiar drooping posturc of the leaves calls attention to this tree. However, the bark, twigs, and lcaves combined 
are not sufficient to set it apart, in the eyes of most people, for it generally passes without question as sugar maple, even when it stands side by side with that tree. It yields sugar abundantly. The wood is a little heavier than that of sugar maple, but the difference cannot be noticed except when the two woods are weighed. Their uses are the same. No maker of furniture, flooring, or finish ever protests against black maple. The tree generally prefers lower and damper ground than sugar maple, and is often found aloug streams.

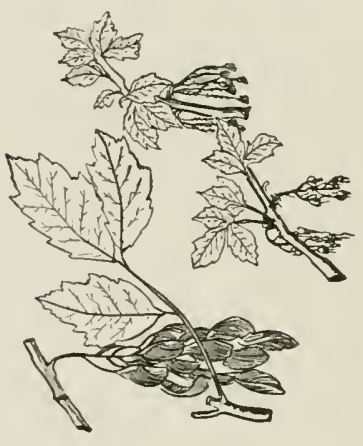


SERVICEBERRY 


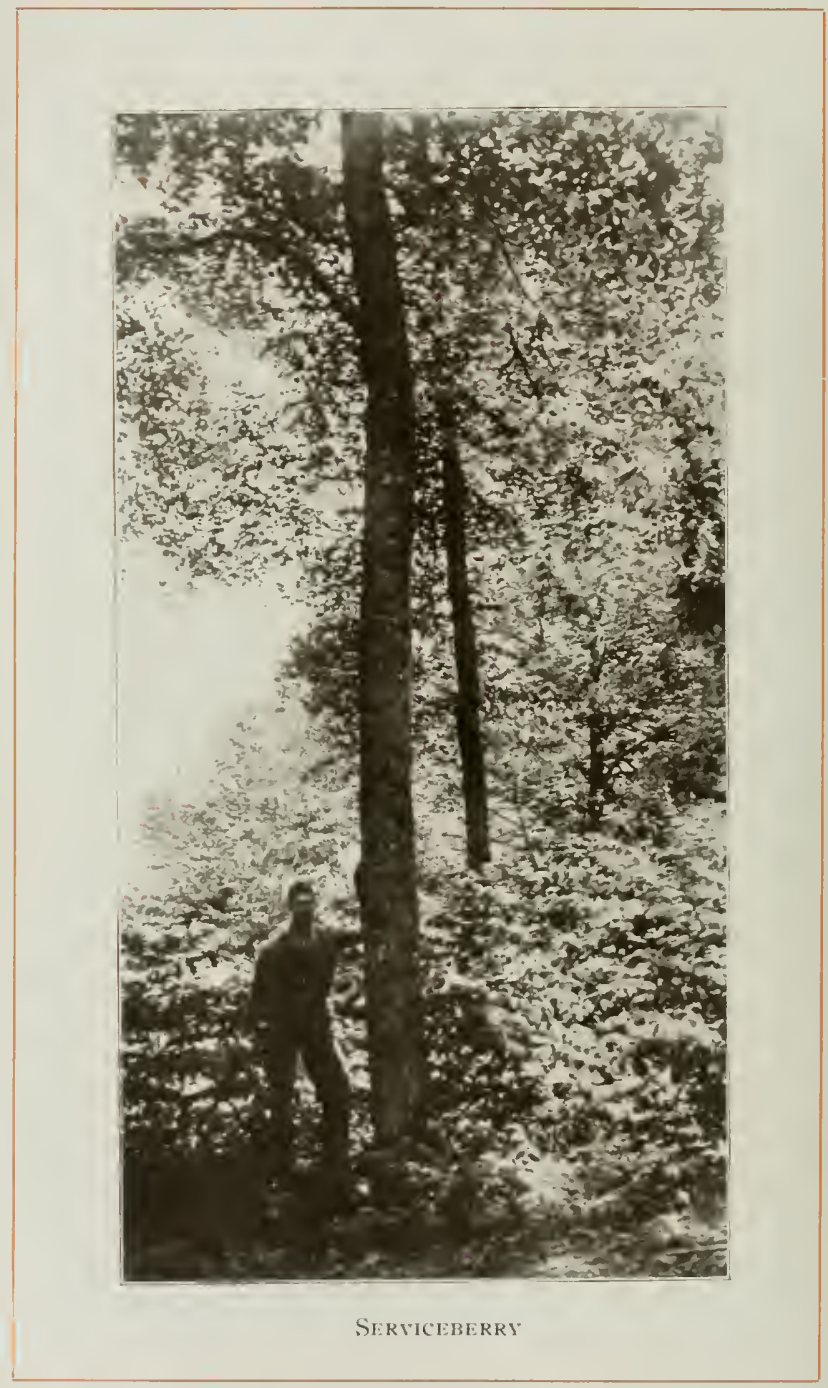




\section{SERVICEBERRY}

\section{(Amelanchier Canadensis)}

$\mathrm{T}$ HIS tree will never be other than a minor species in the United States, but it is not a worthless member of the forest. It belongs to the rose family, and therefore is near akin to the haws, thorns, and crabapples. The genus is found in Europe, Asia, and Africa, as well as in the United States. Two tree species occur in this country, or, according to some botanists, three, one west of the Rocky Mountains, two east.

The serviceberry has a number of names: June berry, service-tree, May cherry, Indian cherry, wild Indian pear, currant tree, shadberry, savice, and sarvice. The northern limit of its range is in Newfonndland, the southern in Florida. It grows westward to Minnesota and Arkansas; but it is not plentiful except in certain restricted localities. It is most abundant among the ranges of the Appalachian mountains, and of its largest size toward the south. It is dispersed through forests generally, a tree or bush here and there; but it prefers the borders of forests, the brinks of cliffs, banks of streams, or some other open space where light is abundant. It prospers most in rich soil but does fairly well in ground thin and dry.

The bloom, where it occurs, is a conspicuous feature of the landscape, though generally a tree on ten or twenty acres represents the density of its stand. The white, showy bloom comes early in spring, when most trees are yet bare of leaves. Occasionally, however, the serviceberry is more abundant, and the rows and clumps of blooning trees along creek banks or about the margins of glades or other openings in the forests, look like distant snowdrifts.

The fruit is a berry a half inch or less in diameter, bright red when fully grown in early summer, and changing to purple when ripe. The seeds are brown and very small, and each berry contains from five to ten. When circumstances are favorable, the tree is a prolific bearer, the slender branches bending beneath the weight. The tree need not reach any particular size before beginning to bear. On some of the severely burtred summits of the Alleghany mountains in West Virginia, 1,000 fect or more above sea level, this tree, when only two or three fect high, bears abundantly. Such trees are probably sprouts from roots of older trunks destroyed by fire. At its best, it reaches a height of forty or fifty fect and a diameter of one or possibly two feet. Trunks of largest size occur among the southern Appalachian ranges.

The wood is heavy and very hard and strong. It is liable to check 
and warp in seasoning, is satiny, and is susceptible of a good polish. Medullary rays are very numerous, but obscure; color, dark brown, of ten tinged with red. The wood is stronger, stiffer and heavier than white oak. It possesses most of the properties to make it a wood of great value, but its scarcity, and the usual small size of the trees, relegate it to the class of minor woods. Some use is made of it in turnery and for other small articles. It is frequently planted in gardens for its bloom and berries. In such situations it lacks some of the charm which it holds as part and parcel of the wildwoods where its early spring bloom is thrown against a background of leafless branches.

Western Serviceberry (Amelanchicr alnifolia) is also called pigeonberry and sarvice. Its botanical name refers to the resemblance of its leaves to those of alder. Its range covers a million square miles, and the species reaches its best development on islands and rich bottom lands of the lower Columbia river. It is found as far south as California, north to Yukon territory, east to Lake Superior and northern Michigan. It is nowhere a tree of attractive size, and is usually a shrub about ten feet tall and one inch thick. Trees are sometimes thirty feet high and six or eight inches in diameter. The fruit is blue-black and sweet, and pleasant to the taste if not overripe. Indians in the northern and western range of this tree gather the berries industriously while they last, and many of the white settlers do likewise. The birds flock to the thickets for their share, and though the berries are small, the bears in the region consider them worthy of prompt and continued attention. The berries are generally a little more than half an inch in diameter, and ripen in July or August, depending on latitude. Cattle, sheep, goats, and deer find this small tree or bush a source of food. They do not object to eating the berries when obtainable, but their principal attack is on the leaves and tender shoots which afford excellent browse. Fortunately, the serviceberry is so tenacious of life that it is next to impossible to browse it to death. If eaten down to the ground, with little left but bare and barked truuks sticking up like bean poles, the roots will throw up sprouts year after year, making the service thicket a permanent browse-pasture. Fire is not able to destroy such a thicket, for, when the tops are burned off, the sprouts will quickly spring up with vigor unimpaired. As a source of food for insects, birds, beasts, and men, few trees, in proportion to size and quantity, are the equal of western serviceberry. Flowers, fruit, leaves and sprouts are all food for something.

Longleaf Service Tree (Amelanchicr obovalis) is by some regarded a variety rather than a species. It occupies in part the same range as serviceberry, but runs much farther north, reaching the valley 
of Mackenzie river in latitude 65. It is found in North Carolina and Alabama, but it is only a shrub in the extreme southern part of its range. The fruit ripens in early summer and is reddish purple. Trees are seldom more than thirty feet high and eight inches in diameter. A variety with large fruit is occasionally planted as an ornamental tree. Unless the crop of serviceberries is unusually plentiful in a locality, the most of it is eaten by birds which temporarily abandon nearly all other sources of food and give their undivided attention to the perishable harvest which must be garnered in at once or it will be lost.

NARrowleAF CRAB (Malus angustifolia) is one of the wild crabapples of the United States. They are of the genus Malus and the thousands of varieties of cultivated apples are derived from them, or from other species found in the old world which are very similar. They belong to the rose family. The narrowleaf crab is found from Pentnsylvania to Florida and westward to Tennessee and Louisiana. It thrives best in open spaces in the forest and is often found in glades and along the banks of streams in the North, while in the South it occurs in depressions in the pine barrens. The flowers are much like those of apple, very fragrant, and in color are white, pink, or rose. When in full bloom, the tree is a beautiful object, and its odor is carried long distances. The fruit is an apple in all respects except size and taste. It is somewhat flattened, and is an inch or less across. It is fragrant when fully ripe, and many a person has been led by appearances to taste, only to meet disappointment. The flesh is hard and sour, and unfit for food in its natural state, but by cooking and artificial sweetening, it is made into preserves. The tree reaches a height of twenty or thirty feet and a diameter of eight or ten inches. It is smaller than the sweet crab. The wood is hard, heary, light brown, tinged with red, with thick yellow sapwood. It is not put to many uses, but is occasionally made into small handles, and levers. It has been mucl used as stock on which to graft apples. Farmers who wanted orchards formerly dug up small crabapples in the surrounding woods and ficlds, planted them in an orchard, and when securely rooted, the apples of desired kinds were grafted on. If successful, the apple finally replaced the crab by spreading its own bark and wood over the entire trunk, until no part of the original stock remained visible. The sweet crab was also employed as a stock on which to graft apples.

SwEet CRAB (Malus coronaria) is the wild crab of the northeastern states, although it intrudes on the region to the southwest to a linited extent. It finds use in ornamental planting in the region of best growth. It is known as American crab, sweet sccnted crab, crab apple, wild crab, crab, American crab apple, and fragrant crab. Its range 
extends from the shores of Lake Erie in Canada, south through New York and Pennsylvania, along the Alleghany mountains to Alabama; west to Minnesota, eastern Nebraska, Kansas, Louisiana, and eastern Texas. It needs moist soil for good growth and the best types are found in the lower Ohio basin. In height this tree rarely exceeds thirty feet and it is bushy, having short rigid limbs. The leaves are rounded and sharply toothed, the blossoms generally white and very fragrant; the fruit small, dry, yellow, tinged with red. The wood is heavy, not strong, heart light red, sapwood yellow. It is used for tool handles, small turned articles, and for carving and engraving.

Oregon Crabapple (Malus rivularis) grows wild from the Aleutian Islands, Alaska, southward to central California, and is of largest size in Washington and Oregon where trees are occasionally forty feet high and eighteen inches in diameter, but they are generally about ten feet high and form dense thickets. The fruit is oblong, ripens late in autumn, is greenish, or reddish, or clear lemon yellow in color, and rather pleasant to the taste. The tree grows slowly, the wood is hard, and light reddish-brown in color, and is suitable for tool handles.

Iowa Crab (Malus ioensis) grows from Minnesota to Texas and is the common crabapple of the Mississippi basin. Large trees are twentyfive feet high and a foot in diameter. It is believed that this tree crosses with the common apple, and produces a variety known as the soulard apple (Malus soulardi). Wild apple (Malus malus) is a European species introduced into this country and now running wild.

Mountan Asu (Pyrus americana) is closely related to the crabs. It occurs from Newfoundland to Manitoba, and southward along the mountains to North Carolina. Trees have compound leaves, red berries the size of small cherries, and reach a height of thirty feet and a diameter of a foot or more. There are several forms or varieties, among them the small fruit mountain ash (Pyrus americana microcarpa) of the Alleghany mountains.

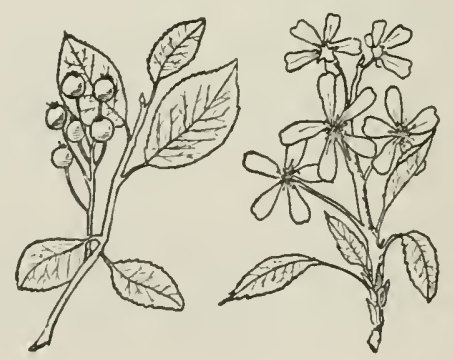


RED HAIV 


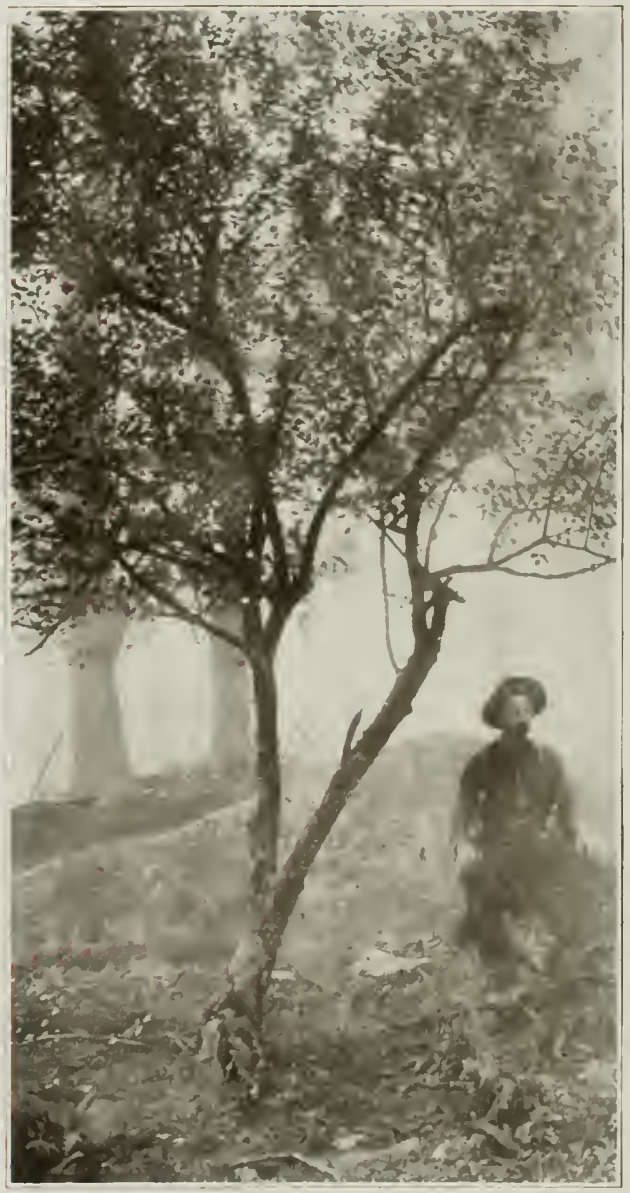

REU HAW 


\section{RED HAW}

\section{(Crategus Coccinoa)}

$\mathrm{T}$ HIS tree belongs to the rose family, and the genus Cratagus consists of a large group of small, thorny trees, scattered through many parts of the world. They are known by their thorns, but comparatively few of them are known by name to the ordinary observer, and they afford a perpetual source of study, victory, and bewilderment to the trained botanist. "No other group of American trees," says Sudworth, "presents such almost insurmountable difficulties in point of distinctive characters. It is impossible, and fortunately unnecessary, for the practical forester to know them all, and exceedingly difficult even for the specialist." More than one hundred species of these thorn trees occur in the United States, exclusive of shrubs. Their bloom resembles that of apple and pear trees. Bees and insects swarm round the flowering trees, assisting in cross fertilization. The various species are aggressive. They force their way into vacant spaces, and their thorns protect them against browsing animals. The wood is sappy and heavy, and for most of the species it is valueless. The growing brambles, however, perform an important service in forest economy. Seeds of various valuable trees are blown by wind or carried by birds and mammals into the thickets where they germinate and get a start under the protecting shelter of the thorns. Finally the seedlings overtop the brambles, gain the mastery, shade the thorns to death, and develop valuable forests. The thorn trees shed their leaves annually. Their seeds are slow to germinate, some not sprouting until the second year. The fruit is worthless for human consumption, but some of it has a tart and not unpleasant taste. It is of many colors and sizes, depending on species.

No attempt is here made to name or to list the species. Such a list would, for most people, be a dull catalogue of names, and many of them in Latin because there are no English equivalents. A few representative species are given. The red haw, though not the most abundant, is widely distributed, and is probably as well known as any. Its range extends from Newfoundland westward through southern Canada to the eastern base of the Rocky Mountains, thence south to Texas and Florida. It covers one-half of the United States. In the northern part of its range the red haw is confined to the slopes of low hills and along water courses, but south in the Appalachian mountains it grows at an elevation of several thousand feet.

It has various names in different regions. It is called scarlet haw, 
red haw, white thorn, scarlet thorn, scarlet-fruited thorn, red thorn, thorn, thorn bush, thorn apple, and hedge thorn. The fact is worthy of note that it is well known and is clearly recognized in every region where it grows, though various names are given it.

The red haw never reaches large size. In rare cases it may attain a height of thirty feet and a diameter of ten inches, but it is usually less than half that size. Where it grows in the open it develops a round crown. The branches are armed with chestnut-brown thorns from an inch to an inch and a half in length. The bright scarlet color of the fruit gives name to the tree. It ripens late in September or in October, and at that time the tree presents a beautiful appearance. The branches frequently remain laden with fruit after the leaves have fallen.

The wood of red haw is of a high character and but for its scarcity would have wide commercial use. It is among the heavy woods of this country. A cubic foot of it, thoroughly seasoned, weighs 53.71 pounds. The tree is of slow growth and therefore the annual rings are narrow, and the wood is dense. The evenness and uniformity of the rings of yearly growth make the wood susceptible of a high polish. The medullary rays are very obscure in red haw, and for that reason the appearance of the wood is much the same, irrespective of the direction in which it is cut. In that respect it is similar to the wood of most members of the thorn family - usually being too small to be quarter-sawed. However, even if the trees were large enough, quarter-sawing would bring out little figure.

Red haw is a lathe wood. It is well suited to some other purposes, and has been used for engraving blocks, small wedges, and rulers, but the best results come from the lathe. If it is thoroughly seasoned it is not liable to crack or check, though cut thin in such articles as goblets and napkin rings. The turner sometimes objects to the wood because of its hardness and the rapidity with which it dulls tools. This drawback, however, is compensated for by the smoothness and fine polish which may be given to the finished article. Red haw checker pieces have been compared with ebony for wearing quality. In color the ebony is more handsome, and on that account is generally preferred.

Perhaps the most extensive use of red haw is in the manufacture of canes. Most of the species of thorn are suitable for that purpose on account of their weight, strength, and hardness. Red haw is not specially prcferred, but is used with others. As a source of wood supply, the tree will never be important, but as an adornment to the landscape it will always be valuable, and at the same time will fill a minor place in the country's list of commercial woods.

Summer Haw (Cratagus astivalis) is a southern species which 
contributes more or less to the food supply of the people within its range. It is known also as May haw and apple haw. The flowers appear in February and March, are about one inch in diameter, and flushed with red toward the apex. The fruit ripens in May, is bright red, very fragrant, and is from half to three-fourths of an inch in diameter. The flesh is of a pleasant taste, and is gathered in large quantities by country people for making preserves and jelly. It is sold in town and city markets, particularly in New Orleans. The range of this thorn tree is from South Carolina and Florida, to Texas. It attains a height of twenty or thirty feet, and a diameter sometimes as great as eighteen inches. It reaches its largest size in Louisiana and Texas. It grows well on land which may be submerged several wecks in winter. The wood has not been reported for any use.

Cockspur (Cratagus crus-galli) may be taken as the type of more than twenty species of cockspur thorns growing in this country. Its other names are red haw, Newcastle thorn, thorn apple, thorn bush, pin thorn, haw, and hawthorn. It grows sonthwestward from Canada to Texas, and extends into Florida. The largest trees are twenty-five feet high and a foot in diameter. The fruit is dull red, half inch in diameter, ripens in September and October, and hangs on the branches until late winter. Hogs eat the fruit when they can get it, and boys utilize the small apples as bullets for elder pop guns. The thorns are formidable slender spines from three to eight inches long, strong, and extremely sharp. They were formerly used as pins to close wool sacks in rural carding mills. The many species of cockspur thorns are multiplied by numerous varieties. Fence posts and fuel are cut from the best trunks.

PEAR HAw (Cratogus tomentosa) is a representative of at least ten species. It is called pear haw without any very satisfactory reason, since the fruit bears little resemblance to pears. It is half an inch in diameter, dull orange red in color, and sweet to the taste, but it is of little value as food. The tree has been occasionally planted for ornament, but never for fruit. The flowers are showy. Trees at their best are fiftcen or twenty feet high and five or six inches in diameter. They have few thorns and such as they have are small. The tree's range extends from New York to Missouri, and along the Appalachian mountains to northern Georgia, and west to Texas and Arkansas. It is known in different parts of its range as black thorn, red haw, pear thorn, white thorn, common thorn, hawthorn, thorn apple, and thori plun.

Hog Haw (Cratagus brachyacantha) is distinguished by its blue fruit. The name indicates that the fruit is unfit for lumnan food but is eaten by swine. In some parts of Louisiana the dense thickets produce 
considerable quantities of forage for hogs. The range is not extensive, being confined to Louisiana and eastern Texas where the tree occurs in low, wet prairies. The largest specimens are forty or fifty feet high and eighteen inches in diameter. It is one of the largest of the thorns, and the best trunks are of size to make small, very short sawlogs, but it does not appear that the wood has ever been manufactured into commodities of any kind. The tree is occasionally planted for ornament.

BLACK HAW (Cratcgus douglasii) reaches its best development on the Pacific coast where trees occur thirty or more feet in height and a foot and a half in diameter. The principal range is west of the Rocky Mountains, from British Columbia to northern California, but it extends eastward to Wyoming, and the tree is found also in northern Michigan. The fruit is black or very dark purple, is edible, and matures in early autumn, falling soon after. The heartwood is brownish-red. No use for the wood has been found on the Pacific coast.

WASHINGTON HAW (Crategus cordata), also known as Washington thorn, Virginia thorn, heart-leaved thorn, and red haw, grows on banks of streams from the valley of the upper Potomac river southward through the Appalachian ranges to northern Georgia, and westward to Missouri and Arkansas. Flowers are rose-colored, the fruit ripens in the fall and hangs till late winter. Trees are twenty or thirty feet high, and a foot or less in diameter. Washington haw is frequently planted in this country and in Europe.

ENGLish HawthoRn (Cratagus oxyacantha) was introduced into this country from Europe and has become naturalized in some of the eastern states. Thirty or more varieties are distinguished in cultivation. It is worthy of note that, although the United States has more than 130 species of thorn trees of its own, with varieties so numerous that no one has yet named or counted all of them, a foreign thorn has been introduced and added to the number.

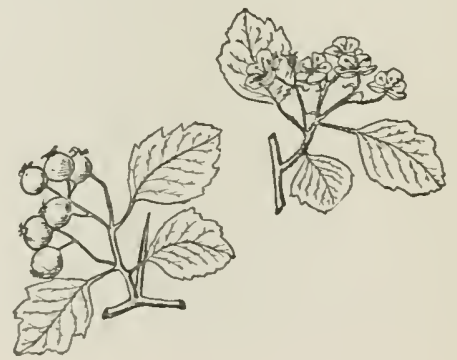


MAHOGANY 


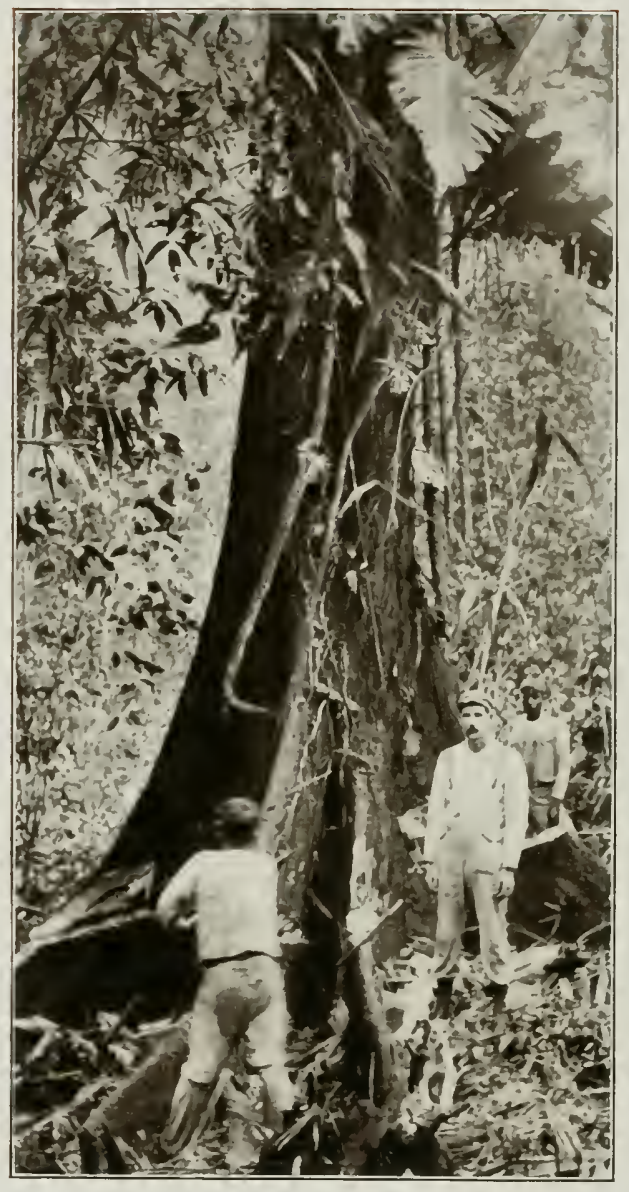

MaHOGANY 


\section{MAHOGANY}

\section{(Swictenia Mahagoni)}

7 HIS tree belongs to the family Meliacea which has about forty 1 genera, all of which are confined to the tropic except Swietenia to which mahogany belongs. This tree has made its way up from southern latitudes and has secured a foothold in Florida where it is confined to the islands and the most southern part of the mainland.

No attempt is here made to settle or even to take part in the disputes among dendrologists as to what mahogany is. There are said to be more than forty different trees which pass as mahogany in lumber markets. Various descriptions and keys have been published for the purpose of separating and identifying different woods which are bought and sold as mahogany. These woods grow on every continent except Europe; but those which pass as mahogany nearly all come from Africa or America. Some are well known, both as to origin and botany, while others are doubtful. Logs sometimes appear in markets and no one knows where they come from, or the species which produce them. It has becn maintained that annual rings will separate true mahogany from the false-that the true has no annual rings. At the best, this evidence is only negative and is worth little, since many tropical trees show no annual rings, and yet are no kin to mahogany. Neither is it certain that true mahogany shows no yearly rings. Some trees do not, but others may. The ring, as is well known, is produced because the tree grows part of the year and rests part. In the tropics where growth is continuous, the ring may not exist, but it sometimes does exist, and thus upsets the theory. Besides, it proves little in the case of mahogany which has a range extending from south of the equator northward into the temperate zone, where there are seasonal changes. It also grows near sea level and at considerable altitudes, and elevation alone might make considerable variation in the character of the wood.

The two most important mahoganies of commerce-leaving botany out of the question-grow in Africa and in America. The most important of the African mahoganies is Khaya senegalensis, and of the American is Swientenia mahagoni. It is the latter which extends its range into the United States, and it alone will be considered in these pages as true mahogany; the status of foreign woods which pass as mahogany will not be discussed.

Leaves of the mahogany tree are three or four inches long, and an inch or more wide. They are compound, with from three to five pairs of leaflets. The tree is an evergreen and presents a finc appearance. The 
flowers appear in July and Angust, are small and cup-shaped. Fruit is four or five inches long and two or more wide. It ripens in late fall or early winter. The nearly square seeds are three-fourths of an inch long. In Florida the tree rarely exceeds fifty feet in height and two in diameter; but in tropical countries it may exceed a height of 100 and a diameter of eight or ten. The bark is thin.

The wood is practically of the same weight as white oak, but is stronger and more elastic. It is exceedingly hard, very durable, and is susceptible of high polish. Medullary rays are numerous but small and obscure. The color is rich reddish-brown, turning darker with age, but the thin saprood is yellow. It is known in Florida as mahogany, madeira, and redwood.

The uses of mahogany are so many and so well-known that it is unnecessary to speak of them in detail. There were importations into the United States nearly three hundred years ago, and it has been coming ever since. One thing about this wood deserves mention: the price has not varied much in three hundred years. Different prices have prevailed, owing to distance from supply and differences in grade and quality; and that holds true today; but for similar grades, the prices have been remarkable for their evenness.

Florida never figured largely in the world's supply of mahogany. At their best, the trees were neither large nor numerous, but their quality was good. Cutting of this timber ceased in Florida about three-quarters of a century ago. The islands and the small area of the mainland where the timber grew, were stripped. The logs were shipped to the Bahama islands and it is said they found their ultimate market in England. A few trees were overlooked here and there, and some that were small seventy-five years ago, have grown to merchantable size since. These have been cut, a few at a time, and the cutting is still going on. The total is now only a few thousand feet a year, and one of the markets for the logs, probably the chief market, is Miami, Florida. The logs are small, and are generally cut and brought in by negroes who find a tree now and then, cut the logs, and float them as near to market as possible, and haul them the rest of the way. The scarcity of the trees may be inferred from the fact that the average resident of south Florida, where the range of the mahogany lies, never saw one. In appearance the tree when seen at a little distance, resembles a young, vigorous black walnut tree.

CHINA TREE (Mclia azedarach) belongs to the same family as mahogany but is of a different genus. It is not native in the United States, but has been extensively planted and is running wild. It is a forest tree in some parts of Lonisiana, but is found under pure forest 
conditions only here and there. As such, the trunk and thin crown look like a forest grown butternut tree in Wisconsin. It is abundant in yards and along streets, where it is often called Chinaball tree. A little of the wood is used. The color resembles mahogany, bnt the texture is much coarser. Annual rings are clearly marked by rows of large pores, and the wood does not polish well. It is sometimes known as pride of India, which country is its native home, or it was carried there from Persia at an early date. A variety, commonly known as the Texas Umbrella tree (Melia azedarach umbraculifera), has been widely planted, and is known by its short trunk and dense, round crown.

SOAPBEERY (Sapindus sapanaria), known also as false dogwood, is a species of south Florida, and is one of three soap trees in this country. It has no family kinship with mahogany, but the appearance of the trees leads some persons to conclude that they are related to the China tree. In fact, one of the species is locally known as wild China and Chinaberry. They are called soap trees because their fruit has a property which causes water to fnam, and the natires of the IVest Indies once used it for soap. The botanical name Sapindus means "Indian soap." The tree is twentyfive or thirty feet high, and ten or twelve inches in diameter. The bloom appears in November in Florida, and the fruit ripens the following spring. The wood is heavy, rather hard, and is light brown, tinged with yellow. It reaches largest size on the Thousand Islands, Florida. Another species is Sapindus marginatus which attains size similar to that of the first. It is found in sonthern Florida, but is not abundant. It grows as far north as the mouth of the St. John river. A third species is Sapindus drummondi which has its range from western Louisiana, Arkansas, and southern Kansas, through Texas, New Mexico, and Arizona, to Mexico. The flowers appear in May and June, and the fruit ripens in September and October, but it hangs on the trees until the following spring. When first ripe, it is half an inch in diameter, and yellow, but when it dries it turns black. Trees attain diameters up to two feet, and heights of forty or fifty. It is commonly supposed to be the Chinaberry, by persons who judge by general appearances, but the two are not related. The wood's appearance suggests the heartwood of ash. It probably reaches its best development in Texas where it is manufactured into boxes, crates, and even furniture, but not in large amonnts. It is reputed to be a rapid grower, and it may be under the most favorable circumstances, but it is usually of rather slow growth. The wood splits readily into thin strips whicl are cinployed in making baskets for harvesting cotton. In western Texas it is made into pack saddle frames.

Mountain Mahogany (Cercocarpus ledifolius) is not a mahogany, and is not 
even in the same family. It helongs to the rose family, and is closely related to the crahapple; but since it is commonly known as mahogany, it is proper to mention it here. Extensive consideration is unnecessary, for the tree is not important as a source of wood. Three species are recognized by some bot anists, four by others. All are western, and are noted for their long-tailed fruit. The generic name refers to that feature. The seed, with its tail, is carried by the wind, or it catches in the wool of sheep and the hair of cattle and goats, or the feathers of birds, and is carried far and near. The mountain mahogany sometimes is thirty feet high, and two in diameter. It grows from 5,000 to 9,000 feet elevation, sometimes on steep cliffs. Its range extends from Wyoming and Montana to Oregon, California, Arizona, and New Mexico. The wood is bright, clear red, or rich dark brown. It reaches its largest size on the mountains of central Nevada. Another species is known as valley mahogany (Cercocarpus parvifolius). It ranges from Nebraska to Oregon, and Texas to California. Its rate of growth is very slow, and it seldom exceeds a height of thirty feet and a diameter of ten inches. The wood is reddish-brown. A third species, called Trask mahogany (Cercocarpus traskice) is chiefly notable on account of its restricted range. It occurs as far as known, in a single canyon of Santa Catalina island, off the southern coast of California. Some of the specimens are twenty feet high and six inches in diameter. A fourth species, or a variety, is known as short-flower mahogany (Cercocarpus parvifolius breviflorus). It occurs in western Texas, southern New Mexico and Arizona, usually at elevations about 5,000 feet above sea level where the largest trees are not more than eight inches in diameter and twenty-five feet high.

VAUQUELINIA (Vauquclinia californica) helongs to the same family as the socalled western mahoganies, that is, the rose family; but it is of a different genus. Its range is largely south of the international boundary, but it extends into southern Arizona where the hest development of the species occurs about 5,000 feet above the sea on grassy slopes. It is seldom more than a bush, and the rood is very heavy and hard, and is dark-brown, streaked with red.

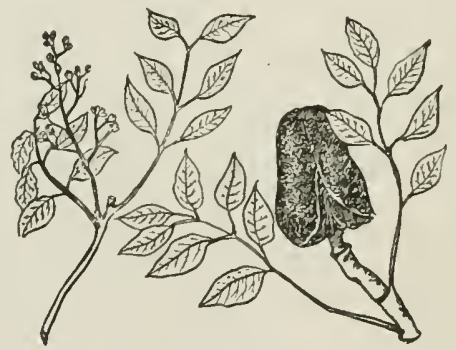


BLACK MILLOH 


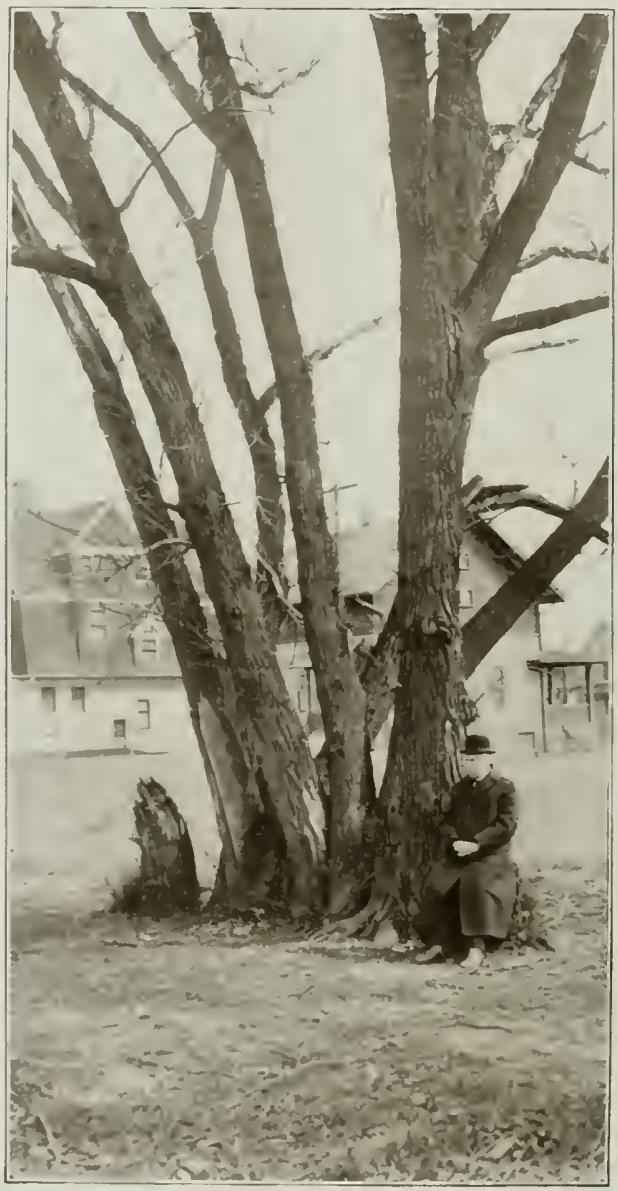

BLACK Willow 


\section{BLACK WILLOW}

(Salix Nigra)

$T$ $\mathrm{HE}$ willows and the cottonwoods belong to the same family of trees, Salicacea, and the family is fairly numerous, and it has some well-defined traits of character. The quinine-bitter of the bark is ever present, but more marked in willows than in cottonwoods. Though quite unpleasant to the taste, it is harmless. The leaves never grow in pairs, and in most instances they fall early in autumn, and some without changing color. Male and female flowers are borne on different trees, and fertilizing is done by insects, often by honey bees and bumblebees. Fruit ripens in late spring, and the seeds are equipped for flight by being provided with exceedingly fine silky hairs. The wind carries them long distances. The trees generally grow in the immediate vicinity of streams or in situations where the soil is damp, but there are exceptions.

The willow family consists of two genera, one the cottonwoods or poplars, the other the willows proper. There are about seventy-five species of willow in America, twenty of them trees. Some, however, are quite small and only occasionally attain sizes which place them in the tree class. The willows are old residents of this continent. They grew in the central portion of what is now the United States in the Cretaceous age, as is proved by their leaf prints in the rocks. They have held their ground ever since, and there is no likelihood that they are about to give it up. Few species are better fitted for holding what they have. A few trees are capable of seeding a large region in a few years, and if soil and situation are suitable, reproduction will be abundant. The willows' tenacity of life is often remarkable. It sonetimes seems next to impossible to kill them by cutting off their tops. There are said to be instances in Europe where willows have been pollarded successively during hundreds of years, the crops of sprouts being used for wickerwork and other purposes. No such records exist in this country, but the willow's sprouting habit is well known. A shoot stuck in the ground will grow, and a fence post will sprout. Many willows develop large stools, or roots, and repeatedly send isp numerous spronts, and it makes little difference how often they are cut, others will come up.

Comparatively few willows that start in life ever become trees. They are suppressed by crowding, or meet misfortunes of one kind or another which keep them small, but occasionally a tree of good size results. Willow trees are usually not old. Probably few reach an age exceeding 150 years. Large trunks, in old age, are apt to be hollow or otherwise defective, though a willow trec will live many years after 
much of its trunk has disappeared. A little green bark on the side, and sprouts from the stump will maintain life long after all usefulness has ceased.

Young willows are usually pliant and tough, old are stiff and brash. They range from sea level up to 10,000 feet or more; grow profusely in the wet lands about the gulf of Mexico, and likewise on the bleak coasts of the Arctic ocean. Commander Peary found willows blooming in considerable profusion on the extreme northern shore of Greenland, where they produce enough growth during the few weeks of summer sunshine to afford the muskox the means of eking out a living during his sojourn in those inhospitable regions.

The identification of willows is one of the most difficult tasks that fall to the botanists. Black willow is unquestionably the most important willow in this country from the lumberman's standpoint. It is the common tree willow that attains size suitable for sawlogs. If a forest grown willow of large size is encountered cast of the Rocky Mountains in the United States, it is pretty safe to class it as black willow. There are some others which grow large, but not many. Planted willows, both large and small, may be foreign species, and white willows, which are not native in this country, but have been widely planted, and are running wild, may be occasionally found of ample size for saw timber.

Black willow's range extends from New Brunswick to Florida, west to the Dakotas, and south to Texas, thence passing into Mexico, New Mexico, Arizona, and California. It attains its best size in the Ohio and Mississippi valleys, though large trees are found in other parts of its range. It is difficult to say what its average size is, for some black willows are only a few feet high and an inch or two in diameter. The largest trees exceed 100 feet in height and three in diameter. An extreme size of seven feet in diameter has been reported. It is not unusual to see willow logs three feet in diameter in mill yards in Louisiana, Mississippi, and Arkansas, and logs four feet in diameter are not so unusual as to excite much comment. The average sizes, however, of willow sawlogs in that region are from eighteen inches to two feet.

The wood of black willow is pale reddish-brown. When freshly cut it is sometimes purple, almost black. When sawed in lumber and exposed to the air the dark color fades. The wood is soft but firm. It has about fifty per cent of the strength of white oak, and forty per cent of its stiffness. It weighs 27.77 pounds per cubic foot; and considering its weiglit, it is tolerably strong and stiff.

Probably 110 other wood in the United States is as systematically cheated out of its just credit as this one. Nany of the oaks arc seldom 
given their proper names, but they are listed as oak in sawmill output, and thus the genus; if not the species is given credit. But willow is almost totally ignored. The United States census in 1910 credited to all the willow lumber in this country an amount less than million and a half feet; yet a single mill in Louisiana, and not a large mill at that, cut and sold four times that much during that year. The wood was cut by hundreds of other mills, some a few logs only, others considerable quantities.

It is sold for various purposes, and much of it goes as cottonwood. In some instances it is called brown cottonwood. Probably ninety per cent is made into boxes, but it has many other uses. It is cut into excelsior, made into rotary cut veneer, and finds place in the manufacture of furniture; it is a common woodenware material; slack coopers make barrels of it; and it is turned for baseball bats.

The supply of black willow in this country is not small. It is usually found in wet situations along streams. Sometimes islands and low flats are taken possession of and pure stands result. The growth is sometimes phenomenal. Trunks may add nearly or quite an inch to their diameter per year when conditions are exceptionally favorable. Instances, apparently well authenticated, are reported of abandoned fields along the Mississippi, which in sixty years grew 100,000 feet of willow per acre.

LONGSTALK WILLOW (Salix longipes) sometimes grows to a height of thirty feet with a diameter of six or eight inches. Its range extends from Maryland to Texas, and is at its best in the Ozark region of southwestern Missouri and northwestern Arkansas.

AlMONDLEAF Willow (Salix amygdaloides) grows across northern United States and southern Canada from New York to Oregon, and occurs as far south as $\mathrm{M}$ issouri and Ohio, and is abundant in the lower Ohio valley. At its best it is seventy feet high and two feet in diameter. The wood is light, soft, and the heartwood is brown.

SMoothleaf Willow (Salix lavigata) attains a diameter of one foot and a height of forty or fifty. It is a Pacific coast tree, ocenrring in California on the western slopes of the Sierra Nevadas up to an altitude of 3,000 feet. It is known as black willow. The wood is pale reddish-brown.

SilverLEAF WiLLOW (Salix sessilifolia) looks like longleaf willow, and though usually a shrub it sometimes is twenty-five feet high and ten inches in diameter. I1 grows from the mouth of the Columbia river to southern California.

YEWLEAF WiLLow (Salix taxifolia) ranges from western Texas, through southern Arizona into Mexico and Central America. Trees are occasionally forty feet high and more than one foot in diameter. A little fuel and fence posts are cut from this willow.

BEBB WiLLow (Salix bebbiana) is nearly always shrubby, but occasionally reaches a trunk diameter of six or cight inches and a height of twenty feet. Its northern limit lies within the Arctic circle, its southern in Pennsylvania, Nebraska, and Arizona. West of Hudson bay it forms almost impenetrable thickets, and in Colorado it ascends mountains to elevations of 10,000 fcet. 
Glatcots W'tLLOW (Solix discolor), commonly known as silver or pussy willow. ranges from Nova Scotia to Manitoba, and southward to Delaware, West Virginia Indiana, Illinois, and Missouri. It is one of the best known willows within its range on account of its flowers which are among the earliest of the season, and very showy The largest specimens are scarcely twenty-five feet high and twelve inches in diameter.

MACKEXZ1E WiLlow (Salix cordato mackenzicana) is not abundant, and is on $\epsilon$ of the smallest of the tree willows. It is nearly alway's a shrub. Its range extends from California nearly to the Arctic circle, where it occurs in gravelly soil on the borders of mountain streams.

MIssotR1 WiLLow (Salix missouriensis) is so named because it occurs principally in Missouri, but its range extends into Kansas and Iowa. It is occasionally forty feet high and a foot in diameter. . It is used for fence posts.

BrgeLow WiLLow (Salix lasiolepis) is generally called white willow on account of its gray bark. It occurs in California and Arizona, and at its best it is twenty-five feet bigh and ten inches in diameter. Some use is made of it as fuel, where other wood is scarce.

Nittalc Willow (Salix nuttallii), called also mountain willow in Montana, ranges from British America, east of the Kocky Mountains, to southern California. Its usual height is twenty or twenty-five feet, and its diameter six or eight inches. In southern California it grows 10,000 feet above sea level.

HOOKER WILLOW' (Salix hookeriana) occurs in the coast region from Vancouver island to southern Oregon, and varies in height from a sprawling shrub to a height of thirty feet and a diameter of one. Little use is made of it.

StLKX: WrLLow (Sulix silchensis), known also as Sitka willow, ranges from Alaska to southern California. The largest specimens are twenty-five feet high and ten inches in diameter. Trunks are largely sapwood and are of little commercial importance.

BROADLEAF IILLOW (Salix amplifolio), known also as feltleaf willow, was discovered in Alaska in 1S99. The leaves are woolly. The largest trees rarely exceed a beight of thirty feet and a diameter of six inches. Its range extends to the valky of the Mackenzie river.

A number of foreign willows have become naturalized in the United States. Among them is white willow (Salix alba), which grows to large size, probably as large as black willow; crack willow (Salix fragilis), so named on account of the brittleness of its twigs; and weeping willow (Salix babylonica). The botanical name is based on the supposition that it was this willow, growing by the rivers near Babylon, on which the captive Hebrews hung their harps. Basket willow is planted for its osiers in several eastern states. It is not a single species, but a group of varieties devcloped by cultivation.

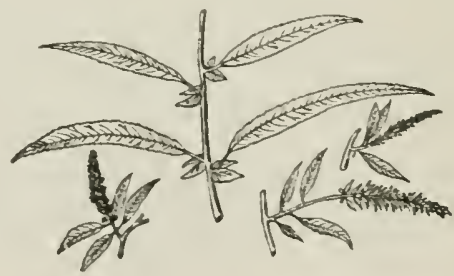


HARDY CATALPA 


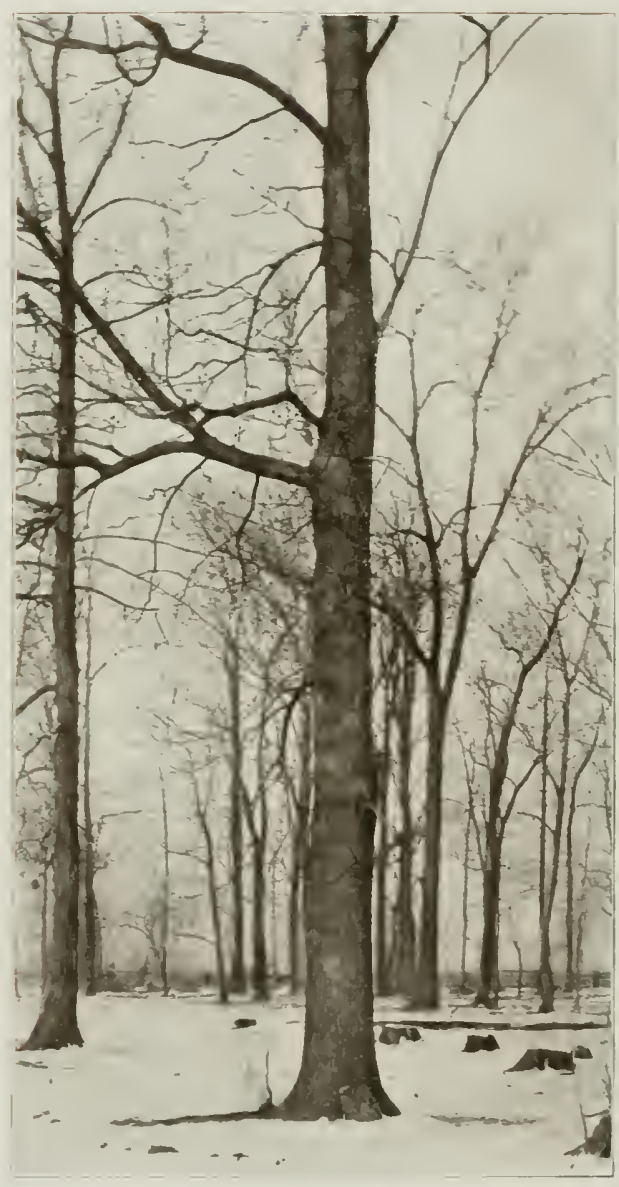

Hardy Catalia 


\section{HARDY CATALPA}

\section{(Catalpa Speciosa)}

T HIS tree belongs to the family Bignoniacee which has its name from Abbe Bignon, librarian of Louis XV. About one hundred genera belong to this family, only three of which reach the size of trees in the United States. These include the catalpas, the desert willow, and the black calabash tree.

Seven species of catalpa are known, two of them occurring in the United States. Others are found in China and the West Indies. The name is an Indian word and was first heard among the tribes of the Carolinas. It seems probable that the name catalpa as applied to a tree and catawba, applied to a grape, have the same origin, and in some way refer to the Catawba Indians, a small tribe-said to be Sioux-that lived two hundred years ago in the western part of the Carolinas and neighboring regions where one of the catalpa species was first heard of by Europeans. The tree in that region is still of ten called catawba.

The two catalpas of this country are known to botanists as Catalpa speciosa and Catalpa catalpa. Much confusion has resulted from attempts to distinguish one from the other. Botanists are able to clear the matter up among themselves, but the general public has not been so successful. John P. Brown, of Connersville, Indiana, specialized on catalpas during many years, and published numerous tracts, pamphlets, and books for the purpose of educating the public to the point where the differences between common catalpa and hardy catalpa could be distinguished. His labor was likewise directed toward inducing land owners to plant catalpa for commercial purposes. Due to his efforts, and otherwise, catalpa was for a time the most advertised plantation tree in this country. Some supposed that hardy catalpa was the wood which was to save the country from a threatened timber famine. Claims made for it were wide and far reaching.

The judgment of history has been-if it may be classed as a matter of history-that the tree fell short of expectation. This does not imply an inferiority of the wood itself, or a slower rate of growth than was claimed for it; but exceptional cases were interpreted as averages, and for that reason the whole situation was overestimated. When all conditions are perfect, hardy catalpa grows rapidly and grows large, but it demands nearly perfect conditions or it will disappoint. It wants ground rich enough and damp enough to grow good crops of corn, and farmers are not generally willing to put that class of land to growing fence posts and railroad ties. 
The range of hardy catalpa before the species was spread by artificial planting, was through southern Illinois and Indiana, southeastern Missouri and northeastern Arkansas, western Louisiana and eastern Texas, and western Kentucky and Tennessee. Its position on the fertile banks of streams, and on flood plains subject to frequent inundation, indicates that the spread of the species was effected by running water. In that case, the dispersal of seeds would be down stream, implying that the starting place of the species was along the lower reaches of the Wabash river.

The catalpa may reach a height of 100 or 120 feet and a diameter of four feet; but few trees attain that size. The leaves are ten or twelve inches long and seven or eight wide, and are considerably larger than those of common catalpa. The flowers appear late in May or early in June, and are showy. The prevailing colors are white and purple, and the blossoms are about two inches long and two and a haif wide.

The fruit is a pod from eight to twenty inches long, and the enclosed seeds are nearly an inch long, shaped like beans. The trees are prolific bearers.

The tree is known by several names in different parts of its range, including the territory where it is known only from plantings. It is called western catalpa to distinguish it from the other species found farther east and south. In Missouri and Iowa it is known as cigar tree. The name Indian bean is an allusion to the large seeds. Shawneewood is another name referring to the supposed interest of Indians in the tree. Shawnee was the name of a tribe of Indians in the Ohio valley in early times.

The wood weighs less than twenty-six pounds per cubic foot, and is soft and weak. It is rated very durable in contact with the soil, and this is one of the chief advantages claimed for it. The annual rings are clearly marked by several bands or rows of large open ducts, and the denser summerwood forms a narrow band. The medullary rays are numerous and obscure. The heartwood is brown, the sapwood lighter. In appearance, the heartwood suggests butternut, but it is coarser, and lacks the gloss shown by polished butternut. Quarter-sawing produces no figure, but when sawed at right angles to the radial lines, the annual rings are cut in a way to give figure resembling that of ash or chestnut.

The wood of this catalpa has been thoroughly tried out for a number of purposes. Furniture and finish have been made of it with varying success, and molding and picture frames are listed among its uses. It is not a sawlog tree. Statistics of lumber cut seldom mention it, though now and then a log finds its way to a mill. Efforts have been made to pass the wood as mahogany, but with poor success. The 
counterfeit is easily detected, since the artificial color which may be imparted to catalpa is about the only resemblance to mahogany.

In the lower Mississippi valiey some success, but on a very small scale, has resulted from attempts to induce catalpa to grow in crooks suitable for small boat knees. The young trunk, after being hacked on one side, is bent and induced to grow the crook or knee. Natural crooks have been utilized in the manufacture of knees for small boats in Louisiana.

Probably ninety per cent of all the catalpa ever cut has gone into fence posts. It is habitually crooked. A straight bole is the exception; though in plantations trees are crowded and pruned until they grow fairly straight, and sometimes trunks of forest grown trees of large size are nearly faultless in their symmetry.

It was once believed in some quarters that catalpa would solve the railroad tie problem by growing good ties quickly. It must be admitted, however, that in spite of extensive plantings, the railroad tie problem has not yet been solved by catalpa.

Common Catalpa (Catalpa catalpa) originated many hundred miles outside the range of hardy catalpa, to judge by the localities in which it was first found by white men. It is supposed to have been indigenous in southwestern Georgia, central Alabama, and Mississippi, and northwestern Florida. Its range has been greatly extended by planting, and it grows in most parts of the country east of the Rocky Mountains, as far north as New England. It has been planted in many parts of Europe. Its leaves, flowers, fruit, and the tree itself are smaller than hardy catalpa. The pods hang unopened all winter. The trunks sometimes are three feet in diameter and sixty high, but are generally small, crooked, rather angular, and poor in appearance, but the leaves and flowers are ornamental. The wood is durable in contact with the ground, and its largest use has been for posts, crossties, and poles.

Desert IIILlow (Chilopsis linearis) does not even belong to the willow family, notwithstanding its names, all of which are based on the presumption that it is a willow. The shape and size of its leaves are responsible for that misapprehension. The very narrow leaves may be a foot long. It is called flowering willow and Texas flowering willow. Its flowers are always emphasized when it is compared with willow, for they are totally different from the willow's characteristic catkins. The flowers appear in early summer in racemes three or four inches long, and continue open during several months in succession. The fruit is a pod seven or nine incles long, and as slender as a lead pencil. It is this pod which gives the plainest hint of its relationship to the catalpas, for it is in good standing in the fanily with them. The sceds resemble very 
small beans with wings at each end. They are light, and the wind disperses them. The tree is a prolific seeder.

The range of this small tree extends across western Texas, New Mexico, Arizona, Utah, Nevada, into San Diego county, California. The tree occurs in dry, gravelly, porous soil near the banks of streams and in depressions in the desert. The wood is weak and soft, the heart brown, streaked with yellow. No use has been found for it. The tree is cultivated for ornament in Mexico and sometimes in the southern states. The flowers look well when they are encountered in the desert. They are white, faintly tinged with purple, with bright yellow spots inside. They are funnel shaped and have the odor of violets.

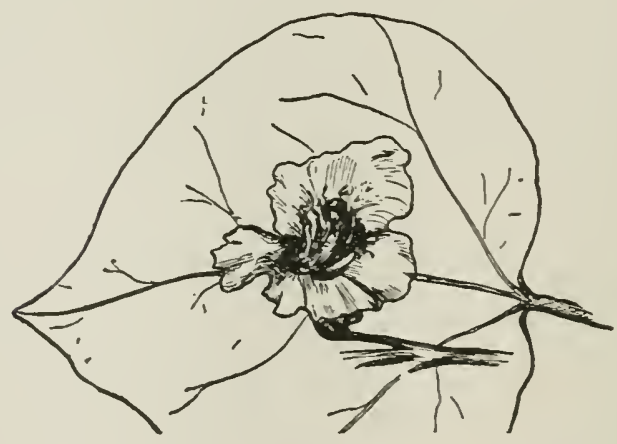


CLCLMBFR 


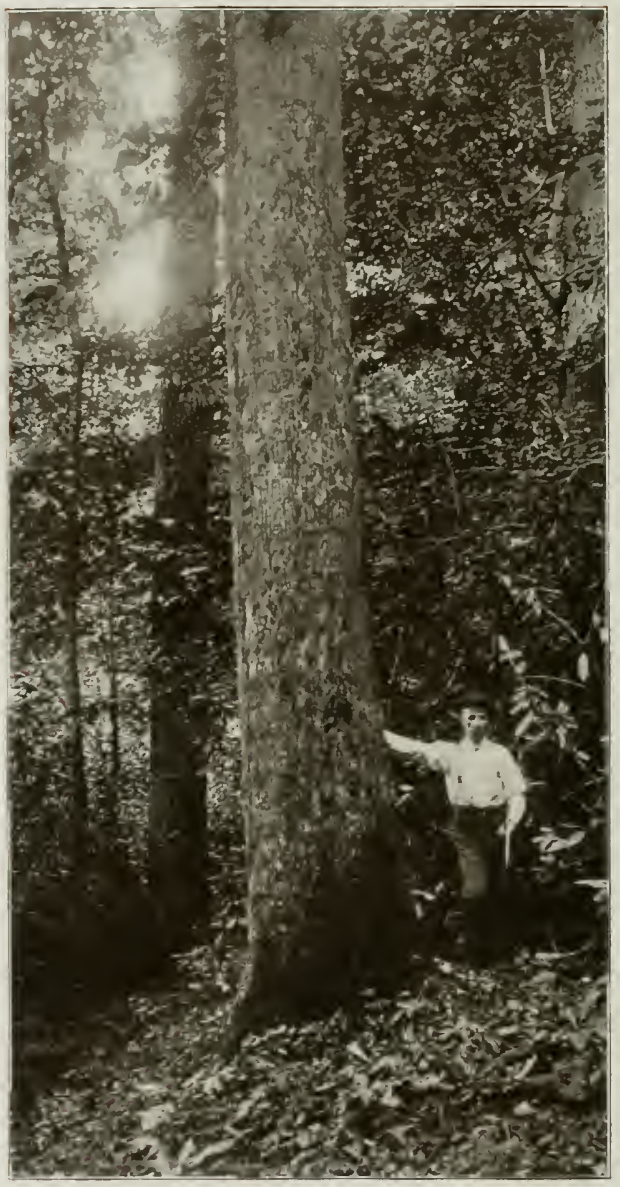

Cecember 


\section{CUCUMBER}

\section{(Magnalia Acuminata)}

7 Hiss tree is a member of the magnolia family which has ten genera in 1 North America, two of them, magnolia and liriodendron, being trees. The family has its name from Pierre Magnol, a French botanist who died in 1715. The genus magnolia has seven species in the Lnited States, all of which are of tree size. They are evergreen magnolia (Magnolia fatida), sweet magnolia (Magnolia glauca), cucumber (Magnolia acuminata), largeleaf umbrella (.Mugnolia macrophylla), umbrella tree (Magnolia tripetala), Fraser umbrella (.Magnolia fraseri), and pyramidal magnolia (Magnolia pramidata). The remaining member of the magnolia family is the yellow poplar (Liriodendron tulipifera). Though of the same family it is of a different genus from the seven other magnolias.

The cueumber is the hardiest member of the magnolia family. It is found in natural growth farther north than any other, yet it has the appearance of a southern tree. All magnolias look like trees belonging in the South. Their large leaves indicate as much, and some of them do not venture far outside of the warm latitudes. It is one of the oldest of all the families of broadleaf trees, and it has been a family that during an immense period of the earth's history has elung near the old homestead where it came into existence countless ages ago. There rere magnolias growing in the middle Appalachian region, and eastward to the present Atlantic eoast, so far in the past that the time can be measured only by hundreds of thousands of years: Leaf prints in rocks, which were onee mud flats, tell the story-though but a page here and there-of the magnolia's ancient history, doubtless antedating by long periods the earliest appearance of man on earth.

Next to the yellow poplar, the encumber tree is the most important species of the magnolia family, at least as a source of lumber. As an ornamental tree it unay not equal some of the others, particularly certain of the southern species which are evergreen and produce large, showy flowers.

The cucumber tree receives its name from its fruit, which looks like a eucumber when seen at a distance, but it is far from being one. Its intense bitter makes it safe from the attacks of birds and beasts. So far as known, it is not eaten, tasted, or tonclied by any living ereatureexcept man. Some of the pioneer settlers, in the days when there was precious little to eat on the fronticrs, discovered a way of extracting the bitter from the wild eucumber, and making some sort of a pickle of the 
remainder; but the art seems to have been lost with the passing of the pioneers of the Daniel Boone type, and the wild cucumber now hangs untouched, and tempts nobody. It is three inches or less in length, generally slightly curved, and is green in color until fully ripe. Even the flowers which produce the fruit are green, with the merest suggestion of yellow. They are so inconspicuous that fer persons ever notice them, even though cucumber trees stand in door yards. The ripe cucumbers are dark red or scarlet, or rather the seeds are, which grow on the surface like grains of corn on a cob, though fewer in number and farther apart. Something seems to be lacking in the machinery by which the flowers are fertilized, with the result that of ten nearly half the seeds which ought to cover the surface of the cucumber, fail to materialize. There are many blank spaces representing flowers which the pollen missed.

There is likewise something missing in the modus operandi of scattering the seeds. They have no wings, and the wind is powerless to carry them. They are as bitter as quinine and no bird, squirrel, or mouse will plant, carry, or touch them. Nature appears to have forgotten to provide any other means for dispersing the seeds of this remarkable tree. When seeds are fully ripe, they drop away from the parent fruit-the cucumber-but the fall of each seed is arrested by a small thread which suspends it from one to three inches below the fruit. There the seeds hang, swinging and dangling in the wind. What part the threads play in the economy of nature is not apparent, unless their purpose is to expose the seeds to a chance of becoming entangled with the wings, feet, or feathers of flying birds, whereby they may be carried a way and dropped in suitable places for growing. There can be no doubt that this happens occasionally, and constitutes one of the methods of seed dispersal. Others are transported by flowing water.

The chances seem to be greatly against the survival of the cucumber tree in competition with maples, birches, pines, and cottonwoods, whose winged seeds are wind-borne; or with oaks, hickories, and walnuts whose heary, wingless nuts are planted hither and thither by accommodating squirrels which are intent only on providing for their own winter wants, but in reality are industrious and effective forest planters. Notwithstanding the disadvantages under which the cucumber tree is placed, it has managed to hold its ground in the forest during immense periods of time, and it seems to be as firmly established now as ever.

The leaves of this tree are from seven to ten inches long, and four to six wide. In autumn before they fall they turn a blotched yellowbrown color. The first severe frost brings them all down in a heap. At sunset the tree may be laden with leaves, and by the next noon all will be on the ground. They are so heavy that the wind does not move 
them far, and they drop in heaps beneath the branches. In color they resemble owl feathers, and the suggestion that comes to one's mind, who happens to pass under a cucumber tree the morning following the first frost, is that during the night some prowler picked a roost of owls and scattered the feathers on the ground.

The range of cucumber extends from western New York to Alabama, following the Appalachian mountains; and westward to Illinois and Mississippi, appearing west of the Mississippi river in Arkansas. It occurs on low rocky slopes, the banks of mountain streams, and on rich bottom land. It is of largest size and is most abundant in the narrow valleys in eastern Tennessee and the western parts of the Carolinas. The tree is from two to four feet in diameter, and sixty to ninety feet high. The trunk is of good form for sawlogs. Among its local names are pointed-leaf magnolia, black lin, magnolia, and mountain magnolia.

The wood of cucumber resembles that of yellow poplar in appearance and in physical properties, except that it is ten per cent heavier than poplar. It usually passes for that wood at sawmill and factory. The Federal census credits it with less than a million feet a year as lumber. That is much too small. It is valuable and finds ready sale. Manufacturers of wooden pumps regard it as the best material for the bored logs. It is worked into interior finish for houses, flooring for cars, interior parts of furniture, woodenware, boxes and crates, slack cooperage, including veneer barrels.

The tree is planted for ornament in the northern states and Europe. The chief value lies in its large, green leaves and symmetrical crown. The red fruit adds to the tree's attractiveness late in summer.

LARGELEAF UMBRELLA (Magnolia macrophlla) is valuable chiefly as a sort of ornamental curiosity, on account of its enormous leaves and flowers. The leaf is from twenty to thirty inches long and ten to twelve wide. It drops in autumn before its green color has undergone much change. The leaves lack toughness, and the wind whips them into strings long before the summer is ended. Thus what otherwise would be highly ornamental hecomes somewhat unsightly. When well protected from wind by surrounding objects, the leaves fare better and last longer. The white, fragrant flowers are likewise remarkable on account of size. They are cup-shaped and some of them are almost a foot across. They pay a penalty no less severe than the leaves pay, on account of large size, and are liable to be thumped and bruised by swinging leaves and branches.

The largeleaf umbrella is a tree of the southern Appalachian mountains although its range extends southwest to Louisiana, and northward from there to Arkansas. It is at its best in decp rich soil of sheltered valleys, occurring in isolated groups, but never in pure forests. It is known as large-leaved cucumber trec, greatleaved magnolia, large-leaved unbrclla trce, and long-lcaved magnolia. The fruit is nearly a sphere, from two to three inches in diameter, and bright rose color when fully ripe. The seeds are two-thirds of an inch long. The smooth, light gray bark is usually less than a quarter of an inch thick. Large trecs are forty or fifty feet high 
and twenty inches in diameter. It is not considered valuable for umber, because of scarcity and small size. The wood is considerably heavier than yellow poplar, and is hard but not strong; light brown in color with thick, light yellow sapwood. Reports do not show that the wood is put to any use. Planted trees are hardy as far north as Massachusetts, and success has attended the tree's introduction in the parks and gardens of southern Europe.

YelLOW Flowered CUCUMBER TREE (Magnolia acuminata cordata) is usually considered a variety of the common cucumber tree, rather than a separate species. The most noticeable feature is the yellow blossom which gives the names by which it is generally known, among such being yellow-flowered magnolia, and yellow cucumber tree. It is not a garden variety, for it grows wild; but it has been cultivated during more than a century, and has undergone changes which are not matched by wild trees. The finest forms of the forest variety are found on the Blue Ridge in South Carolina, and in centra! Alabama. The cultivated tree is distinguished by its darker green leaves, and by its smaller, bright, canary-yellow flowers. The variety has no value as a timber tree, but is widely appreciated as an ornament. Cultivated trees generally remain small in size, and do not develop the long, clean trunks common with the cucumber tree under forest conditions.

UMBRELLA TREE (Magnolia tripetala) is one of the magnolias and should not be confounded with the Asiatic umbrella tree often planted in yards. The flower is surrounded by a whorl of leaves resembling an umbrella, hence the name. It is also known as cucumber, magnolia, and elkwood. The range of the tree extends from Pennsylvania to Alabama and west to Arkansas. It prefers the margins of swamps and the rich soil along mountain streams. Leaves are eighteen inches long and half as wide. They fall in autumn. Flowers are cup-shaped and creasny-white. The fruit somewhat resembles that of the common cucumber tree, but is rose colored when fully ripe. Trees are thirty or forty feet high and a foot or more in diameter. The brown heartwood is light, soft, and weak, and is used little or not at all for commercial purposes. The tree is cultivated for ornament in the northern states and in Europe.

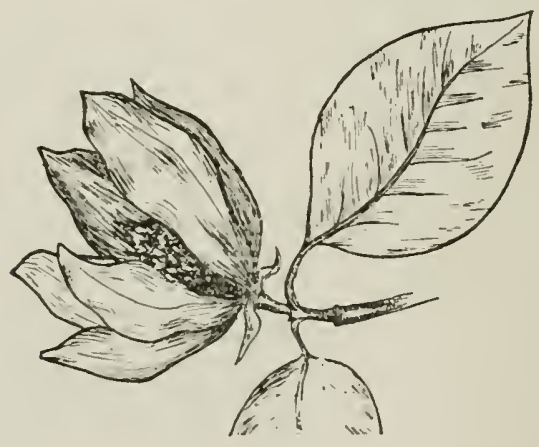


YELLOW POPLAR 


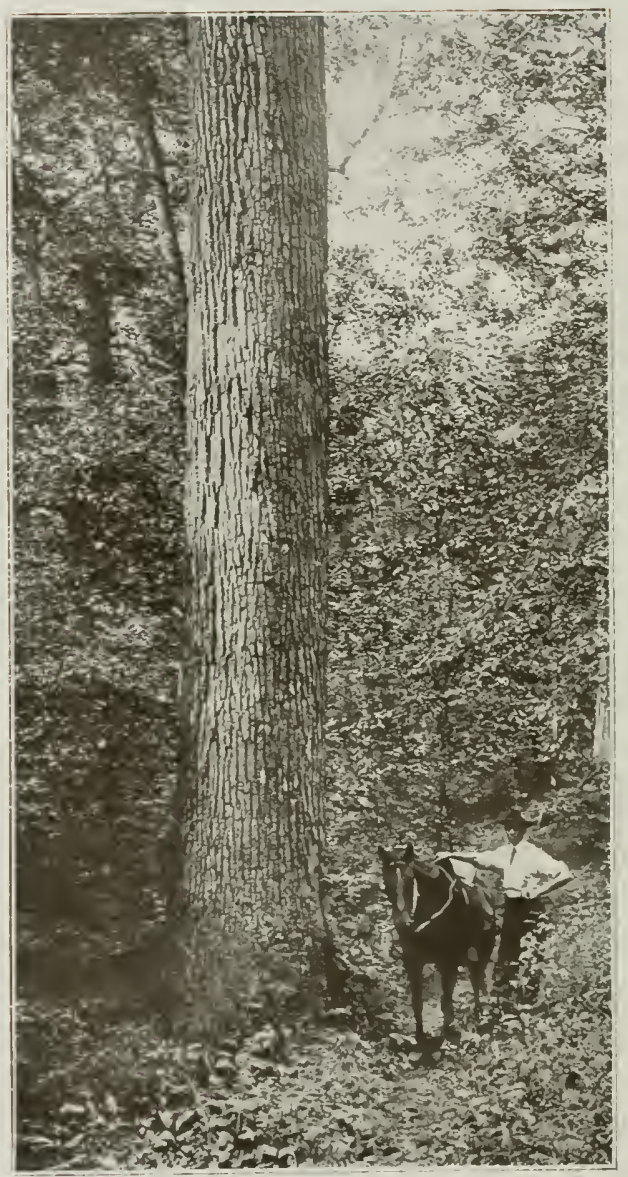

YELLOW POPLAR, 


\section{YELLOW POPLAR}

\section{(Liriodendron Tulipifera)}

$I^{\top}$ diameter of trunk the yellow poplar is, next to sycamore, the largest hardwood tree of the United States, and if both height and trunk diameter are considered, it surpasses the sycamore in size. It belongs to a very old group of hardwoods which have come down from remote geological ages, and the species is now found only in the United States and China. Mature trees are from three to eight feet in diameter and from 90 to 180 in height.

It has many names in different parts of its range, but it is never mistaken for any other tree. The peculiar notched leaf is a sure means of identification. The resemblance of the flower to the tulip has given it the name tulip tree in some localities, and botanists prefer that name. It is so called in Vermont, Massachusetts, Rhode Island, Connecticut, New York, New Jersey, Delaware, Pennsylvania, Virginia, IVest Virginia, District of Columbia, North Carolina, South Carolina, Georgia, Arkansas, Kentucky, Ohio, Indiana, Illinois, and Ontario. Wood users in New England and in some of the other northern states prefer the name whitewood and it is so known, in part at least, in New England, New York, New Jersey, Delaware, South Carolina, Kentucky, Ohio, Michigan, and Illinois. Yellow poplar is the name preferred by lumbermen in nearly all regions where the tree is found in commercial quantities, notably in New York, Pennsylvania, New Jersey, Delaware, Virginia, West Virginia, North and South Carolina, Alabama, Arkansas, Kentucky, Ohio, Indiana, Illinois, Missouri, and Tennessee. The name is often shortened to poplar, which is used in Rhode Island, Delaware, North and South Carolina, Florida, Virginia, IVest Virginia, Ohio, and Indiana. The name tulip poplar is less frequently heard, and blue poplar and hickory poplar are terms used in ITest Virginia, Virginia, and North Carolina, but generally under the inpression that they refer to a different form or species. In Rhode Island it is called popple, in New York cucumber tree, and canoewood in Tennessee and in the upper Ohio valley.

The botanical range of yellow poplar is wider than its commercial range; that is, a few trees are found in regions surrounding the borders of the district where the tree is profitably lumbered. The boundaries of its range run from southwestern Vermont, westward to Lake Michigan near Grand Haven, southward to northern Florida, and west of the Mississippi river in Missouri and Arkansas. The productive yellow poplar timber belt has never been that large but has clung pretty closely 
to the southern Appalachian mountain ranges and to certain districts lying both east and west of them. The best original stands were in Pennsylvania, Maryland, Virginia, West Virginia, western North Carolina, eastern Kentucky and Tennessee, and in some parts of Ohio and Indiana. However, considerable quantities of good yellow poplar have been cut in other regions.

The physical properties of the wood of yellow poplar fit it for many purposes but not for all. It is not very strong and is tolerably brittle. It is light in weight, medium soft, and is easily worked. The annual rings of growth are not prominent compared with some of the oaks, yet select logs show nicely in quarter-sawing. The medullary rays are numerous, but small and not prominent, for which reason bright streaks and flecks are not characteristic of the wood. Yellow poplar is fairly stiff and elastic, but is not of ten selected on account of those qualities. In color it is light yellow or brown. The color gives name to the tree. The sapwood is whiter, and it is the abnormally thick sapwood of some trees which causes them to be called white poplar. The wood has little figure, and it is seldom employed for fine work without stain or paint of some kind. It is not usually classed as long lasting when exposed to the weather, yet cases are known where weather boarding of houses, and bridge and mill timbers of yellow poplar have outlasted the generation of builders.

The quantity of yellow poplar in the country is but a remnant of the former enormous supply that covered the rich valleys and fertile coves in a region exceeding 200,000 square miles. It occupied the best land, and much was destroyed by farmers in clearing fields. It was not generally found in groves or dense stands, but as solitary trees scattered through forests of other woods. The trunks are tall and shapely, the crowns comparatively small. The form is ideal for sawlogs, and very few trees of America produce a higher percentage of clear, first class lumber. That is because the forest-grown poplar early sheds its lower branches, and the trunks lay on nothing but clear wood. In the yellow poplar's region it was the principal wood of which the pioneers made their canoes for crossing and navigating rivers. It is still best known by the name canoewood in some regions. It worked easily and was light, and a thin-shelled canoe lasted many years, barring floods and other accidents. Builders of pirogues, keelboats, barges, and other vessels for inland navigation in early times when roads were few and streams were the principal highways of commerce, found no timber superior to yellow poplar. It could be had in planks of great size and free from defects, and while not as strong as oak, it was strong enough to withstand the usual knocks and buffetings of river traffic. 
Yellow poplar sawlogs have probably exceeded in number any other wood, except white pine, floated down rivers and creeks to market. The wood floats well and lumbermen have usually pushed far up the rivers, ahead of other lumber operations, to procure it. Enormous drives have gone and are still going out of rivers in the Appalachian region.

The uses of yellow poplar are so many that an enumeration is impracticable, except by general classes. These are boxes and woodenware, vehicles, furniture, interior finish, and car building. There is another class consisting of low-grade work, such as common lumber, pulpwood, and the like.

There is a class of commodities which are usually packed in boxes and require a wood that will impart neither taste nor stain. That requirement is met by yellow poplar. It has been an important wood for boxes in which food products are shipped. It is so used less frequently now than formerly because of increased cost, but veneer is employed to a large extent, and while the total quantity of wood going into box factories is smaller than formerly, the actual number and contents of poplar boxes are perhaps about the same. It is a white wood and shows printing and stenciling clearly. That is an important point with many manufacturers who wish to print their advertisements on the boxes which they send out. Woodenware, particularly ironing boards, bread boards, and pantry and kitchen utensils, are largely made of poplar because it is light, attractive, and easily kept clean. It is popular as pumplogs for the same reason.

As a vehicle wood, yellow poplar is not a competitor of oak and hickory. They are for running gear and frames; poplar for tops and bodies. No wood excels it for wide panels. It receives finish and paint so well that it is not surpassed by the smoothest metals. Many of the finest carriage and automobile tops are largely of this wood. In case of slight accidents it resists dints much better than sheet metal.

Cheap furniture was once made of yellow poplar. It now enters into the best kinds, and is finished in imitation of costly woods, notably mahogany, birch, and cherry. No American wood will take a higher polish. It is also much employed as an interior wood by furniture manufacturers. It fills an important place as cores or backing over which veneers are glued.

When used as an interior house fuish and in car building, it is nearly always stained or painted. Many of the broad handsone pancls in passenger cars, whicl! pass for clerry, birch, mahogany, or rosewood, are yellow poplar, to which the finisher and decorator liave given their best touches. 
All poplar lumber is not wide, clear stock, though much of it is. The lower grades go as common lumber and small trees are cut for pulpwood. A large part of the demand for high-grade yellow poplar is in foreign countries, and a regular oversea trade is carried on by exporters. Foreign manufacturers put the wood to practically the same uses as the best grades in this country.

Yellow poplar seasons well, and is a satisfactory wood to handle. When thoroughiy dry it holds its shape with the best of woods. Bluing is apt to affect the green wood if unduly exposed. Fresh poplar chips in damp situations sometimes change to a conspicuous blue color within a day or two. However, millmen do not experience much difficulty in preventing the bluing of the lumber.

Gruind (Gyminda grisebachii) is also called false boxwood, and belongs to the staff family. The name gyminda is artificial and meaningless. The genus has a single species which occurs in the islands of southern Florida where trees of largest size are scarcely twenty-five feet high and six inches in diameter. The wood is very heavy, hard, finegrained, and is nearly black. It is suitable for small articles, but it is not known to be so used, and its scarcity renders improbable any important future use of the wood. The fruit is a small berry, ripening in November. The range of the species extends to Cuba, Porto Rico, and other islands of the West Indies.

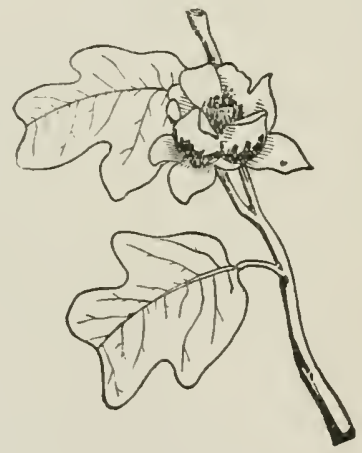


EVERGREEN IIAGNOLIA 


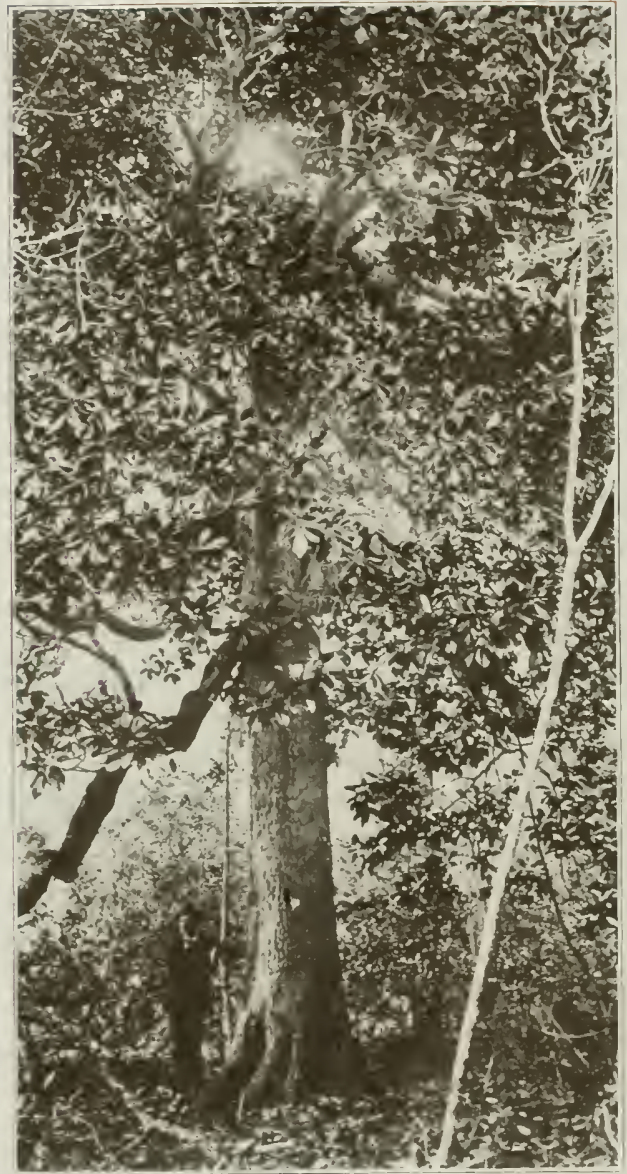

FVERGREEX MAGNOLIA 


\title{
EVERGREEN MAGNOLIA
}

\author{
(Magnolia Fotida)
}

THIS is not a timber tree of first importance. A few years ago it 1 was seldom cut except in very small quantities; but it was found to possess good qualities, and now it goes regularly to the mills which saw hardwoods in the region where it grows. The wood of different magnolia trees, or even the wood of the same tree, shows lack of uniformity. Some of it looks like yellow poplar and compares favorably with it in several particulars, while other of it is very dark, with hard flinty streaks which not only present a poor appearance, but dull the tools of the woodworking machines and create an unfavorable impression of the wood generally. This magnolia holds pretty closely to the damp lands in all parts of its range. The amount of the annual cut is not known, because it goes in with the minor species in most places and no separate account is taken. It is coming into more notice every year, and some manufacturers have been so successful in finding ways to make it serviceable that the best grades are easily sold. The wood does not hold its color very well. The light-colored sapwood is apt to become darker after exposure to the air, and the dark heartwood fades a little. The tree is so handsome in the forest that it is occasionally spared when the surrounding trees are removed.

It is doubtful if any American tree surpasses it as an ornament when its leaves, trunk, flowers, and bark are considered. It is not perfect in all of these particulars; in fact, it possesses some serious faults. The crown is often too small for the tree's heiglit; the branches straggle, many on some parts of the trunk and few on others; the flowers are objectionable because of strong odor which is unpleasant to most people. But these shortcomings are more that: compensated for by splendid qualities. The rich, dark green of the leaves, their size and profusion, their changeless luster, place them in a position almost beyond the reach of rivalry from any other tree.

Those who see this splendid inhabitant of the forest only where it has been planted in northern states, and elsewhere outside of its natural range, miss much of the best it has to give. It belongs in the Soutl. The wet lands, the small elevations in deep swanps, the flat country where forests are dense, are its home. The yellowish-green trunk rises through the tangled foliage that keeps near the ground, and towers fifty feet above, and there spreads in a crown of green so deep that it is almost black. It likes company, and seldom grows solitary. Its associates are the southern maples, red gum, tupelo, cypress, a dozen species of oak, 
and occasionally pines on nearby higher ground. Festoons of grayishgreen Spanish moss often add to the tropical character of the scene. The moss seldom hangs on the magnolia, but is frequently abundant on surrounding trees.

Lumbermen formerly left the evergreen magnolia trees on tracts from which they cut nearly everything else. Large areas which had once been regarded as swamps were thus converted into parks of giant magnolias, many of which towered seventy or eighty feet. The tracts were left wild, and those who so left them had no purpose of providing ornament, but they did so. Many a scene was made grand by its magnolias, after other forest growth had been cut away.

The range of evergreen magnolia is from North Carolina to Florida and west to Arkansas and Texas. The species reaches largest size in the vicinity of the Mississippi, both east and west of it. Trees eighty feet high and four feet in diameter occur, and trunks are often without limbs one-half or two-thirds their length, when they grow in forests.

The common name for the tree in most parts of its range is simply magnolia, though that name fails to distinguish it from several other species, some of which are associated with it. Occasionally it is called big laurel, great laurel magnolia, laurel-leaved magnolia, laurel, and laurel bay. Bull bay is a common name for it in Georgia, Alabama, and Mississippi. It is called bat tree, but the reason for such a name is not known.

Leaves are from five to eight inches long and two or three wide, and dark green above, but lighter below. They fall in the spring after remaining on the branches two whole years.

The odor of the flowers is unpleasant, but they are attractive to the sight, being six or eight inches across, with purple bases. The flowering habit of this tree is all that could be desired. It is in bloom from April till August.

The fruit resembles that of the other magnolias and is three or four inches long and two or less wide. Its color is rusty-brown. The ripe seeds hang awhile by short threads, according to the habit of the family. The wood is stronger than poplar, fully as stiff, and nearly fifty per cent heavier. The annual rings are rather vaguely marked by narrow bands of summerwood. Pores are diffuse, plentiful, and very small. Medullary rays are larger than those of yellow poplar, aud show fairly well in quarter-sawed stock. The wood is compact and easily worked, except when hard streaks are encountered. The surface finishes with a satiny luster; color creamy-white, yellowish-white, or of ten light brown. Occasionally the wood is nearly diametrically the opposite of this, and is of all darker shades up to purple, black, and blue black. The appearance of 
the dark wood suggests decay, but those who pass it through machines, or work it by hand, consider it as sound as the lighter colored wood.

The uses of magnolia are much the same in all parts of its range, and those of Louisiana, where the utilization of the wood has been studied more closely than in other regions, indicate the scope of its usefulness. It is there made into parts of boats, bar fixtures, boxes, broom handles, brush backs, crates, door panels, dugout canoes, excelsior, furniture shelving, interior finish, ox yokes, panels, and wagon boxes. In Texas where the annual consumption probably exceeds a million feet, it is employed by furniture makers, and appears in window blinds, packing boxes, sash, and molding. In Mississippi, fine mantels are made of carefully selected wood, quarter-sawed to bring out the small, square "mirrors" produced by radial cutting of the medullary rays.

Evergreen magnolia has long been planted for ornament in this country and Europe. It survives the winters at Philadelphia. Several varieties have been developed by cultivation and are sold by nurseries.

Southern forests have contributed, and still contribute, large quantities of magnolia leaves for decorations in northern cities during winter. The flowers are not successfully shipped because they are easily bruised, and they quickly lose their freshness and beauty.

Sweer Magnolia (Magnolia glauca) ranges from Massachusetts to Texas and south to Florida. It reaches its largest size on the hummock lands of the latter state. Trees are occasionally seventy feet high and three or more in diameter, but in many parts of its range it is small, even shrubby. Among the names by which it is known are white bay, swamp laurel, swamp sassafras, swamp magnolia, white laurel, and beaver-tree. It inhabits swamps in the northern part of its range, hence the frequency of the word "swamp" in coining names for it. Beaver-tree as a name is probably due to its former abundance about beaver dams, where impounded water made the ground swampy. In the North, sweet magnolia's chief value is in its flowers, which are two or three inches across, creamy-white, and fragrant. They were formerly very abundant near the mouth of the Susquehanna river in Maryland and Pennsylvania, and northward through New Jersey; but the traffic in the flowcrs has destroyed the growth in many places where once plentiful. It is not important as a timber resource, but it is employed for a number of useful purposes where logs of fair size may be had. The sapwood is creamy-white, but the heart is nearly as dark as mahogany, and in Texas it is used to imitate that wood. The brown and other shades combine with fine effect. One of its common uses is for broom handles. Heartwood is worked into high-grade chairs. It takes a beautiful polish.

Fraser Umbrella (Magnolia fraseri) ranges south from the Virginia mountains to Florida and west to Mississippi. It is of largest size in South Carolina where trees are sometimes thirty feet high and a foot or more in diameter. The leaves fall in autumn of the first year; the creamy-white, sweetly-scented flowers are eight or ten inches in diameter, and the fruit resembles that of the other magnolias. The wood is weak, soft, and light. The heart is clear brown, the sapwood nearly white. It has not been reported in use for any commercial purpose. Among its other names 
it is known as long-leaved cucumber tree, ear-leaved umbrella tree, Indian bitters, water lily tree, and mountain magnolia. In cultivation this species is hardy as far north as Massachusetts, and it is planted for ornament in Europe.

PyRAMTD MAgNolia (Magnolia pyramidata) seems to have generally escaped the notice of laymen, and it therefore has no English name except the translation of the Latin term by which botanists know it. Its habitat lies in southern Georgia and Alabama, and western Florida, and it is occasionally seen in cultivation in western Europe. It is a slender tree, twenty feet or more in height. Its flowers are three or four inches in diameter, and creamy-white in color. A tree so scarce cannot be expected to be commercially important.

WESTERN BLACK WiLLOW (Salix lasiandra) is a rather large tree when at its best, reaching a diameter of two feet or more, and a height of fifty, but in other parts of its range it rarely exceeds ten feet in height. It follows the western mountain ranges southward from British Columbia into California. The wood is soft, light, and brittle, and is used little if at all. Lyall willow (Salix lasiandra lyalli) is a well marked variety of this species and is a tree of respectable size.

GLossyleaf Willow (Salix lucida) is a far northern species which has its southern limit in Pennsylvania and Nebraska. It grows nearly to the Arctic circle. Trees twenty-five feet high and six or eight inches in diameter are the best this species affords.

LONGLEAF WrLLow (Salix fluviatilis) is known also as sandbar willow, narrowleaf willow, shrub, white, red, and osier willow, and by still other names. It ranges from the Arctic circle to Mexico, reaching Maryland on the Atlantic coast, and California on the Pacific. In rare cases it is sixty feet high, and two in diameter, but it is usually less than twenty feet high.

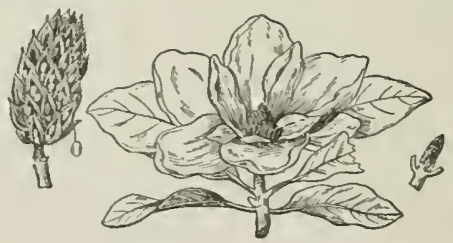


IVAHOO 


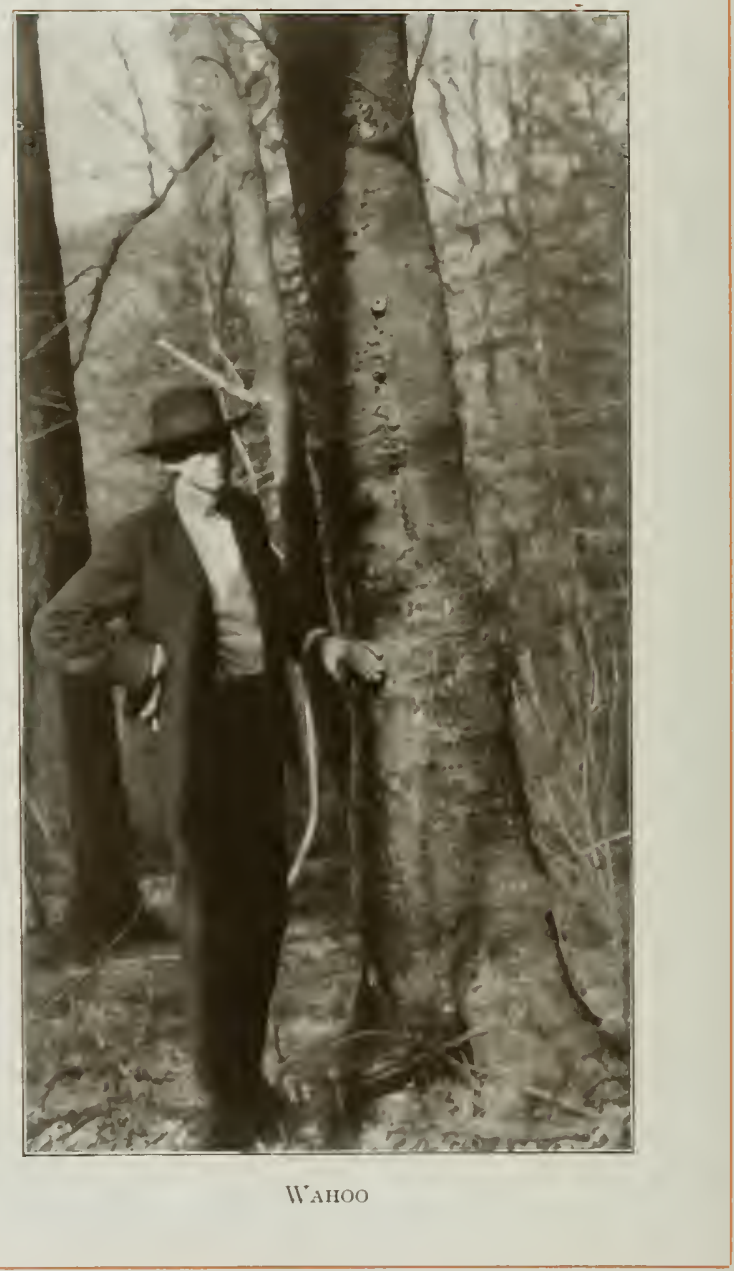




\section{WAHOO}

\section{(Evonymus Atropurpurcus)}

TO one seems to know what the original meaning of the word wahoo was. It is applied to no fewer than six different trees in this country, four of them elms, one a basswood, and one the tree now under consideration. The generic name, Evonymus, appears to be an effort to put somebody's seal of approval on the name, for it means in the Greek language "of good name."

It belongs to the family Celastracea, which means the staff family. Some designate members of this group as "Spindle trees," because formerly in Europe the wood was employed for knitting needles, hooks for embroidering, spindles for spinning wheels, and the like. Unless the members of the family in Europe have wood quite different from that of the wahoo tree in this country, no adequate reason can be found for the use of the wood for spindles or staffs, beeause it is poor material for that purpose. It may be compared with basswood.

This beautif ul little tree, scarcely nnore than a shrub in most regions of its growth, is a widely distributed species, its range extending through western New York to Nebraska, southeastern Sonth Dakota and eastern Kansas, and in the valley of the upper Missouri river, Montana, southward to northern Florida, southern Arkansas and Oklahoma. In these localities it is generally a shrub, rarely reaching a height of more than nine or ten feet. It attains the proportions of a tree only in the bottom lands of southern Arkansas, Oklahoma, and in the lower Appalachian regions. The most favorable habitat of the tree is moist soil along the banks of streams. In the southern and western parts of its range, under favorable conditions of soil and climate, and when isolated from other species, the wahoo tree grows to rather large size and develops a wide flat top of slender spreading branches.

The largest and most beautiful specimens of wahoo grow in the mountainous regions of IVest Virginia, eastern Tennessee, and western North Carolina. In these sections it is no unusual thing for a tree of this species to attain a height of sixty or seventy feet and a diameter of twenty or twenty-four inches. It is never found in pure stands but is isolated along the edge of the forest, and thrives best near water conrses.

The tree is known by a variety of names in the different parts of the country. The Indians are said to have called it wahoo. Burning bush, a very popular name, is especially appropriate, as no brighter dasli of color is displayed by any tree than the scarlet fruit of this growth, which remains on the branches long after the leaves have fallen, often until the 
winter storms beat it to the ground. The growth is also called occasionally by the name bleeding-heart tree, in reference to the blood-red contents revealed by the bursting fruit.

The wahoo in the fall of the year may be identified by the flaming color of its fruit, or rather the seeds of the fruit. The hull bursts and exposes the bright red seeds within. These, contrary to the usual run of red fruits, are not of a glossy surface, and in this the tree is unique. During the summer season, however, identification is not such a simple matter, for the foliage is quite ordinary, and the flat, unassuming flowers have little that is distinctive about them; but as the antumn approaches and the leaves turn a pale yellow color, the tree becomes a conspicuous and beantiful object with its scarlet berries.

The bark of the wahoo is ashen gray, thin, furrowed, and divided into minute scales. On the branchlets it is a dark purplish-brown, later becoming brownish-gray.

The heartwood of wahoo is white, with a slight tinge of orange. The sapwood, scarcely distinguishable from the heartwood, is more nearly white in tone. The wood is heavy and close-grained but not very hard. It weighs when seasoned a little less than forty pounds to the cubic foot. Such of this wood as is sawed into lumber, which is but a small quantity, sells commercially with poplar saps, thus masquerading like its forest fellow, the cucumber tree. The character of the wood is such that it will not stand exposure to the weather any length of time. It is far from durable, but is remarkably clear from defects and answers admirably many purposes for which sap poplar is desirable.

The leaves of the tree are waxy in appearance, opposite, entire, elliptical or ovate in shape, from two to four inches long, one to two broad. They are finely serrate and pointed at both apex and base, and the stems are short and stout.

The flowers, which appear in May and June, are definitely fourparted, presenting a Maltese cross in shape. They are half an inch across, and their rounded petals are deep purple in color. The fruit which succeeds these flowers and which ripens in October is also fotirparted. It is about half an inch across, a pale purple when full size, and hangs on long slender stems. When ripe the purple husk bursts and reveals the seed enveloped in a scarlet outer coat that fits it loosely. The leaves, bark, and fruit of the wahoo are acrid and are reputed to be poisonons.

The wood is one-third heavier than that of yellow poplar, and it is evident that it would not pass as poplar with any one disposed to reject it. It is also much harder than poplar, and is more difficult to season, as it checks badly. The medullary rays are so thin as to be scarcely dis- 
cernible. The wood contains many very small pores. The bark is said to possess some value for medicinal purposes. No special uses for the wood have been reported, and it is too scarce to be of much value. The tree's principal importance is as an ornament, and it shows well in winter borders where the bright colors of the seeds are exposed. It is planted both in this country and in Europe. The plantings seldom or never reach tree size.

FLORIDA Boxwoon (Schefferia frutescens) is of the same family as wahoo but of another genus, and is quite a different kind of tree. The generic name is in honor of Jakob Christian Schaeffer, a distinguished German naturalist who died in 1790. Two species of this tree occur in the United States, one the Florida boxwood, the other a small, shrubby growth in the dry regions of western Texas and northern Mexico. Florida boxwood is a West Indies tree which flourishes in the Bahamas and southward along the other islands to Venezuela. It has gained a foothold on the islands of southern Florida where it has found conditions favorable and it grows to a height of thirty or forty feet, and reaches a trunk diameter of ten inches, but such are trees of the largest size. The leaves are bright yellow-green, about two inches long, and one or less in width. They appear in Florida in April and persist a full year, until the foliage of the succeeding crop displaces them. The flowers which are small and inconspicuous, open about the same time as the leaves. The fruit is a scarlet berry which ripens in November, and has a decidedly disagreeable flavor. The bark is very thin.

When sound wood in sufficiently large pieces is obtainable it is valuable for a number of purposes, but chiefly as a substitute for Turkish boxwood as engraving blocks. The trees are always small in Florida, which is the only place in the United States where they occur, and the largest are often hollow or otherwise defective. The wood weighs 48.27 pounds per cubic foot, thoroughly dry, which is about two pounds heavier than white oak. It is rich in ashes, having about four times as much as white oak. The color of the heartwood is a bright, clear yellow to which is due the name yellow-wood occasionally applied to the tree in the region where it grows, as well as in markets where it is sold. This is not the tree known in commerce as West Indies boxwood, though it may be an occasional substitute. It is said that Florida boxwood was formerly much more abundant in this country than it is now. It was lumbered for the European market at about the same time that the south of Florida was stripped of its mahogany. It is suitable for many: small articles where a hard, even-grained wood is wanted.

IRoNwoon (Cyrilla racemiflora) ranges from the coast region oi North Carolina to Florida, and west near the coast to Texas. It is 
known as leatherwood, burnwood, burnwood bark, firewood, red titi, and white titi. Ten woods besides this are called ironwood in some parts of this country. The name is applied because the hardness of the wood suggests iron. It is not remarkable for its weight nor its strength. The medullary rays are thin and inconspicuous. In color it is brown, tinged with red. It is not apparent why it is a favorite fire wood, for its fuel value does not rate high theoretically, being much below many species with which it is associated. The largest trees rarely exceed a height of thirty feet and a diameter of twelve inches. They flourish in shady river bottoms and along the borders of sandy swamps and shallow ponds.

The tree occasionally assumes the form of a bush and sends up many stems which produce almost impenetrable thickets. Aside from its use as fuel, it is in small demand anywhere. In Texas it is sometimes made into wedges, and similar uses for it are doubtless found in other regions where it is abundant. It is named from Domenico Civillo, an Italian naturalist who died in 1799 .

Titr (Cliftonia monophylla) is of the cyrilla family and is one of three species which occasionally pass under that name. It sometimes reaches a height of fifty feet and a diameter of one or more. Its range follows the coast region from South Carolina to Louisiana. It betakes itself to swamps and flourishes in situations that would be fatal to many species. Half under water during many months of the year it is placed at no disadvantage. It grows equally well in shallow swamps which are rarely overflowed. Near the southern limits of its range in Florida it is reduced to a shrub. It is known as ironwood and buckwheat tree. The last name is due to its seeds which are about the size of a buckwheat grain and otherwise resemble it. The flowers appear in early spring on long racemes, and are very fragrant. The wood weighs about thirtynine pounds per cubic foot, is not strong, but is moderately hard. It is valuable as fuel and burns with a clear, bright flame.

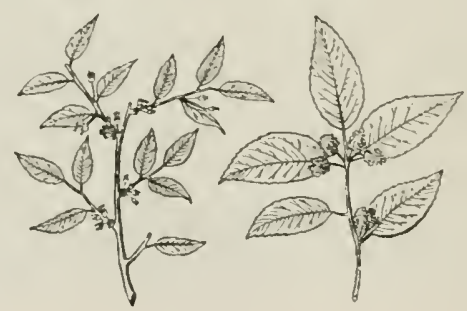


MOLNTAIN IATREI 


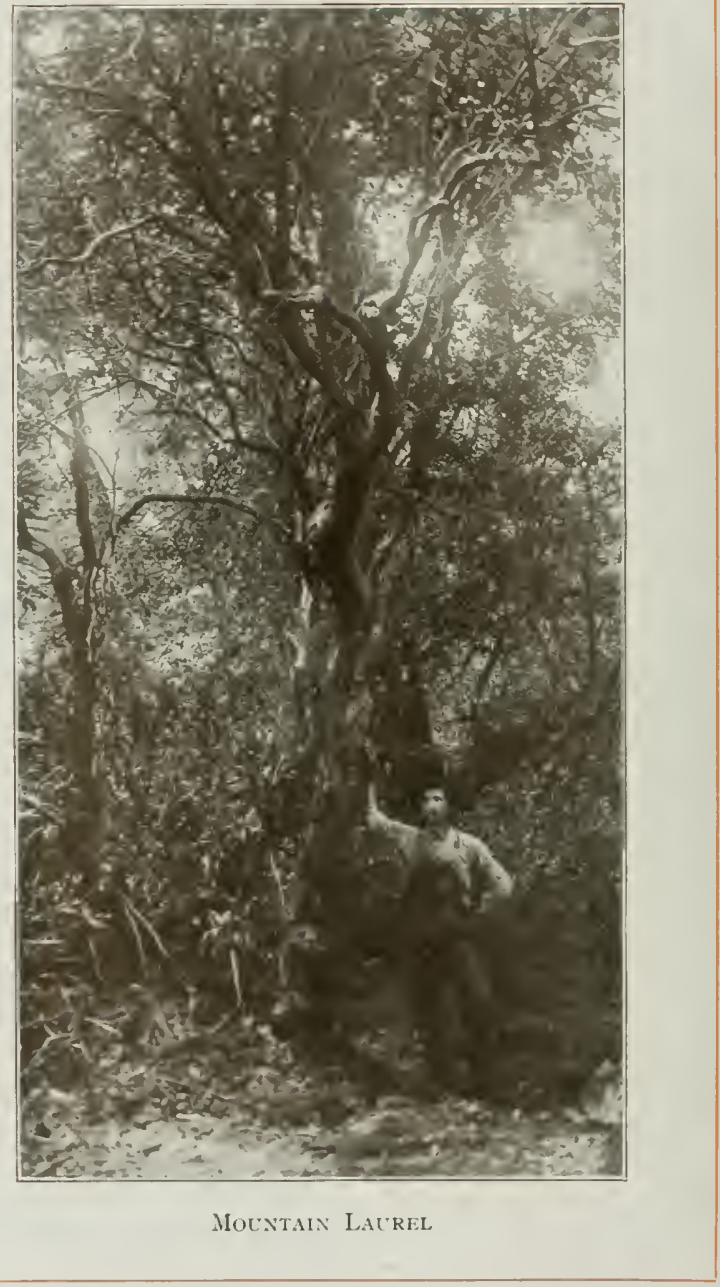




\section{MOUNTAIN LAUREL}

\section{(Kalmia Latifolia)}

T HIS tree belongs to the heath family and not to the laurels, as the name seems to imply. The same is true of rhododendron. The halmia genus has five or six species in this country, but only one of tree size, and then only when at its best. Mountain laurel reaches its best development in North and South Carolina in a few secluded valleys between the Blue Ridge and the western mountains of the Appalachian ranges. The largest specimens are forty or fifty feet high and a foot or a foot and a half in diameter. Trunks are contorted and unshapely, and lumber is never sawed from them.

The tree has many names, most of them, however, are ajplied to the species in its shrubby form. A common name is simply laurel, but that does not distinguish it from the great laurel which is often associated with it. Calico bush is one of its names, and is supposed to be descriptive of the flowers. Spoonwood is one of its northern names, dating back to the times when early settlers, who carried little silverware with them to their frontier homes, augmented the supply by making spoons and ladles of laurel roots. Ivy is a common name, sometimes mountain ivy, or poison ivy. Poison laurel and sheep laurel are among the names also. The leaves are poisonous, and if sheep feed on them, death is apt to follow. The exact nature of the poison is not understood. Sheep scldom feed on the leaves, and do so only when driven by hunger. Other names are small laurel, wood laurel, and kalmia. The last is the name of the genus, and is in honor of Peter Kalm, a Swedish naturalist.

The species is found from New Brunswick to Louisiana, but principally among the ranges of the Appalachian mountains. Its thin bark makes it an easy prey to fire and the top is killed by a moderate blaze. The root generally remains uninjured and sends up sprouts in large numbers. Thickets almost impenetrable are sometimes produced in tluat way.

Flowers and foliage of monntain laurel are highly esteened as decorations, foliage in winter, and the flowers in May and June. The bloom appears in large clusters, and various colors are in evidence, white, rose, pink, and numerous combinations. The seeds are ripe in September, and the pods which bear them birst soon after.

The wood of mountain lanrel weighs 44.62 pounds per cubic foot. lt is hard, strong, ratier brittle, of slow growtl, brown in eolor, tinged with red, with lighter colored sapwood. This description applies to the wood of the trunk; but in nearly all cases where mention is made of the 
wood of this tree, it refers to the roots. These consist of enlargements or stools, often protruding considerably above the ground. If the area has been visited repeatedly by fire, the roots are generally out of proportion to the size of the tops. In that respect they resemble mesquite, except that the enlarged root of mesquite penetrates far beneath the surface while that of mountain laurel remains just below the surface or rises partly above it.

The utilization of mountain laurel is not confined to the trunks which reach tree size. Generally it is the root that is wanted. Roots are usually sold by weight, because of the difficulty of measuring them as lumber or even by the cord. The annual product of this material in North Carolina alone amounts to about $\$ 5,000$ pounds, all of which goes to manufacturers of tobacco pipes and cigar holders. The use of the laurel root for pipes is as old as its use for spoons. Pioneers who raised and cured their own tobacco smoked it in pipes which were their own handiwork. The laurel root was selected then as now because it carves easily, is not inclined to split, does not burn readily, and darkens in color with age. It is cheap material, is found throughout an extensive region, and the supply is so large that exhaustion in the near future is not anticipated.

The wood is employed in the inanufacture of many small articles other than tobacco pipes. Paper knives, small rulers, turned boxes for pins and buttons, trays, plaques, penholders, handles for buckets, dippers, and firewood, are among the uses for which laurel is found suitable.

It is of no small importance for ornamental purposes, and is often seen growing in clumps and borders in public parks and private yards, where its evergreen foliage and its lolom make it a valuable shrub. It is planted in Europe as well as in this country.

GREAT LALREL (Rhododendron maximum) is also in the heath family. More than two hundred species of rhododendron are known, and seventeen are in this country, but only one attains tree size. The generic name means "rose tree," and the name is well selected. The flowers are the most conspicuous feature belonging to this species, and few wild trees or shrubs equal it for beauty. It is not native much west of the Alleghany mountains, but grows north and east to Nova Scotia. It is at its best among the mountains, thrives in deep ravines where the shade is dense, and on steep slopes and stony mountain tops. It forms extensive thickets which are often so deep and tangled that it is difficult to pass through them. This laurel is seldom found growing on limestone. It reaches its largest size in the South. Trees thirty or forty feet high and a foot in diameter occur in favored localities. It grows on the Alle- 
ghany mountains in West Virginia at an elevation exceeding 4,000 feet and there forms vast thickets. Some use is made of the wood for engraving blocks and as tool handles. It is hard, strong, brittle, of slow growth, and light clear brown. It is frequently planted in parks in this country and Europe, and thrce or more varieties are distinguished in cultivation. This laurel's leaves have a peculiar habit of shrinking and rolling up when the thermometer falls to zero or near it. Among the names applied to it are great laurel, rose bay, dwarf rose bay tree, wild rose bay, bigleai laurel, deer tongue, laurel, spoon hutch, and rhododendron.

CAtawba Rhododendron (Rhododendron catawbiense) is a rare, large-flowered species of the mountain regions from West Virginia southward to Georgia and Alabama. The wood is not put to use, and the species is chiefly valuable as an ornamental shrub. It seldom reaches large size.

Sovrwood (Oxydendrum arboreum) follows the Alleghany mountain ranges south from Pennsylvania, and extends into Florida, reaching the Atlantic coast in Virginia, and Indiana, Tennessee, and Louisiana westward. The best development of the species is found among the western slopes of the Big Smoky mountains in Tennessee. It is called sorrel-tree, sour gum, and sour gum bush, on account of the acidity of the leaves when chewed. Arrow-wood, another name, refers to the long, straight stems between the whorls of branches of young trees-those three or four feet high. The stems are of proper size for arrows, and amateur bowmen use them. Those who designate the tree as lily-of-thevalley have in mind the flowers. The shape suggests an opening lily, but the size does not. The flower is about one-third of an inch long, but panicles several inches long are covered with them. They open in July and August, and in September the fruit is ripe. The seed is pale brown and one-eighth of an inch long.

The sourwood tree at its best is fifty or sixty feet high and from twelve to eighteen inches in diameter. The bark of young trees is smooth, but on mature trunks it resembles the exceedingly rough bark of an old black gum. In fact, many people suppose this tree to be black gum, never having noticed the difference of leaf, fruit, and flower. The genus consists of a single species. The wood is heavy, hard, compact, and it takes good polish. The medullary rays are numerous, but thin, and they contribute little or nothing to the figure of the wood. The annual rings show little difference between springwood and summerwood, and consequently produce poor figure when the lumber is sawed tangentially. The pores are many and small and are regularly distributed through the yearly ring. Hcartwood is 
brown, tinged with red, the sapwood lighter. The strength and elasticity of sourwood are moderate. The wood is made into sled runners in some of the mountain districts where it occurs, but no particular qualities fit it for that use. It is occasionally employed for machinery bearings. It has been reported for mallets and mauls, but since it is not very well suited for those articles, the conclusion is that those who so report it have confused it with black gum which it resembles in the living tree, but not much in the wood. Small handles are made of it, and it gives good service, provided great strength and stiffness are not required. Sourwood is not abundant anywhere, and seldom are more than a few trees found in a group.

TREE HUCKLEBERRY (Vaccinium arboreum) is the only tree form of twenty-five or thirty species of huckleberry in this country. The cranberry is one of the best known species. The range of tree huckleberry extends from North Carolina to Texas, and it reaches its largest size in the latter state where trunks thirty feet high and ten inches in diameter occur, but not in great abundance. The fruit which this tree bears bas some resemblance to the common buckleberry, but is inferior in flavor, besides being dry and granular. It ripens in October and remains on the branches most of the winter. The fruit is about a quarter of an inch in diameter, dark and lustrous, and is a conspicuous and tempting bait for feathered inhabitants of swamp and forest. The bark of the roots is sometimes used for medicine, and that from the Irunk for tanning, but it is too scarce to become important in the leather industry: The tree is known in different parts of its range as farkleberry, sparkleberry, myrtle berry, bluet, and in North Carolina it is known as gooseberry. The wood is hard, heavy, and very compact; is liable to warp, twist, and check in drying; polishes with a fine, satiny finish. Medullary rays are numerous, broad, and conspicuous; wood light brown, tinged with red. Small articles are tumed from it.

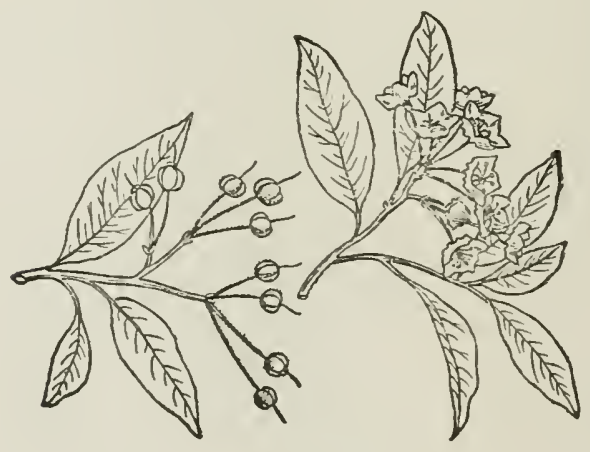


OSAGE ORANGE 


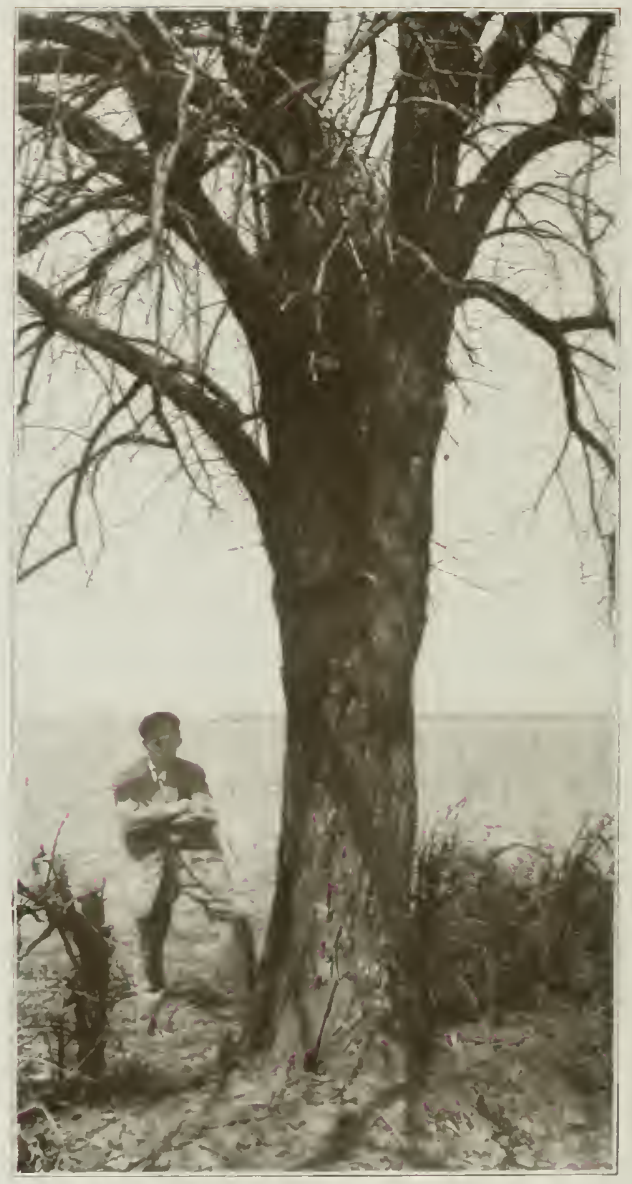

OSAGE ORANGE 


\title{
OSAGE ORANGE
}

\author{
(Toxylon Pomiferum)
}

$\mathrm{O}^{\mathrm{s}}$ SAGE orange belongs to the mulberry family. There are fiftyfour genera, three of which are found in the United States, the mulberries, the Osage orange, and the figs. Osage orange is known by several names, the principal one of which refers to the Osage Indians, who formerly lived in the region where the tree grows. It is called orange because the fruit, which is from two to five inches in diameter, looks like a green orange, but it is unfit for food. In its range most people call it bodark or bodock, that being a corruption of the name by which the French designated it, bois d'arc, which means bow wood. It was so called from the fact that Indians made bows of it when they could get nothing better. Its value as material for bows seems to be traditional and greatly overestimated. It is lower in elasticity than white oak and very much lower than hickory, and, theoretically, at least, it is not well suited for bows. The wood is known also as mock orange, bow-wood, Osage apple tree, yellow-wood, hedge, and hedge tree. The last name is given because many hedges have been made of it.

Osage orange has been planted in perhaps every state of the Union, and grows successfully in most of them. It is one of the most widely distributed of American forest trees, but its distribution has been chiefly artificial. It was found originally in a very restricted region, from which it was carried for hedge and ornamental planting far and wide. Its natural home, to which it was confined when first discovered, embraced little more than ten thousand square miles, and probably half of that small area produced no trees of commercial size. Its northern limit was near Atoka, Oklahoma, its southern a little south of Dallas, Texas; a range north and south of approximately one hundred miles. Its broadest extent east and west was along Red River, through Cooke, Grayson, Fanning, Lamar, and Red River counties, Texas, about 120 miles. Some Osage orange of commercial size grew outside the area thus delimited, but no large amount. Much of that region, particularly south of Red River, was prairie, without timber of any kind; but scattered here and there were belts, strips, thickets, and clumps of Osage orange mixed with other species. On the very best of its range, and before disturbed by white men, this wood seldom formed pure stands of as much as 100 acres in one body, and since the country's settlement, the stands have become smaller or have been entirely cleared to make farms. All accounts agree that the Osage orange reaches its highest development on the fertile lands along Boggy and Blue rivers in Oklahoma, though fine 
bodies of it once grew south of the Red River in Texas, and much is still cut there though the choicest long ago disappeared. Few trees are less exacting in soil, yet when it can make choice it chooses the best. In its natural habitat it holds its place in the black, fertile flats and valleys, and is seldom found on sandy soil. It is not a swamp tree, though it is uninjured by occasional floods. The tracts where it grows are sometimes called "bodark swamps," though marshy in wet weather only.

The tree attains a height of fifty or sixty feet when at its best, but specimens that tall are unusual. Trunks are occasionally two or three feet in diameter, but that size is very rare. At the present time probably ten trees under a foot in diameter are cut for every one over that size.

Rough and unshapely as Osage trees are, they have been more closely utilized than most timbers. Fence posts are the largest item. The board measure equivalent of the annual cut of posts has been placed at $18,400,000$. The posts are shipped to surrounding states, in addition to fencing nearly 40,000 square miles of northern Texas and southern Oklahoma. Houseblocks constitute another important use. These are short posts set under the corners of buildings in place of stone foundations. The annual demand for this kind of material amounts to about $1,000,000$ board feet. An equal amount goes into bridge piling. The principal demand comes from highway commissioners. Telephone poles take a considerable quantity, and insulator pins more.

One of the most important uses of Osage orange is found in the manufacture of wagon wheels, though the total quantity so used is smaller than that demanded for fence posts.

About 10,000 or 12,000 wagons with Osage orange felloes or rims are manufactured annually in the United States. That use of the wood is not new. It began in a small way soon after the settlement of the region. At first the work was hand-done by local blacksmiths and wheelwrights. They found the wood objectionable, from the workman's standpoint, on account of its extreme hardness and the difficulty of cutting it. That objection is still urged against it though machines have taken the place of the hand tools of former times. Saws and bits are quickly dulled, and the cost of grinding, repair, and replacement increases the operator's expense much above ordinary mill outlay for such purposes. On that account many prefer to work the wood green. It is then softer, and cuts more smoothly. If seasoned before it is passed through the machines it is liable to "pull." That term is used to indicate a rough-breaking of the fibres by the impact of knives. The readiness with which the wood splits calls for extraordinary care in boring it, and many felloes are spoiled in finishing them to receive the tenoned ends of spokes. 
A number of commodities are made of Osage orange but in quantities so small that the total wood used does not constitute a serious drain upon the supply. Police clubs are occasionally made as a by-product of the rim mill. Some years ago at the Texas state fair at Dallas, a piano was exhibited, all visible wood being Osage orange, handsomely polished. The rich color of this wood distinguishes it from all other American species. When oiled it retains the yellow color, but unoiled wood fades on long exposure. Clock cases of Osage have been manufactured locally, and gun stocks made of it are much admired, though the wood's weight is an argument against it for gun stocks. Canes split from straightgrained blocks, and shaved and polished by hand, are occasionally met with, but none manufactured by machinery have been reported. Sawmills in the Osage orange region use the wood as rollers for carriages and off-bearing tables. Rustic rockers and benches of the wood, with the bark or without it, figure to a small extent in local trade. It has been tried experimentally for parquetry floors, with satisfactory results. Sections of streets have been paved with Osage orange blocks. The wood wears well and is nearly proof against decay, but no considerable demand for such blocks appears ever to have existed. Railroads which were built through the region years ago cut Osage for ties and culvert timber, but no such use is now reported. The demand for the wood for tobacco pipes is increasing, more than 100,000 blocks for such pipes having been sold during a single year.

Osage orange weighs $\$ S .21$ pounds per cubic foot. It is twentyeight per cent stronger than white oak, but is not quite as stiff, is very brittle, and under heavy impact, will crumble. For that reason, Osage wagon felloes will not stand rocky roads. The bark is sometimes used for tanning, and the wood for dyeing.

RED MULBERRY (Morus rubra) is frequently spoken of simply as mulberry, and is sometimes called black mulberry. The full grown fruit is red, but turns black or very dark purple when ripe. The berry is composed of a compact and adhering cluster of drupes, each drupe about one thirty-sccond of an inch long. What seems to he a single berry is really an aggregation of very small fruits, each resembling a tiny cherry. The mulberry is naturally a forest tree, but it is permitted to grow about the margins of fields, and is often planted in dovr yards for its fruit and its shade. It is looked upon by many as a tame species.

Two mulberries grow naturally in this country. The red species ranges from Massachusetts west to Kansas, and south to Texas and Florida. Its best growth is found in the lower Ohio valiey and the southern foot hills of the Appalachian monntains. The largest trees are seventy feet high and three or four in diameter. If this tree were abundant the wood's place in furniture and finish would be important. The heartwood is dark, of good figure, and fairly strong. It takes a finc polish, and resembles black walnut, though usually of a little lightcr shade. Its largest use is as fence posts. It is durable in contact with the soil. The effect when made into furniture, finish, and various kinds of turnery, is pleasing. Farm tools, particularly 
scythe snaths, are made of it, and it has been reported for slack cooperage and boat building, but such uses are apparently infrequent. The wood is evidently sold under some other name, or without a name, for the total sarmill output in the United States is given in government statistics at only 1,000 feet, which is probably not one per cent of the cut.

Mexican Mulberry (Morus celtidifolia) ranges from southern Texas to Arizona. Trees are seldom more than thirty feet high and one in diameter. The berry is about half an inch long, black, and made up of a hundred or more very small drupes. It is edible, but its taste is insipid. The wood is heavy and is of dark orange or dark brown color. It is suitable for small turnery and other articles, but no reports of uses for it have been found. The tree is occasionally planted for its fruit by Mexicans, but Americans care little for it.

Two foreign mulberries have been extensively planted in this country, and in some localities they are running wild and are mistaken for native species. One is the white mulberry (Morus alba), a native of China; the other is the paper mulberry (Broussonetia papyrifera) a different genus, but of the same family. It is a native of Japan, and has been naturalized in some of the southern states. Nine varieties of the white mulberry have been distinguished in cultivation.

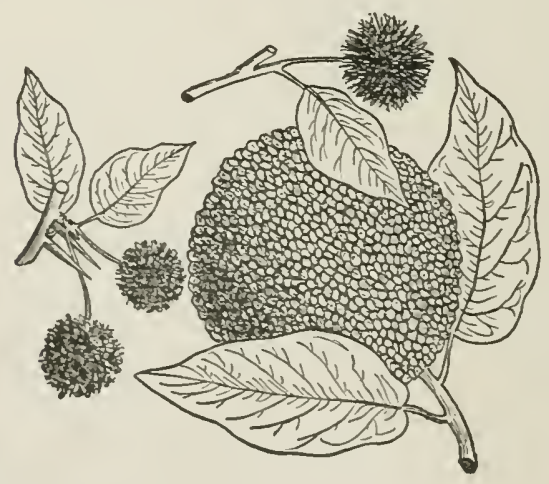


PERSIMMON 


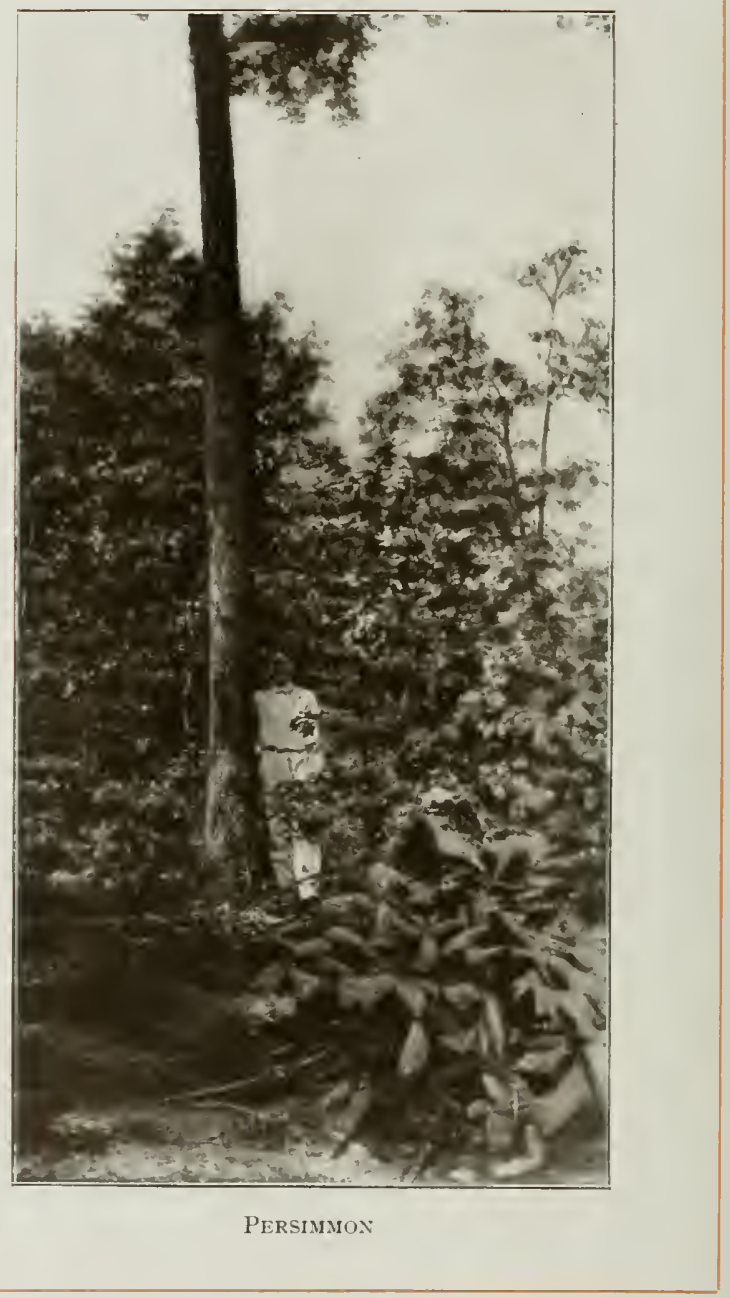




\section{PERSIMMON}

\section{Diospyros V'irginiana)}

$\mathrm{P}$ ERSIMMON belongs to the ebony family, and the family has contribnted to the civilization of the human race since very early times. Some of the oldest furniture in existence, that which was found lidden in the ruins of ancient Egypt, is ebony, and there is evidence among the old records in the land of the Nile that the Egyptians made voyages southward throngh the Red sea and brought back cargoes of ebony from Punt, a region in eastern Africa. The name ebony is believed to be derived from a Hebrew word, probably brought to Palestine by some of Solomon's captains who traded along the south coast of Asia or the east coast of Africa about the time of the building of the first temple. The botanical name for the genus (diospyros) is made up of two words meaning "Jupiter's wheat"-supposed to be a reference to the value of persimmons as food. The name, however, is not as old as the Hebrew word, nor is the Hebrew as old as the references to ebony in the records of Egypt. A piece of the old furniture-rot less than 1,000 years oldis still in existence. It probably matches in age the cedar of Lebanon coffins in the oldest Egyptian tombs.

The ebony family consists of five genera, one of which is persimmon (diospyros). This genus consists of 160 species, only two of them in the United States. Thus the persimmon trees of this country are a very small part of the family to which they belong, but they are a highly respectable part of it. The word persimmon is of Indian origin, and was ised by the tribes near the Atlantic coast. The original spelling was "pessimin," and that was probably about the pronunciation given it by the aborigines.

It has never been called by many names. It is known as date plum in New Jersey and Tennessee, and as possumwood in Florida. The avidity with which opossums feed on the fruit is responsible for the name.

The range of persimmon extends from Connecticut to Florida, and westward to Iowa, Missouri, and Texas. It reaches its largest size in the South. It is of vigorous growth, spreading by means of seeds, and also by roots. The latter is the most common method where the ground is open. Such situations as old, abandoned fields invite the spread of persimmons. Roots ramify under the ground, and spronts spring up, of ten producing thickets of an acre or more. Trees do not generally reach large size if they grow in that way, but their crowded condition does not make them fruitless as ean be attested to by many a boy who penetrates 
the persimmon thickets by means of devious paths that wind with many a labyrinthic turn which takes in all that is worth finding.

The variation in the quality of persimmons is greater than that of most wild fruits. Nature usually sets a standard and sticks closely to it, but the rule is not adhered to in the case of persimmons. Some are twice as large as others; some are never fit to eat, no matter how severely or how of ten they are frosted; others require at least one fierce frost to soften their austerity; but some may be eaten with relish without the ameliorating influence of frost.

The austerity of a green persimmon is due to tannin. It is supposed that cultivation might remove some of this objectionable quality, but no great success has thus far attended efforts in that direction. Japanese persimmons, which are of a different specie, are cultivated with success in California.

The sizes of persimmon trees vary according to soil, climate, and situation. They average rather small, but occasionally reach a height of 100 feet and a diameter of nearly two. Mature trunks are usually little over twelve inches in diameter, and many never reach that size.

The dry wood weighs 49.28 pounds per eubic foot, which is about the weight of hickory. It is hard, strong, compact, and is susceptible of a high polish. The yearly rings are marked by one or more bands of open ducts, and scattered ducts occur in the rest of the wood. The medullary rays are thin and inconspicuous; color of heartwood dark brown, often nearly black; the sapwood is light brown, and frequently contains darker spots.

The value of persimmon depends largely upon the proportion of sapwood to heartwood. That was the case formerly more than it is now; for until recent years the heartwood of persimmon was generally thrown away, and the sapwood only was wanted; but demand for the heart has recently increased. There is much difference in the proportion of heartwood to sapwood in different trees. It does not seem to be a matter of size, nor wholly of age. Small trunks sometimes have more heart than large ones. A tree a hundred years old may have heartwood scarcely larger than a lead pencil, and occasionally there is none. In other instances the heart is comparatively large.

Persimmon has never been a wood of many uses, as hickory and oak have been. In early times it was considered valuable almost wholly on account of its fruit, and that had no commercial value, as it was seldom offered for sale in the market. In the language of the southern negroes who fully appreciated the fruit, it was "something good to run at"--meaning that the ripe persinmons were gathered and eaten from the trees while they lasted, but that few were preserved. 
It is recorded that the "small wheel" of the pioneer cabins was occasionally made of persimmon wood. The wheel so designated was the machine on which wool and flax were spun by the people in their homes. Spinning wheels were of two kinds, one large, with the operator walking to and fro, the other small, with the operator sitting. It was the small wheel which was sometimes made of persimmon. There is no apparent reason why it should have been made of that wood in preference to any one of a dozen others.

The demand for persimmon in a serious way began with its use as shuttles in textile factories. Weavers had made shuttles of it for home use on hand looms for many years before the demand came from power looms where the shuttles were thrown to and fro by machinery. Up to some thirty years ago, shuttles for factories were generally made of Turkish boxwood, but the supply fell short and the advance in price caused a search for substitutes. Two satisfactory shuttlewoods were found in this country, persimmon and dogwood. The demand came not only from textile mills in America but from those of Europe. The manufacture of shuttle blocks became an industry of considerable importance.

Persimmon wood is suitable for shuttles because it wears smooth, is hard, strong, tough, and of proper weight. Ilost moods that have been tried for this article fail on account of splintering, splitting, quickly wearing out, or wearing rough. The shuttle is not regarded as satisfactory unless it stands 1,000 hours of actual work. Some woods which are satisfactory for many other purposes will not last an hour as a shut tle.

The manufacture of shuttles, after the square has been roughed out, requires twenty-two operations. Probably more shuttlewood comes from Arkansas than from any other section, though a dozen or more states contribute persimmon. The total sawmill cut of this wood in the United States is about 2,500,000 feet, but this does not include that which never passes through a sawmill.

The wood has other uses. It has lately met demand from manufacturers of golf heads. Skewers are made of it in North Carolina, and billiard cues and mallets in Massachusetts.

The heartwood is dark and shuttle makers and golfhead manufacturers will not have it. Until recently it was customary to throw it away, because no sale for it could be found. It is now known to be suitable for parquet flooring and for brush backs, and the demand for the heartwood is as reliable as for the sapwood. A little of the dark wood is cut in veneer and is cmployed in panel work, and other is used in turnery. 
The seeds of persimmon furnished one of the early substitutes for coffee in backwoods settlements when the genuine article could not be obtained. They were parched and pounded until sufficiently pulverized. During the Civil war many a confederate camp in the South was fragrant with the aroma of persimmon seed coffee, after the soldiers had added the fruit to their rations of cornbread.

Mexican Persimmon (Diospyros texana) grows in Texas and Mexico. It is most abundant in southern and western Texas, where it suits itself to different soils, is found on rich moist ground near the borders of prairies, and also in rocky canyons and dry mesas. The largest trees are fifty feet high and twenty inches in diameter, but trunks that large are not abundant. The tree differs from the eastern persimmon in that the sapwood is thinner, and the heartwood makes up a much greater proportion of the trunk; the uses are consequently different, since it is taken for its dark wood, the eastern tree for its light-colored sap. The fruit of the Mexican persimmon is little esteemed. It is small, black, and the thin layer of pulp between the skin and the seed is insipid. Until fully ripe it is exceedingly austere. The Mexicans in the Rio Grande valley make a dye of the persimmons and use it to color sheep skins. The fruit's supply of tannin probably contributes to the tanning as well as the dyeing of the sheep pelts. The wood is heavier than eastern persimmon, and has more than three fold more ashes in a cord of wood, amounting to about 160 pounds. The bark is thin and the trunk gnarled. The dark color of the wood gives it the name black persimmon in Texas. Mexicans call it chapote. Sargent pronounces it the best American substitute for boxwood for engraving purposes, but it does not appear to be used outside of Texas. The wood is irregular in color, even in the same piece, being variegated with lighter and darker streaks, and cloudy effects. It ought to be fine brush-back material. It is worked into tool handles, lodge furniture, canes, rules, pen holders, picture frames, curtain rings, door knobs, parasol handles, and maul sticks for artists.

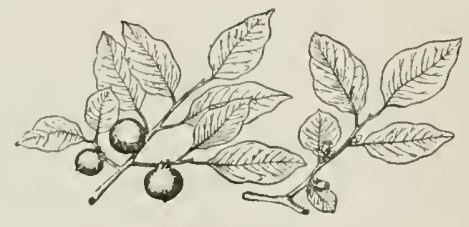


FLOWERING DOCWOON 


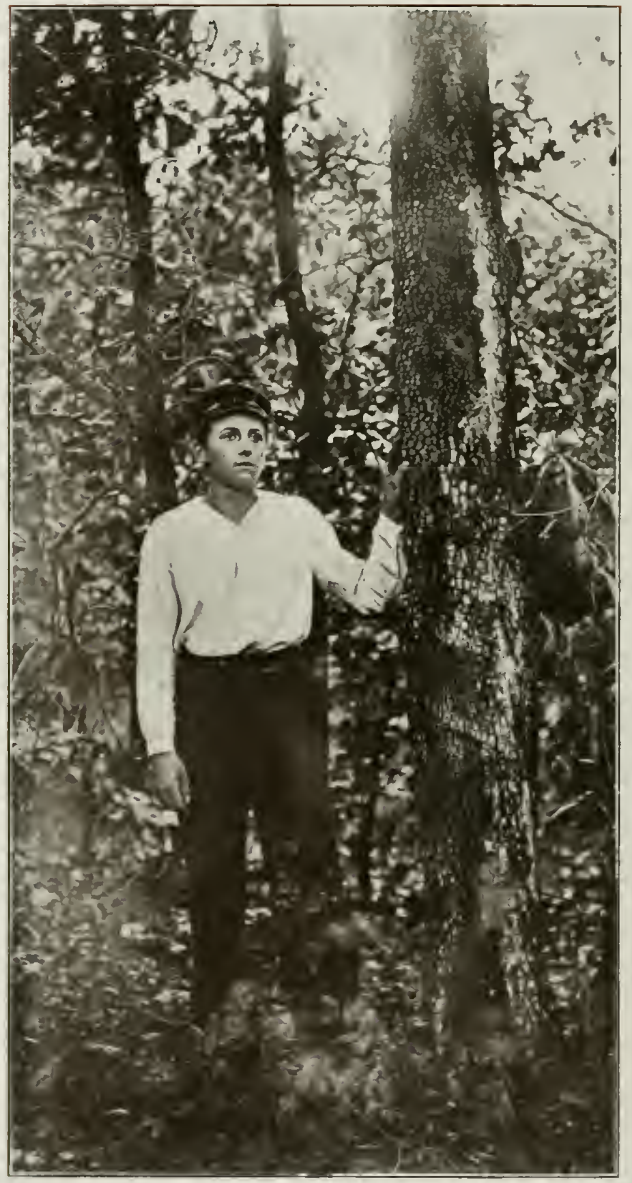

Floweriac; Jur;wot) 


\title{
FLOWERING DOGWOOD
}

\author{
(Cormus Florida)
}

$\mathrm{T}^{\mathrm{H}}$ HE dogwood or cornel fanily is old but not numerous. It originated several hundred thousand years ago and spread over much of the world, but preferred the temperate latitudes. One species at least crossed the equator and established itself in the highlands of Peru. There are forty or fifty species in all, about one-third of them in the United States, but most are shrubs. Black gum and tupelo are members of the family, and are giants compared with the dogwoods. In Europe the tree is usually called cornel, and that has been made the family name. It is a very old word, coitzed by the Romans before the days of Caesar. They so named it because it was hard like horn (cornus meaning horn in the Latin language). They used it as shafts of spears, and so common was that use that when a speaker referred to a spear he simply called it by the name of the wood of the handle or shaft, as when Virgil described a combat which was supposed to have occurred 800 years before the Christian era, and used the words: "Clogged in the wound the Italian cornel stood."

The qualities of this wood which led to important uses among the Romans, have always made dogwood a valuable material. Civilized nations do not need it for spear shafts, but they have other demands which call for large amounts.

The flowering dogwood has other names in this country. It is generally known simply as dogwood, but it is called boxwood in Connecticut, Rhode Island, New York, Mississippi, Micligan, Kentucky, and Indiana; false box-dogwood in Kentucky; New England boxwood in Tennessee; flowering cornel in Rhode Island; and cornel in Texas.

Its range extends from Massachusetts through Ontario and Michigan to Missouri, south to Florida, and west to Texas. The area where it grows includes about 800,000 square miles. It is most common and of largest size in the South, comparatively rare in the Nortl, generally occurs in the shade of taller trees, and prefers well-drained soil, but is not particular whether it is fertile or thin.

The dogwood is valuable as ornannent and for its wood. It was formerly a source of medicine, from roots, bark, and flowers; but it seems to have been largely displaced by other drugs; was once considered a good substitute for quinine, that use having been learned from Indian doctors. The Indians dug roots for a scarlet dye with which the vain warrior stained escutcheons on buckskin, and colored porcupine quills and bald eagle feathers for decorating his moccasins and his hair. 
The dogmood varies in size from a shrub with many branches to a tree forty feet high, eightten inches in diameter, and with a flat but shapely crown. The trunk rises as a shaft with little taper, until the first branches are reached. All the branches start at the same place, and the trunk ends abruptly-divides into branches. Flowers are an important part of the tree, as might be inferred from the prominence given them in the tree's names. In the South the flowers appear in March, in the North in May, and in both regions before the opening of the leaves. The flowers on vigorous trees are three or four inches across, white, and very showy. A dogwood tree in full bloom against a hillside in spring is a most conspicuous object, and is justly admired by all who have appreciation of beauty. The flowers fall as leaves appear, and for some months the tree occupies its little space in the forest unobserved; but in the autumn it bursts again into glory, and while not quite as conspicuous an object as when in bloom, it is no less worthy of admiration. The fall of the leaves reveals the brilliant scarlet fruit which ladens the branches. The berries are just large enough for a good mouthiul for a bird, but birds spare them until fully ripe to the harvest, and they then harvest them very rapidly. The tree is thus permitted to display its fruit a considerable time before yielding it to the feathered inhabitants of the air whose mission in forest economy is to scatter the seeds of trees, when nature provides the seeds themselves with no wings for flying.

The two periods in the year when dogwood is highly ornamental, the flowers in spring before leaves appear, and fruit in autumn after leaves fall, are respousible for this tree's importance in ornamental planting. It is a common park tree, but it is small, generally not more than fifteen feet high, and it occupies subordinate places in the plans of the landscape garden. It is a filler between oaks, pines, and spruces, and it passes unnoticed, except when in bloom and in fruit.

Dogwood is about four pounds per cubic foot heavier than white oak, has the same breaking strength, and is lower in elasticity. It is quite commonly believed that this tree has no heartwood, but the belief is erroneous. It seldom has much, and small trunks of ten none; but when dogwood reaches maturity it develops heart. Sometimes the heartwood is no larger than a lead pencil in trunks forty or fifty years old. The heart is brown, sapwood is white, and is the part wanted by the users of dogwood. Annual rings are obscure and it is a tree of slow growth. The wood is as nearly without figure as any in this country. It seldom or never goes to sawmills. The logs are too small. Most of the supply is bought by manufacturers of shuttles and golf stick heads, in this country and Europe. They purchase it by the cord or piece. It does not figure much in any part of the lumber business, bui is cut, and 
marketed in ways peculiar to itself. Log cutters in hardwood forests pay little attention to it. The dogwood harvest comes principally from southern states. Village merchants are the chief collectors, and they sell to contractors who ship to buyers in the manufacturing centers. The village merchants buy from farmers, who cut a stick here and there as they find it in woodlots, forests, or by the wayside, on their own land or somebody else's. When the cutter next drives to town he throws his few dogwoods in the wagon, and trades them to the store keeper for groceries or other merchandise. It is small business, but in the aggregate it brings together enough dogwood to supply the trade.

Dogwood has many uses, but none other approaches shuttle making and golfhead manufacture in importance. The wood is made into brush blocks, wedges, engraver's blocks, tool handles, machinery bearings as a substitute for lignum-vitæ, small hubs, and many kinds of turnery and other small articles.

Western Dogwood (Cormus nuttallii) is a larger, taller tree than the eastern flowering dogwood. A height of $\mathrm{I} 00$ feet is claimed for it in the low country along the coast of British Columbia, but there are no authentic reports of trees so large anywhere south of the boundary between Canada and the United States. Its height ranges from twenty to fifty feet, and its diameter from six to twenty inches. The appearance is much the same as its eastern relative. Its berries are red, and grow in clusters of forty or less; the bark on old trunks is rough, but is smooth on those of medium size; the flowers are generally described as very large and showy, but the true flower is quite an inconspicuous affair, being a small, greenish-yellow, button-like cluster, surrounded by four or six snowy-white or sometimes pirkish scales which are popularly but erroneously supposed to form a portion of the real flower. The western. dogwood in its native forest of ten puts out flowers in autumn; is well supplied with foliage which assumes red and orange colors in the fall when the showy berries are at their best. However, the tree has not yet won its way into the good graces of landscape gardeners, and has not been much planted in parks. It wants some of the good points possessed by the flowering dogwood. The western tree shows to best advantage in its native forest where it thrives on gentle mountain slopes and in low bottoms, valleys, and gulches, provided the soil is well drained and rich. It runs southward fifteen hundred miles from Vancouver island to southern California. It cares little for sunshine, and of ten is found growing nicely in dense shade. Seedlings do better where shade is deep. The wood is lighter but somewhat stronger than that of the flowering dogwood; is pale reddish-brown, with thick sapwood; is liard, and checks badly in seasoning. Mature trees are from 100 to 150 years. 
Blue Dogwood (Cormus alternifolia) is given that name because of the blue fruit it bears. It has a number of other names, among them being purple dogwood, green osier, umbrella tree, pigeonberry, and alternate-leaved dogwood, the last being simply a translation of its botanical name. It grows in more northern latitudes than the flowering dogwood, and does not range as far south. It is found from Nova Scotia to Alabama, and westward to Minnesota, but its southern habitat lies along the Appalachian mountain ranges. It attains size and assumes form similar to the flowering dogwood. The wood is heary, hard, brown, tinged with red, the sapwood white. It is a deep forest tree, but has been domesticated in a few instances where it has been planted as ornament. The wood seems to possess the good qualities of flowering dogwood, but no reports of uses for it have been made.

Two varieties of flowering dogwood have been produced by cultivation, weeping dogwood (Cornus florida pcndula), and red-bract dogwood (Cormus florida rubra). English comel or dogwood (Cormus mas) has been planted in many parts of this country. The so-called Jamaica dogwood is not in the dogwood family.

ANDROMEDA (Andromeda ferruginea) is a small southern tree of South Carolina, Georgia, and Florida, and in the latter state is sometimes known as titi, though other trees also bear that name. The largest are thirty feel high, if by chance one can be found standing erect, for most of them prefer to sprawl at full length on the ground. The fruit is a small berry of no value. The wood is weak, but hard and sufficiently compact to receive fine polish. The heartwood is light brown, tinged with red.

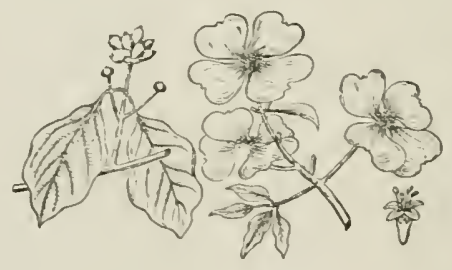


C.ALIFORIIA LALREL 


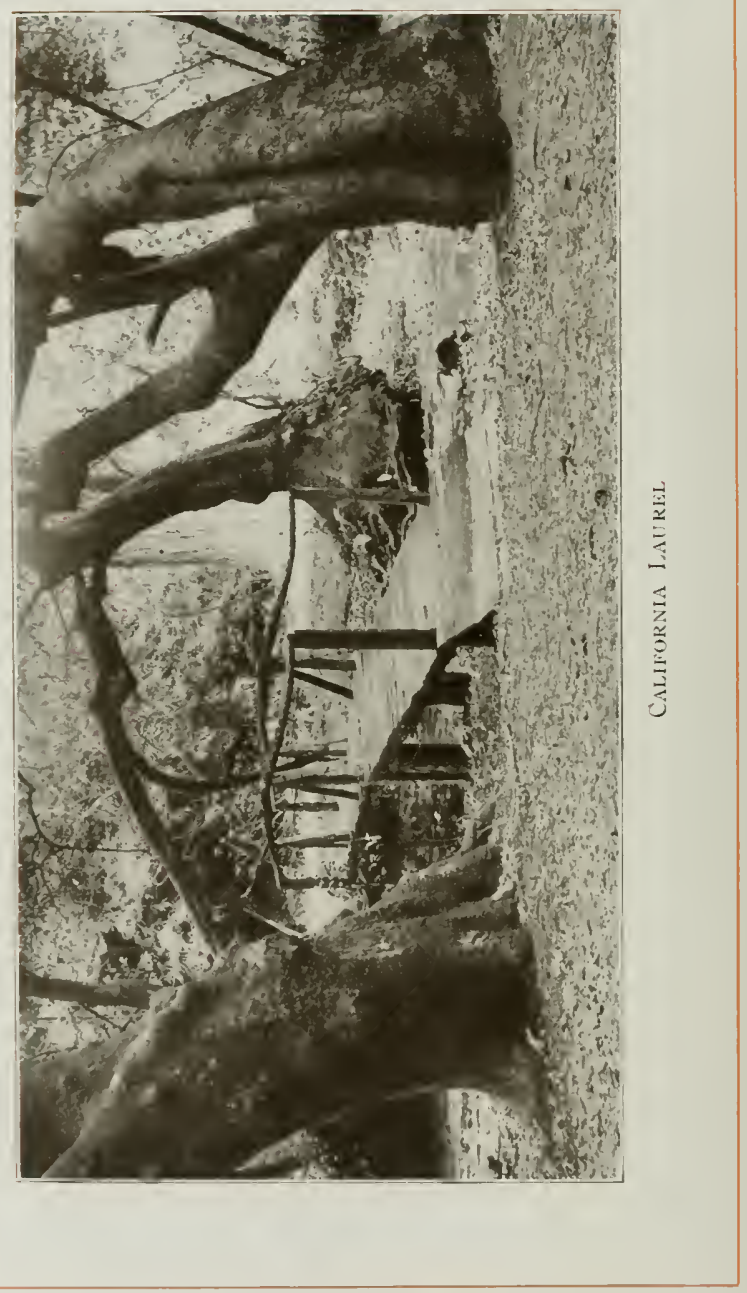




\section{CALIFORNIA LAUREL}

\section{(Umbellularia Californica)}

$\mathrm{T}$

HIS tree's range lies in southern Oregon and in California. It is

a member of the laurel family and is closely related to the eastern sassafras and the red and the swamp bays of the southern states; but it is not near kin to the eastern laurels which, strange as it nay appear, do not belong to the laurel family, notwithstanding the names they bear.

The people of California and Oregon have several names for this interesting tree. It is known as mountain laurel, California bay tree, myrtle tree, cajeput, California olive, spice tree, laurel, bay tree, oreodaphne, and California sassafras.

Those who call it laurel name it on account of its large, lustrous, thick leaves which adhere to the branches from two to six years. All new leaves do not come at once, as with most trees, but appear a few at a time during the whole summer.

The names which connect this tree with sassafras, spice and cajeput are based on odor and taste. All members of the laurel family in this country are characterized by pugent, aromatic odor and taste, and the one under consideration shares these properties in a remarkable degree. When the leaves and the green bark are crushed, they give off a light, volatile oil in follicles which float in the air, likc those of an onion, and when inhaled it produces severe pain over the eyes, and may induce dizziness and violent sneezing. Though the symptoms are alarming to one who is undergoing the experience for the first time, no serious inconvenience follows. Dried leaves are capable of producing a similar effect but with less violence. The California laurel's close relationship to the camphor tree is readily believed by persons who inhale some of the oily spray from the crushed leaves.

Attempts have been made to produce the commercial oil of cajeput, or a substitute for it, by distilling the leaves and bark of this laurel. A passable substitute has been manufactured, but it cannot be narketed as the genuine article. By distilling the fruit a product known as umbellulic acid has been obtained.

The California laurel carries a very dense crown of leaves. This is due partly to the old crops which hang so long, and to the tree's lrabit of lengthening its leading shoots during the growing season, and the constant appearance of young leaves on the lengthening shoots. It can stand an almost unlimited amount of shade itself, and is by no means backward in giving abundance of shade to small growth which is trying 
to struggle up to light from below. It delights in dense thickets, but it prefers thickets of its own species.

Its fruiting habits and its disposition to occupy the damp, rich soil along the banks of small water courses, are responsible for the thick stands. The fruit itself is an interesting thing. It is yellowishgreen in color, as large as a good-sized olive, and looks much like it. The fruit ripens in October, and falls in time to get the benefit of the autumn rains which visit the Pacific coast. Since the trees generally grow along gulches, the fruit falls and rolls to the bottom. The first dashing rain sends a flood down the gulches, the laurel drupes are carried along and are buried in mud wherever they can find a resting place. Germination takes place soon after. The fruit remains under the mud, attached to the roots of the young plants, until the following summer.

The result is that if a laurel gets a foothold in a gulch through which water occasionally flows, lines of young laurels will eventually cover the banks of the gulch as far down stream as conditions are favorable.

The wood of California laurel weighs 40.60 pounds per cubic foot when kiln-dried. That is nine pounds heavier than sassafras. It is very heavy when green and sinks when placed in water. It is hard and very firm, rich yellowish brown in color, often beautifully mottled; but this applies to the heartwood only, and not to the thick sapwood.

Lumbermen have discovered that the wood's color can be materially changed by immersing the logs when green, and leaving them submerged a long time. The beautiful "black myrtle," which has been so much admired, is nothing more than California laurel which has undergone the cold water treatment.

The annual rings of growth are clearly marked by dark bands of summerwood. The rings are of ten wide, but not always, for sometimes the growth is very slow. The wood is diffuse-porous, and the pores are small and not numerous. The wood's figure is brought out best by tangential sawing, as is the case with so many woods which have clearlymarked rings but small and obscure medullary rays. Figure is not uniform; that is, one trunk may produce a pattern quite different from another. The figure of some logs is particularly beautiful; these logs are selected for special purposes. Sudworth says that none of our hardwoods excels it in beautiful grain when finished, and Sargent is still more emphatic when he declares that it is "the most valuable rood produced in the forests of Pacific North America for interior finish of houses and for furniture."

The wood of this tree has more than ninety per cent of the strength of white oak, is considerably stiffer, and contains a smaller amount of 
ash, weight for weight of wood. The species reaches its best development in the rich valleys of southwestern Oregon, where, with the broadleaf maple, it forms a considerable part of the forest growth. The largest trees are from sixty to eighty feet high, an 1 two to four in diameter. In crowded stands the trunks are shapely, and often measure thirty or forty feet to the first limbs; but more commonly the trunk is short.

The boat yards in southwestern Oregon were the first to use California laurel for commercial purposes, but early settlers made a point of procuring it for fuel when they could. The oil in the wood causes it to burn with a cheerful blaze, and campers in the mountains consider themselves fortunate when they find a supply for the evening bonfire.

Shipbuilders have drawn upon this wood for fifty years for material. It is made into pilot wheels, interior finish, cleats, crossties, and sometimes deck planking. Furniture makers long ago made a specialty of the wood for their San Francisco trade. For thirty years travelers admired the superb furniture of the Palace hotel in that city, and wondered of what wood it was made. It was the California laurel. The hotel's furniture was hand-made, or largely so, at a time when woodworking factories were few on the Pacific coast. The furniture was finally destroyed in the San Francisco earthquake. Furniture is still one of the products made of the wood, but the quantity is small. Other products are interior finish; fixtures for banks, stores and offices; musical instruments, including organs ; mathematical instruments, and carpenters' tools, including rulers, straight-edges, spirit levels, bench screws and clamps, and handles of many kinds.

Makers of novelties and small turnery find it serviceable for paper knives, pin trays, match safes, brush backs, and many articles of like kind. One of the largest uses for it is as walking beams for pumping oilwells in central and southern California. The beauty of grain has nothing to do with this use.

Country blacksmiths repair wagons and agricultural implements with this wood. Farmers have long employed it about their premises for posts, gates, floors, and building material. Cooks flavor sonp with the leaves, and ponltrymen make henroosts of poles, believing that the wood's odor will keep insects away. This is probably the old sassafras superstition carried west by early California settlers.

RED BAY (Persea borbonia) is a southern member of the laurel family, and close akin to sassafras and the California laurel. The bark is red, hence the name; but it is known also as bay galls, laurel tree, Florida mahogany, false mahogany, and swect bay. It grows from Virginia to Texas, but is most abundant near the coast, yet it ascends the Mississippi valley to Arkansas. The leaves remain on the tree a full year, but lurn yellow toward the last, in consequence of which the species is not cvergreen. In shape and color the leaves resemble laurel. The fruit is a small, dark blue drupe, 
with thin flesh. The wood is heavy, hard, very strong, rather brittle, bright red, with thin, lighter-colored sapwood. It was once very popular in the South for furniture. Rare pieces, some 150 years old, are still found in southern homes. The wood was exported prior to 1741 from the Carolinas, and the quantity seems to have been considerable. It was then regarded as a finer wood than mahogany. It was exported to the West Indies, where mahogany was abundant, and was made into furniture and finish for the homes of wealthy planters and merchants. An old report describes the wood as resembling "watered satin." It was in early demand by shipbuilders, but it has now ceased to go to boat yards. Except in rare instances, it is not reported by any wood-using industries. In Texas a little is made into pin trays, small picture frames, canes, and shelves. It deserves a more important place, for when polished and finished, it is one of the handsomest woods of this country. Trees attain a height of sixty or seventy feet, and a diameter of two or three.

Swamp Bay (Persea pubescens) attains a height of thirty or forty feet, but is seldom more than a foot in diameter, and is too small for saw timber. The wood is strong, heavy, rather soft, orange colored, streaked with brown, and not as handsome as its larger relative, red bay, which is associated with it from North Carolina to Mississippi. It is an evergreen in some cases, but in others the leaves turn yellow the second spring. The black fruit is a drupe nearly an inch long. The wood is without attractive figure, since its medullary rays are obscure, and the annual rings are indistinct and produce little contrast when the trunks are sawed tangentially. Color is the chief attraction that can be claimed for the wood. A little is occasionally worked into interior finish.

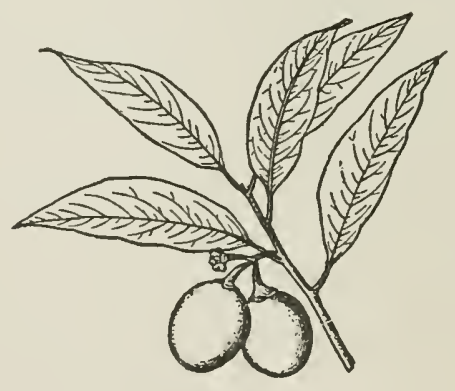


LOCLST 


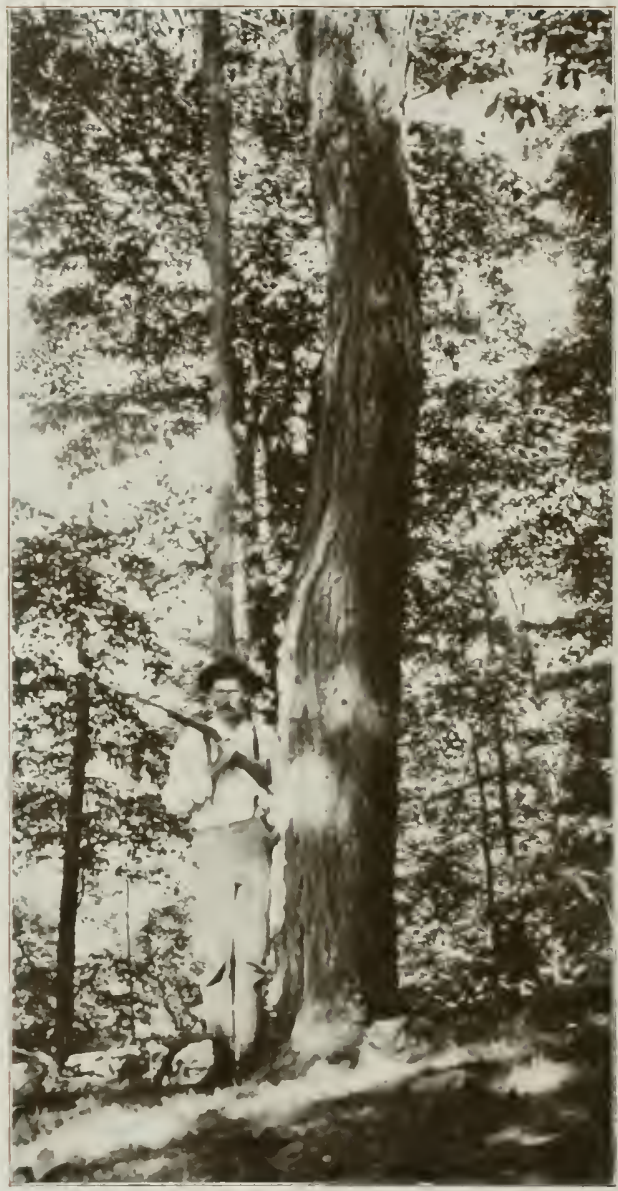

LOCEST 


\section{LOCUST}

\section{(Robinia Pseudacacia)}

L OCUST belongs to the pea family, known in botany as Leguminosa** In most parts of its range it is known simply as locust, but in some localities it is called black locust, an allusion to the color of the bark; yellow locust, descriptive of the heartwood; white locust, referring to the bloom; red locust, probably a reference to the wood, and green locust for the same reason; acacia and false acacia; honey locust, a name which belongs to another species; post locust, because it has always been a favorite tree for fence posts; and pea-flower locust, a reference to the bloom.

Several of the names refer to the color of the wood, and seem contradictory, for yellow, green, and red are not the same; yet the names describe with fair accuracy. Color of the heartwood varies with different trees, yellow with some, tinged with red with others, and sometimes it might be appropriately called blue locust, for the heartwood is nearer that color than any other.

The natural range of locust seems to have been confined to the Appalachian mountain ranges from Pennsylvania to Georgia. It probably existed as a low shrub in parts of Arkansas and Oklahonia. Its range has been extended by planting until it now reaches practically all the states, but is running wild in only about half of them. It has received a great deal of attention from foresters and tree planters. It attracted notice very early, because of its hardness, strength, and lasting properties. At one time the planting of locust came nearly being a fad. In England it was supposed that it would rise to great importance in shipbuilding, and in France it was looked upon as no less important. Books were written on the subject in both English and French. All the details of planting and utilization were discussed. Its generic name, Robinia, is in honor of a Frenchman, Robin. Extravagant claims

*This is a very large family, containing trees, shrubs, and vines, such as locusts, acacias, beans, and clovers. There are 430 genera in the world, and many times that many species. The United States has seventeen genera and thirty species of the pea family that are large enough to be classed as trees. Their common names follow: Florida Cat's Claw, Huajillo, Texan Ebony, Wild Tamarind, Huisache, Texas Cat's Claw, Devil's Claw, Lencæna, Chalky Leucæna, Screwbean, Mcsquite, Redbud, Texas Redbud, Honey Locust, Water Locust, Coffeetree, Horsebean, Small-Icaf Horscbean, Greenbark Acacia, Palo Verde, Frijolito, Sophora, Yellow-wood, Eysenhardtia, Indigo Thorn, Locust, New Mexican Locust, Clammy Locust, Sonora Ironwood, Jamaica Dogwood. These species are treated separately in the following pages, and are given space according to their relative commercial importance in the particular regions where they grow. 
were once made for the wood. When American ships were gaining victory after victory over English vessels in the war of 1812 , it was asserted in England that the cause of American success was the locust timber in their ships. The claim may have been partly true, but other factors contributed to the phenomenal series of successes.

The locust craze died a natural death. Too much was claimed for the wood. Possibilities in the way of growth were over estimated. It was assumed that the tree, if planted, would grow everywhere as vigorously as on its native mountains in Pennsylvania, Maryland, and Virginia, where trees two or three feet in diameter and eighty feet high were found. Experience proved later that nature had planted the locust in the best place for it, and when transplanted elsewhere it was apt to fall short of expectations. Outside of its natural range it grows vigorously for a time, and occasionally reaches large size; but in recent years the locust borer has defeated the efforts of man to extend the range of this species and make it profitable in regions distant from its native home. The tree is often devoured piecemeal, branches and twigs breaking and falling, and trunks gradually disappearing beneath the attacks of the hungry borers. No effective method of combating the pest is known. The planting of locust trees, once so common, has now nearly ceased.

Within its native range, and beyond that range when it has a chance, locust is a valuable and beautiful tree. It is valuable at all times on account of the superior wood which it furnishes, and beautiful when in bloom and in leaf. A locust in full flower is not surpassed in ornamental qualities by any tree of this country. It is a mass of white, exceedingly rich in perfume. It blooms in May or June. During the summer its foliage shows tropical luxuriance with exquisite grace. Its compound leaves are from eight to fourteen inches long, with seven to nine leaflets. They come late in spring and go early in antumn. The tree's thorns, resembling cat claws, are affixed to the bark only, and usually fall with the leaves. The fruit is a pod three or four inches long, and contains four or eight wingless seeds. They depend on animals to carry them to planting places. The pods dry on the branches, and rattle in the wind most of the autumn. The tree spreads by underground roots which send up sprouts. A locust in winter is not a thing of beauty. It appears to be dead; not a bud visible. Its black, angular branches lack every line of grace.

Locust wood is remarkable for strength, hardness, and durability. It is about one pound per cubic foot lighter than white oak, but is thirtyfour per cent stiffer and forty-five per cent stronger. Its strength exceeds that of shagbark hickory, and it is doubtful whether a stronger 
wood exists in the United States. Its hardness is equally remarkable, and is said to be due to crystals formed in the wood cells, and known as "rhaplides." Its durability is probably equal to that of Osage orange, mesquite, and catalpa, but it is not easy to fix a standard of durability by which to compare different woods. Locust is the best fence post wood in this country, because it is usually much straighter than other very durable woods. The posts are expected to last at least thirty years, and have been known to stand twice that long.

For more than 150 years locust was almost indispensable in shipbuilding, furnishing the tree nails or large pins which held the timbers together. It supplied material for other parts of ships also, but in smaller quantities. The substitution of steel ships for wooden lessened demand for locust pins, and in many instances large iron nails are used to fasten timbers together. In spite of this, the demand for locust tree nails is nearly always ahead of supply.

The wood's figure is fairly strong, due to the contrast between the springwood and that grown later, but not to the medullary rays, which are small and inconspicuous. The wood is not in much demand for ornamental purposes. Small amounts are made into policemen's clubs, rake teeth, hubs for buggy wheels, ladder rungs, and tool handles.

The tree grows rapidly where conditions are favorable, and very slowly when they are not. Usually trees of fence post size are twenty years old at least, but trunks thirty five years old have been known to produce a post for each two years of age, though that was exceptional. Railroads, especially in Pennsylvania, planted locust largely a few years ago for ties. It has been reported that in some instances expectations of growth have not been fully realized.

Clamm Locust (Robinia viscosa) was originally confined to the mountains of North Carolina and South Carolina where its attractive flowers brought it to the notice of nurserymen who have enlarged its natural range a hundred if not a thousand fold. It is now grown in parks and gardens not only in the United States east of the Mississippi river and as for north as Massachusetts, but in most foreign countries that have temperate climates. It is usually a shrub, but on some of the North Carolina mountains it attains a height of forty feet and a diameter of twelve inches. The wood is seldom or never used for any commercial purpose. The leaves are from seven to twelve inches long, and contain thirteen to twenty-one leatlets. The Howers appear in June, possess little odor, and are admired solely for their beatty. They are mingled red and rose color. The pods are from two to three and a half inclies long, and contain small, mottled seeds. The wood is hard and heavy, the heart brown and the sap yellow. In its wild haunts it is usually a slirub five or six feet high.

New Mexican Locust (Robinia neo-mexicana) is a small southwestern tree, seldom exceding a height of twenty-five feet or a diameter of eight inches. It ranges from Colorado to Arizona, and takes its name from its prescnce in New Mexico. It reaches its largest size near Trinidad, Colorado. It is found al elevations of 7,000 feet. Leaves are from six to twelve inches long, and the leaflets number from fifteen 
to twenty-one. The flowers appear in May and are less showy than those of the eastern locust. The wood is heavy, exceedingly hard, the heartwood yellow, streaked with brown, the thin sapwood light yellow. This locust is occasionally used locally for small posts or stakes, but is generally too small. It is sometimes met with in cultivation in Europe and the eastern states.

Texan EBory (Zygia flexicaulis) ranges from the Texas coast through Mexico to Lorrer California. It reaches a height of thirty feet or more, and a diameter of two or less. It is a beautiful tree along the lower Rio Grande where it reaches its largest size. The light yellow or cream-colored, very fragrant flowers bloom from June till August; the fruit ripens in Autumn but adheres several months to the branches. Mexicans roast the seeds as a substitute for coffee. The color of the heartwood gives this tree its name, but it is not a true ebony. The wood of the roots is blacker than that of the trunk, and small articles snade of roots resemble black ebony of Ceylon. The trunk wood is liable to be streaked with black, brown, and medium yellow. The rings of annual growth are frequently of different colors. Considerable demand is made upon this wood in Texas for crossties. It is very durable, but is so hard that holes must be bored for the spikes. It is sold in large amounts as cordwood, and it burns well. Other articles made of this so-called ebony are foundation blocks for buildings and rollers for moving houses. It is used also for small turnery.

HUaj1LLO (Zygia brevifolia) has no English name, but Americans in the Rio Grande valley where this tree grows call it by its Mexican name. It is a larger tree in Mexico than on this side of the river. It is not often more than thirty feet high and six inches in diameter, and is generally a shrub. Its beautiful foliage looks like masses of ferns, and the flowers range from white to violet-yellow. The rood is dark, hard, heavy, and is seldom used for anything but fuel.

FLORIDA CAT'S ClAw (Zygia unguis-cati), with a Latin name that would make Julius Caesar stare and gasp, reaches its largest size in the United States on Elliott's Key, Florida. Its name refers to its curved thorns. Trunks twenty-five feet high and eight inches in diameter are the largest in this country. It bears pods, but the leaves are not compound, thus differing from most trees of the pea family. The wood is not put to any use, though it is very hard and heavy, rich red, varying to purple, with clear yellow sapwood. It is said to check badly in drying. The bark is used for medicine in some of the islands of the West Indies.
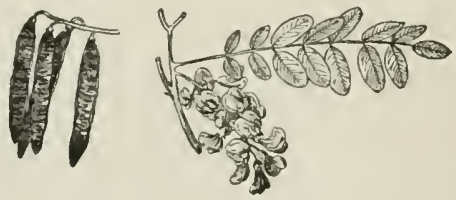
HONEY LOCUST 


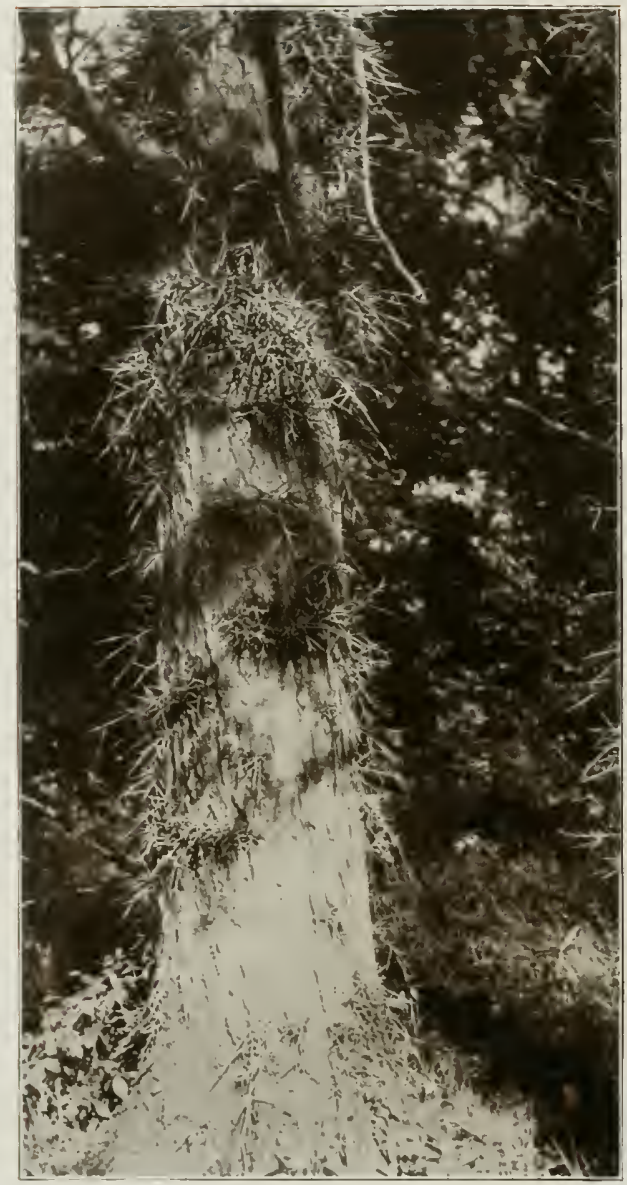

HWNEY LACISI 


\section{HONEY LOCUST}

(Gleditsia Triacanthos)

$\mathrm{T}$ HIS tree has never suffered for want of names, but most of them refer either to the sweetness of the pod or to the fierceness of the thorns. The belief has long prevailed that it was the pods of this tree on which John the Baptist fed while a recluse in the Syrian desert. The tradition should not be taken seriously. It was certainly not this tree, if any, which furnished food to the prophet in the wilderness, for it does not grow in Syria. Some related species may grow there, for species of Gleditsia occur in western Asia as well as in China, Japan, and west Africa. The generic name is in honor of Johann Gottlieb Gleditsch, a German botanist who died in 17 S6.

The name honey locust refers to the pod, not the flowers. The latter are greenish, inconspicuous, and though eagerly sought by bees, they offer no particular attractions to people. Few persons ever notice them.

In some of the southwestern states the tree is called black locust, though for what reason it is not apparent. Sweet locust, by which name it is known in several states, has reference to the pods, as do the names honey, and honey-shucks locust, applied in different localities. Many persons in naming the tree have thorns in mind. It is known as threethorned acacia, thorn locust, thorn tree, thorny locust, and thorny acacia. The botanist who named it considered thorns a characteristic, for Triacanthos means "three-thorned."

No one who has ever had dealings with the thorns, will fail to duly consider them. They are about the most ferocious product of American forests. The tree's trunk and largest branches bristle with them, standing out like porcupine quills, and sharper than any needle devised by human ingenuity. Microscopists use them for picking up and handling minute objects, their points being smootl and delicate though their shafts may be strong and rongh. Thorns are arrested branches, coming from deep down in the wood. No inore can one of them be pulled out than a limb can be extracted by the roots. They come from the center of the tree or limb. Some put out leaves and becone true branches, but others sharpen their points, assume an attitude of hostility, and remain thorns to the end of their lives. Some of them are a foot long, and are so strong that birds flying against them are impaled and meet cruel death. A well-armed trunk is proof against the agility and skill of the squirrel. He cannot negotiate the thorns, and probably he tries only once. The hot pursuit of a dog will not compel him to 
attempt it. All trees, however, are not formidably thorned; some have few, and certain varieties have none.

The honey locust is sometimes called the Confederate pin tree in the South. This is a reference to the Civil war, and the use occasionally made of the thorns by soldiers in mending the rents in their torn uniforms. The thorns were once put to a somewhat similar use among the Alleghany mountains where local factories for carding and spinning country wool employed them to pin up the mouths of wool sacks.

The natural range of honey locust has been greatly extended by man. It was not originally found east of the Alleghany mountains. It grew from western Pennsylvania to northern Alabama and Mississippi, and westward to Nebraska and Texas. It is now naturalized east of the Alleghanies, and southward to the Gulf of Mlexico. Planting for ornamental purposes and for hedges has been the cause of its extension into new territory. In spite of thorns, it is ornamental. Its foliage is thin, and its flowers inconspicuous, but the tree possesses a grace which wins it favor. It grows very rapidly, and in a short time a seedling becomes a respectable tree, and continues its rapid growth a long time. In southern Indiana and Illinois, which is the best part of its range, trees have attained a height of 140 feet and a diameter of six. The average size of forest-grown specimens is serenty-five feet in height, and two or more in diameter.

The leaves are seven or eight inches long, doubly compound; the fruit a pod a foot or more in length, which assumes a twist when ripe, or sometimes warps several ways. The green pod contains a sweet substance of ten eaten by children, but it is believed to be of little value for human food. Cattle devour the pods when in the sugary condition; but they cannot of ten obtain them, because thorns intervene, when the pods wonld otherwise be in reach. In rural districts, a domestic beer is brewed from the young fruit. The juice extracted from it is permitted to ferment, but the beverage is probably never sold in the market.

The pods are in no hurry to let go and fall, even after they are fully ripe. They become dry, distort themselves with a number of corkscrew twists, and hang nntil late fall or early winter, rattling in the wind and occasionally shaking out a seed or two.

Honey locust has never been considered important from the lumberman's standpoint. Sawlogs go to mills here and there, but never many in one place. The wood is not listed under its own name, but is put in with something else. Occasionally, it is said, it passes as sycamore in the furniture factory, though the difference ought not be difficult to detect. It doubtless depends to a considerable degree on the particular wood, for all honey locust does not look alike when converted 
into lumber. Some of that in the lower Mississippi valley might pass as sycamore if inspection is not too conscientiously carried out. The medullary rays, being darker than the body of the wood, suggest sycamore in quarter-sawed stock. Some of it goes into furniture, finish, balusters, newel posts, panels, and molding, particularly in eastern Texas. In Louisiana, where wood of similar texture and appearance might be expected, it is not looked on with favor, but is employed only in the cheapest, roughest work.

The principal use of the wood is for posts and railroad ties. It lasts well, and is strong. Claims have been made that it is generally equal and in some ways superior to locust. It is difficult to see on what these claims are based. It is lighter, less elastic, and much weaker. Figures showing the comparative durability of the two woods are not available, but in like situations, locust would doubtless last much longer. As timber trees, the former may have the advantage over locust in being free from attacks of borers, attaining greater size, and thriving in a much larger area. It has been planted for ornament in other lands than this, and is now prospering in all the important countries of the temperate zone. One variety is thornless, and is known to botanists as Gleditsia triacanthos lavis; another has short thorns.

Water Locust (Gleditsia aquatica) looks so much like honey locust that the two are often supposed to be the same species in Louisiana; yet there are a number of differences. Water locust has fewer thorns and they are smaller, and of ten flat like a knife blade. The pods are entirely different from those of honey locust, being short and wide. The two species share the same range to some extent, but that of water locust is smaller, extending from South Carolina to Texas, Illinois, and Missouri; but the best of the species is west of the lower Mississippi where trees may reach a height of sixty feet and a diameter of two. The wood is heavy, hard, and strong, the heartwood rich bright brown, tinged with red, the sapwood yellow. The wood is much like that of boney locust, and when used at all is employed in the same way.

TEXas Locust (Gleditsia texana) is of no importance as a timber tree, and deserves mention only becanse its extremely restricted range gives it an interest. It exists, as far as known, in a single grove on the bottom lands of the Brazos river, near Brazoria, Texas, where some of the trees exceed 100 feet in height, and a diameter of two. The bark is smooth and thin, the leaves resemble those of honey locust, and the pods are about one-third as long.

Hetsache (Acacia fornesiana) is native along the Rio Grande in Texas, but it is running wild in Florida from planted trees. It is one of the most widely distributed species in the world, both by natural dispersal and by planting; and it is one of the handsomest members of the large group of acacias which includes more than 400 species. It bears delicate double-componnd leaves, small and graceful. A tree in full leaf in its native wilds along the Rio Grande looks like a trembling tluffy mass of green silk. Nature formed the tree for ornament, not for timber. It attains a height of from twenty to forty feet, diameter eighteen inches or less. Trunk usually divides into several branches near the gromnd. Perhaps the only place in this country where the wood is used is in southern Texas where is it called "cassie," a 
shortening of acacia. The wood so much resembles mesquite that locally they are considered the same. Huisache rarps and checks in seasoning, but it is employed in a small way for furniture, usually as small table legs, spindles, knobs, and ormaments. It takes high polish, and resembles the best grades of black walnut, but is much heavier, harder, and stronger. It is next to impossible to drive a nail into it without first boring a hole. When used as crossties, holes must be bored for the spikes. The heartwood resists decay a long time, but the thin sapwood is liable to be riddled by small boring insects, which seldom or never enter the beartwood.

Texas CAr's CLAW (Acacia urightii) is a hardluck tree of western Texas where it is usually found on dry, gravelly hills and in stony ravines. Its twice-compound leaves are among the smallest of the acacias, seldom exceeding two inches in length. The fragrant, light yellow flowers appear from March to May, and the short pods ripen in midsummer, but like so many trees of the pea family, they are in no hurry to fall. The largest trees are thirty feet high and one in diameter, but most people associate cat's claw with low, tangled brush, tough as wire, and armed with curved thorns so strong that their hold on clothing can hardly be broken. Then a cat's claw bush strikes out to become a tree-which is infrequent-it grows rapidly. It has been known to attain a diameter of nine inches in twenty-three years. The beart is dark in color and exceedingly hard. The color varies from nearly red to nearly black, and takes a polish almost like ivory. The thin yellow sapwood is preyed on by boring insects. Heartwood is made into canes, umbrella sticks, tool handles, rulers, and turned novelties.

DEY'u's CLAW (Acaciu greggii) has such paradoxical names as paradise flower, ramshorn, ard cat's claw. It deserves them all where it grows wild on the semideserts of the Southwest from Texas to California. The double-compound leaves are one or two inches long, its bright, creamy-yellow and exquisitely fragrant flowers are the glory of desert places, while its masses of thorns readily suggest the common name by which it is known. The wood is scarce, but extraordinarily fine. It is dark rich red, but clorided with streaks and patches of other shades, becoming at times gray, at others green. No nail can be driven into it, and an ordinary gimlet will hardly bore it. It is so saturated with oil that it is greasy to the touch. It is manufactured into small articles, but apparently is not used outside of the locality where it grows. The wood is often contorted, due to pits and cavities which slowly close as the tree advances in age. They add to rather than detract from the wood's beanty.

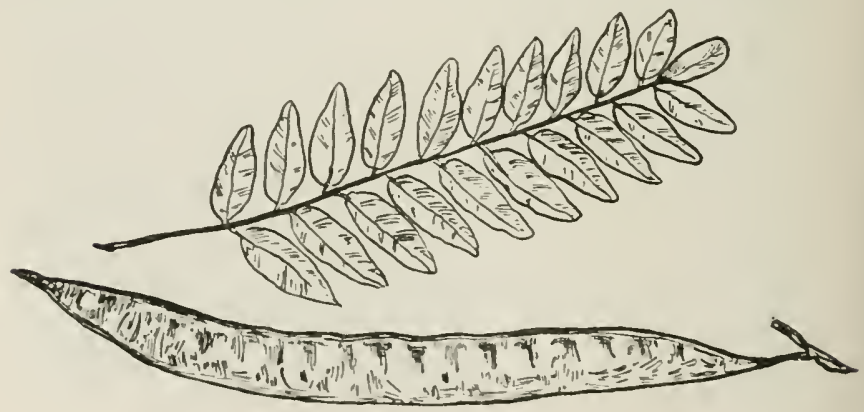


COFFEE TREE 


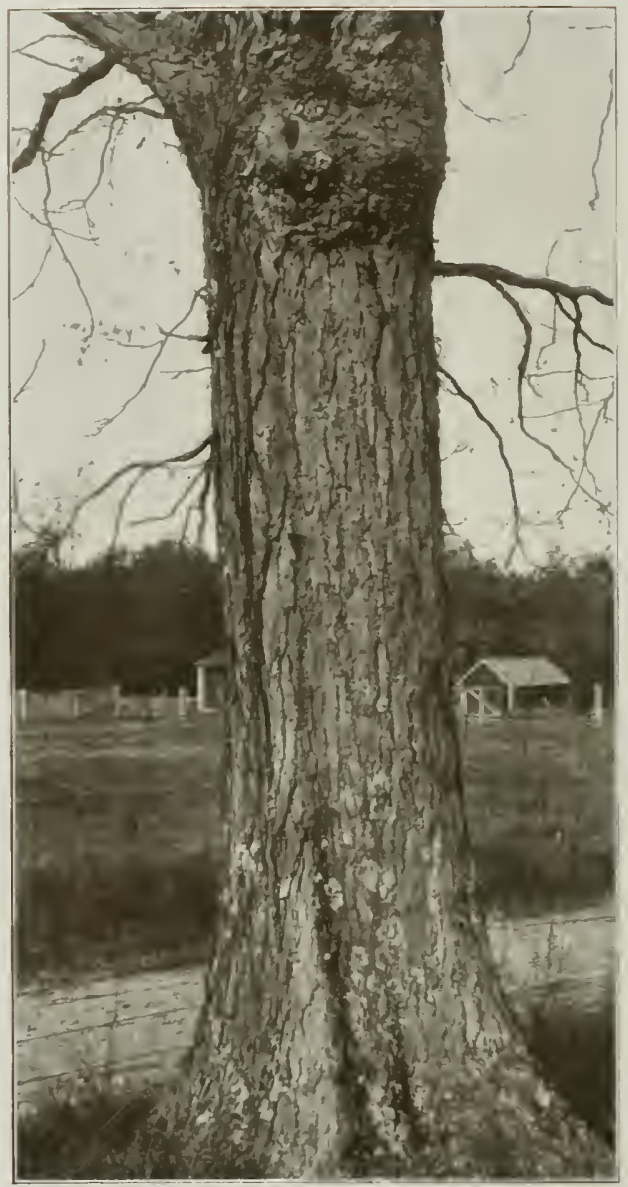

Cuffee TreE 


\section{COFFEETREE}

(Gymnocladus Dioicus)

$\mathrm{T}$ HIS tree is scarce though its range covers several hundred thousand square miles, from New York to Minnesota, and from Tennessce to Oklahoma. It never occurs in thick stands, and usually the trees are widely scattered. Many districts of large size within the limits of its range appear to have none.

The names coffeetree and Kentucky coffeetree refer to the custom of the pioneers, who settled the region south of the Ohio river, and who used the grotesque fruit as a substitute for coffee at a time when the genuine article could not be procured. The seed is a very hard bean that can be procured in abundance, where trees abound.

The beans were sof tened by roasting or parching, and were then pounded into meal with hammers, and boiled for coffee. The beverage was black and bitter, and a little of it would go a long way with a modern coffee drinker. When the Kentuckians were able to procure coffee they let the wild substitute alone.

The name was sometimes varied by calling it coffeenut or coffeenut tree, and sometimes it was known as coffeebean and coffeebean tree. It is less easy to explain why it was called mahogany in New York, and virgilia in Tennessee. Some knew it as the nicker tree, but the reason for the name is not known. Stump tree was another of its names. This was meant to be descriptive of the tree's appearance after it had shed its leaves. It has remarkable foliage, double compound leaves two or three feet long, with four or five dozen leaflets. When leaves fall in autumn it looks as if the tree is shedding its twigs; and when all are down, the stripped and barren appearance of the branches suggests the name stump tree.

The flowers are greenish-purple and are inconspicuous. In this respect they differ from many trees of the pea family which are noted for their attractive bloom. The fruit is among the largest of the tree pods of this country, ranging in length from six to ten inches and from one and a half to two in width. When fully grown they are heavy enough to make their presence felt if they drop on the heads of persons beneath. They are slow to fall, however, and it is not unusual for them to cling to the branches until late winter or early spring.

The coffeetree has been known to attain a diameter of five feet and a height of more than a hundred, but the usual size is about half of that. It prefers rich bottom lands, and the trunks gencrally separate into several stems a few feet above the ground. Only one spccies exists 
in this country, and as far as known, only one other species elsewhere, and that grows in southern China where it is said the natives make soap of the pods. It is not known that any such utilization has been attempted in this country.

The coffeetree's range has been considerably extended by planting for ornament. In summer it is attractive, but from the first autumn frost until the leaves put out the following spring, it is uninteresting. The spring leaves are late, and the branches are bare more than half the year.

The wood is heavy, strong, and durable in contact with the soil. The heart is rich light brown, tinged with red, the sapwood thin and lighter colored. Annual rings are distinct. The springwood is porous and wide, the summerwood dense. The medullary rays are inconspicuous and of no value in giving figure to the wood. When the annual rings are cut diagonally across they give figure like that of ash. The wood of the coffeetree has never been in much demand. Furniture makers may use it sometimes, but specific instances of such use do not exist in manufacturers' reports. There are many places in furniture and finish which it might fill in a satisfactory manner.

It is suitable for fence posts, and that is where it commonly gives service. It is occasionally employed as frame work in house and barn building, but is not sought for that purpose, and is used only when it happens to be at hand. Though the tree has the habit of branching, some of the trunks grow tall and shapely, and are good for two or three sawlogs or railcuts. An occasional tree serves as fuel. Medicine is sometimes made of a decoction of the fresh green pulp of unripe pods; and the leaves are reported to produce a fly poison if soaked in water.

REDBUD (Cercis canadensis) is also known as Judas tree, red Judas tree, Canadian Judas tree, and salad tree. The last name refers to a custom in some parts of its range of making salad of the flowers. It is the flower rather than the bud that is red and gives the tree its name, the bloom being conspicuous in early spring. The tree ranges from New Jersey to Missouri, Texas, Louisiana, and Florida, but reaches its fullest development in southern Arkansas, Oklahoma, and eastern Texas where trunks fifty feet high and a foot in diameter are found. It is shrubby in many parts of its range. Leaves are not compound. The fruit is a pink or rose-colored pod two or three inches in length, and by some is considered nearly as ornamental though not as showy as the flowers. No one ever thinks of redbud as a timber tree or considers its wood, yet it might be used for a number of purposes. It is heavy and hard, but weak; and the heartwood is rich dark brown tinged with red. The tree is planted for ornament in this country and Europe. 
Texas ReDBud (Corcis reniformis) differs somewhat from the common redbud, but it takes a botanist to point out the differences. The largest trees are forty feet high and a foot in diameter; the range extends from eastern Texas into Mexico; the wood closely resembles that of the other species, and is not known to be used for any purpose.

California Redbud (Cercis occidcntalis) is of ten classed as a shrub, but Sudworth gives it a place among the forest trees of the Pacific coast. The pea-shaped flowers are a clear magenta color. The pods turn purple when ripening but afterwards change to russet-brown. The wood is dark yellowish-brown, but because of the smallness of the trunks, it can never be important. The tree is found along the California mountains, six hundred miles north and south; is an abundant seeder, and is valuable as a protection to slopes and ravines, and as an ornament.

Horsebean (Parkinsonia aculeata) is generally called retama in the valley of the lower Rio Grande in Texas where the species attains its largest size. Trees are occasionally thirty feet high and a foot or more in diameter. Trunks usually separate in several stems near the ground. The range extends from southern Texas to California, and the species is naturalized in south Florida, the West Indies, and many tropical countries. Leaves vary in form, and are occasionally eighteen inches long. Fruit consists of pods, each containing from two to eight beans. The yellow flowers are small and fragrant; the bark on young twigs is green, but on older trunks is brown. The brown, however, is easily rubbed off, exposing the green beneath, as may be seen in school grounds in some of the southern towns in Texas where this tree has been planted for ornament, and abrasions, due to children climbing about the spreading stems, keep the bark green. The upper branches are armed with thorns which discourage the climbing propensities of children. The wood is heavy, hard, tinged with yellow, and is made into small novelties, but is not of much importance.

Small-Leaf Horsebean (Parkinsonia microphylla) is well named, for the compound leaves, with four or six pairs of leaflets, are about an inch long, covered with hairs, and fall at the end of a few weeks. Consequently, the tree is bare inost of the year, except for the pale yellow flowers which appear in spring before the leaves, and the clusters of striped pods, each containing from one to three beans. The pods are nearly always present, for they have the pea family habit of adhering to the branches a long time. Trees reach a lieight of fifteen or twenty feet, and a diameter of ten inches or less. The wood is very hard and dense, in color deep yellowish-brown, of ten mottled and streaked with dull red; the sapwood thick and yellow. The wood is suitable for small articles, but its scarcity renders it of little importance. It is found in the 
deserts of southern Arizona and the adjacent parts of California, and is usually a small shrub.

JAMAICA DOGwOod (Ichthyomethia piscipula) is the lone representative of the genus, and is found in this country only in southern Florida. It is not in the same family wit'. he dogwoods, and its name is misleading. The Carib Indians formerly used the leaves to stupify fish and render them easier to catch; hence the botanical name. The leaves are compound, but bear little resemblance to the foliage of most members of the pea family to which this tree belongs. The flowers are the tree's chief source of beauty, and are delicately clustered, hanging in bunches a foot long. The fruit is a pod three or four inches long, with four wings running the full length. The wings are useless for flying. Trees are forty or fifty feet high and two or three feet in diameter; are common in southern Florida and on the islands. The wood is of considerable importance in the region where it grows but figures little in general markets. It weighs 54.43 pounds per cubic foot, and is moderately strong and stiff. In color it is a clear yellow-brown, with thick, lighter colored sapwood. It is very durable in contact with the ground, and in Florida it is used for posts, and occasionally for railway ties. It has been commonly reported as a wood for boatbuilding in Florida, but its importance for that purpose has probably been overstated, since an investigation of the boatbuilding industry in Florida failed to find one foot of this wood in use, although some may be employed but not listed in reports.

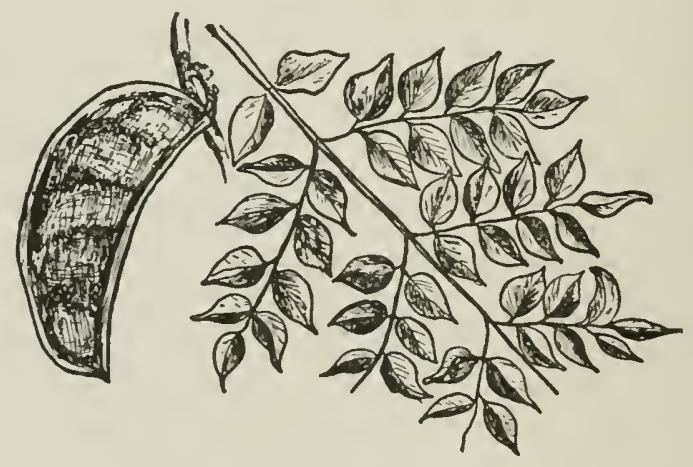


YELLOW- ITOOD 


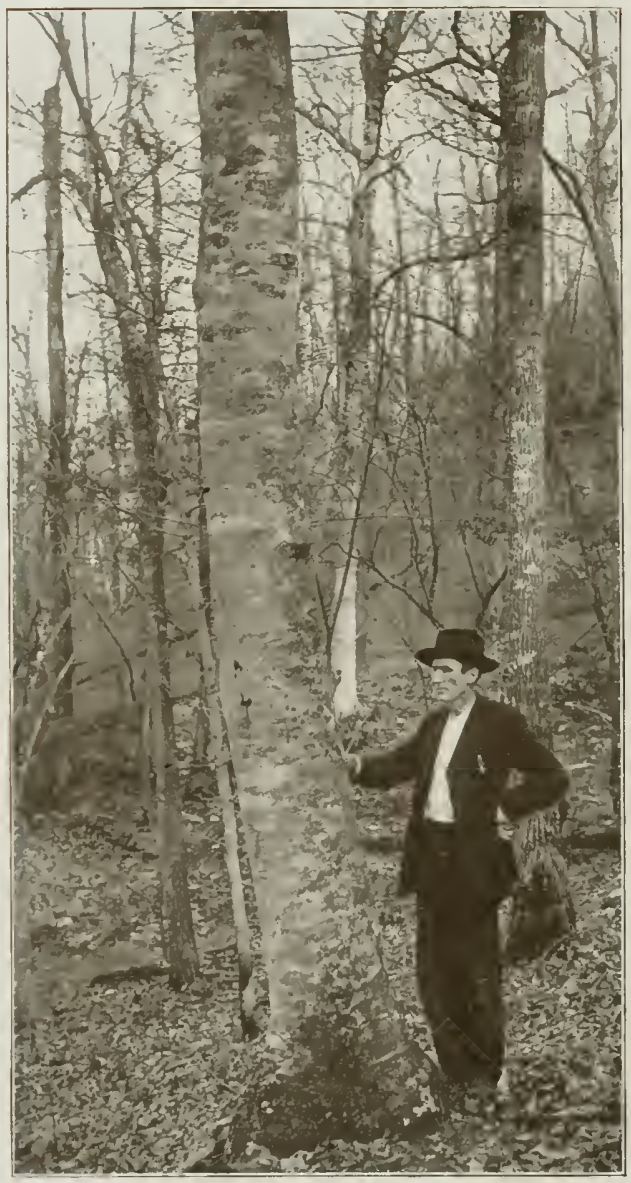

YELLOW-WOOD 


\title{
YELLOW-WOOD
}

\author{
(Cladrastis Lutea)
}

$\mathrm{T}$ HIS wood's color is evidently responsible for its names yellow ash, yellow locust, and yellow-wood in Tennessee, North Carolina, and Kentucky, but no reason is offered for the name gopherwood by which it is known in some parts of Tennessee. The botanical name is based on the brittleness of the twigs. It is the only species of the genus, and it is not known to grow anywhere, except by planting, outside of Kentucky, Tennessee, Alabama, and North Carolina.

It occurs in an area not much exceeding 60,000 square miles, and it is not abundant in that area. It prefers limestone ridges and slopes, and does best where the soil is fertile. It often overhangs the banks of mountain streams, and is most abundant and of largest size in the vicinity of Nashville, Tennessee, where a few trees have reached a diameter of three or four feet and a height of fifty or sixty. A diameter of eighteen or twenty-four inches is a good average.

The tree's habit of dividing six or seven feet from the ground into two or more stems is responsible for the scarcity of trunks suitable for saw timber, even in localities where trees of large size are found. However, an occasional trunk develops a shapely form. It goes to sawmills so seldom that it is never mentioned in statistics of lumber cut or woodutilization.

Most people who are acquainted with this tree, know it as planted stock in parks and yards where it is a favorite on account of its flowers. The bloom may properly be described as rare from two viewpoints. The beauty of its large clusters of white flowers differs from those of all associated trees; and it seldom blooms. One year of plenty is generally followed by several lean years. Those who plant the tree understand this, and feel amply repaid for the long wait, when the flowering year arrives. The planted tree is of ten known as virgilia, that being the name under which nurseries sell it. Flowers appear about the middle of June, in clusters a foot or more in length. It is claimed, but with what correctness cannot at present be stated, that the odor of flowers of different trees varies greatly, being faint with some, and strong and luxurious with others.

The leaves are compound, but have no resemblance to those of locust and the acacias. They are eight or twelve inches long, with five or seven leaflets. In autumn before falling they cliange to a clear yellow, but adhere to the branches until rather late in the season. The fruit, which consists of small pods hanging in clusters, is ripe in September. 
Yellow-rrood is a little below white oak in strength and seven pounds per cubic foot under it in weight; is hard, compact, and susceptible of a beautiful polish. Rings of yearly growth are clearly marked by rows of open ducts, and contain many evenly-distributed smaller ducts. The wood is bright, clear yellow, changing to brown on exposure; sapwood nearly white. Trunks of largest size are generally hollow or otherwise defective.

The uses of yellow-wood have been few. In the days when families in remote regions were under the necessity of manufacturing, growing, or otherwise producing neariy every commodity that entered into daily life, the settlers among the mountains of Kentucky and Tennessee discovered that the wood of this tree, particularly the roots, yielded a clear, yellow dye. The process of manufacture was simple. The wood was reduced to chips with an ordinary ax, and the chips were boiled until the yellow coloring matter was extracted. The resulting liquor was the dye, and it gave the yellow stripe to many a piece of homemade cloth in the cabins of mountaineers.

The women usually attended to the dye making and the manufacture of yarn and cloth; but the men found a way to utilize yellowwood in producing an article once so common in Tennessee and Kentucky that no cabin was without it-the trusty rifle. The gunsmith, assisted by the blacksmith, made the barrel and the other metal parts, but the hunter generally was able to whittle out the wooden stock. Yellow-rood's lightness, strength, and color suited the gun stock maker's purpose, and he slowly hewed and whittled the article, fitted it to the barrel, adjusted it to his shoulder, and completed a weapon which never failed the owner in time of need.

Frijolito (Sophora secundiflora) is found in Texas, New Mexico, and southward in Mexico. The name is Spanish and means "little bean." A common name for it in English is coral bean. Sophora is said to be an Arabic word of uncertain meaning, except that it refers to some kind of a tree that bears pods. It is a species, therefore, which draws its names from four languages, while the name applied to it by Comanche Indians is translated "sleep-bush." The bright scarlet seeds, as large as beans, but in shape like door-knobs, grow from one to eight in a pod, and contain a narcotic poison, "sophorin." It is probable that Indians discovered that the beans, if eaten, produced sleep, hence the name. The tree is from twenty-five to thirty-five feet high, and from six to ten inches in diameter. The leaves are compound, and consist of seven or nine leafiets. The small, violet-blue flowers appear in early spring. They are not conspicuous, but their presence cannot escape the notice of a traveler in the dry, semi-barren canyons and on the 
bluffs where the tree holds its ground. Their odor calls attention to their presence. The perfume is powerful but pleasant, unless the contact is too close. The pods are from one to seven inches long, and hang on the boughs until late winter. It is not believed that birds or mammels distribute the seeds, as their poison renders them unfit for food. Running water appears to be the principal agent of distribution. The tree reaches its largest size in the vicinity of Metagorda bay, Texas. Among the dry western canyons it is usually a shrub. The small size of this tree stands in the way of extensive use of the wood. It burns well and its principal importance is as fuel. The weight is 61.34 pounds per cubic foot; it is hard, compact, susceptible of a beautiful polish; medullary rays are numerous and thin; color is orange, streaked with red, the sapwood brown or yellow. The wood is worked in to a few small articles.

SOPHORA (Sophora affinis) ranges through portions of Arkansas and Texas. It is popularly supposed to be a locust, and is called pink locust or beaded locust, the first name based on the color of the wood, the last on the appearance of the pod which looks like a short string of beads, sometimes three inches in length, but usually shorter. In early times the pioneers manufactured ink from the pods. It was a fairly serviceable article, but was never sold, each family making its own. This tree's flowers appear in early spring with the leaves. Trunks reach a height of twenty feet and a diameter of eight or ten inches; but the habit of separating into several stems a few feet above the ground lessens the use of the wood, even as posts, for the stems are usually very crooked. The tree's preferred habitat is on limestone bluffs, or along the borders of streams, or in depressions in the prairie where small groves often occur. The wood weighs fifty-three pounds per cubic foot, and is very hard and strong. The annul rings are clearly marked with bands of large, open pores; medullary rays are thiu and inconspicuous; color of the heartwood light red, the sapwood yellow. The wood is not sawed in to lumber, but is whittled into canes and tool handles.

Greenbarh ACACIA (Cercidium florilum) is properly named. Its green bark makes up for its scarcity of leaves, and answers the purpose of foliage. The manufacture of the tree's fond goes on in the bark, because the leaves are too small to do the work. The foliage resembles that of locust and acacia in form, but the compound leaves are about an inch in length, and the leaflets are one-sixteenth of an incli long. Flowers are small, but the tree puts on three or four crops of then in a single summer. The pods are two inches long. The tree is found in the United States only in the south and west of Texas, where it is occasionally called palo verde. It attains a height of twenty feet and a diameter 
of ten inches when at its best. The wood is pale yellow tinged with green, and, because of small size, is of little importance.

PALO Verde (Cereidium torreyanum) sheds its leaves and its pods so early in the season that its branches are bare most of the year. Trees are from fifteen to thirty feet high, and some are considerably more than a foot in diameter. Its range covers a portion of sonthern California, the lower part of the Gila valley in Arizona, and extends southward into Mexico. It is a typical tree of the desert, and its extreme poverty of foliage enables it to live in a dry, hot climate. It clings to the sides of desert gulches and canyons, ekes out a dreary life in depressions among desolate dunes and hills of sand and gravel, and spends its allotted period of years in solitude, growing either singly or in small groups where the full foliage at the best time of year is insufficient to offer much obstruction to the full glare of the sun from a cloudless sky. The small flowers have little beauty or sweetness, but what they have is wasted on the desert air. Wayfarers in the barren country use the wood for camp fires.

INDIGo THORN (Dalea spinosa) receives its name from the color of its flowers which appear in June. The tree has few leaves and they fall in a short time. This appears to be a provision of nature to enable the tree to endure the heat and dryness of its desert home. Its range covers the lower Gila valley in Arizona, and extends into the Colorado desert in southern California. It is not abundant, and if it were, it is of a size so small that it is practically valueless for commercial purposes. Some trees are a foot in diameter and twenty feet high. The wood is light, soft, and of a rich chocolate-brown color. It is known also as indigo bush and dalea.

EYSENHARDTIA (Eysenhardia orhocarpa) is so little krown that it has no English name. It grows from western Texas to southern Arizona, but reaches tree size only near the summit of Santa Catalina mountains in Arizona where it is twenty feet or less in height and seldom more than eight inches in diameter. It inhabits an arid region, and bears fruit sparingly, with usually a single seed in a pod. The wood is heavy and hard, light reddish-brown in color, with thin yellow sap. It is not of commercial importance and probably never will be.

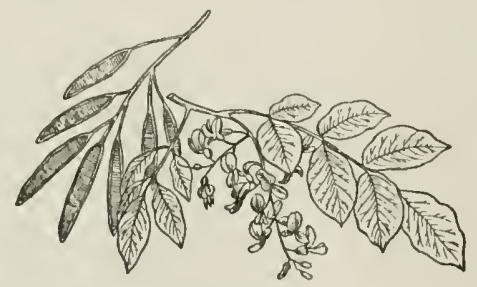


MESQUITE 


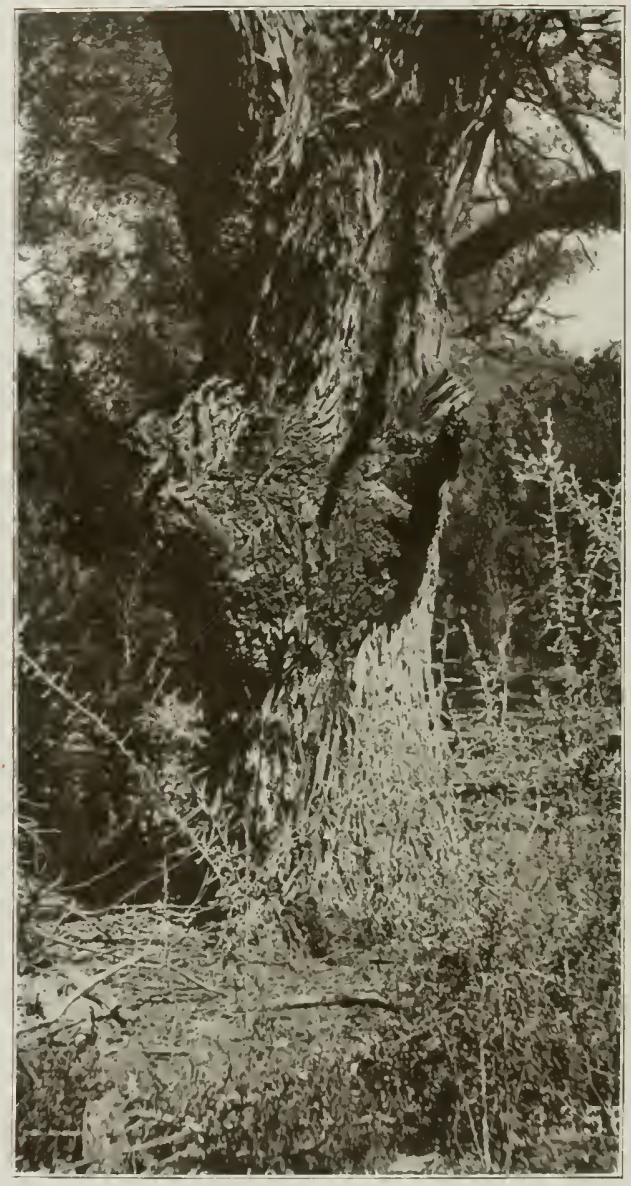

MESOUTTE 


\section{MESQUITE}

(Prosopis Juliflora)

$T^{\prime}$ HERE are known to be sixteen species at least of mesquite in the world, in Asia, Africa, and North and South America. The one here considered has a geographical range of at least seven thousand miles north and south, from Kansas to Patagonia, and an east and west range of four thousand miles, if the naturalized growth in Hawaii may be considered the western outpost of the species. *

The generic name prosopis is a Greek word meaning "burdock;" the rest of the botanical name is Latin, meaning "July flower." Mesquite is an Aztec word (mezquitl), coming down through the Spanish. Other names for the tree are algaroba, honey locust, honey pod, and ironwood.

The largest size of mesquite is found along the Rio Grande in southcrn Texas where trees three feet in diameter and fifty feet high are found, but individuals of that size are rare. The species is supposed not to extend west of New Mexico, but varieties grow farther west.

The leaves are compound, with twenty or more leaflets. The foliage is thin and casts a penumbrous shadow; trees generally occur wide apart, and there is enough sunshine reaching the ground to satisfy grass and other plants growing there. The pods are from four to nine inches long, and each contains from ten to twenty seeds. The principal growth of this tree in the United States is in Texas. It has been planted in Hawaii and has run wild in some of the islands of the group. It is of slow growth, but of remarkable vitality, holds its own, and gains ground in the face of obstacles.

Persons well acquainted with conditions in Texas, both past and present, say that the mesquite area is at least double now what it was when the state came into the Union. Old stands were scattered here and there, but hundreds of square miles which were in grass only, and little of that, half a century ago, now support forests of mesquite. It is perhaps a misnomer to designate some of these stands as forests, for they present a rather ragged and sorry appcarance, but they are forests in the process of forming. The old growth, which is found principally in the counties bordering on the lower Rio Grande, is made up of trunks of large size, but the stands that have come on within the past fifty or sixty years are of smaller trees. A large mesquite trunk is from

* Botanists have had much controversy among thcmselves concerning mesquite, particularly as to what is its correct name. In giving in thesc pages some of the important facts concerning this interesting tree, or group of species and varieties, it is not necessary to touch the points in dispute. 
one to three feet in diameter; a small one from one foot down to an inch or two. A person would need to hunt from center to circumference of Texas to find many mesquite trunks that would make a straight sawlog twelve feet long. The tree is generally one of the most crooked, deformed and unpromising in the whole country; and its habit of dividing into forks near the ground, like a peach tree, makes it still more difficult to make use of. In fact, in winter when mesquite trees are bare of leaves the appearance of a forest reminds the observer of an old, neglected, diseased, moss-grown peach orchard in the eastern states; but in summer the leaves conceal much of the trunk scaliness and deformity, and there is something positively restful and attractive in the prospect of a wide range of these trees, covering hills and prairies. The leaves are compound like the acacias, and are delicate and graceful.

The spread of mesquite in the last fifty or seventy-five years has been attributed to the checking of grass fires which Indians once set yearly to keep the prairies open. The dispersion of the trees is facilitated by the scattering of seeds by cattle which feed on the pods. It is a tree hard to kill. Roots send up sprouts year after year during long periods. Sometimes, but not often in Texas, when adverse eircumstances become so severe that the mesquite tree can no longer survive above the surface, it grows beneath the ground, sending only a few sprouts up for air. "Dig for wood" is a term applied to trees of that kind, when fuel is dragged out with mattocks, grab hooks, and oxen.

The roots of the mesquite penetrate farther beneath the surface for water than any other known tree in this country. Depths of fifty or sixty feet are occasionally reached. Well diggers on the frontiers learned to go to the mesquite for water. Large trunks never develop unless their roots are abundantly supplied with moisture. Railroad engineers on the "Staked Plains" of northwestern Texas turned that knowledge to account in boring wells.

Though mesquite is seldom or never mentioned in the lumber business, it is and has been one of the most important trees of the region. Its fuel value is very great. It has cooked more food, warmed more buildings, burned more bricks, than any other wood in Texas. The tannic acid in it injures boilers and it is not much used for steam purposes. It is very high in ash. A cord of mesquite wood when burned leaves from ninety to one hundred pounds of ashes. This exceeds five fold the ashes left when white oak is burned.

Mesquite is a high-grade furniture material, though it is difficult to work because of its exceeding hardness. Ordinary wood-working tools and machinery will not stand it. Suites of nine pieces are sold in some southwestern cities at $\$ 200$ or $\$ 300$. The merchants find difficulty in 
getting mesquite furniture made. Factories do not want to handle it, though the articles sell higher than mahogany. Large, heavy tables, deeply carved, are sold in some of the cities, but all scem to be made to order and largely by hand. The appearance of the polished and finished wood is a little lighter in color than mahogany. It is not uniform in color, but shades from tone to tone in the same piece. A little of the lighter colored sapwood is worked in with pleasing effect. Some of the tones resemble black walnut, and some suggest the luster of polished cherry.

Mesquite is brittle. Pieces of large size may be broken by a few blows with an ax. It has about half the strength of white oak, and is very low in elasticity. The wood has been used for two hundred yearspossibly for thousands of years - as beams and sills for adobe houses; but it is not required to carry much weight. Spaniards employed it in building their churches and forts within its range. A timber taken from the Alamo, at San Antonio, Texas, in 1912, was said to have served more than 190 years with no sign of decay. Fence posts survive the men who set them. Paving blocks outlast sandstone subjected to the same use. Railroads in southern Texas employ this wood for crossties, but it is so hard that holes inust be bored for the spikes.

Mesquite baskets are made by hand of splits the size of knitting needles, some of white sapwood, others of dark heartwood. Such baskets, large enough to contain five quarts, sell in the curio shops at San Antonio for $\$ 1.25$ each. Some wagon makers insist that mesquite is in the same class with Osage orange for wagon fclloes in lot, dry regions; but it does not appear that much of it is so used. The brittleness of the wood is against it, in 11se as felloes, except for vehicles of the heaviest sort where large pieces are demanded.

Among the uses of mesquite, by-products are an important consideration. The pods are food for farm stock. Before the first railroad reached San Antonio mesquite pods were a regular market commodity. The Mexicans know how to make bread and brew beer from the fruit; tan leather with the resin; dye leather, cloth, and crockery with the tree's sap; make ropes and baskets of the bark. Parched pods are a substitute for coffee; bees store honey from the bloom which remains two months on the trees; riled water is purified with a decoction of mesquite chips; vinegar is made from the fermented juice of the legumes; tomales of mesquite bean meal, pepper, chicken, and corusluncks; mucilage from the gum; and candy and gum drops from the dried sap.

One of the most promising uses for this wood is in turnery. Short leugths can be utilized to advantage. The artistie eolor fits it for the manufacture of lodge gavels, curtain rings, goblets, plaques, trays, and 
numerous kinds of novelties. Spindles for grills and stairways do not suffer in comparison with black walnut, mahogany, cherry, and teak. The wood is porous, annual rings narrow and indistinct, and the medullary rays thin and inconspicuous.

A variety (Prosopis juliflora glandulosa) is found from Kansas to eastern Texas, and also in Arizona and California. It is the common mesquite of eastern Texas. Another variety (Prosopis juliflora velutina) occurs in some of the hot valleys of southern Arizona and southward in Mexico.

SCREWBEAN (Prosopis odorata) is known also as screwpod mesquite, and tornillo. The name is due to the pod's habit of growing in spiral form, there being a dozen or more tight $t$ wists. The flowers appear in early spring and new crops follow until summer. The pods ripen early in autumn or late in summer, and many become infested with grubs. The tree is from twenty-five to thirty feet high, and a foot or less in diameter. Its range extends from western Texas and Utah and Nevada through New Mexico and Arizona to southern California. The wood is stronger and stiffer than common mesquite, but a little lighter. Its uses are much the same, and it has the same habits of growth, including its disposition to develop enormous roots. The name might lead to the conclusion that the flower is rich in perfume, but such is not the case. The tree grows slowly and lives to old age, if it escapes fire and other accidents.

ChalKy Leuc.ena (Leuccha pulvententa), commonly called mimosa, occurs in the United States only in southern Texas, but is somewhat abundant in Mexico, where trees sixty feet high and nearly two feet in diameter are sometimes manufactured into lumber. Along the Rio Grande it is called "tepeguaja" by Mexicans. This name is said to be equivalent to "hardwood," which is an appropriate name. It is very smooth and handsome when finished, and is used for tool handles, small spindles, grills, and other small articles, particularly products of the lathe. In color it resembles the lighter shades of mahogany; weighs about forty-two pounds per cubic foot; foliage extremely delicate and the tree is highly valuable for ornamental purposes. It has been planted ontside of its natural range. The pods sometimes exceed a foot in length.

LEUCENA (Leucana glauca) is small and probably will never be of much importance. Trunks are seldom more than five inches in diameter and twenty feet high. The tree grows in canyons and ravines in western Texas. The compound leaves are six or seven inches long, with thirty or less pairs of leaflets; fruit is a pod six or eight inches long. The rich brown wood is streaked with red.

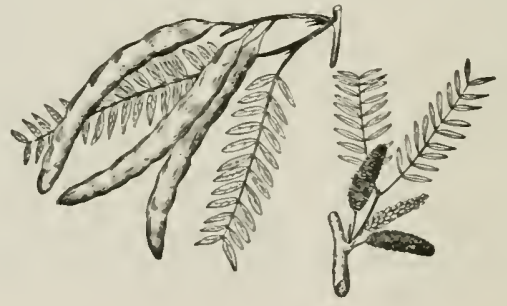


SIVEET BIRCH 


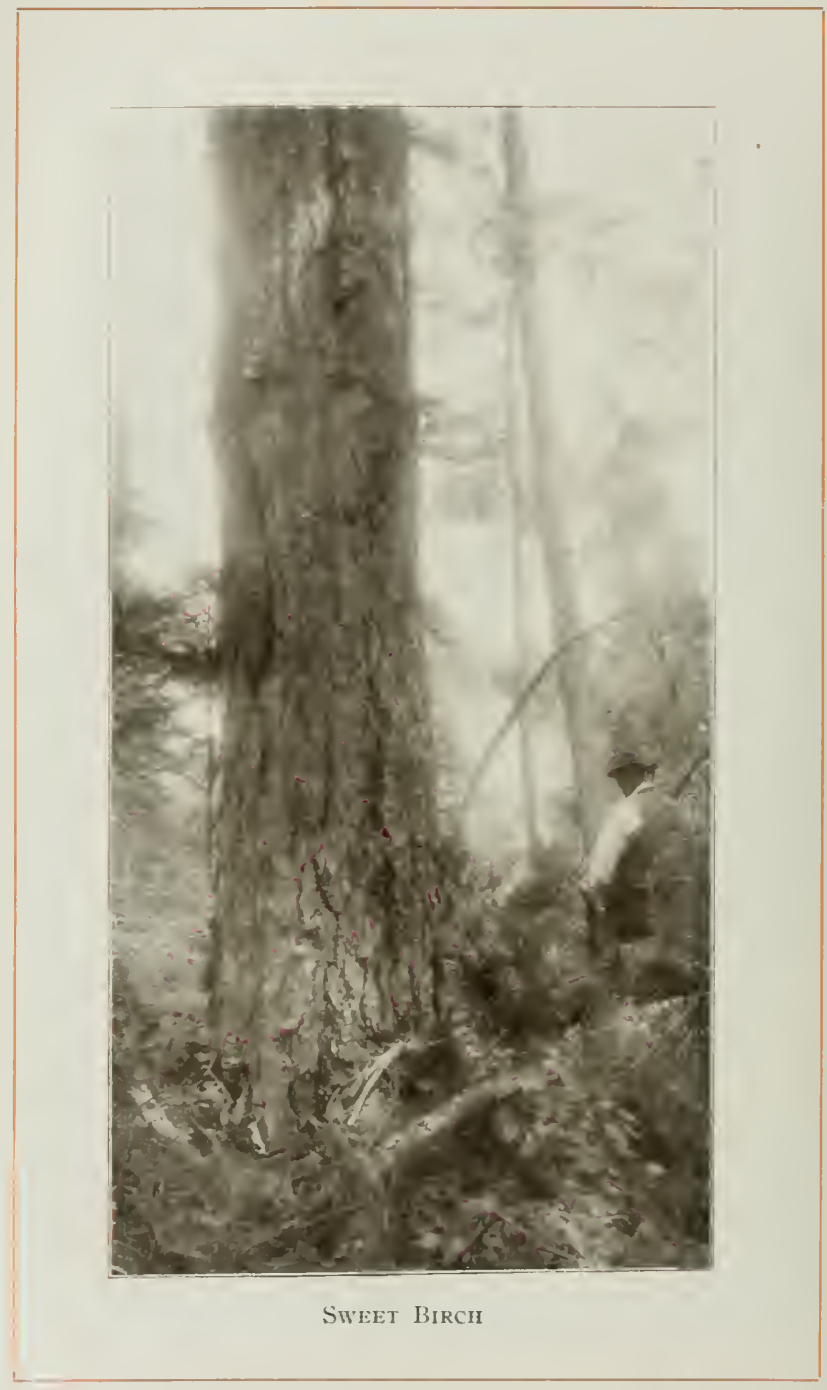




\section{SWEET BIRCH}

\section{(Betula Lenta)}

TEN species of birch occur in the United States, including Alaska. Six are eastern and four western.* Sweet birch is known by that name in many localities, but in others as black birch, cherry birch, river birch, mahogany birch, and mountain mahogany. Its range extends from Newfoundland to northwestern Ontario, south to southern Indiana, Kentucky, and along the Appalachian mountains to Tennessee and North Carolina. Probably the best development of the species is found in the Adirondack region of northern New York, in the northern peninsula of Michigan, through southern Ontario, and along the mountain ranges southward through Pennsylvania and West Virginia.

It attains a height of seventy or eighty feet, and a diameter of two or three. It prefers deep, moist, rich soil, but will grow in comparatively dry, rocky ground. Its seeds are produced in large numbers and are scattered by the wind a hundred feet or more from the parent tree. They lack the wing power and the buoyancy of the seeds of some of the other birches, but they manage to get themselves sown in sufficient numbers, and their powers of germination are good.

The young seedling comes into existence with smooth bark, but it does not keep it through life. As age increases, the bark becomes rough and black. It is not shed in papery rolls and flakes as is the bark of river birch, yellow birch, and paper birch, with which it is associated in some parts of its range. It is generally an easy tree to identify and the black, rough bark is generally a sufficient guide.

The sweet birch is tapped like sugar maple, but not for the same purpose or to the same extent-only an occasional tree. Immense quantities of sap will flow from it during the two or three weeks when the buds are swelling in the spring. It is said that as much as two tons has been known to flow from a medium sized birch in a single season. The sap is made into a beer which has some commercial value, but is chiefly used locally. One of the ways of making it, employed by farmers and woodsmen, is to jug the sap, put in a handful of shelled corn, and let fermentation do the rest.

*The eastern species, which do not extend west of the continental divide, are, Sweet Birch (Betula lenta), Yellow Birch (Bctula lutea), River Birch (Bctula nigra), Paper Birch (Betula papyrifera), White Birch (Betula populifolia) and Blue Birch (Betula carulea.) The western birches, none of which are known to extend much cast of the continental divide, are: Western Birch (Bctula occidentalis), Mountain Birch (Betula fontinalis), White Alaska Birch (Betula alaskana), and Kenai Birch (Betula kenaica). The last two occur in Alaska, but not in United States proper. 
A substance known in commerce as oil of wintergreen is procured almost exclusively from this birch, though occasionally it is made from the small wintergreen plant (Gualtheria procumbens). The product is manufactured in very crude stills made by mountaineers in Pennsylvania and southward along the mountains where sweet birch is abundant. Frequently the woodsman's whole family go into the business, chopping down birch bushes and hacking them with hatchets into chips of the desired sizes. The oil is extracted from the hogged mass by a steaming and roasting process. It is sold by the quart to country storekeepers who ship it to wholesale druggists where it is refined and used to flavor candy, medicine, and drugs. The woodsman who manufactures the oil prefers young birches from half an inch to two or three inches in diameter, and he usually procures them in old logging grounds where seedlings have sprung up. It is said that on an average one hundred small birch trees are destroyed for each quart of oil that goes to market. It is a process wasteful in the extreme.

In the open ground, sweet birch develops a full crown, short trunk, abundance of limbs, with numerous slender, graceful twigs and small branches. Its leaves form a dense mass, and they are so free from attacks by insects and worms that diseased foliage is unusual. That cannot be said, however, of the trunk. It is not particularly liable to disease, but many old trees show the results of decay. It is of slow growth, and a small tree may be much older than its size indicates. The sapwood is generally thick, heartwood forms slowly, and the contrast in color between sap and heart is strong.

The wood of sweet birch had few uses in early times, except fuel. The pioneer sawmill had little to do with it. Lumber was hard to saw and was seasoned with difficulty. Its tendency to warp was too great a tax on the lumberman's patience and ingenuity. The only way he could hold it straight was to cob a few layers in the bottom of a pile, and stack thousands of feet of other lumber on top, and leave it a year or two. That was generally too much trouble, particularly when the wood had slow sale, and the price was low. Birch reached market in large quantities only when modern mills and improved drykilns came into existence.

The wood is heavy, strong, hard, in color dark brown tinged with red. The light brown or yellow sapwood generally makes up seventy or eighty annual rings. The difference between springwood and that of the later season is not clearly marked, and consequently the rings are often indistinct. The wood is very porous, and the pores are diffused through all parts of the ring. They are too small to be seen with the naked eye, except under the most favorable conditions. The medul- 
lary rays are numerous but so small that they appear on the quartered wood merely as a gloss, which, however, gives the surface a rich appear. ance.

Forms known as curly and wary birch are highly esteemed. They are accidents of growth, well developed in birch, and occurring in several other woods. Difficulties are encountered in assigning sweet birch its individual place in the industrial world. As a tree it is well known, but that is not the case when its lumber goes to market. The sweet birch log goes in to the sawmill, but when the lumber goes out at the other end of the mill, it is often simply birch having lost the adjective "sweet" somewhere in the operation. The reason is that sweet birch and yellow birch, quite distinct in the forest, are often mixed and become one, to all intents and purposes, when they reach the market. That is not always the case, but it frequently is. Something depends on the region. The yellow birch's range is more extensive, and in areas where it is abundant, and sweet birch is not, it prevails in the lumber markets. But south and southeast of the great lakes, as well as in the northeasterp part of the country, the two species mingle, and they are apt to go to market simply as birch. The woods may be distinguished by a microscopic examination, but the ordinary observer would make many mistakes if he attempted to tell one from the other in the lumber yard.

The two woods are different in several physical properties. Both are heavy, but sweet birch weighs 47.47 pounds per cubic foot, while yellow birch weighs only 40.84 pounds, according to tests averaged by Sargent. Yellow birch rates a little above the other in breaking strength. Both are very stiff, but yellow birch rates superior. In most respects the two woods are put to similar uses-flooring, interior finish, furniture -but for some purposes sweet birch is preferred. It is substituted of tener for cherry and mahogany, and for that reason is known as cherry birch or mahogany birch. Its color makes the substitution easy, and the appearance of the grain, with a little doctoring with stains and fillers, helps in the deception. The buyer may be deceived as to the exact kind of wood he is getting, but he is not cheated in the quality. Birch is substituted where strength is required, as in the rails of beds, the frames of sofas, davenports, large chairs, and certain parts of large musical instruments. It is much stronger, and fully as hard as cherry or mahogany, and as its appearance is so much like them, the article is actually better on account of the substitution. Swect bircl is largely employed for various parts of vehicle manufacture, particularly for wagon huts and frames of automobiles. It is also much used in the manufacture of sleds, boats, and handles.

The demand is heavy and the supply is diminishing. The tree is of 
such slow growth that few timber owners will be inclined to wait for a second crop, after the old trees have been cut, since 150 years are necessary under forest conditions to produce a merchantable tree.

Sonora Ironwood (Olneya tesola) is a desert tree, and the only representative of the genus. It takes its name from the Mexican state where it is most abundant and where it was discovered in 1852. It grows in southern California and Arizona, and there it thrives in gulches and depressions in the desert, frequently associated with mesquite. It is so heavy that perfectly dry wood will sink in water. The heartwood is deep chocolate-brown, mottled with red, the thin sapwood is lemonyellow. Its hardness renders it difficult to work, and it can scarcely be split. The wood is made in to canes and other small articles of great beauty. It is not abundant, and the small supply is remote from manufacturing centers; otherwise it would be more valuable. It is excellent fuel, but it is burned chiefly by stockmen and miners in their camps. The largest trees are thirty feet high and eighteen inches in diameter. It is an evergreen, and its pea-like flowers brighten many a remote desert place.

WILD TAMARIND (Lysiloma latisiligua) is forty or fifty feet high, two or three in diameter, grows in southern Florida, and has double-compound leaves, four or five inches long. The fruit is a pod one inch wide and five or less in length. The wood weighs forty pounds to the cubic foot, is neither strong nor tough, very low in elasticity, is rich dark brown tinged with red, the sapwood white. It has been reported for boatbuilding, and claims have been made that it is equal to mahogany for that purpose, but the claim is of doubtful validity, in view of the rather poor showing it makes in several physical properties, though it takes good polish.

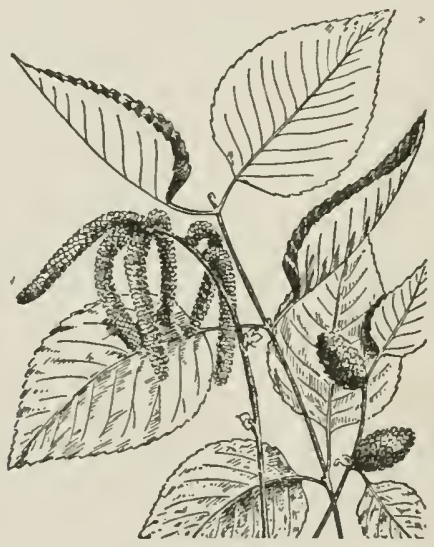


YELLOW BIRCH 


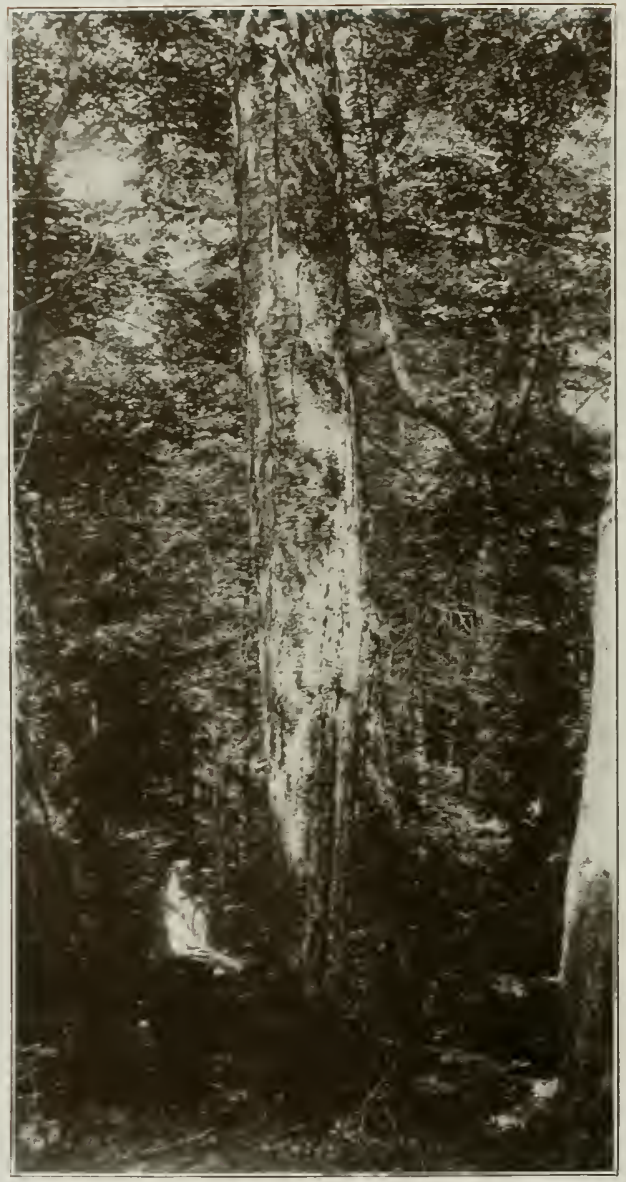

YELLOW BIRCH 


\section{YELLOW BIRCH}

\section{(Betula Lutea)}

T HERE is little likelihood of mistaking the yellow birch for any other as it stands in the woods. Its points of individuality may be discovered on slight acquaintance, and there is little need of studying leaves, flowers, and fruit to find ways of distinguishing this birch from other members of the family. Its tattered, yellow and gray bark fixes it in the memory of all who have seen it a few times. Two other eastern birches have tattered, curling bark also, but they do not look like this. They are the paper birch and the river birch. The former is too white to be mistaken for yellow birch, and the river birch is too much the color of bronze or copper. Yellow birch is named from the color of its bark, the part which shows when the outer layers break and roll back, disclosing the fresh, smooth, satiny layers below. Sometimes the tree is called silver birch, gray birch, or swamp birch.

Its geographic range is bounded by a line drawn from Newfoundland to northern Minnesota, southward through the Lake States, and along the Atlantic coast to Delaware. It follows the Appalachian ranges of mountains to eastern Tennessee and western North Carolina. Generally the tree is small near the southern limit of its range. The best grows in Michigan and Wisconsin, but it is of considerable importance in Minnesota.

Few trees are better equipped than yellow birch to perpetuate their species. It is an abundant seeder, and the seeds are light, winged, and they are scattered by wind over long distances. Sometimes they are carried miles. Of course, most of them fall in unfavorable places, and either do not germinate or perish soon after; but they are not particularly choice in situations, and will grow on bare mineral soil, even in old fields, where they are flooded with sunshine, or they will grow in deep shade where a beam of sunlight seldom touches them. They of ten germinate without touching mineral soil, and take root quickly and grow vigorously.

It is not unusual in the northern part of the trec's range, and on high mountains farther south, to see yellow birches standing on high, spreading roots, two, three, or four feet above the ground. That peculiar attitude is brought about by the manner in which the seed begins to grow. It falls on moss which occupies the top of a $\log$ or a stump. The moss in the deep shade retains much moisture, and the seed germinates, grows, sends roots down the sides of the log or the stump until they strike mineral soil, and become firmly fixed. In course of time the log or stump decays, and the spreading roots continue to sustain the 
trunk, high above the ground. This attitude of the yellow birch tree is very common in damp woods. Occasionally the seed finds lodgment in the moss on top of a large rock. The roots descend the sides until they reach the ground, and as the rock does not decay, the tree grows to maturity on the rock. The most favorable seed bed for this species is a mass of rotten wood where a $\log$ has decayed and fallen to pieces. Frequently such a plot is covered with yellow birch seedlings. They have the space all to themselves, because the seeds of few trees or plants will grow in rotten wood, unmixed with mineral soil.

The trunk of yellow birch averages a little smaller than that of sweet birch, but may equal it in some instances. Trees reach a height of 100 feet and a diameter of three or four, but a more common size, even in the regions of best development, is a height of sixty or seventy feet, and a diameter of two or less.

Yellow birch was a long time coming into use. One of the first things learned about it by early settlers in the region where it was abundant, was that it decays quickly in situations alternately wet and dry. That prejudiced the woodsmen against it, and they were not disposed to give it a fair trial, as long as there was plenty of other timber. All birches are subject to quick decay, if conditions are right to produce it. Yellow birch in the woods sometimes dies standing, and when that happens, the wood falls to pieces so quickly that the bark may remain standing with very little inside of it except powder of decayed wood. This tree is seldom mentioned in early accounts of lumber operations, and practically never with a good word. Operators generally left it standing when they cut the timber which grew with it.

- Yellow birch is heavy, very strong, hard, light brown tinged with red, with thin, nearly white sapwood. The color of the heartwood varies considerably. The pores are very numerous, rather small, and are scattered through the wood with little tendency to run in bands or groups. The springwood blends gradually with the summerwood in a way to make the boundaries of the annual rings somewhat indistinct. Medullary rays are numerous, but very thin and obscure. Quartersawing adds little or nothing to the appearance of the wood. It has poor figure, except an occasional tree with wavy or curly grain, or with burls.

The wood may be readily stained. The pores hold the coloring matter applied, and by varying the application, the appearance of the surface can be varied. The colors of mahogany and of cherry are easily imparted, and yellow birch often imitates those woods.

Vehicle makers choose this wood for its strength and elasticity. In the North it is manufactured into frames for cutters and sleighs of all 
kinds. It is a competitor of sugar maple for that purpose. Hubs are made of it for horse-drawn vehicles, and its hardness gives long wear where the spokes are inserted. That is one of the first points of failure when a soft, inferior wood is used for hubs. The spokes work loose.

Manufacturers of automobiles have tried out yellow birch as material for frames; it has stood the test, and is much used in competition with other woods. The amount demanded for that purpose is not necessarily large, but it must be the best wood that can be had.

This material reaches the markets in all grades. Large amounts are used for packing boxes, crates, and shipping containers. Low grades answer for these purposes, leaving the better sorts for the more exacting industries. The logs are cut in rotary veneer for baskets, and for ply work. Some of the veneer in three-ply is worked into commodities of high class, such as seats and backs of theater chairs.

Birch flooring competes closely with maple for popular favor. It may lack something of maple's whiteness, but it takes no second place in hardness, smoothness, and wearing qualities. It is made into parquet flooring as well as the ordinary tongued and grooved article. As such, the sap matches the light colored woods, and the heart the dark.

It goes into all kinds of interior house finish, from floor to ceiling, and the finest grades are often devoted to stair work. Door and window frames are made of it in large quantities, but it is not suited to outside work exposed to weather, because of its tendencies to decay. It is much employed as door material. Furniture demands the same class of wood. Medium priced articles may be of solid birch, but the best commodities are made of veneers laid upon other woods. Figured birch is a favorite material for that class of work.

The more common commodities manufactured of this wood can be listed only by groups, because of their great number. Novelties constitute a large class. One of the earliest demands was from the manufactures of pill boxes, such as apothecaries use. That was before anyone had tried to sell yellow birch in the general market, and the demand came principally from New England and New York. Another early demand came from coopers who found that barrel hoops of yellow birch were highly satisfactory for certain kinds of vessels. Fish kits were among the first to appear in birch hoops. Small saplings were used, not over two inches in diameter. They are large enougl to make two hoops by splitting. The bark was left on, and the identity of the wood was never in doubt, because when the sapling is of that size, the bark is a fine yellow. It has not yet conmenced to crack open and roll up, as it does later. Millions of birch loops are still produced yearly in the United States, but all of them are not of this species. The hoop business 
has existed much more than a century, and millions of young birches have been cut every year to meet the demand.

Birch broom handles have been a commodity since the first lathe went to work on that product. They are made of all the commercial birches, but yellow birch contributes a large part. Other handles are manufactured of it also, such as are fitted to hand saws, planes, drawing knives, chisels, and augers.

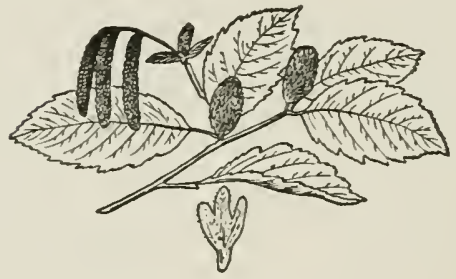


RIVER BIRCH 


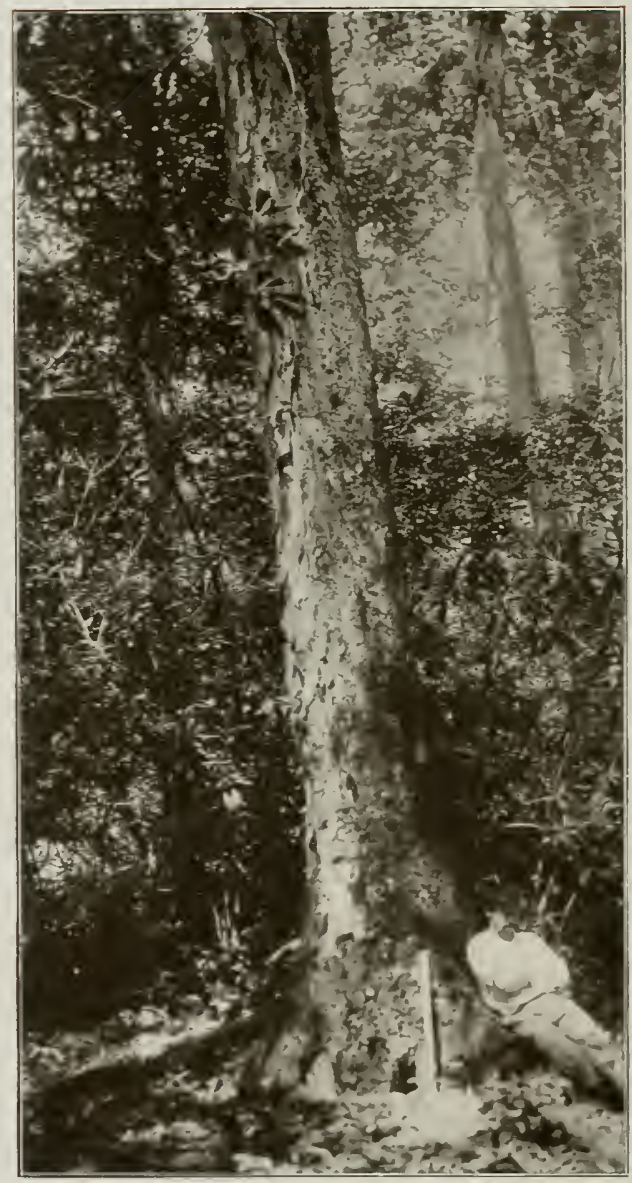

RIVER BIRCH 


\title{
RIVER BIRCH
}

\author{
(i)ctula Vigra)
}

$\mathrm{T}$ HIS tree is known as red birch, river bircl, water birch, blue birch, black birch, and simply as birch. The name red birch refers to the color of the bark which is exposed to view in the process of exfoliation. The trunk is constantly getting rid of its outer bark, and in doing so, the exterior layers are rolled back, hang a while, and are gradually whipped off by the wind. The new bark which is exposed to view when the old is rolled back is reddish. Its color varies considerably, sometimes suggesting the tint of old brass, again it is brown, but people in widely separated regions have seen fit to call the tree red birch because of the color of its bark. The name black birch is not appropriate, though the old bark near the base of large trunks may suggest it. No reason can be assigned for calling it blue birch, unless the foliage in early summer may warrant such a term. River birch and water birch are more appropriate, as these names indicate the situations where the species grows. It clings to water courses almost as closely as sycamore. A favorite attitude of the tree is to lean over a river or pond, with the long, graceful limbs almost touching the water.

Nature seems to recognize the tree's habit of hanging over muddy banks, and has prepared it for that manner of life. Seeds are ripe early in summer when the rivers are falling. They are scattered by myriads on the muddy shores and upon the water. Those which fall in the mud find at once a suitable place for germination, and those whose fortune it is to drop in the water float away with the current or they are driven by the wind until they lodge along the shores, and the receding water leaves them in a few days, and they spring up quickly. Before the autumn or early winter high water comes, they are well rooted in the mud and sand, ready to put up a fight for their lives.

The provision is a wise one. If the seeds matured in the fall, when water is low, they would be strewn along the low shores, and before they could take root and establish themselves, the high water and the ice of winter would destroy them. The seeds need mud to give them a start in life, and they need that start early in summer.

The range of river birch is less extensive than that of the other important eastern birches, yet it is by no means limited. Its eastern boundary is in Massachusetts, its western in Minnesota, and it adlieres fairly well to a line drawn between the two states. Its rauge extends 200 miles west of the Mississippi and covers most of the sonthern states. It is found in an area of nearly 1,000,000 squarc miles, but is scarce in 
most of it. In certain restricted localities it is fairly abundant, but there are thousands of square miles in the limits of its range which have not a single tree. Its greatest development is in the south Atlantic states, and in the lower Mississippi basin.

Trees at their best are from eighty to ninety feet high and from two to four in diameter, but most trunks are less than two feet in diameter. The tree frequently forks fifteen or twenty feet from the ground, or occasionally sends up several stems from the ground. Forms of that kind are practically useless for lumber.

The wood is among the lightest of the birches and weighs 35.91 pounds per cubic foot. It is rather hard, medium strong, the heartwood light brown in color, with thick, pale sapwood. It rates below sweet and yellow birch in stiffness, is very porous, but the pores are quite small, and can scarcely be seen without a magnifying glass. They are diffused throughout the entire annual ring. There is no marked difference in the appearance of the springwood and that of the late season. The medullary rays are very small and have little effect on the appearance of the wood, no matter in what way the sawing is done.

The wood is apt to contain pith flecks and streaks. These are small, brown spots or lines scattered at random through the wood. They are a blemisl which is not easily covered up if the wood is to be polished; but they are small and may not be objectionable. The flecks are caused by insects which, early in the season, bore through the bark into the cambium layer (the newly-formed wood), where eggs are deposited. The young insect cuts a tunnel up or down along the cambium layer, an inch or less in length and a sixteenth of an inch wide. This gallery subsequently fills with brown deposits which remain permanently in the rood. Sometimes these deposits are sufficiently hard to turn the edge of tools.

River birch is widely used but in small amounts. It may properly be described as a neighborhood wood-that is, wherever it grows in considerable quantity it is put to use, but nearly always in a local way. For example, in Louisiana, where it is as abundant as in any other state, it is a favorite material for ox yokes, and no report from that state has been made of its employment for any other purpose. The reason given for its extensive use for ox yokes there is that it is very strong for its weight, and that it resists decay. The yokes there are usually left out of doors when not in use, and the dampness and hot weather cause rapid decay of most woods. The birches are usually listed as quick-clecaying woods, but the verdict from Louisiana seems to be that river birch is an exception.

Plain furniture is made of it, and the manufacturers of woodenware 
find it suitable for most of their commodities. It is sometimes listed as wooden shoe material, but no particular instance has been reported where it has been so used in this country. In Maryland some of the manufacturers of peach baskets make bands or hoops of it, and pronounce it as satisfactory for that purpose as elm.

The supply is not in much danger of exhaustion. The species is equipped to take care of itself, occupying as it does, ground not in demand for farming purposes. When a tree once gets a start it has a chance to escape the ax until large enongh for use.

White Alaska BiRCH (Betula alaskana) is usually called simply white birch where it grows. It is not exclusively an Alaska species though that is the only place where it touches the territory of the United States. It is supposed by some to be closely related to the white birches of northern Asia, but the relationship, if it exists, has not been established. In Alaska it grows as far north as any timber extends. It was first discovered and reported in 1858 on the Saskatchewan river, east of the Rocky Mountains, and its range is now known to extend down the valley of the Mackenzie river toward the Arctic ocean to a point more than 100 miles north of the Arctic circle. It is common in many parts of Alaska both along the coast and in the interior. In some portions of that territory it is an important source of fuel. Trees are from twenty-five to sixty feet high, and from six to eighteen inches in diameter. The bark is thin and often nearly white, separating into thin scales. The tree bears typical birch cones, but larger than those of some of the other species. No tests of the wood's physical properties have been made, but it looks like the wood of paper birch, and will probably attain to considerable importance in the future, since it grows over a large area, and in many parts is abundant. There remain many things for both botanists and wood-users to investigate concerning this tree which has a range of more than half a million squarc miles.

Western BrRch (Betula occilcntalis) is believed to be the largest birch in the world, and yet it is not of much commercial importance in the United States, because of scarcity, occurring only in nortlwestern Washington and in the adjacent parts of British Columbia, as far as its range has been determined. It resembles paper birch, and has often been supposed to be that tree. The people in the restricted region where it grows speak of it simply as birch. The largest trees are 100 feet high and four feet in diameter, clear of limbs forty or fifty feet. $A$ height of seventy feet and a diameter of two are common. The general color of the trunk is orange-brown, the new bark, exposed by exfoliation, is yellow. The tree prefers the border of streams and the sliores of lakes. Though it is the largest of the birches, its seeds are among the 
smallest. They are provided with two wings and are good flyers. Manufacturers of flooring and interior fitish in Washington reported the use of 315,000 feet of this birch in 1911 . That was the only use found for it in the only state where it grows. Information is meager as to the probable quantity of this birch available. It has been reported in Idaho, but exact information on the subject is lacking.

MounTarN BrRch (Betula fontanalis) is a minor species concerning which there has been much contention among botanists. It has finally been called mountain birch because it grows on mountains, as high as 10,000 feet among the Sierra Nevadas in California. It has many local names for a tree so small as to be almost a shrub throughout most of its range: Black birch, sweet birch, cherry birch, water birch, and canyon birch. Its bark is of the color of old copper; wood is light yellowishbrown, with thick white sapwood; 1runks seldom exceed ten inches in diameter and thirty feet high; range extends from northern British Columbia to California, and along the Rocky Mountains to Colorado and possibly further south. The uses of the wood are few.

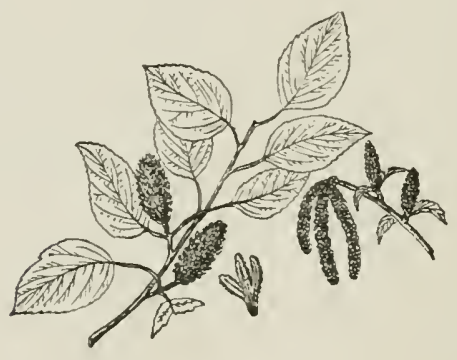


PAPER BIRCH 


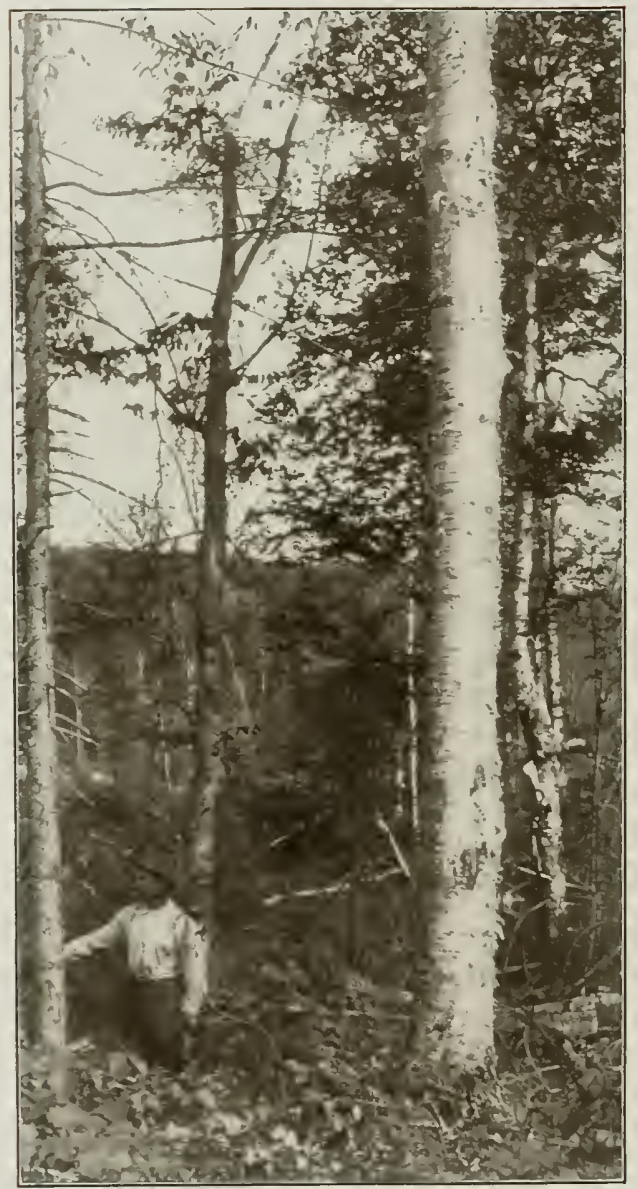

PAPER BIRCH 


\title{
PAPER BIRCH
}

\author{
(Betula Papyrifera)
}

$\mathrm{T}$ HIS tree is called paper birch because the bark parts in thin sheets like paper. It is known as canoe birch from the fact that Indians and early white explorers and travelers constructed canoes of the bark. The name silver birch is an allusion to the color of the bark; and big white birch is the name used when the purpose is to distinguish it from the white birch with which it is associated in the northeastern part of its range. It grows as far north as Arctic British America, east to Labrador, south to Michigan and Pennsylvania, and west nearly or quite to the base of the Rocky Mountains. This indicated area exceeds $1,000,000$ square miles. The quantity of birch of this species in the forests is unknown, but it runs into billions of feet, probably exceeding any other single species of birch. The tree sometimes grows dispersed through forests of other woods, sometimes in nearly pure stands. Persons well acquainted with the species have expressed the opinion that paper birch exists in larger quantities now than at the time when the country was first explored by white men. That can be said of few other species; but probably holds true of lodgepole pine in the West, loblolly pine in the Southeast, and mesquite in the Southwest. Each of these species took advantage of man's presence and influence to extend its range. Cattle spread the mesquite; the lodgepole pine came up in fire-burned tracts; loblolly pine spread into abandoned fields; and paper birch profited by fires which destroyed large tracts of timber.

The seeds are light, are furnished with wings which sail them long distances through the air, and they are quickly scattered over the burned areas where they spring up. In the contest, they are competitors of aspen. Birch often captures the ground, but does not always do it. Some of the largest stands in the Northeast occupy tracts bared by fire half a century or more ago. When paper birch does not find open tracts, it contents itself with sharing ground with other species. That was the usual manner of its growth in the original forests; but it has been quick to seize opportunities to take full possession.

It does not like shade and, if crowded, one of the first things it does is to rid its lower trunk of all branches. Only limbs remait which are at the top where they receive plenty of light. Therefore, forestgrown paper birches have long, clean trunks, though they are not always straight. The largest trees are seventy feet high and three in diameter, but those fifty feet in height and eighteen inches in diameter are above rather than under the average. 
The bark of paper birch has played an important part in American history, story, and poetry. It was the canoe material, the roof, and the utensil in its region. The Indians had brought the art of canoe making to perfection before white men went among them. The bark peels from the trunks in large pieces, and may be separated into thin sheets, which are very tough, strong, and durable. The Indians sewed pieces of bark together, using the long, slender roots of tamarack for thread. The bark was stretched and tied over a frame, the shape of the canoe, and made of northern white cedar, or some other light wood. Holes in the bark, and the partings at the seams, were stopped with resin from balsam fir, wax from balm of Gilead, or resin from pine. The forest supplied all the material needed by the Indian, and a canoe thus made, and large enough to carry 800 or 1,000 pounds, weighed no more than fifty pounds. Frail as it seemed, it was good for long service on rivers and lakes, and could weather storms of no small severity.

White men adopted the bark canoes at once, and learned from Indians how to make them. The daring explorers and venturesome fur traders who threaded every river and navigated every important lake of British America, found the birch canoe equal to every requirement, even to attacking whales in the tidewater of the Arctic ocean. The bark from this birch was used for tents and the roofs of cabins; vessels in which to store or carry food were made of it, as well as beds on which to sleep, and wrapping material for bundles. These uses have now practically ceased; but as sport, recreation, and for the novelty, articles, from canoes to visiting cards, are still made of the bark.

The wood of paper birch is valuable for certain purposes. The trees are largely white sapwood, which is without figure. It is as plain a wood as grows in the forest, but it may be stained. That, however, is seldom done. The heartwood is dark or red, and is made into brush backs and parquet flooring, but the hearts are small, and no large quantity of that wood is used. The largest use of paper birch is for spools, the common kind for thread. Some of larger size are made for use in mills. The sapwood only is accepted by makers of spools. The heart is cut out, and most of it is thrown away or burned under the boilers. The qualities of paper birch which appeal to spool makers are, white color, small liability to warp, and the ease with which it may be cut without dulling the tools. The logs are worked into bars of the various spool sizes, and are carefully seasoned. One of the problems that must be constantly solved is the prevention of sap stain while the bars are seasoning. The wood discolors quickly and deeply.

Tooth picks, shoe pegs, and shoe shanks are other important commodities manufactured from paper birch. It has not yet been 
satisfactorily converted into lumber, because it is more valuable for spools, tooth picks, pegs, and the like. This wood is frequently listed as a pulpwood, and it is quite generally believed that its use for that purpose is important. This is apparently an error, as the wood is not even mentioned in statistics of pulpwood output in this country.

Paper birch weighs 37.11 pounds per cubic foot, is strong, hard, tough; medullary rays are numerous but very small and obscure; wood is diffuse-porous, and earlywood blends gradually with latewood in the annual rings which are not very distinct.

This is one of the woods which does not threaten to become soon exhausted. A supply for half a century, at present rate of use, is in sight, if no more should grow; but in fifty years new forests, now young, will be large enough to use.

KFnai Birci (Betula kenaica) is an Alaska species concerning which comparatively little is known, except that its botanical identity and something of its range have been established. Its small size, and the remote regions where it grows, do not necessarily indicate that it can never be important. Scarcity of other woods may give it a place which it does not now occupy. No reports on the properties of the wood have been made. The bark is deep brown in color. Trees are from twenty to thirty feet high and from twelve to eighteen inches in diameter. The trunks are very short. Cones are an inch or lass in length and the double winged seeds are very small. The name applied to this species relates to the region where the best developed trees have been found. As far as known, the species is confined to the coast region of Alaska and to adjacent islands from the head of Lynn canal westward. It has been reported on Koyukuk river above the Arctic circle.

WHTE BIRCH (Betula populifolia) is known also as gray birch, old-field birch, poverty birch, poplar-leaved birch, and small white birch. It is chicfly confined to the northeastern part of the United States, but grows as far east as Nova Scotia, and west to the southern shore of Lake Ontario. It occurs on the Atlant ic coast south to Delaware, and along mountain ranges to West Virginia. The names describe cither the habits or the appearance of the tree. The bark is white, and is the most prominent feature of a thicket of these graceful but practically worthless little birches. It is called an old-field species because it quickly scatters its small, winged seeds over abandoned farmland and takes possession when it does not have to compete with stronger species. Poverty birch is an allusion, either to the poor ground it occupies or the unpromising nature of the tree itself. The resemblance of its leaves to those of cottonwood leads some people to prefer the name poplar-leaved birch. The tree at its best is seldom more than forty feet high and eightcen inches in diameter. A height of twenty or thirty feet is the usual size. The stem is generally clothed with branches nearly to the ground. The wood is light, soft, not strong or durable, heart light brown, thick sap nearly white. The form and size of the trunk exclude it from sawmills, but it has some special uses: Spools, shoe pegs, and hoops. Its small size does not disqualify it for service along those lines. The tree springs up quickly, grows with fair rapidity, and dies young. It is cut for cordwood in New England and makes good fuel. It takes possession of arcas bared by fire, and protects the ground, furnishing shelter for more valuable specics which come later.

BLUE BrRcis (Betula corrulea) is a small tree of which nore information is to be desired. It is rarely more than thirty feet high with a diamcter of eight or ten 
inches. Its leaves are long-pointed, its cones about an inch in length, the bark is thin, white tinged with rose, and is lustrous. Bark is not easily separated into layers, in that respect differing from the paper birch. The inner bark is of light orange color. It is probably put to no use, unless for fuel or as hoops. It is smallest of New England birches, and its range has not been fully determined, but it is known to grow in Maine and Vermont, and probably will be found in other parts of New England and in the adjacent regions of Canada. It has been compared with a European species of birch, the Betula pendula.

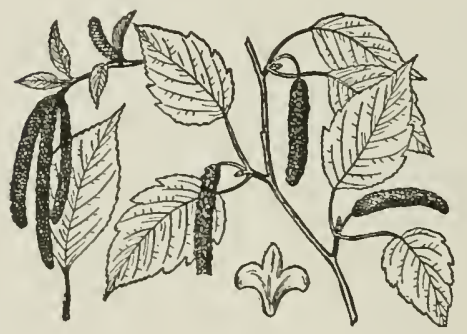


RED ALDER 


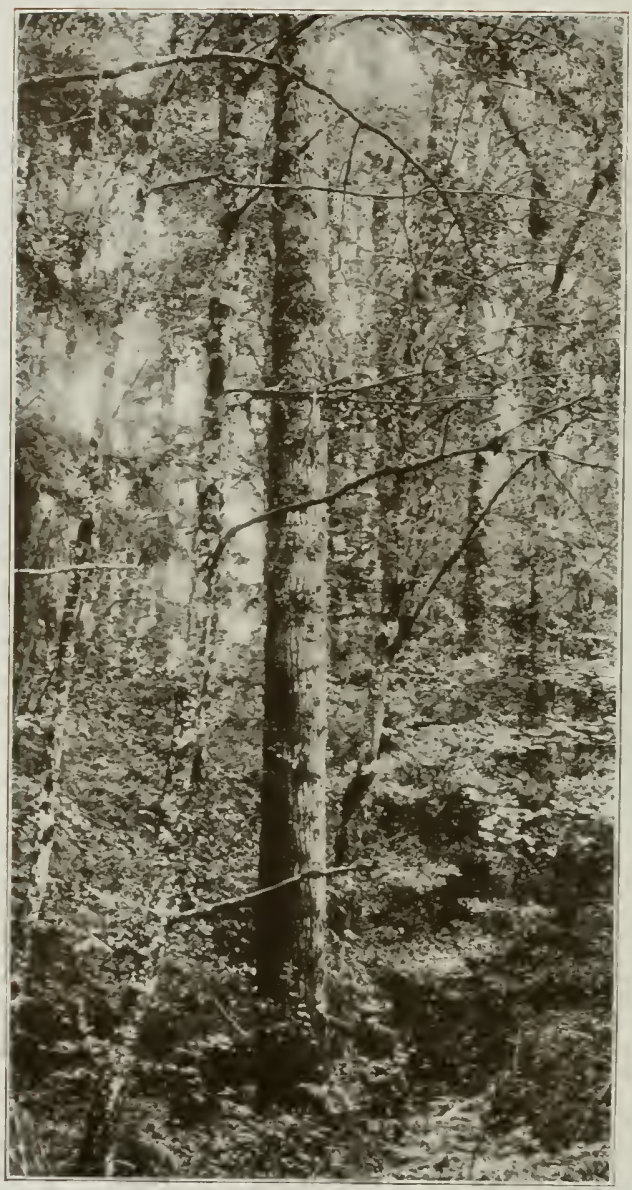

RED Alder 


\section{RED ALDER}

\section{(Alnus Oregona)}

M ANY species of alder are found in various parts of the world, and on both sides of the equator, but chiefly in the northern hemisphere. Some of these are trees, others are slurubs. Six species belonging in the tree class grow in the United States, besides others which remain shrubs. Some trees are burdened with names, changing them with locality, but not so with alder. An adjective may accompany the name, as red, white, seaside, or mountain, to describe it, but it is always alder, no matter where it grows. The different species cover much of the United States, and few large areas are found which have not one or more species. It grows from sea level up to 7,000 feet or more, but some species thrive at one elevation, and others above or below.

The alders are old inhabitants of the earth. They had a place in the Eocene and Miocene forests of the old world and new. It is not apparent that they have either gained or lost in extent of range during the hundreds of thousands of years which measure their tenancy on the earth. They have not been aggressive in pushing their wáy, nor have they shown a disposition to retire before the aggression of other trees. Some alders bear seeds equipped with wings for wind distribution, others produce wingless seeds which depend on water to bear them to suitable situations and plant them. Of course, the water-borne seeds are planted on muddy shores or on the banks of running streams, and the trees of those species are confined to such situations. The alders belong to the birch family.

Red alder is the largest of the alder group in this conntry. Mature trees are from forty to ninety feet high, and from one to three feet in diameter. The northern limit of its range crosses southern Alaska; its southern border is in southern California. It is a Pacific coast tree, with a north and south range of 2,000 miles. Trunks are straight, and branches are generally slender. The largest specimens grow in the vicinity of Puget Sound. The bark is thin, leaves are from three to ten inches long, cones from one-half to one inch in length, seeds have very narrow, thin wings, and are about the size of raddish seeds. The cones remain green in color until the seeds are fully ripe, but they finally turn brown, and seeds are liberated during the fall and winter.

Red alder is given that name because the newly cut wood is liable to change quickly to a reddish-brown. This applies to the whitish sapwood only; but since the trunk is largely sapwood, it is an important matter. It is not apparent whether the change in color is due to attack 
by fungi, or to some chemical change in the sap. It is not believed that the change in color weakens the wood, at least it does not appear to do so immediately. The heart is reddish, and when dressed and polished, it presents a fine appearance.

Red alder when thoroughly air dry weighs about thirty pounds per cubic foot, which is slightly above the weight of basswood. It is strong for its weight, rating only eight per cent below white oak, while in stiffness or elasticity it is about twelve per cent above white oak. It is not difficult to season, is soft, stands weh when made up, and is one of the most important hardwoods of the northwest Pacific coast. More than $2,000,000$ feet a year go to wood-using factories in Washington and Oregon.

The Indians of the Northwest, when they had only stone hatchets or the crudest kinds of metal tools, found red alder a wood which worked so easily that they specialized with it. They made canoes of the largest trunks, and all manner of troughs, trays, trenches, platters, and dugouts, some of no more than a pint in capacity, others holding three or four bushels. The Field Museum in Chicago has a collection of these Indian utensils made of alder. The workmanship shows considerable skill mixed with barbaric art. There are carvings of eagles and bears which are not entirely grotesque. The utensils were designed primarily to contain food at ceremonial feasts, or it was stored for times of scarcity. Among them are cooking vessels of alder in which meat was boiled by filling the troughs with water and dropping in hot stones.

Furniture manufacturers are the largest users of red alder. Carefully selected heartwood, finished in the proper color, looks much like cherry, though it lacks something of the characteristic cherry luster. The sapwood in its natural color resembles the sapwood of yellow birch. The annual rings are defined by narrow bands of dense summerwood. The pores are small and diffused through the entire ring, as with birch. Medullary rays are very thin and do not show much figure; neither do the rings of growth, in tangential sawing, display much contrast. It is, therefore, a figureless wood, entering into practically all grades of furniture, in the region where alder is plentiful, but it shows to particularly good advantage in panels.

Reports on wood-utilization on the Pacific coast list this wood for archery bows but particulars as to amount used, and why it is used at all, are not given. The physical properties of the wood do not seem to fit it for that use. It is wanting in both strength and elasticity which are the prime, almost the only, factors considered in selecting bow wood. No account has been found of any employment of alder for bows by Indians of the region where it grows. 
Broom handle turners in Washington use 350,000 feet of alder a year. The smooth finish which may be imparted to the wood constitutes its chief value for broom handles. It is well liked for porch columns. When the center is bored out, the wood seldom checks. In that respect it resembles yellow poplar. It takes paint well and holds it a long time. Comparatively large amounts are converted into interior finish. It is made into spindles, newel posts, railing, panels, molding, ornaments, and pedestals. Occasionally it is finished in the wood's natural color.

Many minor places are found for red alder. Frames of pack saddles are made of it; it forms parts of pulleys; is available for small turnery; and it is sometimes worked into bodies and compartments for business wagons, such as butchers and bakers use. The bark is rich in tamin and is said to be employed in local tanneries, but no statistics are available showing the annual supply.

White Alder (Alnus rhombifolia) is known simply as alder in the region where it grows. Where this tree and red alder occupy the same range they are commonly supposed to be the same. The range of white alder extends from northern Idaho to southern California. It is the common alder of central California where it attains its best development, and the only alder at low altitudes in southern California. Trees vary in height from thirty to eighty feet, and in diameter from one to three. A common size is fifty feet high and fifteen inches in diameter. Like most alders, it sticks close to water courses, and is usually found in the bottoms of gulches where water flows most of the year. The flowers begin to appear in midsummer as dark, olive-brown catkins less than an inch in length. By midwinter they are fully developed, and the tree is loaded with catkins from four to six inches long and thick as lead pencils. In the gulches among the elevated foothills it is not unusual for trees to be bending beneath snow and flowers at the same time. That is about the period when the seeds of the preceding year complete their dispersal. The cones hang closed nearly a whole twelve months, and when they give up their seeds, they often do it slowly. The seeds are the size of pin heads, and seem to have had wings once, but lost them. The remnants remain, but are of no use. If running water does not carry seeds to new grounds they lie beneath the parent tree. The wood of white alder is five pounds lighter per cubic foot than red aldcr. Its structure is less satisfactory. Medullary rays are irregular, some being thin as those of sweet birch, while others are as broad as rays of chestnut oak. Those of large size scem to be scattered at lraphazard, and are so irregular and uncertain that no dependence can be placed in them for figure. Trees are largely sapwood, which is nearly white when freshly cut, but it quickly turns brown; heartwood is palc, yellow- 
ish-brown. This is said to be one of most quickly-decaying woods of the western forests when logs are left lying in damp woods. The white alder ought to be suitable for nearly every purpose for which red alde- is used.

ILountain Alder (Alnus tenuifolia) is too small to contribute much to the lumber supply of the country, though it may yield fuel in some localities where there is little else. Its sange extends from I'ukon territory to Lower California, a distance of 4,000 miles, and it nearly touches both the torrid and frigid zones. It is found from the Rocky Mountains to the Pacific in the United States. Few trunks exceed twenty-five feet in height or six inches in diameter; but the form is generally brush, in tangled thickets along the courses of mountain streams, and on boggy slopes, up to 7,000 feet in altitude. The wood is light brown, and there are no reports showing its use for any purpose except firewood.

SITKA ALDER (Alnus sitchensis) is one of the smallest of the ahorescent species, and in most instances it is a shrub a few feet high. At its best it is thirty feet high and eight inches in diameter. It grows from Alaska to Oregon, and eastward to Alberta and Montana. It is found in mountain regions 4,000 feet ahove the sea. The wood is valuahle for fuel only. This species was discovered about eighty years ago, but was practically lost sight of until recently. Many persons saw it but supposed it to be one of the other alders.

LANCELEAF ALDER (Alnus acuminata) is a southwestern species, ranging through southern New Mexico and southern Arizona and south 4,000 miles to Peru. In the United States it ascends to altitudes of 4,000 or 6,000 feet where it fringes the banks of streams, and flowrishes in the bottoms of canyons. The largest trees are thirty feet high and eight inches in diameter. Flowers open in February before the appearance of the leaves. The seeds have small wings which are of lit tle or no use.

SEAsIDE ALDER (Alnus maritima) grows in Maryland, Delaware, and Oklahoma, and the largest trunks are thirty feet high and five inches in diameter. It is found on the banks of ponds and streams. The flowers appear in July, and the seeds of last year's crop ripen at the same time. The wood is light, soft, and brown, heart and sap being scarcely distinguishable. The wood is not used.

The European Alder (Aluus glutinosa) has been naturalized in a few places in the United States, and several varieties are distinguished in cultivation. A native shrubby species (Alnus rugosa) is common in many parts of the eastern states. It is not usually listed as a tree, being too small, but it is sometimes twenty-five feet high and three or four inches in diameter. In Europe the charcoal made from alder is considered excellent material for the manufacture of gun powder, and considerable areas of alder in England are held in reserve against an emergency. It is probable that the American alders would answer as well as the European species.

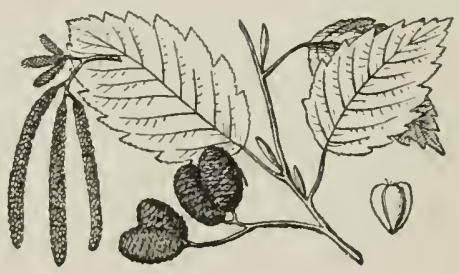


HORNBEA.I 


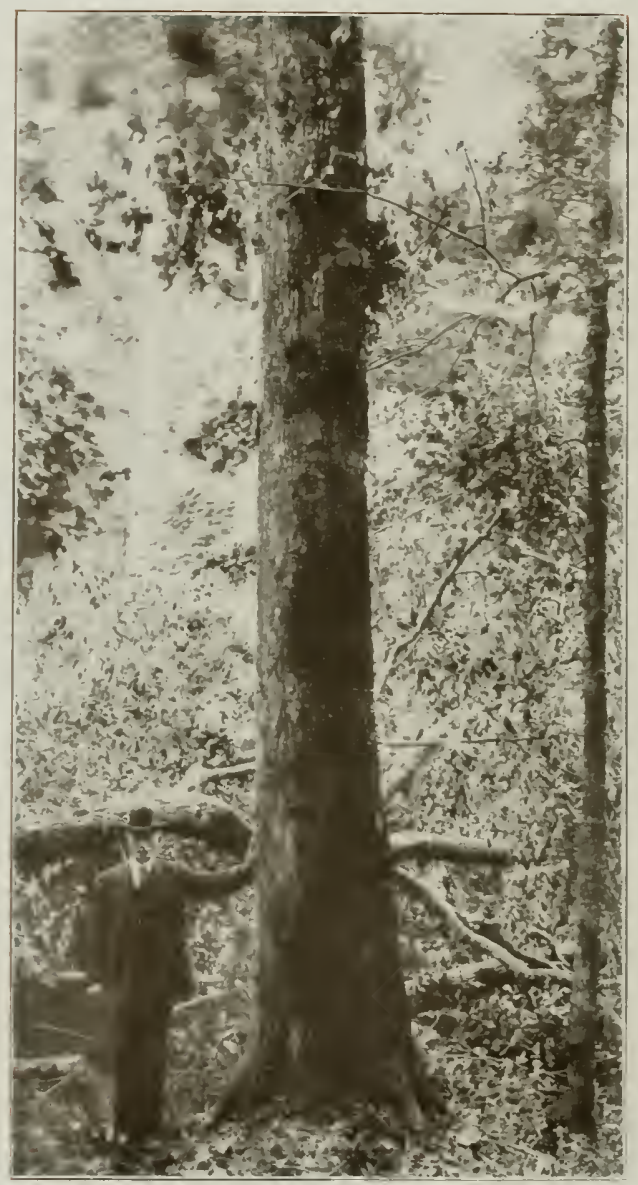

HORNBE.M 


\section{HORNBEAM}

\section{(Ostrya Virginiana)}

T

HIS tree belongs to the birch family and is closely related to the alders and to blue beech. Four species of hornbeam are known in the world, and two of them are in the United States. One is well known to most persons who are familiar with eastern hardwood forests, but the other is seldom seen because of the limited extent of its range.

The well-known hornbeam is found in the valley of the St. Lawrence river, throughout Nova Scotia and Ottawa, along the northern shore of Lake Huron to northern Minnesota, south through the northern states and along the Alleghany mountains to the Chattahoochee region of western Florida; through eastern Iowa, southeastern Missouri and Arkansas, eastern Kansas, Oklahoma and the Trintiy river region of Texas. It is known as ironwood, hop-hornbeam, leverwood, and hardhack.

The Indians were small users of wood except for fuel, but they had places where they put wood to special uses. They chose hornbeam, when they could get it, for one of these places. It was a favorite material for the handles of their stone warclubs. The stone heads were chipped to various forms, but were usually egg-shaped with a groove round the middle for fixing the handle. This was made fast with thongs of rawhide, and was generally nearly or quite two feet long, and slender as a golf stick. Great strength and a high degree of elasticity were required to stand the strain when a warrior swung his club in battle. Hornbeam meets these requirements exactly, and doubtless the Indian found this out by experience. It is about thirty per cent stronger than white oak, and forty-six per cent more elastic. The demand for warclub handles made no great inroads on the hormbeam supply, but it affords proof that the Indians sometimes used good judgment.

The different names of this tree describe some characteristic of the wood or foliage. The fruit resembles hops, hence one of the names. Hardness gives it the other names by which it is known. It is the custom nearly everywhere to call any wood ironwood if it is extra hard. No fewer than eleven species of the United States are known as ironwood in some parts of their ranges.

The leaves of hornbeam are simple and alternate; they taper to a sharp point at the end, while the base is rounded. They are doubly and sharply serrate. In color they are dark green above, and lighter below, tufted in places, resembling birch leaves in some respects, although they are quite different in texture, the leaves of birch being 
glossy, while those of ironwood are rough. They are joined to the twig with a short petiole, hardly a fourth of an inch in length.

The flowers grow in long catkins, staminate ones sometimes more than two inches long, covered with fringed scales. The pistillate catkins c.e usually shorter. Hornbeam blooms in April and Nay and its fruit ripens in August and September. The seed is a small nut equipped with balloon-like wings, intended for wind distribution. The seeds are often carried, rolled, and tumbled considerable distances. They keep on going until their wings are torn off or wear out, or until they become inextricably entangled among twigs or other obstacles. Comparatively few of the seeds ever find lodgment in situations suitable for germination. Consequently, hornbeam is scarce.

It is not easy to state the average size of the hornbeam, though it is usually small and never very large. Sometimes it reaches a height of fifty or sixty feet and a diameter of two or more, but such sizes are unusual. Trees a foot in diameter and forty feet high are more common. The foliage is thin, and the tree is satisfied to grow in shade, provided the shadows are not too dense. The leaves must have a little sunshine, and the flecks that fall through the open spaces in the forest canopy high above, suffice. The hornbeam makes no effort to overtop its fellow trees; but when it grows in the open, as on a rocky bank or ridge, where it catches the full light, the crown puts on more leaves, and multiplies its branches, and it is no longer the lean tree which some of the Indians called it. Forest grown specimens produce clear trunks, but those in the open are limby almost to the ground.

Hornbeam has neither smell nor taste. It burns well, the embers glowing brightly in still air. The weight of a cubic foot of seasoned wood is fifty-one pounds. It is strong, hard, heavy, tough, and exceedingly durable when exposed to variable weather, or when in contact with the soil. It takes a beautiful polish. Trees more than a foot in diameter are often found to be hollow.

The rrood is strong, hard, tough, durable in contact with the soil; heartwood light brown, tinged with red, or often nearly white; thick, pale sapwood which generally does not change to heart for forty or fifty years. The annual rings are not uniform in appearance. Some are easily distinguishable, while others are vague. This variation is due to the irregular development of the dark summerrood in the outer portion of the rings. It is at times distinct and again is hardly discernible.

The wood is diffuse-porous, and the pores are too small to be easily seen by the naked eye. The medullary rays are small and obscure. In quarter-sawed wood they show as a silvery gloss, but the appearance is too monotonous to be attractive. Neither is there striking figure 
when the wood is sawed tangentially, because of the small contrast in the different parts of the yearly ring. Horubeam may, therefore, be listed a mong woods which have little or no figure. No one ever thinks of using it for the sake of its beauty. Because of the small size and limited quantity hombeam will never come into commcrcial prominence. Its uses are almost entirely local and domestic. The lumberman or the farmer selects a hornbeam sapling as being the best material obtainable for making a wagon or sleigh tongue, a skid, or a lever. The farmer often laboriously works a section of the flint-like wood into minor agricultural implements.

The statistics of sawmill cut in the United States do not mention hornbeam even among such minor species as holly, Osage orange, alder, and apple. However, it is known that an occasional log goes to sawmills in the Lake States, and doubtless in other regions, and in some instances the wood is kept separate from others and is sold to fill special orders. Manufacturers of farm tools consider it the best wood for rake teeth. That use has come down irom the time when farmers made their own rakes and pitchforks. They learned the wood's value by experience, and manufacturers cater to the trade.

It is sometimes called lever wood, and that name dates from long ago when the man who needed a lever went into the woods and cut one to suit his needs. The modern lever is usually somewhat different and partakes more of the nature of a handle. They are seen in sawmills where they manipulate the carriage machinery; on certain agricultural implements where their function is to throw clutches in and out of gear; sometimes they are used as the handle by which the rudder of a small boat is controlled; and occasionally the lever has a place as an adjunct of a wagon or log-car brake. In all of these uses strength and stiffness are required, and durability is duly considered.

Wagon makers and repairers find several uses for hornbeam. It would be more frequently employed if it were more plentiful. Nearly any blacksmith who runs a repair shop for vehicles will testify to that. It fulfills every requisite for axles; is made into felloes for heavy wagons; and is considered the best obtainable wood for the tongues of heavy logging wheels and stone wagons.

Among various occasional uses of this wood it is listed by the manufacturers of reels for garden hose; rungs for long ladders; stakes for sleds, and also for cross pieces and parts of runners of sleds; wedges for the makers of machinery; and hammer and hatchet handles. It is a pretty active competitor of dogwood for sone of these uses, and it has been suggested for shuttles, but no report of its use in that capacity seems to have been made. 
One of its most common uses is as fence posts. Few lines of fence are built exciusively of hornbeam posts, because not enough can be had in one place; but posts are cut singly or a few together from Maine to Arkansas, and the aggregate number is large. The wood is said to outlast the heartwood of white oak when in contact with the ground, and it is so strong that posts of small size stand the pull of wires or the weight of planks or pickets.

Hornbeam is of slow growth and there is little reason to believe that it will ever be seriously considered by timber growers; but it will doubtless win its way to favor as an ornamental tree. It has been planted in city parks in New England and elsewhere, and its form, foliage, and habits are much liked. The pale green pods or cones-they are not exactly the one or the other-remain a long time on the branches and are delicately ornamental until after the antumn frosts change their green into brown. Then comes the flying time of the balloon seeds, and that is an interesting period in parks and yards where the tree's habits may be closely studied.

KNOWLTON HoRNBEAM (Ostrya knowltoni) is interesting chiefly on account of its extremely limited range, and its far removal from all its kin. It is an exile in a distant country. It has thus far been found only on the southern slope of the canyon of the Colorado river in Arizona, about seventy miles north of Flagstaff. It occurs at an elevation of 6,000 or 7,000 feet above the sea. Trees are twenty or thirty feet high and twelve or eighteen inches in diameter, and trunks usually divide a foot or two above the ground into three or more branches, which are of ten crooked and contorted. Such sizes and forms could not be of much value for anything but fuel, even if abundant. The heart is light reddish-brown, sapwood thin. The leaves are round instead of pointed at the apex, as with the other hombeam; but the flowers and fruit are mucil the same. Botanists speculate in vain as to how this species happens to be so fa: removed from other members of its family.

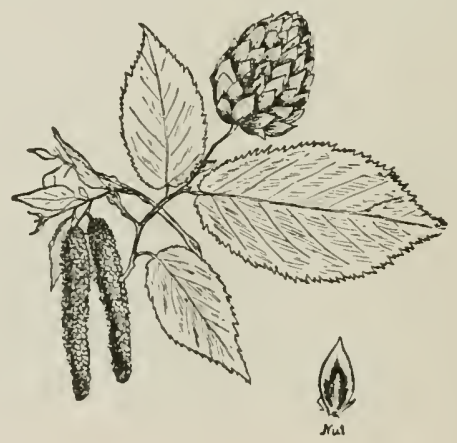


SILVERBELL 


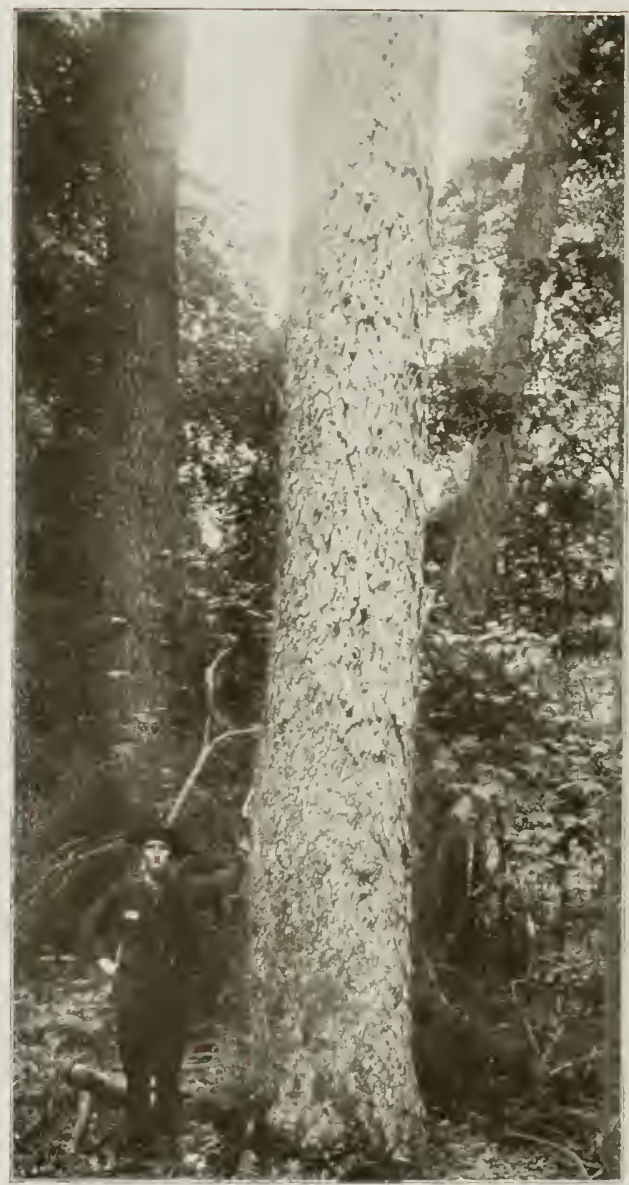

Silterbell 


\section{SILVERBELL TREE}

\section{(Mohrodcndron Carolinum)}

$T$

HIS tree belongs to the storax family, which is not a very numerous family as forest families are generally counted, but it is old and highly respectable. Its members are found in the old world and the new in both North and South America, in Europe, Asia, and the Malay Archipelago. Trees of the storax family produce, or they are supposed to produce, resins and gums, balsams, and aromatic exudations, but some give little or none. The priests and soothsayers of idolatrous nations of ancient times laid great stress on storax. They insisted on having the resin as an adjunct to their superstitious rites. It was the incense offered in their worship, and they compassed sea and land to obtain it for that purpose. It is not improbable that the southern peninsulas of Asia and the far-off Molucca islands were visited in ancient times to procure the incense which ultimately found its way to the Mediterranean regions.

It is, therefore, interesting to find that two members of the old storax family are quietly living in the coast region and among the mountains of the southeastern part of the United States. No one has ever suspected that they might be capable of yielding resinous incense suitable for the altars of heathen gods. They are the silverbell tree, and its little cousin, the snowdrop tree (Mohrodendron diptcrum). They have had common names a long time, but their botanical uames are the resuit of a recent christening. They are named from Charles Mohr who wrote an interesting book on the flora of Alabama. The silverbell tree is the larger of the two and deserves first consideration.

It has a somewhat extensive range, but in some parts it is so scarce that few persons ever see it. It is found from the mountains of West Virginia to southern Illinois, south to middle Florida, northern Alabama, and Mississippi, and through Arkansas and western Louisiana to eastern Texas. Under cultivation, this tree is known as the snowdrop tree in Rhode Island, Pennsylvania, North Carolina, South Carolina, Florida, and Louisiana. In Rhode Island, under cultivation, it is also sometimes known as the silverbell tree, and bears the same name in Alabama, Florida, and Mississippi. In parts of Tennessee it is known as the wild olive trec, and in other parts of the state as the bell tree. In various localities in Alabama it is referred to as the four-winged halesia; and in others as opossumwood. It is indiscriminately known in various sections of Texas as the rattlebox and calicowood, and some of the furniture manufacturers in North Carolina list it as box elder, though it 
is only distantly related to the true box elder. In the Great Smoky mountains in Tennessee, where the species reaches its greatest development, it bears a variety of names, among them being tisswood, peawood, bellwood, and chittamwood.

The tree varies in size from a shrubby form so small that it is scarcely entitled to the name of tree, up to a height of eighty, ninety, and even more than 100 feet with diameters up to nearly four feet. The largest sizes occur only among the ranges of the Great Smoky mountains in Blount, Sevier, and Monroe counties, Tennessee. No reason is known why this tree in that region should so greatly exceed its largest dimensions in other areas; but most species have a locality where the greatest development is reached, and this has found the favorable conditions in the mountains of eastern Tennessee. Some of the trees measure sixty feet or more to the first limbs.

Lumbermen of the country are not generally acquainted with silverbell, as is natural since its commercial range is so limited. It is not listed in statistics of sawmill cut or of veneer mills. The wood-using industries of the country do not report it, except in the one state, North Carolina, and there in very small amounts. Doubtless, it is occasionally used elsewhere, but it escapes mention in most instances. It has been made into mantels at Knoxville, Tennessee, and passes as birch.

The wood is light, soft, usually narrow-ringed, color light brown, the thick sapwood lighter. It weighs thirty-five pounds per cubic foot, and when burned it yields a low percentage of ash. The wood's chief value is due to its color and figure. Best results are not obtained by sawing the logs into lumber, because the handsomest part of the figure is apt to be lost. It is preëminently suited to the cutting of rotary veneer. By that method of conversion the birdseye and the pitted and mottled effects are brought out in the best possible manner. Veneers so cut from logs selected for the figure, possess a rare beauty which no other American wood equals. There is a pleasing blend of tones, which are due to the direction in which the distorted grain is cut. This distinguishes the wood from all others and gives it an individuality. Much of the figure appears to be due to the presence of adventitious buds, similar to those supposed to be responsible for the birdseye effect in maple.

The leaves of silverbell are briglit green at maturity and are from four to six inches long and two or three wide. They turn yellow before falling in autumn. The flowers give the tree its name, for they resemble delicate bells, about one inch in length. They appear in early spring when the leaves are one-third grown, on slender, drooping stems from one to two inches long. The trees are loaded throughout the whole 
crown, and present an appearance that is seldom surpassed for beauty in the forests of this country.

The fruit is peculiar and is not particularly graceful. It has too much the appearance of the load carried by a well-fruited vine of hops. It ripens late in autumn and persists during most of the winter. There is nothing in its color, shape, or taste to tempt birds or other creatures to make food of it, though, under stress of circumstances, they may sometimes do so. The fruit is two inches or less in length and an inch wide, and has four wings, which seem to be practically useless for flight. The seed is about half an inch long.

The bark of the trunk is bright red-brown and about half an inch thick, with broad ridges which separate on the surface into thin papery scales. The young branches wear an early coat of thick, pale wool or hairs, light, reddish-brown during the first summer, but later changing to an orange color.

The botanical range of the species is extensive, though the treeform is confined to a few counties among the southern Appalachian mountains. The northern limit of its range is in West Virginia where it is so scarce that many a woodsman never recognizes it. Unless it is caught while in the full glory of its bloom, it attracts no attention. It is not there a tree, but a shrub, hidden away among other growth, along mountain streams or on slopes where the soil is fertile. The blooming shrub might, at a distance, be mistaken for a dogwood in full blossom, but a closer inspection corrects the mistake.

It is true of this species as of many others that the range has been greatly extended by planting. The bell-like white flowers early drew attention of nurserymen who were on the lookout for trees for ornamental planting. It was carried to Europe long ago, and graces many a yard and park in the central and northern countries of that continent. It now grows and thrives in the United States six hundred miles northeast of its natural range, where it endures the winters of eastern Massachusetts, blooms as bounteously as in its native haunts among the shaded streams of the Alleghany mountains.

SNowdrop TREE (Mohrodendron dipterum) is a near relative of the silverbell tree, and looks much like it, except that it is smaller, has larger leaves, and the flowers are creamy-white. The two occupy the same territory in part of their ranges, but they differ in one respect. The silverbell tree grows with great luxuriance among the mountains while the snowdrop tree keeps to the low country and is seldom or never found growing naturally at any considerable elevation. It prefers swamps or damp situations near the coast. While the silverbcll tree's range includes West Virginia, that of the snowdrop extends no farther north than 
South Carolina. It follows the coast to Texas, and runs north through Louisiana to central Arkansas. Its range has been greatly enlarged by planting, and the northern winters do not kill it on the southern shores of Lake Erie. The largest trees are about thirty feet high and six inches in diameter, but the growth in most places is shrubby. Leaves are four or five inches long and three or four wide. Flowers are one inch long and are borne in profusion. They constitute the tree's chief value as an ornament, though the foliage is attractive. The bloom lasts a month or six weeks, from the middle of March till the last of April. The fruit has two wings instead of four, as with silverbell, but occasionally two rudimentary wings are present. The wood is light, soft, strong, color light brown, with thicker, lighter sapwood. The smallness of the trunks makes their use for lumber impossible. The species is valuable for ornamental purposes only, and has been planted both in this country and Europe. It has a number of names by which it is known in different localities, among them being cowlicks in Louisiana, and silverbell tree in the North where it has been planted outside of its natural range.

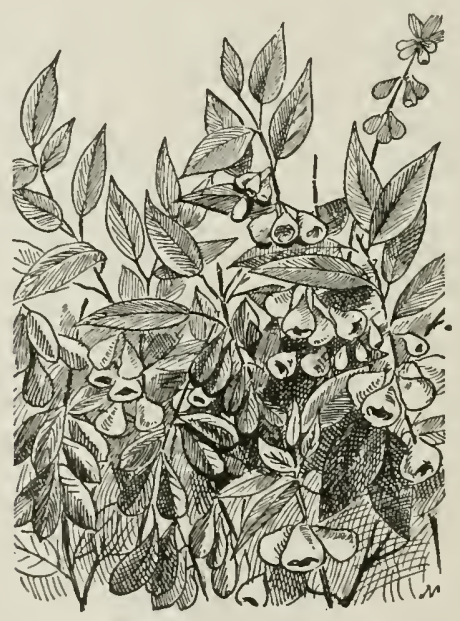


SYCAMIORE 


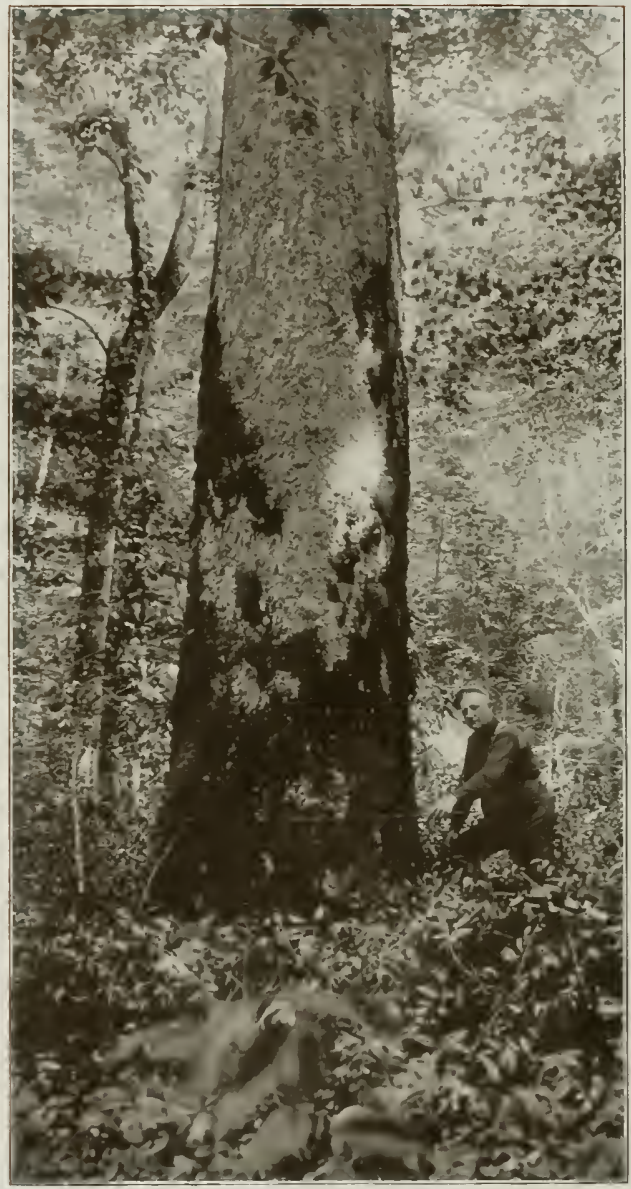

SYCAMORE 


\section{SYCAMORE}

\section{(Platanus Occidentalis)}

$\mathrm{P}$ ROBABLY no person with a practical knowledge of trees ever mistakes sycamore for anything else. The tree stands clear-cut and distinct. Until the trunk becomes old, it sheds its outer layer of bark yearly, or at least frequently, and the exfoliation exposes the white, new bark below. The upper part of the trunk and the large branches are white and conspicuous in the spring, and are recognizable at a long distance. No other tree in the American forest is as white. The nearest approach to it is the paper birch of the North, or the white birch of New England.

Notwithstanding the tree's individuality, it has a good many names. It is generally known as sycamore throughout the states of the Union, but it is frequently called buttonwood in Termont, New Hampshire, Rhode Island, Massachusetts, New York, New Jersey, Pennsylvania, Delaware, South Carolina, Alabama, Mississippi, Louisiana, Texas, Arkansas, Missouri, Illinois, Nebraska, Michigan, Minnesota, Ohio, and Ontario; buttonball tree in several of the eastern states and occasionally in Illinois, Iowa, Ohio, Michigan, and Nebraska; the plane tree in Rhode Island, Delaware, South Carolina, Kansas, Nebraska, and Iowa; the water beech in Delaware; the platane, cottonier, and bois puant in Louisiana. Probably the finest growth of the sycamore ever enconntered was in Ohio and Indiana, and these states still contain isolated patches of magnificent specimens of the wood. The Black Swamp of Ohio was originally a famous sycamore country, of which Defiance was the center of lumber manufacture. Many parts of Indiana produced a good sycamore growth, and a considerable amount of timber of excellent quality still exists, but is now largely owned by farmers who are generally holding it out of the market.

The range of sycamore extends from Maine to Nebraska, and south to Texas and Florida. It is one of the largest of American hardwoods, and in diameter of trunk it is exceeded by none. Trees are on record that were from ten to fourteen feet in diameter, and it was not unusual in the primeval forests for them to tower nearly or quite 125. In height a number of hardwoods exceed it, the yellow poplar in particular; but none of them has a larger trunk than the largest sycamores. However, the mammoths are generally hollow. The heart decays as rings of new growth are added to the outside of the shell. So large were the cavities in some of the sycamores in the original forests that more than one case is on record of their being used by early settlers as places of abode. 
The tree thrives best in the immediate vicinity of rivers and creeks. It needs abundance of water for its roots, but is not insistent in its demand for deep, fertile soil, for it grows on gravel bars along water courses, provided some soil and sand are mixed with the gravel. Great age is doubtless attained, but records are necessarily lacking in cases where the annual rings of growth must be depended upon; because the hollow trunks have lost most of their rings by decay.

Sycamore bears abundance of light seed which is scattered short distances by wind and much farther by running water. Its ideal place for germinating is on muddy shores and wet flats. Here the seeds are deposited by wind and water, and in a short time multitudes of seedlings spring up. Though most of them are doomed to perish before they at tain a height of a few feet, survivors are sufficient to essure thick stands on small areas. The trunks grow tall rapidly, and until they reach considerable size, they remain solid and make good sawlogs. but at an age of seventy-five or 100 years, deterioration is apt to set in; some die, others become hollow, and the result is a good stand of large sycamores is unusual. The veterans are generally scattered through forests of other species.

The statement has often been made in recent years that sycamore is becoming very scarce and that the annual output is rapidly declining. Statistics do not show a declining output. The cut of sycamore in 1909 was approximately twice as great as in 1899. It is true that the supply is not very large, and it never was large compared with some other hardwoods; but it appears to be holding its own as well as most forest trees. The cut in the United States in 1910 was $45,000,000$, and it was credited to twenty-six states. Indiana was the largest contributor, and it had held that position a long time. States next below it in the order named were Missouri, Arkansas, Tennessee, Kentucky, Ohio, and Illinois. Doubtless some of the sycamore lumber now going to market has grown since old settlers cut the primeval stands when they cleared their fields. It will continue to grow, and since it usually occupies waste places, it may be depended upon to contribute pret'y regularly year by year during time to come. It is one of the forest trees which have never suffered much from fires, because it grows in domp situations.

The wood of sycamore weighs 35.39 pounds per cubic foot, is hard, but not strong, difficult to split and work; the annual rings are limited by narrow bands of dark summerwood. The rings are very porous. The medullary rays are rather small, but can be asily seen without a glass. They run in regular, radial lines, close together, and the pores are in rows between. The rays of sycamore vary from the rule with most woods, in that they are darker than the body of the wood. 
One of the earliest uses of sycamore was by farmers who cut hollow trunks, sawed them in lengths of three or four feet, nailed bottoms in them, and used them for barrels for grain. They were called gums. Solid logs two or three feet in diameter were cut in lengths of a foot or less, bored through the center, and used as wheels for ox carts. The ox yoke was often made of sycamore. Butchers used sycamore sections about three feet high for meat blocks. The wood is tough, and continual hacking fails to split it. The use for meat blocks continues at the present time. In Illinois 1,600,000 feet were so employed in 1910 .

One of the earliest employments of the wood for commercial purposes was in the manufacture of boxes for plug tobacco; but it has now been largely replaced by cheaper woods. Its freedom from stain and odor is its clief recommendation for tobacco boxes. Some of it is in demand for cigar boxes.

The modern uses of sycamore are many. It is made into ordinary crates and shipping boxes in most regions where it grows. Rotary cut veneer is worked into berry crates and baskets, and into barrels. Ice boxes and refrigerators are among the products. Slack coopers are among the largest users, but some of the manufactured stave articles belong more properly to woodenware, such as tubs, washing machines, candy buckets, and lard pails.

Furniture makers demand the best grades, and most of the quartersawed stock goes to them, though the manufacturers of musical instruments buy some of the finest. Use is pretty general from pipe organs and pianos down to mandolins, guitars and phonographs. It enters extensively into the making of miscellaneous commodities. As small a toy as the stereoscope consumes much sycamore. Nakers of trunks find it suitable for slats, and it serves as small squares and borders in parquetry. It is a clioice wood for barber poles and saddle trees, and its fine appearance when worked in broad panels leads to its employment as interior finish for houses, boats, and passenger cars.

CAlifornia Srcamore (Platanus racemosa) is one of the three species of sycamore now found growing naturally in the United States. They are survivors of a very old family and appear to have been crowded down from the far North by the cold, or to have made their way south for some other reason. Sycamores flourished in Greenland in the Cretaceous age, some millions of years ago, as is shown by fossit remains dug up in that land of ice and eternal winter. They grew in central Europe, about the same time, but long ago disappeared from there. Sycamores were growing in the United States an immense period of time ago, and were doubtless lifting their giant white branches high above the banks of ancient rivers while the gorgeons bloom of yellow poplars brightencd the forests on the rich buttom lands farther back. Several species of sycamores which grew in the United States during the Tertiary age are now extinct. All seem to have been much like those which have come down to the present day. 
The California sycamore is found in the southern half of that state. and in Lorver California. It grows from sea level up to 5,000 feet, and has the same habits as the larger sycamore of the East, and prefers the banks of streams and the wet land in the bottoms of canyons. It attains a height of from forty to eighty feet, and a diameter of from two to five. Some trees are larger, one in particular near Los Angeles having a trunk diameter of nine feet. The tree is usually extremely distorted and misshaped, leaning, twisted, and forking and reforking until a practical lumberman would pronounce it a hopeless proposition. This applies, however, to trunks which grow in the open, and that is where most of them grow. When they are found crowded in thick stands in the bottoms of canyons, their trunks are shapely enough for short samlogs. The wood is very similar to that of eastern sycamore, and it is used tor similar purposes, when used at all. The balls are strung five on one tough stem, which is from six to ten inches long. The eastern sycamore usually has a stem for each ball. The seeding habits of both trees are the same.

ARIzoNa SYCAMORE (Platanus wrightii) has its range in southern New Mexico, southern Arizona, and neighboring regions in Mexico, where it grows in the bottoms of canyons up to 6,000 feet above sea. The tree attains a height of from thirty to eighty feet, and a diameter of two to five. The trunk is seldom shapely, but often divides in large branches, some of which are fifty or sixty feet long. There are usually three balls on a stem, and the leaf is shaped much like the leaf of red gum, but there is considerable variation in form. The wood resembles eastern sycamore in color and most other features, but when quarter-sawed the flecks produced by the medullary rays are generally smaller, and give a mottled effect. The wood has not been much used, but apparently it is not inferior to eastern sycamore.

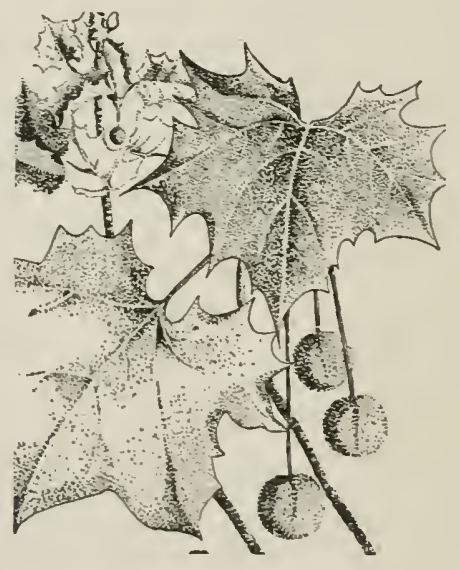


BLACK CHERRI 


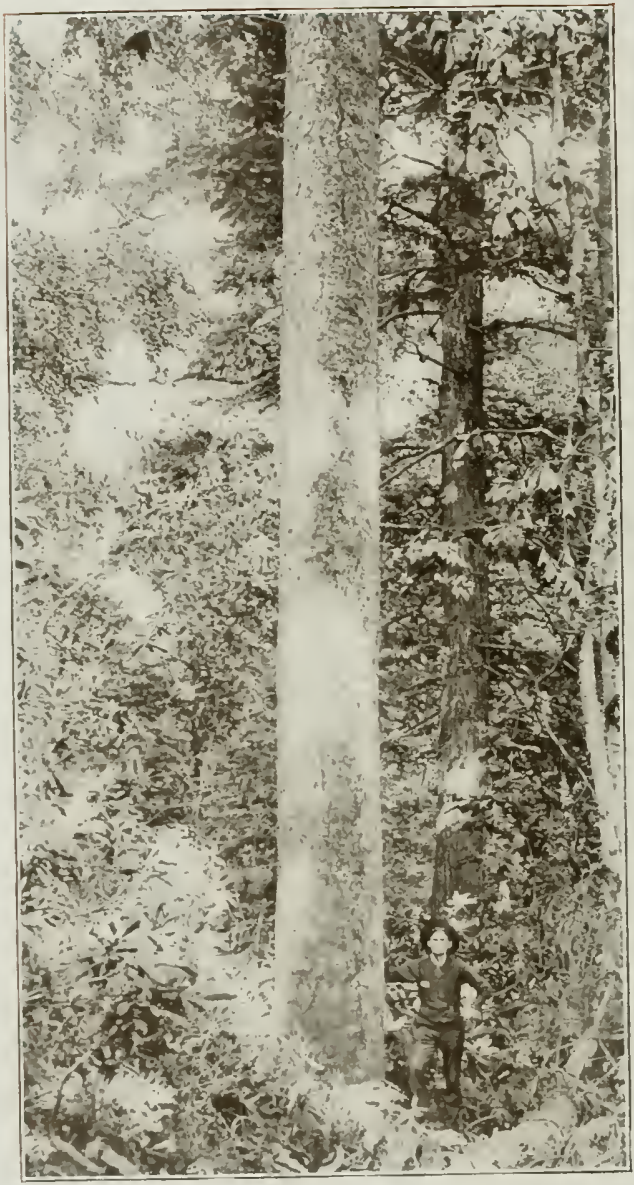

BLACK CherRY 


\title{
BLACK CHERRY
}

\author{
(Prunus Scrotina)
}

$\mathrm{T}$

HIS widely distributed tree supplies the cherry wood of commerce. Its natural range extends from Nova Scotia westward through the Canadian provinces to the Kaministiquia river; south to Tampa bay in Florida and west to North Dakota, eastern Nebraska, Kausas, Oklahoma, and eastern Texas. The tree is known as wild black cherry, wild cherry, black cherry, rum cherry, whiskey cherry, and choke cherry.

Cherry belongs to a remarkably large family and the ordinary observer would never suspect the relationship that exists between it and other growths to which it bears little resemblance. It is in the rose family (Rosacee). It has multitudes of small and large cousins, most of them small, however. Among them are the crabapple, the serviceberry, the haws, thorns, plums, and the peach, besides plants which do not rise to the dignity of trees.

The crown of black cherry is narrow and the branches are horizontal. In height the tree ranges from fifty to one hundred or more feet. The bark is a dark reddish-brown, rough and broken into plates, becoming smoother toward the top. The branchlets are a rich reddish-brown, and are marked with tiny orange-colored dots. The leaves are small, alternate, oblong or oval lanceolate, taper-pointed at the apex and pointed or rounded at the base, finely serrate; at maturity glabrous, firm, glossy, the light colored midrib being very distinct. The flowers are white and grow on pedicels in long slender racemes, which terminate leafy shoots. The fruit is almost black, showing deep red coloring beneath and is a small round drupe; vinous, although not disagreeable to the taste. In most instances a liking for it must be acquired, bnt comparatively few people ever take the trouble to acquire it. The old settlers among the Alleghany mountains had a way of pressing the juice from the drupes and by some simple process converting it into "cherry bounce," a beverage somewhat bitter but it never went begging when the old-time mountaineers were around. This was doubtless what persons had in mind who called it rum cherry. Few fruits, either wild or tame, contain more juice in proportion to bulk. Ripe fruit is employed as a flavor for alcoholic liquors. The bark contains hydrocyanic acid and is used in medicine. The peculiar odor of cherry bark is due to this acid.

In early years the ripening of the cherry crop among the ranges of the Appalachian mountains was a signal for bears to congregate where cherry trees were thickest. The cubs were then large enough to follow their mothers-in August-and it was considered a dangerous 
season in the cherry woods, because the old bears would grow fierce if molested while feeding. The mountaineers knew enough to stay away from the danger points at that time, unless they went there purposely to engage in a bear fight. It was a common saying among those people that "cherry bears" should be let alone.

The cherry's chief importance in this country has been due to its lumber. Unfortunately, that value lies chiefly in the past, for the supply is running low. It never was very great, for, though the species has a large range, it is sparingly dispersed through the forests. In many parts of its range a person might travel all day in the woods and see few cherry trees, and perhaps none. The best stands hardly ever cover more than a few acres. Generally the trees grow singly or in clumps. It appears to be nearly wholly a matter of soil and light, for the seeds, which are carried by birds, are scattered in immense numbers, and only those grow which chance to find conditions just right. The tree wants rich ground and plenty of room, which is a combination not of ten found in primeval forest regions; but, since the country has been largely cleared, cherry trees spring up along fence rows and in nooks and corners. If let alone they grow rapidly, but trunks so produced are of little value for lumber, because too short and limby. In the forest the tree lifts its light crown high on a slender trunk to reach the sunshine, and such trunks supply the cherry lumber of commerce. Near the northern limit of its range it seems to abandon its demand for good soil and is content if it is supplied with light only. It betakes itself to the face of cliffs, sometimes overhanging the sea, and so near it that the branches are drenched in spray thrown up by breakers. It is needless to say that no good lumber is produced under such circumstances.

The first loss of cherry occurred when the farms were cleared. It stood on the best ground, and the land-hungry Anglo-Saxon wanted that for himself. He cut the tall shapely cherry trees, built fences and barns of some of the logs, and burned the balance in the clearing. Then came the pioneer lumberman who did not take much, because his old up-and-down saw, which was run by water, would cut only about a thousand feet a day, and there was plenty of other kinds of timber. But when the steam mill put in its appearance, cherry went fast. Its price was high enough to pay for a long haul. From that day till this, cherry has gone to market as rapidly as millmen could get to it.

Next to walnut, it is the highest priced lumber produced in the United States. The average cut per mill, according to returns of those who sawed it in 1909 , was only 11,200 feet, and the total output that year was only $24,594,000$ feet, contributed by twenty-nine states. The five leading producers were, in the order named, West Virginia, Pennsyl- 
vania, New York, Ohio, and Indiana. The next year the total output fell to $18,237,000$ feet, and cherry went down to a place among the "minor species," such as dogwood, alder, locust, and buckeye. The day of its importance in the lumber industry is past. It has become too scarce to attract much attention, but there will always be some cherry in the market, though veteran trunks, three and four feet through and good for four sixteen-foot logs, will be seldom seen in the years to come.

While good taste ordinarily dictates that cherry be finished in a tone approximating its natural color, it is quite frequent that it masquerades as mahogany. A well-known and perfect method of making cherry look like mahogany is to have the wood rubbed with diluted nitric acid, which prepares it for the materials to be subsequently applied; afterwards, to a filtered mixture of an ounce and a half of dragon's blood dissolved in a pint of spirits of wine, is added one-third that quantity of carbonate of soda, the whole constituting a very thin liquid which is applied to the wood with a soft brush. This process is repeated at short intervals until the wood assumes the external appearance of mahogany. While cherry is employed as an imitation of mahogany, it is in its turn imitated also. Sweet birch is firished to look like cherry, and for that reason is sometimes known as cherry birch.

Cherry weighs 36.28 pounds per cubic foot; it is very porous, but the pores are small and are diffused inrough all parts of the annual ring. The wood has no figure. Its value is due to color and luster. The medullary rays are numercus but small, and in quarter-sawing they do not show as mirrors, like oak, but as a soft luster covering the whole surface.

The principal uses of cherry have always been in furniture and finish, but it has many minor uses, such as tool handles, boxes for garden seeds, spirit levels and other tools, and implements, patterns, penholders, actions for organs and piano players, baseblocks for electrotypes and other printing plates, and cores for high-class panels. Aside from its color, its chief value is due to its comparative freedom from checking and warping. This cherry is one of the few trees that cross the equator. It extends from Canada far down the west coast of South America.

ChOKe Cherre (Prunus virginuma) is widely distribnted in North America from Canada to Mexico. It is said 10 attain its largest size in the Southwest where trees are sometimes forty feet high and a foot in diameter. The name is due to the astringency of the half ripe fruit which can scarcely be eaten. When fully ripe it is a little more tolerable, and is then black, but is red hefore it is ripe. The color of immature cherries deceives the unsophisticated into belicving they are ripe. In Canada the fruit is made into pies and jelly, and it is said the tree is occasionally planted for its fruit. The Indians of former times made food of it. The tree is 
small, and bruised branches emit a disagreeable odor; leaves contain prussic acid, and when partly withered, they are poisonous to cattle. The trunks are nearly always too small for commercial purposes, and are apt to be affected with a fungous disease known as black knot.

WeSTERN Choke CHERry (Prunus demissa) grows from the Rocky Mountains to the Pacific in the United States. It is often regarded as the western form of choke cherry, but it has more palatable fruit, and trees are a little larger, while trunks are so crooked that no user of wood cares to have anything to do with them. The wood is weak, but is hard and heavy.

BrTter Cherry (Prunus emarginata) belongs to the far West, and is found from British Columbia to southern California. In size it ranges from a low shrub to a tree a foot in diameter and forty feet high. The largest sizes are found in western Washington and Oregon. The wood is soft and brittle, brown streaked with green. It is not known that any attempt has been made to put the wood of this tree to any useful purpose. The bark and the leaves are exceedingly bitter. Fruit ripens from June to August, depending on region and elevation, and it is from one-fourth to one-half inch in diameter, black, and intensely bitter.

Hollyleaf Cherry (Prunus ilicifolia) is a California species growing in the bottoms of canyons from San Francisco bay to the Mlexican line. It is rarely more than thirty feet high, hut has a large trunk, sometimes two feet in diameter. The wood is heavy, hard, and strong, and it ought to be valuable in the manufacture of small articles, but fuel is the only use reported for it. The fruit is insipid, and ripens late in autumn. The foliage is much admired and has led to the planting of the species for ornamental purposes.

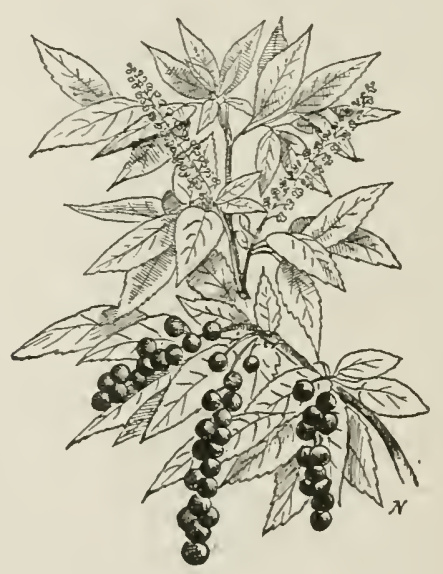


W'ILD RED CHERRY 


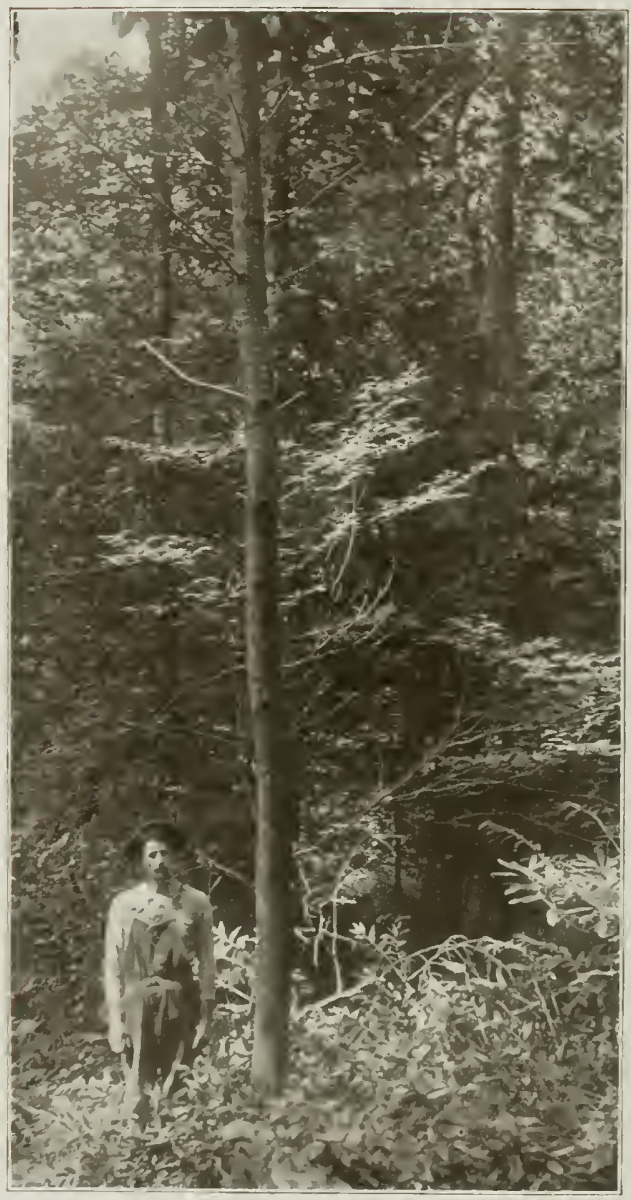

IVILD RED ChERRI 


\title{
WILD RED CHERRY
}

\author{
(Prunus Pennsylvanica)
}

$\mathbf{I}^{\mathrm{N}}$ $\mathrm{N}$ addition to the name wild red cherry by which this tree is known in most parts of its range, it is called bird cherry in Maine, New Hampshire, New York, Pennsylvania, Minnesota, Iowa; red cherry in Maine and Rhode Island; fire cherry in New York and many other localities; pin cherry in Vermont, New Hampshire, New York, Michigan, Iowa, and North Dakota; pigeon cherry in Vermont, New Hampshire, Rhode Island, New York, Ontario, and North Dakota; and wild cherry in Tennessee and New York. Its range extends from Newfoundland to Hudson bay, west to British Columbia, south through the Rocky Mountains to Colorado, and in the East along the Appalachian ranges to North Carolina and Tennessee. It reaches its largest size among the Big Smoky mountains in Tennessee and North Carolina.

It is ordinarily a tree thirty or forty feet high, and from eight to ten inches in diameter, though trunks are sometimes twenty inches through. It grows fast, but is very short-lived. Many stands disappear in thirty years or less, but individuals survive two or three times that long, if they stand in open ground. One of its names is fire cherry, and that fitly describes it. Like paper birch and lodgepole pine, it follows forest fires where the ground is laid bare by the burning. Nature seems to have made peculiar provisions whereby this tree clothes barren tracts which have been recently burned. In the first place, it a prolific seeder. Its small, red cherries are borne by bushels on very young trees. Birds feed on them almost exclusively while they last, and the seeds are scattered over the surrounding country. They have such thick shells that few germinate unless they pass through a moderate fire, which cracks the shells, or at least they do not sprout until they come in direct contact with mineral soil. When a fire burns a forest, thousands of the cherry seedlings spring up. Many persons have wondered where they come from so quickly. They were already scattered among the forest learcs before the fire passed. The heat crazed their shells, and the burning of the leaflitter let them down on the mineral soil where they germinated and soon came up by thousands. The case is a little different with paper birch and with aspen, which are also fire trees. Their sceds cannot pass through fire without perishing, and when birches and aspcns follow a fire it means that the seeds were scattered by the wind after the passing of the fire. Doubtless cherry seeds are often scattered after the fire lias passed; but it is believed that most of those which spring up so quickly have passed through the fire without being destroyed. 
This small cherry is one of the means by which damage by forest fires is repaired. The tree is of little value for lumber or even for fuel; but it acts as a nurse tree-that is, it shelters and protects the seedlings of other species until they obtain a start. By the time the cherry trees die, the seedlings which they have nursed are able to take care of themselves, and a young forest of valuable species is established.

Except in this indirect way, the wild red cherry is of little use to man. The wood is soft, light, and of pleasing color, but trees are nearly always too small to be worked into useful articles. About the only industry of which there is any record, which draws supplies from this source, is the manufacture of pipe stems. The straight, slender, brightbarked branches are cut into requisite lengths and bored endwise, and serve for stems of cheap pipes, and occasionally for those more expensive. The bark, like that of most cherries, is marked by dark bands running part way round the stems. These are known as lenticels, and exist in the bark of most trees, but they are usually less conspicuous in others than in cherry. It is this characteristic marking which gives the cherry pipe stem its value.

Wild red cherry blooms from May to July, depending on latitude and elevation, and the fruit ripens from July to September. The cherries hang in bunches, are bright red, quite sour, and the seed is the largest part. They are occasionally made into jelly, wine, and form the basis of certain cough syrups.

West India Cherry (Prunus spharocarpa) grows near the shores of Biscayne bay, Florida. It there blooms in November and the fruit ripens the next spring. The tree attains a height of from twenty-five to thirty feet, and a diameter of five or six inches. When grown in the open at Miami, Florida, it is larger, and is much liked as an ornament. The thin, smooth bark is brown, tinged with red, and is marked by large conspicuous lenticels. The wood is hard and light, and of light clear red color. It is too scarce to be of much importance, but paper knives, napkin rings, and other novelties made of it are sold in souvenir stores in southern Florida. Its range extends south to Brazil.

Willowleaf Cherry (Prunus salicifolia) is a small tree, also called Mexican cherry, is more common south of the United States than in this country, ranging as far south as Peru. It is found on some of the mountains of southern New Mexico and Arizona.

Laurel Cherry (Prunus caroliniana) is a southern species which sticks close to the coast in most of its range from South Carolina to Texas. It has many names, among them wild peach, wild orange, mock orange, evergreen cherry, mock olive, and Carolina cherry. Leaves hang two years, and the fruit remains nearly one. The latter is black 
and about half an inch long. The withered leaves are poisonous if eaten by cattle. The tree is thirty or forty feet high, and cight or ten inches in diameter. The wood is heavy, hard, and strong, color light brown to dark, rich brown, sometimes of much beauty, but no record has been found of any use for it. The tree is often planted for ornament.

Wild Plum (Prunus americana) is foutd from New Jersey to Montana, southward to New Mexico and Texas, and extends to Florida and Mexico. Its range covers about a million square miles. There are seven or more species of wild plums in the United States. The fruit of all of them is edible. They have been planted accidentally or otherwise in many localities where they were not found before the country wassettled. The plum was an important fruit iu the country's early history. The pioueers gathered wild fruits before planted orchards came into bearing, and the plum was one of the best which nature supplied. Early travelers among the Iudians in the South frequently spoke of Indian peaches. Such references have led some to believe that the peach was native in that region, but it is safe to couclude that what was called the peach was really some species of wild plum. These fruits were among the earliest to become domesticated. In fact, they were abundaut about the sites of Indian towns and old fields, where the savages had scattered seeds without any purpose on their part of planting trees; and early settlers imitated the Indians, and plums were soon growing in the vicinity of most of the cabins. As a forest tree, it usually thrived best on the banks of streams, for there it could find more suushine than in the deep woods, and it bore much more fruit. The ratuges of several species of plums overlapped, and different sizes and colots of fruit were found in the same locality even before white men assisted the spread of species. The common plum, known to botanists as Prunus americana, is recoguized under many names among laymen; amoug these uames are yellow plum, red plum, horse plum, hog plum, August plum, native plum, and goose plum. Usually the plum's skin is red, and the flesh yellow, which accounts for its uames, both red and yellow. The tree ranges in height from twenty to thirty-five feet, and from five to ten inches in diameter. The wood is heavy, hard, and stroug, and dark rich-brown. It is suitable for turnery and small uovelties, but little of it has been used.

Canada Plum (Prunus nigra) appears to be the most northern member of the plum group. It grows from New foundland to Manitoba, and south into the northern tier of states. Its range has been much extcnded by planting, and a number of varieties have appeared. It is twenty or thirty feet high, and five to eight inches in diameter. Flowers appear in April and May, and the fruit is ripe in September and October. The plums are about an inch long, orange-red in color, with yellow flesh. The wood is heavy, hard, and strong. Those who cultivate this tree often do so for the beauty of the flowers, rather than for the value of the fruit. The wood is not uscd for commercial purposes.

BLack Stoe (Prunus umbellata), known also as southern bullace plum, hog plum, and wild plum, ranges from South Carolina, round the coast through Florida, to Louisiana and up the Mississippi valley into Arkansas. The tree is fiftcen or twenty feet high and from six to ten inches in diameter. The fruit ripens from July to September, is black when ripe, and oftcu nearly an inch long. The people where it grows use it for jelly. It is uot reported that the wood is used for any purpose.

Western Plum (Prunus subcordata) grows west of the Cascade mountains from southeru Oregon to central California. It is often a low bush, but at its best forms a tree twenty feet high and six inches in diameter, but its wood is of no cconomic 
importance. Its deep, purple-red plums ripen in autumn and are an excellent wild fruit, juicy and tart. During the fruit season the plum thickets were formerly infested by both bears and Indians, and many a fight for possession took place, with victory sometimes on one side, sometimes on the other. The white inhabitants now make jam and jelly of the fruit.

Aldeghany Sloe (Prunus allegheniensis) is so named because it is best developed among the Alleghany mountains of Pennsylvania. The tree is eighteen or twenty feet high and six or eight inches in diameter. The wood is without value for commercial purposes, but the tree's fruit has some local importance. It ripens about. the middle of August, and is somewhat less than an inch in diameter, with dark, reddish-purple skin, covering yellow flesh.

Chikasaw Plus (Prunus angustifolia) is a well-known wild plum of the South from Delaware to Texas, and north to Kansas. Its natural range is not known, because it bas been so widely planted, accidentally or otherwise, near farm houses and in fence corners. Its bright, red fruit goes only to local markets. Negroes gather most of the crop in the South. The wood is not considered to have any value, but, in common with other plums, it possesses qualities which fit it for many small articles.

Garden Wild Plum (Prunus hortulana) is supposed to have originated in Kentucky from a cross between the Chickasaw plum and the common wild plum (Prunus americana). It has spread from Virginia to Texas. The largest trees are thirty feet high and a foot in diameter. The fruit ripens in September and October, is deep red or yellow, with hard, austere, thin flesh, quite sour. The fruit is called wild goose or simply goose plum in Tennessee and Kentucky. Horticulturists have made many experiments with this plum.

CocoA Plum (Chrysobalanus icaco), also called gopher plum, grows in southern Florida, and its insipid fruit is seldom eaten except by negroes and Seminole Indians. There is little sale for it in the local markets. Trees are sometimes thirty feet high and a foot in diameter. The light brown wood is heavy, hard, and strong, but it is seldom used. The tree grows in Africa and South America as well as in Florida.

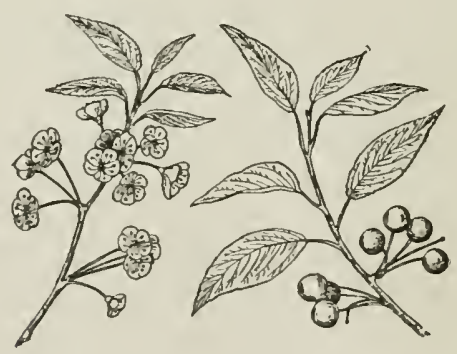


BEECH 


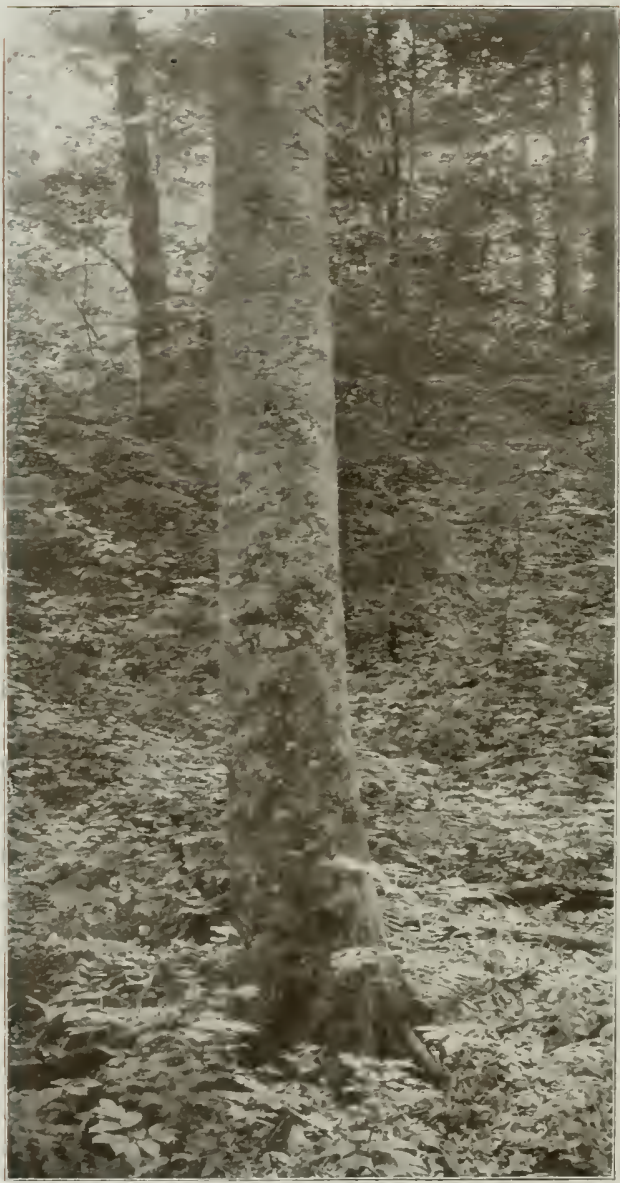

BEECH 


\section{$\mathrm{BEECH}$}

\section{(Fagus Atropunicea)}

$\mathrm{T}$ HERE is only one beech in the United States, and fout or five in Europe and Asia. The southern portion of Sonth America has several species which usually pass for beech. One or more of them are evergreen. Old world species are sometimes planted in parks and cemeteries in this country, but as forest trees they have no importance in the United States and probably never will have. It becomes a simple matter, therefore, to deal with the tree in this country. It is alone, and has no nearer relatives than the chestnuts, chinquapins, and the oaks, all of which are members of the same family, and the beech gives the name to the family-Fagacea. The blue beech, which is common in most states east of the Mississippi river and in some west, is not a member of the same family, though it looks enough like beech to be closely related to it.

The name has come down from remote antiquity. It is one of the oldest names in use. It is said to have descended through thousands of years from old Aryan tribes of Asia which were among the earliest to use a written language. For the want of better material, they cut the letters on beech bark, and a piece of such writing was called "boc." It was but a step from that word to book-a collection of writings. Both beech and book came from the same word "boc" and the connection between them is very evident. The pronunciation has been little changed by the Germanic races during thousands of years, but the Romans translated it into Latin and called it "liber," from wlich we have the word library. Doubtless in very ancient times, say 5,000 years before the building of Solomon's temple, the libraries beyond the Euphrates river consisted of several cords of trimmed and lettered beech bark. Such material being perishable, it has wholly disappeared. The matter is not now directly connected with the lumber interests, but it increases one's respect for beech to know how important a part it must have played in the ancient world, whereby it stamped its name so indelibly upon the language of the most intelligent portion of the human race.

The word buckwheat has the same origin. It means becch wheat, so named because the grains are triangular like beech nuts. The tree is always known as beech in this country, though it may have a qualifying word such as red, white, ridge.

It ustally grows in mixed forests of llardwoods, but it is of ten found in the immediate presence of hemlock and spruce, grows from 
Maine to Florida, and west to Arkansas. Considerable areas are often occupied by little else. This is attested by the frequency with which such names as "beech flat," "beech ridge," "beech woods," and "beech bottom" are encountered in local geography. Perhaps the finest examples of beech growth in the United States occur in the higher altitudes of the lower Appalachian range in eastern Tennessee, and western North Carolina, where trees are frequently encountered, showing a bole of perfectly symmetrical form, of from three to more than four feet in diameter, and of a sheer height of seventy feet before a limb is encountered. The wood which grows in this section is nearly as hard as that of the North, but that growing on lower levels in the South is of a much softer texture and lighter color, the heart being pinkish rather than reddish-brown.

Beech is one of the truly beautiful trees of the forest. In the eyes of many, the beech is as much to be admired as the American elm or sugar maple. Certainly in spring when it is covered with its staminate blossoms, it is a splendid sight, and its perfect leaves are seldom spotted or eaten by insects. In winter, it is particularly interesting. Its beautiful bark then appears very bright. After its fine leaves have fallen, though many of them, pale and dry, cling to the branches throughout the winter, the structure of its massive head is seen to advantage. In the Canadian markets and those of many of the middle and western states, its nuts are gathered and sold in considerable quantities. These nuts are favorite food of both the red and gray squirrel and these rodents collect them in considerable quantities during the late fall, and store them in tree hollows for their winter's supply of food. It of ten happens, in felling beech trees in the winter, that shelled beech nuts to the quantity of a quart or more will be found secreted in some hollow by these provident little animals.

Formerly beech was little used for lumber, but was long ago given an important place as firewood and material for charcoal. Its exceilent qualities as lumber have now made it popular in most markets. The sapwood is comparatively thin and the heart is very much esteemed for many purposes. Nany millions of feet of it are converted into flooring and the "pure red" product is very highly esteemed for ornamental floors. It has not as good working qualities as maple, but still it stays in place even better than does that famous flooring material. Nearly all the large flooring factories of the North, whose principai output is maple, have a side line of beech flooring, and in the South, notably in Nashville, a considerable quantity of the wood is made into flooring. In full growth this beantiful tree is round topped, with wide spreading and horizontal branches, and shows a normal altitude of about sixty 
feet. In this form of growth branches appear on the body very close to the ground, and their ends often trail upon it. In its forest form, where trees of any sort are of commercial importance, it often attains a height of ninety or $100 \mathrm{feet}$, with smooth rounded bole as symmetrical as the pillar of a cathedral, with a diameter of from two to four feet. Its time to bloom is April or May, and its nuts ripen in October. The bark is a light bluish-gray, and remarkably smooth; the leaves are simple, alternate, with very short petioles, oblong with pointed apex and rounded or narrowed base. The ribs are straight, unbranching, and terminate in remote teeth. The fruit is a pair of three-sided nuts with a sweet and edible kernel which grows in a four-celled prickly burr, splitting when ripe.

Beech is an excellent fuel and it has long been used for that purpose. It is so regularly dispersed over the country that most neighborhoods were able to get it in the years when families cut their own firewood. Later, when charcoal was burned to supply primitive iron furnaces, before coke could be had, beech was always sought for. Still later, when large commercial plants were built to carry on destructive distillation of wood, beech was still a favorite. Its modern nses are many. There is scarcely a plant east of the Rocky Mountains, engaged in the manufacture of hardwood commodities, which does not use beech. In Michigan alone nearly $30,000,000$ feet a year are demanded by box makers, and more than that much more by manufacturers of other commodities. It is widely employed for furniture, filing cabinets, vehicles, interior finish, agricultural implements, woodenware, and musical instruments. It is one of the heaviest and strongest of the common hardwoods, and gives long service when kept dry; but does not last well in damp situations.

Beech is strictly a forest tree. This does not mean that it will not grow in the open, but when it does grow there it makes poor lumber, short and limby. The seedlings must have shade if they are to do any good, but after they attain a certain size they can endure the liglit. The roots lie close to the surface of the ground, and the trampling of cattle of ten kills large trees.

BLuE BEech (Carpinus caroliniana) is not in the beech family, but the name by which it is commonly known, and its resemblance to beech, justify its consideration with beech. The bluish color of the bark is responsible for its common name, but it is known by several others, among them being water beech, because it of ten grows on or near the banks of streams, and it seldom seens more at home than when it is hanging over the bank of a creek where sliade is deep and moisture plentiful. It is often called hornbcan and ironwood, and it is clescly 
related to hop hornbeam (Ostrya virginiana). It grows from Quebec, to Florida and from Dakota to Texas, reaching its largest size in eastern Texas where it is sometimes sixty feet high and two in diameter, though this size is unusual. Few trees develop a bole less acceptable to lumbermen. In addition to being short, crooked, twisted, and covered with limbs, it is nearly always ribbed and fluted, so that a log, even if but a few feet long, is apt to be almost any shape except round. The thick sapwood is pale white, heart pale brown. The annual rings are usually easily seen, but they are vague, because of so little difference between the springwood and summerwood; diffuse-porous; medullary rays thin and usually seen only in the aggregate as a white luster where wood is sawed radially. The uses of this wood are many, but the amounts very small. It is made into singletrees and ax and hammer handles in Michigan, wagon felloes in Texas and other parts of the Southwest; levers and other parts of agricultural implements in various localities. It seldom goes to sawmills, is generally marketed in the form of bolts, and is hard, stiff, and strong.

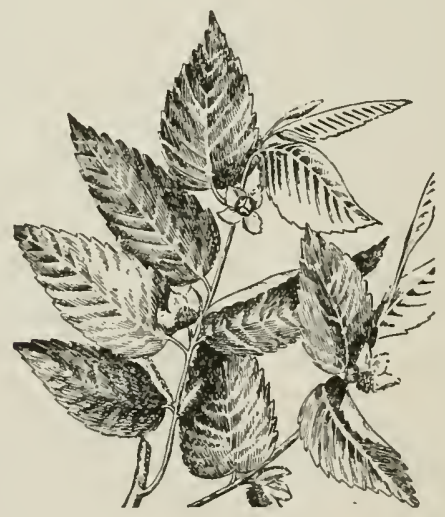


CHESTNUT 


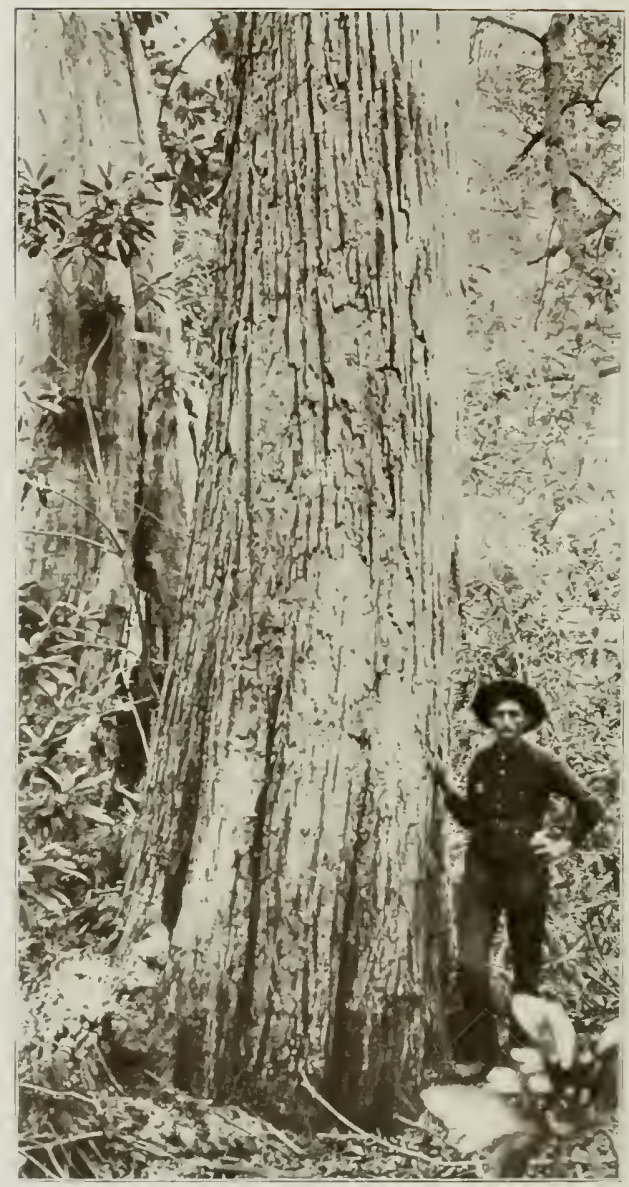

Chestorit 


\title{
CHESTNUT
}

\author{
(Castanea Dentata)
}

$\mathrm{F}^{\mathrm{I}}$ IVE species of chestnut are known, three of them in the United States. One of these, Castanea alnifolia, is a shrub and has no place in a list of trees. Chestnut and chinquapin are the two others. They are in the beech family to which oaks belong also. The ancient Greeks designated these as food trees (Fagacea), not an inappropriate name for chestnut which probably furnishes more human food than any other wild tree. Its range extends from Maine to Michigan and southward to North Carolina and Tennessee. It attains its greatest size in western North Carolina and eastern Tennessee. It is one of the few well-known woods of the United States that does not bear a half dozen or more local names in the various localities of its growth, but the wood is invariably known as chestnut.

Trees vary in size from sixty to 100 feet in height, and from two to four in diameter. Trunks six feet through occur where trees have grown in the open, but such are not tall, and are not valuable for lumber. Chestnut trees are sometimes heard of in this country with trunks ten and twelve feet through, but such must be very scarce, because no one seems to know just where they are located. It is not improbable that in rare cases such sizes have existed. In France and Italy trees much larger are well authenticated, but that chestnut is of a species different from ours.

Chestnut is a very long-lived tree where it is fortunate enough to escape the attacks of worms and disease; but as age comes on, it is almost certain to be attacked. Insects bore the wood, and fungus induces decay. Frequently the heartwood of large trunks is all gone, and the trees stand mere shells with scarcely enough sound wood left to support the diseased tops.

Few species sprout with more vigor than chestnut. In the mountains of eastern Tennessee, W. W. Ashe found that ninety-nine per cent of stumps sprout. This applies as well to veterans of three hundred years as to young growth. Sprouts which rise from the top of a high stump are liable to meet misfortune, because, under their disadvantage they cannot develop adequate root systems; but sprouts which spring from the root collar, or near it, may grow to large trees. It is claimed by some that a chestnut which grows from a sprout has straighter grain than one springing from seed. The latter's trunk is liable to develop a spiral twist, not only of the wood, but also of the bark; but the sproutgrown tree lacks the twist. 
Chestnut blooms in midsummer, and the profusion of pale golden catkins makes the isolated tree a conspicuous object at that time. Bloom is nearly always abundant, but the nut crop fails frequently. Several accidents may happen, but the most frequent cause of scarcity in the chestnut crop is a spell of rainy weather while the trees are in bloom. The rain hinders proper pollenization.

Mfany thousands of bushels of chestnuts are sent to market yearly in the United States. The nuts are smaller but sweeter than those of European chestnut. The largest part of the crop is collected from trees in open ground. Those in dense forests bear only a few nuts at the top. Open-grown trees develop enormous and shapely crowns; and it is not unusual for farmers who value their nut bearing trees to pollard them. This puts the tree out of consideration as a source of lumber. Its branches multiply, but the trunk remains short. It is claimed that a chestnut orchard of good form and in a region where large crops are frequent, is more profitable than an apple orchard. The tree does not demand rich land, but must have well-drained soil. It grows on rocky slopes and ridges, and will prosper where most other valuable trees will barely exist.

It grows rapidly in its early life, but does not maintain the rate many decades. Large trees are old. In the southern Appalachians the ages of telegraph poles forty feet long and six inches in diameter at the top range from forty-five to sixty-five years. Trees of round fence-post size may grow in fifteen years. Few trees will produce posts more quickly or in larger numbers per acre. In some instances nearly a thousand saplings large enough for posts stand on a single acre. Sproutgrowth chestnut of ten forms nearly pure stands of considerable extent.

The value of this tree is in its rood as well as its nuts. More than $500,000,000$ feet of lumber are cut from it yearly. Long before it was much thought of as a sawmill proposition, it was manufactured in large amounts into rails and posts by farmers, particularly in New England and in the Appalachian region. Axes, crosscut saws, mauls, and wedges were the means of manufacture. Lntold millions of fence rails were split before wire fences were thought of. It is a durable wood, made so by the tannic acid it contains. As fence rails, it was more durable than the best oak, and where both were equally convenient, farmers nearly always chose chestnut. On high and dry ridges a chestnut rail fence would last from twenty-five to fifty years, and in extreme cases very much longer, even a full century it is claimed.

Dry chestnut wood weighs 28.07 pounds per cubic foot, which makes it a light wood. Its annual rings are as clearly marked as those of any tree in this country. The springwood is filled with large open 
pores, the summerwood with small ones. The medullary rays are minute, and of no value in giving figure to the wood. Nevertheless, chestnut has strong figure, but it is due solely to the arrangement of the spring and summerwood of the annual rings. It is commonly classed as a course-grained wood. The finisher can greatly alter its appearance by rubbing the pores full of coloring matter. The wood is likewise susceptible to change in tone in the fumes of ammonia, and by similar treatment with other chemicals. The light colors of mission furniture are generally the result of treatment of that kind.

The largest cut of chestnut lumber comes from West Virginia, Pennsylvania, Virginia, and Connecticut. The largest use by any single industry is probably by the manufacturers of musical instruments, though the honor may be divided with furniture, interior house finish, and coffins and caskets. It is much employed as core or backing on which to glue veneers. The lumber of old, mature trees is best liked for this purpose, because it is not apt to shrink and swell, and it holds glue. It is no detriment that it is riddled with worm holes the size of pins. That kind of chestnut is known in the trade as "sound wormy." Some persons claim that such lumber is better as backing for veneer than sound pieces, because it is lighter, is sufficiently strong, and the small holes seem to help the glue to stick. Wormy chestnut is frequently not objected to for outside work because the small holes are not hard to fill and cover up. The uses of chestrut are many. Between 6,000,000 and $7,000,000$ crossties go into railroad construction yearly. From 16,000 to 20,000 tons of wood are demanded annually for tanning cxtract. Every part of the tree is available.

In recent years a disease due to fungus has attacked chestnut forests of Pennsylvania and neighboring regions. It has destroyed the timber on large areas, and the loss threatens to increase. A tree usually dies in one or two years after it is attacked. The fungus works beneath the bark and completely girdles the tree. The spores of the fungus are believed to be carried from tree to tree on the feet of birds, on the bodies of insects, and by the wind.

Goldexleaf Chingrapti (Castunopsis chrysophylla) oceurs on the Pacific coast from the Columbia river to sotthern California. It is of its largest dimensions in the coast valleys of northern California where it oceasionally attains a size equal to the chestnut tree of the eastern states, but in many other parts of its range it is shrubby. It is an evergreen, and its name is deseriptive of the underside of the leaf. Late in summer, flowers and fruit in several stages of grow th may be seen at the same time. The nuts are sweet and edible. In northern California the bark is sometimes mixel with that of tanbark oak and sold to tanneries. The wood is considerably heavier than chestrut, and is sometimes employed in the making of agricultural implements. It bas small and obscure medullary rays, and its pores are arranged more like those 
of live oak than of chestnut; that is they run in wavy, radial lines and not in concentric rings as in chestnut. The heartwood is darker than chestnut.

Chinguapin (Castanea pumila) is a little chestnut that grows from Pennsylvania to Texas. It is generally a shrub or a bush ten or fifteen feet high east of the Alleghany mountains, but in some of the southern states it reaches a height of fifty feet and a diameter of two or more, and is of largest size in southern Arkansas and eastern Texas. It has no name but chinquapin which is an Indian word supposed to have the same meaning that it now has. The nut is from one-fourth to one-half as large as a chestnut, and is fully as sweet. It is sold in the markets of the South and Southwest, but is not an important article of commerce. Where the trees are large enough, the wood is put to the same uses as chestnut. It is manufactured into furniture in Texas, and is bought by railroads for ties.

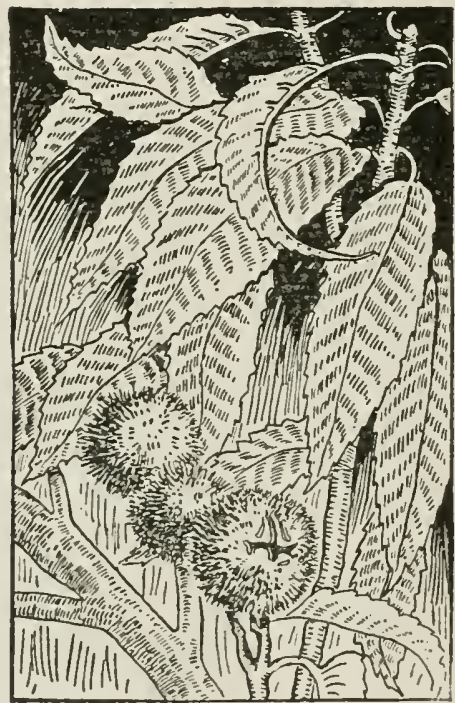


BASSITOOD 


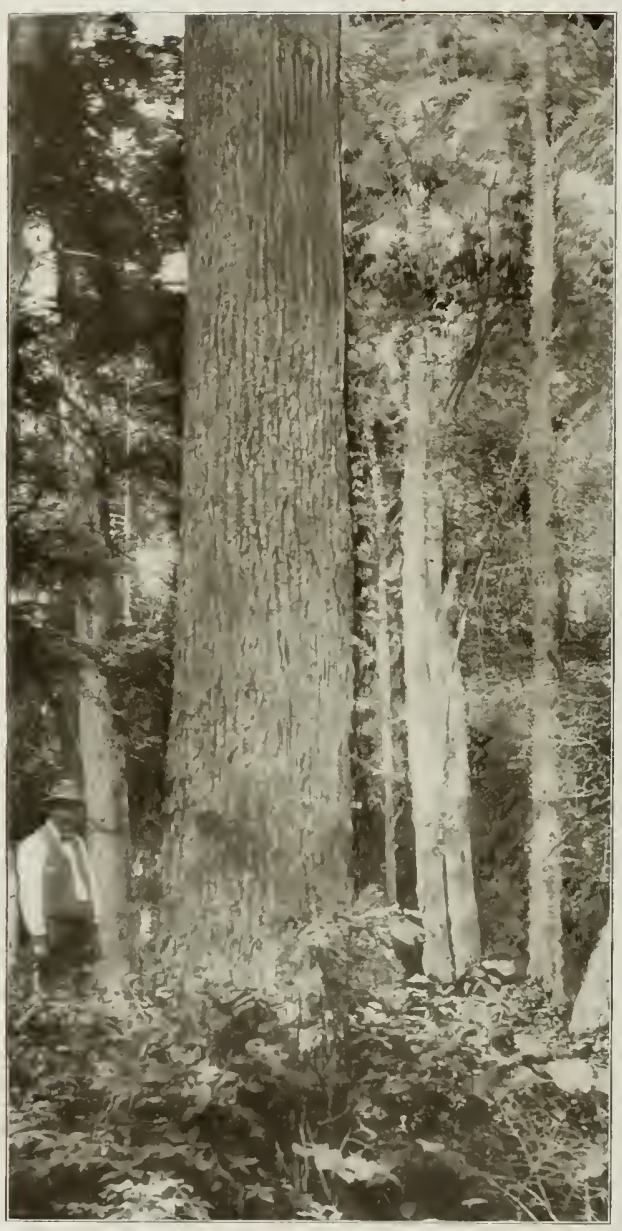

B.ASTWOOD 


\section{BASSWOOD}

(Tilia Americana)

$\mathrm{T}$ HERE are about twenty species of basswood in the world, and from three to six of them are in the United States. Authors do not agree on the number of species in this country. There are at least three, and they occupy, in part, the same range, with consequent confusion. They are much alike in general appearance, and not one person in twenty knows one from the other. The same names apply to all, when they occur in the same region. Few trees carry more names, and with less reason. Basswood is generally not difficult to identify in summer, but in winter a person only slightly acquainted with different trees might take it for cucumber, and if of small size, it might possibly be mistaken for ash or mountain maple. When the tree is bearing leaves, flowers, and fruit, there is no excuse for mistaking it for any other. The fruit, a cluster of four or five berry-like globes, hangs under a leaf, fixed by a short stem to the midrib. This feature alone should be sufficient to identify the basswood in this country.

Among the many names by which this tree is known, in addition to basswood, are American linden, linn, lynn, limetree, whitewood, beetree, black limetree, wickup, whistle wood, and yellow basswood.

The range is extensive, its northeastern boundary lying in New Brunswick, its southwestern in Texas. It reaches Lake Winnipeg, and is found in Georgia. This delimited area is little short of a million square miles. It reaches a height of from sixty to 120 feet, and a diameter of from eighteen inches to four feet. It has a decided preference for rich soil, and the best lumber is cut in fertile coves and flats, or in low land near streams. The largest trees formerly grew in the forests of the lower Ohio valley, but few of the giants of former times are to be found in that region now. They went to market a generation or two ago. The largest cut of basswood lumber now is in Wisconsin, Michigan, and West Virginia, but most of that from West Virginia is white basswood (Tilia heterophylla).

The wood weighs 28.20 pounds per cubic foot, which is more than the other basswoods in this country weigh. The rings of annual growth are not very clearly marked. They may be distinguished, in most cases, by a narrow, light-colored line. This is the springwood. In some trees it is much more distinct than in others. The wood is very porous, but the pores are small, cannot readily be seen with the naked eye, and are scattered pretty evenly through the yearly ring. The modullary rays are small but numerous. They give quarter-sawed lumber a pleasing 
luster, but are too minute to develop much figure. The general tone of the wood is white. It is soft, works easily, holds its shape well, and is tough, but is in no sense a competitor of oak and hickory in toughness, though it shows the quality best in thin panels which resist splitting and breaking.

In the days when it was customary to ceil houses with boards, both overhead and the walls of rooms, carpenters were partial to basswood because of its sof tness. Dressing lumber was then nearly always done by hand, and the carpenter who pushed the jack plane ten or twelve hours a day, looked pretty carefully to the softness of the wood he handled. In tongued and grooved work, as in ceiling and wainscoting, it was not necessary to dress the fitting edges as carefully when basswood was used as in using some others, because it is so soft that fittings can be forced, and cracks may be closed by driving the boards together.

Slack coopers have long employed basswood for barrel headings, and also in the manufacture of various kinds of small stave ware, such as pails, tubs, and kegs. In this use, as in ceiling, the softness of the wood is a prime consideration, because the pressure of the hoops will close any small openings. Its whiteness and its freedom from stains and unpleasant odors are likewise important when vessels are to contain food products. Box makers like the wood on that account, and large quantities are manufactured into containers for articles of food.

Much basswood is cut into veneer, some of which serves in single sheets as in making small baskets and cups for berries and small fruits, but a large part of the output is devoted to ply work. Usually three sheets are glued together, but sometimes there are five. By crossing the sheets, to make the grain of one lie at right angles to the next, plies of great strength and toughness are produced. Trunk makers are large users of such, and many panels of that kind are employed by manufacturers of furniture and musical instruments.

Woodenware factories find basswood one of their most serviceable materials, and it is made into ironing boards, wash boards, bread boards, and cutting boards for cobblers, saddlers, and glass cutters. Its lightness and toughness make it serviceable as valves and other parts of bellows for blacksmiths, organs, and piano players. Makers of gilt picture frames prefer it for molding which is to be overlaid with the gilt or gold. It is serviceable for advertising signs because its whiteness contrasts well with printing. Makers of thermometers use it frequently for the wooden body of the instrument, and yard sticks are made of it. Apiarists find no wood more suitable for the small, light frames in which bees build the comb.

The uses of this wood are so many and so various that lists would 
prove monotonous. The annual cut in this country, exclusive of veneer, is nearly $350,000,000$ feet, and the demand for veneer takes many millions more.

Basswood is named for the bark, and the spelling was formerly bastwood. The manufacture of articles from the bark was once a considerable industry, not so much in this country as in Europe. However, some use has been made of the bark here. Louisiana negroes make horse collars of it by braiding many strands together, and chair bottoms are woven of it in lieu of cane and rattan, and it is likewise woven into baskets of coarse kinds. Bark is prepared for this use by soaking it in water, by which the annual layers of the bark are separated, long, thin sheets are produced, and these are reduced to strips of the desired width.

The annual cut of basswood lumber is declining with no probability that it will ever again come up to past figures; but basswood is in no immediate danger of disappearing from American forests. It is not impossible that it may be planted for commercial purposes. In central Europe, forests of basswood, there called linden, are maintained for the honey which bees gather from the bloom. In this conntry it is often called beetree because of the richness of its flowers in nectar. Possibly bee owners may grow forests for the honey, and when trees are mature, dispose of them for lumber.

WhITE, BAsswood (Tilia heterophylla) attains a trunk diameter as great as that of the common basswood, but is not as tall. Trees sixty or seventy feet high are among the tallest. This species ranges from New York to Alabama, and is found as far west as southern Illinois, and its best development is among the rich valleys and fertile slopes of the Appalachian mountams from Pennsylvania southward. It is the prevailing basswood of West Virginia, and reaches its largest size on the high mountains of North Carolina and Tennessee. It averages about two pounds lighter per cubic foot than the common basswood, but ordinarily neither the lumber nor the standing trees of the two species are distinguished. Only persons somewhat skilled in botany are able to tell one species of basswood from another as they occur in the forests of this country.

Downy Basswoon (Tilia pubescens) is a southern member of the basswood group, and is scarce. Its range extends from North Carolina to Arkansas and Texas. Trees are rarely more than forty feet high and fifteen inches in diameter. The wood is light brown, tinged with red, and the sap is hardly distinguishable from the heart. As far as it is used at all, its uses are similar to those of other basswoods.

SOUTHERN BAsswood (Tilia australis) is confined, as far as is now known, to a small section of Alabama, where it attains a height of sixty feet in rich woodlands. No reports on the quality of the wood have been published, and the species is too scarce to possess much intercst to others than systematic botanists.

FLORIDA BASswood (Tilia floridana), as its name suggests, is a Florida species, and has not been reported elsewhere. It seems to be the smallest of American basswoods, the largest trees being littlc more than thirty feet high. No tests of the wood have been made and no uses reported.

Mrchaux Basswood (Tilia michauxii) has been listed for a long timc, but is 
still not well known. Its range extends from Canada to Georgia and westward to Texas. Trees three feet in diameter and eighty feet high have been reported. Only botanists distinguish it from other species of basswood with which it is associated.

PAWPAW (Asimina triloba) is of more value for its fruit than its wood. It grows from New York to Texas, but in certain localities only. It is the most northern species of the custard apple family, and is usually of little importance above an altitude of 1,500 feet. In Arkansas and some other southwestern regions it is called banana. It is usually a shrub, but may reach a height of forty feet and a diameter of twelve inches. The wood is light, soft, and weak. Pond apple (Annona glabra), called custard apple in some parts of its range in Florida, is a member of the same family. It attains the size of pawpaw, and the wood is similar.

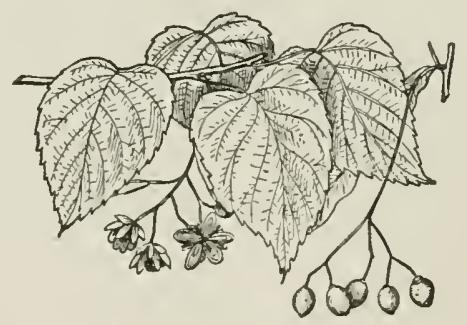


AMERICAN HOLLY 


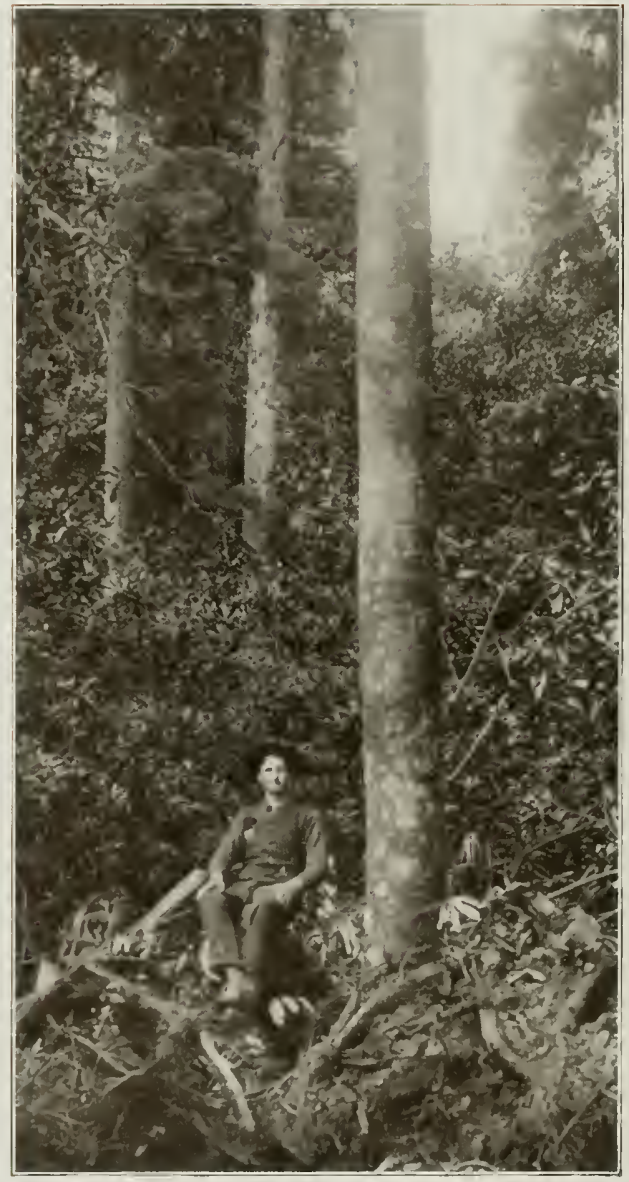

AMERICAN HOLLY 


\title{
AMERICAN HOLLY
}

\author{
(Ilex Opaca)
}

W OLLY is a characteristic member of a large family scattered through most temperate and tropical regions of the world. It belongs to the family Aquifoliacer, a name which conveys little meaning to an English reader until botanists explain that it means trees with needles on their leaves, acus meaning needle, and folium leaf. How well holly, with its spiny leaves, fits in that family is seen at once.

About 175 species of holly are dispersed in various parts of the world, the largest number occurring in Brazil and Guiana. Ilex is the classical name of the evergreen oak in southern Europe.

The glossy green foliage and the brilliant red berries of the holly tree have long been associated in the popular mind with the Christmas season. Mingled with the white berries and dull green foliage of the mistletoe, it is the chief Yuletime decoration, and many hundred trees are annually stripped of their branches to supply this demand. The growth is still quite abundant, but if the destruction and waste continue, American holly will soon be exhansted.

Its range extends from Massachusetts to Texas and from Missouri to Florida. In New England, the trees are few and small, and the same holds true in many parts of the Appalachian region. The largest trees are found in southern Arkansas and eastern Texas. In the North it grows in rather dry, gravelly soil, of ten on the margins of oak woods, but in the South it takes to swamps, and does best on river bottoms where the soil is rich. It is often associated with evergreen magnolia, which it resembles at a distance, though differences are plain enough on close examination. The light, grayish-green barks of the two trees look mirch alike; but the magnolia's leaves are larger, thicker, and lack the briers on the margins.

Holly varies in size from small straggling bushes to well-formed trees fifty or sixty feet high and two or three in diameter. The principal value of holly is not in its wood, but in its leaves and berries. Some persons suppose that holly leaves never fall. That is true of no tree that attains any considerable age. An exanination of a holly thicket, or a single tree, in the spring of the year will reveal a fair sprinkling of dead leaves on the ground, though none may be missed from the branches. Those that fall are three years old, and they cone down in the spring. There are always two full years of leaves on the trees.

Flowers are the least attractive part of holly. Fcw people ever notice the small, unobtrusive cymes, scattered along the base of the 
young shoots in the early spring, with the crop of young leaves. Nothing showy about them attracts attention.

The fruit is the well-known berry, the glory of winter decorations. It is usually red, but sometimes yellow. The latter color is not of ten seen in decorations because it is a poor contrast with the glossy green of the leaves. The berries ripen late in autumn and hang until nearly spring, provided they are let alone. That is seldom their fortune, for if they escape the wreath hunter at Christmas, they remain subject to incessant attacks by birds. Fortunately, the berries are not very choice food for the feathered bevies that fly in winter; otherwise, the trees would be stripped in a day or two. Birds are attracted by the color, and they keep pecking away, taking one or two berries at a bait, and in the course of a long winter they get most of them.

The gathering of holly leaves and berries is an industry of much importance, taken as a whole; but it lasts only a short time, and is carried on without much system. The greatest source of supply is northern Alabama, and the neighboring parts of surrounding states; but some holly is gathered in all regions where it is found. Those who collect it for market make small wages, but the harvest comes at a season when little else is doing, and the few dimes and dollars picked up are regarded as clear gain-particularly since most of the holly harvesters have no land of their own and forage for supplies on other people's possessions.

The seeds of holly are a long time in germinating, and those who plant them without knowing this are apt to despair too soon. The great differences in the germinating habits of trees are remarkable. Some of the maples bear seeds which sprout within a few days after they come in contact with damp soil, certain members of the black oak group of trees drop their acorns with sprouts already bursting the hulls, and mangroves are in a still greater hurry, and let fall their seeds with roots several inches long ready to penetrate the mud at once. But holly is in no hurry. Its seeds lie buried in soil until the second year before they send their radicles into the soil. They are so slow that nurserymen usually prefer to go into the woods and dig up seedlings which are already of plantable size.

Users of woods find many places for holly but not in large amounts. The reported output by all the sawmills in the United States in 1909 was 37,000 fect, and Maryland produced more than any other state. The wood is employed for inlay work, parquetry, marquetry, small musical instruments, and keys for pianos and organs. Engravers find it suitable for various classes of work, its whiteness giving the principal value. It approaches ivory in color nearer than any other American wood. Brush back manufacturers convert it into their choice wares. It is 
occasionally worked into small articles of furniture, but prebably never is used in large pieces.

The wood is rather light, and the vague boundaries between the annual rings, and the smallness and inconspicuousness of the medullary rays, are responsible for the almost total absence of figure, no matter in what way the wood is worked. The so-called California holly (Heteromcles arbutifolia) is of a different family, and is not a holly.

Dahoon Holly (llex cassine) grows in cold swamps and on their borders in the coast region from southern Virginia to southern Florida, and westward to Louisiana. It is often found on the borders of pine barrens, is most common in western Florida and southern Alabama, and when at its best, is from twenty-five to thirty feet high and a foot or more in diameter. The leaves are nearly twice as long as those of common holly, and are generally spineless or nearly so. The fruit ripens late in autumn and hangs on the branches until the following spring. The berries are sometimes bright red, oftener dull red, and those fully up to size are a quarter of an inch in diameter. Some hang solitary, others in clusters of three. The wood is light and soft, weighing less than thirty pounds per cubic foot. The heart is pale brown, and the thick sapwood nearly white. The tree is known locally as yaupon, dahoon, dahoon holly, and Henderson wood. This species passes gradually into a form designated as Ilex myrtifolia, which Sargent surmises may be a distinct species. Another form, narrowleaf dalıon (Ilex cassine angustifolia), is listed by Sudworth.

YAUPON HOLLY (llex vomitoria) is a small, much-branched tree, often shrubby, and at its best is seldom more than twenty-five feet high and six inches in diameter. Its range follows the coast from southern Virginia to St. John's river, Florida, and westward to eastern Texas. It sticks closely to tidewater in most parts of its labitat, but when it reaches the Mississippi valley it runs north into Arkansas. It attains its largest size in Texas, and is little more than a shrub elsewhere. Berries are produced in great abundance, are red when ripe, but they usually fall in a short time and are not much in demand for decorations. The wood weighs over forty-five pounds per cubic foot, is hard, and nearly white, but turns yellow with exposure. The leaves of this holly were once gathered by Indians in the southeastern states for medicine. The savages journeyed once a year to the coast where the holly was abundant, boiled the leaves in water, and produced what they called the "blick drink." It was nauseating in the extreme, but they drank copious draughts of it during several days, then departed for their homes, confident that good health was assured for another year.

Mountain Holly (ller monticola) is so named because il grows among the 
Appalachian ranges from New York to Alabama. It is best developed in the elevated district where Tennessee and North and South Carolina meet near one common boundary. It is elsewhere shrubby. The leaves are deciduous, and the bright scarlet berries are nearly as large as cherries. They fall too early to make them acceptable as Christmas decorations. The wood is hard, heavy, and creamywhite, and if it could be had in adequate quantities, would be valuable. The trees are sometimes a foot in diameter and forty feet high, but they are not abundant. Their leaves bear small resemblance to the typical holly leaf, but look more like those of cherry or plum.

Deciduous Holly (Ilex decidua) is called bearberry in Mississippi and possum haw in Florida, while in other regions it is known as swamp holly because of its habit of clinging to the banks of streams and betaking itself to swamps. It keeps away from mountains, though it is found in a shrubby form between the Blue Ridge and the sea in the Atlantic states, from Virginia southward. It runs west through the Gulf region to Texas, and ascends the Mississippi valley to Illinois and Missouri, attaining tree size only west of the Mississippi. The wood is as heavy as white oak, hard, and creamy-white, both heart and sap. Doubtless small quantities are employed in different industries, but the only direct report of its use comes from Texas where it is turned for drawer and door knobs in furniture factories. Most but not all of the leaves fall in early winter. The berries obey the same rule, some fall and others hang till spring. They are orange or orange-scarlet.

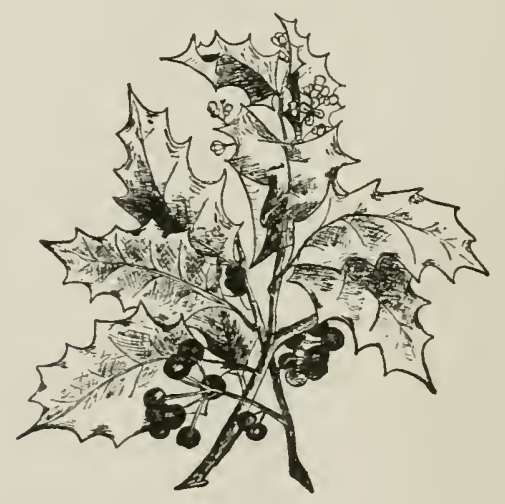


YELLOW BLCKIVE 


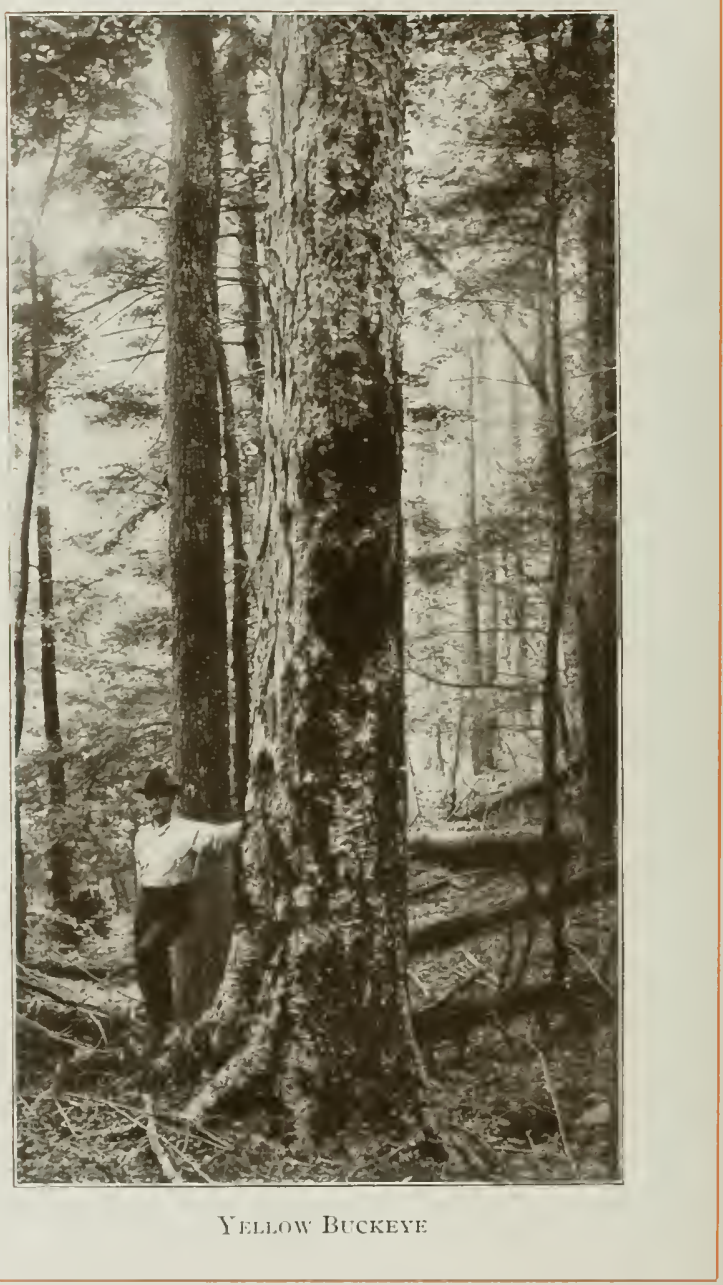




\section{YELLOW BUCKEYE}

\section{(Esculus Octandra)}

$\mathrm{F}$ OUR species and one variety of buckeye are native in the United States, yellow buckeye, Ohio buckeye, California buckeye, sinall buckeye, and purple buckeye. They belong in the horse chestnut family. The so-called Texas buckeye is in a different family, and is not a true buckeye, but is close kin to the soapberry. The buckeyes are named for the large white spot on the smooth, brown nut, resembling the eye of a deer. The yellow buckeye is the most important of the group, is the largest and most abundant. It is known by the name of buckeye in North Carolina, South Carolina, Alabama, Mississippi, Louisiana, Texas, and Kentucky. It is called sweet buckeye in West Virginia, Mississippi, Texas, Missouri, and Indiana, probably owing to the fact that it does not exhale the disagreeable odor characteristic of other members of the family. Yellow buckeye is the term applied to it in South Carolina and Alabama; large buckeye in Tennessee; big buckeye in Tennessee and Texas. It flourishes from Allegheny county, Pennsylvania, southward along the Alleghany mountains to northern Georgia and Alabama, westward along the valley of the Ohio river to southern Iowa, through Oklahoma and the valley of the Brazos river in eastern Texas. It thrives best along streams and in dense, rich woods. It reaches its fullest development on the slopes of the Alleghany mountains in North Carolina and Tennessee.

The leaves of the buckeye are compound, with from five to seven leaflets; flowers appear in May or June and are dull yellow; the fruit is a large brown nut, one or two of which are enclosed in a rough, uneven husk, about two inches or more in diameter. The tree grows from forty to 100 feet in height, and attains a diameter of from one to three and a half feet.

Buckeye grows intermingled with poplar, oak, maple, beech and a variety of other hardwoods. From its comparatively limited growth as compared with the totality of the average hardwood forest, it never has been recognized, and probably never will be, as a distinctive type of American commercial wood. The timber is felled with the other valuable trees surrounding it, and its appearance, when manufactured into lumber is so similar to that of the sap of poplar or whitewood that almost without exception it is assorted witl poplar saps, and goes on the market masquerading as that wood. There is probably not one lumberman in a thousand, handling poplar, that is able to distinguish buckeye from sap poplar in his shipments of tliat wood. 
Sawmills make no distinction between the different species. All that comes is buckeye, but nearly all of it is the yellow species, though doubtless a little of all the others is cut into lumber and veneer, or goes to the slack cooperage shop, or to the pulp mill. The woods of all are quite similar, and they are used for the same purposes. If one is employed in larger quantities than another, it is because it is more convenient, or of better form or larger size.

Early uses of buckeye were as important as those of the present day, though amounts were smaller. Many an Ohio statesman of former times boasted that, as a baby, he was rocked in a buckeye sugar trough for a cradle. They claimed with pride that the prevalance of the custom caused Ohio to be known as the buckeye state, a name which clings to it still. Next to yellow poplar, buckeye was considered the best wood from which to hew the small troughs which collected the sugar water from the tapped maples in early spring; but the range of buckeye did not extend northward into the real maple area, and the troughs like those which rocked the inchoate Ohio statesmen were unknown in the North, but were familiar along the mountain ranges southward. Dough trays, bread boards, chopping bowls, and troughs in which to salt bacon and pork, were hewed from buckeye by farmers and village woodworkers.

It weighs 27.24 pounds per cubic foot; is diffuse-porous, and the slight difference between the wood grown in spring and that of late summer renders the annual rings indistinct. It has little figure, no matter how it is sawed; medullary rays are thin and obscure. Softness is one of the principal qualities, and it is also weak, and is wanting in rigidity. These are its faults, but it has virtues. It is tasteless and odorless, and these properties make it valuable in the manufacture of boxes in which food products are shipped. The reported cut of buckeye in the United States is from $11,000,000$ to $13,000,000$ feet a year. The reports of factories which use the wood in making commodities throw light on the question of actual use. North Carolina works 10,000 feet a year into cabinets and office fixtures; Michigan 100,000 into candy and chocolate boxes, dishes, and bowls; Maryland uses 200,000 feet yearly for practically the same purposes, but with the added commodities of spice drawers and tea chests. Makers of artificial limbs consider buckeye one of their best materials, but it is second to willow. The "cork legs" are usually either buckeye or willow. Pulp mills grind the wood for paper, but it is not separately listed in pulp statistics, and the total cut cannot be stated. It is converted into veneer and finds many places of usefulness, but here, also, no separate figures are to be had.

The nuts are large and abundant, but almost wholly useless for man or beast. Bookbinders make paste of them, as a substitute for 
flour, and with satisfactory results. The paste resists ferments much better than that manufactured from flour; but the demand upon the nut supply for that purpose is very small. Squirrels and other small animals leave buckeyes alone. Some writers, whose acquaintance with this tree was apparently acquired at long range, state that the nuts are food for cattle. No person with knowledge of the buckeye says that. Cattle occasionally eat a few, but are poisoned thereby, and if they recover, they never again have anything to do with buckeyes.

This tree is ornamental during a few months of the year. Its flowers are attractive, and its large, vigorous leaves and conspicuous fruit are admired in summer; but early in the fall the leaves come down, the husks burst from the nuts and strew the ground with unsightly fragments. The tree is seldom planted, but the horse chestnut, a foreign species, takes its place.

OHio Buckeye (Esculus glabra) was once thought to be more abundant in Ohio than elsewhere, hence the name; but its best development is in Tennessee and northern Alabama. The disagreeable odor emitted by the bark gives it the names fetid and stinking buckeye, and it is known also as American horse chestnut. Its range is approximately the same as that of yellow buckeye, but it is a smaller tree, rarely more than thirty feet high, though it is seventy in exceptional cases. In common with other trees of the species, it prefers rich soil along water courses. The wood was formerly in demand for chip hats, but that use has apparently ceased. The sapwood is darker than the heart which is an exception to the general rule. Dark streaks, probably stains due to fungus, occasionally run through the trunk. In weight, strength, and stiffness the wood is approximately the same as yellow buckeye. Its odor is sufficient to distinguish it from that species, and it associates with no other except on rare occasions when it may be found with the small buckeye in western Tennessee and southern Missouri.

CAlifornia Buckeye (.Esculus californica) occurs only in the state whose name it bears. It is a short, much-branched, ill-formed tree; root large and shaped somewhat like an inverted tub, often standing a foot or more above the ground, and the branches rising from it. A tree so formed is without value to the general lumberman, but cabinct makers sometimes grub out the root and saw it transversely into thin lumber or veneer and make small articles which possess considerable figure, due to the involved growth, but little varicty of color. Its tone is light yellow. The tree is found in the central part of California, from near sea level up to 4,500 in the Sierra Nevadas. It gets away from the immediate vicinity of water courses and grows on hillsides. It is heavier than any other American buckeye, and has very thin sapwood. The 
other properties of the wood, and the botanical characters of the tree are common to other members of the species. The seeds depend for their dispersal on running water, when the tree grows by a stream, or on gravity, if situated on a hillside. The seed will not grow unless buried in moist soil, and it retains its vitality only a few months. Few trees in the United States have larger seeds than buckeyes. The tree is short-lived, reaching maturity in most cases in less than a hundred years. It is sometimes planted for ornament in this country and in Europe.

SMALL Buckeye (Esculus austrina) is one of the latest recognized members of the buckeye household. It seldom attains a diameter above five or six inches, or a height of twenty-five feet. It is, therefore, too small to be seriously considered as a source of lumber, and even if trunks were large enough, the species is too scarce to furnish many logs. It grows on rich uplands from western Tennessee and southern Missouri to Texas. The bright red flowers open in April, the fruit falls in October.

PURPLE Buckeye (Esculus octandra hybrida) is a variety characterized by red or purple flowers and by leaves woolly on the under sides, and bark of lighter color than that of yellow buckeye. The range follows the Appalachian mountains from West Virginia southward. It has been reported in Texas also. If the wood is used at all, it goes for the same purposes as yellow buckeye.

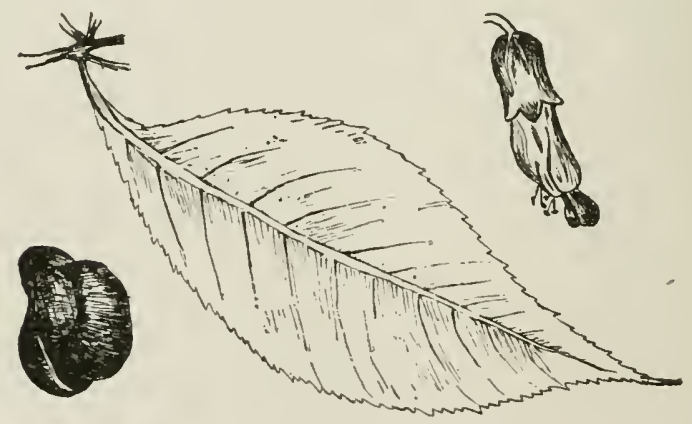


SASSAFRAS 


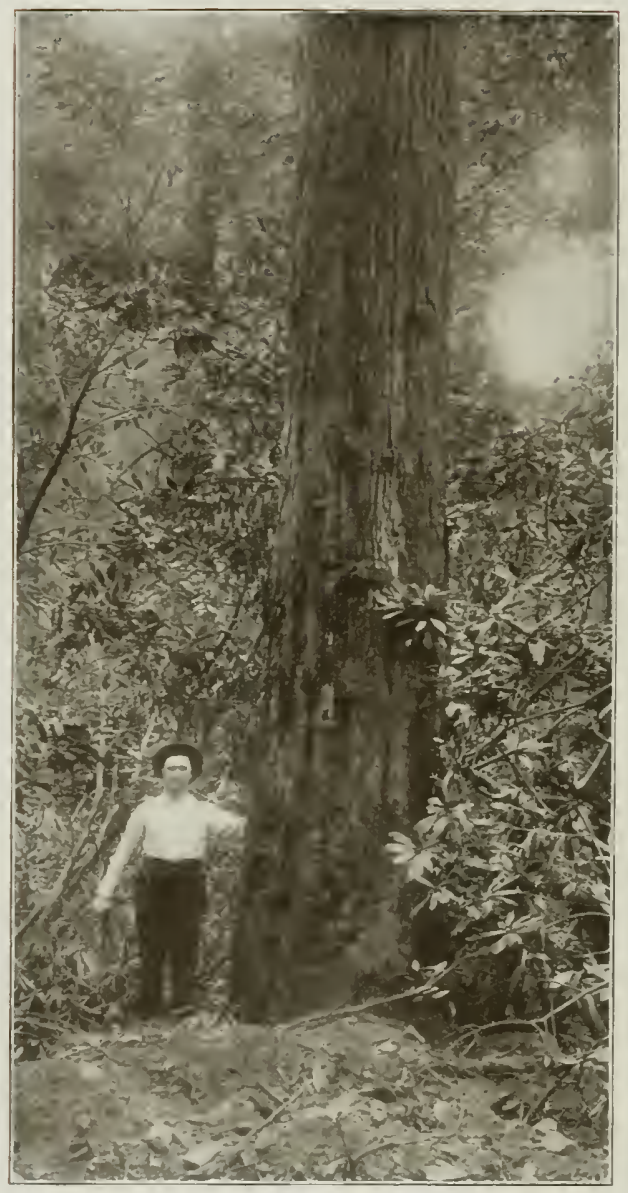

SASSAFRAS 


\section{SASSAFRAS}

(Sassafras Sassafras)

$\mathrm{T}$ HE French settlers in Florida were the first white men to give the name sassafras to this tree, but the Indians called it by that name long before. It was a tree which Indians were sure to name, becanse it had an individuality which appealed to them. It is not known what the real meaning of the word was, when the southern Indians nsed it. After the French adopted the name in Florida, it passed to other colonies and other languages, and has led to numerous disputes since. Many have erroneously supposed that the name is of Latin origin. When the English colony was founded at Jamestown, Virginia, in 1607, the tree was well known by that name, but it was pronounced so variously and spelled in so many ways that it was often almost unrecognizable. It is pronounced variously and spelled differently yet. It is called sassafras in most regions, and in others is saxifrax, sassafas, sassafac, sassafrac, and saxifrax tree.

Its range covers the territory from Massachusetts to Iowa and Kansas, and south to Florida and Texas. Some of that range it has occupied for vast periods of time, for sassafras leaves have been found embedded in the Cretaceous formations of Long Island. Near the northern limit of its range it is gencrally small, often of brush size; but further south it becomes a tree which sometimes exceeds 100 feet in height, and three or four in diameter. The best development of the species is in Arkansas and Missouri.

Sassafras belongs to the laurel family. Strangely enough, the two trees which are usually supposed to be typical laurels-namely, mountain laurel (Kalmia latifolia) and great rhododendron, do not belong to the laurel family, but the heath family. The laurel family to which sassafras belongs includes many species in all parts of the world, some are evergreen, others are not, but all characterized by the strong, pungent odor of their wood or bark, and all having fruit with a single seed like a plum or cherry. The camphor tree from the distillation of whose wood commercial camplor (except synthetic camphor made largely from turpentine) is derived, belongs to this family, as do certain bay trees of the southern states. It was formerly supposed that sassafras existed only in the eastern half of the United States; but a species closely resembling ours, if not identical with it, has recently been found in China. The California laurel (Umbcllularia californica) is in the same family with sassafras.

This tree has had a peculiar listory. It was once supposed to 
possess miraculous healing powers, and was shipped from Virginia to England in one of the first cargoes to go to that country from the present territory of the United States. Its supposed value did not consist in its use as lumber, but in some medicinal property which it was reputed to possess. People appeared to believe that it would renew the youth of the human race. Some portion of this superstition has clung round sassafras to this day, and it is not entirely confined to ignorant people. Bedsteads made of sassafras were supposed to drive away certain nightly visitors which disturb slumber. In southeastern Arkansas and northwestern Mississippi, bedsteads are still made of this wood, with the belief that sleep will be sounder. The same custom doubtless prevails elsewhere. In northern Louisiana floors of sassafras are occasionally laid in negro cabins because of the same superstition, and in the firm belief that it will keep out animals as large as rats and mice. Some of the mountaineers of Kentucky, where each family makes its own soap, insist that the kettle must be stirred with a sassafras stick or it will produce a poor quality of soap. Among the mountains of West Virginia many a farmer equips his henhouse with sassafras poles for roosts, fully convinced that he has put an effective quietus on all tribes, shoals, and kindred of menopon pallidum, and the hens will sleep better.

The production of sassafras oil is perhaps the largest industry dependent upon this tree. Roots are grubbed by the ton and are subjected to destructive distillation. Much of this work is carried on in Virginia where sassafras spreads quickly into abandoned fields, springing up from seeds carried by birds. Veritable thickets soon take possession. Here is where the sassafras oil supply comes from. Contractors of ten clear the old fields and make them ready for tillage, taking the roots for pay.

The wood weighs 31.42 pounds per cubic foot; is very durable when exposed to dampness; is slightly aromatic; inclined to check in drying; the layers of annual growth are marked by rings of large pores; summerwood is quite distinct from the earlier growth; medullary rays are many and thin; color dull orange-brown, the thin sapwood light yellow.

Sassafras goes to sawmills in all regions where it is large enough for lumber, but the total cut is small. Reports from sawmills in 1909 credited this species with only 25,000 feet in the United States, and it was still less in 1910. It is evident that this is only a small portion of the total output, and probably Tennessee alone produces that much. The wood is sold with other species and losses its name, frequently passing as ash. The wood bears considcrable resemblance to ash, in grain and color, but is lighter in weight, and much lower in strength. 
Sassafras was one of the canoe woods of early times along the lower Mississippı and its tributaries. Its two principal advantages over most woods with which it was associated was its light weight and lasting qualities. Canoes of this timber in Louisiana have given continued service for a third of a century.

In all parts of its range, wherever it is of sufficient size, it has been used for posts. It is generally considered good for about twenty years. Large trunks were formerly split for rails, and a few are utilized in that way still, but most timber large enough for rails, now goes to sawmills. In Texas most of the sassafras supplied by sawmills is manufactured into furniture, but is listed as ash. The same thing is done in Arkansas and Missouri, but the use in the latter state is extended to interior house finish and office and bank fixtures. Sometimes it is made the outside wood, and the figure caused by sawing the logs tangentially is accentuated by stains and fillers. The figure of quarter-sawed wood is not attractive because the medullary rays are too small. It lasts well as railroad ties and a few are found in service in many parts of the tree's range, but those who see it in the track are liable to mistake it for chestnut.

A by-product of sassafras deserves mention-tea made from the flowers or from the bark of the roots. It is relished in the early spring, and is popular in most regions where the tree is known. The bark is a commercial commodity. It is tied in small bundles, and the price at retail ranges from a nickel to a dime each. Drug stores and grocers sell it. In the city of Washington in early spring sassafras peddlers canvas the city from center to circumference. They are generally negro men and women who dig the roots on the neighboring hills of Virginia and Maryland, strip the bark, tie it in small bundles, and by diligence and perseverance, succeed in converting the merchandise into money.

Sassafras is often cited as an example of a tree with leaves of different forms. Three snapes are common, and all frequently occur on the same tree, and even on the same twig. One has no lobes, anothcr has one lobe like the thumb of a mitten, and another has three.

LAxcewood (Ocotca catesbyana) is a suall evergreen tree, looks much like laurel, and grows in southern Florida, on the islands and on the mainland in the vicinity of Biscayne bay. It is closely related to sassafras, and the bark has an aromatic odor. It belongs to a group of trees with nearly 200 species scattered in hot regions of both hemispheres. This is the only one belonging to the United States, and it appears to be a newcomer on these shores, from the fact that it lias succeeded in obtaining so limited a foothold. It kceps well south of the region wliere it 
is likely to be frosted and it seldom exceeds a height of thirty feet and a diameter of eighteen inches. The fruit ripens in autumn and is dark blue with flesh thin and dry. The wood is hard, heavy, strong, checks badly in drying, and has a rich brown color, the sapwood being yellow. Rings of annual growth are marked with many small, regularly-distributed open ducts; medullary rays are thin and numerous; wood weighs 47.94 pounds per cubic foot; durable in contact with the soil, beautifully colored, and is highly prized for small cabinet work and novelties. At Miami, Florida, small trunks cut on neighboring hummocks, or brought from the keys, are worked into souvenirs to be sold to visitors. Lancewood fishing rods are among the strongest and most expensive on the market; but little of the material of which they are made grows in Florida. It is also manufactured into billiard ctes and small handles.

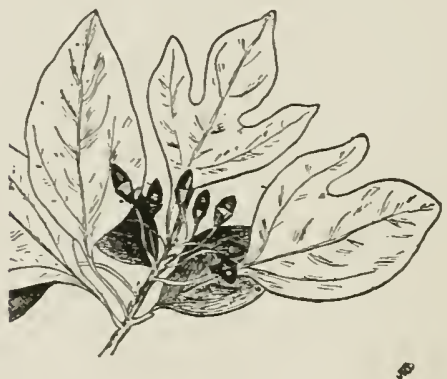


MADRONA 


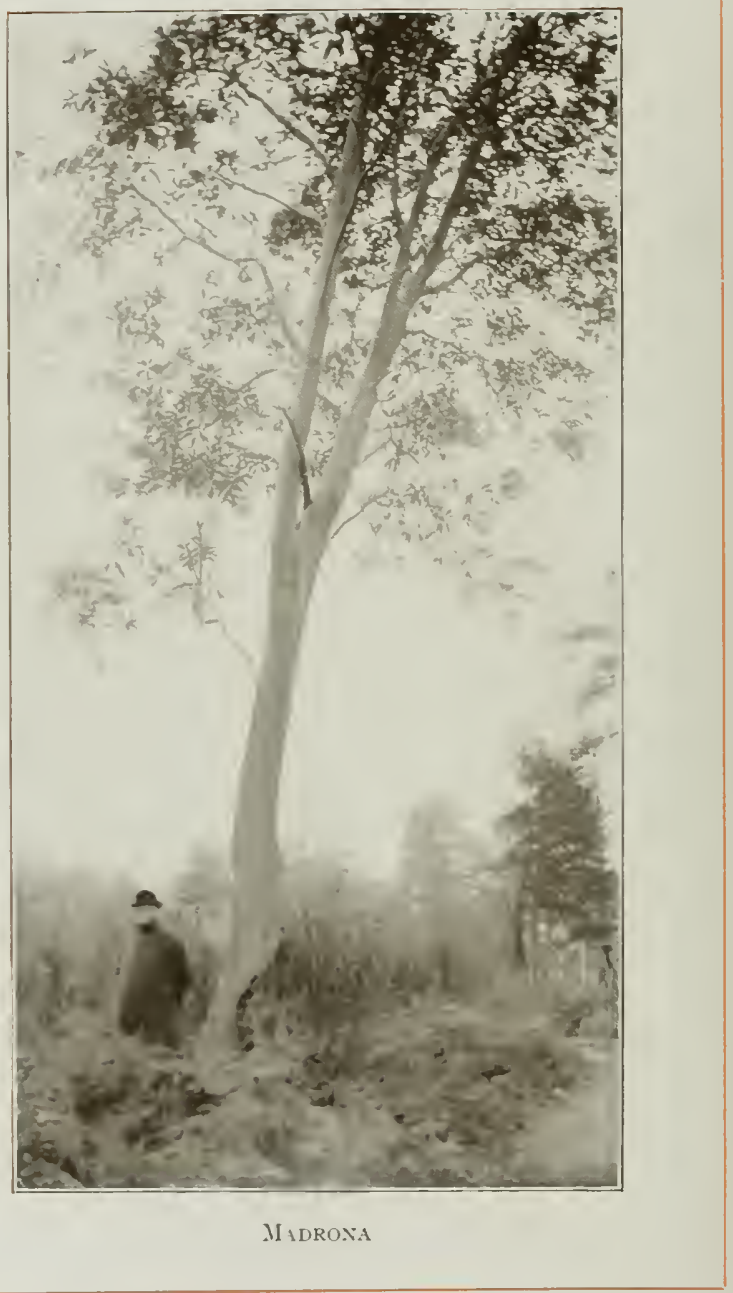




\section{MADRONA}

\section{(Arbutus Menziesii)}

M ADRONA is an interesting tree which ranges from British Colum. bia southward to central California, at taining its greatest development in the redwood forests of northern California, where trees are sometimes one hundred feet high and six or seven feet in diameter. It is not only an interesting tree itself, but it has many interesting relatives, some of which are trees, others shrubs, and still others only small plants or vines. It may be called a second cousin to the common huckleberry, the mountain laurel, trailing arbutus, the azaleas, the tiny wintergreen, and the great rhododendron. It has some poor relations, but many that are highly respectable. It belongs to the heath family, of which there are seventy genera, and more than a thousand species; but less than half of them are in America, the others being scattered widely over the world.

The madrona, when at its best, is one of the largest members of the family; but it is not always at its best. It sometimes degenerates into a sprawling shrub, where it grows on poor ground and on cold, dry mountain tops. It is manifestly not fair to study any tree at its worst, and it is particularly not fair to the madrona, which varies so greatly in its appearance. At one place it may be scarcely large enough to shade the lair of a jackrabbit, and at another it spreads its branches wide enough to shade an army-a small army, however, say, about two thousand men. A tree of that size may be found within a few hours' ride of San Francisco. Its branches cover an area of from eight thousand to ten thousand square feet.

When madrona grows in the open it throws out wide limbs like a southern live oak, though not so large or long. Its crown is rounded and graceful; but when it grows in forests, where other trees crowd it, the trunk rises straight up to lift the crown into the sunlight and fresh air. The madrona is seen in all its glory in northwestern California, where it catches some of the warmth and the moist air from the Pacific. It follows the ranges of the Siskiyou mountains eastward near the boundary of California and Oregon. It is usually mixed with other forest trees, but sometimes large stands nearly pure are encountered, and there the long trunks, rather gray near the ground, but winecolored above, rise in imposing beauty and are lost in the evergreen crowns.

The leaves suggest those of laurel, but are broader. The large clusters of white flowers are among the glories of the vegetable kingdom. 
George B. Sudworth, dendrologist of the United States Forest Service, who usually describes in strictly prosaic terms, breaks away from that habit long enough to compare madrona flowers to lilies of the valley, in his "Forest Trees of the Pacific Slope." The flowers appear from March to May, depending on latitude and elevation.

The brilliant orange-red fruit ripens in the fall, and is often borne in great abundance. It renders the crowns of the trees very beautiful. The fruit is about half an inch long and contains many small angular seeds. The fruit is said to contain a substance which puts to sleep wild creatures that feed on it. The claim is probably mythical, for birds breakfast extravagantly on it in the morning, and apparently do not do any sleeping until after sunset.

This tree was discovered by and named for Archibald Menzies, a Scotch botanist who traveled in the Northwest more than a hundred years ago. It has several local names, among them being madrove, laurel wood, madrone-tree, laurel, and manzanita. The last is the proper name of another small tree which is associated with madrona and is closely related to it.

The wood weighs 43.95 pounds per cubic foot. It is a little below eastern white oak in fuel value, a little above it in strength, and somewhat under it in stiffness. The color is pale reddish-brown, resembling applewood in tone, but generally not quite so dark. The wood is porous, but the pores are very small. Medullary rays are numerous but thin. On account of the rays being of a little deeper red than the other mood, quarter-sawed stock is handsome and of somewhat peculiar appearance. The figure is much like quarter-sawed beech, but of deeper, more handsome color. The contrast between springwood and summerwood is not strong, though easily seen. Generally, the summerwood constitutes about one-fourth of the annual ring. The tree grows slowly, but with much irregularity. The increase in one season may be four or five times as great as in another. The bark exfoliates, and is quite thin.

Madrona has never been put to much use. Difficulties in seasoning it have stood in the way. The wood warps and checks. Similar difficulties with other woods have been overcome, and such troubles should not be unduly discouraging. The beauty of the wood is unquestioned. It presents a fine appearance when worked into furniture, particularly in small panels and turned work, like spindles, knobs, and small posts. When made into grills it shows a surprising richness of tone. The wood polishes almost to the smoothness of holly. Small quantities are made into flooring; a little goes to the furniture makers; lathes turn some of it for novelties and souvenirs; fuel cutters sell it as 
cordwood; and tanbark peelers eut the trees for the thin, papery bark. In that case the trunks are left to decay, unless they happen to be convenient to a cordwood market.

One of the most extensive uses for the wood of madrona is for charcoal burning. Blacksmiths buy it because it is cheaper than coal, and some is used ia shops where soldering and welding are done; but the most exacting demand comes from gunpowder manufacturers. They find this wood almost equal to alder and willow as a source of charcoal suitable for powder.

Mexican MaDrona (Arbutus xalapensis) might properly be called Texas madrona as it oceurs in that state and probably in no other, but its range extends southward into Mexico. It produces a poorly shaped trunk seldom much more than twenty feet high and one foot in diameter, and usually divided into several branches near the ground. It blooms in March and ripens its fruit in midsummer. The tree is found on dry limestone hills, and in the valley of the Rio Blanco, and among the Eagle mountains. Cabinet makers in Texas put the wood to rather exacting uses after they have carefully seasoned it to overcome its natural tendency to check. It is very hard; its color is a little lighter than applewood which it resembles; annual rings are scarcely visible, so regular and even is the year's growth. In Texas the wood is made into plane stocks, tool handles, and mathematical instruments.

Arizona Madrona (Arbutus arizonica) has a restricted range on the Santa Catalina and Santa Rita mountains of southern Arizona, where it ascends to an altitude of 8,000 feet The species extends southward into Mexico. The largest trees attain a height of fifty feet and a diameter of two. Trunks are usually straight and shapely, and show the thin, red bark common to the genus. The wood resembles that of the species in Texas, and doubtless is suited to the same purposes, but no utilization of it has been reported, except for fuel, and for fences and sheds on mountain ranches. When the region becomes more thickly settled, the value of the wood will be appreciated.

Manzanita (Arctostaphylos manzanita) is not generally welcomed by botanists into the tree class. They say it is too small; but it is as large as some of the laurels which go as trees without question, and is shaped much like them. There are several species of manzanita. The word is Spanislı and means "little apple." The name is natural, for one of the most noticeable things about manzanita is the fruit, the size of well-grown huckleberries. It is shaped like an apple, and its tart taste suggests that fruit. The Digger Indians along the footlinlls of the Sierra Nevada mountains in California gather the berries by" the sack, dry them, and keep them for winter-if they can. It is often impossible to keep them because, like other fruit, they are apt to become wormy. When the Indians discover them in that condition they display rare thrift and economy for savages, by soaking the fruit and pressing out the juice, which is said to pass for a pretty fair quality of cider, but it must be quickly cou- 
sumed or it will mother and change to vinegar. Indians now put the berries to use less frequently than in early times when they were nearly always hungry.

Manzanita is of the same family as madrona. Its range extends along the mountains of the Pacific coast ranges from Oregon to Mexico, and inland to Utah. The largest trees are about twenty feet high and a foot or less in diameter; very much divided and branched, with limbs crooked in more ways, perhaps, than those of any other representative of the vegetable kingdom. Thousands of canes are cut from the branches, and if any living man ever saw a straight one he failed to report it. Manzanita grows in almost impenetrable thickets on dry slopes and ridges. Its thin foilage casts so pale a shadow that the tree's shade is little cooler than the boiling sun upon the open naked ground and rocks. The bark is a reddish-chocolate color, and exfoliates in scales of papery thinness. The heart is nearly of the same color as the hark, but the sap is white and very thin. The wood is hard, strong, stiff, but exceedingly brittle. If a branch is sharply bent it will fly into splinters.

The uses of the wood are numerous, but the total quantity demanded is moderate. Novelty stores sell small articles to tourists in California, sometimes passing the wood off as mountain mahogany which does not so much as belong to the same family. The most common articles manufactured by novelty shops from manzanita are canes, paper weight 6 , paper knives, rulers, spoons, napkin rings, curtain rings, cuff huttons, dominos, manicure sticks, jewel boxes, match safes, pin trays, and photo frames.

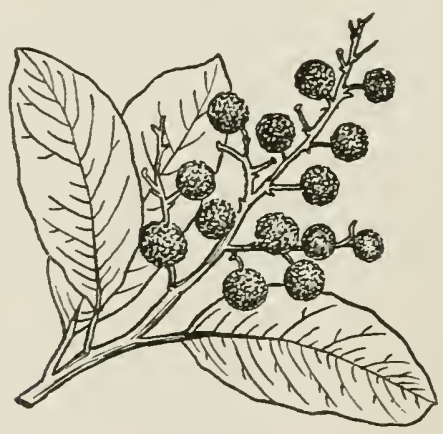


COTTONIVOD 


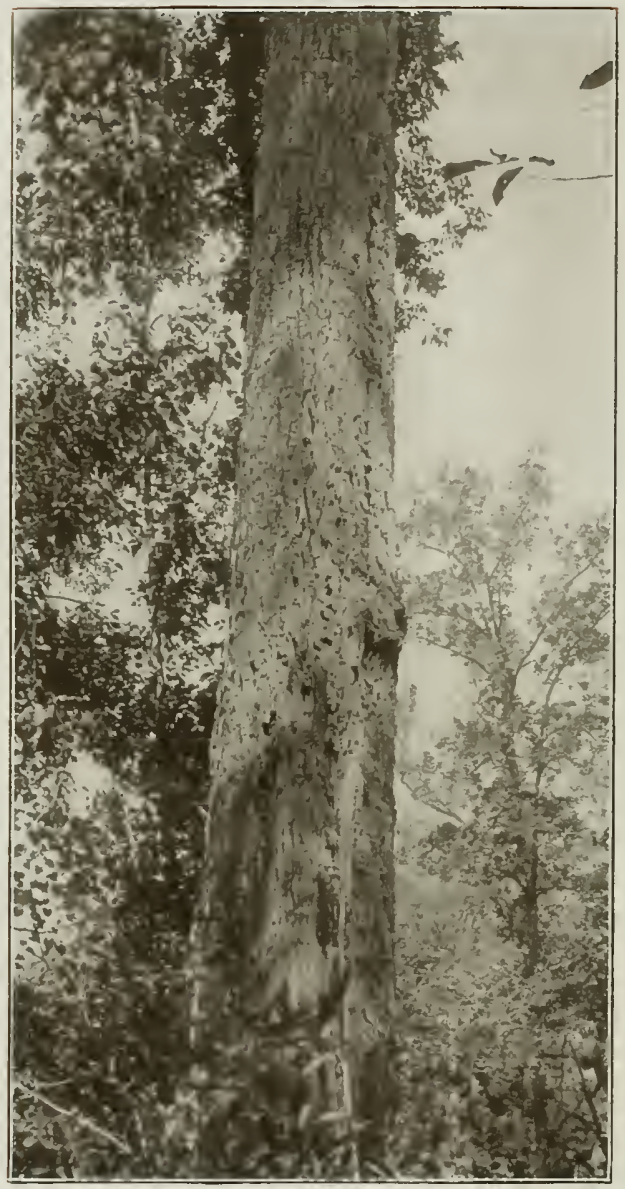

Cottonwoon 


\title{
COTTONWOOD*
}

\author{
(Populus Delioides)
}

H LEVEN species of cottonwood are found in the United States, if all trees of the genus Populus are classed as cottonwoods. It is not universally admitted, however, that they should be so classed. The common cottonwood is the most widely known of all of them, but it is recognized under different names in different regions, viz.: Big cottonwood, yellow cottonwood, cotton tree, Carolina poplar, necklace poplar, broadleaf poplar, and whitewood.

Its range covers practically all of the United States east of the Rocky Mountains. It is rare or missing in eastern New England and southern Florida, and most abundant in the Mississippi valley, and there the largest trees are found. Some exceed 100 feet in height, and four in diameter. Extreme sizes of 140 feet in height with diameters of from seven to nine have been reported. The cottonwood was a frontier tree on the western plains when settlers began to push into the region. It grew as far west as any hardwood of the eastern forests, and was found beyond meridian 100, which was suppozed to be the boundary between the region of rains and the semi-arid country. The cottonwood clung to the river banks and to islands in the rivers, and by that means escaped the Indian's prairie and forest fires which he kindled every year to improve the range for the buffalo. It is supposed that most of the open country east of meridian 100 was originally timbered, and that the Indians destroyed the forests by their long-continued habit of burning the woods and prairies every year to improve the pasture. Cottonwood was the longest survivor, because it grew in damp places where fires did not burn fiercely. Black willow was its most frequent companion on the western outposts of the forests.

The cottonwood was fitted for holding its ground, and pushing forward. Its light seeds are carried by millions on the wind and by water. The tree bears large quantities of cotton (hence the name), and when the wind whips it from the tree, seeds are caught among the fibers and carried along, to be scattered miles away.

*The following species grow in the United States: Cottonwood (Popralus delfoides), Aspen (Populus tremuloides), Largetooth aspen (Populus grandidentata), Swamp Cottonwood (Populus heterophylla), Balm of Gilead (Populus balsamifera), I.anceleaf Cottonwood (Populus acuminata), Narrowleaf Cottonwood (Populus angustifolia), Black Cottonwood (Populus trichocarpa), Fremont Cottonwood (Populus fremontit), Mexican Cottonwood (Populus mexicana), Texas Cottonwood (Populus wislizeni). 
This tree was not much thought of by eastern people who had plenty of other kinds of wood, but pioneers on the plains who had a hard time to get any, found cottonwood useful. It made fences, corncribs, stables, cabins, ox yokes, and fuel. The first canoes made by white men on the upper Missouri river were of cottonwood. Lumber cut from this tree is inclined to warp and check unless carefully handled, and this prejudiced it in the eyes of many; but difficulties of that kind were easily mastered, and instead of being a neglected wood it became popular. Some of the largest early orders came from Germany. Vehicle makers in this country employed it for wagon beds, as a substitute for yellow poplar when that wood's cost advanced. Manufacturers of agricultural implements were pioneers in its use, it being excellent material for hoppers, chutes, and boxes.

Cottonwood weighs 24.24 pounds per cubic foot, which is approximately the weight of white pine. It has about the stiffness of white oak, but only about eighty per cent of white oak's strength, and fifty per cent of its fuel value. The wood is very porous, but the pores are small, usually invisible to the naked eye. The medullary rays are small and obscure. The appearance of the wood is not improved by quartersawing. The summerwood forms a thin, dark line, so faint that the annual rings are of ten scarcely distinguishable. The tree is generally a rapid grower; heartwood is brown, sapwood lighter, but as a whole, this tree produces white wood.

The annual cut is declining. It was little more than half in 1910 what it was in 1899. Some regions where large trees were once abundant now have few. The sawmill output in 1910 for the United Statesincluding several species-was $220,000,000$ feet. The reneer cut was $33,000,000$ feet, $\log$ measure; the slack cooperage staves, chiefly for flour barrels, numbered $44,000,000$; and pulpwood amounted to about $18,000,000$ feet. The lumber cut was largest in the following states in the order named: Arkansas, Louisiana, Mississippi, Missouri, Tennessee, Iowa, Wisconsin, Michigan, Oklahoma, and Minnesota. The tree was lumbered in forty-one states.

Cottonwood is a standard material in several lines of manufacturing. It is made into nearly every kind of box that goes on the market, from the cigar box to those in which pianos are shipped. Manufacturers of food products are particularly anxious to procure this wood, and it is one of the best for woodenware, such as dough boards, ironing boards, and cloth boards. It is used by manufacturers of agricultural implements, interior finish, bank and office fixtures, musical instruments, furniture, vehicle tops, trunks, excelsior, saddle trees, caskets and coffins, and numerous others. 
There is no danger that cottonwood will disappear from this country, but it will become scarce. It is being cut much faster than it is growing, and is losing favor as a planted shade and park tree, because of its habit of shedding cotton in the spring and its leaves in the early autumn.

Swamp CotTonwood (Populus heterophylla) is known also as river cottonwood, black cottonwood, downy poplar, and swamp poplar. Its range describes a crude horseshoe, running from Rhode Island down the Atlantic coast in a narrow strip, where it is neither abundant nor of large size; touching northern Florida; running westward to eastern Texas and thence up the Mississippi basin and the Ohio river to southwestern Ohio. There is nothing handsome about its appearance with its heavy limbs and sparse, rounded crown. In the eastern range the average height is probably not more than fifty feet but in the fertile Mississippi valley it reaches 100 and has a long merchantable bole three feet in diameter. Its bark is rugged, dirty-brown and broken into loose, conspicuous ridges. It is easily distinguished from the other cottonwoods by the orange-colored pith in the twigs. The buds are rounded and red and have a resinous odor. Sawmills and factories never list this wood separately. It comes and goes as cottonwood. Its uses are the same as those of common cottonwood. The two species grow in mixture throughout the entire range of the swamp cottonwood.

Texas CotTonwood (Populus wislizeni) is a rather large tree and is the common cottonwood in the upper valley of the Rio Grande in New Mexico and western Texas. The yellowish color of the twigs is apt to attract attention. The wood is used about ranches and occasionally a log finds its way to local sawmills; but its importance is limited to the region where it grows.

Mexican Cottonwood (Populus mexicana) extends its range north of the Mexican boundary into southern Arizona and southwestern New Mexico. It is abundant in Mexico where the largest trees are eighty feet high and three or four in diameter. It is smaller near the northern limits of its range, and there it hugs the banks of mountain streams. Stockmen use the trunks, which are usually small enough to be called poles, to make fences and sheds.

NARRowleaf CotTontwood (Populus angustifolia) is a mountain species which manages to live in the semi-arid regions from the Rocky Mountains of Canada to Arizona, but is seldom found below an elevation of 5,000 feet, and it ranges up to 10,000. Trunks are eighteen inches or less in diameter, and fifty or sixty feet high. The seeds are larger than those of most other cottonwoods. It being a semi-desert species, its wood is appreciated where it is accessible, and it has local uses only. 
Lanceleaf CotTonwood (Populus acuminata) is a small tree with limited range, growing in the arid region along the eastern base of the Rocky Mountains, southward from the Black Hills. It is found also north of the Canadian border. It is usually fifteen or eighteen inches in diameter, and thirty or forty feet high. Trunks seldom go to sawmills, but some local use is made of the wood. Trees are occasionally planted for shade in towns of western Nebraska and Wyoming.

Fremont Cottonwood (Populus fremontii), called white cottonwood in New Mexico, but elsewhere simply cottonwood, grows from western Texas to California, and as far north as Utah and Colorado. It sometimes attains a diameter of five or six feet and a height of 100 . The Indians in New Mexico formerly made rude, clumsy ox carts of this wood, without a scrap of iron or other metal in the vehicles. One of the carts is preserved in the National Museum, Washington, D. C. The wood is tough and light, but it is dull white, with no attractive figure. Even the annual rings are hardly distinguishable. Logs are occasionally sawed into lumber, and farmers in western Texas make wagon beds of it.

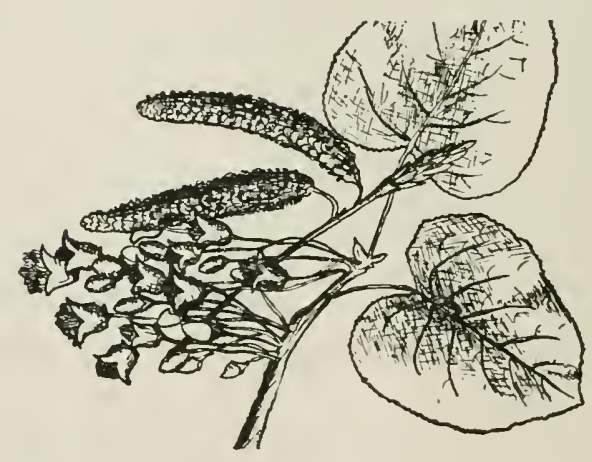


BALM OF GILEAD 


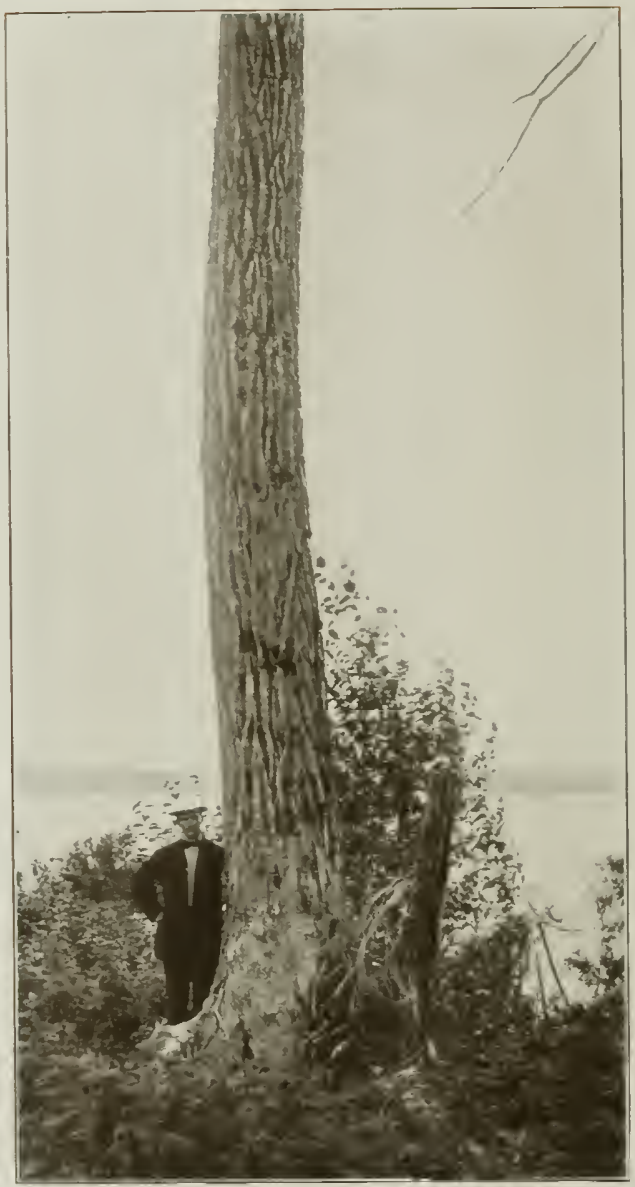

BALII OF GILEAI) 


\title{
BALM OF GILEAD
}

\author{
(Populus Balsamifcra)
}

THIS tree is known in different regions by the following names: 1 Balsam, balm of Gilead, cottonwood, poplar, balsam poplar, and tacamahac. The usual name, balm of Gilead, is applied in recognition of the supposed healing virtue of the wax which covers the buds and young leaves. It has long been used in medicine, but its exact value is still a matter of discussion. The wilc. Indians of the North discovered a use for the balsam in mending their bark dishes, and plugging knot holes in the wooden trenchers. The wax is slow to dissolve in water, and it resisted for a long time such soups as were known to the redman's culinary art. Bees know the value of the wax and use it to seal cracks and crevices in their hives and to hold the comb in place. It is popularly believed that the economy of the wax on the buds is to keep them from freezing. That view is erroneous, for it would take more than a coating of wax to keep the buds warm with the thermometer from fifty to seventy degrees below zero, as it is every winter in some parts of this tree's range.

Balm of Gilead is a native of the North from the Atlantic to the Pacific, but its finest growth is about the headwaters of the Mackenzie river, on Peace and Laird rivers, and the lower valley of the Athabaska. Sixty years ago Sir John Franklin reported that most of the driftwood of the Arctic ocean was this species. Since that time the range has been more definitely determined, and it is now known that the tree grows so far north that it is for some weeks in darkness, and again in summer for some weeks in unbroken sunshine. It grows in Alaska nearly 200 miles north of the Arctic circle. Its natural range southward reaches New England, New York, Michigan, Nebraska, Nevada, and Oregon.

Trees of all sizes abound, from mere shrubs in the outskirts of its range to trunks 100 feet high and six feet in diameter in favored localities. In the United States the best timber seldom exceeds thirty inches in diameter and sixty or seventy feet in height. The bark on limbs and young trunks is brownish-gray, frequently so tinged with green that it is noticeable at a considerable distance; but usually large trees have reddish-gray bark with deep furrows and wide ridges. Year-old twigs are clear, shiny reddish-brown; end buds are about an inch long, the side buds somewhat shorter.

The wood is not distinguishable in appearance from that of the other poplars or cottonwoods, but it is lighter than most of them, weighing 22.65 pounds per cubic foot, has a breaking strength which places it among the weakest woods, but in stiffness making a much 
better showing. The pores are small, numerous, and are distributed equally through all parts of the wood.

Balm of Gilead bears seeds abundantly and scatters them widely. It must do its planting quickly in the short summers of the cold North. It sticks close to alluvial flats, banks of rivers, borders of lakes and swamps, and gravelly soils. It grows to a diameter of fifteen inches in about forty-five years.

Though balm of Gilead is not one of the most important timber trees of this country, its place is by no means obscure. No separate tally is kept of it among woods cut for pulp, but it goes with aspen and other similar species as "poplar." A little better account is kejt of the amount passing through wood-using factories. The annual quantity so reported in Illinois is $2,775,000$ feet, and it is made into boxes and crates. The lumber is shipped from the North, since it does not grow as far south as Illinois. The situation is different in Michigan, for balm of Gilead grows there. The amount going yearly into factories in that state is reported at $4,912,000$ feet. It is made into many commodities, but boxes and crates take most of it. The wood is reduced to veneer and converted into berry buckets, grape baskets, fruit and egg crates, and other small shipping containers. It is made into excelsior and woodwool which are used as packing material. Druggist's barrels are manufactured from this wood. These are small, two-piece vessels, bored hollow, with a closely fitting lid, and varying in size from a couple of inches high, to nearly a foot. They contain powders, perfumes, pills, and other commodities in small bulk. The wood is worked into pails, tubs, and kegs. Furniture makers put balm of Gilead to use in several ways. It is cut thin for shelving; it is made into panels, and is employed as cores over which to lay veneers of more expensive materials. Woodenware factories generally keep it in stock in the northern states.

The supply is ample at present to meet all demands. Cutters of pulpwood probably take more than sawmills, and are satisfied with smaller timber. Trees are often planted for ornament, but few if any have yet been propagated for forestry purposes.

Hatry Balm of Gilead (Populus balsamifera candicans) is not a species but a variety, and it is so different from balm of Gilead that it is entitled to a place of its own. Ordinarily it passes under the common names applied to balm of Gilead. It is a cultivated tree in eastern Canada and northeastern United States, where it has escaped from cultivation and is running wild. Both Sargent and Sudworth say that nothing is definitely known of the tree's native range; while it has been claimed by others that it once grew wild in Michigan but was destroyed by lumbermen. Probably most planted balm of Gileads are of this 
variety, as they are very ornamental. It is a large tree with branches less upright and crowns more open than in the wild species. The leaves are wide, heart-shaped, and are usually silvery white beneath with minute hairs on the margins, on the veins, and leaf stems. It is not improbable that this variety could be more profitably planted for forestry purposes than the species which grows wild; but there is no present indication that foresters favorably consider either of them.

LARGetooth ASpen (Populus grandidentata) is named on account of the shape of the leaves. It is sometimes called aspen, popple, white poplar, and large poplar. The wood weighs 28.87 pounds per cubic foot, and is the heaviest of the poplar group except Fremont cottonwood of the arid southwestern regions. The wood is white, attractive, but not strong. It was formerly manufactured into chip hats and shoe heels in New England, and is now used for baskets, crates, boxes, buckets, refrigerators, excelsior, and pulp. Northern factories usually give it the general name "poplar," and for that reason its importance in the lumber trade is underestimated. Trees may reach a height of seventy feet with a diameter of two; but a height of forty or fifty is more usual. The species' range extends from Nova Scotia to Minnesota, southward to Delaware and Illinois, and along the Appalachian mountains to North Carolina and Tennessee.

Gumbo Limbo (Bursera simaruba) is a south Florida species and is known also as West Indian birch. It is in a family by itself with no near relative. It is not a birch. The wood is spongy and very light, weighing less than nineteen pounds per cubic foot. It decays with remarkable rapidity. Branches thrust in the ground take root and grow. An aromatic resin, exuding from wounds in the bark, is manufactured into varnish. The leaves are substituted for tea, and gout remedies are made from the resin. Large trees are fifty feet high and two feet or more in diameter. Another Florida tree, not in the same family as this, is also called gumbo limbo (Simaruba glauca), paradise tree, and bitter wood. Ailanthus (Ailanthus glandulosa) is in the same family as paradise tree, but is not native in this country, though extensively planted here.

Angelica Tree (Aralia spinosa). This is a small tree, which usually develops little or no heartwood. The springwood, or the inner and porous part of the ring, is broad and yellow, the summerwood, or exterior part of the ring, is narrow and dark. The wood's figure, due to the marked contrast between the outer and inner portions of the rings, is strong. When finished it shows a ricly yellow, but somewhat lighter than dwarf sumach which it resembles. It is made into small shop articles, like button boxes, photograph frames, pen racks, stools, and arms for 
rocking chairs. Its range extends from Pennsylvania to Texas. It is sometimes known as Hercules' club.

ASPEN (Populus tremuloides) is widely known but not everywhere by the same name. It is called quaking asp, mountain asp, aspen leaf, white poplar, popple, poplar, and trembling poplar. The peculiarity of the tree which is apt to attract attention, and which gives it most of the names it carries, is the leaf's habit of being nearly always in motion. The day is remarkably still if aspen foliage is not stirring. This is due to the long, flat leaf stem, which is so limber that it offers little resistance to air currents. The difference in color between the upper and lower sides of the leaves affords sufficient contrast to attract notice, and for that reason a person will observe the motion of aspen leaves when he might fail to see a similar movement among the leaves of other species where the contrast of colors is not so marked. Aspen is credited with being the most widely distributed tree of North America. It grows from Tennessee to the Arctic ocean, from Mexico to northern Alaska, from Labrador to Bering strait. It is found at sea level, and at 10,000 feet elevation among the mountains of California. Its very small seeds grow in enormous numbers. Winds carry them miles, and scatter them by millions. They spring up quickly when they fall on mineral soil. This places it in the class with "fire trees"-those which take possession of burned tracts. Paper birch is in this class. Aspen has replaced pines over large burned areas of the Rocky Mountains. It grows quickly but is weak if it has to contend with other trees. If crowded it speedily gives up the fight and dies. The wood is not strong, but is useful for several purposes. Next to spruce and hemlock, it is the most important pulpwood in this country, and it is coming into considerable use as lumber. The whiteness of the wood-it looks much like bollymakes it a favorite for small boxes and vessels for shipping and containing foods. It is made into jelly buckets, lard pails, fish kits, spice kegs, sugar buckets and a long line of similar articles. It turns well, and is made into wooden dishes. Michigan alone uses two and a half million feet of it a year; and it is in demand along the whole northern tier of states from Maine to Washington, but because it is not separately listed in lumber output, it is difficult to say how much is used. Trees are usually small, though trunks three feet in diameter are not unknown. It grows rapidly, and may be expected to fill an important place in this country's future timber supply. There will be no occasion to plant it by artificial means, for nature will attend to the planting.

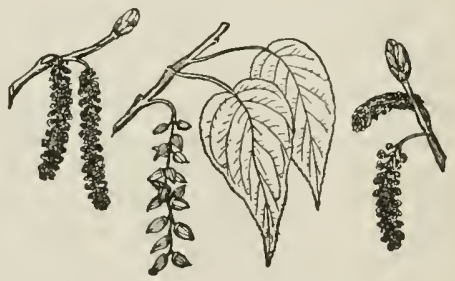


BLACK COTTONIFOOD 


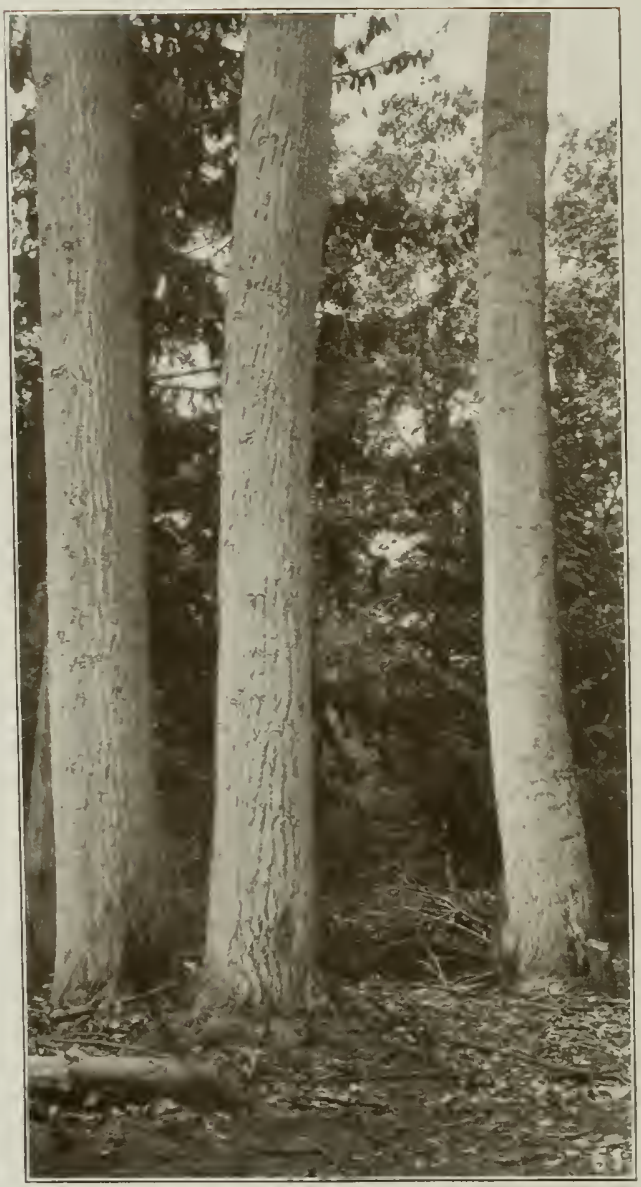

BLACK COTTONWOOD 


\section{BLACK COTTONWOOD}

(Populus Trichocarpa)

$\mathrm{T}$ HIS member of the cottonwood group is a strong tree that holds its ground in various latitudes and at many elevations, ranging from sea level up to eight or nine thousand feet, and in latitude from Alaska to southern California, a distance of nearly three thousand miles. Its east and west extension is more restricted and seldom exceeds four hundred miles. Its habitat covers an area of half a million square miles, and in that space it finds conditions which vary so greatly that the tree which can meet them must possess remarkable powers of adaptation.

Beginning in Alaska and the interior of Yukon territory, it has an arctic climate. It there not only grows on the coast, but it strikes the interior. It appears on the headwaters of several streams which flow into the Mackenzie or Hudson bay. It passes soutl through British Columbia and enters the United States west of the Rocky Mountains. It has been reported as far east as Idaho and Montana, but further information is needed before its limits in that direction can be definitely fixed.

When it enters California it prefers the elevated valleys and canyons of the Sierra Nevadas, though it occurs sparingly among the coast ranges. It is generally found in the Sierras at elevations of from 3,000 to 6,000 feet, though it occurs between $S, 000$ and 9,000. Among the San Jacinto mountains of southern California it grows at an altitude of 6,000 feet.

When it occurs at low levels it is isually found on river bottoms and sand bars, in sandy and humous soils, and there the largest trees are found. At higher elevations it is more apt to occur in canyon bottoms and gulches, in moist, sandy or gravelly soil, and in such situations the black cottonwood is smaller. The best growth occurs where the climate is humid and the precipitation is great. Beyond the reach of sea fogs, where the tree depends on soil moisture chiefly, it is smaller.

It is an intolerant tree. It must have light. When it is crowded a tall, slender trunk is developed and the small crown is lifted clear above its competitors into the full light. If it cannot succeed in gaining that position its growth is stunted or the tree mcets an early death.

The black cottonwood is the greatest of the cottonwoods. This country produces no other to match it, and, as far as known, the whole world has none. The Pacific coast is remarkable for the giant trees it produces, but most of them are softwoods-the redwoods, the 
bigtree, the sugar pine, Douglas fir, western larch, noble fir, Sitka spruce and western red cedar. This cottonwood is the largest of the Pacific coast hardwoods. In trunk diameter it is excelled by the weeping oak in the interior valleys of California, but when both height and diameter are considered, the black cottonwood is in the West what yellow poplar is in the East, the largest of the hardwoods.

Sargent says this Lree reaches a height of two hundred feet and a diameter of eight, but Sudworth is more conscrvative and places the trunk limit at six feet. The average size is much below the figures given, but abundance of logs exceeding three feet in diameter reach the sawmills of Washington and Oregon.

Old trees range from 150 to 200 years in age, but trees under 100 years old are large enough for saw timber. Records of the ages of the largest trunks have not been reported.

Black cottonwood is a prolific seeder, but the seeds do not long retain their vitality. If they find lodgment in damp situations, where other conditions are farorable, the rate of germination is high. Seedlings are of ten very numerous on wet bars.

The excellent quality of the wood and its suitability for many purposes bring it much demand on the Pacific coast. In the state of Washington more than $30,000,000$ feet were used by wood-using industries in 1910. Smaller quantities were reported in Oregon and California.

In strength the wood is approximately the same as common cottonwood, but in stiffness it much exceeds the eastern species. Its elasticity rates high, and compares favorably with some of the valuable eastern hardwoods. In weight it is slightly under common cottonwood. Trees are of fine form, nearly always straight, and are generally free from limbs to a considerable height.

The wood is grayish-white, soft, tough, odorless, tasteless, longfibered, nails well, is easily glued, and cuts into excellent rotary veneer with comparatively small expenditure of power. It does not split easily after it has undergone seasoning, and this property commends it to box makers. It is little disposed to shrink and swell in atmospheric changes. The absence of odor and taste gives it much of its value for box making, because foods are not contaminated by contact with it.

It is manufactured into reneer berry baskets and is one of the most suitable woods on the Pacific coast for that purpose. Candy barrel makers use it in preference to most others, and a long line of woodenware articles draw much of their material from this source. Many thousands of cords are cut yearly for the pulp mills, where material for paper is produced. Black cottonwood and white fir are the principal woods used for pulp on the Pacific coast. 
Not only is it used for rotary-cut veneer, but it is made into cores or backing on which veneers of costly woods are glued in the manufacture of furniture, interior finish and fixtures for banks, stores and offices. It serves in the same way in casket making, and is demanded in millions of feet.

It is employed in amounts larger than any other wood by excelsior mills in the northern Pacific coast region. It is the only wood demanded by that industry in Washington and $6,400,000$ feet were cut into that product in 1910 .

Slack coopers find it as valuable in their business in the far West as the common cottonwood is in the East, and hundreds of thousands of staves are made yearly. It is in demand for the manufacture of flour barrels and those intended for other food products.

Trunk makers use it in three-ply veneers for the bodies, trays, boxes and compartments of trunks and for suit cases. Though soft and light, it is very tough, and slieets of veneer with the grains placed transversely resist strains much better than solid wood of the same thickness.

Vehicle makers employ black cottonwood for the tops and shelves of business wagons. Another of its uses is as bottoms of drawers for bureaus, wardrobes, and chiffoniers, and as partitions in desk compartments. A full line of kitchen and pantry furniture is made wholly or in part of this wood in the regions where it is cheap and abundant.

The cottonwoods belong to a very ancient race of broadleaf trees, and like several others, they seem to luave had their origin, or at least a very early home, in the far North, where intense cold now excludes almost every form of vegetable growth except the lowest orders. The Cretaceous age saw cottonwoods growing in Greenland. The cotton which then, as now, carried the seeds and planted them fell on more hospitable shores then than can now be found in the far frozen North. The genus was not confined to the arctic and subarctic regions, however, for there were cottonwoods at that time, or later, in more southern latitudes. There were many species in the central portion of this country, and also in Europe, long before the ice age destroyed all the forests north of the Ohio and the Missouri rivers. Some of the old species long ago ceased to exist, but others appear to have come down to the present time without great change.

The cottonwood shows wonderful vitality, which is doubtless a survival of the characteristic which enabled it to come down from former geologic epochs to the present time. A danuged and mutilated tree will recover. A broken limb, thrust in the ground, will grow.

BLAck Poplar (Populus nigra) is quite distinct from black cottonwood, though 
both belong to the same family. The latter is a Pacific coast species, while the former belongs in Europe, although it may have been introduced into that country from Persia or some other eastern region. It is common in the United States, on account of having escaped from cultivation. The best known variety of this tree is the Lombardy poplar (Populus nigra italica). It is easily recognized by the characteristic attitude of the branches which grow upward close against the trunk. The crowns of the trees are very long and slender, sometimes not ten feet across though fifty feet high. Their slimness gives the trees the appearance of being much taller than they really are. They were formerly popular for planting along lanes and in door yards. Their slender and pointed spires cut the horizon with a peculiar effect. Planting is less common now than formerly, because people have come to know the trees better. They are probably the most limby of all the members of the cottonwood group. The long trunks are masses of knots when the limbs have been trimmed away, and any desire to make lumber of the trees is apt to be discoiraged, though not infrequently logs go to local sawmills, and farmers haul the boards home to put them to some use about the place. In Michigan and Ohio, box makers use the lumber for the rougher and cheaper articles which they turn ont.

The most discouraging thing about Lombardy poplar is the tendency of the trees to send up sprouts. The living trees do it, and the stumps are worse. The sprouts are not confined to the ground immediately round the base of the tree, but spring up many feet or many yards distant, until they produce a veritable jungle. Years are often required to complete their extermination by grubbing and cutting.

White Poplar (Populus alba) is a European species but has become naturalized in the United States. It is widely planted as a shade tree, and has escaped from cultivation. It may be known by the white undersides of its small leaves, and by its yellowish-green bark which remains smooth, except on large trunks. It is not yet important as a source of lumber, but the vigor of its growth indicates that it may sometime become so. The wood is soft, white, and light. Some persons consider the tree objectionable as an ornament because of its habit of sending up sprouts from the roots, and because its woolly leaves collect dust and smoke until they are almost black by the end of summer.

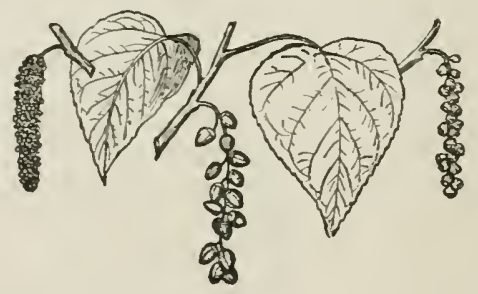


M.ANGROVE 


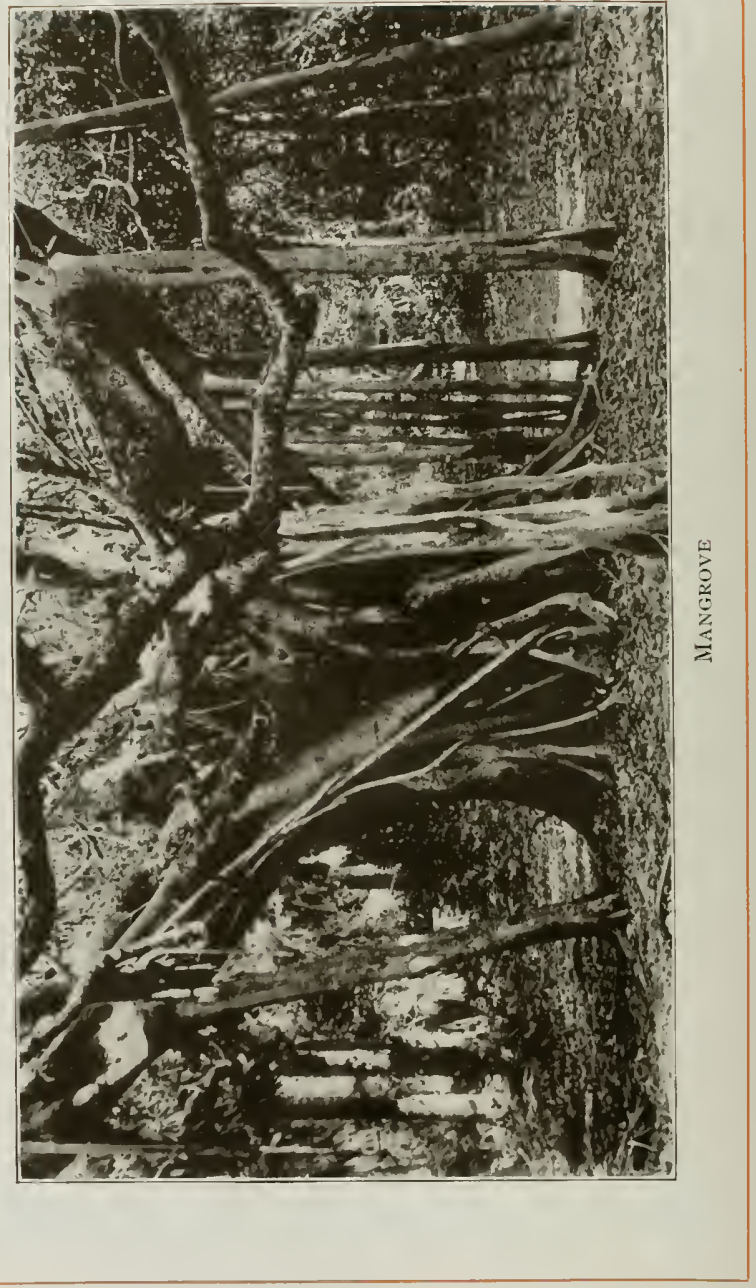




\title{
MANGROVE
}

\author{
(Rhizophora Mangle)
}

$\neg$ HE mangrove family is large and widely scattered, but only one 1 member has gained a foothold in the United States, and it occupies only limited areas in south Florida, at the delta of the Mississippi, and on the coast of Texas. The family's fifteen genera are confined to the tropics, with a little overlapping on the temperate zones. The botanical name Rhizophora refers to the tree's peculiar roots, and mangle is the Spanish for mangrove. This is one of the few trees in this country which are known by a single name. It is always called mangrove, and at tains its best development in Florida.

The leaves hang two years, are from three to five inches long and one or two wide. Flowers are not showy, but they are ncarly always present, blooming the year round, the yellow blossom about an inch in diameter. The fruit proper is about an inch long, but its habit of sprouting while still on the tree and sending down a long stem-like root, gives the impression that the fruit is several inches long, sometimes a foot.

It is not an easy matter to state the average size of mangrove trees. Peculiar habits of growth make measurements difficult. Neither is it easy to tell where a tree begins and where it ends. Mangrove thickets along some of the rivers of south Florida, within the influence of tide water, are strange forms of vegetation. If the foliage alone is considered from a little distance, it reminds one of a row of fig trees in Louisiana or California. The color and general appearance suggests fig trees. A nearer approach reveals beneath the crowns a mass of roots, stems, and limbs, joined with the ground beneath and the crowns above. In addition to these, there are many others that dangle from above, like rope ends, some ncarly touching the ground, others several feet above. These are roots or limbs, by whichever name one cares to call them. They grow from overhead branches, and strike for the ground. When they touch the soil, they quickly anchor themselves, and become stems. They then look like slender poles set as props under the branches of an overladen fruit tree.

This strange habit of growth gives the tree its character. Most mangroves stand in water. They fringe the banks of rivers and bayous, extending the fringe as far as the water is shallow. Growth of that kind is generally from ten to twenty feet high, and the largest stems from an inch in diameter up to three or four; but these dimensions cannot be taken as limits to size. Sometines the trees are sixty or seventy feet high, but those which stand in water seldom reach that size. 
Trees which bave their beginning in the water sometimes end their days high and dry on the land.

The mangrove is a land builder. The sycamore and willow are land builciers on a small scale, along northern water-courses, but mangrove excels them a hundred or a thousand fold where it grows on the low shores of Florida. The seed is prepared for land-building work before it drops from the tree. It sprouts a long, peculiar root-it looks like a very slender, big-ended cucumber-the large, heavy end down. This attains a length of several inches or a foot. When it drops from the branch, the end sticks in the mud and takes root, grows, and produces a tree. But generally it falls in water, and not on a mud bank. In that case it floats away, the heavy end down, the light end barely appearing on the surface. Winds and currents drive it about until the lower tip finally touches bottom in some shallow place. There it takes root, and unless circumstances are extremely adverse, it holds fast, finally becomes a tree, sends branches down from above to take root at the bottum of the water, and a clump is produced. The tangled mass of stems and roots catches driftrood and mud, resulting finally in a little island, and later the island is joined to the mainland. Thus the land is built. Many large flats in Florida owe their origin to this tree. When land is permanently above water, the mangrove loses, to some extent, its ability to send roots down from the limbs. Nature seldom does something for nothing, and since the mangrove's aerial roots no longer serve a useful purpose in nature's economy, they are dispensed with. Trunks then reach much larger size, and become timber instead of thickets. The accompanying picture shows a mangrove that no longer stands in water, and its habit of growth is changing.

Thickets of mangrove are useful, not only in building new land, but in protecting that already built. Frequently the force of waves is broken, which otherwise would destroy low shores. Tremendous seas, in time of storms, will roll over thickets of mangrove without uprooting them or breaking the stems. Again nature's fine engineering is apparent. When men build lighthouses which must endure the shocks of waves, they have learned to construct them of open beams and lattice work. The wave passes through without delivering the full impact of the blow to the structure. No solid masonry will stand what a comparatively light open frame will endure without injury, because it allows the waves to pass on. A large wave may strike with a force of 6,000 pounds to the square foot. The mangrove thickets are like the open-framed lighthouse-they let the waves pass through and spend their force gradually beyond, but they hold the shore against washing.

Admirable and wonderful as is nature's provision for protecting the 
land by a fringe of lattice work of branches and stems, the marvelous efficiency of the provision has been greatly increased in another way. Suppose, for illustration, that cottonwood instead of mangrove formed the protective thickets along stormy shores. The first hour of heavy seas would reduce the trees to fragments. The weak, brittle trunks and limbs would quickly break to pieces. But mangrove passes through storm after storm unharmed. It is scarcely believable that accident accounts for the fact that the best wood for the place is in the place; but it is probable, rather, that ages of development and natural selection gave to mangrove the qualities which make possible the accomplishment of its work. It is one of the strongest, and as far as available data may be depended upon, it is absolutely the most elastic wood in the United States. Shellbark hickory is rated high in both strength and elasticity; but mangrove rates higher. Sargent gives hickory's measure of elasticity at $1,925,000$ pounds per square inch; but mangrove's is $2,333,000$ pounds.

It is thus fitted in the highest manner to perform the work needed. It plants itself in the right place; develops stems which will endure most and suffer least; possesses enormous strength for resisting force, yet is so extremely elastic that the force of waves is exhausted upon the trunks and branches without flattening them upon the ground or crushing them. Few things of the vegetable world show more perfect adaptation to environment. The wood's very heaviness seems to add one more quality fitting it for its place. When a trunk falls in the water, it does not float away as most trees would, but sinks like iron, lies on the bottom, helps to hold the forming island or bar in place, and in its death as in its life it is a land-builder. Its efficiency in that particular is increased by the fact that it is little affected by marine borers which, in the warm, brackisl1 waters, usually destroy wood in a short time.

Mangrove is not important commercially, though it is used for a number of purposes. The wood weighs 72.4 pounds per cubic foot, takes good polish, though it is inclined to check in drying; it contains many small pores; medullary rays numerous and thin; color reddish-brown streaked with lighter brown. The principal use of the bark is for tanning and the trunks for piles. It is well fitted for fence posts, but not many have been used in the region where it grows. It rates high as fuel, but its great weight increases transportation charges if the haul is long.

Tanbark peelers in Florida have cut much of the large mangrove forest. They took the bark, and abandoned the trunks. There is no likelihood that the species will be extcrminated. Much of the growth is practically inaccessible, and the trunks are too small to tenipt bark peelers, and cordwood cutters find plenty of material more convenient. 
OTHER SPECIES. - Two other trees of this country are called mangrove though they are not even in the same family. One is the black mangrove (Avicennia nutich), called also blackwood and black tree. It is a Florida species of the family Verbenacece, and has some of the mangrove's habits. It takes root and grows on muddy shores and is a land builder. The largest trees are sixty or seventy feet high and two in diameter, but are usually less than thirty feet high. The bark is used in tanning, and no use for the wood is reported, except for fuel. White mangrove (Laguncularia racemosa), known also as white but tonwood, is a Florida species. It attains a height of thirty or forty feet and a diameter of a foot or more. It reaches its largest size on the shores of Shark river, Florida. The wood is dark yellow-brown, and the bark is rich in tannin, and the tree may become valuable as a source of tanbark.

Near akin to white mangrove is Florida buttonwood (Conocarpus erecta) which is highly esteemed as fuel. It burns slowly like charcoal. Trees are from twenty to fifty feet high. Its range lies in southern Florida. Black olive tree (Terminalia buceras) belongs in the south Florida group, and the wood is exceedingly hard and heavy. The trunk is often two or three feet in diameter, but lies on the ground like a $\log$, with upright stems growing from it. Tanners make use of the bark.

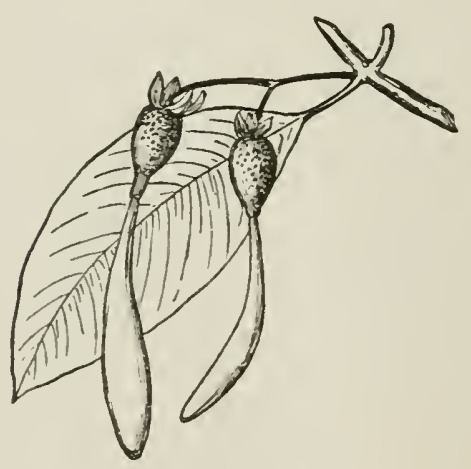


CABBAGE PALMETTO 


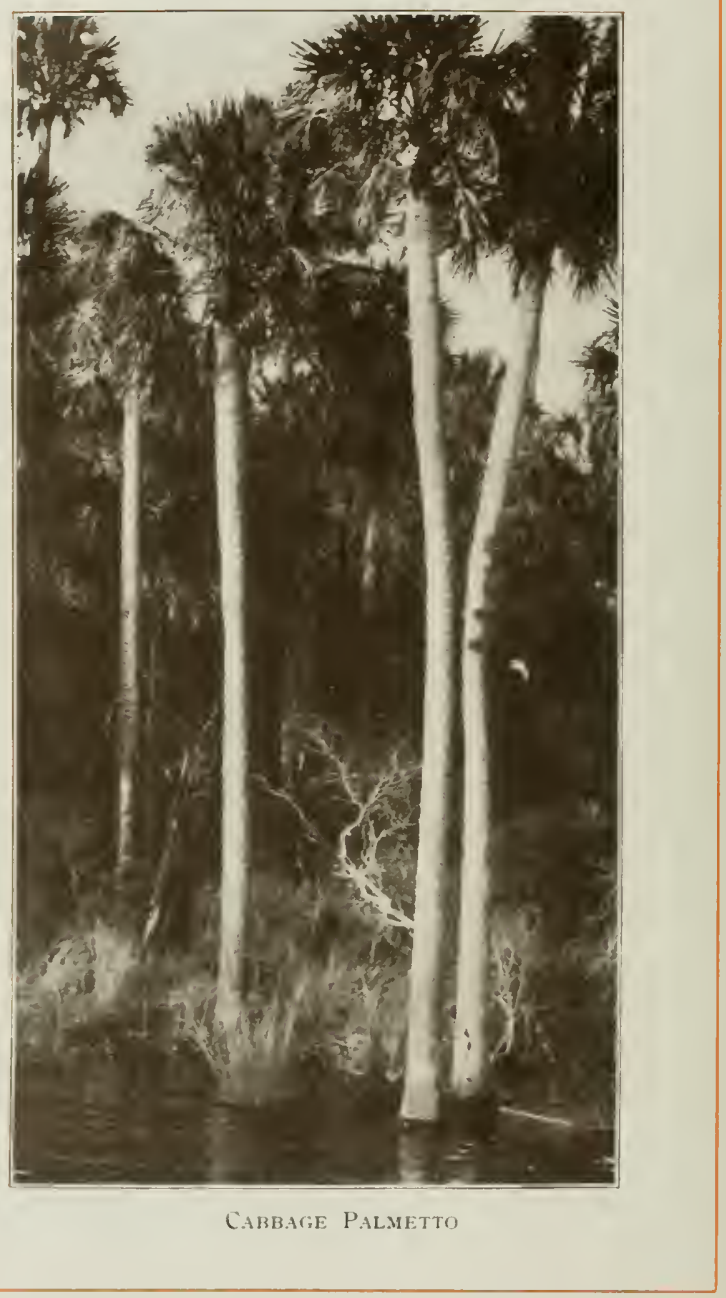




\section{THE PALMS}

I UMBERMEN in this country could get along very well without the 1 palms, as they are little used for ordinary lumber. Their wood does not grow in concentric rings, like that of the ordinary tree. The stems are usually single, eylindrical, and unbranched. The fruit is berry-like, and is usually one seeded, though sometimes there are two or three. When a seed sprouts, it puts out at first a single leaf, like a grain of corn. About 130 genera of palms are recognized in the world, most of them in the tropics, but several in the United States are of tree size. Botanists divide the palms of the United States into two gronps, the palm family and the lily family. The yuecas belong in the lily family. In the very brief treatment that can be given the subject here, it is not necessary to recognize strict family divisions.

Cabbage Palmetto (Sabal palmetto) grows in the coast region from North Carolina to sonthern Florida, and west to the Apalaehieola river. It is sometimes called Bank's palmetto, cabbage tree, and tree palmetto. The name cabbage is due to the large leaf-bud in the top of the stem which is cooked as a substitute for cabbage. A sharp hatchet and some experience are necessary to a successful operation in extracting the bud from the tough fibers which surround it.

This palm is a familiar sight in the coast region within its range. The tall trunks, with tufts of leaves at the tops, suggest the supposed scenery of the Carboniferous age. Usually the trunks, in thick stands, rise straight like columns from twenty to forty feet high, but oecasionally they bend in long, graceful curves, as if the weight of the tops caused them to careen, which is probably what does happen. They vary in diameter from eight inches to two feet.

The leaves are five or six feet long, and seven or eight wide, with stems six or seven feet long. Flowers occur in racemes two feet or more in length. The fruit is spherical and about a third of an inch in diameter. The roots are an important part of this palm, and are adapted to their environment, forming a rounded mass four or five feet in diameter, while small rope-like roots, half an inch in diameter, penetrate the wet marshy soil fifteen or twenty feet. The large, globe-like mass gives support in the soft soil, and the stringy roots supply water and mineral substances essential to growth. The wood is light, soft, pale-brown, with numerous hard, fibro-vascular bundles, the outer rim about two inches thick and much lighter and softer than the interior. The most important use for the wood at present is as wharf piles. It lasts well and is ideal in form. It is of historical interest that Fort Moultrie which defended Charleston, 
South Carolina, in the Revolutionary war, was built of palmetto logs. When the British made their memorable attack in 1776, their cannon balls buried in the spongy logs without dislodging them, and the fort successfully withstood the bombardment of ten hours, and disabled nine of the ten British ships taking part in the assault.

The wood is employed to a small extent in furniture making, and the bark for scrubbing brushes. Some of the finest forests of palmetto in Florida are much injured by fire that runs up the trunks to feed on stubs of leaves.

Silktop Palmetro (Thrinax parviflora) and silvertop palmetto (Thrinax microcarpa) are species met with on some of the islands off the coast of southern Florida.

Mexican Palmetro (Sabal mexicana) is much like cabbage palmetto in size and general appearance, and is put to similar uses, except that the leaf-bud does not appear to be used as food. The tree occurs in Texas along the lower Rio Grande, and southward into Mexico where the leaves are employed as house thatch by improvident Mexicans and Indians who do not care to exert themselves to procure better roofing material. In the vicinity of Brownsville, Texas, trunks of this palm are employed as porch posts and present a rustic appearance. They are said to last many years. The average size of trunks in Texas is fifteen or twenty feet high and a foot or less in diameter, but some much larger are found in Mexico. Some of the wharfs along the Texas coast are built on palmetto piles. It is said the trunks are not as strong as those of the cabbage palmetto in Florida.

SaRgent Palm (Pseudophonix sargentii) is interesting but not commercially important, but may become so as an ornamental plant. It is occasionally planted on lawns in south Florida. Leaves are five or six feet long with stems still longer. The clusters of flowers are sometimes three feet in length. A single species is known, occurring on certain keys in southern Florida, and is so limited in its range that it would be possible to count every tree in existence. A grove of 200 or 300 trees occurs on Key Largo.

Royal PALM (Oreodoxa regia) is one of the largest palms of this country. It is said to reach a height of eighty feet, but such sizes are rare. The trunk rises from an enlarged base, and may be two feet in diameter. Bark is light gray in color, and its appearance suggests a column of cement. Leaves are ten or twelve feet long, and the stems increase the total length to twenty feet or more. Flowers are two feet in length, and in Florida open in January and February. The fruit is smaller than would be expected of a tree so large. It is a drupe about the size of a half-grown grape. The wood is spongy, but the outer 
portion of the stem is strong and is made into canes and other small articles. Trunks are sometimes used as wharf piles. This palm's range is confined to south Florida in this country, but it is common in the West Indies. In Miami and other towns of southern Florida it is much planted for ornament.

FANLEAF PALM (Neowashingtonia filamentosa) also called Washington palm, California fan palm, Arizona palm, and wild date, ranges through southern California, and occupies depressions in the desert west of the Colorado river. There are said to be several forms and varieties. It ranges in height from thirty-five to seventy feet and in diameter from twenty to thirty inches. Trunks are of nearly the same diameter from bottom to top, or taper very gradually. They usually lean a little. Dead leaves hang about the trunks and blaze quickly when fire touches them, but the palm is seldom killed by fire. The small black fruit is about a third of an inch in diameter, and of no commercial importance; wood is little used; and the tree is chiefly ornamental, and has been much planted in California.

Mohave Yucca (Yucca mohavensis) is one of a half dozen or more palms of the yucca genus and the lily family. 'Trees of this group are characterized by their stiff, sharp-pointed leaves, some of which are called daggers and others bayonets. Both names are appropriate. The Mohave yucca takes its name from the Mahave desert in California, where it is occasionally an important feature of the doleful landscape. The ragged, leather-like leaves, forming the tops of the short, weird trees, rattle in the wind, or resound with the patter of pebbles when sandstorms sweep across the dry wastes. It is believed to be onc of the most slowly-growing trees of this country. Trunks are seldom more than fifteen feet high and eight or ten inches in diameter. The wcod is spongy and interlaced with tough, stringy fibers. Stockmen whose ranges include this tree, make corrals of the stems by setting them in the ground as palisades. When weathered by wind and made bone dry by the sun's fierce heat, the trunks are reduced to almost cork-lightness. Other yuccas are the Spanish bayonet (Yucca treculcana) of Texas; Joshua-tree (Y ucca arborcsccus), which ranges from Utah to California and is known as tree yucca, yucca cactus, and the Joshua; Schott yucca (Yucca brcvifolia) of southern Arizona; broadfruit yucca (Y ucca macrocarpa) of southwestern Texas; aloe-leaf yucca (Yucca aloifolia) with a range from North Carolina near the coast to Louisiana; and Spanish dagger (Yucca gloriosa), on the coast and islands of South Carolina.

Gravi Cacrus (Cereus giganteus) is a leafless tree of Arizona and attains a height of forty or sixty feet, diameter of one or two. About twenty genera of cactus are known in the world and a large number of species. Two genera, the cercuses and 
opuntias, have representatives of tree size in this country. The two genera differ in form. Cereus in the Latin language means a candle, and the cactuses of that genus stand up in straight stems like candles, or have branches like old-fashioned candlesticks. The opunitas have flat, jointed stems, like thick leaves. Giant cactus bears flowers four inches long and two wide; fruit two inches long and one wide, and edible. Indians derive a considerable part of their food from this cactus. They use the wood for rafters, fences, fuel, lances, and bows. The trunks consist of bundles of fiber, very hard and strong. In the dry region where this cactus grows, the woody parts of fallen stems last long periods, some say for centuries, but there are no records. Schott cactus (Cereus schottii) and Thurber cactus (Cereus thurberi) are found in southern Arizona and southward in Mexico.

ChOLLA (Opuntia fulgida) ranges from Nevada southward into Mexico. It is popularly called "divil's tongue cactus," but there are other species with the same . name. Trunks are occasionally ten or twelve feet high, and the wood is made into canes and small articles of furniture, but as lumber it is not important. The fruit is not eaten. A closely-related species is known as tassajo (Opuntia sponsior). It is found on the dry mesas of southern Arizona where trunks may be ten feet high and a few inches in diameter. It has the same uses as cholla. A third species is Opuntio versicolor of southern Arizona. It is similar to the other opuntias. Attempts have been made to grow spineless varieties of this group of cactuses. It is believed that cattle, sheep, and goats would thrive on the pulpy growth, if the thorns could be gotten rid of. The semi-desert regions of the Southwest produce enormous quantities of cactus of many kinds, and if those worthless species could be made way with and thornless varieties substituted, it is probable that much land now worthless would becorne valuable.

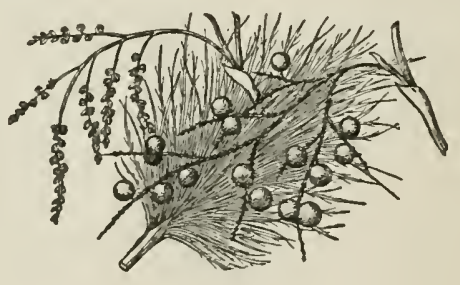




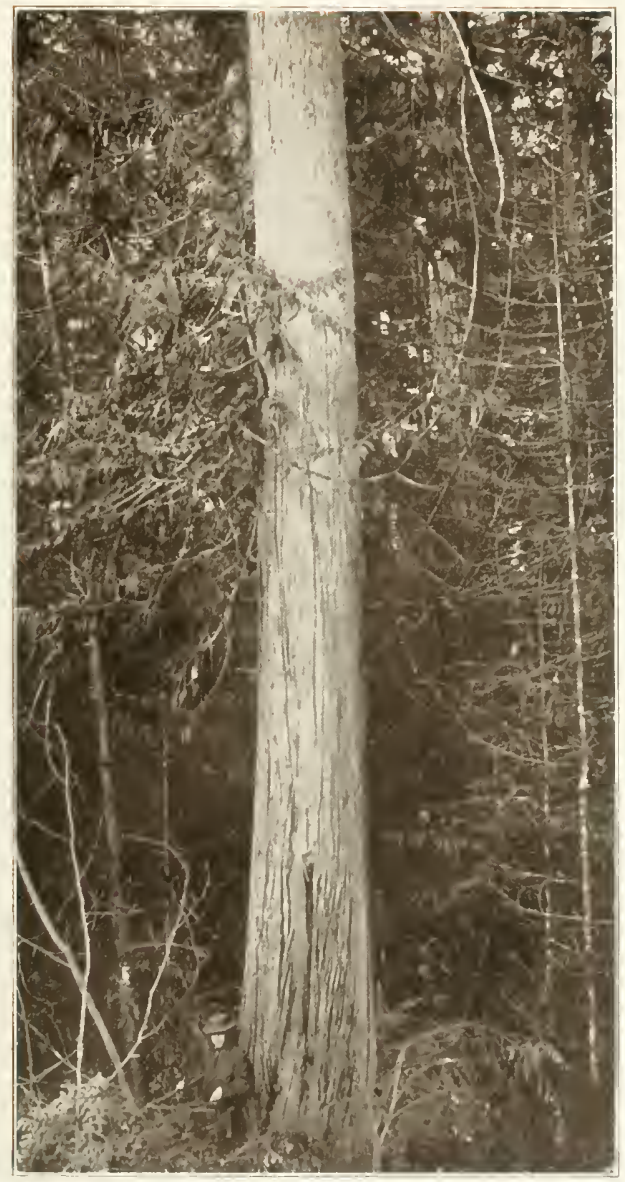

V' LLLOW CEIAR 



\section{MINOR SPECIES}

A considerable number of trees grow in this country which, taken singly, are of small importance, but in the aggregate they fill a place which would be difficult to fill without them. Most of them are local, and are seldom heard of outside of the regions where they grow. Some are small, and for that reason are not demanded by the ordinary user of lumber; but small size is not necessarily a bar to the use of a wood. Many places may be filled by pieces too small for the sawmill. Sometimes a diminutive trunk contains material of extraordinary hardness, or it may be polished to a rare smoothness, or the colors may be exquisite. Numerous commodities can be successfully manufactured from blocks or billets which are only a few inches in diameter and a foot or two in length. This is particularly true of some of the rare hardwoods of Florida and southern Texas where tropical species have extended their ranges northward over the borders of the United States. Some of the small trees in that group are known by name in only the immediate locality where they grow, and their qualities are scarcely appreciated even there. In some instances railroad ties are hewed from wood which is fit for the finest furniture.

It is no uncommon thing for Jexicans along the Rio Grande to warm their huts and cook their meals with fuel chopped from trunks of Texas ebony, algarita, cat's claw, bluewood, huisache, retama, and junco. Those who have traveled among the Indian rancherias of New Mexico and Utah have grown familiar with the peculiar odor filling the air in the vicinity of camp fires. It is the smoke of the rare junipers which the Indians burn for fuel; and yet it is wood of such soft tones and exquisite blending of colors that the shades of a Persian rug suffer by comparison. Among the ten thousand islands which fringe the coasts of south Florida, and also annong the hummocks of the mainland, are rare trees whose wood is unsurpassed in hardness, fineness of texture, and beauty. These are not being used at all, or only as fuel to feed some fisherman's or camper's fire, or to make a smoke to drive away mosquitoes. The time will come when small and scarce woods will be sought, if they are valuable for any special purpose. In preceding pages of this book many minor species have been listed and briefly described in connection with those more important, and with which they are closcly related. There are more than a hundred others which were necessarily omitted from former pages. A few of these deserve at least a brief mention, and are listed in the following paragraplis.

Kaeberlinia (Kaberlinia spinosa) is commonly considered a 
curiosity; a tree without a relative in the world, and without leaves, flowers, or fruit. The popular notion is wrong, of course, for no tree is without relatives, and none without leaves, flowers, and fruit, or something that takes their place. The flowers, leaves, and fruit of this tree are small and escape notice of the casual observer, but they exist. Its nearest relative in this country is the paradise tree of Florida and the ailanthus introduced from China. It has a small, thorny, crooked trunk; the wood is dark, turning nearly black with exposure; it is rich with oil; and it is very hard. The species grows in certain places along the Rio Grande. The wood is made into canes, rulers, knife handles, turned articles, and a little furniture of the smaller kinds. The trunks are too small for ordinary sizes of lumber.

GUM Elastic (Bumelia lanuginosa) ranges from Georgia to Texas, and in Florida is called black haw. Children in Texas mix its berries with chewing gum, to increase the quantity, and the name which they apply to it is "gum stretch it." An exuded resin is also used for chewing gum. Trees are sometimes sixty feet high and two in diameter, and a considerable number of logs go to hardwood mills, where they lose their name, and possibly appear as ash lumber, or occasionally as maple. The wood is white, tinged with yellow, and is manufactured into agricultural implements. A scarce and smaller species, known as buckthorn bumelia and ironwood (Bumclia lycioides) covers nearly the same range. From a tree of the same family in southern Asia the gutta percha of commerce is obtained. Other woods of the same family in this country are mastic (Sideroxylon mastichodendron) of south Florida, a tree sometimes sixty feet high and three feet in diameter, useful for boat building; satinleaf (Chrysophyllum monopyrenum), also of Florida, a tree twenty-five feet high and one in diameter, the wood very heavy, hard, and strong; tough bumelia (Bumelia tenax), ranging from South Carolina to Florida, a tree twenty feet high and six inches in diameter, called black haw in some parts of its range; saffron plum or ant's wood (Bumelia angustifolia), growing in Florida and Texas, the trunk twenty feet high and six inches in diameter; wood orange colored, and the fruit sweet; bustic (Dipholis salicifolia), in south Florida, a tree forty feet high and eighteen inches in diameter, with wood exceedingly hard, strong, and heavy, and dark brown or red in color; wild sapodilla or dilly (Mimusops sieberi), a tree of south Florida with rich, very dark brown wood, height of tree twenty feet, diameter one foot.

DWARF Sumach (Rhus copallina) is known by many names. It is distinguished from staghorn sumach by its smooth branches, those of staghorn being hairy. Sumach's chief importance is due to its value as tanning material. Leaves and small branches are used. The family has 
some well-known mombers in other parts of the world, among them the mangoes. The name dwarf sumach is not well selected, for the species is nearly as large as any other sumach. Trees are sometimes thirty feet nigh and ten inches in diametcr. The tree's range extends from New England to Florida and Texas. It reaches its largest size west of the Mississippi river. In the East and North it is usually a shrub. Trees of largest size are not believed to exceed fifty years in age. The wood is richly striped with yellow and black. Balls turned of it, seven inches in diameter, are used for newel-post ornaments, and smaller balls are made for use in darning stockings. Cups are turned on the lathe, and the bright stripes in the wood give the wares a striking appearance. It was formerly much employed for spiles in tapping maple trees for sugar making. Staghorn sumach (Rhus hirta) is of a different species but of the same genus. Its range extends from New Brunswick nearly to the Mississippi river. Its name refers to the down on the young branches resembling the velvet on the horns of a deer at certain seasons. The tree is known as Virginia sumach and hairy sumach. Its compound leaves are sometimes two feet long--two or three times the size of dwarf sumach's. Trunks have been reported forty feet high and more than a foot through. The uses of this wood are the same as of dwarf sumach, including tanning. It is more abundant east than west of the Alleghanies. Poisonwood (Rhus metopium) belongs to the same family. It is known in Florida as doctor gum, hog plum, coral sumach, bumwood, and mountain manchineel. The juice is exceedingly poisonous, and gum produced by wounding the bark is reported to have medicinal value. Trees are sometimes forty feet high and two feet in diameter. The American smoke tree (Cotinus cotinoides) is another member of the sumach family. It is found in the southern states from eastern Tennessee to Texas. It is nowhere common, and its only reported use is as fence posts. Trees may be a foot in diameter and thirty feet high. The wood is a bright clear orange color, and a yellow dye has been manufactured from it. Poison sumach (Rhus vernix) is not the same as poisonwood, though sometimes the two are confounded. It is usually a shrub, and rarely twenty feet high. It is overloaded with names, as might be expected of a plant considered as dangerous as this. Anong its names are poison elder, poison dogwood, swamp sumach, poison oak, poisonwood, poisontree, and thunderwood. It grows from New England to Georgia, and west to Minnesota and Louisiana. It is apt to occur in wet swamps, and Sargent pronounces it "one of the most dangerous plants of the North American flora." A black, lustrous varnish can be made of the acrid poisonous juice, and this may sometime give the species a commercial value. When the skin is poisoned by contact with this tree, 
an effective remedy may be found in a saturated alcoholic solution of acetate of lead, if applied as a wash within an hour or two after the poisoning occurs. A wash with pure alcohol is also effective if applied within an hour. Following either treatment the skin should be thoroughly washed with soap and water. Western sumach (Rhus integrifolia), a closely related California species, is a small evergreen, seldom more than twenty feet high and a foot in diameter. The wood is heavy, hard, and red, is used as fuel, and occasionally in small turnery. The fruit is a berry half an inch long.

CASCARA BUCKTHORN (Rhammus purshiana) is of the buckthorn family, and is known by many names on the Pacific coast where the species is best developed. It grows as far east as Colorado and Texas. Cascara sagrada, its Mexican name, is often used for this tree. It is known also as bearberry, bearwood, yellow-wood, pigeonberry, coffeeberry, bayberry, and California coffee. The tree's usual size is from ten to thirty feet high and twelve to twenty inches in diameter. It is often shrubby, and is more valuable for its bark than its wood. Large quantities are peeled for medicinal uses, and many trees are thus destroyed. A little of the wood is burned as fuel, and some is made into handles. Yellow buckthorn (Rhamnus caroliniana), with a range from New York to Texas, and evergreen buckthorn (Rhamnus crocea), a California species, are closely related to cascara buckthorn, but are of comparatively little importance. Blue myrtle (Ceanothus thyrsiflorus) is a California species, sometimes called wild lilac or blue blossoms. It ranges in height from thirty-five feet, among the redwoods on the Santa Cruz mountains, to only one foot high on some of the wind-swept coasts. The wood is pale yellowish-brown, and is somewhat used for novelties. Tree myrtle (Ceanothus arboreus), often known as lilac, is also a California tree, closely related to blue myrtle, but is of smaller size and of very restricted range. Its prospective value lies more in its bloom than in its wood. Naked-wood (Colubrina reclinata), a Florida species, is of a kindred genus. Trees are sometimes fifty feet high and three in diameter. The wood is hard, very strong, and is dark brown tinged with yellow.

LiGNUM-VITE (Guajacum sanctum) grows in Florida, and a species which is probably the same is found in south Texas along the Rio Grande. In Texas the tree is known as guayacou, which name has come down from the times when the Carib Indians ruled the West Indies. That was their name for the tree. The annual rings are usually too vague and too involved to be counted, but the tree is known to be of slow growth. The wood is pitted and it contains cavities and creases; but the clear wood is very hard and of fine and various colors. It is dark 
green, brown, black, yellow and of mixed colors, and clouded effects, all in the same block. Small pieces of furniture, like bureau cabinets, present attractive combinations of colors. The wood is of such exceeding hardness that it turns, breaks, or batters the carpenter's tools. Candlesticks, egg cups, goblets, vases, checker pieces, dominos, boxes, trays, canes, paper knives, and sonvenirs are manufactured in a small way. Trees attain a height of thirty feet and a diameter of two or more. The compound leaves adhere to the branches until those of the following season appear. The fruit is an orange-colored pod threefourths of an inch long.

PRICKLY ASH (Xanthoxylum clava-herculis). Some know this species as toothache tree, tear-blanket, sting-tongue, and Hercules' club. The wood shows little difference in color between heartwood and sap, and bears some resemblance to buckeye. It takes good polish and some of it looks like birdseye maple, but the figure does not seem to be due to adventitious buds. It has been made into picture frames and looks well. It is a rapid grower, and since its color fits it for the stencil, it might be worthy of consideration for box material. Trees reach a height of twenty-five or thirty feet, and a diameter of a foot or more. Its range extends from Virginia to Texas. Satinwood (Kanthoxylum cribrosum) is of the same genus, but it does not grow north of Florida where it is sometimes called yellow-wood. Mature trees are a foot or more in diameter and twenty-five or thirty-five feet high; wood heavy, exceedingly hard and brittle, but not strong; color light orange. It has some use as furniture material, and for certain classes of handles which need not be strong. Wild lime (Xanthoxylum fagara) is a similar tree, growing in both Florida and Texas, but it is of small size. Hoptree (Ptelea trifoliata) is another member of the family. Its fruit is sometimes substituted for hops for brewing beer. It is known also as wafer ash, wahoo, and quinine tree; the last name being due to its bitter bark. It grows from Canada to Florida, and west to New Mexico, and seldom exceeds twenty feet in height. Baretta (Helictta parvifolia) which occurs as a small tree in southern Texas, is a near relative. Torchwood (Amyris maritima), so named because of its fine properties as fuel, grows in southern Florida, sometimes reaching a height of forty feet and a diameter of one. Canotia (Canotia holacantha) is a sinall, scarce trec of Arizona and California and has fine-grained, rich brown wood.

NANNYBERRY (Tiburnum prunifolium), known as black haw, sloc, sheepberry, and stagbush, grows from Connecticut to Oklalıma and is usually a shrub which springs up along highways and hedges, but it sometimes reaches a height of twenty feet and a diameter of eight inches. It is valuable in some localities in the inanufacture of canes and unt- 
brella sticks. Rusty nannyberry (Viburnum rufotomentosum) is a similar species, but attains a larger size, and grows from Virginia to Texas. The wood may be known by its disagreeable odor. Sheepberry (Vibernum lentago) has a more northern range, from Quebec to Saskatchewan, and south along the mountains to Georgia.

Blue Elder (Sambucus glauca) is one of three tree elders in the United States, the others being Mexican elder (Sambucus mexicana) and red-berried elder (Sambucus callicarpa). They are ornamental rather than useful. The three species occur on the Pacific coast. The largest recorded size of an elder was forty feet high and twenty-eight inches in diameter. Its age was about fifty years.

FRINGE TREE (Chionanthus virginica) is known also as white fringe, American fringe, white ash, old man's beard, flowering ash, and sunflower tree. Its natural range extends from Pennsylvania to Florida and west to Texas, but it has been widely planted in this country and Europe. It is seldom more than twenty feet high and eight inches in diameter. The bark possesses medicinal value. Devilwood (Osmanthus americanus) belongs to the same family, but to a different genus. It grows from North Carolina to Florida and west to Louisiana. The largest trunks are a foot in diameter and forty feet high. The wood is strong, heavy, hard, dark brown, and difficult to work.

BLACK IRONwood (Rhamnidium forreum) of Florida is among the heaviest, probably is the heaviest, wood of the United States. It weighs $\$ 1.14$ pounds per cubic foot, and when a hundred pounds of the wood is burned, it leaves eight pounds of ashes-the highest in ash of all woods of the United States. Its fuel value is very high. Trees are small, seldom more than thirty feet high and six inches in diameter. Bluewood (Condalia oborata) is a related Texas species, called also log. wood and purple haw. It produces heavy, hard, close-grained wood, light red in color. Trees six inches in diameter and twenty-five feet high are fully up to the average. Along the lower Rio Grande it forms dense, tangled thickets. Red ironwood (Reynosia latifolia) of southern Florida belongs to a related species, and is sometimes called darling plum, because its purple fruit is edible. The tree is small, the wood heavy, hard, strong, and of rich brown color. White ironwood (Hypelate trifoliata) belongs to a different family. It occurs in Florida where trees are sometimes thirty-five feet high and eighteen inches in diameter. The heavy, hard, rich brown wood is durable in contact with the ground, and is used for fence posts, handles, and boats. Inkwood (Exothea paniculata) is of the same family as white ironwood but of a different genus. It is also a Florida species and is known in some localities as ironwood. The tree is occasionally a foot in diameter and forty feet 
high, wood very hard, heavy, and strong, and bright red in color. It is used by boat builders, for wharfs, and as handle wood.

Cinnamon BARK (Canella winterana), also called whitewood and wild cinnamon, is a south Florida species seldom more than twenty-five feet high and ten inches in diameter. The wood is exceedingly heavy, hard, and strong, and of dark reddish-brown color. The wild cinnamon bark of commerce comes from this tree.

Joewood (Jaquinia armillaris) grows in the Florida everglades. The dark and beautiful medullary rays of this wood may sometime make it valuable for turnery and small novelties. Trunks seldom exceed six or seven inches in diameter. Marlberry (Icacorea paniculata) belongs in the same family with joewood. Trunks are small, but the hard, rich brown wood is beautifully marked with dark medullary rays.

Crabwood (Gymnanthes lucida) is known chiefly by the fine canes made of it. The tree occurs in southern Florida where it is sometimes known as poisonwood. It is dark brown, streaked with yellow. Trunks more than eight inches in diameter are unusual. Manchineel (Hippomane mancinella) is of the same family, and occurs in Florida. The wood is light and soft.

Singleleaf Pinon (Pinus monophylla). This is the only pine in this country with single needles. They are one and one-half inches long, and are curved like the old fashioned sewing awl used by shoemakers. The needles fall during the fourth and fifth years. The cones are one and one-half or two and one-half inches long. The trees are small, averaging fifteen or twenty feet high and eight or twelve inches in diameter. Its range covers portions of Utah, Arizona, Nevada, and California, but it occupies dry, sterile regions as nearly under desert conditions as can be found in this country. The tree maintains a foothold on the eastern slope of the Sierra Nevada mountains at an altitude of 9,000 feet and it descends into the Colorado desert in California at an elevation of 2,000 feet. It endures winter cold below zero on the mountains, and summer temperature of 122 in the Mojave desert. It is fitted to live in a dry, sterile region. The leaves are smail and the branches bear few of them. The thin foliage uses little water, which is a fortunate circumstance, for there is little to use. Slow growth is the result. The trunk often adds less than an ineh to its diameter in twenty years. The trees form very open forest, resembling old orehards, and the greenness usually associated with pine landscapes is gencrally wanting. The singleleaf pine has filled an important place in the development of the region, and furnishes an example of the great service which a small, crooked tree can give when it is the only one to be had. Mines worth nuany millions of dollars have bcen worked with little of any other wood. 
This has been the fuel for the kitchen, the engine house, the blacksmith shop. It has supplied the props, posts, stulls, and lagging for the underground operations. Fences for stock corrals, sheds, stables, cabins, and bridges have been constructed of the small, crooked trunks and the distorted limbs, when no other wood could be had in fifty or a hundred miles. Extensive tracts have been cut clean in the vicinity of mines. The product of the singleleaf pine forest cannot be measured in board or $\log$ feet, because of the smallness of the trunks and branches, but by the cord. The wood is medium heavy, rather high in fuel value, very weak, brittle, and soft. The resin passages are few and small, color yellow or light brown, the sapwood nearly white. In contact with the soil the wood is not durable, but its principal use has been in a very dry climate, and it lasts well there. It is the most important of the nut pines.

It produces enormous crops which are larger some years than others. John Muir believed that the singleleaf pinon's annual nut yield surpassed California's yield of wheat. Only a small part of the nut crop is ever put to use by man. Scattered over mountains, mesas, and deserts, 100,000 square miles in extent, most of the nuts fall and decay, though the animals of the rocks and sands, and the birds of the air live on them while they last. The Indians of the region long looked upon the nut crop, as the Egyptians upon the overflow of the Nile-a guarantee against famine. The Indians are not so dependent on the nuts now as formerly because scattered settlements throughout the region supply other sources of food. Many nuts are still gathered, and are sold in stores from San Francisco to Denver. They look like peanuts, but are richer in oil, and if eaten raw they speedily cloy the appetite. The Indians usually roast them, and frequently crush them into meal. When the harvest is ripe the Indians gather from all sides and camp during a month or more, thrash the cones from the trees with poles, extract the nuts, and keep up the operation until all present needs are supplied, and every available basket is filled for future use. The packhorses and burros of the mining country in Nevada where this pine grows, acquire a liking for the nuts. They are as nourishing as oats, and the pack animals like them better. Indians do considerable business collecting the nuts and selling them by the gunny sack to pack trains, for horse feed. A single Indian will sonietimes gather thirty or forty bushels, for which he can get a dollar a bushel when he has carried them to market.

The singleleaf pine's future will be about as its past has been, as far as can now be foreseen. Little planting will ever be done, nor is it necessary. Nature plants all that the sterile soil will support. It is of 
too slow growth to tempt the forester. A century is required to produce a fence post, and 200 years for a crosstie. Forest fires do little injury, for the ground is generally so bare that fire dies out of its own accord in a short distance. The tree can never be planted much for ornament. Even if it would grow ontside of its dry habitat, it possesses no more beauty than a half-dead apple tree in a neglected orchard. The trunks resemble mesquite in Texas; but the Texas tree is redeemed by the beauty of its foliage in summer, while the foliage of the singleleaf pine is so pale and thin that it attracts no attention.

Carolina Hemlock (Tsuga caroliniana) is of far less importance than its northern neighbor which goes south along the Appalachian mountains to meet it. The two species mingle on the mountain tops from southwestern Virginia to northern Georgia. The Carolina hemlock is usually confined to altitudes 2,500 or 3,000 feet above sea level, and prefers rocky banks of streams. It does not usually occur in dense stands of even moderate size, as the northern hemlock does. A few trees in clumps or scattered solitary represent its habit of growth. Typical development of the species occurs on the headwaters of the Savannah river in South Carolina. For a long time this hemlock and its northern relative were supposed to be the same. Botanists did not formerly separate them, and the mountaineers do not generally do so now. There are several differences, however, which may be observed upon close examination, and by comparing tle two species. The Carolina hemlock's leaves have more rows of stomata and therefore are a little whiter on the under side. The leaves are also longer, and the cones are larger. The tree does not attain the dimensions of the northern species, its average size being forty or fifty feet in height, and two or less in dianteter. It is not abundant, and has never been and never can be much used for commercial purposes. It is an attractive park tree and has been widely planted.

Lmber P1Ne (Pinus flexilis) owes its name to its long, drooping branches. It is often called white pine, Rocky Mountain white pine, western white pine, and limber twig pine. It is not the tree usually called western white pine (Pinus monticola), but is a high mountain species, ranging from the Rocky Mountains of Montana to western Texas: it grows also on the mountains of Arizona, Utah, Nevada, and California. The upper limit of its range in the Sierra Nevadas is $[2,000$ feet. It descends to an altitude of only 4,000 feet in the Rocky Mountains, and forms open, scattered stands of round-topped trees of little commercial value, and is usually associated with western yellow pine or Rocky Mountain cedar. At altitudes of $\$, 500$ or 10,000 feet it is more stunted, and associates witl Lyall larch and other high mountain 
species. Intermediate between its lower and its higher belts it produces a little merchantable lumber. The wood is light, soft, medium brittle, of slow growth and with narrow bands of summerwood. The resin passages are large and numerous. The wood, when a choice trunk is found, resembles that of eastern white pine; but generally the trunks are inferior in size and form. The heartwood is light, clear yellow, the sapwood nearly white. Trees range in height from thirty to fifty feet, and one to three in diameter. A sawlog ten feet long is about as much as can be had from a trunk, and of course, when compared with commercial trees, it holds a low place; but in some remote mountain regions it is the principal wood available, and to that extent it is of importance. When green, the wood is very heavy, and sometimes will sink. It is used for posts and in the mines. The farmer seasons posts on the stump. He peels the trees six months before cutting them. They immediately exude resin over the whole peeled surface, and the tree quickly dies. At the end of six months the trunk is seasoned, and is cut for posts. The ends are smeared with resin. Such posts have lasted twenty years with little decay. Railroads make ties of fire-killed limber pine. Charcoal burners use it also. The growing trees resist the fumes of copper smelters better than any other species associated with it.

Parry Pinon (Pinus quadrifolia). The names by which this tree is known in the region where it grows indicate one of its leading features, a bearer of nuts. It is called nut pine, Parry's nut pine, pinon, and Mexican pinon. The nuts exceed half an inch in length, are reddish-brown, and the wings narrow and small. They cannot carry the nuts far, and the species is not spreading. Reproduction takes place beneath the parent tree, and frequently the old trunk dies without having succeeded in planting a single seed to perpetuate the species. The nuts are nutritious, and are eagerly sought by birds, rodents, and larger animals, including human beings. The cones are seldom two inches long, and the leaves are little more than an inch. They are usually in clusters of four, and fall the third year. The tree's characteristics betray its enviromment. It is fitted for dry, sterile situations. Its abnormally large seeds provide food for the seedling until it can get its rootlets deep enough in the poor soil to get a start. The Parry pinon's range is confined to the extreme southern part of California and to Lower California where it occupies arid mesas and low mountain slopes. It is common on Santa Rosa mountains, California, at an elevation of 5,000 feet. It is too small to be worth much for lumber, the usual height being less than thirty feet, the trunk diameter from ten to sixteen inches. The wood is medium heavy, weak, low in elasticity, but rather high in fuel value. The annual rings are very narrow, and the thin bands of summerwood are not conspicuous. It is one of the slowest-growing of the pines, and probably it is surpassed in that respect by lodgepole pine alone. Its only uses are fuel, a few fence posts, and small ranch timbers.

Knobcone Pine (Pinus attenuata). This pine is known as prickly-cone pine, sun-loving pine, sunny-slope pine, narrow-cone pine, and knobcone pine. Its leaves are in clusters of three, and are four and five inches long. The cones are from three to six inches long. They often adhere to the branches thirty or forty years, and may 
become entirely overgrown and hidden by bark and wood-hence the name knobcone. The wood is light, soft, weak, brittle; the growth is slow and the annual rings are narrow. The resin passages are large and numerous. The average height of the mature knobcone pine is from twenty-five to forty feet, and the trunk diameter eight to twelve inches. It grows on dry mountain regions of California and Oregon, and is not a valuable timber tree. A little is occasionally sawed in small dimensions, but the principal use is for mine props. It is short lived, even when it does not fall a victim to accidents. In accordance with the provisions of nature, it prepares for early death by bearing seeds when only five or six feet high. The cones act as storing places for seed, sometimes during the whole life of the tree. Thus a knobcone pine may hold in its tightly closed cones the seeds produced during the tree's whole life. When death overtakes it, the cones open and scatter the seeds. The accumulated crops may total three or four pounds of secds. Fire usually kills the trees, but the heat is generally not sufficient to burn the cones. When they open soon after the fire has passed, they find a bared mineral soil ready to receive them. The knobcone pine lives in adversity and usually dies by violence.

Arizona PINe (Pinus arizonica). This tree is confined to the mountains of southern Arizona at from 6,000 to 8,000 feet above sea level. It is the prevailing pine near the summit of the Santa Catalina mountains. Nuch of the timber is of small size and yields only inferior lumber; but when larger trunks are obtainable, the lumber grades with western yellow pine, and goes to market with it. Arizona pine is medium light, soft, not strong, rather brittle, of slow growth, with the summerwood comparatively broad and very resinous; color, light red or of ten yellow, the sapwood lighter yellow or white. The leaves are in clusters of five and are tufted at the ends of the branches. They are from fise to seven inches long, and are deciduous the third year.

DWARF JUNIPER (Juniperus communis) is an interesting tree because its range practically runs round the world in the north temperate and frigid zones, but in the United States the only reported use of the wood is in southern Illinois where it grows on the limestone hills and is occasionally cut for fence posts. In nearly all other parts of its range in this country it is little more than a shrub. Some trees with a spread of limbs twenty feet across are only three or four feet high. The seeds mature slowly, not ripening until the third year; and they often hang a year or two after ripening. The wood is narrow-ringed, hard, very durable in contact with the soil, of light brown color, with pale sapwood. In Europe the aromatic fruit of this tree is used in large quantities to flavor gin, but there is no report that it has becn so employed in this country. In the United States it occurs in Pennsylvania and northward, and northward from Illinois, and throughout the Rocky Mountains north of Texas. It occurs on the Pacific coast north of California. It grows from Greenland to Alaska, and through Siberia, and northern Europe.

Drooping JUniper ( $J$ uniperus faccida) is confined in the United States to the Chisos mountains in western Texas, but grows in Mexico. The tree attains a height of thirty feet and a diameter of one. Its name refers to its graceful branches. It lias been planted in this country less than in soththern Europe and northern Africa. The bark is light cinnamon-brown, and easily separates in loose, papery scales. The lumberman will never go far to procure drooping juniper logs. They are too small, scarce, and of form too poor. The wood has the usual charactcristics of the junipers which grow in western mountains. It looks more like alligator juniper than any other. In Texas it goes to the lathe to be manufactured into candlesticks, pin boxes, picture molding, aud other articles of turnery. 
Utah JUNIPER (Juniperus utahensis) is known also as juniper, desert juniper, and western red cedar. The last name is properly applied to a different tree in Washington and Oregon. The Utah juniper occupies the great basin between the Rocky Mountains and the Sierra Nevadas, particularly in Utah, Nevada, California, Arizona, and Colorado. It thrives best about 8,000 feet above the sea, but descends to 5,000 feet or less. It is a desert tree, usually small, often a mere shrub, but occasionally attaining a height of twenty feet or more and a diameter of one or two. The trunk is irregular in shape, and is generally deeply fluted. The wood is light brown in color, though it varies greatly in different specimens, and even in the same tree. The sapwood is thick and nearly white. The tree has not been much used except for fence posts and fuel. The Indians of the region eat the berries raw or bake them in cakes. 


\section{INDEX TO COMMON NAMES}

\begin{tabular}{|c|c|}
\hline Acacia............ & 53.5 \\
\hline African mahogany ....... & 4633 \\
\hline Ailanthus ........... & 676 \\
\hline Alaska cypress. . . . . . . . . & 121 \\
\hline Alaska pine .......... & 193 \\
\hline Alder............... & 589 \\
\hline Algaroba............ & 559 \\
\hline Alleghany sloe ....... & 622 \\
\hline Alligator juniper ..... & 111 \\
\hline Alligat or-wood........ & 325 \\
\hline Almondleaf willow & 471 \\
\hline Aloe-leaf yucca .... & 693 \\
\hline Alpine fir ............ & 166 \\
\hline Alpine larch. ........ & 88 \\
\hline Alpine spruce. . . . . . . & 195 \\
\hline Alpine western spruce.... & 196 \\
\hline Alpine whitebark pine ..... & 37 \\
\hline Alternate-leaved dogwood. & 526 \\
\hline Alvord oak.............. & 220 \\
\hline 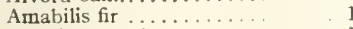 & 165 \\
\hline American apple .......... & 553 \\
\hline Amerjcan arborvitae ..... & 97 \\
\hline 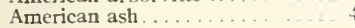 & 409 \\
\hline American crab.... ........... & 453 \\
\hline American fringe ........... & 700 \\
\hline 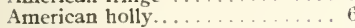 & 643 \\
\hline 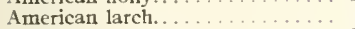 & SO \\
\hline American linden. . . . . . . . . . & 637 \\
\hline American planert ree . . . . . . . . & 397 \\
\hline American smoke-tree . . . . . . . . . & 697 \\
\hline Andromeda $\ldots \ldots \ldots \ldots \ldots . . . .$. & 526 \\
\hline Angelica-tree .......... & 676 \\
\hline 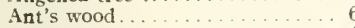 & 696 \\
\hline Apple haw............... & 459 \\
\hline Arhorvitæ. . . . . . . . . . & 97 \\
\hline Arizona cork fir........... & 154 \\
\hline Arizona cypress... . . . . . . & 142 \\
\hline Arizona madrona ... & 663 \\
\hline Arizona palm.............. & 693 \\
\hline 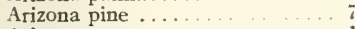 & 705 \\
\hline Arizona spruce . . . . . . . . . . & 135 \\
\hline Arizona sycamore. . ........ & 610 \\
\hline Arizona white oak .... & 218 \\
\hline 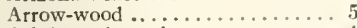 & 507 \\
\hline Ash-leaved maple .......... & 445 \\
\hline Aspen.............. & 675 \\
\hline Aspen-leaf ........... & 675 \\
\hline August plum............ & 621 \\
\hline Bald cypress . . . . . . . . . & 139 \\
\hline Balm of Gilead ....... & 673 \\
\hline 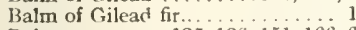 & 145 \\
\hline Balsam ......135, 136, 151, 166, 6 & 673 \\
\hline Balsam fir $\ldots \ldots \ldots \ldots \ldots 145,151,1$ & 159 \\
\hline Balsam poplar . . . . . . & 673 \\
\hline Baltimore oak ....... & 205 \\
\hline Banana .............. & \\
\hline & \\
\hline Barren oak............. & \\
\hline
\end{tabular}

Barren scrub oak ... . ... 2\$3

Bartram oak ... . . . 322

Basket elin... . . . . _ . . 393

Basket oak....... 208, 229

Basket willow ...... . . 472

Basswood ........ . . 637

Bat-tree .......... . 494

Bayberty .......... 698

Bay poplar........... $\quad 337$

Bay-tree ........... _. . 529

Beaded locust ...... . . . . 555

Bearberry........... . . 646, 698

Bear oak.............. . 315

Bearwood. ............. . . 698

Beaver-tree ....... .... 495

Bebb willow........... 471

Beech .......... ... 625

Beetree .......... ...6.6.6. 637

Bell-tree ........ 601

Bellwood .......... . 602

Berlandier ash ...... .... 418

Big huckeye....... . . . . 6149

Big-bud .......... . . 363

Big-bud hickory .... . .. 363

Bigcone pine ......... 68

Bigcone spruce ....... . . . 172

Big cottonwood........... 667

Bigelow willow . ...... . . . 472

Big hickory nut . . . . . . . . 363

Big laurel .......... ... 194

Bigleaf laure]. . . . . . . . . . . 507

Bigleaf maple ... . . . . . . 439

Big pine............ . . . 31

Big shellbark ......... . . 369

Bigtree............ . 175

Big white birch. ...... $5 \mathrm{S3}$

Bilmore ash ......... .. 124

Birch.............. 565

Bird cherry .......... . . 619

Bishop's pine. ......... . . 69

Bitter cherry............. 616

Bitter hickory ......... . . . . 361

Bitternut ........... . 367

Bitternut hickory. ...... 361

Bitter pecan.............3ti1, 375

Bitter walnut .......... 361

Bitter waternut........ . . 374

Bitterwood................ . . . . 6

Black ash . . . . . $415,416,423,445$

Blackbark pine............. 75

Black birch ........56.5,577,580

Black calabash .............. 475

Black cherry ..............613

Black cottonwood....... 667, 6it9, 679

Black gum ............. 159,331

Black liaw ................. 460

I3lack hickory . . . . . .36t, 367, 696, 699

Black ironwood. ............ T00 
Black jack................. 283

Black jack oak .............. 291

Black larch ................ 80

Black limetree. . . . . . . . . . . . 637

Black locust... . . . . . . . . . .535, 541

Black mangrove ... . . . . . . . . . 688

Black maple. . . . . . . . . . . . . . $\$ 47$

Black mulberry ... . . . . . . . . 513

Black oak... . . . . . 259, 260, 271,277

Black olivetree ............. 688

Black pine.......... $63,67,70,75$

Black poplar ............... 681

Black slash pine ............. . 55

Black sloe. . . . . . . . . . . . . . . 621

Black spruce . . . . . . . . . . . . . . . 129

Black thorn ... . . . . . . . . . . 459

Blacktree..................68s

Black walnut. . . . . . . . . . . . . 343

Black willow ................ 469

Black wood ................... 688

Bleeding-heart tree... . . . . . . . . . . 500

Blister pine ............ 145, 151

Blue ash $\ldots \ldots \ldots \ldots \ldots \ldots \ldots 417,422$

Blue beech .........

Blue birch ............5t;.5, 577,5 55

Blue dogrwood. . . . . . . . . . . . . . . 526

Blue elder................. 700

Blue jack oak ................ 285

Blue myrtle . . . . . . . . . . . . . . . . . . 698

Blue oak... . . . . . . . . 205, 213, 226

Blue spruce ................. 136

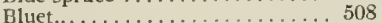

Bluewood ................ 700

Bodark ................. 511

Bodock .................... . 511

Bog spruce. . . . . . . . . . . . . . 130

Bois d'arc ................. 511

Bois inconnu. . . . . . . . . . . . . 405

Bottom shellbark ... . . . . . . 369

Bow-wood ............... 511

Box elder .............. .415,601

Box oak. . . . . . . . . . . . . . . 223

Box white oak.................. 223

Boxwood ................. 523

Bracted fir .................. 157

Brash oak................. 223

Brewer oak ................ 220

Bristlecone fir .............. 171

Bristlecone pine.............. 19, 38

Broadfruit yucca... . . . . . . . . . 693

Broadleaf maple. . . . . . . . . . . . . 439

Broadleaf willow . . . . . . . . . . . 472

Broom hickory .............. 367

Brown ash................ 423

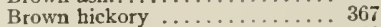

Brown pine ............... 43

Buckeye ... . . . . . . . . . . . . . . 649

Buckthorn bumelia ........... 696

Buckwheat-tree.. . . . . . . . . . . . 502

Bullace plum ................ 621

Bull bay ................... 494

Bull pine $\ldots \ldots \ldots \ldots \ldots \ldots \ldots \ldots 49,75$
Bumwood................ 697

Burning bush................ 499

Burnwood ................ 502

Bur oak .................. 211

Bustic ................... 696

Butternut.................. 349

Buttonball ................ 607

Buttonwood.................. 607

Cabbage palmetto.............. 691

Cabbage-tree. . . . . . . . . . . . . . 691

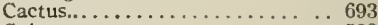

Cajeput... . . . . . . . . . . . . . . 529

Calico-bush ............... 505

Calicowood................... 601

California bay-tree... . . . . . . . . 529

California black oak. ... . . . . . . 285

California blue oak. . . . . . . . . . 229

California box elder . . . . . . . . . 447

California buckeye . . . . . . . . 619,651

California chestnut oak......... 313

California coffee .............. 698

California fan palm. . . . . . . . . 693

California hemlock spruce ....... 193

California holly ............ 645

California juniper... . . . . . . . . 112

California laurel . . . . . . . . . 529, 655

California live oak .......... 307

California nutmeg. . . . . . . . . . . 201

California olive ............. 529

California post cedar . . . . . . . . 109

California red bud............ 549

California red fir. . . . . . . . . . 164

California sassafras ... . . . . . . . . 529

California scrub oak .......... 237

California swamp pine ........ 69

California sycamore . . . . . . . . 609

California tanbark oak... . . . . . 313

California walnut ............ 351

California white oak. ......... 249

California white pine ........ 67

Canada plum ............... 621

Canadian Judas tree... . . . . . . . . . 548

Canadian red pine.......... 61

Canoe birch................ 583

Canoe cedar ................ 115

Canoewood.................. 487

Canotia ..................... 699

Canyon birch. ............. 580

Canyon live oak ............ 308

Carolina cherry ... . . . . . . . 620

Carolina bemlock ........... 703

Carolina pine. ............. 49

Carolina poplar. ............ 667

Cascara buckthorn. . . . . . . . . . . 698

Cascara sagrada . . . . . . . . . 698

Catalpa. ................ 475

Catawba ................. 475

Catawba rhododendron ........ 507

Cat spruce ................ 130

Cedar ............9i, $97,109,118$

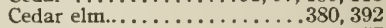

Cedar pine................ 57

Cereuses................... 693 
Chalky leucæna. ............ 562

Chapman oak ............... 208

Chat tahoochee pine ... . . . . . 202

Check pine. .............. . 70

Checkered-barked juniper ...... 111

Cherry birch . . . . . . . . . . . 565,5,580

Chestnut................. 631

Chestnut oak ............241,313

Chickasaw plum ............ 622

Chihuahua pine ........... 76

Chinaberry ............... 665

China-tree .............. 661

Chinquapin ..............6. 631

Chinquapin oak........... . . 247

Chittamwood .............. 602

Cholla ................... 691

Cigartree............... 476

Cinnamon bark. ............ 701

Cinnamon oak. ............. 286;

Clammy locust . . . . . . . . . 537

Clift elm................. $3 \$ 5$

Cocisspur . . . . . . . . . . . 459

Cocoa plum .............. 622

Coffeebean .............. 547

Coffee-berry. ............... 698

Coffeenut .................. 547

Coffeetree................... 547

Colorado blue spruce . . . . . . . . 136

Common catalpa .......... . 475,477

Common thorn ............. 459

Cornel .................... 523

Coral bean............... 551

Coral sumach................ 697

Cork-barked Douglas spruce . . . . 169

Cork elm. . . . . . . . . . . 380, 385, 399

Cork pine ............... 19

Corkwood. . . . . . . . . . . . . 423

Corky elm ... . . . . . . . . . . . 399

Cotton gum............... 337

Cottonwood ...........6667,673

Cotton-tree............... 667

Coulter pine ................. 68

Cowlicks ................... 604

Cow oak. ................ 229

Crab ................... 453

Crab apple ............. 453

Crabwood. ................. 701

Crack willow ............... 472

Creeping pine............. 37

Cuban pine................ $\$ 5$

Cucumber................... 481

Cucumber-tree... . . . . . . . . . 487

Currant-trce... . . . . . . . . . . . . 451

Custard apple ................. 640

Cut-leaved maple ............ 445

Cypress ................70, 139

Dahoon holly............... 645

Darling plum .............. 700

Darlington oak .............. 295

Date plum. ............... 517

Deciduous holly ............. 646

Deer tongue ............... 507

Delmar pine.................... 44
Desert juniper. $\ldots \ldots \ldots \ldots \ldots \ldots \ldots . . .705$

Desert willow. . . . . . .......4 477

Devil's claw ........ ...... 541

Devil's tongue cactus. . . . . . . . 691

Devilwood ................. 700

Digger pine ............... 75

Dilly. . . . . . . . . . . . . . . . . . 696

Doctor gum ............... 697

Dogwood ................... 523

Double fir................... 151

Double spruce. . . . . . . . . . . . . . 130

Douglas fir. . . . . . . . . . . . . . 169

Douglas spruce . . . . . . . . . . . . 169

Douglas-tree ................. 169

Down-cone. .................. 166

Downy basswood ............ 639

Downy-cone subalpine fir . . . . . 166

Downy poplar ...............669 669

Drooping juniper . . . . . . . . . 705

Drummond maple............. 436

Duck oak ................ 320

Durand oak .................. 208

Dwarf ash ................ 412

Dwarf chest nut oak............ 247

Dwarf cypress. . . . . . . . . . . . 181

Dwarf juniper............... . . 705

Dwarf maple............. 442,446

Dwarf marine pine. . . . . . . . . . 69

Dwarf rose bay. ............. 507

Dwarf sumach . . . . . . . . . . . . 696

Dwarf walnut ................. 351

Dyer's oak ................. 271

Ebony....................... 517

Elder................... . 700

Elderleaf ash. ............. 416

Emory oak.................. 238

Engelmann oak. ............. 231

Engelmann spruce. . . . . . . . . 135

English cornel .............. 526

English dogwood . . . . . . . . . . . 526

Eriglish hawthorn. .......... 460

Europeat alder. . . . . . . . . . . . . 592

Evergreen buckthorn. . . . . . . . 698

Evergreen cherry ........... 620

Evergreen magnolia .........451,493

Eysenhardtia .............. 526

False acacia. . . . . . . . . . 535

False box-dogwood............ 523

False mahogany ............. 531

False shagbark ............ 346

Fanleaf palm ............... 693

Farkleberry.................. 508

Fat pine. ................ 43

Feather-cone red fir. .......... 157

Feather-leaf. ............... 97

Fetid buckeyc. ................ 651

Fetid yew... .............. 202

Fighting wood ................. 199

Finger-cone pine. ............ 25

Fir balsam. .............. 151

Fire cherry................... 619

Firewood .................. 502

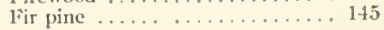


Florida asb. ............... $\$ 12$

Florida basswood ............ 639

Florida boxwood... . . . . . . . . . . 501

Florida buttonwood ........... 688

Florida cat's claw . . . . . . . . . . 538

Florida mahogany ........... 531

Florida maple . . . . . . . . . . . . 435

Florida pine ............... 43

Florida torteya... . . . . . . . . . 202

Florida yew .................201

Flowering ash ............. 700

Flowering cornel ............. 523

Flowering dogwood . . . . . . . 523

Flowering willow............ 477

Forked-leaf blackjack . . . . . . . .

Forked-leaf white oak ........ 217

Four-winged halesia. . . . . . . . 601

Foxtail pine .......... 19, 38, 39

Fragrant crab . . . . . . . . . . . . 453

Fraser fir ................. 151

Fraser umbrella ............481, 495

Fremont cottonwood. . . . . . 667, 670

Fremontia ............... 400

Frijolito ................ 551

Fringe ash .............. 412

Fringetree .............. 700

Gambel oak... .............. 214

Garden wild plum.............. 622

Georgia oak. ............... 267

Georgia pine ............... 43

Giant arborvitæ .............. 115

Giant cactus ................ 693

Gigantic cedar. .............. 115

Glaucus willow .............. 472

Glossyleaf willow ............. 496

Golden cup oak. . . . . . . . . . . . . 308

Golden fir .................... 164

Goldenleaf chinquapin ........ 633

Gooseberry.... . . . . . . . . . . . . 508

Goose plum ............621, 622

Gopherwood................... 553

Gowen cypress. . . . . . . . . . . . . . . 184

Grand fir .................. 163

Gray birch. ................. . . 555

Gray elm ............... 380

Gray pine. ................. 75

Great California fir ............ 163

Great laurel. ............ 494, 505

Great western larch . . . . . . . . . . 86

Green ash. . . . . . . . . . . . . . 422

Greenbark acacia ............. 555

Green osier... . . . . . . . . . . . 526

Gregg ash. ................411

Guayacon ................. 698

Gum ...................... 325

Gum elastic. . . . . . . . . . . . . . . 696

Gum stretch it ............... 696

Gum-tree ................. 325

Gyminda ............... 49

Hackberry.................. 403

Hackmatack ............80, 86
Hack-tree. . . . . . . . . . . . . . 403

Hairy balm of Gilead. . . . . . . . 674

Hardbark hickory... . . . . . . . . 363

Hardhack ..... . . . . . . . . 595

Hard maple. . . . . . . . . . . . 427

Hard pine............43,61, 63

Hardshell. . . . . . . . . . . . . . . . 363

Hardwoods................ 4

Hardy catalpa. . . . . . . . . . . . 475

Haw .................. 459

Hawthorn. . . . . . . . . . . . 459

Healing balsam ............... 151

Heart-leaved thorn............ 460

Heart pine. .............. 43

Heartwood. .............. 5

Heavy pine ............. 67

Heavy-wooded pine............ 67

Hedge. . . . . . . . . . . . . . 511

Hedge-tree. . . . . . . . . . . . . 511

Hemlock... . . . . . . . . . . . . 187

Hemlock spruce . . . . . . . 187, 193, 195

Hercules' club ... . . . . . . .676, 699

Hickory . . . . . . . . . . . . . 357

Hickory elm. . . . . . . . . . . . . . . 385

Hickory oak. . . . . . . . . . . . . 308

Hickory pine............... 38,52

Hickory poplar. . . . . . . . . . . . . 487

High-ground willow oak ......... 286

Highland oak. . . . . . . . . . . 296

Hog haw. . . . . . . . . . . . . . . 459

Hog plum...............621, 697

Holly... . . . . . . . . . . . . . . . 643

Holly-leaf cherry. . . . . . . . . . 616

Honey locust ...........535, 541, 559

Honey-shucks locust ......... 541

Honey pod. . . . . . . . . . . . . . 559

Hooker's oak. . . . . . . . . . . . . 249

Hooker willow. . . . . . . . . . . 472

Hoop ash. . . . . . . . . . . . . 403,415

Hooptree . . . . . . . . . . . . . . 415

Hop hornbeam . . . . . . . . . . . 595

Hoptree . . . . . . . . . . . . . . . . 699

Hornbeam ..............595, 627

Horsebean ... . . . . . . . . . . . 549

Horse chestnut . . . . . . . . . . 651

Horse plum ............... 621

Huajillo ... . . . . . . . . . . . . 538

Huckleberry.................. 508

Huckleberry oak. . . . . . . . . . . 309

Incense cedar . . . . . . . . . . . . . . 109

Indian bean. . . . . . . . . . . . 476

Indian cherry .............. 451

Indian pear ..............451

Indigo thorn ............... 556

Inkwood ................ 700

lowa crab........ . . . . . . . 454

Iron oak ..............223, 308

Ironwood. ...501, $502,559, \dot{5} 9 \dot{5}, 627,696$

Ivy .................. 505

Jack oak... . . . . . . . . . . . . 319

Jack pine. . . . . . . . . . . . . . . . 69

Jamaica dogwood ........... 526,550

Jeffrey pine .............. 75 
Jersey pine......... .... 57

Joewood. ........... .... 701

Joshua-tree . . . . . . . . . . . . . 693

Judas-trce ................. 548

Juneberry................... 551 Juniper .......7( $, 91,99,109,118,706$

Juniper-bush............... 91

Juniper cedar................. 99

Juniper-tree . . . . . . . . . . . 403

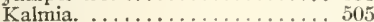

Kenai birch.............565,585

Kingnut................... 369

Kingtree. .................. . . 51

Knobcone pine . . . . . . . . . . . 704

Knowlton hornbeam . . . . . . . . 598

Koberlinia................ 697

Lanceleaf alder. . . . . . . . . . . . . . . . . 592

Lanceleaf cottonwood . . . . 667,670

Lancewood... . . . . . . . . . . . . 657

Larch . . . . . . . . . . . 79,165

Large buckeye............. 649

Largeleaf umbrella ......... \$\$1, 483

Large poplar ...............675

Largetooth aspen . . . . . . . 667,675

Laurel . . . . . . . . . 494, 505,507,529

Laurel bay ... . . . . . . . . . . . . . . 494

Laurel cherry. . . . . . . . . . . . . . 620

Laurel-leaved niagnolia. . . . . . 494

Laurel oak . . . . . . . . . . . . 29. 295, 319

Laurel-tree ... . . . . . . . . . . . . 531

Lea oak .................. 292

Leathet leaf ash. . . . . . . . . . . 418

Leatherwood.......... . . . 400,502

Leucæna ................... 562

Leverwood ................... 595

Lignum-vitæ . . . . . . . . . . . . 698

Lilac. ........................ 698

Limber pine .......... . . 19, 703

Limber-twig pine . . . . . . . . . 703

Linn .................6. 637

Liquidamber . . . . . . . . . . . . 325

Little shagbark ............ 346

Little sugar pine. . . . . . . . . . 25

Little walnut ... . . . . . . . . . . . 351

Live oak. ...... . . . . 253,313

Loblolly pine. ......... 55

Locust. . . . . . . . . . . . . . . . . . 535

Lodgepole pine ............ 73

Logwood ................... . . 700

Lombardy poplar. . . . . . . . . . 68 6

Longcone pine . ............ 68

Longleaf pine.............. 43

Longleaf service . . . . . . . . . 452

Longleaf willow... . . . . . . . . . . 496

Longleaved pine............. 63

Longchat .............. (i3

Longshucks pine ............ 55

Longstalk willow. . . . . . . . . 471

Longstraw pine ............ . 55

Lovely fir ................. 165

Lovely red fir ................. 165

Lowland spruce pinc ......... 51

Low maple. ................ 435
Lyall willow.......... 496

Lynn .................. . 637

Mackenzie willow .......... 472

Macnab cypress... . . . . . . . . . . 178

Madrona..................66 661

Magnificent fir ............. . If If.

Magnolia.................. 494

Mahogany ............ $[63,5.17$

Mahogany birch ............ 565

Manchineel................. 701

Mangrove ................ 685

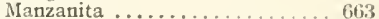

Maple .................... 439

Marlberry. ............... 701

Mastic ...................... 696

Maul oak ............... . 308

May cherry ................ 451

May haw .................. 459

Meadow pine............. .45, 55

Menzies' spruce ... . . . . . . . . . 133

Mesquite................559,562

Mexican cottonwood ........667, 669

Mexican elder ............... 700

Mexican madrona ................ 663

Mexican mulberry.............. 514

Mexican palmetto. ............ 692

Mexican persimmon ........... 517

Mexican pinon .......... 19, 33, 704

Mexican walnut.............. 351

Mexican white pine .......... 19

Michaux basswood. . . . . . . . . . . . 639

Mimosa ..................... 562

Minor species .................. . 695

Missouri willow. ............. 473

Mocker nut ............. . 356,363

Mocker nut hickory ........... 363

Mock olive ................ 620

Mock orange .............511,620

Mohave yicca ................693

Monterey cypress .............. I 14

IIonterey pine ........... 69

Hoose elm .............. . 39I

Moose maple .............. I35

Morehus oak ............. 297

Mountain alder. . . . . . . . . . . 5 50 ?

Monntain ash........... 111, 451,675

Mountain balsam . . . . . . . 151, 166

Mountain birch. . . . . . . . . . . 5 5 )

Mountain cedat. ....... . I11

Mountain elm .......... 399

Mountain hemlock ...... 195

Mountain holty............. 645

Mountain ivy............ . 505

Mountain juniper . . . . . . . . . . 99

Mountain laurel. . . . . . . . . 505, 529

Mountain mahogany .... $\quad 199,465$

Mountain manchined..... ... 697

Mountain maple ....... $\quad[3.5,441$

Mountain pine. ........ 25

Mountain spruce. ... . . . . . . . . 135

Mountain white oak. ......... 213

Mulberry ................. 513

Myrtleberry. ............... 508 
Myrtle-tree... . . . . . . . . . . . . 529

Myrtle oak. . . . . . . . . . . . . 297

Nakedwood ................. 698

Narrowberry ... . . . . . . . . . . 699

Narrowcone pine... . . . . . . . . 704

Narrowleaf cottonwood. . . . 667, 669

Narrowleaf crab ............. 453

Narrowleaf willow. . . . . . . . . . 496

Native plum .............66 621

Necklace poplar............. 667

Netleaf oak ................ 219

Nettle-tree ............... 403

New England boxwood........ 523

Newcastle thorn ... . . . . . . . . 459

New Mexican locust ... . . . . . . . 537

New Mexican pinon........... 28

Noble fir ................. 157

Nootka cypress. ............. 121

North American red spruce. . . . . 127

North Carolina pine ... . . . . . . . 49

North Carolina shagbark hickory. 376

Northern cork elm ........... 385

Northern spruce pine ......... 19

Northern white cedar.......... 97

Norway pine ............... 61

Nutmeg hickory ............ 374

Nutpine $\ldots \ldots \ldots \ldots \ldots 28,33,68,704$

Nuttall willow ............. 472

Oak-barked cedar. . . . . . . . . 111

Obispo pine................ 69

Ohio buckeye. . . . . . . . . 649,651

Oldfield birch............... $5 \$ 55$

Oldfield pine .............. 49

Old man's beard. ........... 700

Olivetree. . . . . . . . . . . . . . . 337

One-berry... . . . . . . . . . . . . . . . 403

One-seed juniper ............. . 99

Opossum wood ............. 601

Opuntias...................694

Oregon ash................ 421

Oregon balsam .............. 166

Oregon crabapple... . . . . . . . . 454

Oregon fir.................. 163

Oregon maple .............. . 439

Oregon oak ................ 235

Oregon pine. . . . . . . . . . . . . . 169

Oregon white oak. .......... 235

Oreodaphne .............. 529

Overcup oak ............. 217. 223

Osage appletree............. 511

Osage orange. ............. 511

Osier willow ............... 496

Pacific post oak............. 235

Pacific yew . . . . . . . . . . . . . . . 199

Pale-leaf hickory... . . . . . . . . . 345

Palmet oak .............. 310

Palms..................... 691

Palmetto ................. 691

Palo blanco ................ 406

Palo verde. . . . . . . . . . . . . . 556

Paper birch . . . . . . . . . . . 565, 583

Paper mulberry... . . . . . . . . . . 514

Paradise-tree. ............ 676
Parry nut pine ...... . . 19, 704

Parry pinon. ............... 703

Parry's spruce. . . . . . . . . . . . 136

Patton's spruce. . . . . . . . . . . . 196

Peach oak ............... 313

Pea-flower locust . . . . . . . . . . . 535

Peawood.................... 602

Pear haw ................ $\$ 59$

Pear thorn. ................ 459

Pecan .............. 357, 373

Pecan nut . . . . . . . . . . . . 373

Pecan tree ................ 373

Persimmon................ . 517

Pessimin. .............. 5l

Pigeonberry . . . . . . . . . . 452, 526

Pigeon cherry .............. 619

Pignut ................ 356,361, 367

Pignut bickory ............. 367

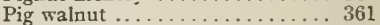

Pin cherry ............... 619

Pine.................... 19

Pink locust. . . . . . . . . . . . . 555

Pin oak............ 20 $24,24,301$

Pinon ................ 19, $2 \mathrm{~s}$

Pinon pine. ..............25, 33

Pin thorn ................ 459

Pitch pine..........43, $45,49,63$

Planertree ................ 397

Plane-tree. . . . . . . . . . . . . . 607

Plum ... . . . . . . . . . . . . 621.622

Poison dogwood ........... 697

Poison elder . . . . . . . . . . . . . . 697

Poison ivy . . . . . . . . . . . . 505

Poison lautel................ 505

Poison oak. ............... 697

Poison sumach ............. 697

Poisontree ................ . 697

Poisonwood...............697, 701

Pond apple. . . . . . . . . . . . . . 640

Pond cypress ................ 141

Pond pine............... o o

Poorfield pine ............. 49

Poot pine. ............... 51

Poplar................ 457, 673

Poplat-leaved birch ........... 585

Popple .............4, 6,675

Poppy ash ............... . 424

Possum haw . . . . . . . . . . . 646

Possum oak. .............. 320

Possumwood ............... 517

Port Orford cedar . . . . . . . . . . 123

Post cedar . . . . . . . . . . . 103, 109

Post locust. . . . . . . . . . . . . 535

Post oak. ................ . 223

Poverty birch .............. 5.55

Powcohiscora.............. . 355

Price oak .................. 315

Pricklecone pine... . . . . . . 69, 704

Prickly ash ................ 699

Prickly pine .............. 52

Prickly spruce. . . . . . . . . . 136

Prince's pine .............. T0

Puget sound pine ............ 169 
Pumpkin ash ............. 423

Pumpkin pine.............. 19

Pumpkin-tree ............ 166

Punk oak. ................ 320

Purple buckese. .......... 649,652

Purple dogwood .......... . 526

Purple haw ............... 700

Pyramidal magnolia ........ \$\$1, 496

Quaking asp............... 675

Ouinine-tree... . . . . . . . . . . . . . . . 699

Rattlebox................... 601

Red alder. . . . . . . . . . . . . . 589

Red asb ................ 423

Redbark fir ............... 164

Redbark pine.............. T5

Red bay.................. 531

Red-berried elder ........... . 700

Red birch ................ 57

Red-bract dogwood . . . . . . . . . 526

Redbud................. 548

Red cedar............. 91, 109

Red elm............... 393, 399

Red fir ...........157, 161, 169

Red gum .................... 325

Red haw... . . . . . . . . . 457, 459, 460

Redheart hickory............ 357

Red hickory................. 363

Red ironwood . .............. T00

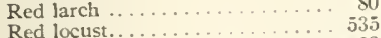

Red locust.................. . 435

Red maple. ................ 513

Red oak...... 259, 265, 277, 280, 259

Red oak....................61, 169

Red plum .................. 621

Red silver fir. . . . . . . . . . . . 165

Red spruce... . . . . . . . . . . . . 127

Red thorn ................ 458

Red titi. ... . . . . . . . . . . . . 502

Red willow.................. 496

Redwood .................. 181

Retama................... . 549

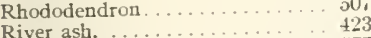

River ash. ............. 565, 577

River cottonwood. . . . . . . . 667

Rock chestnut oak. ........... 241

Rock elm................ 340, 355

Rock maple. . . . . . . . . . . . . . 127

Rock oak.... . . . . . . . . . . . 241

Rocky Mountain juniper. . . . 2 2i9, 226

Rocky Mountain oak. . . . 703

Rocky Jountain white pitte. .... 503

Rose bay ................ 49, 55

Rosemary pine ............49, 692

Royal palm .................... 603

Rum cherry. .................. . . 700

Rusty nannyberry ... .... . . $\quad 200$

Sadler oak ........... $\quad 220$

Safiron plum......... 5- 5

Salad-tree........... . . . . 436

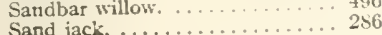

Sand pine ........... if

Sapwood pine ... . . . . . . 75

Sargent palm .... . . . . . 692

Sarvice......... ........ 451

Sassafac ............ 655

Sassafas ....... . . . . . . 655

Sassafrac ........... 655

Sassafras................ 655

Satinleaf ........... 696

Satin walnut............ 325

Satinwood ...................... 699

Savice ................451, 452

Savin................. 91

Saxifrax................... 6505

Scalybark hickory........... 357

Scarlet haw ................ 457

Scarlet maple... . . . . . . . . . 433

Scarlet oak................. . 277

Schott cact us... . . . . . . . . . . . . 694

Schott yucca............... 693

Screwbean ... . . . . . . . . . . . . . 562

Screw-pod................. 562

Scrub oak.............220, 247, 2s3

Scrub pine............ $3 \vec{i}, 5 \overline{4}$, 70

Seaside alder. . . . . . . . . . . . . . 592

Second growth............. . 357

Serviceberry. . . . . . . . . . . . . 451

Service-tree ............... 451

Shadberry ................451

Shagbark hickury. .........355, 357

Shasta red fr................ 16.5

Shawneewood ............... 4 it

She balsam. . . . . . . . . . . . . . 151

Sheepberry.... . . . . . . . . . 699, 700

Sheepbush ................ $55 t$

Sheep laurel. . . . . . . . . . . . . . . 505

Shellbark .............. . 356, 357

Shellbark hickory. . . . . . . . . 369

Shingle cedar. .............. 115

Shingle oak ............ 301,319

Stin oak. . .205, 256

Shoepeg maple ............. 433

Short-flower mahogany... . . . . . 4tio

Shortleaf pine ............. 49

Shortleaved pine. ............

Shortshat. ............... 49

Shrub willow. ............... $490^{\circ}$

Sierra brownbark pine. ....... 6 .

Silktop palmetto. . . . . . 692

Silky willow. .............. 4.2

Silverbell tree ........ (i) . but

Silver fir ........ 159, 163, 16.5

Silverleaf willow........ 471

Silver-leaved maple ... ....... 129

Silver maple. . . . . . . . . . . . . 429

Silver pitse............... 145

Silver spruce ........... 136,145

Silvertop palmetto..... . . . . . . 692

Single-leaf pinon. .... . . . 19, 701

Single spruce. ............ 130

Sir Joseph Lank's pine .. . $45,-19,55$

Slash pine.

Sitka alder. ........... . 592 
Sitka spruce.,............. 133

Skunk spruce . ............. 130

Slippery elm .........380, 391, 400

Sloe ..................., 699

Small buckeye ...........649, 652

Small fruit mountain ash ...... 45t

Small-leaf elm ................ 399

Small-leaf horsebean . . . . . . 549

Small laurel ................ 505

Small pignut ............... 346

Small pignut hickory: . . . . . . 346

Small white birch ............. 585

Smooth cypress. ........... 142

Smooth-leaf willow. .......... 471

Snowdrop-tree ............601, 603

Soapberry ................. 465

Soap-tree ................ 465

Soft maple ............... 429

Soft pine... ...........19, 25

Softwoods...............

Soledad pine $\ldots \ldots \ldots \ldots \ldots \ldots, 64$

Sonora ironwood. . .......... 568

Sophora ................. 555

Sorrel-tree . . . . . . . . . . . 507

Soulard crab ............ 454

Sour gum ..........337, 339, 507

Sour gum bush ........... 507

Sour tupelo ................ 339

Sourwood. .............. 507

Southern basswood........... 639

Southern mountain pine ...... 52

Southern red juniper ......... 94

Southern red oak ............... 265

Southern white cedar. ........ 103

Southern yellow pine. .......... 43

Spanish bayonet. ........... 693

Spanish dagger ............. 693

Spanish moss. . . . . . . . . . 256

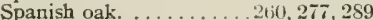

Spanish red oak ............ 289

Sparkleberry .............. 508

Spice-tree .................. 529

Spoon-hutch . ........... 507

Spoonwood................. 505

Springwood …........ 7

Spotted oak .........266, 271, 320

Spruce.............127, 169

Spruce pine ......45,49,51,57, 187

Spruce-tree.................. 1s7

Stackpole pine............. 151

Stagbush .................. 699

Staghorn sumach . ......... 697

Star-leaved gum. ............ 325

Stave oak. ................ 205

Stiffness of wood............. 11

Sting-tongue ............. 699

Stinking ash $\ldots \ldots \ldots \ldots \ldots \ldots, 445$

Stinking buckeye ...........651

Stinking cedar ..........201, 202

Stinking savin ................ 202

Strength of wood ............ 11

Striped maple ............... 447

Stone-seed Mcxican pinon. ...... 33
Stump tree............... 54T

Sugar ash. ............... 445

Sugarberry ..........403, 405, 406

Sugar maple.............. 427

Sugar pine................ 19,31

Sugar-tree ............. 427

Sumach.................6 696

Summer haw ............. 458

Summerwood............... 7

Sunflower-tree. ............. 700

Sun-loving pine. . . . . . . . 704

Sunny-slope pine............. 704

Swamp ash............416, 422

Swamp bay .................. 531

Swamp cedar. ............. 103

Swamp chestnut oak . . . . . . . 229

Swamp cottonwood . . . . . 667, 669

Swamp hickory ..........361,375

Swamp holly................ 646

Swamp laurel.............. 495

Swamp magnolia................ 495

Swamp maple ...........429,433

Swamp oak .........225, 249, 301

Swamp poplar ..............669

Swamp sassafras ............. 495

Swamp Spanish oak .......... 301

Swamp tupelo .............. 337

Swamp white oak ...........217, 229

Swampy chestnut oak........ 241

Sweet bay ................. 531

Sweet birch ............. 565, 580

Sweet crab. ............... 453

Sweet gum ............... 325

Sweet locust.............. 541

Sweet magnolia .............481, 495

Sweet scented crab. ......... 453

Switch-bud hickory . ............ 367

Sycamore . . . . . . . . . . 397, 607

Table mountain pine . . . . . . . . 52

Tacamahac................ 673

Tamarack.............79, 86

Tanbark oak ............241, 271

Tassajo ................. 694

Tear-blanket................... 699

Texan ebony.............. 538

Texan red oak. ............... 265

Texas ash ............... 411

Texas buckeye.............. 649

Texas cottonwood..........667, 669

Texas flowering willow....... 477

Texas redbud ................. 549

Texas umbrella-tree. ......... 465

Thick shellbark. . . . . . . . . . . 369

Thomas elm ................. 385

Thorn apple .............. 459

Thorn bush ............. 459

Thorn locust ............ 541

Thorn plum ............... 459

Thorn-tree............... 541

Thorny acacia. ............... 541

Thorny locust .............. 541

Three-leaved maple .............. 445

Three-thorned acacia. ........ 541 
Thunderwood ..............6.697

Thurber cactus . . . . . . . . . . . 694

Tideland spruce............. 133

Tisswood ................... 602

Titi .............. 502,526

Toothache-tree ............. 699

Torch pine. ............. 55

Torchwood ................. 699

Tornillo................... 562

Torrey pine ............... 64

Tough bumelia .............. 696

Tourney oak .............. 315

Trask mahogany. ............ 466

Tree huckleberry... . . . . . . . . . . 508

Tree myrtle.................... 698

Tree palmetto...............691 691

Tree yucca ... . . . . . . . . . . . 693

Trident oak................ 292

Tuck-tuck ............... 157

Tulip poplar.............. 487

Tulip-tree. ................ 487

Tupelo ................. 337

Turkey oak ............2\$3, 286

Umbrella tree ........481, 484, 526

Upland hickory ............ 357

Upland willow. .............. 285

Utah juniper............... 706

Valley mahogany ............. 466

Valley oak................. 249

Valparaiso oak ............. 308

Vauquelinia ................. 466

Vine maple................441

Virgilia ................. 547

Virginia pine ............ 55

Virginia thorn. ............. 460

Wadsworth oak............... 225

Wafer ash................ 699

Wahoo .......385, 399, 492, 499, 699

Wahoo elm................ 399

Wainut. .................... 343

Wainut-tree ................. 343

Washington haw ............. 460

Washington palm. ........... 693

Wrashington pine... . . . . . . . . 193

Washington thorn............ 460

Water ash ..........422,424,445

Water beech ............... 607

Water birch .............577,580

Water bitternut.............. 375

Water elm ................. 380

Water hickory. .............. 375

Water maple..........429,433, 435

Water oak .......... 295, 319, 320

Water Spanish oak. .......... 301

Water white oak. ........... 217

Weeping dogwood.............. 526

Weeping oak................. 249

Weeping spruce.............. 136, 195

Weeping willow.............. 472

Vestern birch.............. .565,579

Western black willow... . . . . . . 496

Western catajpa .............476

Vestern cedar. ........... 115,118
Western choke cherry ....... 616

Western dogwood ............. 525

Western hemlock ............ 193

Western hemlock fir ............. 193

Western hemlock spruce........ 193

Western juniper ............ 118

Western larch ............. 85

Western plum..............621

Western red cedar ......115, 118, 706

Western serviceberry. . . . . . . . 452

Western shellbark............ 369

Western spruce. . . . . . . . . . . 133

Western sumach.............. 698

Western walnut . ............. 351

Western white fir ............. 163

Western white oak ............ 235

Western white pine ....... 19, 25,703

Western yellow pine.......... 67

Western yew................. 199

West 1ndian birch .........6.676

West Indian cherry . . . . . . . 620

Weymouth pine .............. 19

Whiskey cherry.............613

Whistlewood ...............6 637

White alder................ 591

White Alaska birch ..... . 565,579

White ash..........409,422, 700

White balsam ..........159, 166

White bark ................. 37

Whitebark maple ........... 436

Whitebark pine. ........... 19, 37

White basswood ............ 639

White bay ................ 495

White birch .........565,579,585

IThite buttonwood. . . . . . . . 688

White cedar ..........97, 103, 109

White cottonmood ......... 670

White elm ...........379, 385, 397

IThiteheart hickory .......... 363

White hickory .........357, 361, 367

White fir...........159, 163, 166

White ironwood ............ 700

White laurel................. 495

Whiteleaf oak........... 273

White locust ............. 535

White mangrove. . . . . . . . . . 688

White maple ............. 433, 439

White mulberry ............ 514

White oak ...20 205, 208, 213, 223, 235

White pine ........... 19,51,703

White poplar ...........675,682

White spruce ..........130, 135, 136

White stem pine. ............ 37

White thorn............... 459

White titi. ................ 502

White walnut ..........355, 357

White willow. ............. 472

Whitewood...........487, 607,701

Wickup................. 637

Wild apple. ............... 454

Wild black cherry........... 613

Wild cherry. ...........613,619

Wild china. ............. 465 
Wild cinnamon..............701

Wild crab. ................ 453

Wild date. ................ 693

Wild lilac ................. 699

Wild lime. ................. 699

Wild olive-tree ...........337,601

Wild orange ............... 620

Wild peach............... 620

Wild plum................. 621

Wild red cherry...............619

Wild rose bay .............. 507

Wild sapodilla. . ............ 696

Wild tamarind ............. 568

Wild thorn. . . . . . . . . . . . . 459

Williamson's spruce... . . . . . . . 195

Willow ................... 469

Willow-leaf cherry ........... 620

Willow oak............ 279, 295

Wing elm. ................ 399

Witch elm ............... 399

Witch hazel. . . . . . . . . . . . 328

Wood laurel .................. 505

Woolly oak ............... 315

Yaupon................... 615
Yaupon holly............... 645

Yellow ash. ............... 553

Yellow bark oak ............ 271

Yellow basswood............ 637

Yellow birch ............565,571

Fellow buckeye.............. 649

Fellow buckthorn. . . . . . . . . . 699

Yellow-butt oak ............... 271

Yellow cedar.............113, 121

Yellow chestnut oak.......... 247

Yellow cottonwood........... 667

Yellow cypress .............. 121

Yellow fir ............... 163, 169

Yellow-leaf willow ..........4 471

Yellow-flowered cucumber-tree .. 481

Yellow locust..............535, 553

Yellow oak..............247, 271

Yellow pine..............43, 63

Yellow plum ............... 621

Yellow poplar ............481, 487

Yellow spruce .............. 127

Yellow-wood ........5i1, 5j3, 6939,699

Yew.................. 199, 201

Yucce. ................... 693 


\section{INDEX TO LATIN NAMES}

Abies amabilis ............ 165

Abies arizonica ............... 154

Abies balsamea. ............. 145

Abies concolor ............... 159

Abies fraseri................ 151

Abies grandis.............. 163

Abies lasiocarpa ............ 166

Abies magnifica.............. 164

Abies nobilis ............... 79,157

Abies shastensis ............ 165

Abies venusta ................. 171

Acacia farnesiana............. 543

Acacia greggii ............... 544

Acacia wrightii .............. 544

Acer circinat um ............ 441

Acer floridanum ............ 435

Acer glabrum............442,446

Acer leucoderma ................ 436

Acer macrophylium ........... 439

Acer negundo ............. 445

Acer negundo californicum ...... 447

Acer nigrum.............. 447

Acer peunsylvanicum... . . . . . . 447

Acer rubrum .............4 433

Acer rubrum drummondii. ...... 436

Acet saccharinum. .......... . 429

Acer saccharum............... 427

Acer spicatum. ........... 435

Esculus austrina ................ 652

Esculus californica .......... 651

Aisculus glabra............. 651

Esculus octandra. ........... 649

Aisculus octandra hybrida ..... 652

Ailantbus glandulosa... . . . . . . . 676

Alnus acuminata............ 592

Alnus glutinosa ................. 592

Alnus maritima . . . . . . . . 592

Alnus oregona ................. 589

Alnus rhombifolia. .......... 591

Alnus rugosa................. 592

Alnus sitchensis.............. 592

Alnus tennuifolia .......... 596

Amelanchier alnifolia. ......... 452

Amelanchier canadensis. ........ 451

Amelanchier obovalis. .......... 452

Amyris maritima ........... 699

Andromida ferruginea ........ 526

Annona glabra................ 640

Aralia spinosa............. 675

Arbutus arizonica. . . . . . . . . . . 663

Arbutus menziesii. ............ 661

Arbutus xalapensis. ............. 663

Arctostaphylos manzanita...... 663

Asimina triloba ............... tito

Avicennia nitida. ...........688

Betula alaskana .............. 579

Betula corrulea ............56i.5, 585

Betula fontinalis ............565, 580
Betula ketraica ......... 565, 5855

Betula lenta................. 565

Betula lutea..............565,571

Betula nigra.............. 565, 577

Betula occidentalis . . . . . . . 565, 579

Betula papyrifera. ........ 565, 583

Betula pendula................ 586

Betula populifolia. .........565,585

Broussonetia papyrifera.......... 514

Bumelia angustifolia .........696

Bumelia lanuginosa ............ 696

Bumelia lycoides............... 696

Bumelia tenax.............. 696

Bursera simaruba ............ 677

Camæcyparis lawsoniana ....... 123

Camecyparis nootkatensis ....... 121

Camæcyparis thyoides. ....... 103

Candalia obovata ............ 700

Canella winterata. ........... 701

Canotia holocantha............ 699

Carpinus caroliniana...........6.627

Castanea detutata ...........6.631

Castanea pumila. ............ 634

Castanopsis chrysophylla.......6 633

Catalpa catalpa............475,477

Catalpa speciosa........... 475

Celastraceæ .................. 499

Celtis mississippiensis........403, 405

Celtis occidentalis ............. 403

Celtis reticulata.............. 406

Cercidium floridum............... 555

Cercidium torreyanum ......... 556

Cercis canadensis ............5. 548

Cercis occidentalis.............. 549

Cercis reniformis ............ 549

Cercocarpus leditolius............ 466

Cercocarpus parvifolius........ 466

Cercocarpus parvifolius breviflorus $\$ 66$

Cercocarpus traskiæ ........... 466

Cereus giganteus ............ 693

Cereus schottii.............. 694

Cereus thurberi. . . . . . . . . 694

Chilopsis linearis ............ 477

Chionanthus virginica ........ 700

Chrysobalanus icaco. ..........6.622

Chrysophyllum monopyrenum ... 696

Cleanothus arboreus ...........6.698

Cleanothus thyrsiflorus ........ 698

Clcdrast is lutea. ........... 553

Cliftonia monophylla............ 502

Columbrina reclinata........... 698

Conocarpus erecta........... 688

Cornus alternifolia ........... 526

Cornus florida................ 523

Cortus forida pendula......... 526

Cormus florida rubra. .......... 526

Cornus nuttallii. ........... 525

Cotinus cotinoides. . . . . . . . . 697 
Cratægus ............... 457

Cratægus æestivalis ........... 458

Cratagus brachyacantha. ...... 459

Cratægus coccinea. . . . . . . . . . 457

Cratægus cordata ............ 460

Cratægus crus-galli. . . . . . . . . . . 459

Cratægus douglasii ............. 460

Cratægus oxycantha............ 460

Cratægus tomentosa. . . . . . . . . . . 459

Cupressus arizonica . . . . . . 139, 142

Cupressus glabra. . . . . . . . . . . 139, 142

Cupressus goveniana ... . . . . . 139, 181

Cupressus macnabiana. . . . . . 139, 178

Cupressus macrocarpa........ 139, 141

Cupressus pygmæa.. . . . . . . 139, 184

Cyrilla racemiflora............ 501

Delea spinosa. . . . . . . . . . . . 556

Dendropogon usenoides. . . . . . . 256

Diospyros texana ........... 520

Diospyros virginiana . . . . . . . 517

Dipholis salicifolia............. 696

Evonymus atropurpureus. . . . . . . 499

Exothea paniculata .......... 700

Eysenhardtia orthocarpa........ 556

Fagus atropunicea ...........6.625

Fraxinus americana........... 409

Fraxinus anomala.............. 412

Fraxinus berlandieriana........ 418

Fraxinus biltmoreana......... 424

Fraxinus caroliniana ........... 424

Fraxinus cuspidata... . . . . . . . 412

Fraxinus floridana ............ 424

Fraxinus greggis . . . . . . . . . 411

Fraxinus lanceolata . . . . . . . . . 422

Fraxinus nigra.............. 415

Fraxinus oregona ........... 421

Fraxinus pennsylvanica........... 423

Fraxinus profunda........... 423

Fraxinus quadrangulata ........4 417

Fraxinus texensis. ........... 411

Fraxinus velutina. ........... 418

Fremontodendron californicum .. 400

Gaultheria procumbens... . . . . . 566

Gleditsia aquatica............. 543

Gleditsia texana ............... 543

Gleditsia triacanthos ... . . . . . . . 541

Guajacum sanctum........... 698

Gyminda grisebachii........... 490

Gymnanthes lucida.......... 701

Gymnocladus dioicus. ........... 547

Hamamelis virginiana ......... 328

Helietta parvifolia . ... . . . . . . 699

Heteromeles arbutifolia. . . . . . . . 645

Hicoria alba.......... $356,363,364$

Hicoria aquatica. ............ 375

Hicoria carolinæ-septent rionalis .. 376

Hicoria glabra. .... 356, 361, 361, 367

Hicoria laciniosa. . . . . . . . . . . . 369

Hicoria minima .......... 361, 364

Hicoria myristiceformis ....... 374

Hicoria odorata............. 346

Hicoria ovata............. 355,356

Hicoria texana ............. 375
Hicoria villosa. . . . . . . . . . 345

Hippomane mancinella . . . . . . 701

Hypelate trifoliata............ 700

Icacorea paniculata .......... 701

Ichthyomethia piscipula ........ 550

Ilex cassine ...............6.645

Ilex cassine angustifolia. . . . . . . 645

Ilex decidua... . . . . . . . . . . . 616

Ilex monticola. .............6 645

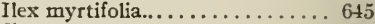

Ilex opaca ................ 643

Ilex vomitoria. .............. 645

Jaquinia armillaris........... 701

Juglans californica . . . . . . . . . . 351

Juglans cinera. . . . . . . . . . . . . 359

Juglans nigra. . . . . . . . . . . . 243

Juglans rupestris.............. 351

Juniperus barbadensis.......... 94

Juniperus californica ... . . . . . 112

Juniperus communis. . . . . . . . . 705

Juniperus flaccida. ........... 705

Juniperus monosperma . . . . . . . 99

Juniperus occidentalis .......... 118

Juniperus pachyphloea ... . . . . . 111

Juniperus sabinoides ... . . . . . . 99

Juniperus scopulorum ... . . . . . . 124

Juniperus utahensis . . . . . . . . . 706

Juniperus virginiana........... 91

Kalmia latifolia.............505, 655

Khaya senegalensis. . . . . . . . . . 463

Kœberlinia spinosa............ 695

Laguncularia racemosa ........ 688

Larix americana.............. \$ 80

Larix laricina. ............... 79

Larix lyallii.................... 88

Larix occidentalis. .......... S5

Leitneria floridana ........... . 423

Leucæna glauca. . . . . . . . . . . . . 562

I.eucæna pulverulenta.......... 562

Libocedrus decurrens ... . . . . . . . 109

Liquidambar sty raciflua ... . . . . 325

Liriodendron tulipifera. . . . . . . . 4S!

Lysiloma latisiliqua .......... 568

Magnolia acuminata. ......... 4 S1

Magnolia acuminata cordata. .... $4 S 1$

Magnolia foetida ..........481, 493

Magnolia fraseri ...............4 481

Magnolia glauca ............4S1, 495

Magnolia macrophylla........ 4S1, 483

Magnolia pyramidata. . . . . .4S1, 496

Magnolia tripetala.........481, 484

Malus angustifolia............453

Malus coronaria. . . . . . . . . . . . . 453

Malus ioensis. . . . . . . . . . . . . 45t

Malus malus. . . . . . . . . . . . . . 454

Malus rivularis .............. 454

Malus soulardi. .............. 451

Meliaceæ..................... 463

Melia azedarach ............444

Melia azedarach imbraculifera .... 165

Mimusops sieberi.............. 696

Mohrodendron carolinum ........ 601

Mohrodendron dipterum. . . . . . . 601 
Morus alba ............... 514

Morus celtidifolia ............ 514

Morus rubra... . . . . . . . . . . . . . 513

Neowashingtoniana filamentosa .. 693

Nyssa aquatica............. 337

Nyssa biflora ................ 340

Nyssa ogeche ............. $33 \overline{7}, 339$

Nyssa sylvatica ... . . . . . . . . . 337

Ocotea catesbyana........... 657

Olneya tesota .............. $56 \$$

Opuntia fulgida... . . . . . . . . . . . 694

Opuntia sponsior............. 691

Opuntia versicolor ............ 694

Oreodoxa regia ............. 692

Osmanthus americanus ........ 700

Ostrya knowltoni ............ 599

Ostrya virginiana............... 595

Oxydendron arboreum.......... 507

Persea borbonia ............ 531

Persea pubescens ............ 532

Picea breweriana. . . . . . . . . . 136

Picea canadensis ............. 130

Picea engelmanni .............. 135

Picea mariana. ............. 129

Picea parryana............... 136

Picea rubens ............... 127

Picea sitchensis. . . . . . . . . . . 133

Pinus albicaulis ............ 19, 37

Pinus aristata .......... 19, 38, 43

Pinus arizonica.............. 43,705

Pinus attenuata ............. 704

Pinus balfouriana ............19, 39

Pinus cembroides ...........19, 33

Pinus chihuahuana .........43, 76

Pinus clausa..............43, 46

Pinus contorta...........43, 73

Pinus coulteri ..............43, 68

Pinus divaricata.............43, 69

Pinus echinata..............43, 49

Pinus edulis .............. 19, 28

Pinus flexilis .............. 19, 703

Pinus glabra ..............43, 51

Pinus heterophylla. . . . . . . .43, 45

Pinus jefferi. .............. 75

Pinus lambertiana ....... . . $19,25,31$

Pinus monophylla......... 19, 701

Pinus monticola ........... .19, 25

Pinus muricata.............. 13,69

Pinus palustris . . . . . . . . . . 13

Pinus ponderosa............43, 67

Pinus pungens.............43, 52

Pinus quadrifolia .......... 19, 704

Pinus radiata... . . . . . . . . .43, 69

Pinus resitiosa . . . . . . . . . . . .43, 61

Pinus rigida. . . . . . . . . . . .43, 63

Pinus sabiniana.............43, 75

Pinus serotina. ..............43, 57

Pinus strobiformis..........19, 27

Pinus strobus............. 19, 25

Pinus tæda................. 43,55

Pinus torreyana ............43, 64

Pinus virginiana............43, 57

Planera aquatica............. 397
Platanus occidentalis. ........607

Platanus racemosa... . . . . . . . . 609

Platanus wrightii ...........610

Populus acuminata.........666, 670

Populus alba............... 652

Populus angustifolia..........667, 669

Populus balsamifera ........6667,673

Populus balsamifera candicans ... 673

Populus deltoides . .......... 667

Populus fremontii .........667,670

Populus grandidentata.......667,675

Populus heterophylla. . . . . . .667, 669

Populus mexicana.........667,669

Populus nigra .............. 681

Populus nigra italica ......... 652

Populus tremuloides.........66 667,676

Populus trichocarpa . . . . . . .667, 669

Populus wislizeni .........6667,669

Parkinsonia aculeata .......... 549

Parkinsonia microphylla... . . . . . . 519

Prosopis juliflora.............. 559

Prosopis juliflora glandulosa. .... 562

Prosopis juliflora velutina ....... 562

Prosopis odorata ............ 562

Prunus allegheniensis .......... 622

Prunus americana............. 621

Prunus angustifolia ..........622

Prunus caroliniana. ...........620

Prunus demissa. . . . . . . . . . . . 616

Prunus emarginata. . . . . . . . . 616

Prunus hortulana. . . . . . . . . . . 622

Prunus ilicifolia .............6 616

Prunus nigra............... 621

Prunus pennsylvanica ......... 619

Prunus salicifolia ........... 620

Prunus serotina..............6 613

Prunus sphærocarpa...........6.620

Prunus subcordata. ..........621

Prunus umbellata. ...........621

Prunus virginiana. . .........615

Pseudophoenix sargentii......... 692

Pseudotsuga macrocarpa .. .... 172

Pseudotsuga taxifolia........... 169

Ptelea trifoliata............... 699

Pyrus americana. . . . . . . . . . . 454

Pyrus microcarpa. ........... 451

Ouercus acuminata............ 247

Ouercus agrifolia... . . . . . . . . . . 307

Ouercus alba............ . . . . 205

Ouercus alvordiana............. . . 220

Õuercus arizonica. . . . . . . . 205, 218

Ouercus brevifolia..... . . . . . . . 255

Ouercus breviloba................ 20s

Quercus breweri ........... 205, 220

Ouercus californica. . . . . . . . . . . 285

Quercus catesbri. . . . . . . . . .259, 253

Quercus chapmani ............. 208

Quercus chrysolepis . . . . . . . . . 308

Quercus chrysolepis palmeri ..... . 301

Ouercus chrysolepis vaccinifolia.. 309

Ouercus coccinea............ . 277

Ouercus densiflora ...... .... ... 313

Quercus digitata . . . . . . .259, 239 
Quercus douglasii............ 213

Quercus dumosa...........205, 237

Quercus emoryi ...........205, 238

Quercus engelmanni.........205, 231

Quercus gambelii .........205, 214

Quercus garryana ..........205, 235

Quercus georgiana .........259,267

Quercus heterophylla. . . . . . . . 322

Quercus bypoleuca. ........259,273

Quercus imbricaria. . . . . . . . 259, 319

Quercus laurifolia ..........259, 319

Quercus leana ............... 292

Quercus lobata ..........205, 249

Quercus lyrata.............205, 217

Quercus macrocarpa .........205, 211

Quercus marilandica.........259,291

Quercus michauxii .........205, 229

Quercus minor............. 223, 241

Quercus morehus . . . . . . 259, 297

Quercus myrtifolia.........259, 297

Quercus nigra ...........259, 320

Quercus oblongifolia..........205, 226

Quercus palustris . . . . . . . . 259, 301

Quercus phellos ...........259, 279

Quercus platanojdes ........205, 225

Quercus pricei ............259, 315

Quercus prinoides ........... 205

Quercus prinus ........... 205, 241

Quercus pumila ............259, 315

Ouercus reticulat: . . . . . 205, 219

Quercus rubra. ............. 259

Ouercus sadleri................205, 220

Quercus texana ............259, 265

Ouercus tomentella............ 315

Quercus toumeyi..............205, 315

Quercus tridentata. .......... 292

Quercus undulata..........205, 219

Qurecus velutina..........259, 271

Oercuus virginiana. . . . . . . . 205, 253

Quercus wislizeni ..........259, 296

Reynosia latifolia.............. 700

Rhamnidium ferreum........ 700

Rhamnus caroliniana ......... 698

Rhamnus crocea. ............. 698

Rhamnus purshiana .......... 698

Rhizophora mangle........... 685

Rhododendron catawbiense .... 507

Rhododendron maximum....... 506

Rhus copallina ............. 696

Rhus hirta............... 697

Rhus integrifolia. ........... 698

Rhus metopium ............ 697

Rhus vernix................ 697

Robinia neomexicana......... 537

Robinia pseudacacia............. 535

Robinia viscosa. ........... 53i

Sabal mexicana. ............... 692

Sabal palmetto ............. 691

Salix alba .............. 172

Salix amplifolia............. 472

Salix amygdaloides.......... 471

Salix babylonica. ............. 472

Salix bebbiana............ 471
Salix cordata mackenzieana...... 472

Salix discolor. ............... 472

Salix fluviatilis ............... 496

Salix hookeriana. ............ 472

Salix lævigata............... 471

Salix lasiandra.............. 496

Salix lasiandra lyalli ............. 496

Salix lasiolepis............. 472

Salix longipes .............. 471

Salix lucida ................. 496

Salix missouriensis............. 472

Salix nigra. .............. 496

Salix nuttallii .............. 472

Salix sessifolia. .............. 471

Salix sitchensis ........... 472

Salix taxifolia ................ 471

Sambucus callicarpa.......... 700

Sanbucus glauca. .............. 700

Sambucus mexicana. ......... 700

Sapindus drummondi .......... 465

Sapindus marginatus........... 465

Sapindus saponaria........... 465

Sassafras sassafras ............... 655

Schæfferia frutescens .......... 501

Sequoia sempervirens............ 1s1

Sequoia washingtoniana ....... 175

Sideroxylon mastichodendron.... 692

Simarouba glauca ........... 676

Sophora affinis ............. 555

Sophora secundiflora ......... 554

Swietenia mahagoni ........... 463

Taxodium distichum ............. 139

Taxodium imbricarium ........139, 141

Taxus brevifolia ............... 199

Taxus floridana. ............ 201

Terminalia buceras .......... 6s8

Thrinax microcarpa.............. 692

Thrinax parviflora ........... 692

Thuja occidentalis ........... 97

Thuja plicata................. 115

Tilia amerciana ............ 637

Tilia a ustralis ............. 639

Tilia floridana................. 639

Tilia heterophylla. ........637, 639

Tilia michauxii .............. 639

Tilia pubescens.............. 639

Toxylon pomiferum.......... 511

Tsuga canadensis .............. 187

Tsuga caroliniana........... 157,703

Tsuga heterophylla........... $18 \bar{i}, 193$

Tsuga mertensiana. ..........187, 195

Tumion californicum ........... 201

Tumion taxifolium. ............ 202

Ulmus alata. ................ 379, 399

Ulmus americana ................. 379

Ulmus crassifolia ............. 379,392

Ulmus pubescens ...........379, 391

Ulmus racemosa.............. 379,385

Ulmus serotina . . . . . . . 379, 393

Umbellularia californica ......529,655

Vaccinium arboreum......... 508

Vauquelinia californica ........... 466

Viburnum lentago............ 700 
Viburnum prunifolium.......... 699

Viburnum rufotomentosum...... 700

Xanthoxylum clava-herculis..... 699

Xanthoxylum cribrosum ....... 699

Xanthoxylum fagara.......... 699

Yucca aloifolia .............. 693

Yucca arborescens ............ 693

Yucca brevifolia............. 693
Yucca gloriosa................ 693

Yrucca macrocarpa ............ 693

Yucca mohavensis .......... 693

Yucca treculeana ............ 693

Zygia brevifolia... . . . . . . . . . 538

Zygia flexicaulis ............ 538

Zygia unguis-cati .......... 538 





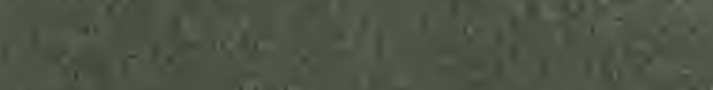

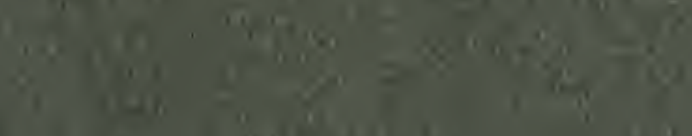

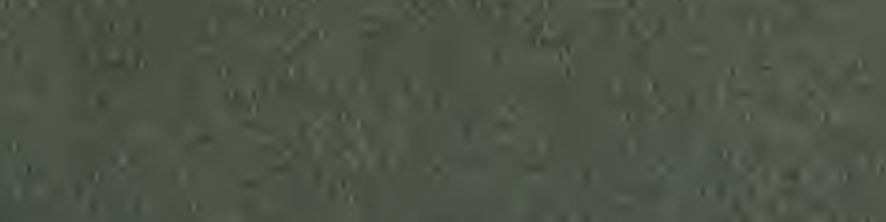

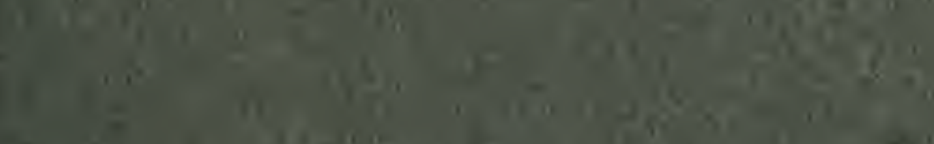

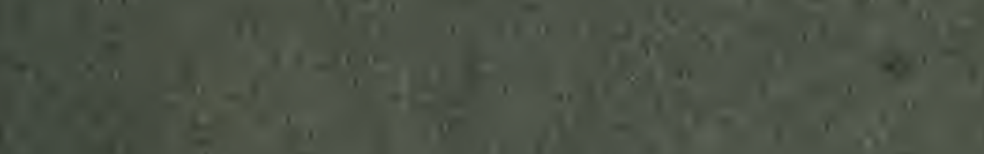

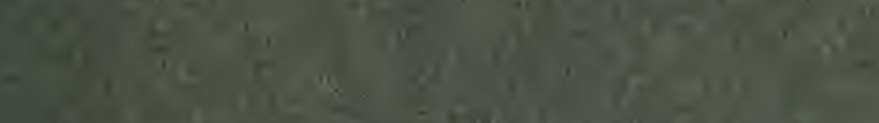

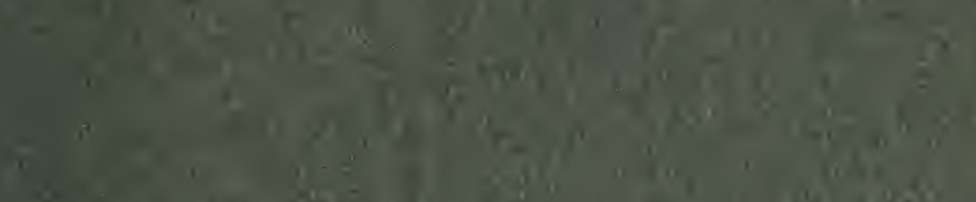

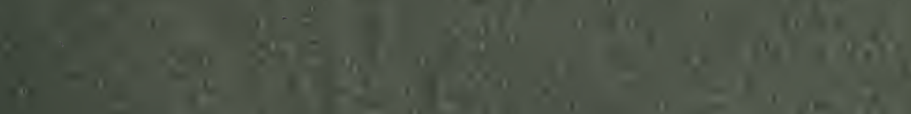

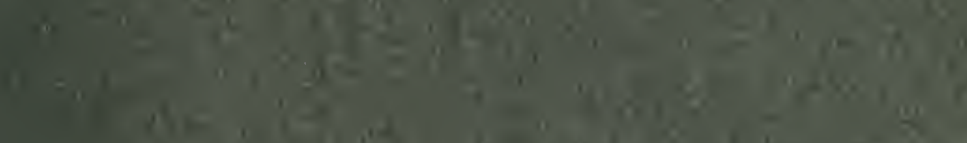

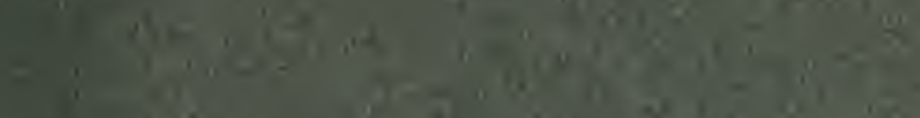

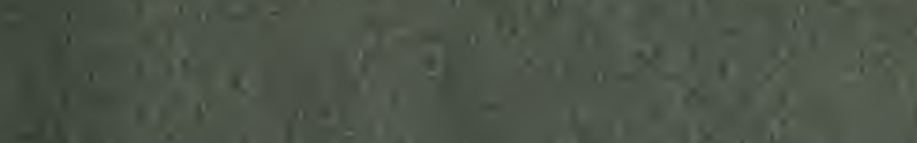

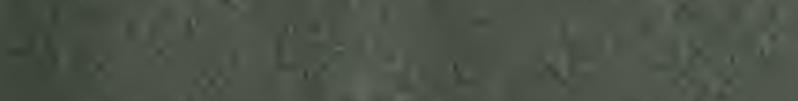

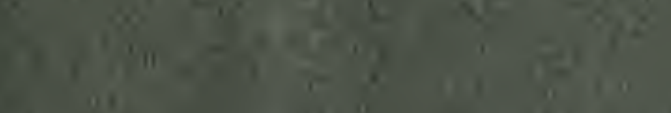

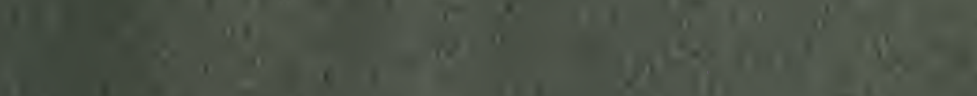

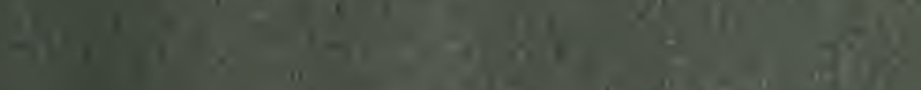

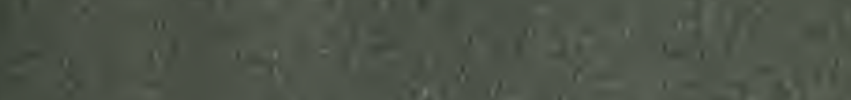

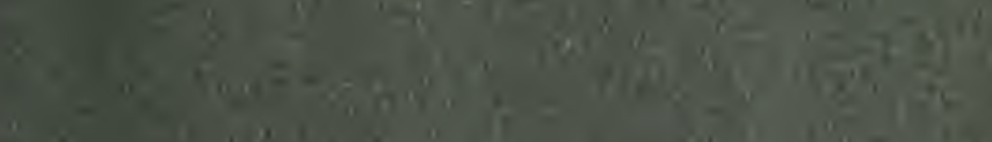

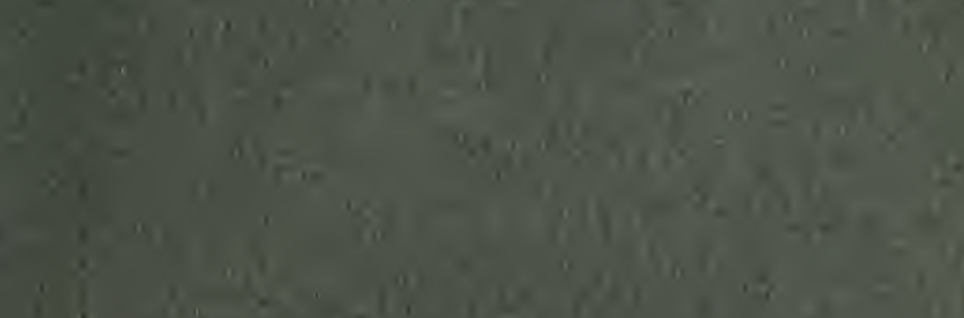




\section{STORAGE}

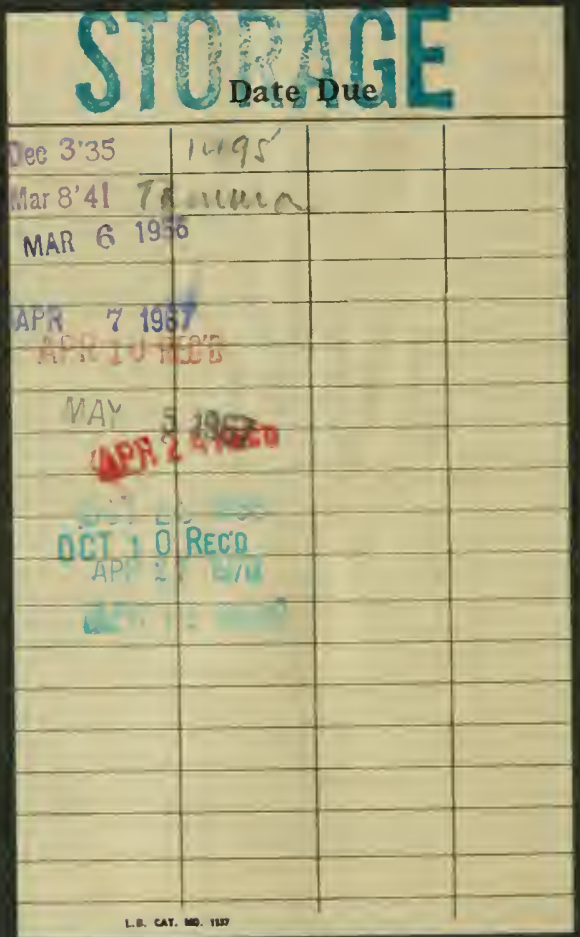




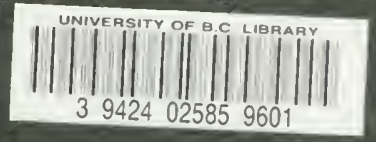

\section{STORAGE}




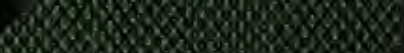

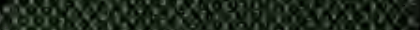

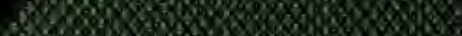

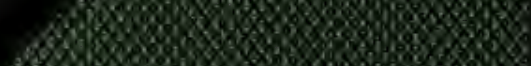

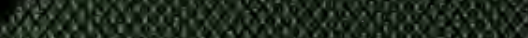

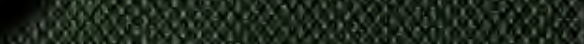

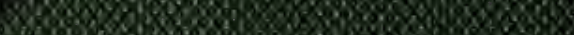

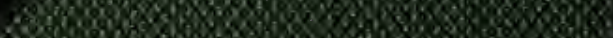

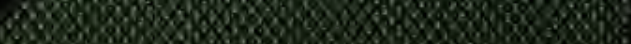

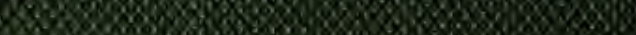

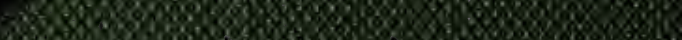

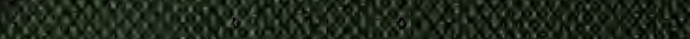

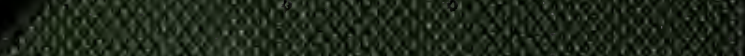

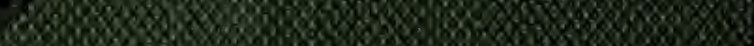

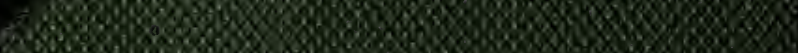
150.0.

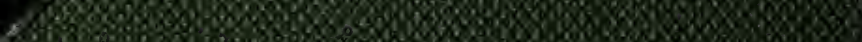

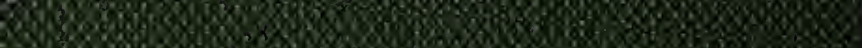
SE0.0.

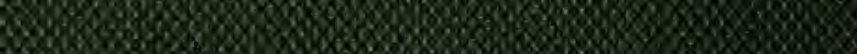

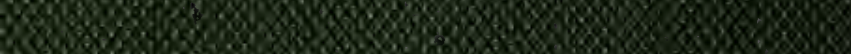

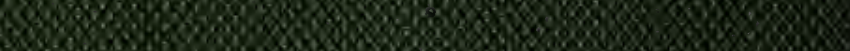

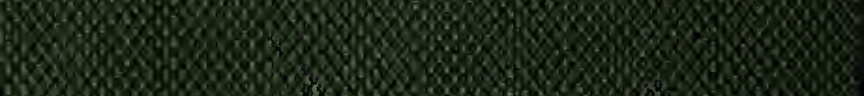

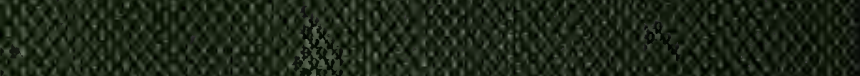

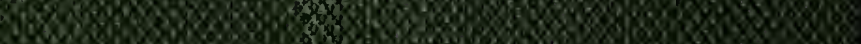
Ex

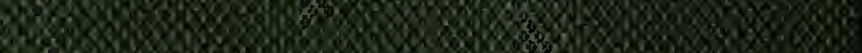
ar. How S.

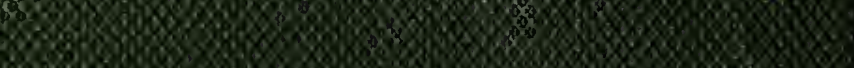

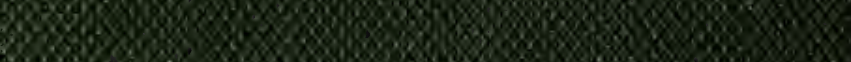
W. W. WWatrow

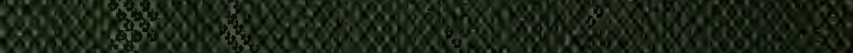
SW0

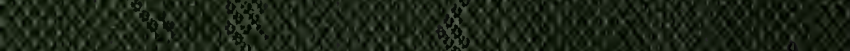

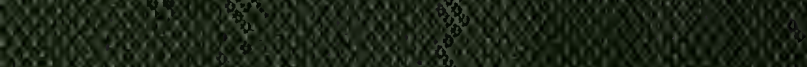

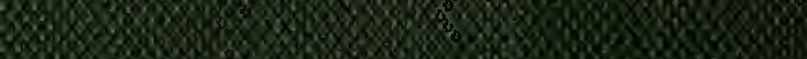

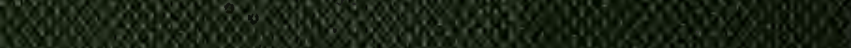

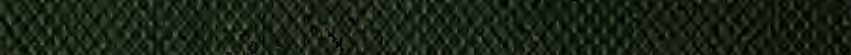

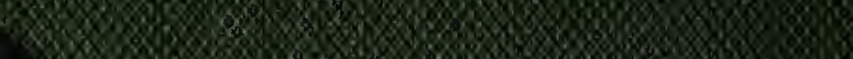

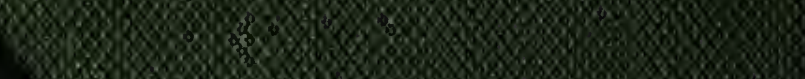

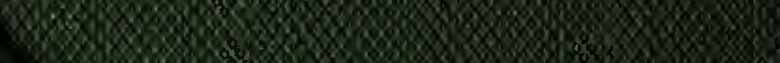

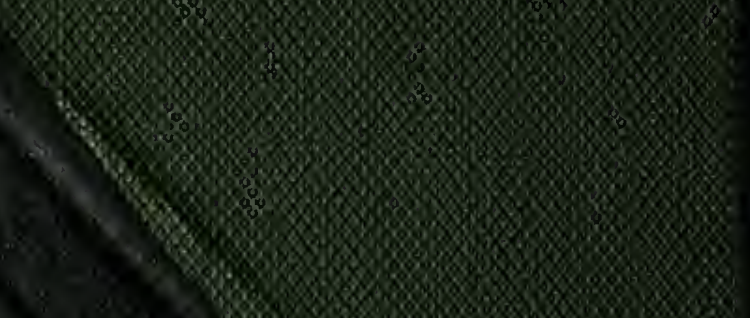

